
Mat. 110 
Angus Mattreson. 


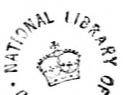


PUBLICATIONS OF THE UNIVERSITY OF MANCHESTER

CELTIC SERIES

No. I.

An Introduction to Early Welsh 
Sherratt \& Hughes

Publishers to the Victoria University of Manchester Manchester: 34. Cross Street

London: 33 Soho Square W. 


\section{AN \\ INTRODUCTION}

TO

\section{EARLY WELSH}

BY

The Late JOHN STRACHAN, LL.D.,

Professor of Greek and Lecturer in Celtic in the University of Manchester

MANCHES'TER

At the University Press 
University of Manchester Publications No. XL.

$$
\begin{aligned}
& \sum^{R A R Y} O_{A} \\
& \text { सा2 }
\end{aligned}
$$

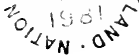




\section{PREFACE}

THIS book is the outcome of the courses of lectures on Welsh grammar and literature given by the late Professor Strachan at the University of Manchester during the sessions $1905^{-6}$ and 1906-7. Indeed, the Grammar is in the main an expansion of notes made for these lectures. For the numerous quotations from early Welsh literature contained in the Grammar, as well as for the Reader, Strachan made use not only of published texts, notably those edited by Sir John Rhys and Dr. J. Gwenogvryn Evans, but also of photographs specially taken for the purpose, and of advance proofs of the edition of the White Book and of the photographic facsimile of the Black Book of Chirk, about to be published by Dr. Evans, both of which were lent by him to Strachan. The Reader includes Middle Welsh Texts selected as likely to be of most value for illustration or of special interest. The very valuable work done by Dr. Evans in relation to these texts was of the greatest assistance to Professor Strachan, and as an expression of gratitude for the help thus given, as well as in recognition of the services rendered to Welsh scholarship by Dr. Evans, it was the intention of the author to dedicate his book to him.

The idea of working up his notes into a book that might serve as an introduction to the study of older Welsh seems first to have occurred to Strachan in the spring of 1907. On the fifth of April he wrote to Mr. R. I. Best, the Secretary of the School of Irish Learning in Dublin: "I have been thinking of drawing up a little primer of Early Welsh. With that the language of Middle-Welsh prose should be child's play 
to learn. However, that may or may not come off." And to his old friend Dr. P. Giles of Emmanuel College, Cambridge, he wrote on the same day: "I think I must draw up and print outlines of Middle-Welsh grammar. I cannot well teach without some book, and the beginner is lost in the wilderness of the Grammatica Celtica." His original intention evidently was to publish a mere sketch of the grammar, somewhat like his Old-Irish Paradigms. But at the suggestion of his friend and colleague, Professor T. F. Tout, he decided to expand the Grammar on the larger and fuller lines of the present volume. At the same time the plan of adding a Reader of excerpts from mediæval Welsh literature took concrete shape in the course of conversations and correspondence with Dr. Evans. On both these tasks he began to work during the Summer Term of 1907. With what amazing rapidity he must have toiled to have all but completed the work by the end of the following August! Giving up a visit to Germany to which he had long been looking forward, he devoted the whole long vacation to the preparation and printing of his book. At the moment of his death, on the 25 th of September, both the Grammar and Reader were in type, and he had read a first, and in some cases a second, proof. Writing to Professor Thurneysen a week before his death, he says that he had then only the notes and vocabulary to add.

After Professor Strachan's death, at the request of the Publications Committee of the Manchester University, Professor Kuno Meyer of the University of Liverpool kindly undertook the task of reading final proofs of the Grammar and Reader, and of adding a Glossary, an Index and a list of contents. In this task, which involved very considerable labour, he obtained the assistance of Mr. Timothy Lewis, who had worked for two years under Professor Strachan, and who returned 
from Berlin whither he had gone to continue his studies with Professor Zimmer, and devoted the winter to help with the completion of the book. Mr. Lewis verified the quotations in the Grammar where this was possible; drew up the Glossary, prepared the Index, and revised proofs. An old student of Professor Meyer's, the Rev. Owen Eilian Owen, placed his collection of Old and Middle-Welsh words at his disposal for the elucidation of rare and difficult vocables, while both Mr. Owen and Mr. J. Glyn Davies read proofs of the whole book, many valuable suggestions being due to them. But Professor Meyer and Mr. Lewis are solely responsible for the Glossary.

There can be no doubt that if Strachan had lived to complete the book himself, he would have made alterations and additions in several places both in the Grammar and Reader, and would have still further normalised the spelling in his critical versions of sections IV. and V. in the Reader. It will be observed that his treatment of the texts varies greatly. Except in the sections just mentioned, he does not seem to have aimed so much at the construction of a critical text as at the presentation of a clear, precise, and intelligible version, which would at the same time serve to introduce the student to the characteristic features of Middle Welsh orthography. In the Corrigenda some necessary emendations ${ }^{1}$ have been indicated by Professor Meyer

1. From a collation of the poems printed from the Red Book with the original, it appears that the following corrections should be made :-

P. 233, 1. 4, for dog read dong

ib., 1. 19, for aghneat read agkaeat

P. 235, 1. 29, for goawr read goaur

P. 236, 1. 2, for can read kan

P. 237, 1. 22, for uvulldabt read uvulltalt

P. 238, 1. 9, for dyrnact read dyrnnavt

ib., 1. 11, for diffirth read diffyrth

ib., I. 18, for vedissyawt read vedyssyaut

ib., 1. 20, for adueil read atueil 
who has also added some further variants (marked $a, b$, $\& c$.) in the foot-notes.

Strachan had left behind no material for the Glossary except a first rough list of words. In drawing it up use was made of a letter to Thurneysen, in which he expressed his intention to arrange the words according to their actual sounds. His only doubts were about the phonetic value of final $c, t, p$. On this point he wrote: "Of course final $b$ is common, also certain of my texts write $d$ for $d$. But none of them have $g$ for final $g . "$ In accordance with modern pronunciation, Professor Meyer considered it desirable to substitute the letter $g$, though the period at which final $c$ became voiced has not yet been established.

No notes to the texts were found among Strachan's papers. He had brought back from Peniarth, from MSS. No. 22, 44, 45, and 46, a large number of variants to the Story of Lear and that of Arthur, which he would no doubt have used for his notes. Those to Lear have been printed in an Appendix; but the Peniarth versions of Arthur seem to differ so much from those of the Red Book and the Additional MS. 19,709 that they would have to be printed in full.

Since the great work of Zeuss, this is the first attempt to write a grammar of Early Welsh on historical principles. It was the hope of the author expressed in letters to friends that his work would stir up Welsh scholars to investigate more thoroughly than they have done hitherto the history of their language. But no one was more conscious of the gaps still left by his work than Strachan himself. " It is only a beginning," he wrote to Thurneysen. "I hope people will make some allowance for the difficulties of the work and the scanty amount of trustworthy material. One is continually finding out something new." References to the need of further investigation will be found in many places throughout the Grammar. His own discoveries 
of the functions of $r y$, of the relative forms of the verb, and his account of the uses of the verbal prefixes $a$ and yo point out the way to future investigators in this neglected field of research. To these discoveries he was led by his unrivalled knowledge of Irish grammar, so intimately connected in its origins with that of Welsh that he believed no true progress possible without their parallel study. " It is absurd to think," he once wrote to Mr. Best, " that either branch of Celtic can be satisfactorily studied apart from the other;" and to Mr. Giles: "Without the knowledge of Irish early Welsh grammar is rather like a book sealed with seven seals.",

The circumstances under which this book has been produced having been thus indicated, it remains to express acknowledgement of the work of the scholars who have contributed towards the result: first to those whose assistance to Professor Strachan in his lifetime he would specially have desired to recognise; in particular to Dr. Evans who furnished the editions both published and unpublished of the Welsh texts which were used in compiling the Reader; to the late Mr. Wynne of Peniarth who freely gave access to the MSS. in his possession; and to Sir John Rhys (joint editor of the Red Book and of other texts) and to the Fellows of Jesus College, Oxford, who afforded every facility in their power; secondly to those who since the author's death have enabled his work to be presented to the public, especially to Professor Tout who initiated the idea of preparing the book for publication and undertook the arrangements for it; to Professor Kuno Meyer, whose long and intimate association with Strachan in his Celtic studies specially fitted him to undertake the duty of revising the whole work and seeing it through the press; to Mr. Lewis in assisting Professor Meyer particularly in the preparation 
of the Glossary; and to Mr. O. Eilian Owen and Mr. J. Glyn Davies for their help in reading proofs. The title of the book was chosen by Strachan himself.

It has been the earnest wish of those who have taken part in preparing this work for publication that it should appear in a form worthy of the reputation and memory of the distinguished scholar whose career was cut short so sadly in the midst of his full literary activity, and that the results of his devoted labours and profound learning should not be lost to students of the Welsh language.

February, 1909. 


\section{TABLE OF CONTENTS}

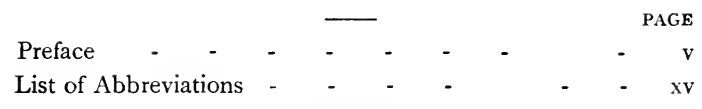

\section{GRAMMAR}

The numbers refer to the paragraphs.

Sounds and sound changes $\mathbf{I}-\mathbf{2 2}$.

Vowels and diphthongs $\mathrm{I}$; vowel quantity 2 ; accented vowels $2 \mathrm{~A}$; unaccented $2 \mathrm{~A}$; consonants classified 3 ; orthographical variations 3 ; accent 4 ; changes of vowels 5 ; changes of vowels due to $i$ vowel preserved 6 ; changes due to a lost vowel 7 ; vowel variation due to accent 8 ; prothetic vowel 9 ; epenthetic vowel I0; consonantal changes II; sound changes within the sentence 12 ; table of consonant mutations 13 ; vocalic mutation or lenation 14 ; general exceptions to rules of lenation 15 ; lenation of noun and adjective 16 ; lenation of pronoun 17; lenation of verb 18 ; nasal mutation 19-20; spirant mutation 21 ; $h$ in sentence construction 22 .

The Article 23-24.

The Noun 25-29.

Numbers and cases 25 ; syntax of the cases 26 ; formation of plural 27-28; collective nouns 29 .

The Adjective $30-39$.

Gender 30 ; formation of plural 31 ; concord 32 ; number 33 ; order in sentence 34 ; predicative noun and adjective with $y n$ 35; adjectival phrases 36 ; comparison 37 ; construction of comparative and superlative 38 ; the equative 39 .

The Adverb 40.

The Numerals $4 \mathrm{r}-44$.

Cardinals and ordinals $4 \mathrm{I}$; syntax of cardinals and ordinals 42 ; distributives 43 ; multiplicatives 44 .

The Pronoun 45-90.

Personal pron. $45-5^{\mathrm{I}}$; independent pron. $45-47$; infixed pron. $48-5 \mathrm{I}$; pron. with preposition $52-54$; possessive pron. 55-56; possessive adjs. 57-59; hun, hunan etc. 6o; demons. pron. 61-62; article + substantive + adverb 63 ; indefinite prons. and adjs. 64-72; substantives in a pronominal function $73-78$; interrog. prons. $79-81$; relat. prons. $82-89$; expression of case in the relative $86-89$; substitutes for the relative 90 . 
Preverbal particles $9 \mathrm{I}-97$.

The particle $y d 9 \mathrm{I}-94$; the particle $r y$ 95-97.

The Verb 98-16r.

Conjugation of the verb 98- 126 : verbal classes 98 ; voice 99 ; number 100-101; person 102-3.

The moods 104 ; the indicative 105-109; present 106 ; imperfect 107; preterite 108 ; pluperfect 109.

The subjunctive IIo-II4: formation of subj. IIo; tenses I I I ; usages of subj. I I 2-I I 4 .

The imperative I 15 .

The participle passive in edic I 16 ; verbal in-adzey 117 . The verbal noun: formation of I I 8-1 I9; usage I $20-126$. Paradigm of the regular verb I $27-139$ : types 127 ; pres. and fut. indic. $128-\mathrm{I} 30$; imperf. indic. and conditional I 31 ; pret. and perf. indic. act. I 32 ; pret. and perf. indic. pass. I 34 ; plupf. indic. I35-1 36 ; imperat. 137 ; pres. subjunctive 138 ; past subj. I 39 .

Irregular verbs: mynet 140; dvvot I4I; gzeneuthur 142; greybot $\mathrm{I}_{43}$; adnabot $\mathrm{I}_{44}$; caffel $\mathrm{I}_{45}$; rodi $\mathrm{I}_{4} 6$; tawer $\mathrm{I}_{47}$; moes 148 ; hwde 149 ; med 150 ; heb $15 \mathrm{I}$.

The substantive verb: paradigm 152 ; remarks on subst. vb. I 54 ; on copula $155^{-1} 5^{8}$; position of copula I 59 .

Compounds of bot 160-161.

The Preposition $162-197$.

The Conjunction $198-234$.

Negative particles $235-238$.

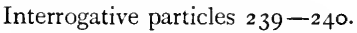

Responsive particles $240-24 \mathrm{I}$.

The Interjection $243-244$.

\section{READER}

PAGE

I. Lear and his Daughters - $\quad$ - $\quad$ - $\quad$ - $\quad$ - 139

From Ystorya Brenhined y Brytanyeit, printed in Red Book of Hergest, ed. J. Rhŷs and J. G. Evans, vol. ii, pp. 64-69. The variants are from Brit. Mus. MSS. Add. 19,709 .

II. The Story of Arthur - - $\quad$ - $\quad$ - 145

From the same source, pp. 184-232.

III. The Hunting of Twrch Trwyth - - _ - 193

An excerpt from the story of Kulhwch and Olwen. Chapters 1-6 are from the White Book of Rhydderch (Peniarth MIS. 4), with variants from the Red Book (Rhŷs-Evans, vol. i, pp. 126-128); chapters 7-25 from the Red Book (ib. p. 128, l. 13-p. 142, l. 19). 
IV. The Procedure in a Suit for Landed Property $\quad{ }_{208}$

From the oldest copy of the Laws of Howel Dda contained in the Black Book of Chirk (Peniarth MS. 29). The variants are from Aneurin Owen's Ancient Laws of Wales, vol. i, pp. 142-156. The text in the right-hand columns is a critical edition with normalised spelling by Strachan.

V. The Privilege of St. Teilo - - - $\quad$ - $\quad 222$

From Evans-Rhŷs, Liber Landavensis, p. 118. The text in the right-hand columns is a critical edition with normalised spelling by Strachan.

VI. Moral Verses

From the Red Book, col. 1031, printed in Skene's Four Ancient Books of Wales, vol. ii, pp. 249-250.

VII. Doomsday - $\quad$ - $\quad$ - $\quad$ - $\quad$ - 227

From the Book of Taliessin, printed in Four Ancient Books, vol. ii, pp. 118-123. Strachan has made no use of the variants printed in 1/yryrian Archaiology, p. $72 \mathrm{ff}$.

VIII. To Gwenwynwyn - $\quad$ - $\quad$ - $\quad$ - $\quad$ - $\quad$ - 233

From the Red Book, col. 1394, where it comes after several poems ascribed to Llywelyn Vardd; printed in Myryrian Archaiology, p. 176a, where it is ascribed to Cynddelw.

IX. Cynddelw to Rhys ab Gruffudd - - - $\quad$ - 234 (a) from Black Book of Carmarthen, ed. J. G. Evans, fo. 39b; (b) from Red Book, col. 1436.

$\mathrm{X}$. A Religious Poem - - - - - - 237

From Black Book of Carmarthen, fo. 20a, and from Red Book, col. 1159.

XI. A Dialogue between Ugnach Uab Mydno and Taliessin - - - - - - $\quad 239$

From Black Book of Carmarthen, fo. 51a.

XII. Winter - - - - - - - - $24 \mathrm{I}$

From Black Book of Carmarthen, fo. 45 a.

Glossary

Appendix

Index -

Corrigenda 



\section{LIST OF ABBREVIATIONS}

Anc. Laws. Ancient Laws and Institutes of Wales, edited by Aneurin Owen. I 84 I.

Arch. Archiv für celtische Lexikographie.

Arch. Cambr. Archaeologia Cambrensis.

BB. Black Book of Carmarthen, edited by J. G. Evans. Oxford. I 888.

BCh. Black Book of Chirk. ${ }^{1}$

Bezz. Beitr. Bezzenberger's Beiträge zur Kunde der indogermanischen Sprachen.

Bret. Breton.

CM. Ystorya de Carolo Magno, from the Red Book of Hergest, edited by Thomas Powell. I 883 .

Corn. Cornish.

Cymrod. Y Cymmrodor, embodying the Transactions of the Cymmrodorion Society of London. $1877 \mathrm{ff}$.

CZ. Zeitschrift für celtische Philologie.

E. Lh. Archæologia Britannica, by Edward Lhuyd. Oxford. I 707 . Eng. English.

Eriu The Journal of the School of Irish Learning, Dublin.

FB. The Four Ancient Books of Wales by W. F. Skene. Edinburgh. 1868 .

Gaul. Gaulish.

Hg. Selections from the Hengwrt Mss. edited by Robert Williams, vol. I. 1876 ; vol. II. London. 1892.

Ir. Irish.

KZ. Kuhn's Zeitschrift für vergleichende Sprachforschung.

LA. The Elucidarium and other tracts in Welsh from Llyvyr Agkyr Llandewivrevi, edited by J. Morris Jones and John Rhŷs. Oxford. I 894

1. The references in the Grammar are to the pages of the photographic facsimile about to be published by J. G. Evans. 
Lat. Latin.

Laws, see Anc. Laws.

Leg. Wall. Cyfreithjeu Hywel Dda ac eraill, seu Leges Wallicae, edited by W. Wotton. Londini. I 730 .

Lhuyd, see E. Lh.

Lib. Land. Liber Landavensis, edited by J. G. Evans and J. Rhŷs. Oxford. 1893 .

Loth Mab. Les Mabinogion traduits en entier par J. Loth. Paris. I 889.

MA. The Myvyrian Archaiology of Wales. Denbigh. I870.

Mart. Cap. The Old-Welsh Glosses on Martianus Capella edited by Wh. Stokes in the Archaeologia Cambrensis for 1873 , p. I ff. and in Beiträge zur vergl. Sprachforschung VII. p. $3^{8} 5 \mathrm{ff}$.

Mid. Middle.

Mod. Modern.

O. Old.

Ox. gl. Glossae Oxonienses, edited in Zeuss-Ebel, Grammatica Celtica, p. 1052 ff. Berlin. I 87 I.

Pughe A Dictionary of the Welsh Language by W. Owen Pughe. 2. ed. Denbigh. 1832 .

RB. The Red Book of Hergest edited by J. Rhŷs and J. G. Evans, vol. I. (Mabinogion), Oxford. I887; vol. II. (The Bruts), Oxford. I 890 .

Rev. Celt. Revue Celtique.

Rhŷs, Celt. Heath. J. Rhŷs, Lectures on the Origin and Growth of Religion as illustrated by Celtic Heathendom. 3. ed. I 898 .

Rhŷs, Lect. J. Rhŷs, Lectures on Welsh Philology. 2. ed. London. 1879.

WB. The White Book of Rhydderch. ${ }^{1}$

1. The references in the Grammar are to the pages of the edition about to be published by J. G. Evans. 


\section{$\S \S$ I, 2.] SOUNDS AND SOUND-CHANGES.}

\section{SOUNDS AND SOUND-CHANGES.}

\section{Vowels AND Diphthongs.}

I. Middle Welsh has the following system :-

Vowels :-a, e, i, o, u, w, y.

Diphthongs :-ae, oe, ei, eu, aw, ew, iw, yw, wy.

NoTE.-The following are the more important orthographical variations:

(a) $\mathbf{u}$ is written $\mathbf{u}$ or $\mathbf{v}$, e.g. un or vn one. That $\mathbf{u}$ already in O.W. approached to an $\mathrm{i}$ sound is shown by the spelling Dinoot (from Lat. Donatus) in Bede for what in $O . W$. would be normally Dunaut, later Dunawt.

(b) $\mathbf{w}(=\mathrm{u}$ in sound) is in Mid. W. commonly written $\mathrm{w}$ or 6 ; in $\mathrm{O} . \mathrm{W}$. it is written $u$, and in some Mid.W. MSS, $u$ or $v$, e.g. O.W. crunn round, later crunn, crvnn, cronn, crwnn. The same applies to $w$ in diphthongs, e.g. O.W. dui two, later duy, dvy், doy, dwy; O. W. bleu hair, later bleu, blev, ble, blew.

(c) $\mathrm{y}$ is in O.W. written i, in Mid.W. MSS. i, e, $\dot{y}, \mathrm{y}$, e.g. O.W. hinn these, later henn, hỷnn, hynn.

(d) The diphthongs ae, oe, are in $0 . \mathrm{W}$. ai, oi, later ai, ay, ay, ae; oi, oý, oy, oe, e.g. O.W. air slaughter, later ay்r, ayr, aer; O.W. coit wood, later coýt, coyt, coet.

(e) The diphthong eu appears in U.W. as ou, e.g. aperthou offerings, later abertheu. In final position in Mid.W. -eu sometimes appears as -e, e.g. minhe on my part = minheu ; in Mod.W. it is written -au, e.g. pennau heads $=$ Mid. W. penneu.

(f) For wy, oy and oe are also found, e.g. boy = bwy he may be, moe= mwy greater.

\section{VOWEL QUANTITY.}

2. The quantity of vowels depends not on their prehistoric quantity, but on the nature of the syllables in which they stand. Apart from dialectal variation, the following may serve as approximate rules, at least for the period subsequent to the shifting of the accent (\$ 4$)$. 
A. Accented vowels are :-

(a) Long.

(a) In monosyllables ending in a vowel, e.g. tȳ house.

$(\beta)$ In monosyllables ending in a single consonant, e.g. dȳn man (=O.Ir. duine), gwlād country (= O.Ir. flaith), māb son, glān pure (= O.Ir. glan), glās green (=O.Ir. glas), crȳch curly.

NoTE.-s always goes back to an earlier ss; $\mathrm{ch}$, th, $\mathrm{ff}(=\mathrm{f}$ in sound) to an earlier double consonant, e.g. crȳch curly = Gaul.Crixos, brith variegated $=$ Ir. mrecht, cloff lame = Low Lat. cloppus; here the reduction to a single consonant was prior to the operation of the above law. In Mod. W. a vowel is short before final $c, t, p$; these final sounds occur only in late borrowings.

(b) Half-long, in open syllables of polysyllabic words, e.g. dì-nas city: dīn fortress (=Ir. dūn), tà-deu fathers: tād father.

(c) Short.

(a) In monosyllables originally ending in a double consonant (with the above exceptions), e.g. pĕnn head (=Ir. cenn), trw̌m heavy (=Ir. tromm), părth part (from Lat. part-em).

$(\beta)$ In closed syllables of polysyllabic words, e.g. pĕnneu heads: pĕnn, ŭndeb unity: ūn one (=Ir. ōen). The vowel is somewhat shorter in polysyllables like penneu than in monosyllables like penn.

B. Unaccented vowels are short. This rule also applies to proclitic words like heb without, fy mine, dy thine.

\section{The Consonants.}

3. The consonants may be classified :-

\begin{tabular}{|c|c|c|c|c|c|c|}
\hline \multirow[b]{2}{*}{ Gutturals } & \multicolumn{2}{|c|}{ Explosives. } & \multicolumn{2}{|c|}{ Spirants. } & \multicolumn{2}{|c|}{ Nasals. } \\
\hline & $\begin{array}{c}\text { Voiceless. } \\
\text { C }\end{array}$ & $\begin{array}{c}\text { Voiced. } \\
\mathrm{g}\end{array}$ & $\begin{array}{l}\text { Voiceless. } \\
\text { ch }\end{array}$ & $\begin{array}{c}\text { Voiced. } \\
(\bar{\zeta})\end{array}$ & $\begin{array}{c}\text { Voiceless. } \\
\text { ngh }\end{array}$ & $\begin{array}{c}\text { Voiced. } \\
\operatorname{ng}(=\imath \partial)\end{array}$ \\
\hline Dentals & $t$ & d & th & đ & $\mathrm{nh}$ & $\mathrm{n}$ \\
\hline Labiodentals & & & $\mathrm{ff}(=\mathbf{f})$ & $\mathbf{v}$ & & \\
\hline Labials & $p$ & b & & & $\mathrm{mh}$ & $\mathrm{m}$ \\
\hline
\end{tabular}




\section{§3.] SOUNDS AND SOUND-CHANGES.}

Liquids. Voiceless:-11, rh; voiced:-1, r.

Semivowels : $-\mathrm{y}$, w.

Sibilant :-s.

Breath :-h.

Note.-The following are the more inportant orthographical variations :-

(a) For O.W. $\mathbf{c}=\mathbf{k}$, both $\mathbf{c}$ and $\mathbf{k}$ found in Mid.W., $\mathbf{c}$ particularly at the end of a word; e.g. $\mathrm{O}$.W. cimadas fitting, Mid.W. kyvadas and cyvadas. In Mid.W. sc, sp became sg, sb, e.g. kysgu by kyscu to sleep, ysbryd from Lat. spiritus.

(b) With regard to the graphic representation of the mediæ the following may be noted. In Old British the symbols $c, t, p$ were taken over from Latin with their Latin values. In the course of time, before the loss of final syllables, c, t, p, when they stood between vowels, or after a vowel and before certain consonants, beeame in sound media $g, d, b$, but continued in $\mathrm{O}$. W. to be usually written $\mathrm{c}, \mathrm{t}, \mathrm{p}$, c.g. trucarauc eompassionate $=$ Mid.W. trugarawc, Mod.W. trugarog, dacr tear $=$ Mid.W. dagyr, atar birds = Mid. W. adar, datl gl. foro = Mid. W. dadyl, etn bird=Mid. W. edyn, cepistyr halter (from Lat. capistrum) $=$ Mid. W. kebystyr. In Mid.W. g, $d, b$ are regularly written in the interior of a word (except that $c, t, p$ may appear in composition, e.g. rac-ynys fore-island, kyt-varchogyon fellowhorsemen, hep-cor to dispense with, or in inflexion and derivation under the influence of the simple word, e.g. gwlatoed, by gwladoed countries: gwlat, gwaet-lyt bloody: gwaet). But final $\mathrm{g}$ is regularly expressed by $\mathrm{c}$, and final $\mathrm{d}$ by $\mathrm{t}$ (except in certain MSS. such as BB. which express d regularly by $d$ and use $t$ to express the spirant d). Final $p$ for $b$ is not so universal; there are found, e.g. pawp, pop, everyone, every by pawb, pob, and mab son, heb said.

(c) The spirant $f$ is in $O . W$. written $f$, and this orthography survives in Mid.W., but the usual Mid.W. symbol is ff or ph. In 0 . W. the tenuis is sometimes traditionally written for the spirant, e.g. cilcet gl. tapiseta (from Lat. culcita) $=$ Mod.W. cylched.

(d) With regard to the graphic representation of the voiced spirants the following may be noted. $\mathrm{g}, \mathrm{d}, \mathrm{b}, \mathrm{m}$ were taken from Latin with their Latin values. In time, between vowels and before and after certain consonants, they became spirants $\overline{5}, \mathrm{~d}, \mathrm{v}$, but continued to be written $\mathrm{g}$, d, b, m, e.g. scamnhegint gl. levant=later ysgavnheynt, colginn gl. aristam $=$ Mod. $W$. colyn sting, cimadas fitting $=$ Mod. W. cyfaddas, abal apple = later aval. In $O$. W. the spirant $\mathrm{g}$ had already been lost in part, e.g. nertheint gl. armant by scamnhegint, tru wretched=Ir. truag wretehed. In Mid. W. the spirant $\mathrm{g}$ has disappeared. The spirant $\mathrm{d}$, which in Mod. W. is written dd, is in Mid. W. usmally expressed by d, e.g. rodi to give $=$ Mod.W. rhoddi, except in certain MSS. such as BB. which use the symbol $t$, e.g. roti=rhoddi. The spirant $v$ in Mid. W. is written $u, u u, v$, $\mathrm{fu}, \mathrm{f}$, the last particularly at the end of a word, (e.g. cyuadas, cyvadas, cyfuadas, cyfadas fitting $=0 . \mathrm{W}$. cimadas, Mod. W. cyfaddas), in Mod. W. f; in certain MSS., however, such as BB. it is expressed by w, e.g. calaw reeds =calaf. In $\mathrm{O} . \mathrm{W}$. final $\mathrm{v}$ has been already lost in part, e.g. lau hand = Ir. lānl, and in the course of time it tends more and more to disappear, e.g. in Mid.W. the superlative ending -af appears also as -a. 
(e) The guttural nasals ng (i.e. $\partial$ as in Eng. sing) and ngh are often written $\mathrm{g}$ and $\mathrm{gh}$, e.g. $\log =\mathrm{llong}$ ship, agheu death $=$ angheu.

(f) The voiceless 1 is in $0 . \mathrm{W}$. written 1 at the beginning of a word, e.g. lau hand=Mid.W. llaw, elsewhere 11, e.g. mellhionou gl. violas. In Mid.W. it is in all positions written 11 or $\Pi$. For the voiceless $\mathbf{r}=$ Mod.W. rh, Early Welsh has no special symbol; it is written $\mathbf{r}$.

(g) The semirowel $\mathrm{g}$ is in O.W. written $i$, e.g. iechuit gl. sanitas, mellhionou gl. violat: in Mid. W. it is expressed by $i$, e.g. ieith speech, or $y$, e.cr. engylyon ungels. In the initial combinations hw (from an earlier sv), which in Mid. W. appears as chw or dialectally as hw, and gw from an earlier $w), w$ is in $0 . W$. expressed by u, e.g. hui you = Mid. W. chwi, guin wine (from Lat. uinum) $=\mathrm{MI}$. W. gwin; in Mid. W. it is eommonly written 6 , w, but in some MSS. u, v, e.g. g6ynn, guynn, grynn white; but in Mid.W. O.W. initial guo- becomen go-. In other positions in Mid.W. w is expressed by $6, w$, sometimes by u, uu, $v$; here it comes from 0 . W. gu, e.g. $O . W$. neguid nev=Mid.W. newyd, neuyd, neuuyd, nevyd, 0 . Il' petguar four=Nid. W. petwar, petuar, petvar. It is to be noted that initial $g w$ from an earlier $w$ does not form a syllable even before a consonant; thus gwlad country from *ulatis=Ir. flaith kingdom is monosyllabic.

\section{The ACCEnT.}

4. In accented words in Mod.W. the accent, with certain exceptions, falls on the penult, e.g. pechádur simer, tragywyddol eternal. This accentuation, however, has replaced an earlier system which was common to all the British dialects and is still preserved in the Breton dialect of Vannes, according to which the accent fell on the last syllable, e.g. parawt ready. The effect of this earlier accentuation is seen in the weakening of vowels in syllables that according to the later system would have borne the accent, e.g. pechadúr sinner from Lat. peccātōrem: pechaẃt sin from Lat. peccātum, O.W. Dimét, Mid.W. Dyvet: Demetae, O.W. hinhám, Mid.W. hynhaf oldest : hen old, Mid.W. llynghes fleet: llong ship, O.W. cilchét, Mid.W. cylchet from Lat. culcita, Mid.W. drysseu doors: drws door. The date of the change of accent has not yet been accurately fixed; with it seems to be connected the change of aw to $o$ in final syllables, e.g. Mid.W. pechawt $=$ Mod.W. pechod, of which there are sporadic instances in early Mid.W., e.g. rymdywod (=rym dywawt), BB. $28^{2}{ }_{3} 3$. 


\section{Changes of Vowels.}

Changes due to a vowel which follows or which originally followed.

5. The quality of a vowel is liable to be influenced by the vowel of the following syllable. Sometimes the infecting vowel remains, e.g. Ceredic from Old British Coroticus, eyt goes $=$ O.W. egit by O.W. agit, menegi to show by managaf $I$ show. Sometimes the infecting vowel has been lost, e.g. trom f. by trwm m. heavy from ${ }^{*}$ trummā, ${ }^{*}$ trummos (where it will be seen that the short vowel of the masculine exerted no influence, while the long vowel of the feminine did), brein ravens (by bran raven) from *brani, earlier *branoi, cyrn horns (by corn horn) from * cornī, earlier *cornoi, dreic dragon (by pl. dragon) from *dracī, from *dracū from Lat. dracō, ceint $I$ sing (by cant he sang) from * ${ }^{*}$ canti, from * cantū, from * cantō, Meir from Lat. Maria, yspeil spoil from Lat. spolium. The infection may extend back more than one syllable e.g. menegi: managaf, deveit sheep: davat a sheep. The following are the changes of the kind which are important for inflection :-

\section{A. Changes due to an $i$ Vowel Preserved.}

6. a > e, e.g. ederyn a bird: adar birds, peri to cause: paraf I cause, edewis he promised: adaw to promise, cerit was loved: caru to love, llewenyd, O.W. leguenid joy: llawen joyous.

ae > ei, e.g. meini stones: maen stone, seiri artisans: saer.

\section{B. Changes due to a Lost Vowel.}

7. (a) The lost vowel is $\bar{a}$.

y $>$ e, e.g. berr f.: byrr m. short. The variation in brith, f. braith variegated is of the same kind; brith comes from *mrictos, braith from *mrectā, *mrictā.

$\mathrm{w}>$ o, e.g. trom f.: trwm m. heavy.

(b) The lost vowel is $\mathbf{i}$ (of various origin).

a > ei, e.g. meib sons: mab son, meneich monks: manach 
monk; geill is able: gallaf $I$ am able, gweheird he forbids: gwahardaf $I$ forbid, ceint $I$ sang: cant he sang.

ae $>$ ei, e.g. mein stones: maen stone, Seis Saxon (from *Saxī, *Saxū, Saxō): Saeson (from Saxŏnes).

Final aw $>$ eu, $y$, e.g. teu is silent: tawaf I am silent, edeu, edey, edy leaves: adawaf $I$ leave.

e $>$ y, e.g. hyn older: hen old, cestyll castles: castell castle, gwyl sees: gwelaf $I$ see, gweryt helps: gwaret to help.

o > y, e.g. pyrth gates: porth gate, escyb bishops: escob bishop, tyrr breaks: torraf I break, egyr opens: agoraf I open, try turns: troaf $I$ turn.

oe > wy, e.g. wyn lambs (from ${ }^{*}$ ognī): oen lamb (from *ognos).

$\mathrm{w}>\mathrm{y}$, e.g. bylch gaps: bwlch gap, yrch roebucks: ywrch roebuck.

NoтE 1.--In the $3 \mathrm{sg}$. pres. indic. act. of the verb the prelistoric ending is uncertain; geill might come phonetically from either *gallit or * gallyet. In verbs containing radical o, infection is found only in the $3 \mathrm{sg}$. pres. indic. act., e.g. tyrr he breaks, but torri to break, torrynt they broke, torrir is broken. In shaping the conjugation of these verbs analogy seems to have played a large part, but the details of the development are obscure.

NoTe 2.-It will be observed that in the case of $\mathrm{i}$ infection the infection extends back to a preceding a, e.g. deveit, edewis, egyr.

NoTE 3.-There is also a variation between ae and eu, ei, e.g. caer eity : pl. ceuryd, ceyryd; aeth he went: euthum I went.

\section{Vowel Variation due to Accent.}

8. Celtic $\overline{\mathbf{a}}$ became in British ō; the ō stage is seen in Bede's Dinoot from Lat. Donātus, and in early Irish loanwords which came from Latin through Britain, e.g. trindōit Trinity from Lat. trinitātem. In Welsh, during the period of the older accentuation this $\bar{o}$ became in accented syllables aw, e.g. Dunaẃd, trindaẃt, in unaccented syllables $\mathbf{o}$. To this are due variations like O.W. cloriou gl. tabellae: sg. clawr, Mid.W. marchogyon horsemen: marchawc horseman, moli to praise: mawl praises, and the proclitic pob every (=Ir. căch): accented pawb everyone (=Ir. cãch). After the shifting of the accent from the ultima to the penult, aw in accented words of more than one syllable became $\mathbf{0}$, 
e.g., Mod.W. márchog = Mid.W. marchawc, but Mod.W. paẃw $=$ Mid.W. pawb. For other instances of vowel weakening in unaccented syllables see $\$ 4$.

\section{Prothetic Vowel.}

9. Before words which in O.W. began with $\mathrm{s}+$ consonant there developed in the Mid.W. period a prothetic y, e.g. ysgriven writing: O.IV. scribenn, ystavell chamber: O.W. stabell, ystrodur packsaddle: O.W. strotur, yspeil spoil: O.W. * speil, from Lat. spolium.

\section{EPENTHETIC VoweL.}

10. Before a final liquid, nasal, or $\mathbf{v}$, an epenthetic vowel is often written, which, however, does not count metrically as a syllable.

(a) Consonant +1 , e.g. mynwgyl by mynwgl neck $=$ Mod. W. mynwgl; kenedel, kenedyl by kenedl race=O.W. cenetl, Mod.W. cenedl; kwbwl, kwbyl by kwbl whole = Mod.W. cwbl; tavyl sling = Mod.W. tafl.

(b) Consonant $+r$, e.g. hagyr by hagr $u g l y=$ Mod.W. hagr; lleidyr by lleidr robber=Mod.W. lleidr; llestyr vessel $=$ O.W. llestr, llestir, Mod.W. llestr; dwvyr, dwvwr by dwvr water $=$ Mod.W. dwfr.

(c) Consonant $+\mathrm{m}$, e.g. talym space $=$ Mod.W. talm.

(d) Consonant $+\mathrm{n}$, e.g. gwadyn by gwadn sole $=$ Mod. $\mathrm{W}$. gwadn; dwvyn deep = Mod.W. dwfn.

(e) Consonant $+\nabla$, e.g. dedyf custom $=$ Mod.W. deddf; baraf, baryf beard = Mod.W. barf; twrwf, twryf by twrf noise.

\section{Consonantal Changes.}

II. The following changes of consonants in combination are of importance for accidence :-

(a) In the Indo-Germanic parent language $d$ or $t+t$ became $t^{\text {st }}$, and $t^{8} t$ in Celtic became ss, e.g. W. llas was killed = Ir. -slass from *slat'tos : llad kill=Ir. slaidid hews. 
(b) act >aeth, or, with $\bar{i}$ infection, > eith; ect $>$ eith; wct $>$ wyth; wcn, wgn > wyn, e.g. aeth he went from *act, but imdeith I travelled from *actī (earlier *actū, *actō): Mid.W. eyd goes $=\mathrm{O} . \mathrm{W}$. egit, agit ; dyrreith he returned, from ${ }^{*}$-rekt : $\sqrt{ }$ reg-; amwyth he defended from *amukt: amwgaf $I$ defend, of which the verbal noun is amwyn from *amucn...

(c) rt > rth, e.g. cymmerth he took from ${ }^{*}$ com-bert: cymmeraf I take.

(d) Before a labial $\mathbf{n}$ becomes $\mathrm{m}$, e.g. $\mathbf{y}$ maes in the field from yn maes.

(e) $\mathrm{nd}, \mathrm{mb}>\mathrm{nn}, \mathrm{mm}$, e.g. vyn nyvot, vy nyvot my coming from vyn dyvot; ym mwyt, y mwyt into food from yn bwyt.

(f) nc, nt, mp. At the end of a word nc, mp remained, e.g. ieuanc young, pump five; nt remained in accented monosyllables, e.g. dant tooth (but proclitic can, gan with=O.W. cant); in words of more than one syllable it appears as nt or $n$, e.g. ugeint and ugein twenty, carant and caran they love. In the interior of a word nc, nt, mp develop regularly in the penultimate syllable to $\mathrm{ng}, \mathrm{nn}, \mathrm{mm}$, in the antepenult to $\mathrm{ngh}, \mathrm{nh}, \mathrm{mh}$, e.g. tranc cessation: trengi to cease; angen necessity (from *ancen =Ir. ècen): anghenawc necessitous; O.W. hanther half, later hanner; dant tooth: danned teeth: danhedawc toothed; O.W. pimphet fifth, later pymmet; cymmell compulsion (from Lat. compello): pl. cymhellyon. The regular development, however, is liable to be affected by analogy.

NoTE 1.- The cause of the different treatment in the penult and the antepenult is the accent. In early W. the accent was on the last syllable (\$ 4); the syllable immediately preceding the accent would be most weakly accented, the syllable before that would have a secondary accent, e.g. änghenawc, dănhedaẃc, cy̆mhellyón.

(g) Before h-

(a) $\mathrm{g}, \mathrm{d}, \mathrm{b}$ become tenues, e.g. teckaf most beautiful from *teg-haf: tec (phonetically teg) beautiful, tebycko from *tebyg-ho he may think: tebygu to think, plyckau to fold from * plyg-hau : plyc (phonetically plyg) fold; calettaf hardest from ${ }^{*}$ caled-haf : calet (phonetically caled) hard, cretto he may believe from ${ }^{*}$ cred-ho: 
credu to believe, bwyta to eat from *bwyd-ha: bwyt (phonetically bwyd) food; cyvelyppaf most like from ${ }^{*}$ cyvelyb-haf: cyvelyp (phonetically cyvelyb) like, attepo from *ad-heb-ho he may answer: attebu, digaplo he may cease to calumniate from *digabl-ho: digablu, llwyprawt from *llwybr-hawt will course: llwybraw to course.

$(\beta)$ đ becomes th, e.g. diwethaf last from *diwed-haf : diwed end, rotho he may give from *rod-ho: rodi to give, rythau to set free from *ryd-hau: ryd free.

$(\gamma) \mathrm{v}$ becomes f, e.g. tyffo he may grow from *tyv-ho: tyvu to growe, dyffo he may come: dyvod to come, coffau to remember from *cov-hau : cof memory.

NOTE 2.-Instances of $\mathrm{ff}$ from $\mathrm{v}$-h are not numerous, they have commonly been replaced by analogical forms, e.g. araf-hau to make gentle, digrif-af most entertaining. So th from $\mathrm{d}+\mathrm{h}$ becomes rarer and rarer in Mid.W., where e.g. rotho is replaced by rodho and rodo; the old forms are most persistent in the case of the tenues c, t, p. (ef. \$ r ro)

(f) th $+\mathrm{d}>$ th, e.g. athiffero who may defend thee from ath-differo. But here commonly the $\mathrm{d}$ is written etymologically.

(g) $d+d$ became apparently d, e.g. adyn zeretch from ad-dyn (ad-=Ir. aith-, with sense of Lat. re-).

\section{Sound-Changes within the Sentence.}

I2. Within the sentence closely connected word groups are liable to changes similar to those that take place within individual words. As within the word vowel-flanked consonants were reduced, e.g. cegin kitchen from Lat. coquina, niver number from Lat. numerus, so in a word group, e.g. *tōtā mārā great people became tud vawr. As within the word nc became ngh, nt became nh, mp became mh ( $\$ I$ ), nd became nn, e.g. crwnn round by Ir. cruind, $\mathrm{mb}$ became $\mathrm{mm}$, e.g. camm crooked from Old British cambos, so in word groups, e.g. vyn cynghor my counsel became vy ghynghor, vyn penn my head became vym penn, vy mhenn, vyn dyvot my coming became vyn nyvot, yn bwyt into food became ym mwyt, y mwyt. But, on the one hand, a 
particular mutation may spread analogically, if it becomes connected with some grammatical function; thus in Welsh it became the rule that after all feminine nouns in the singular a following adjective was mutated, though in Celtic only certain classes of feminine nouns ended in a vowel. On the other hand, the change may analogically disappear altogether, or the mutation may be restricted to certain phrases as in the case of the nasal mutation after numerals $(\$ 20 \mathrm{c})$. In sound groups there are three kinds of initial change ( $\mathrm{I}$ ) vocalic mutation or lenation, which originated from cases where the preceding member of the group originally ended in a vowel, (2) nasal mutation where the preceding member originally ended in $\mathbf{n}$, (3) spirant mutation where the preceding member ended in certain consonants, most commonly $\mathbf{S}$ but also $\mathbf{c}$.

NoTE.-In reading Early Welsh texts the student must be careful not to be misled by the orthography, which does not consistently express the initial changes. Thus if he should neet with, e.g. $\mathrm{y}$ gwlat the country for y wlat, or vyn dyvot for vyn nyvot, that is only an arehaistic or etymological ortlography which is no evidence of the actual sound at the time.

\section{r3. Table of Consonant Mutations.}

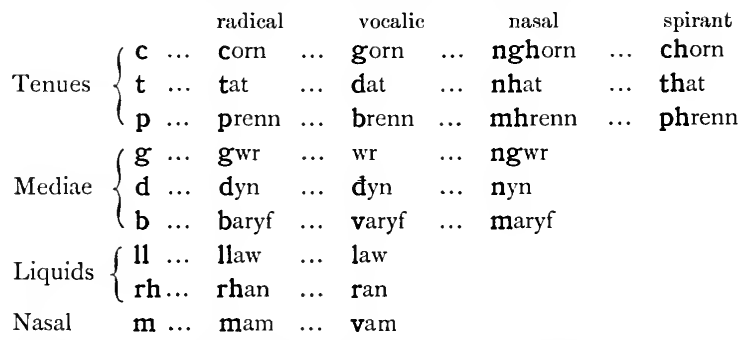

NoTE 1 .- In vocalic mutation $g$ became first the spirant 3 , which was early lost (\$ 3d). From the fact that initial $\mathrm{g}$ was thus lost, many words which originally began with a vowel in time assume an initial $\mathrm{g}$; e.g. y ord his hammer (=lr. ord) resembled externally y wr his man, and this superficial resemblance led to gord (for ord) like gwr. The principle is the same as in the development of initial $f$ before a vowel in Mid.Ir.

NoTE 2.-As in Mid.W. the spirant is commonly written $d(\S 3 \mathrm{~d})$, the vocalic mutation of initial $d$ is not discernible in writing.

NoTE 3. - In Mid.W. initial rh is written $r$, so that the unmutated and the mutated forms are indistinguishable $(\$ 3 \mathrm{f})$. 


\section{Vocalic Mutation or Lenation.}

14. The history of Welsh lenation has still to be written. In some respects, particularly with regard to lenation after the verb, the subject is full of difficulty. In the development of lenation analogy played a large part, so that to some extent the usage would differ at different periods. And the fixing of the rules of lenation for a particular period is complicated by the fact that the mutation is not consistently expressed in writing. The following are the chief facts about lenation in Mid. W. prose; the material is taken from the Red Book of Hergest.

15. General exception to the rules of lenation. After final $\mathbf{n}$ and $\mathbf{r}$ initial $\mathbf{l l}$ and $\mathbf{r h}$ were regularly unmutated, e.g. yn llawen gladly, y llaw = O.W. ir lau the hand. For th the rule is seen in Mod.W., e.g. yn rhydd freely, y rhan the part. As rh was not written in Mid. W. this distinction is not discernible there.

\section{A. Lenation of Noun and Adjective (including nominal ADJECTIVAL PRONOUNS).}

I6. (a) After the article.

After the article in the sg. fem. the initial consonant of a following noun or adjective is lenated, e.g. y gaer the city, yr dref to the town, y vrenhines the queen. But y llaw the hand ( $\mathrm{I}_{5}$ ).

(b) After the noun.

(a) After a noun in the feminine singular or the dual an adjective is lenated, e.g. morwyn benngrech velen a curlyhaired auburn maid, deù vilgi vronwynnyon vrychyon two whitebreasted brindled hounds. Also when the adjective is separated from the noun, e.g. kaer uawr a welynt, vwyhaf or byt they saw a large town, the largest in the world.

NOTE 1.-After the masc. sg. and the plur. lenation of the comparative is found in sentences of the following type: ny welsei dyn eiryoet llu degach. . . noc oed hwnnw no man had ever seen a host fairer than that RB. 90,13; na welsynt llongeu gyweiryach y hansawd noc wynt that they had not seen ships better equipped than they RB. $27,3$. 
( $\beta$ ) After a noun in the fem. sg. or the dual a following genitive is lenated when it is equivalent to an adjective, e.g. kist vaen a stone chest; deu vaen vreuan two millstones.

Note 2.-The genitive is lenated after meint, ryw, kyvryw and sawl (\$ 76-7), e.g. y veint lewenyd the amount of gladness; pa ryw wysc what kind of dress? kyvryw wr such a man; y sawl vrenhined all the kings. Further, the genitive of proper names is lenated after certain nouns, e.g. Cadeir Vaxen Maxen's Seat; Caer Vyrdin Carmarthen; Llan badarn lit. Padarn's Church; Ynys Von Island of Mon; Eglwys Veir Mary's Church; Gwlat Vorgan the land of Morgan ; pobyl Vrytaen the people of Britain; ty Gustenin the house of Custenin (cf. Mod.W. ty Dduw); mam Gadwaladyr mother of Cadwaladr; Branwen verch Lyr Branwen daughter of Llyr; gwreic Vrutus wife of Brutus; deu vab Varedud two sons of Mareulud.

$(\gamma)$ After proper nouns there is lenation of a following noun or adjective denoting a characteristic of a person, e.g. Llud vrenhin King Llud, Peredur baladyrhir Peredur of the long spear.

No'TE 3.-The initial consonants of mab son and merch llaughter are lenated, e.g. Pryderi uab Pwyll Pryderi son of Puyll, Aranrot verch Don Aranrod daughter of Don.

NOTE 4.-Further instances of lenation in apposition are, e.g. ewythred Arthur oedynt, urodyr y nam they were uncles of Arthur, his mother's brothers, Giluaethwy ac Euyd . . . y nyeint, ueibion y chwaer Gilvaethwy and Evyd his nepheu's, his sister's sons. Aranrot nereh Don dy nith, uerch dy chwaer Aranrot daughter of Don thy niece, thy sister's danghter.

( $\delta)$ Lenation is found in the genitive of the verbal noun, particularly when it is separated from the governing word, e.g. menegi uot y crydyon wedy duunaw declaring that the cobblers had united; a dyuot ... yn y vedwl uynet y hela and it came into his mind to go to hunt; a ryuedu o Owein yr mackwy gyuarch gwell idaw and Owein zeondered that the youth should greet him.

(c) After the adjective.

(a) When an adjective in the positive degree precedes, the noun is lenated, e.g. brawdoryawl garyat brotherly love, dirvawr wres excessive heat, amryuaelyon gerdeu divers songs. So after the pronominal adjective holl all, e.g. holl gwn all the dogs, holl wraged all the women.

NoTe 5.-For the comparative the material to hand from RB. is seanty ;

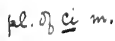
with lenation: yn llei boen less pain 146, without lenation: mwy gobeith greater hope 95, muscrellach gwr a more helpless man 13 . In $\mathrm{KB}$. II. 
there are some instances of lenation after mwy more. After the superlative in RB. non-lenation seens to be the rule; in RB. II. lenation is more frequent.

Note 6.-In Celtic, when the adjective preceded the noun, it formed a compound with it, e.g. hen-wrach old hag (\$ 34a), and in composition the lenation of the second element was regular, e.g. eur-wisc golden dress, bore-vwyt morning-food, brealfast. In Welsh, when the adjective came to be used freely before the noun, the lenation of the old compounds was retained in the positive.

NoTE 7.-On the analogy of lenation in compound words and of lenation of the noun following the adjective, in poetry, when the genitive precedes the noun, it may lenate, e.g. byd lywyadwr the ruler of the uorld, o Gymry werin of the host of the Cymry.

$(\beta)$ When an adjective is repeated, e.g. mwy vwy vyd greater and greater will be.

(d) After YN forming adverbs, and with predicative nouns and adjectives ( $\$ 35)$, e.g. yn vynych often, yn borth as a help, yn wreic as a wife. But yn llawen gladly (\$ I5).

Note 8. -With regard to their influence upon a following word it is necessary to bear in mind that predicative yn lenates, that $\mathrm{yn}$ in is followed by the nasal mutation ( $\$ 20 \mathrm{~b})$ and that yn with the verbal noun, e.g. yn mynet going (\$ 126a), does not affect a following consonant.

(e) After numerals.

(a) After cardinal numbers.

un one. After the fem., lenation seems to be regular, e.g. un wreic one woman, un vil one thousand, yr un gerdet the same going. Initial 11 is regularly uninfected, e.g. un llynges one fleet. After the masc. the usage seems to vary, e.g. vn geir one word RB. $197=$ WB. 123 , but vn eir RB. II. 222, yr un march the same horse RB. 9, but neb vn varchawc any horseman RB. II. 278 , yn un uaes in one field RB. Ir 4 .

Note 9.-In Irish, oin regularly mutates a following consonant. According to Rowlands, Mod. W. un mutates in the fem.

deu, dwy two. After these lenation is regular, e.g. deu barchell two pigs, deu lu two hosts, dwy verchet two daughters. But deu cant tzero hundred RB. II. passim.

chwech, chwe six:-chwech wraged six women RB. I8, I6 ; but chwe blyned six years RB. II. 387, 404.

seith seven: seith gantref seven cantreds RB. 25,44 , seith 7. years cata $\bar{\pi}$ mumerals) gelfydyt seven arts RB. II. 200, seith wystyl seven hostages RB.

celfygyd, $f$. an ant; $k$ l. celfygoden gurystyl, m. a hostage; ple gurystion. 
II. 327. But usually without lenation seith cantref, seith cuppyt seven cubits, seith cant seven hundred, seith punt seven pounds, seith meib seven sons. mab; kl. meib, meibon; for fel $0.42 a$.

wyth eight: wyth drawst eight beams RB. I I I, 2 I, wyth gant eight hundred RB. II. 386, but wyth cant 39, 40, 230, 257, 258, $3^{8} 5$, wyth temyl eight temples IoI, wyth tywyssawc eight chiefs 14 .

naw nine. After this lenation is occasionally found, e.g. naw grag f. step:- - en rad nine ranks LA. I 7 .

mil thousand: mil verthyr a thousand martyrs RB. II. I99.

10.- In pumwyr five men, seithwyr seven men, nawwyr nine men, canwr a hundred men, there seems to be composition.

$(\beta)$ After ordinal numbers.

After the feminine ordinals from three onwards there is lenation, e.g. y dryded geinc the third branch, y seithvet vlwydyn the seventh year, yr vgeinuet vlwydyn the twentieth year.

11.--The same rule seems to hold with eil other, second, e.g. yr eil marchawc the seeond horseman, but yr eil vlwydyn the second year, and with neill one of tro, e.g. y neill troet the one foot, but y neill law the one hand.

(f) After the pronoun.

(a) After the possessives dy thy and y his, e.g. dy davawt thy tongue, ath lu and thy host; y benn his head, ae rud and his cheek.

$(\beta)$ After interrogatives, e.g. pa le, py le where? pa beth what thing?

( $\gamma$ ) In apposition, e.g. ynteu Bwyll he Preyll, hitheu wreic Teirnon she the wife of Teirnon; ef Vanawydan he Manazeydan; on hachaws ni bechaduryeit because of us sinners.

(g) After the verb.

(a) After the verb lenation is found not only of the object but also of the subject, whether the verb immediately precedes the lenated form or is separated from it, e.g. mi a wnn gyghor da I know good counsel, y gwelynt uarchawc they saw a horseman, ny mynnei Gaswallawn y lad ynteu Caswallazen did not desire to slay him. The proportion of lenation to non-lenation differs 
in different parts of the verb. After certain parts of the verb lenation is absent or exceptional. Such are $3 \mathrm{sg}$. and $3 \mathrm{pl}$. pres. ind. act., 3 sg. pres. subj. act. and the passive forms. After the 3 sg. of the pret. ind. act. non-lenation of the subject is the rule; in RB. lenation of the object is occasionally found when it directly follows the verb, e.g. y kavas Uendigeit Uran he found Bendigeit Vran, frequently when the subject precedes it, e.g. y lladawd Peredur wyr yr iarll Peredur slew the earl's men.

$(\beta)$ After most of the forms of the verb "to be"lenation is found, most consistently in the predicate from its close connexion with the verb, but also in the subject whether it follows the verb immediately or is separated from it, e.g. ot wyt uorwyn if thou art a maid, yd ym drist ni we are sad, yssyd urenhin who is king, yssit le there is a place, nyt oed uwy it was not greater, oedynt gystal they were as good, mi a uydaf borthawr I am gatekeeper, ni a vydwn gyuarwyd we will be guides, ny bydei vyw he was not alive, y bydynt barawt they should be ready, ny buost gyvartal thou hast not been just, tra uu vyw while she lived, pan uuant veirw when they were dead, buassei oreu it would have been best, byd lawenach be more joyous, bit bont let him be a bridge, bydwch gedymdeithon be ye comrades, tra vwyf vyw while 1 live, tra vych vyw while thou livest, tra vom vyw while zee live, mal na bont ueichawc so that they may not be pregnant, pei bewn urathedic if $I$ were wounded, a vei vawr which should be great, gwedy $\mathrm{y}$ beym uedw after we were intoxicated, nyt oes blant t there is no offspring, budugawl oed Gei Kei was gifted, y hwnnw y bu uab to him there was a son, cyt bei lawer o geiryd though there were many cities, nyt oes in gyghor we have no counsel, oed well ytti geisaw it were better for thee to seek, tost vu gantaw welet it pained him to see. There is, however, no lenation after ys, e.g. ys gwir it is true (unless the subject be separated, e.g. kanys gwell genthi gyscu since she prefers to sleep); after nyt, nat, neut, e.g. nyt llei is not less, neut marw he is dead; after os, e.g. os gwr if he is a man; after ae e.g. ae gwell is it better? after yw, e.g. pan yw Peredur that it is Peredur (unless the subject be

caer, $f ; p$ ceyryg have, scuere. 
separated, e.g. hawd yw gennyf gaffel $I$ think it easy to get); after yttiw, e.g. a yttiw Kei yn llys Arthur is Kei in Arthur's court? after mae, e.g. $\mathrm{y}$ mae llech there is a flagstone (unless the subject be separated, e.g. y mae yma uorwyn there is here a maiden); after maent, e.g. y maent perchen there are oweners; after byd, e.g. ny byd gwell it will not be better (unless the subject be separated, e.g. or byd gwell genwch bresswylaw if ye think it better to dzell) ; after boet, e.g. poet kyvlawn dy rat titheu may thy prosperity be complete; after bo, e.g. pan uo parawt when it is ready (unless the subject be separated, e.g. pan uo amser in uynet when it is time for us to go).

(h) In adverbs and adverbial phrases.

In the interior of a sentence the initial consonant of an adverb or an adverbial phrase is often lenated, e.g. nyth elwir bellach byth yn vorwyn thou shalt never more be called a maiden, ny orffowysaf vyth $I$ will never rest, pan daeth y paganyeit gyntaf y Iwerdon when the pagans came first to Ireland, bydwch yma vlwydyn y dyd hediw be ye here a year to-day, bu farw ... . vis whefrawr she died in the month of February, pebyllaw a oruc lawer o dydyeu he encamped many days. In the same way lenation is found in preposition and suffixed pronoun, e.g. ny eill neb vynet drwydi no en-gyd m. strike, one can go through it, a gymero yr ergit drossof $i$ who shall take the blow, east. 'blow in my stead, hir uu gennyf i y nos honno that night seemed long to me.

NoTE 12.-In origin this is only a special case of post-verbal lenation, like the corresponding change in Irish, for which see Pedersen, KZ. xxxv. 332 sq.

NOTE 13.-Lenation is found of the initial consonants of some prepositions and conjunctions : $a r=0$.W. guar (Ir. for), gen by can, wedy by gwedy $=0 . W$. guetig, wrth $=0 . W$. gwrth, dan by tan, dros $=0 . W$. trus, drwy by trwy $=0$. W. troi, ban by pan, bei hy pei. The reason of the weakening here, however, seems to be that the words are pretonic.

(i) After the prepositions am, ar, att, $\underline{\text { can }}, \underline{\text { heb }}, \underline{\mathrm{o}}(\underline{\mathrm{a}}), \underline{\tan }$, tros, trwy, uch, wrth, $y$, and frequently after the nominal preposition hyt, e.g. am betheu about things; ar vrys in haste; att Bwyll to Pwyll; gan bawb with every one; heb vwyt without food; o gerd of music; dan brenn under a tree; dros 
vor across the sea; trwy lewenyd through joy; uch benn above; wrth Gynan to Cynan; y vynyd upzerards; hyt galan Mei till the first of May.

(k) After a negative in phrases like na wir it is not true RB. I0.5; na well it is not better RB. 61.

(1) After mor how, so and neu or, e.g. mor druan how wretched; neu vuelyn or horn.

(m) After interjections.

(a) The vocative is lenated after a, ha, oia, och, ub e.g. a vorwyn $O$ maiden; oia wr ho! man; och Ereint alas! Gereint; ub wyr alack! men. But without any preceding particle lenation of the vocative is found, e.g. dos vorwyn go, maiden.

( $\beta$ ) After llyma, llyna, and nachaf, e.g. llyma luossogrwyd yn ymlit see! there is a host following RB. II. 302 ; llyna uedru yn drwc there is bad behaviour; nachaf uarchawc yn dyuot behold! a horseman was coming.

\section{B. Lenation of the Pronoun.}

I7. The pronoun is lenated :-

(a) As subject or object, or emphasizing an infixed or suffixed pronoun or possessive adjective, e.g. elwyf ui $I$ might go, gallaf i $I$ can, ny buum drwc i $I$ was not evil, y rodaf inneu $I$ will give, arhowch uiui wait for me, na chabla di uiui do not blame me, nyt atwaenwn i didi $I$ did not recognise thee, ath gud ditheu which hides thee, ohonaf $\mathrm{i}$, ohonaf inneu by me, vy ysgwyd i my shield, dy

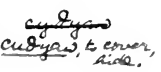
zgan? to grogi di thy hanging, dy lad ditheu thy slaying.

susif, haus. Note 1.-But after final $\mathrm{t} t$ is usual, e.g. y rodeist ti thou hast given, gan dy genyat ti with thy leave, dy vot titheu thy being.

(b) Sometimes in apposition, e.g. ni a awn ui a thi we will go, $I$ and thou, keisswn ninneu ui a thi let us seek, I and thou.

(c) After other lenating words, e.g. gwae vi woe to me, neu vinneu or $I$, neu ditheu or thou.

C 


\section{Lenation of the Verb.}

I8. The verb is lenated :-

(a) After infixed pronoun of sg. 2, e.g. yth elwir thou art called.

(b) After relative a, e.g. govyn a oruc he asked.

(c) After the interrogative pa, py, e.g. hyt na wydat pa (or py) wnaei so that she did not know what she should do; py liwy di why dost thou colour?

(d) When the copula follows the predicate (§ I59), e.g. llawen uu y uorwyn the maiden was glad.

(e) After the verbal particle yt (§ 9I note 2 ) in the older language, e.g. yt gaffei he should get.

(f) After the verbal particle ry (but cf. $\$ 2$ I note), e.g. ry geveis I have got. Similarly after neur ( $\$ 95$ note), e.g. neur gavas he has got.

peri, to cause, make, (g) After the interrogative a, e.g. a bery di woilt thou effect?

(h) After the conjunctions pan, tra, yny, e.g. pan golles when parhion, to remann, he lost, tra barhaawd while it lasted, tra vwyf as long as I am, yny glyw till he hears, yny welas till he saw, yny vyd till he is.

(i) After the negatives ny (including ony, pony) and na (with the exception of the tenues $\$ 2$ Ie), e.g. ny allaf $I$ cannot, ny ladaf $I$ will not slay, kany vynny since thou dost not desire, pony wydut ti didst thou not know? na ovyn di do not ask, Duw a wyr na ladaf i God knows that I will not slay.

NoTE.-But after ny, na the rule of lenation is not absolute. In particular initial $\mathrm{m}$ is commonly unchanged, e.g. ny mynnaf $I$ do not desire, hyt na mynnei so that he did not desire. Further, initial b of forms of bot to be is commonly unlenated, e.g. ny bu gystal it was not so good; a wypo na bo miui who shall know that it is not I. But in the imperative lenation seems to be the rule, e.g. na uit amgeled gennwch be not troubled. Nonlenation after ny comes from the oll non-relative forms (\$2I note). $\mathrm{Na}$ originally ended in a consonant (nac), so that after it the lenation is irregular; so far as it lenates it lias followed the analogy of ny.

\section{Nasal Mutation.}

I9. Nasal mutation is very irregularly written in Mid.W.MSS. The mutation of $\mathbf{n c}$ is expressed by $\mathbf{g k}$ or $\mathbf{g h}$, the mutation of $\mathbf{n t}$ 
commonly by $\mathrm{nt}$, rarely by $\mathrm{nh}$, the mutation of $\mathrm{mp}$ commonly by $\mathrm{mp}$, sometimes by $\mathrm{mph}$ or $\mathrm{mh}$. The mutation of $\mathrm{ng}$ is expressed by $\mathrm{gg}$ or $\mathrm{ngg}$, the mutation of $\mathrm{nd}, \mathrm{nb}$ by $\mathrm{n}$ or $\mathrm{nd}$, and $\mathrm{m}$ or $\mathrm{mb}$.

20. Nasal mutation is found :-

(a) After vyn $m y$, e.g. vygkynghor, vyghynghor my connsel, vyntat, vynhat my father, vympenn, vymphen, vymhen $m y$ head, vyggwreic (gwreic) my zeife, vynggwely my bed, vynyvot, vyndyvot my coming, vymaraf (baraf) my beard. baryf.

(b) After yn in, into, e.g. ygkarchar, ygharchar in prison, ymperved, ymherved in the centre, ymhoen (poen) in punishment; yn diwed (=yn niwed) in the end; ymbwyt, ymwyt (bwyt) into food.

(c) In certain phrases after numerals (chiefly with blyned years and dieu, diwarnawt days), e.g. pump mlyned five years, chwech mlyned RB. II. 397 (more usually chwe blyned) six years, seith mlyned seven years, wyth mlyned eight years, naw mlyned nine years, naw nieu nine day's, deng mlyned ten years, dec nieu ten days, deudec niwarnawt twelve days, pymtheng mlyned fifteen years, ugein mlyned twenty years, deugeint mlyned forty years, cant mlyned a hundred years, can mu a hundred kine, trychan $\mathrm{mu}$ three hundred line.

NoTE. - This usage started from those numerals which in Old Celtic ended in $\mathrm{n}$ : seith (ef. Ir. secht $\mathrm{n}$-, Lat. septem; final $\mathrm{m}$ in Celtic became $\mathrm{n}$ ), naw (ef. Ir. nōi n-, Lat. novem), dec (ef. Ir. deich n-, Lat. decem), cant (ef. Ir. cêt n-, Lat. centum).

\section{Spirant Mutation.}

2I. This is found :-

(a) After the numerals tri three and chwe(ch) six, e.g. tri chantref three cantreds, tri pheth three things, chwe thorth six loaves.

(b) After y her, e.g. y chlust her ear, y throet her foot, y phenn her head.

(c) After the prepositions ac, a with, tra beyond, e.g. a chledyf with a sword, a thi with thee, tra thonn beyond wave. 
(d) After the conjunctions a(c) and, no(c) than, o if, e.g. mam $\frac{\text { Froed ma foot; }}{\text { ke. truid }}$ a that father and mother, traet a phenn feet and head; gwaeth no chynt worse than before: o chigleu if he has heard.

NoTE 1.-After $\mathrm{kwt}$ where spirant change is found: $\mathrm{cv}$ threwna where it settles BB. $44^{\mathrm{b}}$, but $\mathrm{kwt}$ gaffei (caffei) where he should get WVB. 453 ; $\mathrm{cf}$. cud vit BB. $44^{\mathrm{b}}$, cwd uyd where it will be FB. 146.

(e) After the negatives ny and na(c), e.g. ny chysgaf $I$ will not sleep, ny thyrr does not break, ny phryn does not buy; na chwsc do not sleep, na thorraf that I do not break, na marchawc na phedestyr neither horseman nor footman.

NoTE. 2.-But in the early poetry ny produces the spirant change only when it is non-relative; when it is relative a following $\mathbf{c}, t$, or $\mathrm{p}$ is lenated, e.g. ny char he does not love, but ny gar who does not love. In the early poetry there is the same diflerence of treatment after the verbal particle ry, e.g. ry charas has loved, ry garas who has loved. This distinction letween non-relative and relative forms must have extended to all consonants capable of mutation, but in the case of the other consonants confusion set in earlier. In later Mid. W. after ny the non-relative form has been generalised in the case of words beginning with $c, t, p$, the relative form, with certain exceptions, in the case of words beginning with other mutable consonants (ef. $\$ 18$ i). After ry the relative form was generalised. For further details see Eriu III. pp. $20 \mathrm{sq}$.

\section{$\mathrm{h}$ in Sentence Construction.}

22. After certain words $\mathrm{h}$ appears before a following word beginning with a vowel.

(a) After the infixed and the possessive pronoun m, e.g. am $\mathrm{h}$ ymlityassant who follozed me, om h-anvod against my zeill.

(b) After the infixed pronoun e, e.g. ae h-arganvu who perceived him.

(c) After y her, e.g. y h-enw her name.

NoTE.-In Irish also h appears after a her, e.g. a h-ainm her name. The Irish and Welsh $\mathrm{h}$ here comes from the original tinal $\mathrm{s}$ of the possessive.

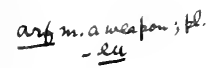

(d) After an our, e.g. an h-arueu our arms.

(e) Aften eu, y their, e.g. eu $\bar{h}$-arueu their arms.

(f) After ar before ugeint twenty, e.g. un ar h-ugeint twenty one. 


\section{THE ARTICLE.}

23. In O.I. the article is ir throughout, e.g. ir pimphet eterin the fifth bird, dir finnaun to the fountain. In Mid.W. yr remains before vowels and h, e.g. yr amser the time, yr alanas (from galanas) the bloodfine, yr henwr the old man; before other consonants except $\mathrm{y}$ it becomes $\mathrm{y}$, e.g. $\mathrm{y}$ bwyt the food, y wreic (from gwreic) the woman; before $y$ the usage varies, e.g. yr iarll or $\mathrm{y}$ iarll the earl. But if the article be fused together with a preceding conjunction or preposition, or if the $\mathrm{y}$ be elided after a preceding vowel, then ' $r$ remains, e.g. y nef ar dayar heaven and earth, yn gyuagos yr gaer near to the city, gwiryon yw'r uorwy்n ohonof $\mathrm{i}$ the maiden is innocent as regards me.

\section{Syntax of the Article.}

24. (a) In addition to its use before common nouns the article appears regularly before the names of certain countries, such as $\mathrm{yr}$ Affrica Africa, yr Asia Asia, yr Alban Scotland, yr Almaen Germany, yr Eidal Italy, yr Yspaen Spain, e.g. vn yw yr Asia, deu yw yr Affrica, tri yw Europa Asia is one, Africa is two, Europe is three FB. 216. Occasionally the article appears before names of persons, e.g. yr Beli mawr (=y Beli uawr WB. r9r) to Beli the Great RB. 93, 2; mwyhaf oe vrodyr y karei Lud y Lleuelys Llud loved Llevelys more than any of his other brothers ib.

(b) The article is not used before a noun followed by a dependent genitive, e.g. gwyr ynys y kedyrn the men of the island of the strong, unless it be accompanied by a demonstrative pronoun, e.g. or meint gwyrtheu hwnnw from that amount of miracles, or unless the genitive be the equivalent of an adjective, e.g. y werin eur the golden chessmen, y moch coet the wild pigs (lit. the pigs of the wood), $\mathrm{y}$ peir dateni the cauldron of rebirth, the regenerative cauldron. 


\section{THE NOUN. \\ Numbers and Cases.}

25. In Welsh the old Celtic declension is completely broken down. Of the three genders the neuter has been lost. The dual, which, as in Irish, is always preceded by the numeral for two, in some classes of nouns would phonetically have fallen together with the singular; in Welsh this has been generalised so that the dual (apart from forms like deu ychen tze oxen) coincides in form with the singular; a trace of the dual inflection remains in the lenation of a following adjective, e.g. deu vul gadarn (from cadarn) two strong mules, deu vilgi vronwynnion vrychion tzo whitebreasted brindled greyhounds. In the regular inflexion there remains only one case for each number; in the singular this corresponds sometimes to the old nominative, e.g. car friend=Ir. carae, sometimes to the form of the oblique cases, e.g. breuant zindpipe = Ir. brăge, g. brāgat; a few traces of lost cases still survive in phrases, e.g. meudwy hermit (lit. servant of God), where dwy is the genitive of duw; erbynn against ( = Ir. ar chiunn), where pynn (from * pendi, from * pendū) is the dative of penn head; peunyd every day, peunoeth every night, where peun-, which in O.W. would be *poun-, comes from *popn-, the old accusative singular of pob every.

\section{Syntax of the Cases.}

26. As in Irish, the nominative may stand absolutely at the beginning of the sentence to introduce the subject of discourse, e.g. y wreic honn ym penn pythewnos a mis y byd beichogi idi, lit. $(M-8 \cdot, 149)$ this zoman, at the end of a fortnight and a month there will be conception to her. In prose the genitive follows the noun on which it depends, e.g. enw y mab the name of the son; in poetry it may precede, e.g. byt lywaydur = llywaydur byt the ruler of the world; sometimes, as in Irish, it is used after an adjective meaning with respect to a thing, e.g. ny by்dy anuodlawn y phry்t thou wilt not 
be displeased with her form. The accusative can be recognised only from the construction; in poetry the accusative of a place-name is common after verbs of motion, e.g. dywed y down Arwystli say that we will come to A rwystli MA. I92

\section{Formation of the Plural.}

27. A. The plural is based on Old Celtic plural formations.

(a) Plural with $\overline{1}$ infection ( $\$ 7 \mathrm{~b})$, e.g. march horse: meirch, manach monk: meneich, maen stone: mein, oen lamb: wyn, asgell wing: esgyll, corn horn: cyrn, escob bishop: escyb, gwr man: gwyr.

Note I.-This represents the old plural formation of -o- stems, e.g. meirch from ${ }^{*}$ marcī from *marcoi. In part, however, it might represent the plural of -i-stems, ef. Ir. sñili eyes: sñil eye. In dagr tear the plur. deigr (=Ir. dēr) comes from *dacru, the phur. of a neut. -u- stem.

NoTE 2.-Many substantives which regularly form their plural otherwise, particularly such as form their plural in -ion, follow this inflexion after numerals above two, e.g. tri gweis three boys, seith meib seven sons s/unions fares. v. $M-g .212$ ke. dagram, s. N.P. raigrym] (GC. 2 283).

(b) Plural in -eu, -ieu (O.W. -ou, -iou), e.g. gen jaze: geneu, penn head: penneu, cledyf sword: cledyveu, pebyll tent: pebyllyeu, glin knee: glinyeu.

Note 3.--ou, -eu started from -oues, the nom. pl. of -u- stems, ef Gaulish Lugoves.

(c) Plural in -on -ion, e.g. medyc physician: medygon, cenaw zelp: cenawon, lleidr robber: lladron, mab son: meibyon, dyn man: dynyon, gelyn enemy: gelynyon. This is the common ending of adjectives.

NOTE 4.-morwyn maiden becomes in the plural morynyon.

Note 5.- -on is based on -ornes, the nom. pl. of masc, and fem. -n-stems, ef. Gaulish Lingones. The borrowed lleidr robber: lladron represents an older *latrī (from * latrū latrō): * "latrǒnes; similarly dreic dragon: dragon, Seis Saxon: Saeson.

(d) Other old consonantal plurals, e.g. car relative: carant (from * carants: * carantes = Ir. carae: carait), ci dog: cwn (from *kuū: *kunes), ych $o x$ : ychen, brawt brother: broder, troet foot: traet, ty house : tei (an old neut.-s-stem, cf. Ir. tech : 
tige). Under the influence of \$27a carant became cereint, broder became brodyr; in the same way may be explained nei nephew: neieint, gof smith: goveint. Some neut. -n-stems make their plur. in -ein, e.g. enw (O.W. anu) name: enwein, cam step: cemmein; here *-en might have been expected as in Ir. beim blow : bēmmen; the change of *-en to -ein may be explained as above.

28. B. The plural is formed by various suffixes, many of which appear in the formation of abstract nouns.

(a) -awr, -iawr, e.g. ysgwyt shield: ysgwydawr, gwaew spear: gwaywawr (also gwaewar, gwewyr), cat battle: cadyawr.

NoTs.-This formation is mostly poetical.

(b) -awt (=-awd), e.g. pysc fish: pyscawt, gorwyd steed: gorwydawt.

(c) -et (=-ed), e.g. merch daughter: merchet, pryf zxorm: pryvet.

(d) -ed (=-ed), e.g. bys finger: byssed, dant tooth: danned, gwreic woman: gwraged.

(e) -eit, -ieit (=-eid, -ieid), e.g. mil animal: mileit, barwn baron: barwneit, barwnyeit.

(f) -i, e.g. llestyr vessel: llestri, cawr giant: cewri, saer artificer: seiri.

(g) -ot (=-od), e.g. hyd stag: hyddot, llwdn beast: 1lydnot.

(h) -oed (=-oed), e.g. mor sea: moroed, ieith language: ieithoed.

(i) -yd (=-yd), e.g. avon stream: avonyd, gwlat country: gwledyd, chwaer sister: chwioryd.

29. C. Some nouns are collective, with a singular formation in -ynn masc., -enn fem., e.g. adar birds: ederyn a bird, calaf reeds: celevyn a reed, coll hazles: collenn a hazle, tywys cars of corn: tywysen a corn ear. 


\section{THE ADJECTIVE.}

\section{GENDER.}

30. There is a special form of the feminine only in the singular, and only in adjectives containing $\mathbf{y}, \mathbf{w}$, which in the feminine became e, o (\$7a), e.g. gwynn zhite: gwen, melyn yolloze: melen, bychan small: bechan, brith variegated: breith, llwmm bare: llomm, crwnn round: cronn.

In the singular the adjective is lenated after a feminine noun, e.g. gwreic dec a beautiful zoman ( $(\mathrm{I} 6 \mathrm{~b} a)$; in the plural there is no lenation.

Note.-In the Celtic adjective there were -0- stems, -i- stems and -ustems, which are distinguishable in O.Ir., e.g. tromm heavy from * trummo-s, cruind round from *crundi-s, and il much from *pelu-s. Only the -o- stems had a fem. in $-\bar{a}$, so that only in these is the Welsh change of vowel etymologically justified. But in Welsh, after the loss of final syllables, the three classes were indistinguishable in the nasculine, and the vowelchange in the feminine spread analogically from the -o- stems to the others, e.g. crwnn from * crundis formed a feminine cronn after the analogy of tromm : trwmm, etc.

\section{Formation of the Plural.}

3r. The plural is formed:-

(a) By change of vowel e.g. bychan small: bychein, ieuanc young: ieueinc.

(b) By adding -on, e.g. du black: duon, gwineu bay: gwineuon.

(c) By adding -yon (its usual formation), e.g. gwynn white: gwynnyon, melyn yellow: melynyon.

\section{CONCORD.}

\section{Gender.}

32. In the singular the attributive adjective agrees in gender with its noun, e.g. gwas melyn an auburn lad, morwyn benngrech velen a curly-headed auburn maiden. With the predicative adjective agreement is also found, e.g. un ohonunt oed amdrom one of them was very heavy RB. 54, I 7, oed amdroch 
llynges the fleet was shattered MA. $15^{\mathrm{b}}$, bit wenn gwylyan the seagull is white FB. 247, llem awel keen is the wind FB. 255, ys lledan y lenn its mantle is broad FB. 146, bolch y lauyn his blade is notched MA. $\mathrm{I}^{\mathrm{a}}$; but here the masculine form is also found, e.g. llym awel keen is the wind BB. $45^{\mathrm{a}} \mathrm{x}$, pan yw gwyrd llinos when the linnet is green FB. I33, oedd bwlch llafn yn llaw gynnefin the blade was notched in a practised hand MA. $217^{\mathrm{b}}$, guaedlyd y lein bloody is his spear MA. $184^{\mathrm{a}}$.

\section{Number.}

33. With the attributive adjective there is concord, the dual or a singular noun preceded by a numeral having the construction of the plural, e.g. danned hiryon melynyon long yellow teeth, deu vackwy wineuon ieueinc two auburn young lads, pedeir meillionen gwynnyon four white blades of clover. But there are many exceptions; with certain adjectives the singular is regularly used; such are adjectives in -awc, -awl, -eid, -ic, comparatives and superlatives, some other simple adjectives such as mawr great, tec beautiful, and compound adjectives; e.g. gwyr arvawc armed men (but exceptionally o vrenhined coronogyon of crowned kings WB. p. $90^{\mathrm{a}}$ ), llygeit hebogeid hawklike eyes, niveroed mawr great numbers, dyrnodeu calet-chwerw hard bitter buffets. With the predicative adjective there are found on the one hand, e.g. bychein ynt wynteu they are small RB.6o, wynteu a veynt veirw they would be dead Hg. I. I38, oedd beilch gweilch heroes were proud MA. $217^{\mathrm{b}}$, kertoryon neud ynt geith now poets are captive MA. $157^{\mathrm{b}}$, on the other hand, e.g. cadarn oed $\mathrm{y}$ holl aelodau all sg. his limbs were strong CM. 26, balch iawn yw dy eiryeu thy zeords are right haughty CM. 34, marw ynn they are dead MA. I64, rud ynt wy they are red FB. 284 , doeth y veirt his bards are learned MA. $262^{\mathrm{a}}$, ys da y gampeu his feats are good MA. $237^{\mathrm{b}}$. The whole subject needs a thorough investigation.

\section{Order.}

34. (a) In Welsh, as in the other Celtic languages, the adjective normally follows the noun, e.g. dyn doeth a wise man, gwreic 
dec a fair woman, arveu trymyon heavy arms. In Celtic, when the adjective preceded, it formed a compound with the noun, e.g. Gaulish Cambo-dunum, which would in W. be *cam-đin, O.Brit. Cuno-maglos lit. lofty chief $=\mathrm{W}$. Cynvael, W. hen-đyn old man (=Ir. sen-duine) from * seno-dunyos, W. prif-đinas chief city (cf. Ir. prïm-dūn chief fort), W. hen-wrach old hag, which would in Irish be ${ }^{*}$ sen-fracc. From this principle $\mathrm{W}_{*}$ has departed in that, under conditions the details of which have still to be investigated, the inflected adjective may precede the noun, e.g. bolch-lauyn a cutting blade MA. $263^{\mathrm{a}}$, gwen llaw white hand MA. $153^{\mathrm{b}}$, amryvaelon gerdeu various songs.

(b) In various phrases the noun with the preposition o, a follows the adjective, e.g. ys drwc a gedymdeith a uuost di thou hast been a sorry comrade, bychan a dial oed an lloski ni our burning were a small revenge, ys dyhed o beth it is a strange thing.

\section{The Predicative Noun and Adjective WITH YN.}

35. A predicative noun or adjective is often preceded by yn (lenating), e.g. gwedy llosci canhwyll ohonei yn oleuat idaw after she had lighted a candle as a light to him, mi ath roessum yn wreic $\mathrm{y}$ Uanawydan I have given thee as a wife to Manazyddan, ych gelwir chwi yn Grystonogyon ye are called Christians, neum goruc yn oludawc he has made me wealthy, a phob ty a welei yn llawn o win and every house he saw full of wine, yd oed ef yn holliach he was quite well, un a welei yn amdrom one (fem.) he saw very heavy, paham y maent hwy yn varw o newyn why are they dead with hunger? $\mathrm{mi}$ a wnaf seith cant ohonawch yn ueirw $I$ will make seven hundred of you dead men, an gunel in rit may He make us free, eu gwneuthur yn rydyon to make them free, eu clusteu yn gochyon their ears red, eu harwydyon yn purwynn their standards pure white. The concord after the feminine and the plural still needs investigation. 


\section{Adjective Phrases.}

36. In place of a simple adjective may be found an adjectival phrase, e.g. gwr dirvawr y veint a man of huge size (lit. a man huge his size), eurwalch balch bolch y daryan a proud golden hero with hacked shield (lit. hacked his shield), gwreic digonach y thecket a woman of more perfect beauty, dyrnodeu diuessured eu meint mighty buffets, drwc a dyn y thygetuen a woman of unhappy fate (lit. ill of a woman her fate), ys drwc a wyr eu dihenyd vydem ni we should be men of an ill ending, pan yttoedynt yn digrifaf gantunt eu gware zolhen they zere most interested in their play, y wreic vwyhaf a garei the woman whom he most loved.

\section{COMPARISON.}

37. (a) The regular suffix of the comparative is $x^{-a c h}$, of the $\times g, d, b$, hecome superlative -haf (for the phonetic changes see $\S \mathbf{I I g}$ ), e.g.-

Positive.

tec (= teg) beautiful

tlawt (= tlawd) poor

cyffelyb like
Comparative.

tegach
tlodach
cyffelybach

Superlative.

\section{teckaf tlottaf cyffelyppaf}

Notw.-In Mod. W. the consonantism of the superlative has spread to the comparative, e.g. teg, tecach, tecaf.

(b) The following are irregular :-

$\begin{array}{lll}\begin{array}{l}\text { agos } \\ \text { cyfagos }\} \text { near }\end{array} & \text { nes (Ir. nessa) } & \text { nesaf (Ir. nessam) } \\ \begin{array}{l}\text { bychan small } \\ \text { da good }\end{array} & \text { llei (Ir. lugu) } & \text { lleiaf (Ir. lugem) } \\ \text { drwc evil } & \text { gwell } & \text { goreu } \\ \text { hawd easy } & \text { gwaeth } & \text { gwaethaf } \\ \text { hen old (Ir. sen) } & \text { haws } & \text { hawsaf } \\ \text { hir long (Ir. sīr) } & \text { hwy (Ir. siniu) } & \text { hynaf } \\ \text { ieuanc young } \text { (Ir. ōac) } & \text { ieu (Ir. ōa) } & \text { hwyaf (Ir. sīam) } \\ \text { isel loze (Ir. ìssel) } & \text { is } & \text { isaf } \\ \text { * llydan liroad (Ir. lethan) } & \text { llet (Ir. letha) } & \text { llettaf } \\ \text { mawr sreat (Ir. mōr) } & \text { mwy (Ir. mōa) } & \text { mwyhaf (Ir. mōam) } \\ \text { tren strong (Ir. trēn) } & \text { trech (Ir. tressa) } & \text { trechaf (Ir. tressam) } \\ \text { xchel high (Ir. ūassal) } & \text { uch } & \text { uchaf }\end{array}$




\section{Construction of the Comparative and Superlative.}

38. (a) The comparative is followed by no, before vowels noc than, e.g. ny bu hwy no hynny it was not longer than that, mwy a vyrywys ef y dyd hwnnw noc undyd more he threw on that day than on any single day.

(b) The superlative is followed by the preposition o, e.g. y uorwyn deckaf onadunt the fairest maiden of them.

(c) In sentences like the more the better the superlative is used, e.g. pei vwyhaf y lladei ef y march pellaf vydei hitheu y wrthaw ef the more he struck the horse the farther she was from him RB. 9, I3; goreu yw gennyf i bo kyntaf the sooner it is the better it pleases me RB. I 2, 4 .

\section{The Equative.}

39. The possession by two objects of a quality in the same degree is expressed by a derivative in -het (=-hed) from the adjective preceded by cyn-, cy-, e.g. kynduhet (du) ar muchud as black as jet, kyngadarnet (cadarn) ac Adaf as strong as Adam, kyndecket (tec) a hi as fair as she, kynvelynet (melyn) ar eur as yellow' as gold, kynehofnet (ehovyn) a hynny as fearless as that, kynwynnet (gwynn) ar eiry as white as snow', kygadarnet a brenhin as strong as a king, kyduet ar muchud as black as jet, kywynnet ar alaw as white as the lily.

NoTE 1.-The Celtic preposition com- would in Welsh become cym-, cyn-, cyf-, cy- according to the following sound, and would be liable to various changes in connexion with a following consonant, e.g. com + vowel $>$ cyf, com $+1->$ cyfl-, com + w- > cy-, com + p-> cymh-, com + b- > cymm-, com $+\mathrm{g} \cdot>$ cyng-, com $+\mathrm{d} \cdot>$ cynn-, ete.; there is an interesting example of the regular development in cythrymhet (trwmm) RB. 112, for ntr becomes thr. But the form cyn- with analogical lenation became the general form before all sounds, though for a time it had to contend with cy-, the form which would arise in Celtic before initial w. For a discussion of the formation see Zimmer KZ. xxxiv. 161 sq., Loth Rev. Celt. xviii. 392 sq., Stern CZ. iii. $135 \mathrm{sq}$.

NoTE 2.--Equality may also be expressed by mor-a, e.g. pryf mor dielw a hynny a creature so vile as that, am gytlafan mor anwedus ac a wnaethoed on account of a crime so base as he had committed.

\section{THE ADVERB.}

40. The adverb is regularly formed from the adjective by prefixing yn (lenating), e.g. yn vawr (mawr) greatly, yn llawen gladly, 
yn drwmm (trwmm) heavily, yn well better, yn vwyhaf most. But, if it precedes the verb, the adjective is used without yn, e.g. mynych y dywedut thou didst often say; in the following sentence both forms occur: kanys mwy y karyssei ef hi nor rei ereill eiryoet. a hitheu yn y dremygu ynteu yn vwy nor rei ereill for he had always loved her more than the others, while she contemned him more than the others RB. II. 65 .

\section{THE NUMERALS.}

4I. Cardinals and Ordinals.

\begin{tabular}{|c|c|}
\hline i. un One, etc. & First, etc. \\
\hline ii. deu, f. dwy & eil \\
\hline iii. tri, f. teir & trydyd, f. tryded \\
\hline iv. petwar, pedwar, f. pedeir & $\begin{array}{l}\text { petwyryd, petweryd, f. pet- } \\
\text { wared; also pedwyryd, etc. }\end{array}$ \\
\hline v. pump & pymhet \\
\hline vi. chwech, chwe & chwechet \\
\hline vii. seith & seithvet \\
\hline viii. wyth & wythvet \\
\hline ix. naw & nawvet \\
\hline x. dec, deng & degvet \\
\hline xi. un ar dec & unvet ar dec \\
\hline xii. deudec & deudegvet \\
\hline xiii. tri, f. teir, ar dec & trydyd, f. tryded, ar dec \\
\hline $\begin{array}{l}\text { xiv. petwar, pedwar, f. pedeir, } \\
\text { ar dec }\end{array}$ & $\begin{array}{l}\text { petwyryd, etc., f. petwared, } \\
\text { etc., ar dec }\end{array}$ \\
\hline xv. pymthec, pymtheng & pymthegvet \\
\hline xvi. un ar bymthec & unvet ar bymthec \\
\hline xvii. deu, f. dwy, ar bymthec & eil ar bymthec \\
\hline xviii. tri, f. teir, ar bymthec & trydyd, f. tryded, ar bymthec \\
\hline $\begin{array}{l}\text { xix. petwar, pedwar, f. pedeir, } \\
\text { ar bymthec, un eisieu } \\
\text { o ugein }\end{array}$ & $\begin{array}{l}\text { petwyryd, etc., f. petwared, } \\
\text { etc., ar bymthec }\end{array}$ \\
\hline $\mathrm{xx}$. ugeint, ugein & ugeinvet \\
\hline
\end{tabular}

NotE.-The form deng is found only before nouns beginning with certain sounds, ef. Rev. Celt. XXVIII. 201. 
xxi.-xcix. In O.W. trimuceint is found for thirty. The usual reckoning, however, is by multiples of twenty :-deugein( $(t)$ (O.W. douceint) forty, deugeintvet fortieth, trugein(t) sixty, trugeinvet sixtieth, petwarugein $(\mathrm{t})$ eighty, petwarugeinvet eightieth. The intermediate numbers are expressed by addition, e.g. un ar hugein(t) twenty-one, dec erydyr ar hugeint thirty ploughs, deudec brenhin ar hugeint thirty-two kings, deng mlyned a deugeint fifty years, deudeng mlyned a thrugeint seventytwo years, petwyryd ar ugeint twenty-fourth. This reckoning may extend beyond a hundred, e.g. pedeir gwlat a seith ugeint one hundred and forty-four countries.

c.-ccios. Cant hundred, canvet hundredth. From this the other hundreds are formed by prefixing the cardinals:-deucant or deugant, trichant, petwarcant, pumcant, chwechant, seithcant, wythcant, nawcant. Mil thousand, dwy vil=two thousand, etc. Un vlwydyn ar bymthec ar hugeint a deucant $=236$ years; chwech marchawc a thrugeint a phumcant $=566$ horsemen; deudeng mlyned a thrugeint ac wythcant $=872$ years; deg mlyned a phetwar ugein a chant a mil $=I I 90$ years. ccios. myrd myriad.

\section{Syntax of the Cardinals and Ordinals.}

42. (a) After deu, dwy, the singular (i.e. historically the dual $\S 25)$ form is regularly used; but there are exceptions, e.g. deu ychen two oxen (where, however, the form might be dual), dwy chwiored two sisters LA. 39, RB. II. 39, dwy burloywduon hirueinon aeleu two brilliant black long slender eyebrows (by dwy ael) LA.93, deu rudellyon lygeit tworuddyeyes ib., deu perffeithloyw gochyon rudyeu two perfect brilliant red cheeks ib., deu nyeint two nephews RB. II. 69, dwy wraged two wives ib. 239 dwy vlyned two years ib. 240. As to the higher numbers the general rule is that, if there be a plural with internal vowel change ( $\$ 27 \mathrm{a})$, the plural is used, e.g. tri meib three sons, but otherwise the noun is in the singular, e.g. teir ynys three islands (pl. ynysed), petwar marchawc four horsemen (pl. marchogyon). There are, however, 
exceptions, e.g. teir chwioryd three sisters, pump gwraged five zomen, trychant tei three hundred houses; so very often with dyd day pl. dieu, and blwydyn year pl. blyned. Compare the exceptions after deu above. Another mode of expression is, e.g. tri chawr o gewri three giants, lit. three giants of giants.

(b) The ordinals precede the noun, e.g. y betwared vlwydyn the fourth year. But cyntaf usually follows, e.g. y marchawc kyntaf the first horseman; sometimes, however, it precedes, e.g. ky்ntaw geir a dywedaw the first word that I will say BB. $4 \mathrm{I}^{\mathrm{b}} \mathrm{I}$. The ordinal may denote not the order in a series, but, as also in Irish, one of a certain number, e.g. odena y kerdus er tir a naw kedemdeith ganthav, ar nauvet a las ar hynt thence he came to land with nine comrades, and one of the nine was slain at once Arch. Cambr. 1866 p. I I 4, y try்dy gwr a dienghis o Gamlan one of the three men who escaped from Camlan WB. 463; e tredyt anhebchor one of the three indispensables BCh. 8 .

\section{Distributives.}

43. These are expressed by prefixing pob every to the cardinal, e.g. eu bwrw pob dec pob deudec throwing them by tens and twelves Hg. II. r6o, gwin $\dot{y}$ bid hi $\dot{y}$ vedwen in diffrin Guy a sirth $\dot{y}$ chegev pop vn pop dvy happy the birch in the valley of the Wy'e, whose branches fall by twos and threes BB. $24^{\mathrm{a}}$.

\section{Multiplicatives.}

44. These are expressed by gweith $\mathrm{f}$. preceded by the cardinal, e.g. unweith once, dwy weith twice, teir gweith thrice, pedeir gweith four times etc.

\section{THE PRONOUN.}

\section{Personal Pronouns.}

\section{The Independent Pronoun.}

45. Independent pronouns fall into three sub-divisions, (a) the simple pronoun, (b) the emphatic pronoun, (c) the conjunctive or contrasting pronoun (I also, I on my part, I on the other hand, 
etc.) When attached to a verb as its subject the pronouns are liable to weakening, e.g. vi, $\mathrm{i}$ for $\mathrm{mi}$, di for ti, ditheu for titheu. Classes (a) and (c) are used also to reinforce an infixed pronoun (\$49a), a pronominal preposition $(\$ 52)$, or a possessive pronoun $(\$ 56)$, or possessive adjective $(\$ 58)$; then, too, they are liable to the same reduction ( $\$ \mathrm{I} 7 \mathrm{a})$.

(a) Simple.

(b) Emphatic.

(c) Conjunctive.

$I$, me mi, vi, vy, i, y. mivi, myvi, myvy, minheu, minneu, vivi, vyvi.

We, us ni, ny. nini, nyny. inneu.

Thy, thee ti, di, dy, de. tidi, tydi, dydi, ninheu, ninneu. dydy.

$Y e$, you chwi. chwichwi.

He, him ef (O.W. em). efo. She, her hi, hy. hihi. titheu, ditheu.

They, them (h)wy, (h) wyntwy.

chwitheu. ynteu. hitheu. (h)wynteu.

\section{(h)wynt.}

NoтE 1.-In chwi the $w$ may be omitted after $w$ in the verb, e.g. ewchi go ye, dowchi come ye.

NoTE 2.-wy is the earlier form, which became wynt under the influence of the ending -nt of the 3 plur. of the verb, just as O.Ir. è they became in Mid.Ir. iat. In Mid.W. wynt is particularly used when it precedes the verb, e.g. wynt a welynt they saw, but y gwelynt wy; this, however, is a later distinction, in earlier Welsh wy is used everywhere, e.g. wy gwnaethant they did, wy ladassant they slew.

46. The independent pronouns are used as the subject of a sentence, as the object of a sentence, where, however, they enter into concurrence with the infixed pronoun $(\$ 48)$, (which, to judge from Irish, was the original method of expressing the object), after prepositions which did not enter into a unity with the pronoun $(\S 52)$, and after some conjunctions. The following examples will illustrate the usage :-

(a) mi a wnaf $I$ will do; pan y gweleis i ef when I saw him; nyt yspeilwys ynteu vi he did not strip me; a rithwys Duw cyn no mi whom God created before me; ti a wely thou wilt see; a wely di dost thou see? kymer dy hun ef take it thyself; nyt oes seith cantref 
well noc wy they are not seven cantreds better than they; gyt ac wynt along with them.

(b) kynt y kyuarchawd ef well y mi no miui idaw ef he greeted me before I greeted him; pa le y keisswn i dydi? pan geissych di vyvi, keis parth ar India "where should I seek thee?" "When thou seekest me, seek tow'ards India"; gofyn a oruc idi ae hihi oed yn peri hynny he asked her if it was she who was causing that.

(c) Mivi a rodaf vyg cret, heb hi, na charaf i dydi ac nath vynnaf yn dragywydawl. minneu a rodaf vyg cret, heb y Peredur, na dywedaf ynneu eir byth wrth Gristiawn yny adewych ditheu arnat vyg caru i yn vwyhaf gwr "I pledge my faith," said she, "that I do not love thee and that I will not desire thee to all eternity." " $I$, on my part," said Peredur, "pledge my faith that I will never speak a word to Christian soul, until thou shalt confess that thou lovest me more than any man;" ac yn keissaw bwrw y gelein ar y march yn $y$ kyfrwy, y dygwydei ynteu yr llawr ac y dodei hitheu diaspat and as she sought to cast the corpse on the horse into the saddle, it kept falling to the ground, and she raised a cry.

NoTE.-ynteu etc., is also used before a proper name, e.g. y wybot dy atteb di am hynny y deuthum i. Rof i a Duw, heb ynteu Bwyll, llyna vy atteb i ytti, "I have come to learn thy answer about that." "Between God and me," said Puyll, "here is thy answer" RB. 11. cf. RB. 25, 65, 77, 79, 81, etc., wynteu y Galissyeit CA. 1 ; before a conmon noun, e.g. sef a wnaeth ynteu yr eryr this the eagle did RB. 78, a hitheu wreic Teirnon a gyt.synnyws and the wife of Teirnon agreed RB. 22 ; after a proper name, e.g. Troilus ynteu lleiaf nab y Briaf oed herwyd oet Troilus was Priam's youngest son RB. II. 7 , so RB. 14 , II. 8, 9, 14, 22, Castor a Pholux wynteu a aethant Castor and Pollux went RB. II. 9, y Telepus ynteu RB. II. 17; after a common noun, e.g. a gwyr Troea wynteu a ymhoelassant and the men of Troy on their part returned RB. II. 20; and in instances like: $\mathrm{y}$ gelwit hi Lundein neu ynteu Lwndrys it vas ealled Llundein or Lu'ndrys RB. 93, neu ynteu ony edy hynny udunt or again if you do not allow them that RB. II, 44. Cf. Mod. W'. ynte.

47. Issem, ysef, sef. In O.W. the pron. em is used with iss, is is in phrases like issem $\mathrm{i}$ anu that is his name. From issem comes in Mid.W. ysef, sef, e.g. ysef a rodaf inneu this is what I will give; sef, gwreic a vynnawd ${ }_{\lambda}$ Kicua that was the wife he desired, Kigfa; ssef a gafas yn y chyghor fo y ynyalwch this is what she resolved upon, to flee into a vilderness; sef y kyrchassant y dref uchaf o Arllechwed they made for the highest town of Arllechwedd; 
arglwyd, heb ynteu, minneu a allaf dy rydhau ditheu. sef ual y gallaf "Lord," said he, "I can free thee. This is how I can do it;" ssef y gwelynt varchawc then they saw a horseman. In a similar way ef is used by itself, e.g. pan dyuu y thymp idi, ef a dyuu $y$ hiawnbwyll idi when her time of labour came, then her right senses came to her.

48.

\section{Infixed Pronoun.}

Sing.

Plur.

$\begin{array}{ll}\text { I. me -m- } & \text { us -n- } \\ \text { 2. thee -th- } & \text { you -ch- } \\ \text { 3. him, her, it -s-, -e- } & \text { them -s-, -e- }\end{array}$

REMARKS.

49. (a) The infixed pronoun may be strengthened by putting the corresponding simple or conjunctive pronoun after the verb, e.g. a thydi am gwely $\mathrm{i}$ and thou shalt see me, euo ath gud ditheu he zerill hide thee.

(b) In the third person -e- is used after the relative particle a, e.g. mi ae gwelaf $I$ see him, and after the conjunction tra, e.g. trae llathei pob tri while he slewe them by threes BB. $48^{\mathrm{a}}$, mi ae kynhalyaf hyt trae gallwyf $I$ shall maintain it as long as I can $\mathrm{Hg}$. I, 4; elsewhere -s- is used. After the verbal particle yd-, however, if the verb begins with a consonant, there is no visible pronoun of the third person, e.g. y gwelaf $I$ see her RB. 278, 6; a phan i gweles meibion Collwyn and when the sons of Collwyn saw him MA. $729^{\mathrm{a}}$; if the verb begins with a vowel yh appears, e.g. $\dot{y}$ hanuones sent it WB. I04, y hedewynt they left them WB. I86; similarly after yny until, e.g. ny dygaf i un daryan yny hanuono Duw im $I$ shall not bear any shield till God send it to me Hg. I. I5. After pan when the infixed pronoun is regularly preceded by $y-$, e.g. pan yth wnaethpwyt ti when thou wast made; in the third person it is pan $\mathrm{y}(\mathrm{h})$, e.g. pann y harcho udunt when he asks it of them LA. $5^{6}$.

(c) In early poetry in connexion with ny and ry there are in the third person special forms, nwy, nyw, rwy, ryw, used when the verb is relative, e.g. ir nep nuy hatnappo to one who does not 
recognise it $\mathrm{BB} .4^{\mathrm{b}}$, nyt kerdaur nyu moluy he is not a poet zoho does not praise him MA. 174, y ren rwy digonsei the King who had diganem made them $\mathrm{FB}$. ${ }_{3} 8$. In non-relative usage the infixed pron. after ny is -s-, the form of the non-relative infixed pronoun after ry I have not been able to establish.

Note.-The infixed pronoun may, as in Irish, anticipate a following object, e.g. ai torro hac ay dimanuo $\dot{y}$ bryeint hunn who shall violate and diminish this privilege, ay enrydedocao $\dot{y}$ breint hunn who shall respeet this privilege Lib. Land. 121, y harehwn ni dy drugared we ask thy mercy RB. II. 44.

50. The infixed pronoun follows :-

(a) The relative particle a, e.g. mynn y gwr a-n gwnaeth by Him who made us, Duw a-ch nodho may God protect you, mi a-e harhoaf I will await him, her, it, or them, a-e lladawd ef who killed him, y niver a-e gwelei wynt the multitude that saw them.

(b) The verbal particle yd, e.g. $y$-m gelwir I am called, ywch kymhellasant they have compelled you.

(c) The infixing particle a- (\$94), e.g. a-m bo may there be to me, a-th volaf $I$ zeill praise thee, a-s rodwy trindawt trugared may the Trinity give him mercy, gwedi a-n gwelwch after ye see us, pei a-s archut if thou hadst asked it, kyt a-m llatho though he should slay me. So when this a- has been replaced by $\mathrm{y}-$, e.g. y-s rodho Duw ymi may God give it me LA. I 2 I.

(d) The verbal particle ry- in the earlier language, e.g. ry-m goruc he has made me. But in later Mid.W. the pronoun is infixed before ry- by means of yd-, e.g. $y$-th ry gereis I have loved thee.

(e) The particle neu-, e.g. neu-m goruc he has made me MA. I $4 \mathrm{I}^{\mathrm{a}}$, neu-s cud hides it FB. 272.

(f) Sometimes in early poetry dy- of compound verbs, e.g. $\mathrm{dy}-\mathrm{m}$ ryd gives me.

(g) The negatives, e.g. ny-m oes there is not to me, ny-s gweleis I have not seen him, her, it, or them, cany-ch gwelas neb since no one has seen you; na-m gommed do not refuse me, mi a debygaf na-ch rydhawyt $I$ think that you have not been freed.

NoTE.-In later Mid.W. nys seems sometimes to be used merely in a relitive sense, e.g. yn y wlat ny-s ry welsei in the country that he had not scen RB. 114, 13= $\dot{y} n \dot{y}$ wlad ny ry welei WB. 471 . This usage may have 
developed from cases where the nominative stands at the head of the sentence introducing it (\$26), e.g. amheu yr hynn a dywedwch chwi ny-s gwnaf i lit. doubting of what you say I will not do it. A meaningless -s-, however, is found when the verb is non-relative, e.g. nys gohiryassant they did not delay RB. II. 48.

(h) Certain conjunctions :-tra-e llathei while he slew them BB. $48^{\mathrm{a}}$, yny-m byrywyt i till I was thrown RB. 169, o-s lledy if thou slayest him Hg. I. 368. Some conjunctions are followed by the infixing $a$, see above (c).

5I. The infixed pronoun commonly expresses the accusative relation. With the verb 'to be,' however, it regularly expresses its dative relation, e.g., am bo may there be to me, may I have, vn tat ae bu one father they had; it may further express the dative relation with other verbs, e.g. y perfeith garyat hwnnw an rodho yr yspryt glan may the Holy Spirit give us that perfect love LA. 103, an gunel iechid may He work salvation for us BB. $20^{\mathrm{b}}$.

\section{Pronoun WITH PREPOSITION.}

52. In Welsh as in Irish the pronoun is regularly fused together with the preposition. After ac with and gwedy after, however, the pronoun follows separately, e.g. a mi with gwedy ni after $u s$; the explanation seems to be that the usage of these words as prepositions is secondary. With respect to the formation, the following points may be noted.

(a) In the first and second persons (except after $\mathrm{y} t$ ) there is an intervening vowel a, o (aw), or $\mathbf{y}$ (and in 2 pl. also $\mathbf{w}$ ), so that in these persons there are the following series :-

Sing.

$$
\begin{aligned}
& \text { I. -af, -of, -yf } \\
& \text { 2. -at, -ot, -yt }
\end{aligned}
$$

Plur. -am, -om, -ym -awch, -och, -wch, -ych

(b) In the $3 \mathrm{sg}$. masc. the ending is -aw, in the $3 \mathrm{sg}$. fem. $-\mathrm{i}$ (infecting a preceding vowel) and -ei, e.g. oheni and ohonei; sometimes the infected vowel spreads analogically, e.g. $3 \mathrm{pl}$. ohenynt. In the $3 \mathrm{pl}$. the oldest ending was $-\mathrm{u}$, whence developed later -ud (i.e. -ud), -unt, -ynt. In the third persons $-a w,-u$, etc., are commonly preceded by a dental. 
(c) In the I sg. and 3 pl. there are also endings -wyf, -wynt.

(d) After the prepositions ar, o, am are inserted respectively -n-, -hon-, -dan- (i.e. the prep. tan under). In the 3 pl. there are certain other insertions.

53. The forms assumed by the pronouns in connection with the several prepositions will be seen from the following table :-

Sing. Plur.

am about I. amdanaf, ymdanaf amdanam

2. ymdanat

amdanawch

$3^{\mathrm{m}}$. amdanaw, ymdanaw amdanunt, ymdanunt, 3f. ymdeni, amdanei, amdanadunt, ymymdanei danadud, ymdanadunt, amdanwynt

ar on

I. arnaf

arnam

2. arnat

arnawch, arnoch

3m. arnaw

3f. arnei, arni, erni $\}$

arnunt, arnynt, arnadud, arnadunt

att to

I. attaf

attam

2. attat

$3 \mathrm{~m}$. attaw

3f. attei, etti

attawch

attunt, attadunt

can, gan I. genhyf, gennyf with

2. genhyt, gennyt 3m. gantaw, ganthaw, gentaw

3f. genti, genthi

genhym, gennym genhwch, gennwch gantunt, ganthu, ganthud, ganthunt

heb I. hebof

without 2. hebot

$\left.\begin{array}{l}\begin{array}{l}\text { 3m. hebdaw } \\ 3^{\text {f. }} \text { hebdi }\end{array}\end{array}\right\}$

hebdunt

is belowe $\quad 3$ f. adisti 
nem except
of
2.
nemoch
o from
I. ohonaf, ohanaf,
ohonam, ohonom ohonof
2. ohonat, ohonawt, ohonawch ohonot
$3 \mathrm{~m}$. ohonaw
3f. oheni, ohoni, ohonei, ohonu, ohonunt, ohanei, ohenei $\int \begin{aligned} & \text { ohenynt, onadu, } \\ & \text { onadunt }\end{aligned}$
rac before I. ragof
ragom, rogom
2. ragot
3m. racdaw, rogdaw $\left.\begin{array}{l}\text { f. recdi, racdi, rocdi, } \\ \text { rygthi }\end{array}\right\} \begin{gathered}\text { racdu, racdunt, } \\ \text { rocdunt }\end{gathered}$
ragawch, ragoch

$$
\begin{array}{ll}
\text { ro between } & \text { r. yrof - } \\
& \text { 2. yrot - } \\
& \text { 3m. yrydaw } \\
& \text { 3f. yrydi }
\end{array}
$$
yrom yryoch, yroch -
yrydunt

rwng be- $\mathbf{I}$.

tween yrynghom

ryngoch 3 m. ryngtaw, ryngthaw,

ygrythaw

3f. ryngthi ryngdunt, ryngtunt, ryngthunt, ryndynt

Note.-In O.W. there is also a 3 pl. igridu Lib. Land. XLIII. 1. 9, and in poetry from cyfrwng a $3 \mathrm{pl}$. cyfryngthud.

$\begin{array}{cll}\begin{array}{c}\text { tan, dan } \\ \text { under }\end{array} & \begin{array}{l}\text { I. adanaf } \\ \text { 3m. ydanaw, adantaw }\end{array} & \begin{array}{l}\text { ydanam } \\ \text { adanunt, ydanunt, } \\ \text { adanadunt }\end{array} \\ \begin{array}{c}3^{\text {f. deni, adanei }} \\ \text { tros over }\end{array} & \begin{array}{l}\text { I. trossof } \\ \text { 2. trossot }\end{array} \\ & \begin{array}{l}\text { 3m. trostaw } \\ \text { 3f. trosti }\end{array}\end{array}$

Usually with initial $d$, drossof etc. 
trwy I. trwydof

through 2. trwydot

$\left.\begin{array}{l}3 \text { m. trwydaw } \\ 3^{f .} \text { trwydi }\end{array}\right\}$

uch above $\mathbf{i}$.

$\left.\begin{array}{l}3^{\text {m. odyuchtaw }} \\ 3^{\text {f. }} \text { oduchti }\end{array}\right\}$

wrth

tozeards

$$
\text { I. wrthyf }
$$

2. wrthyt

$\left.\begin{array}{l}\text { 3m. wrthaw } \\ \text { 3f. wrthi }\end{array}\right\}$

y (O.W. di) I. im

to

2. itt

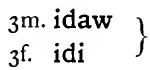

yn in

I. ynof

2. ynot

$\left.\begin{array}{l}3 \text { m. yndaw } \\ 3^{\text {f. }} \text { yndi }\end{array}\right\}$

yr for
I. yrof -
2. yrot -
$3 \mathrm{~m}$. yrdaw

wrthym

wrthych, wrthywch

wrthu, wrthunt

in

ywch

udu, udud, udunt

ynoch

yndunt

erom
yroch no, between.
yrdunt, erdunt

54. The above forms may be strengthened by the addition of the simple or the conjunctive pronouns, e.g. arnaf $i$, gennym ni, itti, ohonawch chwi, idaw ef, erni hi, udunt hwy; yrof inneu, attat titheu, gennwch chwitheu, ohonei hitheu, attunt wynteu.

55. Possessive Pronouns.

I. mine meu

2. thine teu

3. his eidaw hers eidi ours einom, einym yours einwch, einywch

theirs eidud, eidunt 
56. They are used (a) alone, (b) preceded by the article, (c) preceded by a possessive adjective, (d) after a noun, which may be preceded by a possessive adjective. They may be strengthened by a following personal pronoun. The following examples will illustrate the usage :-

(a) y sawl a uo meu all that are mine; ny bo teu dy benn may not thy head be thine, milwriaeth kymeint ac a oed eidunt all the valour that was theirs, y rei a oed eidaw ef those that were his, nyt yttoed y llew yn deu ytti the lion was not thine Hg. I. 63, nyt oes petrus genyf gaffel holl Freinc yn einym $I$ have no doubt that we should get all France as ours RB. II. in 6.

(b) neb un mor wedus cledyf ar y ystlys ar meu i none whose swort on his side is so becoming as mine; y mae y meu i y lle hwnn this place is mine; ath gedymdeithas yssyd adolwyn gennyf $\mathrm{y}$ gaffel. keffy, myn vyg cret, a dyro ditheu y teu, "and I would pray to have thy friendship." "Thou shall have it, by my faith, and give me thine;" deu parth vy oet a deu parth y teu ditheu trothirds of my life and two-thirds of thine; dwc uendith Duw ar einym gennyt take with thee God's blessing and ours; ef a daw y dwyn yr einwch he will come to carry off your property; py darpar yw yr einywchi yna zehat preparation is that of yours there? nyt oed olwc degach nor eidi there was no aspect fairer than hers.

(c) pa vedwl yw dy teu ti zohat purpose is thine? mivi a dodaf vyg korff yn erbyn y eidaw I reill set my body asainst his.

(d) ar dy drugeinuet or rei teu ditheu with sixty of your men CM. 8; o rei eidaw ef of his LA.; or petheu einym nynhev of our things LA. 164; dy ymadrawd teu di thy speech Hg. II. I.

57. Possessive Adjectives.

a

$\mathrm{b}$

a

b

I. my vy, vyn(before explosives) 'm our an, yn 'n

2. thy $\mathrm{dy}$

3. his $\mathbf{y}$

'th your ach, ych, awch 'ch her $\mathbf{y}$

'e, 'y their eu, y

'e, 'y

'e, 'y 


\section{Remarks.}

58. (a) The $\mathrm{b}$ forms occur in fusion with a preceding preposition or conjunction. Such forms in the $2 \mathrm{pl}$. seem to be comparatively rare, e.g. ych plith in your midst by yn ych plith LA., etc. ach rydit and your freedom RB. II. I 89; more usually yn awch medyant chwi in your power RB. II. 50 .

(b) With the prep. $y$ in the third persons there is a variety of

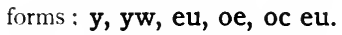

(c) The possessives may be strengthened by the addition of a simple or conjunctive pronoun after the noun.

59. Examples: (a) vy arveu my arms, vy nyuot (dyvot) my coming, an meirch ninneu our horses, dy benn thy head, awch cledyveu your swords, y wreic ef his wife, y phenn her head, eu hieith their tongue.

(b) ym tat to my father, am arveu and my arms, yn porthi ni supporting us (lit. our supporting), ath teulu with thy household, ach rydit and your freedom, ydys ych gwahawd you are invited, ywch didanu to comfort you, och pechodeu from your sins, ae waet ynteu and his blood, y (=yw IVB.) letty to his lodging RB. 284 , ae ueirch yw y rei hynn and these are his horses RB. 28, oe chladu to bury her, y cheissaw to seek her, oe hanvod against her will, oe harveu from their arms, y kestyll to their fortresses, oe gwlatoed to their countries, oc eu porthi to support them.

Note.-Sometimes, as in Irish, the possessive seems to anticipate a following genitive, e.g. $\dot{y} n$ y geissaw ẏnteu Peredur seeking for Peredur WB. 140, y hwyneb hitheu Riannon the face of Riannon RB. 18, 27, am $\dot{y}$ mỷnwgỳl (without y RB. 117, 19) y uorwy்n about the neck of the maiden WB. 475 .

\section{SELF.}

60. This is expressed by sg. hun, hunan, pl. hun, hunein added to personal pronouns or to possessive pronouns or adjectives, e.g. my hun, myvy vy hun $I$ myself, ohonaf vy hun by me myself, ym vy hunan to me myself, vym penn vy hun my ozen head, arnom ny hunein upon us ourselves; dy hun thou thyself, yth 
person dy hunan in thy own person; or tat ehunan from the father himself, ny digawn ehunan he is not able himself, ef ae byryawd ehun he cast himself, idaw ehun to himself; hi ehunan she herself, ohonei ehunan by her herself; wynt ehun they themselves, yr etholedigyon ehunein the elect themselves, yrydunt ehun WB. $2 \mathrm{II}=$ yryngtunt ehunein RB. 272 between themselves, yn eu cnawt ehun in their own flesh, yn eu rith ehunein into their owe form.

\section{Demonstrative Pronouns.}

6I. hwnn this, hwnnw that.

$\left.\begin{array}{lll}\left.\begin{array}{c}\text { Sing. } \\ \text { M. hwnn } \\ \text { F. honn } \\ \text { N. hynn }\end{array}\right\} \text { hynn } & \begin{array}{c}\text { Sing. } \\ \text { hwnnw } \\ \text { honno } \\ \text { hynny }\end{array}\end{array}\right\}$ hynny

62. These pronouns are used :-

(a) absolutely, e.g. beth yw hwnn? heb y Peredur wrth y kyfrwy. kyfrwy yw, heb yr Owein "What is this?" said Peredur, with reference to the saddle. "It is a saddle," said Owein; Peredur oed y enw, a ieuhaf oed hwnnw Peredur was his name and he was youngest; yna y kymerth ynteu yr hutlath. camma di dros honn, heb ef then he took the magic wand. "Step over this," said he; yn ol honno y kerdwys ef he went after her; a hyn a dywedaf ytti and this $I$ will tell thee; $\mathrm{mi}$ a wnaf na chaffo ef viui vyth. pa ffuryf vyd hynny? heb y Pwyll "I will effect that he shall never get me." "How zeill that be?" said Pwyll; yn ol hynny after that.

(b) After a substantive preceded by the article, e.g. ger llaw auon a elwit yn yr amser hwnnw Sabrina, yn yr amser hwnn y gelwir hitheu Hafren, beside a river that was called at that time Sabrina, at this time it is called Severn; yn yr ynys honn in this island; y nos honno that night; yr anniveileit hynn these animals; yr enweu hynny those names. Similarly in the plural with rei, e.g. pa ryw aniveileit yw y rei hynny? what kind of animals are those? 
(c) Preceded by the article, e.g. dywet, heb y Gereint, py fford oreu inni gerdet or dwy hyn. Goreu itt gerdet hon, heb ef, ot ey yr hon issot ny deuy trachefyn vyth " Tell," said Gereint, "which of these two roads is best to travel." "It is best for thee to travel by this one," said he; "if thou travel by the lower one, thou wilt never come back." It may be followed by a genitive, e.g. Heuel ar doythyon . . . . a ossodassant eu hemendyth ar honn Kemry holl Howell and the wise men set their curse and that of all the Welsh $\mathrm{BCh}$. I. In particular yr hwnn, etc., is frequently followed by a relative clause, e.g. bei dywetut ti y peth a ovynnaf ytti, minneu a dywedwn yr hynn a ovynny ditheu if thou zeouldst tell the thing that I desire of thee, I would tell that which thou desirest; ef a vennyc fford itti ual y keffych yr hynn a geissy he will show thee a road so that thou mayest obtain what thou seekest; pwy bynnac... . a dremyckont dysgu yr hynn a dylyynt y wneuthur whoever despise learning what they ought to do ; Bryttaen oreu or ynyssed yr hon a elwit gynt y wen ynys Britain, the best of the islands, which was formerly called the IVhite Isle; yr heul yn yr hwnn y mae tri pheth the sun in which are three things. In this usage the plural is $\mathbf{y}$ rei, e.g. gwraged oll eithyr y rei oed yn gwassanaethu all the women except such as were serving; gweirglodyeu . . . yn y rei y maent ffynhoneu gloew eglur or rei y kerdant ffrydeu meadow's in which are clear bright springs, from which issue streams. This device for expressing an inflected relative is particularly common in the translation literature.

\section{Article + Substantive + Adverb.}

63. Some adverbs have a demonstrative force along with a substantive preceded by the article, e.g. deu ychen, y lleill yssyd or parth hwnt yr mynyd ar llall or parth yma two oxen, one of them is on yonder side of the monntain, the other on this side; beth yw y rei racko? what are those yonder? att y vorwyn draw to the maiden yonder. 


\section{IndEFINITE PRONOUNS AND Adjectives.}

64. neb (=Ir. nech) some one is used :-

(a) Substantivally, e.g. a weleist di neb hast thou seen any one? nyt adwaeney neb efo no one recognised him.

(b) With the article before a relative clause, e.g. ediuar uyd yr neb ae wnaeth whoever has done it will repent it; ny chigleu i dim or neb a ouynnwch chwi I have heard nothing of him of whom you ask RB. I 29.

(c) Adjectivally, e.g. gwell yw dedyf Cristonogaeth no neb dedyf or byt the law of Christendom is better than any law in the world.

65. pawb (=Ir. cāch) every one is used substantively, e.g. sef a orugant pawb or teulu that is what each one of the household did; Peredur a rodes y bawp gystal ae gilyd Peredur gave to every one as much as to the other.

66. pob (the unaccented form of pawb, = Ir. cach, cech) is used adjectivally, e.g. pob peth every thing. Pob is also used with un one, e.g. pob un onadunt every one of them; the plural is pob rei, e.g. a phob rei ohonunt o bop parth a gladassant y rei meirw and both sides buried the dead RB. II. 30.

67. oll all, e.g. y deulu oll all his household; gwraged oll all the women; cewri ynt oll they are all giants. Before a noun is found holl, e.g. yr holl gwn all the dogs. In composition with numerals there appear ell, ill, yll e.g. ell deu, ill deu, yll deu both; ell pedwar, yll pedwar all four.

NотE.-A compound hollre is found, e.g. $\dot{y}$ rolre seint all the saints BB. $36^{\mathrm{a}}$, yn holre oludoed in all wanner of wealth LA. 165, hollre genedyl anifeileit every kind of animals LA. 166.

68. arall another, pl. ereill, is used :-

(a) Substantivally, e.g. kymer ef a dyro y arall take it and give it to another; da arall the goods of another; penneu rei a dygynt, llygeit ereill, a chlusteu ereill, a breicheu ereill they took away the heads of some, the eyes of others, and the ears of others, and the arms of others.

(b) Adjectivally, e.g. marchawc arall another horseman; y 
gymeint arall as much again; arveu gwell nor rei ereill arms better than the others.

69. neill one of two, e.g. y neill or llewot one of the two lions; y gwydyat vot yndaw y neill ae gwr ae gwreic he knew that there was in it either a man or a woman Hg. I. 54; ar y neill law y gwr oed Peredur yn eisted Peredur zeras seated on one hand of the man; pob un ar neilltu each one separately.

70. y llall the other, pl. y lleill, e.g. y kymerth Peredur hanner y bwyt idaw ehun ac adaw y llall yr vorwyn Peredur took half of the food to himself and left the other to the maiden; ar vn y bydei borth ef idaw a gollei y gware, ar llall a dodei awr and the one whom he was helping lost the game, and the other raised a shout; paham na chadarnnhawyt y lleill velle why zere not the others thus strengthened? LA. 8; cwymp y lleill the fall of the others LA. 8; y daw y llall his other son-in-laze, an brodyr y lleill our other brethren LA.

7I. y neill, y lleill, -y llall the one-the other, e.g. y neill ohonunt yn was gwineu ar llall yn was melyn one of them an auburn lad, the other a yellow lad; yn y orfei y lleill ar y llall till the one overcame the other. With a substantive arall is used in place of 1lall, e.g. or neill tu-or tu arall on the one side-on the other side.

72. y gilyd is used for the other in expressions like:-dyrnodeu calet a rodei bawp onadunt $\mathbf{y}$ gilyd each of them gave hard buffets to the other; yn un or teir person noe gilyd in one of the three persons than in another; or mor pwy gilyd from sea to sea; corph ni glivit pa leueir y gilit body, who hearest not what thy fellow say's BB. $10^{\mathrm{b}}$.

NOTE. -y gilyd (=Ir. a chēle) means literally his fellow, but, as in Irish, the phrase has become petrified in this form, and is used without respect to gender, number, or person.

\section{Substantives in a Pronominal Function.}

73. dim thing, e.g. kymer gret y mackwy na dywetto dim or a welas yman pledge the youth that he will not tell aught of what he has seen here; heb allel gwneuthur dim lles without being able to do any good. 
74. peth m. thing, e.g. kymmer dy varch nu a pheth oth arueu take thou thy horse then and some of thy arms; onyt ef a wyr peth or hynn unless he knows something of this.

75. rei, e.g. rei onadunt some of them, rei drut rei mut some bold, some dumb FB. I64, cf. $\$ 62$ (c).

76. ryw m. kind, e.g. pa ryw chwedleu yssyd gennyt what kind of newe hast thou? na allei neb ryw dyn marwawl datkanu so that no mortal man could proclaim; ymlad ar ryw dyn hwnnw to fight such a man as that RB. II. 182; gwelet y ryw gatwent honno to see such a fight as that ib. 58; drwy y ryw edewidyon twyllodrus hynny through such false promises as those ib. 104. Similarly cyvryw, e.g. yr kyfryw wr hwnnw to a man of such a kind ib. 65.

NoTE.-Observe that in expressions like $\mathrm{y}$ ryw dyn hwnnw the pronoun is attracted in gender and number to the noun preceding. Cf. the similar attraction with sawl below.

77. sawl f. multitude and meint greatness, e.g. yr sawl a 4i-ange. dihagassei oe wyr yn vyw to those of his men who had escaped alive; yr honn (sc. breich) a ladawd y sawl gewri which slew so many giants; by sawl nef ysyd how many heavens are there? y sawl nifer hwnnw such a number as that RB. II. I39; y ssawl vlwynyded hynny so many years as that ib. 44; colli y meint gwyr a oed idaw to lose all the men that he had ib. 46; blyghau a oruc Goronilla rac meint oed o varchogyon gyt ae that Goronilla became angry because there were so many soldiers with her father ib. 66; ymerbynyeit ar ueint allu hwnnw to encounter such a force as that ib. 348 ; yn y veint perigyl honno in so great danger as that ib. 160; y veint uudugolyaetheu hynny such great victories as that ib. 199 .

78. un one, e.g. eithyr bot yn prudach pryt Gwydyon noc un y gwas except that the aspect of Groydyon was graver than that of the lad.

\section{InterRogative Pronouns.}

79. pwy who, what, used substantivally, e.g. pwy wyt who art thou? y bwy y rodit (they discussed) to whom it should be given 
RB. 258 ; dywet pwy a uu yma tell who was here; govyn pwy yw eu tystyon to ask who are their zeitnesses; pwy yw dy enw di what is thy name? LA. I 28 ; pwy well genhyt which dost thou prefer? WB. 487 ; dayar pwy y llet neu pwy y thewhet the earth, what is its breadth or what its thickness? FB. I33; pwy kynt ae tywyll ae goleuat what was first, darkness or light? FB. $30 \mathrm{I}$. In the sense of what thing? is used pa beth, py beth, commonly abbreviated to peth, beth, e.g. peth yw y rei racko what are those yonder?

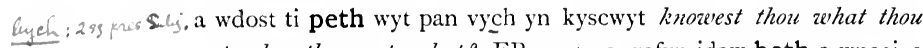
art zehen thou art asleep? FB. 145; a gofyn idaw beth a wnaei a phwy oed and asked him what he was doing and who he was.

Note - The use of pwy before a noun is exceptional, pwy ystýr WB. $454,456=$ pa ystyr RB. $101=$ py ystyr 103 .

80. pa, py what? adjectivally, e.g. pa drwc digoneis inheu ytti what evil have I done to thee? py drwc yw hynny what evil is that? This interrogative enters into various phrases, e.g. pa le, py le (also ble) where? pa veint, py veint how great? pa ryw, py ryw of what kind? pa sawl hoze many? Pa and py are also found with the addition of un, pl. rei, e.g. pa un wyt titheu zeho art thou? ef a ovynnawd udunt pa rei oedynt he asked them who they were.

Note 1. $-\mathrm{Pa}$ and py seem to be used without distinction of meaning. In the Mlabinogion when the Red Book has pa the White Book has very frequently py.

NoTE 2. - In the earlier literature pa and py are found also without a noun, e.r. pa roteiste oth olud what hast thou given of thy wealth? BB. 10 pa wnaf what shall I do? FB. 282 : hyt na wydat or byt pa wnaei ( = py wnaei WB. p. 212) so that she did not know at all what she should do RB. 273 ; py holy di y mi what seekest thou of me? RB. 128. ef. further FB. 127 , 145, 216, MA. 189. Cf. also pa daruu y Garadawc what has been the fate 39s, Pros. Sud of of Caradare? RB. 41, , 50 59,287 (= py WB. p. 221), py derw itti 176; pathawr dan- Jod, to afpen, (= pa-th-dawr) what does it matter to thee? WB. 430= pythawr p. 215; Duw reen py bereist lyvwr Lord God, uhy hast Thou made a eoucard? FB. 251 ; py liny di why dost thou colour? RB. 102.

NoTE 3.-Pa and py are followed by a preposition in pahar for what? e.g. pahar e roet for what it was qiven BCli. 30 ; paham, pa rac, py rac and pyr (=py yr) why? e. o. pyr (= py rac RB. 126) $\dot{y}$ kỷuerchỳ dy் why dost thou call? WB. 486.

Note 4.-pa diw, py diw. The following oceurrences of this may be noted :- ( Quid (i. pa diu, lit. for what) tibi Pasiphae pretiosas sumere vestes? Ox. $41^{a}$. Cunctis genitoris gloria uestri laudetur celsi thronus est cui 
regia caeli, where est eui regic eaeli is translated literally and unidiomatically by issit padiu itau gulat Iuv. $39^{\mathrm{b}}$. Gwynn y uyt py diw y rodir kerennyd Duf a hoedyl hir blessed is he to whom is given the fricndship of God and long life FB. 308. (If a man gives a thing, and a dispute arises between two men as to to which of them it has been given, the word of the donor shall decide) pa dyu y rodes to whom he gave it $\mathrm{BCh}$. 31. pa diw y damweinei y uudugolyaeth to which the victory should fall RB. II. 57 (so with y to, y by diw y damweinhei y uudugolyaeth onadunt 162, ef. CN. 32 ). pa diw bynnac y mynnynt hwy y rodi hi to whomsoever they desired to give it RB. 1I. 24 , ef. further 181, 185. Here the use of yd, not a $(\S 84)$, indicates that diw is a prepositional phrase (= to him, to it? $)$.

8I. pwy bynnac, pa, py-bynnac, pa beth bynnac, peth bynnac. The addition of pynhac or pynnac gives the sense of whosoever, whatsoever, e.g. pwy bynnac ae kaffei whoever should take it; pa dyn pwyllauc benac a ladho enuyt whatever sane man shall slay an idiot; pa le bynnac y gwelwn vwyt wherever I saze food; py fford bynnac y ffoynt whatever way they fled; peth bynnac a dywettei Peredur whatever Peredur said.

\section{Relative PRONOUNS.}

82. In Welsh there is no inflected relative. In clauses which according to the Welsh idiom are relative, relativity is expressed by the relative particle a when the clause is positive, by the negative ny (cf. $\$ \mathbf{2 I}$ note) when the clause is negative, e.g. pechodeu a gyffesser ac ny wneler yr eilweith sins that are confessed and that are not committed a second time. Before the details of relative usage are considered, there are several general points to be noted.

83. (a) The relative $\mathbf{a}$ is not used :-

(a) Before the relative form yssyd, syd who is, which is, e.g. nifer a uu ac a uyd uch nef is nef meint yssyd the multitude that has been and that will be, above heaven, below heaven, all that there are $\mathrm{FB}$. II 4 .

$(\beta)$ Before the verb pieu (\$I6I), e.g. Efrawc iarll bioed iarllaeth yn $\dot{y}$ gogled Evrawc the earl had an earldom in the north.

$(\gamma)$ Regularly in the earlier Welsh, and usually throughout the Mid.IW. period before the verbal particle ry, e.g. mi ryth gereis I have loved thee. 
( $\delta)$ Before the copula when preceded by the predicate (§ I59), e.g. llawen uu he was glad; pwy wyt who art thou? (but pwy a uu yma who was here?)

(b) (a) In Mid.W. prose a is frequently absent before oed was, e.g. Arthur oed yg Kaerllion Arthur was in Caerllion. In the Mabinogion the White Book has often a oed when the Red Book has oed, cf. WB. $227,229,250,453$, with RB. IоI, I65, I66, I83.

$(\beta)$ In early poetry a is very often omitted, e.g. Duu vet (= Duw a ved) God nules BB. $15^{\mathrm{a}}$ by Duw a wet $13^{\mathrm{a}}$. The details have still to be investigated.

84. In certain constructions the preverbal particle yd (= Mod.W. yr) seems to enter into concurrence with relative $\mathbf{a}$, and in Mod.W. grammars $\mathrm{yr}$ is given along with a as a relative particle. This, however, comes from reading English syntax into Welsh; historically, the use of $\mathrm{yd}, \mathrm{yr}$ points to a non-relative construction. In the Celtic languages the rules for the use of the relative are peculiar. In particular it should be noted that in Welsh an adverbial or prepositional phrase is not as such followed by the relative construction, e.g. mwyhaf oe vrodyr y karei Lud y Lleuelys Llud loved Llevelys more than any of his other brothers; pan uei mwyhaf yd ymgerynt when they most loved one another; bit chwero $\dot{y}$ talhaur in $\dot{y}$ diwet bitterly will it be paid for in the end; mi a brynaf dy gerennyd. pa delw, heb ynteu, y pryny di "I will buy thy friendship." "In what way," said he, "wilt thou buy it?"

lle y gwelych eglwys wherever thou seest a church; or lle yd oed from the place where he was; yn y rei y maent ffynhoneu in which there are fountains; ar hynny att $\mathrm{y}$ kwn $\mathrm{y}$ doeth ef thereafter he came to the hounds. With the first instance may be contrasted expressions like y wreic vwyhaf a garei the roman whom he most loved, where without mwyhaf the clause would be relative, y wreic a garei the zoman whom he loved; similarly gwreica da it a wedei to wed reould suit thee well WB. 453 .

85. In the Celtic sentence the verb normally comes first, e.g. y kymerth y marchawc y march the horseman took the horse. In Irish, when part of the sentence is to be emphasised it is brought 
forward by means of the copula, e.g. is e beres it is he who carries; sometimes the copula is omitted. In Welsh a part of the sentence is emphasised in the same way; the copula form, however, is regularly omitted. Thus in the example given above, if the subject were to be emphasised, the sentence would run: y marchawc a gymerth y march; if the object, y march a gymerth y marchawc. In accordance with the preceding paragraph, if the subject or object be thus brought forward, the following clause will be relative in form, but not if an adverbial or prepositional phrase be brought forward, e.g. mwy y karei he loved more; attunt yd aeth he went to them. of $\mathbf{a}$.

NotE.-In the development of Welsh yd tends to spread at the expense

\section{The Expression of Case in the Relative.}

86. In the relation of subject or object of a following verb, in positive clauses a is used (except in so far as it must or may be omitted, $\$ 83$ ), in negative clauses ny, e.g. y gwr a doeth the man who came; y vorwyn a weleist the maiden whom thou hast seen; $\mathrm{y}$ wreic yssyd yno the woman who is there; meibon ny ellynt ymlad boys who could not fight.

87. In connection with the use of a, ny, the following points call for special notice :-

(a) or a (Mod.W. ar a), neg. or ny, ar ny, lit. of that which (or which not), of what (or what not), e.g. pawb or a oed yno everyone who was there (lit. of that which was there); or a welsei o helgwn ny welsei cwn unlliw ac wynt of all the hounds that he had seen he had never seen hounds of the same colour as they; pob peth or ny damweinassant eiroet everything that has never happened LA. 33; nyt oes neb or ath welei ar nyth garei no one who saze thee would not love thee; pob peth or a uu ac yssyd ac a vyd everything that was and is and will be (where rel. a is regularly omitted before yssyd); llawer or yssyd da many who are good. In the above examples the relative $\mathbf{a}$ appears in positive clauses. But after or $=$ of that by which, etc., in accordance with $\S 84$, yd is used, e.g. gorchymynneu 
Duw a wneynt o bop fford or y gellynt they did God's commandments in every way in zehich they could LA. I 19 ; ffo. . a oruc Pandrassus a gwyr Groec y gyt ac ef y bob mann or y tebyckynt caffel dianc Pandrassus with the Greeks fled to every place from which they thought to find escape RB. II. 44. In sentences like: paup or y rodho y brenhyn ofrum idaw everyone to whom the king gives a present, or ba hustyng bynnac . . . or y kyfarffo y gwynt ag ef every whisper that the wind meets RB. 6o, the use of $\mathrm{yd}$ is due to the form of the relative clause $(\$ 89)$.

Note.-As Zimmer has shewn, CZ. II. 86 sq. or, ar is made up of the preposition $\mathrm{o}$, $\mathrm{a}$ + the article $\mathrm{yr}$. Similarly $\mathrm{yr}=\mathrm{y} t 0+\mathrm{yr}:$ ef a dely medhecynyat rad $\mathrm{yr}$ a uo en e llys he is obliged to give free medical attendanee to such as are in the palace BCh. 18.

(b) Without an antecedent a, neg. ny, is used in the sense of what as the subject or the object of a sentence, in a genitive relation, and after a preposition, e.g. a gahat o uedic da what was got of good physicians; mi a wnaf yssyd waeth it I shall do what is worse for thee; ýs tir (=dir) nithiau ny bo pur it is necessary to sift what is not pure BB. $42^{\mathrm{b}}$; y kymerth yntev gwrogaeth a oed yno onadunt he received the homage of such of them as were there $\mathrm{RB}$. 267 ; yr a welsynt o vwyt on account of what they had seen of food; or a glywyssynt o gerd of what they had heard of song; mi a vydaf wrth a dywedeisti I shall follow thy advice; hyt na cheffwch byth werth un geinawc oc yssyd yn y dref so that you shall never get a pennyzerth of what is in the town $\mathrm{Hg}$. II. 169 . In a sentence like: sef a oruc Scuthyn yn llaten g(ineuthur yr oedit yn y erchi idaw Scuthyn did gladly what was asked of him LA. I I , the form of the relative sentence does not admit of a ( $\$ 88)$.

88. The genitive relation whose, of which, is expressed with the help of the possessive adjective before the noun on which in English the whose would depend. In Welsh, if the noun following the possessive be not under the government of a preposition the clause is relative, if it be under the government of a preposition the clause is non-relative, e.g. (a) Teithi Hen a oresgynnwys mor y kyuoeth Teithi Hen whose kingdom the sea submerged RB. 108; peth arall ny ellych byth y gaffel another thing that thou wilt never be able to get; 
(b) y gur y buost neithwyr yn $\mathrm{y} d \mathrm{dy}$ the man in whose house thou wert last night; y gwr y buost yn y geissaw the man whom thou hast been seeking.

NoTE.-In: yr hymn a odologyssynt ae a yttoedynt yn y damunaw that which they eraved and uere desiring RB. II. 34, a is nsed where the above rule would require yd. In MA. $267^{\mathrm{a}}$ oceurs : gwr an dotyw gwall oe golli a man from uhose destrution loss has tome to me. Further exceptions seem to be very rare; I have noted : amperffeith yw caru y peth y galler y gassau it is imperfect to love the thing that may be hated LA. 86 ; wrth na bu yn dyn y bei arnaf i y ofyn beenuse there was no living man the fear of whom wras on me CM. 30.

89. Where in English the relative is preceded by a preposition (to whom, etc.) in Welsh the relation is expressed by a preposition + personal pronoun, and the clause is non-relative, e.g. hýny elých $\dot{y} r$ koet $\dot{y}$ dodhwỳt trwyddaw till thou goest to the avood through which thou hast come WB. 228 ; yno y byd eneideu ry darfo udunt penydyaw there are souls that have finished penance (lit. to whom penance is past) LA. I 29.

Note 1.- In the inverted sentence (\$ 85) Madawe uab Maredud a oed idaw Powys Madawg son of Maredudd had Powys RB. 144, the clanse is expressed relatively. Similarly in another special type of sentence: Achelarwy a uu lawen gantaw Aehilles was pleased RB. II. 31, ef. RB. II. $189 \cdot 20$, RB. I. $94 \cdot 5$. In the translation literature a number of exceptions occur:-y rei a no ragor arnunt those on whom there is me-eminenee LA. 32, ef. $130 \cdot 27,131 \cdot 2,135 \cdot 8,149 \cdot 17$, all in sentences of the same type; $y$ rei liynny a ry daroed (=earlier W. rydaroed) udunt gwrthlad Maxen those who had suceeeded in expelling Maxen RB, II. 111; mein a ellit gwneuthur gweith onadunt stones from which building eould be made RB. II. 167; gwr...a wedo idaw a man to whom it is fitting CN. 77.

NoTE 2.-The following is an exceptional construction:--gwelet $\mathrm{y}$ bed a vymnei trw y kaffei (=trw yt gaffei WB. 453) gwreicka he wished to see the grave through which he might be able to marry RB. 101; na chadarnhao dyn kelwyd trwy twng trwy y colletto y gymodawe that a man shall not confirm a falsehood by an oath through which he may ruin his neighbour. LA. 143; trwy y bei through which there should be LA. 144.

\section{Substitutes for the Relative.}

90. Particularly in the translation literature there are various devices for getting an equivalent of the relative admitting of a casual construction. Such are yr hwnn, pl. y rei (\$ 62c), y neb (\$ 64b), y sawl (\$ 77). 


\section{THE VERB.}

\section{Preverbal Particles.}

\section{The Particle yd.}

9I. In Mid.W. prose this particle usually appears as yd (i.e. yd) before a vowel or $\mathrm{h}$, as $\mathbf{y}$ before other consonants. But by the side of yd there is found from the fourteenth century $\mathrm{yr}$, which in Mod.W. has completely superseded yd.

NoTE 1._Occasionally y appears before h, e.g. $\mathrm{y}$ hanoed RB. II. 109, y hanoed LA.

NoTE 2.-In RB. yt with lenation appears before a consonant in yt gweirwyt (from cyweirwyt) 120 . In the WB. version of the Kulhweh story yt (i.e. yd) is more frequent: ýt gaffei, ẏt gaffo 453, ẏt uo 458, ýt werthey 470 , yt vỷd 471 , yt uerwit 478 . In BB. yt (=yd) is regular before vowels: it oet $10^{\mathrm{b}}$, it aethant $11^{\mathrm{a}}$, it imne $15^{\mathrm{b}}$, it elher $17^{\mathrm{a}}$, yt hoet $22^{\mathrm{b}}, 23^{\mathrm{a}}$, it adcorssant $23^{\mathrm{b}}$, it vif $25^{\mathrm{b}}$, it arwet $51^{\mathrm{a}}$, it aw $51^{\mathrm{b}}$; it is written id twice in id aeth $49^{\mathrm{a}}$ marg. Before consonants there appears both $y$ and yd ( $=\dot{y}$ t of WB.); the latter lenates, thongh the change is not always expressed. Before $\mathrm{g}, \mathrm{t}, \mathrm{d}, \mathrm{ff}, \mathrm{s}, \mathrm{m}, \mathrm{n}, \dot{\mathrm{y}}$ only appears: $\dot{y}$ godriccawr $5 \mathrm{l}^{\mathrm{a}}$; $\dot{y}$ tirran $1^{\mathrm{b}}, \dot{y}$ talhaur $16^{\mathrm{a}}, \dot{\mathrm{y}}$ tereu $32^{\mathrm{a}}, \dot{\mathrm{y}}$ tragho $35^{\mathrm{b}} ; \dot{\mathrm{y}}$ deuthan $1^{\mathrm{b}}, \dot{\mathrm{y}}$ daeth, $\dot{y}$ doethan $2^{\mathrm{a}}$, $\dot{y}$ doethan $2^{\mathrm{b}}$, $\dot{\mathrm{y}}$ darparan $3^{\mathrm{a}}, \dot{\mathrm{y}}$ dylanuan, $\dot{y}$ daruuan $3^{\mathrm{b}}$, $\dot{y}$ diadaud $10^{\mathrm{b}}, \dot{\mathrm{y}}$ dinwassute $11^{\mathrm{b}}$, $\dot{\mathrm{y}}$ deuth, $\dot{\mathrm{y}}$ del $21^{\mathrm{a}}$, $\dot{\mathrm{y}}$ doeth $22^{\mathrm{b}}, \dot{\mathrm{y}}$ deuthant $23^{\mathrm{b}}$, $\dot{y}$ deuant $25^{\mathrm{a}}$, $\dot{y}$ dav $32^{\mathrm{a}}$, $\dot{y}$ dinwassune $44^{\mathrm{a}}$, $\dot{y}$ duc $44^{\mathrm{b}}, \dot{\mathrm{y}}$ diwedi $51^{\mathrm{b}}$, ý dodir $53^{\mathrm{b}} ; \dot{y}$ ffoes $22^{\mathrm{b}} ; \dot{y}$ sirthei $50^{\mathrm{a}} ; \dot{y}$ mae $13^{\mathrm{b}}, 32^{\mathrm{a}}, 34^{\mathrm{a}}, 34^{\mathrm{b}}$, $35^{\mathrm{a}}, 41^{\mathrm{b}} ; \dot{y}$ nottv $\dot{y} 38^{\mathrm{b}}$. Before $\mathrm{p}$ and $\mathrm{r}$ yd only : id pridaw $21^{\mathrm{a}}$, yd portheise $27^{\mathrm{a}}$; yd rotir $23^{\mathrm{b}}$. Before other consonants the usage varies,-c: $\dot{y}$ kuýnan (infixed pron.?) $2^{\mathrm{a}}, \dot{y}$ kisceisse $25^{\mathrm{a}}$, $\dot{y}$ keweis (infixed pron.?) $43^{\mathrm{b}}$, but id gan $8^{\mathrm{a}}$, id keiff $43^{\mathrm{a}}$, id cuitin $48^{\mathrm{a}}$, $\dot{y} d$ gan $54^{\mathrm{a}}$. gw: $\dot{y}$ gvna $34^{\mathrm{b}}$, $\dot{y}$ gweleise $36^{\mathrm{a}}, 36^{\mathrm{b}}$, y guýstluy $38^{\mathrm{a}}$, $\dot{y}$ guiscav $41^{\mathrm{b}}$, but id woriv $9^{\mathrm{a}}$, yd welese $27^{\mathrm{a}}$, ýd vna $32^{\mathrm{a}}$. b: $\dot{y}$ bu $33^{\mathrm{b}}, \dot{\mathrm{y}}$ bit $28^{\mathrm{a}}$, but $\dot{\mathrm{y} d}$ vei $34^{\mathrm{b}}$, $\dot{\mathrm{y} d}$ vo, $\dot{\mathrm{y} d}$ vit $42^{\mathrm{a}}$, $\dot{\mathrm{y} d}$ uit $44^{\mathrm{b}}$. Il : $\dot{y}$ llas $36^{\mathrm{b}}$, $\dot{y}$ lleinw $5 \mathrm{l}^{\mathrm{a}}$, but id lathennawr $26^{\mathrm{a}}$, id lathei $48^{\mathrm{b}}$. In the O.W. glosses it only appears: it dagatte Mart. Cap. $4^{\mathrm{b}}$, it darnesti Iuv. p. 88. From all this it nay be inferred that there was a period in Welsh when the particle was yd before vowels, yd with lenation before consonants. As to the origin of non-lenating $y$, it is probable that it started from verbs beginning with d. As adyn wretch comes from *ad-đyn, so, e.g. *yd đuc would give *yd uc. From association with the other forms of the verb this would naturally come to be regarded as $y$ duc, and hence, probably with the help of $y$ containing an infixed pronoun $\left(\$ 50^{\mathrm{b}}\right)$, y might spread as the general form before consonants. As to the later yr: $y$ for $y d: y$, it is probably due to the influence of the forms of the article $\mathrm{yr}: \mathrm{y}$.

NoTE 3.-In ac yr gyscwys RB. 28, ual yr lygryssit RB. 54, ual yr notayssynt CM. 57, yr=y ry, ef. $\$ 93$ note 4 . 


\section{Usage of yd.}

92. In normal Mid.W. prose the particle yd, which has no appreciable meaning, is, with certain exceptions, used regularly before indicatives and subjunctives, e.g. yd af yn egyl gyt ac wynt I will go as angel along with them; y deuei y kythreul the devil used to come; ac yno y gwelas ef pedeir gwraged and there he saw four women; yn y lle y gwelsei Gynon in the place where he had seen Cynon; lle y gwelych eglwys wherever thou seest a church; val y gwelas y gwr Peredur yn dyuot as the man saw Peredur coming; megys y mynnei ehun as he himself desired; hyt y buant as long as they were.

93. But it is not used :-

(a) at the beginning of a clause before a subjunctive of wish or command, e.g. diwyccom-ne a digonhom o gamuet may zee make atonement for the iniquity which we have done $\mathrm{BB} . \mathrm{1} 5^{\mathrm{b}}$; hanpych gwell hail! dos titheu ar Arthur ... ac erchy்ch hỷnny idaw go thou to Arthur and ask that of him WB. 454; Agamemnon... a dwawt . . gossottynt hwy y neb a vynnynt yn y le ef Agamemnon said they should set whomsoever they pleased in his place RB. II. 24.

Note 1,-Contrast yng ngoleu addef nef yt nodder in the light of the heavenly home may he be protected MA. $174^{\mathrm{a}}$.

(b) When the verb is repeated in answers, e.g. a bery di? paraf wilt thou effect? I will.

(c) In such instances as the following:-Bei dywedut ti y mi y peth a ovynnaf ytti, minneu a dywedwn y titheu yr hwnn a ovynny ditheu. Dywedaf yn llawen, heb yr Owein "if thou wouldst tell me what I ask of thee, $I$ would tell thee what thou askest." " $I$ will tell gladly," says Owein; ath gedymdeithas yssyd adolwyn gennyf y gaffel. Keffy myn vyg cret "and I pray to obtain thy friendship." "Thou shalt obtain it by my faith;" ac yna y dywawt Peredur: diolchaf ynneu y Duw na thorreis vy llw and then Peredur said: "I give thanks to God that I have not broken my oath" (cf. the use of na $\$ 237 \mathrm{c}$ ). 
(d) When the predicate precedes the copula, e.g. llawen vuant they were glad.

Note 2.-But with verbs of naming yd with an infixed pronoun is used when the predicate precedes, e.g. Peredur ym gelwir $I$ am ealled Peredur.

(e) After a negative, e.g. ny welas he did not see; pony wdost dost thou not know?

(f) In relative construction, e.g. ef a doeth he came.

(g) After the interrogative a, e.g. a wely di dost thou see?

(h) After the particle neut, e.g. neud ynt geith now they are slaves MA. $157^{\mathrm{b}}$.

(i) After mad well, e.g. mad devthoste happily didst thou come, BB. $44^{\text {a }}$, unless there be an infixed pronoun, e.g. mat yth anet happily wert thou born FB. Iо I.

(k) After moch soon (= Ir. mos), e.g. moch guelher soon will be seen BB. ${ }^{\mathrm{b}}$.

(1) After certain conjunctions, e.g. can buost since thou hast been; kwt gaffei where he should get WB. 453; cyn gwnel though he does; kyt dywetto though he should say; o gwely if thou seest; pan welsant when they saw; pei kaffwn if I should get; tra vych while thou art; yny digwyd till he folls. But it is used with an infixed pronoun after pan, e.g. yr pan yth weleis since $I$ saw thee; so after tra (but cf. $\$ 49^{b}$ ), e.g. hyt tra yn dygyrcher so long as we are visited RB. 105.

NoTE 3.-After gwedy after the usage is not very clear. Before a following vowel, we have on the one hand gwedy ed eystedont after they sit $\mathrm{BCh}$. 53, gwedy yd elont after they go $\mathrm{H} g$. I. 11, gwedy yd elom after we go $\mathrm{H}$ g. II. 146, on the other hand gwedy aruerych after thou dost practise LA. 90. Before a following consonant, in BCh. gwedy y (e.g. gwedy e kafo after he gets 34 ) is more common than gwedy (e.g. gwedy roder after she is given 130); in BB. is found wide kjwisscaran (leg. kyंwisscarun) after ue separate $12^{\mathrm{b}}$; gwy்di darffo after it is over $4^{\mathrm{b}}$; in Mid.W. prose gwedy is much more common than gwedy $y$, but it is a question how far gwedy comes after fusion from gwedy $y$. It is to be noted that infixing a- (\$ 94) is found after gwedy as well as after the conjunctions which are not followed by yd; this would seem to suggest that the use of yd after gwedy was not original, but there is need for further investigation based on fuller material.

NoTE 4.-In Mid.W. prose yd is sometimes found before ry, even when there is no infixed pronoun, e.g. fford $\mathrm{y}$ ry [d]uuost the way by which thou hast eome W B. 138; ym pob gwlat or y rýfuum in every eountry in which I have been ib. 144; y ry dugassei he had bronght RB. II. 139; megys y ry wnathoed as he had done ib. 161. Cf. the instances of yr $\$ 91 \mathrm{n} .3$. 
94. In later Mid.W. the use of yd is more extensive than at an earlier period. In the archaic prose of the story of Kulhwch and Olwen it is often wanting in the White Book version where it is present in the Red Book, and in the earlier poetry it is rarer still ; the conditions of the earlier usage have still to be investigated. It may be noted that in earlier Welsh, when yd is not syntactically permissible, a- is used to infix a pronoun, e.g. a-m bo may there be to me $\mathrm{BB} .17^{\mathrm{b}}$; ath uendiguiste he has blessed thee $18^{\mathrm{a}}$; as attebwys answered them $\mathrm{FB}$. 139; as redwn (leg. rodwn) we will give it WB. 475. In prose this usage survives after fome conjunctions, e.g. gwedy an gwelwch after ye see us Hg. II. 1 ; gwedy as cladawch hi after ye bury her LA. 81; pei as rodei if he gave it RB. 136. This a tends to become $y$ under the influcnce of the infixed pronoun after $y d(y-m$, etc.), e.g. ys po may there be to him BB. $53^{\text {b}}$; bei yscuýpun if I had known it BB. $41^{\mathrm{a}}$; bei $\dot{\mathrm{y} s}$ gattei if it had permitted it WB. $424=$ pei as gattei RB. 274 ; kyt ym lladho though he slay me RB. $280=$ kyt am llatho I'eniarth MS. 4. With fusion, e.g. peis mynnynt if they desired it LA. 69.

\section{The PARTICLE ry.}

95. The particle ry, which corresponds etymologically to the Ir. verbal particle ro-, and resembles it in its uses, is in Welsh a disappearing particle; it is much less frequent in Mid. W. prose than in the early poetry.

Note.-Ry is sometimes reduced to r, e.g. nỳr darffo WB. $230=n y$ darffo RB. 168; nar geueis that I did not get $\mathrm{Hg}$. II. 265; ar ethynt (v.l. a ethynt) that have passed RB. II. 205; ar doethoed (=a dathoed RB. 197) who had eome WB. 62 ; wedyr vligaw (= wedy y vlingaw Hg. II. 112) after his flaying CM. 102. From neu + ry has come the common Mid. W. neur, cf. neur dialawd (= neu ry dialawd WB. 404) he has avenged RB. 259; neur daroed (= neu rý daroed WB. 402) it wes over RB. 258. For $\mathrm{yr}=\mathrm{y}$ ry see $\S 91$ n. 3 .

96. In Mid. W. prose ry is used :-

A. With the indicative.

(a) Optionally with the perfect (as distinguished from the preterite, $\S$ ro8), e.g. uý llýsuam ry் dy்gvy்s (=a dynghwys RB. 102) im my stepmother has sworn to me IVB. 454 ; pawb ry gauas (=a gauas RB. I13) $\dot{y}$ gyjuarws everyone has received his boon WB. 470; drycheuwch y் fỷrch uý aeleu ry் syrthwýs (=a syrthwys RB. I I9) ar aualeu vý llygeit raise the forks of my eyelashes which have fallen on my eyeballs WB. 478 ; llawer dyd yth ry gereis $I$ have loved thee many a day RB. i 8 ; nỳs ry geueis (=nys keueis RB. 1 26) I have not got him WB. 487; ny ry giglef i eirmoet dim y wrth y uorwyn I have never heard anything of the 
maiden RB. I I3; a ffan ry dyuu amser mab a anet a elwit Bown and when the time was come, there was horn a son who was called Bown Hg. II. I 9.

(b) Optionally with the pluperfect, e.g. gwallocau a oruc ý rýn rý adawsei (=yr hyn a adawssei $\mathrm{RB}$. IоI) he neglected what he had promised WB. 453 ; a thrist oed genthi, kany ry welsei (c kany welsei RB. i 16 ) eiroet $\dot{y}$ uýnet ae eneit ganthaw a delhei $\dot{y}$ erchi ẏ neges honno and she was sad, for she had never seen anyone who came on that quest depart with his life WB. 474; a chael yn y uedwl na ry welsei eiryoet mab a that kyndebycket ar mab y Pwyll and he thought that he had never seen son and father so like as the boy was to Pwyll; a chynn ymgyweiryaw yn y gyfrwy neur ry adoed heibyaw and before he had settled himself in his saddle, she had passed by. In the sentence: dechreu amouyn a gwyrda y wlat beth uuassei $y$ arglwydiaeth ef arnadunt hwy y vlwydyn honno y wrth ry uuassei kyn no hynny he began to ask the nobles of his country how his rule over them had been that year compared with what it had been before RB. 7, ry uuassei seems to express priority relatively to the preceding buassei.

B. With the subjunctive.

(a) With the present subjunctive ry appears sometimes when it has a perfect sense, e.g. ohonot ti ýt gaffo ef kany்s ry gaffo (=yr nas kaffo RB. IOI) o arall from thee he shall get (offspring) though he has not got it from another WB. 453 ; kyt ry wnelych di sarhaedeu ... kyn no hynn nys gwney bellach though thou hast committed outrages before this, thou shalt not commit them further RB. 99 ; yno $\mathrm{y}$ byd eneideu ry darffo vdunt penydyaw there are the souls that have ended their penance LA. I29. But also without ry, e.g. a chyn gwnel gameu it .. ny buost ti hawlwr tir a dayar eiryoet and though he has wronged thee, thou hast never been a claimant of land and earth RB. 44 .

(b) With the past subjunctive, when it has the sense of a pluperfect, ry not infrequently appears, e.g. mýnet a oruc serch $\dot{y}$ uorwy்n ẏm pob aelawt itaw ky்nnys rý welhei (= yr nas gwelsei RB. 102) eiroet love for the maiden entered every limb of him though 
he had never seen her WB. 454 ; ny்d oed waeth kỷarwy்d yंn y wlad ny ry welei (= nys ry welsei RB. I x 4) eiroet noc ýn ý wlad ehun he was not a worse guide in a country that he had never seen than in his own country WB. $47 \mathrm{I}$; a chyn lawenet vu a chyt ry delei idaw iechyt and he was as joyous as though health had come to him RB. II. I83; pei mi ry wascut (=a wascut RB. I I6) uelly ny oruydei ar arall uyth rodi serch im if it had been me whom thou hadst so squeezed, no other one would ever have been able to show me love WB. 474. But also without ry, e.g. pei ys gwypwn ny down yma if $I$ had known it, I would not have come hither RB. 29, 20.

C. With the infinitive when it has a perfect or pluperfect sense, e.g. adnabot a oruc ry gaffel dyrnawt ohonaw he perceived that he had got a buffet; gwedy ry golli eu kyrn after their horns had been lost RB. 194 .

97. In early Welsh poetry the use of ry is much more common than in prose; there it has also some syntactical uses which have been lost in prose (cf. Eriu II. 215 sq.)

(a) With the indicative preterite, when it has a perfect sense, ry is much more frequent than in the prose language. As in the case of Irish ro, the general definition of this usage is that the past is viewed from the standpoint of the present. There may be a reference either to the personal experience of the speaker, e.g. mi ryth welas $I$ have seen thee BB. $51^{\mathrm{a}}$, rim artuad $I$ hare been blackened $\mathrm{BB} .12^{\mathrm{a}}$, or to an indefinite past, e.g. ry gadwys Duw dial ar plwyf Pharaonus God has kept vengeanee on Pharaoh's people FB. 170.

With respect to this usage, however, the following points have to be noted:-

1. ry is not found:-

(a) After a negative, e.g. ni threghis ev hoes their life has not passed away BB. $11^{a}$; contrast ry treghis eu hoes FB. 128. There are rare exceptions in the later poetry.

$(\beta)$ After mad uell, e.g. mad devthoste $\dot{y} g$ corffolaeth happily hast Thou come in to the flesh BB. $44^{\mathrm{a}}$.

$(\gamma)$ After the interrogative a, e.g. a gueleiste gureic hast thou seen a woman? BB. 22b. But in prose a ry fu has he been? WB. 121.

2 . ry is not preceded by relative a. In the later poetry there are very rare exceptions.

3. A pronoun is infixed after ry; it is not put before it with yd or a, e.g. ry-n gwarawt has helped us $\mathrm{FB}$. 126, os Dofyd ry-n digones if it is the Lord that has made us FB. 113 . In the later poetry there are rare exceptions.

(b) With the subjunctive of wish it is used optionally in positive (but never in negative) sentences, e.g. ry phrinomne di gerenhit may we buy Thy friendship BB. $44^{\mathrm{b}}$; rym gwares dy voli may Thy praise help me FB. 109 , by ath uendicco may it bless thee $\mathrm{BB} .18^{\mathrm{a}}$; but ny buve trist may I not be sad $\mathrm{BB} .17^{\mathrm{b}}$. 
(c) With the present indicative :-

1. Ry may express possibility, e.g. ry seiw gur ar vn conin a man can stend on a single reed $\mathrm{BB}$. $45^{\mathrm{a}}$.

NoTE. - In prose there is an instance of ry with the present indicative in: ef a ry eill ych neckau he may refuse you $\mathrm{RB}$. 60 . With gallu, ry is also found in the potential, e.g. ef ar allei vot yn wir a dywedy di what thou sayest may be true $\mathrm{Hg}$. I. 81, similarly 224, 267, 272; withont ry: ef a allei llawer mab colli $\dot{y}$ eneit many youths might lose their life WB. 100. From the perfect sense inherent in the verb, ry is found with the present and imperfect of darvot to be finished, e.g. os $\dot{y}$ uwrw ry derýw if he has been throu'n WB. 125; neur daroed idaw diffeithaw traean Iwerdon he had already laid waste the third part of Ireland RB. 135.

2 . In a subordinate clause of a general sentence it may have the sense of a perfect, e.g. ti a nolyd a ry geryd Thou savest those whom Thou hast loved FB. 180. The same sense is found in the subjunctive, when that mood is syntactically required, e.g. ry brynw[y] nef nyt ef synn whosocver has purehased heaven will not be confounded FB. 307; a ry gotwy glew gogeled ragtaw let him who has angered a brave man shun him MA. 191.

(d) In the later poetry it is used with the future, or with the subjunctive in a future sense, without any apparent meaning, e.g. arth o Deheubarth a dirchafuy. ry் llettaud $\dot{y}$ wir ew tra thir mýnvy் a bcar from the South will arise. His men will spread over the land of Mynwy BB. $30^{\mathrm{a}}$; bydinoed Katwaladyr kadyr y deuant. ry drychafwynt Kymry, kat a wnant the hosts of Cadvaladr mightily will they come. The Cymry will rise up, they will give battle FB. 126.

\section{Conjugation of the Verb.}

\section{Verbal Classes.}

98. In Celtic as in Latin there were various types of verbal conjugation. In Old Irish the different types may still to a great extent be distinguished, e.g. 3 sg. -beir carries from *beret, -guid prays from *godit (cf. Lat. capit), -cara loves from * carāt (cf. Lat. amat), -lēici leaves from *lancit or the like (cf. Lat. audit or monet; in Celtic ē became $\overline{\mathbf{1}}$ ). In Welsh the several types have become obscured. There remain, however, some traces of an original difference. Such are the different forms of the $3 \mathrm{sg}$. pres. ind., e.g. geill (to gallu to be ahle) which would go back to *gallit or the like, cymmer takes which would correspond to an Ir. con-beir and would go back to com-beret, car loves=Ir. -cara ; further the various forms of the $3 \mathrm{sg}$. pret. act. in -as, -es, -is and of the pret. pass. in -at, -et, -it. In particular should be noted such series as geilw (to galw, to call): gelwis: gelwit; ceidw (to cadw to preserve): cedwis: cedwit; llysg (to llosgi to 
burn): llosges: 1losget; ceiff (to caffael to get): cavas: cavat. Here there is great need for a collection of material from early texts. In some cases an original radical conjugation is indicated by certain formations peculiar to verbs of the root class, e.g. the $-t$ preterites aeth $=$ Ir. -acht and cymmerth $=$ Ir. con-bert to pres. $\mathbf{a}=$ Ir. -aig and cymmer = Ir. con-beir; the pret. gwarawt = Ir. fo-räith to gwaret to help; and preterites passive like llas = Ir. -slass to llad to kill.

\section{Voice.}

99. There are two voices, the active and the passive. The deponential form which is found in Old-Irish has disappeared in Welsh.

\section{Number.}

I00. In the active there are two numbers, the singular and the plural. In the passive there is only one form for both numbers.

I0I. In the concord of a verb with a plural subject Welsh shews certain peculiarities :-

(a) If the subject be unexpressed, or if it be a personal pronoun, the verb is in the plural, e.g. y doethant, y doethant wy, wynt a doethant they came.

NoTE.-Exceptions are rare, e.g. os wynteu ae med hi if it is they that possess it RB.91 ; poet wynt athiffero let it be they who defend thee CHI. 35; nyt wy dyweit geu llyfreu Beda the books of Beda do not lie FB. 159 ; wy a gynheil y bit they support the world FB. 217; hwy a orfyt they shall prevcil MA. $141^{\mathrm{b}}$. An example with the copula is: $\dot{\mathrm{y}} \mathrm{s}$ hwy $\mathrm{yr}$ rei hynny (=sef yw y rei hynny RB. 121) Nynhýaw a Pheibyaw they are Nynnyaw, and Peibyaw WB. 480.

(b) Otherwise in the prose of the Mabinogion the singular is the usual construction, e.g. y kerdwys y kennadeu the messengers set out; beth yw y rei racko? egylyon ynt what are those yonder? They are angels. But sometimes the verb is in the plural, particularly in WB. and in the more archaic texts, e.g. y deu vrenhin a nessayssant the two kings drew near RB. 5 ; a meicheit Matholwch a oedynt (=oed RB. 35 ) ar lan $\dot{y}$ weilgi and the swineherds of Matholwch were by the shore of the sea WB. 50 ; $\dot{\mathbf{y}}$ trywy்r a ganant eu kÿrn the three sound their horns WB. $485=$ RB. I 25, I 8 ; 
naw brenhin coronawc a oedynt wỷr idaw nine crowned kings who were his men RB. 244 ; seithwy்r a oýdy்nt y danaw seven men were under him (by naw eglwys ereill a vydei there were nine other churches) WB. $385=$ RB. 245 ; ỳ rei a oedynt (=oed RB. 165) yn gwassanaethu those who were serving WB. 227; bliant oedy்nt (=oed RB. I65) y llieinyjeu y bwrt the tablecloths were of fine linen WB. 227 ; kwt yंnt (=ble mae RB. Ior) plant y gwr where are the children of the man? WB. 453. Sometimes the plural is found with a collective noun, e.g. gwelsant niuer Otgar eu meint the people of Odgar saw their number RB. I 36, 3. In the earlier poetry the plural is quite common, and in corresponding constructions in Old Irish the plural is regular. In Welsh there has been an encroachment of the singular upon the plural, as there has been in later Irish.

\section{Person.}

I02. In the active there are three persons of each number. In the passive there is only a third person, the first and second persons being expressed, as in Irish, by means of pronouns, e.g. y-m gelwir I am called, y-th elwir thou art called, ny-n cerir we are not loved, ny-ch cerir ye are not loved; kattwer vi let me be kept.

NOTE.-In the third person there are instances of an infixed pronoun, when the verb is non-relative, e.g. kyt ys galwer though they are colled LA. 88, megys pei as gossottit as if it were placed $\mathrm{Hg}$. I. 304; but, on the other hand, e.g. na rodher that it be not given RB. 258 , pan ollyngit when it was set free $\mathrm{Hg}$. I. 315. The matter ealls for further observation.

103. The verb regularly agrees in person with the subject, e.g. mi a welaf $I$ see, ti a wely thou seest, ny a dywedwn we say, $\mathrm{mi}$ a thi a ryuelwn thou and $I$ will fight, mi a Bown a wysgwn yn arueu ymdanam a thitheu a wysgy ymdanat Bown and I will put on our arms, and thou wilt put on thine. In the passive, where there is no distinction of person, the third person is used everywhere, e.g. mi a gerir I am loved. The 3 sg. copula form ys is used, like the corresponding Ir. is, with pronouns of the first and second persons, e.g ys mi (=Ir. is mē) it is $I$. 
Occasionally in a relative clause the verb is in the $3 \mathrm{sg}$. when the antecedent is in the first or second person, e.g. mi rýth welas $I$ have seen thee BB. $5^{\mathrm{I}^{2}}$; ae ti a eirch uy merch? ys $\mathrm{mi}$ ae heirch is it thou who askest for my daughter? It is I who ask for her WVB. 479; mi ay் had[e]ilyjawd I built it WB. 394.

NoTE.-These last examples represent the original construction, which has in Welsh been replaced by congruence witl the pronoun. The $3 \mathrm{sg}$. is the regular construction in Breton, e.g. me guelas $I$ saw, in Cornish, e.g. why a ergh ye seek, and in Old Irish, e.g. is me asbeir it is I who say.

\section{The Moods.}

I04. There are three finite moods, the indicative, the subjunctive and the imperative. The Celtic languages have developed no proper infinitive; the place of the infinitive in Welsh as in the other Celtic languages is taken by a verbal noun, with nominal inflexion and with nominal construction. There is a passive participle in -edic and a verbal of necessity in -adwy (corresponding to the Irish verbal of necessity in -thi).

\section{The Indicative.}

105. The tenses of the indicative are present, imperfect, preterite, and pluperfect. Syntactically the present serves also as a future; in the earlier language, however, there are also special future forms (§ I30). The imperfect is used both as an imperfect indicative and as a conditional (in the latter usage it corresponds in usage to the Irish secondary future). The preterite is used both as preterite and as perfect; in the latter usage it is often preceded by ry, particularly in the earlier language $(\$ 96,97)$. The pluperfect is a new development of the British division of Celtic; it has the same endings as the imperfect, and has been formed to the preterite stem on the analogy of the imperfect to the present. It is used (a) as a pluperfect indicative, (b) as a pluperfect conditional, in which sense, however, the imperfect continues to be used in Mid.W., (c) as a pluperfect subjunctive, in which usage it tends in Mid.W. to replace the past tense of the subjunctive ( $($ III). The following examples will illustrate the uses of the tenses of the indicative. 


\section{Present.}

106. (a) Actual present, e.g. beth yw hwnn? Kyfrwy yw what is this? It is a saddle; ti a wely $\dot{\mathrm{y}}$ sawl vory்y yon hygar yssy்d $\dot{y} n$ $\dot{y}$ llýs hon thou seest all the amiable maidens who are in this court WB. I 55 .

(b) Consuetudinal present, e.g. ef a wy்l pawb or a del ý mýwn ac nýs gwẏl neb efo he sees everyone who enters and no one sees him WB. $15^{6}$.

(c) Of an action lasting into the present, e.g. ys gwers yd wyf yn keissaw a olchei vyg cledyf $I$ have been seeking for a while some one to burnish my sword RB. I 26 ; pump mlyned ar ethynt yr pan yttym ni yn arueru or ryw seguryt hwnnw five years have passed away since we have been enjoying that ease RB. II. 205.

(d) Historic present, e.g. nyt kynt yd yskynn ef ar y uarch noc yd a hitheu hebdaw ef no sooner did he mount his horse than she passed him RB. II ; nachaf gwr du . . . a welant lo! they saw a black man WB. 486 ; a phan daw (=doeth WB. p. 204) hyt lle yd oed Gwenhwyvar kyuarch gwell a oruc idi and when he came to the slace where Gwenhwyvar was he greeted her RB. 262 ; gossot a oruc ynteu ar y marchawc... yny hyllt y daryan ac yny dyrr yr aruev he made an onset on the horseman, till he cleft the shield and broke the arms RB. $27 \mathrm{I}$.

(e) As future, e.g. dywet y Arthur pa le bynnac y bwyf i gwr idaw vydaf, ac o gallaf lles a gwassanaeth idaw, mi ae gwnaf. A dywet na deuaf y lys vyth yny ymgaffwyf ar gwr hir say to Arthur that wherever I am I will be his man, and if I can do him advantage and service, I will do it. And say that I will never come to his court till I encounter the tall man.

\section{IMPER FECT.}

r07. (a) Of an action going on or a state existing in past time, e.g. val y kyrchei ef y bont ef a welei varchawc yn dyuot as he was making for the bridge, he saw a horseman coming WB. p. 216; nyt y fford a gyrchei y tref or bont a gerdawd Gereint it was not by the road that went from the bridge to the town that Gereint went 
WB. p. 2 I 7 ; yma ẏd oedwn ýn kerdet ui ar gwr mwýaf a garwn. ac ar hỷnny $\dot{y}$ doeth tri chawr o gewri attam we were travelling, $I$ and the man whom I most loved. And thereupon there came to us three giants WB. 44I ; pan deuthum i yma gyntaf, eingon gof a oed yma, a minneu ederyn ieuanc oedwn when first I came here there was here a smith's anvil, and I was a young bird RB. I29.

Note 1.- Note the nse of the imperfect with a negative in such sentences as the following: nyt eynt hwy oe bod they would not go willingly RB. 32; yr hynny ny thawei yny dygwydwys kysgu arnei for all that she vould not be silent, till sleep fell upon her RB. II. 51 .

NoTE 2.-The imperfects of clybot to hear and of gwelet to see are frequent in narrative, parallel with the preterite of other verbs, e.g. y dyd yd aeth ef parth a chaer Dathyl, troi o vywn y llys a wnaeth hi; a hi a glywei lef corn the day that he went towerds Caer Dathyl, she walked within the eourt, and she heard the sound of a horn RB. 74,6; a dyuot yr brifford ae chanlyn a orugant. A choet mawr a welynt y wrthunt. A ffarth ar coet $\mathrm{y}$ denthant. Ac yn dyuot or koet allan y gwelynt pedwar marchawe aruawe. Ac edrych a orugant arnunt and they eame to the highway and followed it. 'And they saw before them a great wood. And they went towards the wood. And they saw four armed horsemen eoming out of the wood. And they gazed upon them RB. 270, 19.

(b) Representing in indirect speech a present indicative of direct speech, e.g. a galw a wnaeth attaw y verch hynaf idaw Goronilla a gofyn idi pa veint y karei hi efo. A thygu a wnaeth hitheu $y$ nef a daear bot yn vwy y karei hi euo noe heneit ehun. A chredu a wnaeth ynteu idi hynny, a dywedut, kan oed kymeint y karei hi euo a hynny, y rodei ynteu draean y gyuoeth genti hi y wr a dewissei yn ynys Prydein and he called to him his eldest daughter Goronilla, and asked her how much she loved him. And she swore by heaven and earth that she loved him more than her own life. And he believed her in that and said that, since she loved him so much as that, he would give the third of his kingdom with her to the man whom she should choose in the island of Britain RB. II. 65.

(c) Of a repeated or customary action in past time, e.g. a phy beth bynnac a dywetei ar y dauawt, ef ae kadarnhei oe weithret ae arueu and whatever he said with his tongue, he used to make it good by his deeds and his arms RB. II. 4I; kymeint ac a wnelit y dyd or gweith, tranoeth pan gyuotit neur daruydei yr dayar y lynku as much of the work as was done by day, overnight when they arose the earth had swallowed it RB. II. I4I; ar rwym a wneyit 
yna rwng deu dyn a wnaethpwyt y rwng Gereint ar uorwyn and the bond that used to be made then between two persons was made between Gereint and the maiden RB. 262, 25.

(d) As secondary future or conditional.

(a) As a secondary tense to the future, e.g. can gwýdywn i $\dot{y}$ dout ti ym keissyaw i for I knew that thou wouldst come to seek me WB. 249; diheu oed genthi na deuei Ereint uyth she was sure that Gereint rouid never come WB. 44I ; ny wydyat hi beth a wnaei she did not know what she should do RB. 268, 29.

$(\beta)$ In the apodosis of a future or possible conditional clause, e.g bei gwnelhit uýg ky்ghor i ny் thorrit kýfreitheu llýs yंrdaw if my counsel were followed, the law's of the court would not be broken on his account WB. $45^{8}$; pei clywhut ti ymdidan y marchogyon racco... mwy vydei dy oual noc y mae if thou heard the discourse of yonder horsemen, thy anxiety would be greater than it is.

$(\gamma)$ In the apodosis of a past or impossible conditional clause, e.g. py ham vilein, heb ef, y gadut ti efo heb y uenegi imi. Arglwyd, heb ef, ny orchymyneisti euo imi; pei as gorchymynnut nys gadwn "why, villain," said he, "didst thou let him go without letting me know?" "Lord," said he, "thou didst not give me such instructions. If thou hadst instructed me I should not have let him go" WB. p. 216; pei oet idaw, ef a ledit (=ladyssit RB. 193, 8) if he had been of age, he would have been slain WB. I 7 .

Note 3. To bot to be the regular conditional is bydwn. The imperfect oed, however, (like Ir. ba) is used in a modal sense in expressions like the following: oed well genhýf ( = Ir. ba ferr limm) noe ẏssy்d ỳm gwlat bei oll ẏt nei val hỳun I should prefer to all that is in my kingdom that it should be all like that WB. 487.

\section{Preterite.}

I08. (a) As preterite (the regular narrative tense), e.g. ac ýmhoy lud a oruc ar $\dot{y}$ marchawc, ac ar $\dot{y}$ gossot kỷntaf $\dot{y}$ uwrw ýr llawr $\dot{y}$ dan draet $\dot{y}$ uarch. a thra barh[a]awd $\dot{y} r$ un or pedwarugein marchawc, ar ý gossot kỷntaf $\dot{y}$ by்ryawd pob un onadunt. Ac o oreu $\dot{y}$ oreu $\dot{y}$ doe[t]hont attaw eithýr $\dot{y}$ iarll. Ac ýn diwethaf oll $\dot{\mathrm{y}}$ doeth $\dot{\mathrm{y}}$ iarll attaw and he turned on the horseman, and at the 
first onset he threw him to the ground, under the feet of his horse. And while there remained one of the eighty horsemen, at the first onset he overthrew every one of them. And there came to him always one better than the last, except the earl. And last of all the earl came to him WB. 432 ; y gysgu yd aethant y nos honno. a phan welas y meichat lliw y dyd, ef a deffroes Wydyon that night they went to sleep. And when the swineherd saw the hue of day, he aroused Greydyon RB. 78, I2.

(b) Corresponding to a perfect in indirect speech, e.g. a thranoeth Agamemnon a wyssywys y bobyl y gyt, ac a diwadawd na bu ef eiryoet chwanawc yr amherodraeth honno. ac a dywawt nas kymerth ef hi onyt o uedwl iawn and next day Agamemnon summoned the people together, and denied that he had ever been desirous of that sovereignty. And he said that he had not taken it except with just intention RB. II. 24 .

(c) As perfect, e.g. coet ry welsom ar y weilgi yn y lle ny welsam eiryoet vn prenn we have seen a wood upon the sea where we have never seen a single tree RB. 35, 24; pwy a ganhadwys itti eisted yna who has given thee permission to sit there? WB. p. 25 ; Bendigeit Uran ar niuer a dywedassam ni a hwylyassant parth ac Iwerdon Bendigeit Vran and those whom we have mentioned set out towards Ireland RB. 35, I4.

\section{Pluperfect.}

I09. (a) As pluperfect indicative, e.g. or a welsei ef o helgwn y byt ny welsei cwn un lliw ac wynt of all the hounds that he had seen anyzehere he had never seen dogs of the same colour as them RB. I, 2 I; ual y gnottayssei tra uu yn llys Arthur kyrchu twrneimeint a wnaei he resorted to tournaments as he had been wont to do while he was in Arthur's court RB. 268, 6; a dyuot kof idaw y dolur yna yn uwy no phan y cawssei and then there came to him the recollection of his sorrow more than when he had received it WB. p. 2 I 8 .

(b) As pluperfect conditional, e.g. buassei well itti pei rodassut nawd yr mackwy it would have been better for thee if thou hadst given protection to the lad; a phei nat ystyriei yr Arglwyd Duw ohonunt 
wy, ef a wnaethoed oual tra messur udunt and if the Lord God had not considered them he would have caused anxiety beyond measure to them Hg. II. $7 \mathrm{I}$.

(c) Replacing the subjunctive in a pluperfect sense, e.g. bei buassut wrth vy gyghor $i$, ny chyuaruydei a thi na thrallawt na gofit if thou hadst followed my counsel, neither affliction nor trouble would have come nigh unto thee Hg. II. I23; pei doethoed ef yn y lle wedy dilyw, wynt a dywedynt y mae vrth Noe ac Effream y dywedassei Duw pob peth or a dywedessynt if he had come immediately after the Flood they would have said that it was to Noah and Abraham that God had said everything that they had said LA. I 7.

\section{The Subjunctive Mood.}

The Formation of the Subjunctive.

IIo. The sign of the subjunctive is $\mathbf{h}$; for the changes that $\mathbf{h}$ undergoes in conjunction with a preceding sound see $\$$ IIg. Examples:-sg. 3 pres., coffaho: coffau to remember; carho: caru to love; sorho: sorri to be angry'; talho: talu pay; prynho: prynu to buy; mynho: mynnu to desire; bendicco: bendigaw to bless; cretto: credu to believe; atteppo: attebu to answer; llatho: llad to slay; tyffo: tyvu to grow. After a preceding h, $\mathbf{h}$ is lost by dissimilation, e.g. parhao: parhau to continue; amheuo: amheu to doubt. Further $\mathrm{h}$ does not appear after $\mathrm{ch}$, e.g. archo: erchi to ask, after ff, e.g. caffo: caffael to get, after 11 , e.g. gallo: gallu to be able, or after s, e.g. keisser BB. $26^{\text {b }}$, llafassed BB. $27^{\mathrm{a}}$, yssynt WB. 467 . In the present tense the subjunctive has distinctive endings; in the past tense the endings are the same as in the imperfect indicative, so that here the $\mathbf{h}$ is the only distinguishing mark, except in the few verbs that have a special subjunctive stem.

NOTE 1.-In Mid.W. a new h subjunctive is formed analogically to the indicative of verbal stems ending in d, e.g. cerdho RB. $293=$ certho WB. p. 211 : cerdet to go, lladho WB. p. $210=$ llatho WB. 419 : llad, rodhom RB. $115=$ rothom $W B$. 458 : rodi to give; from stems ending in $v$ the regular form is rare, tyffei : tyvu WB. 453, but prouher: provi prove BB. $3^{\text {b }}$, safhei : sevyll to stand WB. $466=\mathrm{RB}$. 110 . There are already in Mid.W., particularly in its later period, examples of complete confusion 
of the subjunctive with the indicative stem, e.g. clywut RB. $274=$ clývut WB. $423=$ clywhut WB, p. 212 : clybot to hear, clywych RB. $270=$ clywhych WB, p. 209 , guelud : gwelet to sce BB. $29^{\mathrm{b}}$, talo RB. $268=$ talho WB. 415 , sorro : sorri BB. $28^{b}$, cenich : canu to sing BB. $42^{\text {b }}$, medrei $\mathrm{RB}$. $76=$ metrei WB. 104 : medru aim at, mynnei RB. $277=$ mynhei WB. p. 214, cerdo RB. $273=$ certho WB. p. 211 , llado RB. $270=$ lladho WB. p. $210=$ llatho WB. 419 , rodo RB. $286=$ rotho WB. p. 220 , yvei : yvet to drink BB. $48^{\text {b }}$. This confusion has spread analogically from cases like gallu, erchi, etc., where the subjunctive stem was in Old Welsh identical with the indicative, and from cases where later the two forms fell together by the operation of phonetic law, e.g. mynho to mynno, like minheu $I$ to minneu. The old forms are most persistent in stems in $\mathrm{g}, \mathrm{d}, \mathrm{b}$.

Note 2.-The earlier history of the Welsh subjunctive is very obscure. Vendryès, however, in the Mémoires de la Societé de linguistique de Paris, XI. $258 \mathrm{sq}$. has made it probable that $\mathrm{h}$ came from prehistoric s, so that the formation would resemble that of the Irish $s$-subjunctive, from which, however, it differs in that in Welsh there must have been a vowel between $s$ and the final consonant of the verbal stem. The explanation given by Stern, CZ. III. $383 \mathrm{sq}$. is untenable. In Early Welsh there are two subjunctives identical in formation with the Irish $s$-subjunctive :-duch may he lead from *douc-set : dwyn to lead, and gwares may he help from * vo-ret-set : gwaret to help.

\section{The Tenses of the Subjunctive.}

III. In early Welsh, as in Irish, the subjunctive had two tenses, a present, which syntactically had the function of a present and of a perfect, and a past, which syntactically had the function of an imperfect and of a pluperfect; in the sense of perfect and pluperfect the subjunctive may be preceded by ry ( $\$ 96 \mathrm{~B}$.) In the later Mid.W. period the past subjunctive in a pluperfect sense tended to be replaced by the pluperfect indicative ( $\$$ IO9c); sometimes in the same passage one text has the original subjunctive while another has the pluperfect indicative, e.g. kynn nys ry welhei WB. $454=\mathbf{y r}$ nas gwelsei RB. 102, 5 though he had not seen her; pei as gorchymynnut IVB. p. 2 I6 = pei as gorchymynnassut RB. 280, 7 if thou hadst commanded it. The indicative origin of the usage is particularly clear in forms like pei doethoed if he had come LA. 17.

NOTE.-This substitution is parallel to the general tendency to replace the subjunctive stem by the indicative; it was noted above that no instances have been found of subjunctive $h$ after s; thus, if ysswn from yssu to eat might be either indicative or subjunctive, a pluperfect indicative like carasswn $I$ had loved might easily have come to be used in a subjunctive sense. In ry wnelsut WB. p. $223=$ gwnelut WB. 445, RB. 290 , a pluperfect has been formed analogically to the past subjunctive gwnelut (§ I42). 


\section{The Usages of the Subjunctive.}

I12. A thorough investigation of the uses of the subjunctive as contrasted with the indicative in Mid.W. is still wanting ${ }^{a}$. The following examples may serve to illustrate the principal types; further instances will be found under the conjunctions. Under the various headings are given, so far as they occur, $(\alpha)$ instances of the present subjunctive, $(\beta)$ instances of the past subjunctive.

II3. A. The subjunctive in main clauses.

(a) Wish.

(a) an duch ir gulet may He bring us to the feast BB. $20^{\mathrm{b}}$; Duw a rotho da itt may God give good to thee IVB. p. 204 ; ny bo teu dy benn may not thy head be thine RB. 103, 6 .

NoтE.-A wish with reference to the past is expressed by the indicative, e.g. Och Iessu na dyffv wy nihenit $O$ Jesus! that my death had eome (lit. Alas! Jesus, that my death did not eome) BB. $25^{\mathrm{b}}$; och Gindilic na buost gureic vould, Cynddilig, that thou hadst been a woman BB. $46^{3}$.

(b) Command.

(a) yscythrich fort a delhich ti. a llunhich tagneuet make smooth a road that thou mayest come and cultivate peace BB. $4^{2}$; dos ... ac erchych hynny idaw go and ask that of him RB. 102, $\mathrm{r}$; dyuot a wnelhych gennyf come with me RB. i 8 , 2 ; dabre genhiw nym gwatter come zeith me, let me not be refused $\mathrm{BB} .5 \mathrm{I}^{2}$.

$(\beta)$ In indirect speech a command is transferred to the past subjunctive, e.g. Agamemnon ... a d[y]wawt y peidei ef ar llywodraeth honno yn llawen ... a gossottynt hwy y neb a vynnynt yn y le ef Agamemnon said that he would gladly give up that command, and that they should set zehomsoever they pleased in his place RB. II. 24.

(c) Futurity. This usage is common in poetry, but rare in prose.

(a) ohonot ti ẏt gaffo ef kanyंs ry gaffo o arall from thee he shall get it, though he has not got it from another WB. 453; nyth atter ti (= nyth ellyngir di RB. 104, 8) y mýwn thou shalt not be admitted IVB. 457 ; nyt arbettwy car corff y gilyd one kinsman will not

a $A$ becrinning has been made by Atkinson, On the Use of the Subjunctive Mood in Welsh, "Transactions of the Royal Irish Academy, 1894," pp. 459 sq., but he deals only with the present subjunctive. 
spare the body of another FB. I 27; cad a uyt ym Mynyt Carn a Thrahaearn a later there will be a battle in Mynydd Carn, and Trahaearn will be slain MA. $\mathbf{1}^{2} 2^{\mathrm{a}}$.

II4. B. The subjunctive in subordinate clauses.

(a) Negatively after verbs of thinking, swearing, etc.

(a) ny thybygaf inheu na wypych ti haedu ohonaw ef hynny I do not think that thou dost not know that he has deserved that RB. II. I57; hyt na bo neb a wypo na bo ti vo Gwrlois so that no one may know that thou art not Grorlois RB. II. I79; mi a tynghaf dynghet idaw na chaffo ef enw yny kaffo gennyf i $I$ lay this fate on him that he will not get a name till he gets it from me RB. 69, 21 ; o rodwch gret na wneloch gam idi if ye pledge yourselves to do her no wrong $\mathrm{RB}$. II $7, \mathrm{I} 5$.

Note 1.-But in indirect speech as such the indicative is the mood used. With the last example contrast: y Duw y dygaf vyg kyffes nae werthin nae ellwng nas gwnaf i $I$ vow to God that I will neither sell it nor let it go RB. 56,8 ; similarly 215,15 .

$(\beta)$ nyt er tebygu ohonaw ef na bei deilwg it zeras not because he thought that it was not worthy RB. II. 26 ; neb or ae gwelei ny wydyat na beynt eur no one who saze them kneze that they zeere not gold RB. 62, r. After a primary tense :-na wn ... pei kahwn dysc nas gwẏpwn $I$ do not know that, if I got instruction, $I$ would not know how to do it WB. 127.

(b) In indirect interrogation.

(a) aet un y wybot pwy vo let some one go to learn zeho he may be RB. 9, I ; manac y mi pa furyf y gallwyf hynny showe me hoze I can do that RB. 3, 4; yny wyper a uo byw until it be known whether he will live RB, 26I, 4 ; y edrych a allwyf y dial arnaw to see whether I can avenge him on him RB. 204, I2; dewis ae ti a elych yr llys ae titheu a delych gyt a mi y hela ae minneu a yrro vn or teulu choose whether thou wilt go to the court, or whether thou wilt come with me to the chase, or whether I shall send one of the household RB. 237,9 .

$(\beta)$ heb wybot pwy vei eu gelynyon pwy vei eu gwyr ehunein without knowing zeho were their enemies, who their own men RB. II. I05; val yd oed Kynan Meiradawc yn pedrussaw beth a wnelei as Kynan Meiradazy was hesitating as to zohat he should do 
RB. II. I I4; a medylyaw pa ffuruf y gellynt ymlad ar deu lu and they considered how they could fight with the two armies RB. II. 76 ; ef a peris y dwyn yw lys y edrych a uei vyw he caused him to be brought to his court to see whether he would live WB. p. 222.

Note 2.-But in dependent interrogation as such the subjunetive is not required, e.g. ny wn i pwy wyt ti $I$ do not know who thou art RB. 2 ; govyn a orue pwy oedynt a pha le pan hanhoedynt a phy daear y magyssit arnei a phy achaws $\mathrm{y}$ dathoedynt $\mathrm{y}$ deyrnas ef he asked who they were, and whence they eame, and in what land they had been reared, and for what reason they had come to his hingdom RB. II. 131; gouyn a wnaeth ae offeiryat oed ef he asked if he vas a priest $\mathrm{Hg}$. I. 33; edrych yn y ehyleh a orue a yttoed ef yn deffroi she looked round about her to see if he was araking RB. 274, 30.

(c) Concessive clauses:-

(a) a chyt archo ef ytti yr eil na dyro and though he ask thee for a second (blow), do not give it RB. 3, r9; tydi am gwely i kany welwyf i dydi thou shalt see me, though I do not see thee RB. I73, I8.

$(\beta)$ a chyt bei lityawc ef wrthi hi ef a gymyrth y rybud and though he was angry with her, he took her werarning WB. p. 215.

(d) Conditional clauses:-

( $\beta$ ) e.g. pei as gwypwn mi ae dywedwn if I knew it, I zoould tell it RB. I 30,5 ; bei ýs cuyjpun...ny்s gunaun if I had known it $I$ would not have done it $\mathrm{BB} .4 \mathrm{I}^{\mathrm{a}}$; or gwnelei ef hynny ynteu a rodei y verch idaw ef if he did that he would give him his daughter RB. II. 26.

Note 3.-In present conditional clauses the present indicative with $\mathrm{o}$ is used $\left(\S 224^{a}\right)$.

(e) Clauses of comparison:-

(a) gwnaet iawn mal y barno goreugwyr y llys let him give satisfaction as the nobles of the court shall decide RB. 26I, 4 .

$(\beta)$ mal y dyckei eu teghetuenneu y ffoassant they fled as their fortunes led them RB. II. 73. Of unreal comparison, e.g. llyma yssyd iawnhaf itti.. dyuot yma auory ym kymryt i mal na wyppwn i dim y wrth hynny that is thy most proper course, to come here to-morrow to take me as if I knew nothing about it WB. p. 215.

(f) Temporal clauses:-

(a) o lladaf i y gwr racco mi ath gaf ti tra vynhwyf. a gwedy nath vynhwyf mi ath yrraf ymdeith if I slay yonder man, I will 
take thee as long as $I$ desire; and when $I$ no longer desire thee, I will cast thee forth WB. p. $2 \mathrm{I} 5$; pan agorer y creu beunyd yd a allan when the sty is opened every day, it goes out RB. 78, 7 ; pan delych dy hun yth wlat ti a wely a wneuthum yrot ti when thou thyself comest to thy land, thou wilt see what I have done for thee RB.6; ny luniaf i esgydyeu idi yny welwyf y throet $I$ will not shape shoes for her till I see her foot RB. 70, 24.

$(\beta)$ a pheri yr kigyd gwedy y bei yn drynyaw kic dyuot idi a tharaw bonclust arnei beunyd and he made the butcher, after he had been cutting up the flesh, come to her and box her ears every day RB. 34, 9; a ffan uei hỳttraf Gereint y llawenhaei y gwr and whenever Gereint prevailed, the man rejoiced WB. 398 ; tra uei y mywn coet ar vric y coet $\mathrm{y}$ kerdei while he w'as in a wood, he would travel on the top of the wood RB. Io8, 2 I ; y byryw [y]t y kalaned yn y peir yny uei yn llawn the corpses were throw'n into the cauldron till it was full RB. 39,23 .

(g) Final clauses, and clauses following verbs of effecting, commanding, desiring, etc.

(a) carchara wynt hyt nat elont dracheuyn imprison them so that they may not go back RB. 34, I4; mi a wnaf na chaffo ef viui vyth I shall effect that he shall never get me RB. I3, 16; ny allaf i na chysgwyf I cannot refrain from sleep RB. 277, 4; sef y harchaf itt na mynnych wreic my request of thee is that thou shalt not seek a wife RB. 100, 20.

$(\beta)$ ereill a gyghorei it rodi dy uerch y un o dylyedogyon y deyrnas hon ual y bei vrenhin gwedy ti others counselled thee to give thy daughter to one of the nobles of this kingdom, so that there might be a king after thee RB. II. II4; Andromacta...a anuones at Briaf y beri idaw wahard Ector nat elei y dyd hwnnw yr vrwydyr Andromache sent to Priam to get him to prevent Hector from going to the battle that day RB. II. 22 ; adolwyn a wnaeth Elenus na wnelit hynny Helenus begred that that might not be done RB. II. $3^{2}$.

No'TE 4.- But in mere consecution the indicative is used, e.g. ar y llech y mae kawe aryant wrth gadwyn aryant mal na ellir eu gwahanu on the fag there is a silver goblet on a silver chain, so that they cannot be separated RB. 167; kyscu a wneuthum i ual na wybuum pan aeth ef $I$ slept so that I did not know when he went RB. $247,26$. 
(h) Relative clauses, including similar clauses of a non-relative type.

(a) wely di a wnelych here is what thou must do RB. 271, 23; kein wlad nef boed ef yt el the fair land of heaven, may it be there that he goes MA. ${ }_{26}$ b; a vo penn bit bont let him zero is head be bridge RB. 36 ; y gymeint a wypwyf $\mathrm{i} \mathrm{mi}$ ae dywedaf all that $I$ know I will tell RB. I3I; o mynwn nineu arueru o rydit a vo hwy if we wish to enjoy freedom any longer; pwy bynnac a vynno kanlyn Arthur bit heno y Ghernyw gyt ac ef whoever wishes to accompany Arthur, let him be with him to-night in Cornerall RB. I60; kymer y march kyntaf a welych take the first horse that thou seest RB. 9; na uyd...yr a dotter yndi vyth however much be put into it it will never be (full) RB. I 5; ny cheiff ymwan...y gwr ny bo gyt ac ef $\mathrm{y}$ wreic vwyhaf a garho no man will be allowed to contend who has not with him the lady whom he most loves RB. 252; a oes ohonawch chwi a adnapo $\mathrm{y}$ uarchoges racco is there any one of you who knows yonder horsewoman? RB. 8; keis ath ladho seek someone to slay thee RB. 5 ; gwna ty...y geingho ef make a house in which he may find room RB. $37,2 \mathrm{I}$

$(\beta)$ Sef y gwelei y llew yn y ganlyn ... ual milgi a uackei ehun he saze the lion following him like a hound that he had reared himself RB. 187 ; pedeir meillonen gwẏnny่on a dy்uei ỳn ẏ hol my்n yd elhei four white blades of clover grew after her zeherever she zvent WB. 476 ; digavn oed hỷnny yn tal gwasanaeth a uei uwy nor un a wneuthum i that were sufficient as pay for a greater service than that ze'hich I have done WB. 426 ; a pheth bynnac a dywettei Peredur wrthi chwerthin a wnay hitheu yn uchel and whatever Peredur said to her, she laughed aloud RB. 237; a chymeint oed eu gwybot ac nat oed ymadrawd ... yr isset y dywettit ... nys gwypynt and such was their knowledge that there was no conversation, however low it was uttered, that they did not know RB. 94, I8. After a primary tense: kynhebic yw yr neb a wasgarei gemeu mawrweirthyawc dan draet moch he is like one who should scatter precious stones under the feet of szerine RB. II. I 22. 


\section{The Imperative.}

I15. In the active the imperative has two persons in the singular and three in the plural ; in the passive it is identical in form with the subjunctive. The negative is na. Examples:-gat $\mathrm{i}$ mi vynet allow me to go; na wiscet dim ymdanei let her not put anything on; kyrchu tref arall a wnawn let us make for another tozen; na rodher let there not be given. The only idiom that calls for special notice is the following:- $\mathrm{mi}$ a rodaf vy iarllaeth yth uedyant a thric gyt a mi $I$ will give my earldom into thy possession, if thou wilt stay with me (lit. and stay with me) RB. 278 , I4.

\section{The Participle Passive in -edic.}

II6. Examples:- arueu y gwyr lladedic the arms of the slain men; ynteu madeuedic yw ganthaw y godyant ef as for him, the injury done to him is forgiven ly him WB. 404; Gwawl ... a doeth parth ar wled a oed darparedic idaw Gwawl went to the feast that was prepared for him RB. 14, 22.

\section{The Verbal in -adwy.}

II7. Examples:-nyt barnadwy yn volyant it is not to be judged a praise $\mathrm{Hg}$. II. 83 ; nyt kredadwy it is not to be believed CM. I I ; a chanys credadwy yw y anedigaeth credadwy y varwolyaeth and since his birth is credible, his death is credible CM. $2 \mathrm{I}$; midwyf bard moladwy I am a poet worthy of praise FB. 203 ; odit a uo molediw $f_{t} w$ are zerthy of praise $\mathrm{FB} .272$; os da gennyt ti ac or byd ragadwy bod it if thou approvest and if it is pleasing to thee RB. II. I33; a phrofadwy yw ry golli ohonaf $\mathrm{i}$ vyn ngolwc and it is clear that I have lost my sight $\mathrm{Hg}$. I. 83 ; vegys bilein profadwy like a proved villain $\mathrm{Hg}$. II. I 29. 


\section{The Verbal Noun or Infinitive.}

Formation.

II8. The following are the chief types of formation of the verbal noun :-

(a) The prehistoric suffix has disappeared, so that the verbal noun is now identical in form with the stem of the verb. Examples: ammeu doubt: amheu-af $I$ galw call: galw-af doubt gellwng let go: gellyng-af cyvarch ask : cyvarch-af dianc escape : diangh-af diodef suffer: diodev-af gwarandaw listen: gwarandaw-af llad slay: llad-af

Further in some denominatives, e.g. bwytta eating: bwytta-af, cardotta begging, lledratta stealing, pyscotta fishing.

II9. (b) The verbal noun still shows a suffix.

(a) -i, e.g.-

bod-i drozen: bod-af

cyvod-i rise : cyvod-af erch-i (O.W. erchim) ask: arch-af meneg-i shew : manag-af

( $\beta$ ) $-\mathrm{u}$, e.g.-

can-u sing: can-af car-u love : car-af dysg-u teach: dysg-af gall-u be able: gall-af mol-i (O.W. molim) praise: mol-af

per-i cause : par-af tew-i be silent : taw-af torr-i break: torr-af

gwassanaeth-u minister:

gwassanaeth-af

mynn-u desire : mynn-af pryn-u buy : pryn-af

This is the common form of the verbal noun from denominatives in -ha-, e.g. cennatta-u send message: cennatta-af, dynessa-u approach: dynessa-af, rydha-u free: rydha-af.

$(\gamma)$-aw, e.g.-

gwisg-aw clothe: gwisg-af bedydy-aw baptize: bedydy-af lliw-aw colour: lliw-af medyly-aw think: medyly-af 
(ס) -at, -et, -ut, e.g.-

adeil-at build: adeil-af

cerd-et go : cerd-af gwel-et see: gwel-af

dywed-ut (also dywedwyt) ymchoel-ut turn: ymchoel-af say : dywed-af

(є) Various suffixes found only in a few verbs :-

cymryt take: cymmer-af dyffryt protect: differ-af edvryd restore: adver-af goglyt shun : gogel-af

adolwyn entreat : adolyg-af dwyn lead: dyg-af amwyn protect : amyg-af

ehed-ec fy : ehed-af ered-ic plough : ard-af

caffael, cael get: caff-af gadael (by gadu) allon :

gad-af

chwerthin laugh: chward-af igian $s o b$ : igi-af darllein read: darlle-af

llevain cry: llev-af dilit follow : dilyn-af ymlit pursue: ymlyn-af godiwes overtake: godiwed-af arhos await: arho-af

red-ec run : red-af

gallel (by gallu) be able: gall-af sev-yll stand: sav-af

\section{USAGE.}

I20. The infinitive, being merely a verbal noun, has all the constructions of a noun; it has, however, become so far attached to the verbal system that it forms a perfect by prefixing the particle ry (§ 96c). Examples :-

(a) nyt oed vynych yt gaffel bud it was not a common thing for vou to get profit; mynneu a ryuedeis gallu ohonaw ef mynet yn dirybud y mi $I$ wondered that he could go without informing me; gwedy llad y gwyr hynny after those men had been slain; cyn awch mynet ymdeith atteb a geffwch before you depart (lit. before your 
going) you shall get an answer; heb y uenegi imi without showing it to me; y eu gochel to avoid them.

(b) gwedy clybot yn Rufein ry oresgyn o Garawn ynys Brydein after it had been heard in Rome that Carazen had conquered the island of Britain. Sef a wnaethant llidiaw yn vwy no meint am ry wneuthur ac wynt kyfryw dwyll a hwnnw they zere exceeding wroth that such treachery had been done to them RB. II. 75 .

I2I. The verbal noun has no distinction of voice. If it depends upon gallu to be able or dylyu to owe, then, if the sense be passive, gallu and dylyu are put in the passive, e.g. gwreic y gellir dywedut idi y bot yn deckaf or gwraged a woman of whom it can be said that she is the fairest of zomen; ni a atwaenwn y neb a dylyer y kymryt y gantaw we knowe those that ought to be taken from him RB. $16,20$.

122. The agent with the verbal noun is commonly expressed by the preposition $\mathrm{o}$ following the noun (cf. the corresponding Irish construction with do), e.g. gwedy gorwed ohonaw ef ar traws yr auon after he had lain across the river; gwedy ry gyscu ohonaw after he had slept; rac dy lad ohonaw lest thou shouldst be slain by him. It may also be expressed by the preposition y, e.g. tygu llyein mawr udunt wynteu y vot yn wir they swore great oaths that it was true Hg. II. I3 I kymryt ofyn mawr y Vradmwnd Bradmond became sore afraid $\mathrm{Hg}$. II. I 33; gwedy udunt oresgyn yr holl wlat after they had conquered the whole country RB. II. I I6; gwedy y Amic gaffel kennyat after Amic had got permission Rev. Celt. IV. 2 I 8 ; nyt oed neb o vilwyr y vort gronn heb idaw eu bwrw oll yr llawr there zeras no one of the zearriors of the Round Table that he had not throwen down Hg. I. 9; yr y pawb disgynnu though everyone else dismounted RB. 105, 7. Or the verbal noun may be preceded by a possessive adjective, e.g. gwedy eu dyuot yr weirglawd after they came to the meadoze Hg. I. 9.

r23. The verbal noun is often used in periphrasis with gwneuthur to do, e.g. dysgynnu ar y pren a wnant they will alight upon the tree; ac yna ymlad a wnaem ninneu am y maen and then we would fight for the stone; a cherdet recdi yr coet a 
oruc $\dot{y}$ uorwyn and the maiden went on to the wood; rodi penn y karw a wnaethpwyt y Enid the head of the stag was given to Enid.

124. The verbal noun may carry on the construction of a finite verb, e.g. drýchauel $\dot{y}$ wýneb a oruc ynteu ac ydrých arnei ýn llidiawc he raised his face and looked on her angrily WB. 419; kennatau y mab a orucpwyt, ae dyuot jnteu yr llýs and the boy was sent for and came to the court WB. 454; ac a dywawt na wnaethpwyt oe bleit ef drwc yn y byt y Briaf, namyn rodi Esonia idaw ef o achaws y dewret and he said that on his part no evil in the world had been done to Priam, but that Hesione had been given to him for his valour RB. II. 5; pan bebillo Lloegir in tir Ethlin a guneuthur Dýganhuy dinas degin when the English shall encamp in the land of Ethlin, and make Deganwy a strong fort BB. $2 S^{a}$; pan gyfodes y bobyl a chael Lawnslot megys yn uarw when the people rose and found Launcelot like one dead $\mathrm{Hg}$. I. I 55 .

I25. Without a preceding finite verb the verbal noun may serve as an historical infinitive, e.g. tra yttoed vilwyr Arthur yn ymlad ar gaer, rwygaw o Gei y uagwyr a chymryt y carcharawr ar $y$ geuyn while Arthur's warriors were fighting with the city, Kei broke through the wall and took the prisoner on his back RB. 131, 28; deuy yrof a Duw, heb ynteu. ae dwyn gyt ac ef yr uort oe hanuod, ac erchi idi vwyta yn uynych "betzeen God and me thou shalt come," said he. And he took her to the table against her will and asked her repeatedly to eat RB. 289; a gwedy disgynnu Arthur yr tir dyuot seint Iwerdon attaw y erchi nawd idaw and after Arthur landed, the saints of Ireland came to him to ask his protection RB. ${ }_{3} 6$; dyuot (= dyuot a oruc RB. 126) $\dot{y}$ porthawr ac agori $\dot{y}$ porth the porter came and opened the gate WB. 487.

126. The verbal noun has special uses with certain prepositions.

(a) With yn the verbal noun has the force of a present participle (cf, the Irish construction with $o c$ ), e.g. val y gwelas y gwr...Peredur yn dyuot as the man saw Peredur coming; lleidyr...a geueis yn lletratta arnaf a thief whom I caught stealing from me. It is often used with the substantive verb to express continuing action; e.g. yr hynny hyt hediw yd wyf i yn darparu gwled ytti from that time 
till to-day I have been preparing a feast for thee RB. I 82 ; canys ar $\mathrm{y}$ medwl hwnnw yd wyt titheu yn trigyaw since it is on this purpose that thou art fixed RB. 253; ual yd oed y sarff yn dyuot or garrec, $\mathrm{y}$ tharaw a oruc Owein a chledyf as the snake was coming from the rock, Owein struck it with a sword. When the verbal noun precedes the verb yn may be added, but it is more commonly omitted, e.g. yn eisted yd oedynt ar garrec Hardlech they were seated on the rock of Harlech RB. 26, yn adolwc y mae y ti arglwyd (=adolwyn itti arglwyd y mae Erbin WB. p. 205) ellwng Gereint y uab attaw he entreats thee, Lord, to let go his son Gereint to him RB. 264; dywedut yrydunt ehun $\mathrm{y}$ maent they are saying among themselves WB. p. 2 I I medylyaw yd wyf I am considering RB. 75, 26 (but yd wyf yn medylyaw RB. 76, 22).

(b) With gwedy after the verbal noun has the force of a perfect participle (cf. the use of Irish iar n-), e.g. y mae gvedy my்net gyd a Gwenhwỳvar yं hỷstavell he has gone with Gwenhzeyvar to her chamber WB. 408, a phan yttoedynt gwedy gware talym, sef y klywynt kynnwryf mawr when they had played a while, they heard a great din RB. 157 ; a ffan welas $\dot{y}$ gwr...Gereint gwedy caffel dyrnawd and when the man saw that Gereint had received a blow WB. 398; Enỳt a oed heb gýscu $\dot{y}$ my்wn ystauell wẏdrin, ar heul $\dot{y} n$ týwỷnnu ar ý gwely, ar dillad gwedy ry lithraw $\dot{y}$ ar $\dot{y} d w \dot{y}$ uron ef Enid was sleepless in a chamber of glass, with the sun shining on the bed, while the clothes had slipped from his breast WB. 416 .

(c) With can with and tan under the verbal noun is used in sentences like the following: Pascen...a gyffroes y bobyl honno... gan adaw udunt anheruynedic amylder o eur ac aryant Pascen stirred up that people, promising them an unlimited abundance of gold and silver RB.II.169; tywyssawc Kernyw ae hymlynawd gan eu llad the prince of Comwall followed them slaying them RB. II. I9I ; dyuot dracheuynt at Wenhwyuar dan gwynaw y dolur she came back to Gwenhwyuar bewailing her anguish RB. 249; (wynt) a gyrchassant parth a Ruuein dan anreithaw a wrthwynepei udunt they set out towards Rome, plundering all who resisted them RB. II. 75 . 
PARAdigm of the Regular Verb.

127. Types: caru to love, and the denominative rydhaü to set free. Forms in brackets are forms that have not been noted from a verb of the type.

\begin{tabular}{lccc}
\multicolumn{4}{c}{ INDiCATIVE. } \\
Ping. & plur. & sing. & plur. \\
car-af & car-wn & rydha-af & rydha-wn \\
cer-i, cer-y cer-wch & rydhe-y & rydhe-wch \\
car & car-ant & rydha & rydha-ant \\
cer-ir & & rydhe-ir &
\end{tabular}

IMPERFECT AND CONDITIONAL.

$\begin{array}{clll}\text { I. car-wn } & \text { car-em } & \text { rydha-wn } & \text { (rydha-em) } \\ \text { 2. car-ut } & \text { car-ewch } & \begin{array}{l}\text { rydha-ut } \\ \text { ryda-ewch }\end{array} \\ \text { 3. car-ei } & \text { cer-ynt } & \begin{array}{l}\text { rydha-ei } \\ \text { rydhe-it }\end{array} & \text { rydhe-ynt } \\ \text { pass. cer-it } & & \text { rydhe }\end{array}$

Preterite and Perfect.

\begin{tabular}{|c|c|c|c|}
\hline $\begin{array}{l}\text { I. } \text { cereis } \\
\text { 2. cereis-t } \\
\text { 3. } \text { caras }\end{array}$ & $\begin{array}{l}\text { carass-am } \\
\text { carass-awch } \\
\text { carass-ant }\end{array}$ & $\begin{array}{l}\text { rydheeis } \\
\text { rydheeis-t } \\
\text { rydha-awd } \\
\text { rydha-wyt }\end{array}$ & $\begin{array}{l}\text { rydhaass-am } \\
\text { rydhaas-awch } \\
\text { rydhaass-ant }\end{array}$ \\
\hline
\end{tabular}

Pluperfect.

I. carass-wn (carass-em) (rydhaass-wn) (rydhaass-em)

2. carass-ut (carass-ewch) (rydhaass-ut) (rydhaass-ewch)

3. carass-ei (carass-ynt) rydhaass-ei rydhaess-ynt pass.carass-it (rydhaass-it)

IMPERATIVE.

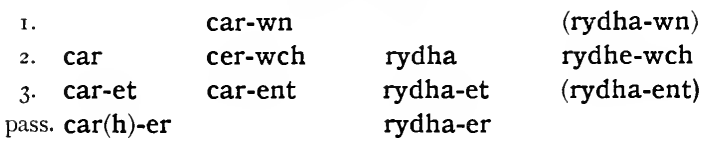

G 
SUBJUNCTIVE.

Present.
I. $\operatorname{car}(\mathrm{h})$-wyf $\operatorname{car}(\mathrm{h})$-om
rydha-wyf
rydha-om $\operatorname{car}(\mathrm{h})$-oef
2. $\operatorname{cer}(\mathrm{h})$-ych $\operatorname{car}(\mathrm{h})$-och
rydhe-ych
(rydha-och)
3. $\operatorname{car}(\mathrm{h})$-wy $\operatorname{car}(\mathrm{h})$-wynt
car(h)-oe car(h)-oent
$\operatorname{car}(\mathrm{h})-0 \quad \operatorname{car}(\mathrm{h})$-ont rydha-o
rydha-wynt
rydha-ont
pass. $\operatorname{car}(\mathrm{h})$-er
rydha-er
Past.
I. $\operatorname{car}(\mathrm{h})$-wn $\operatorname{car}(\mathrm{h})$-em rydha-wn (rydha-em)
2. $\operatorname{car}(\mathrm{h})$-ut $\operatorname{car}(\mathrm{h})$-ewch rydha-ut rydha-ewch
3. $\operatorname{car}(\mathrm{h})$-ei cer(h)-ynt rydha-ei
pass. cer(h)-it rydhe-it
rydhe-ynt

Remarks on the Verbal Paradigm.

Present and Future Indicative.

I28. (a) sg. 3. Many verbs show vowel infection (\$ 5), e.g. eirch : arch-af $I$ ask, ceidw : cadw-af $I$ preserve, ceiff : caff-af $I$ get, geilw : galw-af $I$ call, "lleinw: llanw-af $I$ fill, peir : par-af $I$ cause, peirch : parch-af $I$ honour, seif : sav-af $I$ stand, teifl : tafl-af $I$ cast, etteil : attal-af $I$ stop, gweheird : gwahard-af $I$ forbid, lleveir: llavar-af $I$ speak, edeu, edy : adaw-af $I$ leave, edeu: adaw-af $I$ promise, gwerendeu, gwerendy: gwarandaw-af I listen, teu : taw-af I am silent, tereu, tery: traw-af I strike, gwyl: gwel-af I see, gweryt: gwared-af $I$ help, cyll : coll-af $I$ destroy, dyt: dod-af $I$ put, llysg: llosg-af $I$ burn, hyllt: hollt-af $I$ split, ryd: rod-af I give, tyrr: torr-af I break, egyr: agor-af $I$ open, envyn: anvon-af $I$ send, ervyll: arvoll-af $I$ receive, erhys : arhos-af $I$ an'ait, defiry : deffro-af $I$ arouse, ffy : ffo-af $I$ flee, try: tro-af I turn. It should be noted that, except in the $3 \mathrm{sg}$. of the present, 
no vowel but $a$ is subject to infection in the verb, e.g $2 \mathrm{pl}$. gwel-wch, rod-wch, ffo-wch (cf. \$ 7 note I).

Note.-Irregular are: menyc: manag-af $I$ shew; dyweit: dywed-af I say.

(b) From the denominatives in -hau, -a spreads as an ending to other verbs, e.g. cerda : cerdet to go, teruyna : tervynu to end. Further, it is added again to the denominatives, e.g. gnottaa: gnotta-af $I$ am wont. Form -áa comes by contraction in Mod.W. -á.

129. In the older language some other forms appear.

sg. I. By -af, -if is sometimes found, e.g. gwneif $I$ will make FB. 62 , cenif I will sing MA. $140^{\mathrm{a}}$, gweinif i $I$ will seme $142^{\mathrm{a}}$, cerif i I will love $147^{\mathrm{b}}$.

sg. 2. In this person there is also an ending -yd (i.e. yd, cf. Bret.-ez, Corn. -yth), e.g. ceryd thou lovest, gwesceryd thou scatterest, dywedyd thou sayest, nodyd thou protectest, clywyd thou hearest. Cf. Arch. Cambr. 1873, pp. $143 \mathrm{sq}$.

sg. 3. In $O$. Irish there are two forms of the ending, a longer which is found only in simple verbs, and a shorter which is used in compound verbs, and also in simple verbs when a negative or certain other particles precede, e.g. berid (from *bhereti) he cremies, but nī beir (from *bheret) he docs not corry, do-beir he gives. In Early Welsh there are traces of a similar distinction of ending, e.g. pereid $y$ rycheu. ny phara ae goren the trenches remain, he who made them remains not $\mathrm{FB} .2 \mathrm{~S} 9$; and in the proverb: trengid golnd, ni threing molnd wealth perishes, fame perishes not. Further examples of the ending are: prinit buys, agit, egit goes $(=\mathrm{Mjd}$.W. eyt FB. 304) in the O.W. glosses; llicrid : llygru destroy, reuhid : rewi freeze, ottid : odi snou, gosgupid suceps, tohid : toi eover BB. $45^{\mathrm{a}}$, meccid: magu nourish BB. $45^{\text {b }}$, briuhid : briwaw break Bls. $46^{\text {a }}$, cf. further Arch. Cambr. 1872, pp. 303 sq., 1873 , pp. $145 \mathrm{kr}$. It will be seen that the $h$ which appears in the old future ( 530$)$, and in the subjnnetive has also made its way into these presents. In nsage Nicl.W. arrees with $0 . I r$. in that the longer ending is not fonnd when the verb is preceded by a negative, it differs from 0 . Ir. in that the longer ending lias spread to compound verbs. In early poetry there seem to be instances of a corresponding present in -awt (which wonld originally belongr to $\bar{a}$-stems, ef. $O$. Bret. -ot in fieriot $g r$. ridolet, $O$. Ir. caraid, from *caräti, loves, Lat. amat): barywhaud grous a beard, gvỳrhaud bends IiB. 45a, llewychawt shines FB. 117, gwisgawt elothes FB. 307 .

pl. 3. In the O.W. glosises by the ending -ant in itercludant gl. subigant there appears also -int in limnint gl. tondent, nertheint gl. armant, scamnhegint gl. levant. This ending seems to survive in Mid.W. poetry, e.g. diurýssint hasten BB. $45^{\mathrm{a}}, 54^{\mathrm{b}}$ (cf. pan vryssyant FB. $25 \%$ ), dywedynt will say FB. 223, torrynt will brerk FB. 229 . It seems probable that this served as a primary ending, but the matter demands further investigation.

Passive.- In the passive there is found in poetry and occasionally in proverbs a variety of forms in -tor, e.g. megittor will be nowished $\mathrm{BB}$. $31^{\mathrm{b}}$; kenhittor will be sung BB. $26^{\mathrm{b}}$, kwynitor is lamented FB. 280 ; kymysgetor is miaed FB. 181, kyrbwylletor will be mentioned FB. 200; 
traethattor will be discoursed FB. 137, canhator is sung FB. 209 : brithottor is variegated BB. 17 ${ }^{\mathrm{a}}$. Cf. Areh. Cambr. 1872 pp. 305 sq., Dottin, Désinences verbales en $R, 177 \mathrm{sq}$. These forms, which are clearly based on the longer form of the $3 \mathrm{sg}$. act., are especially common in the poetry of the twelfth century. Their syntactical function is present or future.

I30. In Early Welsh there are also some specially future forms:

sg. 3 (a) -hawt (i.e. -hawd), e.g. parahaud will contimue BB. 50 briuhaud will break BB. $29^{\mathrm{b}}$, methawd will fail WB. 457, lletawt will spread FB. 236, llwyprawd (:llwybraw) will travel MA 232. Cf. CZ. III. 402 .

(b) After a negative, -haw : ny chaffaw will not get $\mathrm{BP}$. $4^{\mathrm{b}}$, nys gwnaw will not make $\mathrm{FB}, 126$; but also a wnaw who will make $\mathrm{FB}$. 150 .

P1. 3. -hawnt, e.g. O.W. cuinhaunt gl. deflebunt, gwnahawnt will make FB. 124, pebyllyawnt will encamp FB. 212.

Pass, -hawr, e.g. agorawr will be opened WB. 456, ffohawr there will be flight FB. 126, talhaur will be paid BB. $16^{\text {a }}$, nỳn lladawr we shall not be killed WB. 475, edmýccaur will be honoured BB. $29^{\mathrm{b}}$. Cf. Dottin, op. eit., $169 \mathrm{sq.,} \mathrm{CZ.} \mathrm{III.} 403$.

NoTE.-There also occur forms of the type of -ettor, -attor above, e.g. torredawd will break FB. 236, llettatawt will spread FB. 129, dyggettaur will be led BB. 13", lloscetawr will be burned FB. 119, galwetawr will be ealled FB. 165.

\section{Imperfect Indicative and Conditional.}

I3I. sg. 3. (a) In poetry there is also an ending -i, infecting a preceding a, e.g. ceri loved, nodi protected, torri broke, clywi heard. Cf. Arch. Cambr. I 874, p. I i 7, Cymmrod. IX. 54, Rev. Celt. VI. I6.

(b) 'There is also an ending -at (i.e. -ad); see the irregular verbs gwybot ( $\$$ I43), adnabot (\$ I44), pieu ( $\$$ I60), and the verb bot (\$ I52). So in the plup. ry dywedyssyat had said MA. $485^{b}$.

pl. 3. In this person there is an ending -eint:-achubeint IVB. $466=$ pass. achubit RB. I 10, 28 , caneint LA. $95=$ cenynt Hg. II. 447, deueint, syrthyeint LA. 97, traweint Hg. II. I84, llauuryeint ib. 2 I 3 ; cf. the subjunctive ket yvein though they drank FB. 66, wyntwy yn llad gyt as ledeint they slaying though they sleze them FB. $276=\mathrm{a}$ chin ri llethid ve latysseint and before they were slain they had slain FB. 38 , cf. Cymmrod. IX. 67. This -eint is an analogical formation to sg. 3 -ei.

NoTE.-Nore peeuliar is ny lesseint BB. $32^{a}$ which seems to mean they were not slain (ef. yt lesseint FB. 2\$5, lleseint MA. 194ª), apparently based on llas was slain ; of. further meithyeint was reared? lledeseint were slain? colledeint were destroyed? Fl3. 264, MA. 94 . 


\section{Preterite and Perfect Indicative Active.}

I32. sg. 3. In this person there is a variety of endings.

(a) -as, e.g. bradas betrayed, caffas got, gwelas saw.

(b) -es, e.g. agores opened, dodes put, gweles saw.

(c) -is, e.g. erchis asked, edewis left, gelwis called.

(d) -wys, becoming -ws, e.g. bendigwys and bendigws blessed, cyscwys and cyscws slept. In the southem dialect-ws became the characteristic ending in this person.

(e) -awd (i.e. awd), e.g. parawd caused, cerdawd journeyed, parhaawd continued. This is an encroaching ending, whence comes the Mod. literary Welsh ending -ođ.

NoTE.-In early poetry there is an absolute ending -sit (corresponding to the present ending -it (\$ 129), e.g. kewssit got, prynessid bought, delyessid (: dala) held. Cf. Arch. Cambr. 1873, pp. 151 sq. It corresponds to the 0 . Bret. ending in tinsit gl. sparsit, toreusit gl. attriuit.

I pl., $3 \mathrm{pl}$. In these persons by -sam, -sant, there appear also -som, -sont.

Plur.-In the plural there are three types of formation, (a) -sam, etc., (b) -assam, etc., (c) -yssam, etc., e.g.-

(a) cawsam, cawsawch, cawsant : caffael get, kymersam, kymersant : cymryt take, gwelsam, gwelsant : gwelet see.

(b) dywedassam: dywedut say, lladassant: llad slay, nessaassant: nessaü approach.

(c) dodyssam, dodyssant: dodi place, kwplayssam: kwplaui complete, nessayassant: nessaü approach.

I33. In Mid.W., as in Mid.Ir., the s-preterite has become the prevalent formation, in which the other types of the preterite tend to merge. But particularly in poetry, and especially in the $3 \mathrm{sg}$., there are examples of two other types of the preterite.

(a) The t-preterite (corresponding to the Irish t-preterite, e.g. asbert he said: asbeir says).

canu $\operatorname{sing}$ : sg. I ceint and ceintum, sg. 2 ceuntost, sg. 3 cant.

gwan pierce: sg. I gweint, sg. 3 gwant.

cymryt take: sg. 3 kymerth, kymyrth.

diffryt protect: sg. 3 differth, diffyrth. 
mynet go: aeth (=Ir. acht) reent (\$ I40); in composition doeth (\$ I4I), and sg. I ymdeith went about, sg. 3 ymdaeth.

gwneuthur make: gwnaeth (\$ I42).

magu nourish: sg. 3 maeth, pl. 3 maethant.

dyrreith returned $(\sqrt{ }$ reg- $)$.

amwyn protect: sg. 3 amwyth.

dydwyn ling: sg. 3 dydwyth.

(b) Forms with reduplication, or unreduplicated forms of the type of O.Ir. rāith ran: rethid mus.

clybot hear: sg. I kigleu (=Ir. cũala from ${ }^{*}$ cuklova) and kiglef, sg. 3 kigleu.

adnabot recognize : atwaen ( $\$$ I44).

dywedut say: sg. 3 dywawt, also dywot, dywat (cf. Ir. adcuaid has related from *ad-co-fäith).

godiwes overtake: sg. 3 godiwawd.

gwaret help: sg. 3 gwarawt (=Ir. fo-rāith helped).

The same form of inflexion is exhibited by :-

amwyn defend: sg. 3 amuc.

dwyn lead: sg. I dugum, sg. 2 dugost, sg. 3 duc, pl. I dugam, pl. 3 dugant.

gwneuthur make: goruc (\$ I42).

Here seems to belong also amkawd said, pl. 3 amkeudant, frequent in the WB. text of Kulhwch and Olwen.

\section{Preterite and Perfect Indicative Passive.}

134. In origin the Welsh like the Irish preterite passive developed out of a past participle passive in -to-, identical in formation with Latin participles like captus, amatus, etc.

(a) In llas (=Ir. -slass): llad slay and gwys (=Ir. -fess): gwybot know, the $\mathbf{t}$ of the suffix together with the dental of the root has become ss, s ( $\$$ IIa; cf. Lat. missus : mitto, etc.).

(b) -at, e.g. gwelat: gwelet see, caffat: caffael get.

(c) -et, e.g. dodet : dodi place, llosged : llosgi burn.

(d) -it, e.g. edewit: adaw promise, erchit: erchi ask, gelwit: galw call. 
(e) -wyt, liable to become -wt, e.g. cymerwyt: cymryt take, hewyt: heü soze, lladwyt: llad slay, kennatawyt: kennataü send.

(f) Forms in -pwyt, e.g. dywespwyt and dywetpwyt: dywedut say, clywspwyt, clywyspwyt: clybot hear, dechreuspwyt: dechreu legin, roespwyt: roi give, kanpwyt: canu sing, gwanpwyt: gwanu pierce, ducpwyt: dwyn lead, maethpwyt: magu nourish, gwassanaethpwyt: gwassanaethu serve, talpwyt : talu pay. Cf. Cymmrod. IX. 75 sq.

\section{Pluperfect Indicative.}

I35. Corresponding to the three types in the plural of the preterite active, there are in the pluperfect three types (a) -swn, (b) -asswn, (c) -ysswn, e.g. :-

(a) cawssei : caffael get, gwelsei, gwelsynt, pass. gwelsit : gwelet see, edewssit: adaw leave.

(b) mynasswn : mynessynt, pass. mynassit : mynnu desire, cysgassei : cysgu sleep, lladassant, pass. lladessit: llad slay, gnottaessynt : gnottaỉ be accustomed.

(c) archyssei, pass. erchyssit, archyssit: erchi ask, managyssei: menegi shew, lladyssit: llad slay, mynnessynt : mynnu demand, gnottayssei : gnottaii be accustomed.

I36. (a) In the active there is a periphrastic pluperfect with -oed was in athoed ( $(\mathrm{I} 40$ ), doethoed ( $(\mathrm{I} 4 \mathrm{I})$, gwnaethoed ( $\$ \mathrm{I} 42$ ). Forms in -oed occur also from caffael get, e.g., sg. I cawssoedwn, sg. 2 cawssoedut, sg. 3 cawssoed, cassoed, cawssoedyat, pl. 3 cassoedynt, pass. cassoedit; further mynnassoed : mynnu; planasoed; rodassoed, roessoed; rassoed, pass. rossoedit: rodi. Cf. Cymmrod. IX. 76 sq.

(b) In the passive there are some periphrastic forms with -oed:sg. 3 archadoed had been asked: erchi ask, dysgadoed : dysgu teach, ganadoed, ganydoed: geni be born, managadoed: menegi shew; further cathoed: caffael get. Cf. Cymmrod. IX. 77 . 


\title{
Imperative.
}

137. sg. 2. From denominatives in -haü a spreads as an ending to other verbs, e.g. prydera: pryderu be anxious, paratoa: paratoi prepare. Further $\mathbf{a}$ is added again to the denominatives, e.g. cwplaä : cwplaü complete, naccaä: naccaü refuse. From -áä comes Mod.IV. -á.

sg. 3. There appears sometimes an ending -it, e.g. bernit (v.l. barned): barnu judge MA. $182^{b}$, elhid: mynet go WB. $3 \mathbf{1}^{\mathrm{a}}$, gobwyllit: gobwyllaw take heed FB. 199, gwrthledit: gwrthlad repulse LA. 26, gwrthottit: gwrthot repel FB. I25, rwydheyt: rwydhaü make easy RB. 228 , madeuit: maddeu forgive $\mathrm{Hg}$. II. 185 , rothit: rodi give $\mathrm{BB} .47^{\mathrm{a}}$. It will be observed that these forms shew the subjunctive stem.

\section{Present Subjunctive.}

I38. In the $3 \mathrm{sg}$. and $3 \mathrm{pl}$. the 0 forms become the regular forms in Mid.W. Sometimes o spreads to the I sg., e.g. gwysgof WB. 97. In the pass. an wy form appears in rothwyr FB. rog.

NотE.-For duch may he lead, gwares may he help, see $\$ 110$, note 2 .

\section{Past Subjunctive.}

I39. In the passive by -it there is found sometimes -et: cladhet WB. $469=$ cledit RB. I I 2 : cladu bury, gofynnet WB. p. $220=$ gouynnit RB. 286 : govynnu ask, llafassed : llavassu dare BB. $27^{\text {* }}$.

\author{
IRREGULAR VERBS. \\ I40. mynet go. \\ Indicative. \\ Present and Future.
} sing. plur.

I. af awn

2. ey ewch

3. a ant pass. eir

Note 1.-sg. 3 absolute O.W. agit, egit, Mid.W. egt. 
§ I40.] IRREGULAR VERBS.

IMPERFECT AND Conditional.

I. awn sing.

2. aut

3. aey

aem

plur.

pass. eit

eynt

Preterite and Perfect.

(a) I. euthum

aetham

2. aethost

aethawch

3. aeth

aethant, aethont

pass. aethpwyt

Note 2.-sg. 3 absolute eithyd FB. 179, 188.

(b) I. athwyf, adwyf, ethwyf, ethym edwyf

2. athwyt, adwyt

3. ethyw, edyw ethynt, edynt

Note 3.-Forms (b) have a perfect sense, ef. § I4I, note 4.

\section{Pluperfect.}

I. athoedwn

2.

3. athoed, adoed athoedynt

IMPERATIVE.

I.

awn

2. dos

ewch

3. aet

aent

Note 4.--sg. 3 also elhid (\$ I37).

Subjunctive.

Present.

I. el(h)wyf

2. el(h)ych

3. el

pass. el(h)er el(h)om

el(h)och

el(h)wynt, el(h)ont

Note 5.-Also, in future sense, sg. 3 aho RB. 140, 16, pl. 3 ahont FB. 128. 


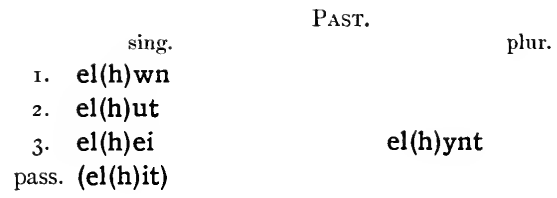

I4I. dyvot come.

INDICATIVE.

Present and Future.
I. deuaf
deuwn, down
2. deuy, doy deuwch
3. daw
deuant, doant

$X \|$ Note 1.-sg. 2 doit (i.e. doyđ) BB. $51^{\text {bl }}$.

NOTE 2.-In poetry there is also another set of forms in a future sense: 1 dybydaf

3. $\left\{\begin{array}{l}\text { dybybyd } \\ \text { dypi, dybi, dyvi } \\ \text { deupi, deubi }\end{array}\right.$

dybydant

Note 3.-Preceded by dy-: sg. 3 dydaw, pl. 3 dydeuant, pass. dydeuhawr.

ImPERFECT AND Conditional.

I. down

2. dout, deuyt

3. deuei, deuhei, doey, doynt

$$
\text { doi }
$$

pass. deuit

Preterite and Perfect.

(a) I. deuthum, doethum doetham

2. deuthost, doethost, doethawch, doethoch daethost

3. doeth, deuth, daeth deuthant, doethant, dothant, doethont

pass. deuthpwyt, doethpwyt 
(b) $\mathrm{x}$. sing.

plur.

2. dyvuost

3. dybu, dyvu, deubu

dybuant, dyvuant

(c) I. dothwyf, dodwyf dodym, deuthym

2. dothwyt, dodwyt dodywch, doethywch

3. doethyw, dothyw, dodyw, dedyw dodynt, dethynt

Note 4.-Forms (b) are chiefly poetical, but dyvuost, dyvu, dyvuant oceur in the prose of WB. Forms (c) are perfect in sense; in later Mid.W. they are replaced by forms (a), e.g. deuth RB. 126, $9=$ dodỹw WB. 486, deuthum RB. 105, $21=$ dothwẏf WB. 459 , doeth RB. 115, 25, deuth RB. $126,9,=$ dodýw WB. 473,486 .

\section{Pluperfect.}

I. dathoedywn

2.

3. doethoed, daethoed, doethoedynt, dothoedynt dathoed, dothoed

IMPERATIVE.

I. down

2. dyret, dabre dowch

3. deuet, doet deuent, doent

Note 5.-There is also a $3 \mathrm{sg}$. deuit Hg. II. 51, and delit Hg. I. 4, 307.

Subjunctive.

PRESENT.

r. $\operatorname{del}(\mathrm{h}) \mathrm{wyf}$

del(h)om

2. $\operatorname{del}(\mathrm{h}) \mathrm{ych}$ del(h)och

3. del del(h)wynt, del(h)ont

pass. del(h)er

Note 6.-There are also forms sg. 1 dybwyf, sg. 3 dyppo, dyffo, dyvo, * deupo, dideuho, pl. 3 dyffont, pass. dyffer.

r. $\operatorname{del}(\mathrm{h}) \mathrm{wn}$

PAST.

2. del(h)ut

del(h)ewch

3. del(h)ei

del(h)ynt

Note 7.-There is also $3 \mathrm{~kg}$. dybei and dyffei. 


\section{2. gwneuthur to make.}

Present and Future.

sing.

I. gwnaf

2. gwney

3. gwna plur.

gwnawn

gwnewch

gwnant

pass. gwneir

NoTE 1.-Fut. sg. 3 gunahaud BB. $27^{\text {b }}$, gwnawt FB. 224 , gwnaw FB. 126, 150, pi. 3 gwnahawnt FI3. 124.

\section{IMPERFECT AND CONdITIONAL.}
I. gwnawn
gwnaem
2. gwnaut gwnaewch
3. gwnaei
gwnaent

pass. gwneit

\section{Preterite and Perfect.}

(a) I. gorugum

gorugam

2. gorugost

3. goruc

gorugant

pass. gorucpwyt

(b) I. gwneuthum

gwnaetham, gwnaethom

2. gwnaethost gwnaethawch

3. gwnaeth, gwneuth gwnaethant, gwnaethont pass. gwnaethpwyt

Note 2.-In poetry there is also sg. 3 goreu, cf. Mid.Bret. guereu.

NoTE 3.-The gwnaeth forms encroach at the expense of the goruc forms, e.g. gorucpwyt WB. $452,477,487=$ gwnaethpwyt RB. $100,118,127$.

\section{Pluperfect.}

I. gwnathoedwn

2. gwnaethodut

3. gwnaethoed, gwnath- gwnathoedynt oed, gwnadoed

pass. gwnathoedit 
IMPERATIVE.

$$
\text { sing. }
$$

I.

2. gwna

3. gwnaet pass. gwnel(h)er plur.

gwnawn

gwnewch

gwnaent

\section{Subjunctive.}

\section{Present.}

I. gwnel(h)wyf

2. gwnel(h)ych gwnel(h)och

3. gwnel

pass. gwnel(h)er

$$
\text { gwnel(h)wynt, gwnel(h)- }
$$$$
\text { ont }
$$

Note 4.-sg. 3 also gunelwy் BB. $24^{\mathrm{a}}$, gunaho BB. $35^{\mathrm{b}}$, gwnaho FB. 119 , * 235 , pl. 3 gvnahont BB. $31^{\mathrm{a}}$, gwnahon FB. 155 . With fut. ending gwnelawr FB. 213.

$$
\text { PAST. }
$$

I. gwnel(h)wn

2. gwnel(h)ut

4. gwnel(h)ei

gwnel(h)ynt

pass. gwnel(h)it

I43. gwybot know.

Indicative.

Present.
I. gwnn
gwdam, gwdom
2. gwydost, gwdost gwydawch, gwdawch, gwdoch
3. gwyr gwydant, gwdant

pass. gwys

\section{IMPERFECT.}

I. gwydwn, gwydywn

gwydem, gwydyem

2. gwydut, gwydyut

3. gwydat, gwydyat

pass. gwydit

gwydynt 


\section{Iterative Present and Future.} sing.

I. gwybydaf

2. gwybydy

3. gwybyd

gwybydwch

gwybydant

pass. gwybydir

Note 1.-In poetry there is also $3 \mathrm{sg}$. gwybi.

ItERATIVE IMPERFECT AND CONDITIONAL.

I.

2. gwybydut

3. gwybydei

pass. gwybydit

Note 2.-This comes to be used for the past subjunctive, e.g. Bei ath wybydem if we had knoun thee FB. 122.

\section{Preterite and Perfect.}

I. gwybuum

2. gwybuost

3. gwybu

gwybuant

pass. gwybuwyt

\section{Pluperfect.}

3.

gwybuyssynt

pass. gwybuassit

IMPERATIVE.

I.

2. gwybyd

3. gwybydet, gwypet

pass. gwybyder gwybydwn gwybydwch

gwybydent

Subjunctive.

Present.
I. gwypwyf
2. gwypych
3. gwypwy, gwypo
pass. gwyper

gwypom

gwypoch

gwypwynt, gwypont 


$$
\begin{array}{ll} 
& \text { PAST. plur. } \\
\text { sing. }
\end{array}
$$

I. gwypwn

2. gwyput

3. gwypei

gwypynt

I44. adnabot recognize.

INDicative.

Present.

I. adwaen, adwen, atwen atwaenwn

2. atwaenost etweynwch, atweynwch, etwenwch

3. १. edwyn, atwen

atwaenant

IMPERFECT.

I. atwaenwn adwaenam

2. atwaenut

3. atwaenat, atwaeniat atwaenynt

pass. etweinit

Iterative Present and Future.

I. adnabydaf, etnebydaf adnabydwn

2. adnabydy

3. adnebyd, ednebyd adnabydant

pass. adnabydir

Iterative Imperfect and Conditional.

I. adnabydem

2.

3. adnebydei

\section{Preterite and Perfect.}

I. adnabuum

adnabuam

2.

3. adnabu adnabuant 


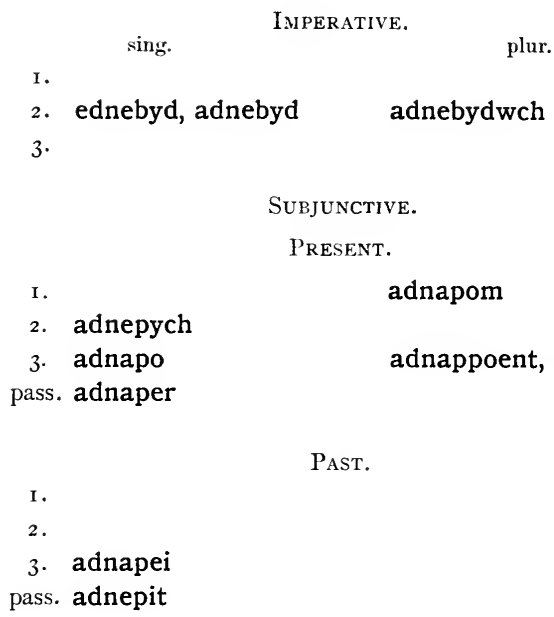

I.

2. adnepych

3. adnapo

pass. adnaper

PAST.

I.

2.

3. adnapei

pass. adnepit

145. caffael, caffel, cahel, cael get.

INDICATIVE.

Pres. and Fut.:-caffaf, ceffy, ceiff, etc.; also caf, cehy, cey, etc.

Imperf. and Cond. :- caffwn, etc, also cawn, etc.

Pret. and Perf. :-ceveis, ceis, ceveist, cavas, cawssam, cawssawch, cawssant, cawssont; pass. caffat, cavat, cahat, cat.

Cewssynt 178,31 Pluperf. :- $(a)$ cawsswn, etc., (b) cawssoedwn, etc. $\left(\S 13^{a}\right)$.

Subjunctive.

Pres, :-caffwyf, etc.

Past :- caffwn, etc., also cahwn, cawn, etc.

NotE.-For an enumeration of forms see Cymmrod. IX. 111 sq. 
146. rodi, roi give.

The peculiarity of this verb is that it has forms with and without d, e.g. ind. pres. sg. 2 rody and roy, imper. sg. 2 ro, subj. pres. sg. 3 rotho, rodo and ro. In the ind. pret, by rodeis, rodeist, rodes occur roesum, roesost, roes, and in the pass. by rodet, also roespwyt. In the plup. by the regular forms occur sg. 2 roessut, sg. 3 roessei, royssei, roessoed, rasoed, pl. 3 rassoedynt.

I47. tawr, dawr.

This verb is used impersonally, e.g. ny-m-tawr it does not concern me RB. 284,28 , pathawr (= pa-th-đawr) what does it concern thee? RB. 279 , I9, ny-m-torei $\mathrm{WB} .172=\mathrm{ny}-\mathrm{m}$-torei RB. I. 238 , it would not concern me, ni-m-dorbi BB. $30^{\mathrm{b}}$. In the same sense is found the compound didawr; verb. noun didarbot Hg. I. 320 .

148. moes give.

Only as imperative:-sg. 2 moes, pl. 2 moeswch.

I49. hwde take. Used only as imperative.

I50. med says.

Inflected in the present and imperfect; it is used in quotation, e.g. a wdost di pwy yw ? heb hi. gwnn, heb ynteu. Edyrn uab Nud yw, med ef "dost thou know who he is?" says she. "Yes," said he. "He is Edyrn son of Nudd, he says," RB. 259; y gouynnei beth yssyd yman. Broch, medynt wynteu he asked what was there. "A badger," said they RB. I5.

I5I. heb says.

This word, of adverbial origin and uninflected, is used like Ir. ol to give the very words of the speaker, heb ef says he, heb wynt they say, etc.

Before a proper name heb is followed by y, yr, e.g. heb y Goewin, heb y Gwenhwyfar, heb yr Arthur. The same is not infrequently found before a pronoun, e.g. heb y mi RB. 32, 7, heb yr ynteu RB. 245 , I $8 \mathrm{\imath}=$ heb ynteu WB. 386 , p. 217 , heb yr ef $W B .386=$ heb ef RB. 245 , heb yr wynt WB. $185=e b$ wynt WB. p. $93^{\mathrm{a}}$; cf. Mod. W. ebr. No satisfactory explanation of this has yet been given. 


\section{The Substantive Verb bot to be.}

\section{Paradigm.}

Indicative.

I52. Present.

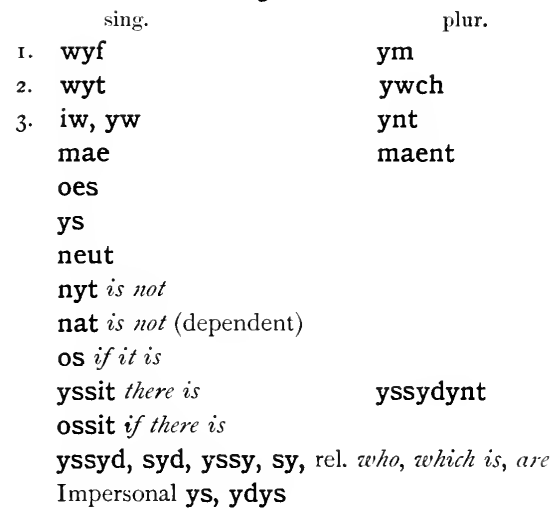

\section{Past.}

I. oedwn

oedem

2. oedut, oedyt oedewch

3. oed, oedat, oedyat oedynt Impersonal oedet

NоTE 1.-There are also forms preceded by ytt, yd: yttwyf, yttiw, ydiw, yttoedwn, etc.

Iterative Present and Future.
I. bydaf
bydwn
2. bydy
bydwch
3. byd
bydant

Note 2.-Specially future forms: sg. 3 bythawt, bydhawt, bydawt, biawt, bi; pl. 3 bydawnt.

Note 3.-In poetry there seems to be a consuetudinal sg. 3 bit, cf. FB. 245,247 , where the imperative sense does not suit. 


\section{ItERATIVE IMPERFECT AND CONIDITIONAL. sing. plur.}

I. bydwn

bydem

2. bydut bydewch

3. bydei bydynt impers. bydit

NoTe 4.--Poetical forms: sgr. 3 buei, bwyat, pl. 3 buyint (i.e. bwyynt).

$$
\text { Preterite and Perfect. }
$$

I. buum, bum

2. buost

3. bu impers. buwyt

I. buasswn

2. buassut

3. buassei buam buawch buant, buont

\section{Pluperfect.}

buassynt, buessynt, buyssynt

\section{IMPERATIVE.}

$\begin{array}{ll}\text { I. } & \text { bydwn } \\ \text { 2. byd } & \text { bydwch } \\ \text { 3. bit, boet, poet } & \text { bint }\end{array}$

Note 5.-bynt is clearly imperative BCh. 17, ef. bint LA. 81. RB. 105 has bint where WB. 457 has the future bythawd.

\section{Subjunctive.}

\section{Present.}
I. bwyf, bof
2. bych
3. bo

bom, bwym

boch

bwynt, boent, bont

NoTe 6.-There are, particularly in poetry, analogieal subjunctive forms from the indicative stem : $\mathrm{sg}$. 1 bydwyf, sg. 2 bydych, sg. 3 bytho, pl. 3 bydont.

\section{PAST.}
I. bewn
beym
2. beut
3. bei

\section{beynt}

NoTE 7.-Both in poetry and in prose the past indicative is eften used for the subjunetive, e.g. kyny bydwn WB. $172=$ kyn ny bewn RB. 238 . The impersonal pan uythit WB. $104=$ pan vydit $\mathrm{RB}$. 76 is a subjunctive form based on the indicative. 


\section{REMARKS ON bot. Present and Imperfect.}

I53. The precise syntactical functions of the various forms of these tenses still require a detailed investigation, particularly their uses in early poetry. From the material to hand the following points of prose usage may be noted, (A) where the forms have the function of a substantive verb predicating existence, (B) where the forms are merely copular.

I54. A. Substantive verb.

(a) In the 3 sg. pres. he is, etc., is expressed by mae, pl. maent, unless the verb is preceded by the negative or by other preverbal particles and conjunctions which are not followed by the particle yd (\$93 g sq.), e.g. yma y mae brenhin Iwerdon here is the king of Ireland; o ellwng Riannon or poen y mae yndaw from releasing Riannon from the punishment in which she is; nat gan y vod y mae yn dyuot that it is not with his will that he is coming; y mae y enw yn barawt his name is ready'; y maent yn symudaw enweu they are changing names. Mae is also used in the sense of where are? e.g. mae Ynwl iarll . . . ae wreic ae uerch. maent $(=y$ maent RB. 256) ýn yे loft racco where are Ynwl and his wife and his daughter? They are in the chamber yonder WB. 400. In the sense of there is, there are yssit, yssydynt are found, e.g. yssit nas keffych there is something that you will not get RB. I 2 sq. ; chwedleu porth y gennyt. ysydynt gennyf hast thou tidings of the gate? I have RB. I26. If the verb is preceded by a negative, etc., then (a) if the subject is definite yttiu, ydyw, pl. yttynt, ydynt are used, $(\beta)$ if the subject is indefinite oes is used, e.g.-

(a) nyt yttiu y clawr y lle kyntaf y kefeist the board is not where thou didst get it first RB. 24I ; nat ydiw y uorwyn honno yn y byt that that maiden is not in the world RB. I 3 ; nyt yttynt namyn pedwar they are only four CM. 46 ; neut ydynt yn gynyon boneu vy esgyll the stumps of my wings are like wedges RB. I 30 ; a yttiw Kei yn llýs Arthur. yttiw is Kei in Arthur's court? He is WB. I 43. 
$(\beta)$ nyt oes yndi neb nyth adnapo there is no one in it who will not recognize thee $\mathrm{RB}$. 3 ; a oes borthawr. oes is there a porter? There is RB. ro3. With o if, the definite form is ot ydiw, e.g. ot ydiw yg karchar if he is in prison RB. 179 , the indefinite ossit, e.g. osit rann y mi oth uab di if I have any part in thy son RB. I09; osid ay hammehuo if there is any one who doubts it $\mathrm{BCh}$. 53. The relative form is yssyd, e.g. y gwr hir yssyd yno the tall man who is there; pa ryw chwedleu yssyd gennyt. nyt oes namyn da what kind of news hast thou? Only good nezes.

Note 1.-In poetry yssit is found also with a definite subject, e.g. yssit imi teir kadeir $I$ have three seats $\mathrm{FB}$. 154; yssit ym argluyd I have $a$ lord MA. 176. It seems to be a disappearing form, ef. $\mathrm{g}$ mae yni beth a wnelom we have something to do $\mathrm{Hg}$. 1. 10, y mae $\mathrm{ym}$...a wnelwyf 69. Ossit also seems to be a disappearing form; for ossit a uynho if there is anyone who desires WB. 122, RB. 197 has : or byd neb kyehofnet.

(b) In the first and second persons the subject is always definite, and here after negatives etc., yttwyf, ydwyf are usual both in the present and in the imperfect, e.g. nyt yttwyf (=nyt ydwyf i WB. 437) yn ansawd I am not in a condition WB. p. 219 ; nyt yttoedwn i yn holi dim ytti $I$ was not claiming anything from thee R13. 5. In the third persons of the imperfect there is in the Mabinogion a very general distinction after negatives etc., between (a) yttoed, ydoed when the subject is definite, (b) oed when the subject is indefinite, e.g. (a) ẏdrých ýn ý chỳlch a oruc a yttoed ef ýn deffroi she looked about her to see if he was stirring WB. 424 ; pann yttoed (= pan ydoed WB. 99) y dyd yn dyuot when the day was coming RB. 72 ; tra yttoed ef yn hynny while he was in that RB. I 33 ; yny yttoy்d y chwýs ar gwaet yn dwyn lleuuer $\dot{y}$ llyggeit udunt until the sweat and the blood were taking the light of their eyes from them WB. 398 ; (b) nyt oed dim yno there was nothing there RB.; Gereint a ofynnnawd y wr y ty a oed getymdeithon idaw . . . oes, heb ynteu Gereint asked the master of the house if he had friends. "I have," said he.

Note 2.-But there are a good many instances of (b for (a) : nat oes (=nat ydiw RB. 113) hi yn y byt that she is not in the vorld WB. 470; kwt ynt plant y gwr where are the children of the man? WB. 453 ; pan oed $\mathrm{y}$ dyd yn golenhau when the day was beeoming light $\mathrm{RB}$. 72 ; yny oed yn y eidaw ef Ardudwy till Ardudvy was in his possession RB. 77; yny oed y

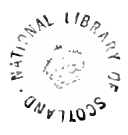


gwaet yn lliwaw y llenn till the blood was colouring the mantle WB. $391=$ RB. 249; yny oed (= hyny yttoed WB. p. 218) eu llygeit yn colli eu lleuuer till their eyes were losing their light $\mathrm{WB} .435=\mathrm{RB}$. 283 .

NoTE 3.-In a number of eases the ytt-, yd- forms are found not preceded by a negative, etc.: berth yd ytwyt (=yd wyt RB. 115) finely thou art WB. 473; yth ewyllys yd ydym we are at thy will RB. 66 ; hyt yd ydiw dayar as long as the earth is $\mathrm{WB} .459=\mathrm{RB} .105$; ar hynny yd yttoed yn deffroi thereupon he was stirring WB. p. 2l2; yma yd yttoedwn (=yd oedwn WB. 441, RB. 287) yn kerdet there I was journeying WB. p. 221 ; ual yd yttoed yn kerdet WB. $170=$ RB. 236; ymlodeu dy dewred yd yttwyt (=yt vyt WB. $413=y d$ wyt RB. 266) thou art in the flower of thy might WB. p. 2'7; for: o hynny yd yttoed RB. 218, WB. 149 has ac liyny yttoed, and for ae yd yttoed yn troi RB. 215 WB. 145 has y doeth yd ydoed yn troi. So in the present impersonal forms occur: vyg karcharu yd ydys (yd ydys om. WB. 235) $I$ am imprisoned RB. 187; yn y gyveistydyaw yd ydys (=yd yttys WB. 167) it is being besieged RB. 233, by yd ys yn kadw or enw hwnnw that name is preserved RB. 60 ; yd ys yn lluydaw yn an hol there is a hosting after us RB. 63, 1.

NoTE 4.-In $\mathrm{Hg}$. I. yttiw, ete, are not unfrequently copula forms, e.g. gwell yttiw vy marw it is better that I should die 145 , pa un ytwyt who art thou 95; ef. hyny yttoedynt (=yny oedynt WB. 446, RB. 291) kystal ac $\mathrm{y}$ buont oreu eiroet till they were as good as they had ever been WB. p. 223 .

I55. B. Copula.

(a) In the third person of the present there is a variety of forms :-

(a) ys, used (like Ir. is) at the beginning of a clause before its predicate, e.g. is gwell it is better; is gohelyon hwnn he is a remnant; ýs $\mathrm{mi}$ ae heirch it is $I$ who ask her. It is often preceded by the conjunction can, e.g. kanys gwell yw genyt ti since thou preferrest: kanys arnam ni y berneist since it is on us that thou hast passed judgment.

$\chi \quad$ Note 1.- In poetry ys is used with an infixed personal pronoun, e.g. yssim ediuar $I$ repent $\mathrm{BB}$. $51^{\mathrm{a}}$, ef. $\mathrm{O}$.Ir. issum ēcen it is necessary for me.

$(\beta) \mathbf{y w}$, used when the predicate precedes, e.g. negessawl yw wrthyt he has business with thee; pwy $\mathrm{yw}$ hi who is she? miui yw Liwyt I am Llwyd; y deu lygat yw y dwy lynn the treo lakes are his two eyes; nyt gwr yw hwnnw that is not a man; kanys mawr yw since it is great. It is also used after the conjunction pan, e.g. y dyuedassant wynteu pan yw merchet ieirll oedynt they said that they were daughters of earls (cf. $\$ 226,5$ ).

$(\gamma)$ ynt is the plural form, e.g. bychein ynt wynteu they are small; nyt ynt iach they are not zehole. 
(ס) nyt is a negative form, e.g. nyt oet ymi gwreicka it is not time for me to wed; nyt egy்lýon yं rei racko those yonder are not angels; nyt wyntwy bioed yr antur it is not to them that the adventure belonged.

( $\epsilon)$ nat is the dependent negative, e.g. menegwch ... nat hawd gennyf ynheu nae lad ef nae diuetha declare that it is not easy for me to slay him or to destroy him.

(§) os is the form with o if, e.g. os da gennyt ti if it seems good to thee; os wynteu ae med hi if it is they that have it in their power.

$(\eta)$ ae is the interrogative $=i s$ it ? e.g. ae gwell is it better? ae kyscu yd wyt ti art thou asleep?

$(\theta)$ ponyt is the interrogative $=i$ is it not? e.g. ponyt dros y neb yssyd yna is it not for one who is there?

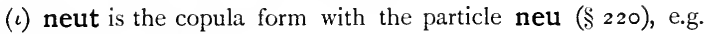
neut araf he is gentle.

(к) The relative form is positively yssyd, negatively nyt, e.g. kanys mi yssyd athro itt for it is I who am thy teacher; gwaew nyt gwaeth a spear that is not worse.

( $\lambda$ ) mae seems to be used where according to $\$$ I59 the predicate follows, e.g. am hỷnny் $\dot{y}$ may் reit $\dot{y}$ titheu uot therefore it is necessary for thee to be WB. 396, o achaws hynny y mae dygassawc yr adar yr tylluan because of that the birds are enemies to the owl RB. 80; yंn y mae goreu y gwyr where the men are best WB. I I 9. Mae is used also in indirect speech, e.g. menegi $\dot{y}$ Arthur mae mi ath výryawd to declare to Arthur that it is I who have thrown thee WB.; ereyll a deueyt e may hyn eu y naud others say that this is his protection $\mathrm{BCh} .9$.

( $\mu$ ) Otherwise the forms wyf, etc., are used for the copula, e.g. pwy wyt who art thou, yd ym drist ni we are sad, nyt oed ef nes idi he was no nearer to her.

\section{bydaf and bydwn.}

I56. bydaf is used :-

(a) As an iterative or consuetudinal present, e.g. mi a uydaf borthawr y Arthur bop duw kalan Ionawr I am Arthur's gate- 
keeper every New Year's Day RB. ı०3, 7 ; lle ny bo dysc ny byd dawn where there is no learning there is no gift FB. 244.

(b) As an historical present, e.g. ual y bydant yn eisted wynt a welynt gwreic as they were sitting they saw a woman RB. 8; a chyuaros Gereint a oruc yny uyd yn agos idi and she waited for Gereint till he was near her RB. 27 I, I.

(c) As a future, the most common use, e.g. y gyt a mi y bydy yn dyscu marchogaeth thou shalt be with me learning horsemanship; mi a vydaf athro it $I$ shall be thy teacher.

I57. bydwn is used:-

(a) As an iterative or consuetudinal past, e.g. a phei vwyhaf uei y vrys ef pellaf vydei hitheu y wrthaw ef the greater his haste the further she was from him RB. 9, 5 .

(b) Describing a single action in past tense: ual y bydynt yn eisted wynt a welynt $\mathrm{y}$ wreic as they were sitting they saw the woman RB. 9, 29.

(c) As a secondary future or conditional, e.g. wynt a welsant or kaffei vedic da $\mathbf{y}$ bydei vyw they saw that if he got a good leech he would live RB. 2 I 2 , 2.

\section{Past Subjunctive.}

I58. The following forms are to be noted: pei yt uewn $\mathrm{i}$ (=bei etu(nni WB. 7I) yn dechreu vy ieuenctit if $I$ had been in the beginning of my youth RB. 5I, 24; beyt uei ar y ffuryf iawn if she had been in her proper form RB. I 75, I 8; ar mul ae kanlynawd megys pei at uei milgi and the mule followed him as if it had been a hound Hg. I., $33^{6}$; hi a vynnei pet vei hi a Lawnslot yn y fforest she would that she and Launcelot were in the forest Hg. I., 368; a phettut un wreic di or byt, ny mynnwn i ddim ohonat ti and if thou wert the only woman in the world, I would desire nothing of thee Hg. II., 315. Like the modern pettwn these forms seem to express unreality. 


\section{Position OF THE COPUla.}

I59. In Middle Welsh prose in positive affirmative sentences (with the exception of ys which always precedes the predicate) the normal position of the predicate is before the copula, e.g. Lunet wyf i I am Lunet, cennadeu ym ni we are messengers, llawen vu he was glad, reit vyd it will be necessary', trwy gynghor Branwen uu hynny oll all that was through the advice of Branwen. But the predicate follows the copula in the imperative, in negative and interrogative sentences, in subordinate clauses, and very generally when an adverb or an adverbial phrase precedes, e.g. a vo penn bit bont let him who is head be bridge, nyt da dy gyghor thy advice is not good, a wyt uorwyn art thou a maiden? o byd reit if it is necessary, tra vu da as long as it was good, ual y bydynt gadarnach so that they would be stronger, paham ydwyf trist i why am I sad? yna y bu marw there he died, undyd ym penn y vlwydyn y bu barawt on the same day at the end of the year it was ready. But after adverbs and adverbial phrases there are instances where the predicate precedes, e.g. yna ryued uu gan Arthur hynny then Arthur wondered at that Hg. I., 339; am hynny reit vyd therefore it will be necessary Hg. I., 3I I (by am hynny y byd reit 307 ); ar eil vlwydyn mab mawr oed and the second year he was a big boy RB. 69. 4.

Note 1.-This order seems to have developed from sentences in which a copula form ys, etc., preceded, snch as, e.g. canys gwr uuassei lit. since it is a man that he had been, os byw vyd lit. if it is alive that he shall be. Thus the development wonld be parallel to that of sentences like Peredur a oruc Peredur did (\$ 85).

Note 2.-In the early poetry the copula freely precedes the predicate, as in Irish. And in the more archaic prose there are instances of the same order, e.g. oed dyhed (=ys oed gryssyn RB. 116) keln y ryw was hwnn it vere a grievous thing to hide such a lad as that WB. 475 ; oed melynach, oed gwynnach WB. $476=$ melynach oed, gwynnach oed RB. 117; oed reit WB. $487=$ asoed reit $R B .126,27$; oed glyssyn $W B .151=y s$ oed gryssyn RB. 220 ; oed dyhed mawr, oed iawn RB. 173; oed well RB. 176. As to as oed, ys oed the as, ys is in origin the infixing particle a (\$ 94) with an infixed pronoun which has become meaningless, cf. as bwyf may I be! MA. $142^{\mathrm{b}}$; this usage has developed from eases like ys caffo drugared may he find merey! MA. $224^{\mathrm{b}}$, where formally $\mathrm{s}$ may be an anticipation of the object. 
Compounds of bot.

I6o. ar-gan-vot perceive, can-vot perceive, cyv-ar-vot encounter, dar-vot to be ended, gor-vot overcome, han-vot to be sprung.

INDICATIVE.

Present.

sing.

I. canhwyf; handwyf, handym, hanym, henym hanwyf, henwyf

2. handwyt, hanwyt,

henwyt

3. cenyw; deryw, derw; derynt; henynt henyw; garyw

NOTE 1.-sg. 3 handit RB. 71,178 , and frequently in poetry; ef. Cymmrod. IX. 116, CZ. III. 389. hanvit Hg. I. 200.

2. handoedut

sing. plur.

3. canoed; daroed; hannoedynt

handoed, hanoed

Future.

I. gorvydaf

2. gorvydy; henbydy

3. cyvervyd; dervyd;

hanbyd, henbyd

pass. gorvydit gorvydwn

cyvarvydwch

Iterative IMPERfect And Conditional.

3. cyvarvydei;gorvydei; gorvydynt

hanbydei

pass. gorvydit

NoTE 2.- $-\mathrm{sg} .3$ handei RB. 85 . 
Preterite and Perfect.

I. arganvum; cyvarvum; darvuam ; gorvuam gorvum

2. cyvarvuost;gorvuost gorvuawch, gorvuoch

3. arganvu; darvu; gorvu, arganvuant; gorvuant pass. arganvuwyt ; cyvarvu-

wyt; gorvuwyt

Pluperfect.

3. cyvarvuassei; darvuassei ;

gorvuassei

pass. gorvuessyt

IMPERATIVE.

3. hanvit

Note 3.-sg. 3 derffit RB. 155.

Subjunctive.

Present.

I.

2. henpych

3. arganffo; cyvarffo;

cyvarffom; gorffom darffo ; gorpo, gorffo; hanffo

pass. gorffer

\section{cyvarvoent}

? gor ifout 182,5

pass. gorffer

\section{PAST.}

3. cyvarffei; darffei; hanffei gorffei
\[ (191,6) \]

cyverffynt

Pieu.

I6r. The primary use of pieu is in interrogation, direct or indirect, in the sense of whose is? e.g. pieu y gaer, heb wynt. nyt oes yn y byt ny wypo pieu y gaer honn "whose is the city?" said they. "There is no one in the world who does not knowe to whom this city belongs" RB. I 26 ; Peredur a ovynnawd pioedynt gwyr wy Peredur asked whose men they were Hg. I. 3I4. But it is 
frequently used with lenation bieu, etc., but not preceded by relative $\mathrm{a}$, in a non-interrogative sense to whom belongs, e.g. Effrawc iarll bioed iarllaeth y gogled to Effraze the earl belonged the earldom of the north RB. 193, I; Duw bioedynt they belonged to God $\mathrm{Hg}$ I. 426. The inflexion follows that of bot, e.g.

\section{INDICATIVE.}

Pres. :-Sg. 2. piwyt; 3. pieu; pl. 3. piewynt.

Imperf.:-Sg. 3. pieuoed, pioed, piewed, pieuat; pl 3 . pioedynt.

Fut.:-Sg. 3. pieivyd : pl. r. pieivydwn.

Condit.:-Sg. 3. pieivydei.

Pret.:-Sg. 3. pieivu, pieuu.

Subjunctive.

Pres.:-Sg. 3. pieuvo.

Past :-Sg. 3. pieiffei, pieuvei.

Note-_cf. Bezz Beitr. XVII. 292 sq. In: ni ae pieifydwn we shall possess them CM. pieu has developed into a transitive verb to possess, as it did in Cornish, cf. Cymmrod. IX. 100.

\section{THE PREPOSITION.}

162. ac, a with; with the article ar; with possessive pronouns am, ath, ae etc., e.g. minneu a chwaryaf a thitheu $I$ shall play with thee; wrth ryuelu a Gwrtheyrn to fight with Vortigern; yny oedynt gynefin ac ef till they were familiar with him; taraw a oruc Owein a chledyf he struck Orein with a sword; llanw crochan a dwfyr to fill a vessel with water; taw ath ucheneidaw have done with thy sighing; peidaw a bwyta a oruc he stopped eating; in amvin ev terwin a guir Dulin defending their land from the men of Dublin. It is often used after verbs compounded with ym, e.g. ymadaw a oruc Arthur ar llyn Arthur left the lake; ymgolli ae gedymdeithon to lose his comrades; a doy $\mathrm{y}$ ymwelet ac Arthur wilt thou come to see Arthur?

I63. ach. In the phrase ach y law beside him. 
I64. am (Ir. imm) about, on account of, e.g. corn canu am y vynwgl a horn about his neck; gwisc ymdanat dress thyself; am y uagwyr ar karcharawr on the other side of the wall from the prisoner; iawn y medreis i am benn y carw rightly did $I$ determine about the head of the stag; hyt na dywedit am vn vorwyn vwy noc amdanei so that there was not more talk about any maiden than about her; am hanner bwytta amofyn a oruc y gwr about the middle of the meal the man asked; haelaf oed am rodyon he was most liberal with respect to gifts; y oual am y wreic his anxiety about his wife; or sarhaet a wnathoed am adaw y llys for the outrage which he had committed in leaving the court ; dothyw am Oweyn Owein has perished MA. $25^{2^{\mathrm{a}}}$; a dery் am Keduỹv has $K$. perished? BB. $\mathrm{I}^{3}$; trist oed am angeu y uab he was grieved because of the death of his son. In the phrase am benn, e.g. yn y del y iarll ... am penn y lle hwnn until the earl comes to attack this place; pan yttoedynt pawb yn mynu mynet am penn y Saeson when they zere all eager to attack the Saxons.

ymdan, e.g. ymdan y varch about his horse.

y am (O. W. diam) from off, e.g. y dynnu y wisc hela y amdanaw to pull off his hunting dress; dogyn o arueu $\mathrm{y}$ am hynny plenty of arms besides WB. p. 225 ; o lu uii nyn e am e mam ay tat ae y brodir a chuarit by the oath of seven people including her mother and her father and her brothers and her sisters BCh. $3^{6 .}$

165. ar on, etc., ar uarch on a horse; Lawnslot a eistedawd y vwyta ar y bwrd Launcelot sat down at the table to eat; edrych a wnaeth Manawydan ar y dref Manazeyddan looked upon his tozen; y dodet ar yr avon Hafren the river was called the Severn; ae geuyn ar yr heul and his back toz'ards the sun; cymryt cleuyt arnaw a oruc he pretended to be ill; rac meint karyat y brenhin arnei because of the greatness of the king's love for her; rac caffael y gaer arnaw lest the city should be taken on him; y wassanaethu arnaw to wait upon him; taerwn arnei ehun diuetha y mab let us insist that she herself killed her son; nyt gwerth arnaw ef dim it is not worth anything; hitheu . . . a gytsynnywys ar anvon y mab y Pwyll she agreed to send the boy to Preyll; dyuot a oruc ef ar 
(=att RB. 287 ) Enyd he came to Enid WB. p. $22 \mathrm{I}$; a roti $\dot{\mathrm{y}}$ uanec ar (=att RB. I16) y kymhar and he gave the glove to his reife WB. 473 .

In phrases, e.g. ar y drydyd with two others; ar y ganuet with a hundred men; sef y key yn nef ar y ganuet thou shalt receive in heaven a hundredfold; ar vrys in haste; am eu carcharu ar gam because they were wrongfully imprisoned; ar gel secretly; ar gyhoed publicly; y marchawc y gwnaethpwyt ar y odeu the knight for whom it has been made; y marchogyon goreu a oed ar $\mathrm{y}$ helw the best horsemen that were in his possession; ar hynny after that; ar hyt y glynn along the valley; ar hyt y dyd throughout the day; ar eu hol after them; ar uedwl mynet with the intention of going; ar uessur llad y benn with the purpose of cutting off his head; ar tal y pebyll before the tent; ar tal y lin on his knee; ar draws yr avon across the river; y tharaw ar draws y hwyneb he struck her across her face.

Note 1.-For the phrase ar y ganvet see Rev. Celt. 28, p. 206.

y ar (O.W. diar), odyar from, e.g. y dygwydawd yn varw y ar y uarch he fell dead from his horse; byrywch awch blinder $\mathrm{y}$ arnawch cast your weariness from you.

NOTE 2.-But $y$ ar is used also in the sense of on, e.g. $y$ gwelynt wreic $y$ ar uarch they saw a woman on a horse RB. 248.

NoTE 3.-In O.W. guar (=Ir. for), e.g. guar ir dreb gl. edito, guar ir henn rit above the old ford Lib. Land. 73. In Lib. Land. is also found ar, ef. Ir. ar. In Mid. W. the two prepositions are confused.

I66. att to, e.g. dyuot a oruc att y uorwyn he came to the maiden; y chwedyl a doeth att Uatholwch the tidings came to Matholwech; dyret y gyt a mi hyt att Arthur come with me to Arthur.

I67. can, gan (corresponding in sense to Ir. la) with, by, e.g. mynet a oruc Mabon ganthaw Mabon went with him; ef a edewis genthi dwy iarllaeth he left with her two earldoms; a chan gennyat y ewythyr cychwyn ymeith and with his uncle's leave he set out; nawd a geffy . . gan uynet dracheuyn y fford y deuthost thou shalt have mercy on condition that thou returnest by the way by 
which thou hast come; hyny yttoed eu llygeit yn colli eu lleuuer gan y chwys ar gwaet till their eyes were losing their light with the sweat and the blood; atteb nys kauas ef genthi hi he got no answer from her; ny phrynit dim ganthunt nothing was bought from them; ny chollet oen eiryoet ganthaw not a lamb had ever been lost by him; gan lan y weilgi by the shore of the sea; os da gan y uorwyn da yw gennyf ynneu if it pleases the maiden, it pleases me; drwc vyd gantunt it will be displeasing to them.

y gan from, e.g. cymer gedernit y ganthaw take security from him; annerch y genhyf $\mathbf{i}$ ef greet him from me.

168. cer, ger near by, e.g. ker tir Tyssilyaw by the land of Tyssilyaw MA. $237^{\mathrm{b}}$; ger glan yr avon by the bank of the river; ae kymerth ger $\mathrm{y}$ avwyneu he took him by his reins $\mathrm{CM} .5^{6}$; yn ymauael ar ebawl geir y vwng seizing the foal by its mane. In some phrases:- ger bronn, e.g. ae vwrw ger bronn Owein and threw it before Owein; ar abat . . . a doeth ac ef hyt geyr bronn yr allawr and the abbot took him before the altar; ger llaw, e.g. ae dodi ger llaw y gerwyn and placed it beside the cauldron.

169. cyvrwng between, e.g. kyfrwg deu yंskyuarn Twrch Trwyth between the ears of Twrch Trwyth; cyfrwng mor a glan between sea and shore.

I70. cyn before, e.g. kynn y nos before night; cyn myned mab Cynan y dan dywawd before Cynan's son went under the sod MA. $140^{2}$.

I7I. cyt union serves as a preposition in the phrases cyt ac, y gyt ac together with, e.g. mynet a orugant gyt ar mackwy they went along with the youth; yn gorymdeith y gyt ar amherawdyr walking together with the Emperor.

I72. eithyr (=Ir. echtar) outside of, except, beyond, e.g. neb rýw dim ny welynt eithyr guydlwdyn they saw nothing except wild beasts; a phan welas Chyarlys hynny ryuedu a oruc eithyr mod and when Charlemagne saw that he reas astonished beyond measure.

dieithyr, e.g. ef a edewis y holl longeu ... dyeithyr un llong he left all his ships except one ship.

odieithyr, e.g.gwede mỷnet Arthur odieithýr y் llýs after Arthur 
went out of the palace; ef . . . ae cassaawd odieithyr messur he hated him beyond measure.

I73. erbyn (prep. er + dat. of penn liead $=$ Ir. ar chiunn cf. § 25) against, before, by, e.g. mi ae paraf... yn gyniachet erbyn penn $\mathrm{y}$ mis ac y gallo marchogaeth I will make him so well by the end of the month that he reill be able to ride; ar abat yna erbyn y law ae kymmerth and the abbot then took him by his hand.

I74. gwedy, wedy (O.IV. guetig) after, e.g. gwedy y gawat goleuhau a oruc yr awyr after the shower the sky cleared; wot y crydyon wedy duunaw ar y lad that the cobblers had conspired to slay him; hyd guedy gosper till after evening.

I75. heb (=Ir. sech) past, without, besides, e.g. nyt kynt yd yskynn ef ar y uarch noc yd a hitheu hebdaw ef no sooner did he mount his horse than she passed him; heb dant yn y phenn without a tooth in her head; abreid vu eu hattal heb torri eu hamot they could hardly be kept from breaking their covenant; y kahat o ynys Prydein ehun trugein mil o varchogyon aruawc heb deg mil a adawssei urenhin Llydaw there was got from the island of Britain itself sixty thousand armed horsemen besides ten thousand that the King of Brittany had promised. In the phrase heb law, e.g. pan yttoed honno yn kerdet heb law Breint when she was going past Breint RB. II., 246.

176. herwyd according to, by, e.g. herwyd anyan according to nature; herwyd vyg gallu i according to my pozer ; a chymryt y mab herwyd y draet and he seized the boy by his feet.

177. hyt (a prepositional use of hyt length) as far as, up to, e.g. o vor Ut hyd vor Iwerton from the English Channel to the Irish Sea MA. 202 ${ }^{\mathrm{a}}$; hyt dyd brawt until Doomsday; educher (= hyt ucher) until evening.

NoTE.--In O.W. there are also prepositional phrases behet, e.g. behet hirmain as far as the long stone Lib. Land., bet rit ir main as far as the ford of the stone ib., and cihit, e.g. cihit i nant to the valley, cihitan, e.g. cihitan clouuric Lib. Land., and cihitun, e.g. cihitun ceng ir esceir Ox. gl.

I78. is (=Ir. is) below, e.g. is nef below heaven. In the phrase islaw below', e.g. kawc a oed islaw y drws a bowl that was below 
the door; y dodit islaw y teulu he was placed beneath the household; odis, e.g. neur disgynnassei Arthur . . odis Kaer Vadon Arthur had descended beneath Caer Vaddon RB. I 5 I, 22 ; adhis Guaissav Lib. Land. $24 \mathrm{r}$.

I79. ithr (only O.W. = Ir. etir) between, e.g. ithr ir dwy ail between the treo eyelashes Mart. Cap.

180. mynn (a nominal preposition $=$ Ir. mind a holy relic, an oath) by (in oaths), e.g. myn dy law di . . mi a af y gyt a thi by thy hand $I$ will go with thee; myn vyg cret nyth gredaf by my faith I do not believe thee.

I8I. mywn (nominal preposition) in, e.g. wynteu a dywedassant bot adanc mywn gogof they said that there was a monster in a cave; ryuedu ... a orugant bot mywn un dyn ... hanner hynny o nerth they marvelled that half as much strength should be in one man; neuad a welsant y mywn (=o vewn WB. p. 93a) y gaer they saw a palace within the city RB. 87, 7 .

182. nes (cf. nes nearer) until, unless, e.g. ny cheffir Mabon vyth . . . nes caffel Eidoel Mabon will never be got till Eidoel is got; nes dyuot Guilenhin urenhin Ffreinc ny helir Twrch Trwyth vyth hebdaw unless Groilenhin King of France comes, Twrch Trwyth will never be hunted without him RB. 1 24, 28 .

183. o, a of, from, by; with the article or; with possessive pronouns om, oth, oe etc.; before pronouns beginning with a vowel there is also a form oc: oc awch of your, oc eu of their, oc a of what, e.g., mil o bunneu aryant a thousand pounds of silver; $\mathrm{y}$ rann vwyhaf or vlwydyn the greatest part of the year; mawr a beth yw gwelet dwyawl dial ar y bobyl a great thing it is to see divine vengeance on the people; pebyll o bali a tent of satin; yn llawn or dwfyr full of the water; kany cheffynt o ennyt wiskaw eu harueu for they got no time to put on their arms; pei karei Duw wynt o dim if God loved them at all; aduet o oet ripe in years; wytt ditawl o bob chwant thou art free from every desire; o mynwn nineu arueru o rydit if we wish to enjoy freedom; na naccaa ui ohonunt do not refuse them to me; ef a gychynnwys o Arberth he set forth from Arberth; yn dyuot or coet allan 
coming out of the wood; am lad ohonat titheu y gwr priawt because her hushand has been slain by thee; na ellir kynnal dy gyuoeth di namyn o vilwryaeth ac arueu that thy dominion can be maintained only by valour and arms. In phrases, e.g. o achaws because of; oe vod with his will; oe hanvod against his will; or diwed at last; o hynny allan from that time forth; o barth y vam on his mother's side; oc eu plith from among them.

184. parth part, in parth ac, parth ac att towards, e.g. bryssyaw a orugant parth ar mwc they hastened towards the smoke, yn dyuot ar hyt y dyffryn parth ac attaf coming along the valley tozerards me.

I85. py (=Ir. co) to; with possessive pronoun pwy, py, e.g. or mor pwy gilyd from one sea to the other; ar ffo o le py gilyd in fight from place to place; ac yna y kymerth Seint Alban Amphibalus yd oedit awr py awr yn y dwyn oe verthyru ac y kudywys yn y dy ehun=quorum Albanus confessorem sum Amphibalum a persecutoribus insectatum et iam iamque comprehendendum primum in domo sua occuluit RB. II. 107.

I86. rac before, against, on account of, e.g. mal heu rac moch meryerid like scattering pearls before swine; kymer di y pedwar meirch a gyrr rac dy vronn take the four horses and drive them before thee; kerdet a orugant racdunt hyt att vwyalch Gilgwri they went on till they came to the blackbird of Kilgwri; am notwy rac auar may he protect me against grief; nys kelaf ragot I zill not hide it from thee; ffo ditheu ymeith rac dyuot ohonaw flee forth lest he should come; yn keissaw diffryt y deu wr rac eu bodi in seeking to save the two men from drowning; llidiaw a oruc Arthur rac hwyret y gwelei y vudugolyaeth yn dyuot idaw Arthur was angry because he saw the victory coming to him so slowly; y kenir efferenneu rac y eneit masses are sung for his soul; yn aballu rac newyn dying of hunger.

y rac from, e.g. ninheu a dygwn y racdunt yr eidunt we will take their property from them RB. II. 207.

187. rwng, y rwng between, e.g. rwg nef a dayar between heaven and earth; y rwng deuglust Twrch Trwyth between the 
ears of Twrch Treyth; pany bei ammot yrof am gwlat amdanunt if there were not a covenant between me and my land about them; rwng dicter a llit taraw ym plith y llygot a wnaeth between rage and anger he struck among the mice; dywedut y ryngthunt ehunein y maent they are saying among themselves; rwg deu onadunt between two of them RB. II. I4I; y kerdwys y ryngtaw a Ruuein he set out to Rome RB. 85, cf. ib. I2, 24.

odyrwng from between, e.g. a ducpwyt yn teirnossic odyrwng y vam ar paret who when three nights old was taken from between his mother and the wall RB. 129 , 10.

188. tan, dan, ydan, adan (cf. O.W. guotan) under, e.g. ffynnawn a welwn dan y prenn $I$ saw a fountain under the tree; y clywei dygyuor ... y dan(=dan IVB. $92=$ adan RB. 66) baret yr ystauell he heard a commotion under a wall of the chamber RB. 67,15 ; gobennyd dan penn y elin a cushion under his elboze; dan wynt a glaw under wind and rain; y ellwng y gwn dan $\mathrm{y}$ coet to let loose his dogs in the roood RB. I, Io; awn adanunt (=ydanunt RB. 48) a lladwn let us attack and slay them IVB. 67 ; yny uyd y llygot yn gwan adan y groft until the mice zere falling upon the field RB. 53, 27, cf. RB. 28, 29; dyuot a wnaeth Corineus at Locrinus dan dreiglaw bwyell Corineus came to Locrimus brandishing an axe.

I89. trag, tra beyond, across, e.g. ton tra thon toid tu tir wave beyond wave covers the side of the land $\mathrm{BB} .45^{\mathrm{a}}$; ac eigyl racdaw draw dra thonneu and angels before him yonder across the zevaves MA. $196^{\mathrm{a}}$; maith dy dreisiau drag Euas great are thy deeds of violence across Evas MA. I 4.5; oes trag oes age beyond age $\mathrm{FB}$. 230 ; tra messur beyond measure F-B. 155 ; rybud drae gilyd = quotidianos rumores RB. II. I3 I.

NoTE.-Often in the phrase drachefyn back, by which there are also forms with possessive adjectives, e.g. tra-m-kefyn WB. $232=$ drachefen RB. 169,16 , tra-th-gefyn WB. $124=$ drachefyn RB. 198,25 , dra-e-gefyn CM. 73 , dra-e-chefyn RB. 177 , 12 , dra-e-kefyn CM. 45 , also forms like drach eu kevyn Hg. I. 301.

I90. trus, tros, dros across, e.g. trus ir minid across the 
mountain Lib. Land; ual yd oed . . yn kerdet dros vynyd as he was journeying across a mountain; yny ehedawd y glot dros wyneb y deyrnas until his fame flew over his dominion; y ymlad dros y wlat to fight for his country; y rodes Hengyst atteb idaw dros y gedymdeithyon Hengist anszered him on behalf of his companions; pan allassant wy gyntaf talu drwc dros da as soon as they were able to return evil for good.

I9I. trwy, drwy (Ir. tre) through, e.g. trwy y koet through the wood; trwy gynghor Branwen through the advice of Branwen; ar tes oed vawr, ar arueu trwy y chwys ar gwaet yn glynu wrth y gnawt and the heat ze'as great, and the armour by reason of the szereat and blood was sticking to his flesh; ar dyd hwnnw ar nos honno a treulassant trwy gerdeu a didanwch and that day and that night they spent in songs and entertainment WB. p. 204; Arthur drwy amlaf rodyon ae henrydedei Arthur honoured him with many gifts.

I92. tu side in tu ac, tu ac att toweards, e.g. pan daw tu ar drws when he goes towards the door; yn dyuot... tu ac attat coming towards thee.

I93. uch (Ir. uas) above, e.g. uch nef above heaven; yn eisted uch penn y weilgi sitting above the sea; uch law y bont... y gwelynt kastelltref above the bridge they saze a fortified town.

diuch: diuch i lan Lib. Land. 73 .

oduch, e.g. oduch y dwvyr above the water WB. p. $90^{\mathrm{b}}$; eithyd oduch gwynt he went above the wind FB. I 79 ; pei delhei $\dot{y}$ byt oduchti if the world should come above it WB. $48 \mathrm{I}$.

I94. wrth (O.W. gurth, Ir. fri) against, towards, etc., e.g. ny ellir dim wrth a uynho Duw nothing can \&e done contrary to what God wills; pan yuei o wual yuei urth peduar when he drank from the horn, he would drink against four BB. $48^{\mathrm{b}}$; wrth y drws llyma vab bychan lo! at the door was a little boy; yn eu pobi wrth $\mathrm{y}$ tan being cooked at the fire; yn dyuot wrth $\mathrm{y}$ diaspat coming at the cry; pob kyfryw aniueileit a ducpwyt yno wrth eu haberthu every kind of animals was led there to be sacrificed; reit oed ym wrth gynghor I had need of counsel; $y$ 
dynu a orugant wrth raffeu y mywn they pulled him in zeith ropes; wrth ych kynghor y bydaf I will follow your advice; llew wrth aer a llwfr wrth eirchyeid a lion for battle and a weakling towards suppliants; cyt bei lityawc ef wrthi hi though he was angry zeith her; wrthyt ti y mae vy neges my business is with thee; yn glynu wrth y gnawt sticking to his flesh; y dywawt y dat wrthaw his father said to him; sef a wnaeth gwyr Rufein drychafel Geta yn vrenhin... wrth hanuot $y$ vam o Rufein the men of Rome raised Geta to be king because his mother was sprung from Rome; wrth hynny therefore; $\mathbf{y}$ wrth from, e.g. yr pan athoed $\mathbf{y}$ wrthunt hwy since he had gone from them; ny ry giglef $\mathrm{i}$ eirmoet dim y wrth y uorwyn I have never heard anything of the maiden.

I95. y (O.W. di, Ir. do) to. With the article yr ; with possessive adjectives ym, yth, yw, etc. $(\$ 58 b)$, e.g. dyuot yw (=y RB. 284) lety came to his lodging WB. p. 219; gwyr Troea ae hymlityassant y eu llogeu the men of Troy pursued them to their ships; y. deuynt drannoeth oc eu hamdiffyn they would come on the following day to defend them; deu uab oed im I had two sons; keuyjnderw dy (=y RB. 1 oo, I3) Arthur oed he was a cousin of Arthur WB. 452; or tu draw yr bont on the further side of the bridge; heb wybot yr kawr without the knowledge of the giant; mi ae talaf ywch $I$ will pay it to you; ni ae dywedwn itti we will tell it to thee; gouyn a oruc Gwrhyr idi Gwrhyr asked her; na hawl ef ynni do not demand him of us; pan daruu udunt darllein when they had finished reading.

Note. - In Irish do $=$ to (ef. Bret. da), di $=$ from. Already in Old Welsh di has the sense of Ir. do, e.g. map di Iob=Ir. macc do Iob a son of Jupiter, anu di Iuno $=\mathrm{Ir}$. ainm do Iuno a name of Juno, di erchim to ask. The sense of from is kept before other prepositions, e.g. di am later y am from off, $\mathrm{y}$ wrth from, and in some phrases, e.g. blwydyn y hediw a year from to-diey, $\mathrm{y}$ dreis by violence, $\mathrm{y}$ werth WB. p. $214=$ ar werth RB. 277,21 for a price.

196. yn (Ir. i n-) into, in. With possessive pronouns ym, yth, e.g. kyllell a edýw y mwyt a llýnn y mual (the) knife has gone into (the) food and (the) drink into the horn; dyuot a orugant hyt yn lle yd oed karw Redynure they came to where the stag of 
Redynvre zaas; ny் chlýweist yth wlat dy் hun eiryjoet kerd kỷstal ac a ganant hwy thou hast never heard in thy own country such song as they will sing; ny byd vy eneit ym korff my life will not be in my body; pa ry்w weith $\dot{y} d$ wỳti yndaw in zhat manner of work art thou engaged? ym penn y seith mlyned at the end of the seven years; gormod vyd agheu gwas kystal ac Edern yn sarhaet morwyn the death of so excellent a youth as Edern will be too much for an insult to a maiden. In many phrases :- dwy (ystondard) yssyd yn y vlaen a dwy yn y ol two standards are before it and two after it; yn ol y twryf y daw kawat after the noise will come a shozeer; ym bron close by'; yg kylch y tan round about the fire; edrych a orugant yn eu kylch they looked around them; yg gwyd Arthur in the presence of Arthur; nat elych ym herbyn that thou shalt not go against me; yn herwyd gweledigaeth according to appearance; y mywn cadeir in a chair; ef a chwbwl or a gollassei hyt yn oet y tlws lleihaf a gafas he got all that he had lost even to the smallest treasure; ef a welei bebyll ym plith y pebylleu ereill he saw a tent among the other tents; y vrenhines a eistedawd yn ymyl Galaath the queen sat beside Galahad.

197. yr, er for, on account of, since, e.g. oes obeith gennyt ti ar gaffel dy ellwng ae yr aur ae yr aryant hast thou any hope of obtaining thy liberation either for gold or for silver? py glot a geffy ti yr llad gwr marw what fame zeilt thou get for slaying a dead man? nyt yr drwc itti y deuthum I have not come to thee for evil; pei tebygwn $\mathrm{y}$ wneuthur ohonat ti yrof $\mathrm{i}$ beth if I thought that thou zeouldst do something for me; yr y byt na wnewch hynny for the world do not do that; yr Duw a wdost ti dim y wrth Uabon for God's sake, dost thou knowe anything of Mabon? yr mwyn y gwr mwyhaf a gery arho vi for the sake of the man whom thou most lovest, wait for me; pa hustyng bynnac yr y vychanet a uo y rwng dynyon whatever whisper, however low, there is between men; yr a uyrit yndi ny bydei lawnach no chynt however much was throwen into it, it was not fuller than before; oed llesach yr march pei ass archut yr meittyn it would have been better for the horse if thou hadst asked it a while ago; y gwr y buost yr ys talym o amser yn 
y geissaw the man whom thou hast been seeking for a long time (lit. since it is a while of time).

NoTE.-This preposition is frequent with oet time, together with a possessive adjective, e.g. ny ry giglef i eirmoet $I$ have never heard; na welsei eiryoet that he had never seen. The form eiryoet becomes petrified into a phrase used of all persons, e.g. ny chiglef i eiryoet $I$ have never heard; ny chlyweist eiryoet thou hast never seen.

\section{THE CONJUNCTION.}

I98. a and; ac before vowels and the negative particles ny, na, and sometimes before other consonants; with the article, ar; with possessive adjectives: am, ath, ae etc., e.g. vyg kewilyd am llit my disgrace and my anger; a phryderu a oruc yn uawr and she was very anxious. $\mathrm{a}-\mathbf{a}$ both and, e.g. $\mathrm{y}$ gwassanaeth goreu a allwyf $\mathrm{i}$ mi ae gwnaf ac idaw ac y uarch the best service that I can I will render both to him and to his horse; a hediw a pheunyd both to-day and every day. After the comparative of equality (\$ 39), e.g. vn kyndecket a hi one so fair as she; similarly, a honno a aei trwy gallonneu y dynyon ae hofnockaei yn gymeint ac y collei y gwyr eu lliw ac eu nerth and that went through the hearts of the people and terrified them so that the men lost their hue and their strength. Introducing an accompanying or qualifying circumstance, e.g. gwelem . . mynyd mawr geir llaw y coet a hwnnw ar gerdet we sawe a great mountain beside the wood, and it walking RB. 35, 26; goueileint a delis yndaw o gamhet idaw attal y mab gantaw ac ef yn gwybot y vot yn vab y wr arall he was seized with great sadness because of the wrong that he did in keeping the boy with him though he knew that he was the son of another man RB. 22, 20; nyt a mi yn uyw yd aho ef y Gernyw he shall not while I live go to Cornwall RB. 140, 16. Adversatively, e.g. mi a rodaf y carcharawr itti ac ny darparysswn y rodi y neb $I$ will give thee the prisoner, although $I$ had not intended to give him to anyone RB. I2S, 26.

199. achaws (nominal conjunction) because, e.g. galw Gwrhyr Gwalltawt (leg. Gwalstawt) Ieithoed, achaws (om. WB. 47 I) yr holl ieithoed a wydyat he summoned, Gworhyr, the interpreter of 
tongues, because he kneze all languages RB. I14, I4; o achaws na chaffant gennyt because they do not get from thee RB. 85, 26 .

200. am na because not, e.g. tristuart uytaf am na daw $I$ shall be a sorrozeful bard because he zoill not come MA. $183^{\mathrm{b}}$; am na weles ef yno na gwr na gwreic ryued vu ganthaw he was astonished because he saze there neither man nor zeroman Hg. I., 154.

20I. yr awr (nominal conjunction) when, e.g. yr awr y kenych ef a a y nywl ymdeith zehen thou soundest it the cloud will vanish WB. 45 I : yr awr yे rodes un llef arnaw yd aeth $\dot{y}$ nywl ymdeith when he blew a single blast on it the cloud vanished, ib.

202. can for, since; neg. can ny; with the present of the copula, canys, e.g. ỳr hỷnny் hỳt hediw $\dot{y} d$ wýf $\mathrm{i}$ ỳn darparu gwled $\dot{y} t \mathrm{i}$, can gwỳdywn i $\dot{y}$ dout ti $\dot{y} m$ keissyaw i from that time till today I have been preparing a feast for thee, for I knew that thou wouldst come to seek me WB. 249; kanýs gollỳngy ỳr hỷnny mi a rodaf it pedeir punt ar ugeint o aryant since thou wilt not let it go for that, $I$ will give thee twenty-four pounds of silver WB. 78 ; a chanys vy lles i yd oedut ti yn y uenegi im, manac pa fford vei hynny and since thou zert shewing me my advantage, shew how that might be RB. I 77,15 .

NoTE.-The copula form canys comes to be used simply in the sense of can, e.g. a chanys nys gwnn (=a chanys gwnn WB. 76) since $I$ do not know it RB. 54, 30.

203. cwt, $\mathrm{cw}$ where, e.g. kwt ynt plant $\dot{\mathrm{y}}$ gwr where are the children of the man? WB. 453 ; mýnet a oruc yे brenhin $\dot{y} g$ kyghor kwt gaffei wreic the king took connsel where he could get a wife ib.; a wdosti cwd uyd nos yn arhos dyd knowest thou where is night waiting for day? FB. I46; a thrýdit rỷuet yेv merwerit mor, cv threia, cud echwit, cvd a, cvd ymda, cv treigil, cv threwna and the third wonder is the tumult of the sea where it ebbs, where it swells, where it goes, where it moves about, where it rolls, where it settles BB. $44^{\mathrm{b}}$.

204. cyn before, (a) with indicative, e.g. gwr a rodei gad kyn dybu i dyt a man who used to give battle before his day came MA. $14 \mathrm{I}^{\mathrm{a}}$; (b) with subjunctive, e.g. gweinif $\mathrm{i}$ hagen ym Reen ri 
cyn bwyf deierin I yet will serve my Lord King before I am of the earth MA. $142^{2}$, a chin ri llethid ve llatysseint and before they were slain they had slain BB. $36^{\mathrm{b}}$.

205. cyt, cyn, though; negative cyn ny, cyny, cany.

(a) With indicative, e.g. kid y lleinv keudaud nis beirv calon though it fills the body, it does not stir the heart BB. $51^{\mathrm{a}}$; cyd doeth ef nid aeth yn warthegawc though he came, he did not go with spoil of cattle MA. $140^{\mathrm{b}}$.

(b) With subjunctive, e.g. kỳn nỳ buỳf arglwỳdes, heb i, mi a wnn beth ẏw hỷnny் "though I am not a lady," said she, "I know what that is" WB. 51 ; ked archwyf ym llyw y lloergant yn rot, ef am ryt yn geugant though I ask of my sovereign the moon's orb as a gift, he will assuredly give it me MA. $2 \mathrm{I} 2^{\mathrm{a}}$; a thydi am gwely i kany welwyf $\mathrm{i}$ dydi and thou wilt see me, though I see thee not RB. 173; a chyt bei lityawc ef wrthi hi, ef a gymyrth y rybud and though he was angry with her, he took the warning WB. p. 215 ; nyt oed ef nes idi yna no chyn bei ar y gam he was no nearer to her there than though he had been at a walking pace; neur daruydei yr dayar y lynku heb wybot dim y wrthaw mwy no chyn ny ry fei eiryoet vch y dayar the earth had swallowed it so that nothing more was known of it than though it had never been above the earth RB. II., I 4 I ; annoc y Brytanyeit megys kyt bei un onadunt he incited the Britons as though he had been one of them RB. II., 94.

NoTE.-In the verb "to be" after cyt the $3 \mathrm{sg}$. imper. regularly takes the place of the $3 \mathrm{sg}$. pres. subj., e.g. ar nab a geiff enw kyt boet drwe gennyt $\mathrm{ti}$ and the boy shall get a name though it displease thee RB. 69, 23.

206. cyt union in the phrase y gyt ac, e.g. y gyt ac y doethant rac bron Kynan y hannerchassant o bleit amberawdyr Rufein as they came before Cynan they greeted him on behalf of the Emperor of Rome RB. II. 113; y gyt ac nat oes since there is not BCh. 8I.

207. delw (nominal conjunction) as, e.g. delw yt wytt pen rieu pen reith yt wyf pen prifueirt om prifyeith as thou art head of princes, head of law, I am head of chief bards from my most excellent speech MA. I 57 a. 
208. eissoes however, nevertheless, e.g. a dic vu wreic y melinyd wrth Peredur, ac eissoes y melinyd a rodes aryant yn echwyn idaw and the miller's wife was wroth with Peredur; nevertheless the miller gave him a loan of money RB. 229.

209. eithyr na except that not, e.g. ac erbyn auory y vot yn gystal ac y bu oreu, eithyr na byd llyueryd gantaw and by the morrow he will be as good as he ever was, except that he will not have the power of speech RB. $3 \mathrm{I}$.

210. gwedy after; negative gwedy na:-(a) with indicative, e.g. keugant kýwraghaun (MS. -um) wide kywisscarun (MS. -an) verily we shall meet after we part BB. $\mathbf{I}^{\mathrm{b}}$; a gwedy na allwys Kaswallawn kael y gwr... gogyuadaw Auarwy a oruc and after Kaswallawn could not get the man, he threatened Avarzey.

(b) With subjunctive, e.g. a gwedy byryer llawer yndi, ef a ovyn itt and after a quantity has been thrown into it, he will ask thee RB. I4; mwy boen yw koffau kyuoeth gwedy coller it is a greater torment to remember power after it is lost RB. II. 67 ; kanys ymdiret a wnaei ef caffel clot ... gwedy y gorffei ar y alon for he trusted that he would get fame after he had conquered his enemies RB. II. 7 ; kanys gwedy darffei idaw ef llad Galogryuant diogel oed ganthaw y lledit ynteu gwedy hynny for after he had slain Galogryvant he was sure that he would be slain after that $\mathrm{Hg}$. I. I I 4 ; a gwedy na chaffei dagneued o neb ryw ford y gantaw, sef a wnaeth anuon y geissaw nerth a chanorthwy y gan Ulkesar and after he could not get peace from him in any way, he sent to seek support and help from Julius Caesar RB. II. 89.

2II. hagen yet, howevere, e.g. a phan deuthant yno tybygu rylad Kei. wynt a welsant hagen, or kaffei vedic da y bydei vyw and when they came there, they thought that Kei had been killed. They saze, however, that if he got a good leech he would live RB. 2 I 2 , I I.

2I2. herwyd, yn herwyd (nominal conjunction) according as,

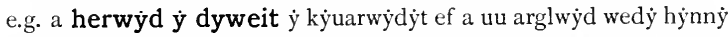
ar Wyned and as the story says, he was lord over Gwynedd after that IVB. I I ; a gwedy eu hannoc uelly yn herwyd y gallei, erchi a wnaeth dineu delw efydeit drwy danawl geluydyt and after he had 
thus exhorted them to the best of his power, he asked that a bronze effigy should be cast through the art of fire RB. II. 138.

213. hevyt further, also, likewise, e.g. $\dot{y}$ Duv $\dot{y}$ harchaw arch hewid of God I reill ask a request still BB. $36^{\mathrm{a}}$, ac enryuedodeu ereill heuyt a weleist yno and other wonders likewise thou sawest there RB. $233,2$.

2I4. hyt (nominal conjunction).

I. as long as, as far as.

(a) With the indicative, e.g. ti a geffy y kyfarws a notto dy benn ath dauawt, hyt y sych gwynt, hyt y gwlych glaw, hyt y treigyl heul thou shalt have the gift that thy mouth and thy tongue indicate, as long as wind dries, as long as rain wets, as long as the sun revolves RB. 105, 25 ; hyt y gwelir ymi gwlat ffrwythlawn yw hon as far as appears to me, this is a fruitful land RB. II. I 6 ; nyt aeth neb is nef hyt yd aeth ef no one under heaven went as far as he FB. 197.

(b) With the subjunctive, e.g. taw hyt y mynnych be silent as long as thou wilt RB. 13,8 .

2. hyt na so that not.

(a) With indicative (of consequence), e.g. drycyruerth a wnaeth hyt nat oed well genti y byw noe marw she made lamentation so that she did not deem her life better than her death RB. $5 \mathrm{I}$, I 8.

(b) With subjunctive (of purpose), e.g. carchara wynt hyt nat elont dracheuyn imprison them so that they may not go back RB. 34,14 .

2I5. lle (nominal conjunction) where; regative lle ny, e.g. lle y gwelych eglwys kan dy pader wrthi wherever thou seest a church, recite thy pater to it $\mathrm{RB}$. I95; am uenegi ohonaf i ytti dy les lle nys metrut dy hun because I shewed thee thy advantage where thou didst not think of it thyself RB. I 77 .

216. mal, val (O.W. amal=Ir. amail).

I. as, when.

(a) With indicative, e.g. sef mal yd eistedassant that is how they sat WB. p. 224 ; pei gwypwn vot yn da gennyt ti mal y mae da gennyf $\mathrm{i}$ if I knew that it pleased thee as it pleases me RB. 213 ; ual y daw y mywn arganuot yr adanc a wnaeth as he came in, he perceived the monster RB. 226, 5 ; $\dot{\mathrm{y} d}$ adnabu $\dot{\mathrm{y}} \mathrm{r}$ amherawdyr $\dot{\mathrm{y}}$ wlat 
mal y gwelas the emperor recognised the country when he saw it WB. 186.

(b) With subjunctive, e.g. mi wnaf ual y dywettych di $I$ shall act as thou mayest direct RB. 276 ; hwẏnt ae torry்nt ual y dyckid attunt they broke them as they were brought to them.

2. as if (with past subjunctive), e.g. mal pei teu uei as if it were thine RB. I27; dyuot yma auory ym kymryt i mal na wyppwn i $\operatorname{dim} \mathrm{y}$ wrth hynny to come here to-morrow to take me as if I knew nothing about it WB. p. 215.

3. so that.

(a) With indicative (of consequence), e.g. kyscu a wneuthum i ual na wybuum pan aeth ef $I$ slept so that I did not know when he went RB. 247,27 .

(b) With subjunctive (of purpose), e.g. par weithon wahard y llongeu ... ual nat el neb y Gymry issue now a prohibition to the ships so that no one may go to Wales RB. 34, 12 ; ereill a gyghorei itt rodi dy uerch y un o dylyedogyon y deyrnas hon ual y bei vrenhin gwedy ti others advised thee to give thy daughter to one of the nobles of this kingdom so that he might be king after thee RB. II. I 4 .

217. megys; megys na.

I. as, e.g. y gwledychwys Peredur gyt ar amherodres pedeir blyned ar dec, megys y dyweit yr ystoria Peredur ruled with the empress for fourteen years, as the story tells RB. 232 ; megys $y$ gallwys gyntaf ef a aeth parth a Chaerwynt as soon as he could he went towards Caerwynt RB. II. I 73; megys y del y coelbrenn udunt $\mathrm{y}$ deholir as the lot falls to them they are banished RB. II. I 3 I.

2. as if, e.g. ymgaru a orugant megys na ry ymwelynt drwy lawer o yspeit kyn no hynny they embraced one another, as if they had not seen one another for a long time before that RB. II. I 86.

3. so that, e.g. pa achaws na ladwn ni y mynach hwnn megys y kaffo Gwrtheyrn gwedy hynny y deyrnas why do we not slay this monk, that Vortigern may thereafter get the kingdom? RB. II. I29.

218. myn where, e.g. dyuot a orugant myn yd oed yr heussawr they came to where the herdsman was RB. I I 5,13 ; mỳn yd vo truin ỳd uit trev wherever there is a nose, there mill be a sneeze BB. $42 \mathrm{a}$. 
2I9. namyn, namwyn except, but.

e.g. nỳt edewis uỷnet namyn hỷt yd elhut titheu $I$ did not promise to go except so far as thou shouldst go WB. 472 ; paham y kymerwn ninneu hynny y gan y taeogeu lladron . . . namyn eu llad hwy oll why do we take this from these thievish churls and not rather slay them all? RB. 49 ; y prenn a dyfawd yn dec . . . namyn na thyfawd neb ryw ffrwyth arnaw the tree grew fairly, except that no manner of fruit grew upon it Hg. I. I 30.

220. I. neu $=($ Ir. nō) or, e.g. nỳt oed un llestẏr . . namẏn eur neu aryant neu uuelýn there was not a single vessel...except gold or silver or horn WB. 227.

22I. 2. neu, before vowels neut; with the present of the copula neut; with ry, neur ( $\$ 95$ note), with infixed pronoun: neu-m, etc. The original meaning may have been now, but the precise force of the particle is not altogether clear.

e.g. pan douthume attad oeth bichan vi anuad. neu rimartuad oth laur kiueithad when I came to thee, my ill was small; now I have been blackened through thy...co-operation BB. I I $^{\mathrm{b}}$; och, heb $\mathrm{y}$ Riannon, paham y rody di atteb uelly; neus rodes uelly arglwydes yg gwyd gwyrda, heb y mackwy "Alas!" said Riannon, "why dost thou answer so?" "I have so answered, lady, before nobles," said the youth RB. 13; neus gwarchae mynwent y mynwes daear, neud gwar gwawr trydar now the graveyard imprisons him in the bosom of the earth, now the light of battle is gentle MA. I60 ${ }^{\mathrm{a}}$; neu chwitheu pan doethawch. neur doetham y erchi Olwen whence have ye come? We have come to ask for Olwen RB. II8. Many examples will be found in MA. $275^{\mathrm{b}}$.

222. no, noc than; with the article, nor; with possessive adjectives nom, noth, noe etc., e.g. oed melýnach y fenn no blodeu $\dot{y}$ banadyl her head was yellower than the blossom of the broom WB. 476 ; noc amws naw gayaf oed mwy he was bigger than a stallion of nine years WB. 472 ; nachaf $\dot{y}$ twrýf ẏn dýfot yn vwy. . . noc y dywedassei $\dot{y}$ gwr du behold the din became greater than the black man had said WB. 23I; a llawenach uuwyt wrthyf y nos 
hono nor nos gynt I had greater welcome that night than the night before WB. 233 .

With the particle et, nocet, nocyt, nogyt, e.g. dial Duw arnaf onyt dewissaf (leg. dewissach) genhyf uy agheu oe law ef nocet o law arall God's vengeance on me if I would not rather die by his hand than by the hand of another WB. p. 210 ; pa beth yssyd iawnach weithon nocyt na chretter idaw what is more proper now than that he should not be believed? CM. 76 .

NoTE.-For et see Rev. Celt. VI. 57.

223. nu, now, e.g. nu nẏm car i Guendit now Gwendydd loves me not BB. $25^{\mathrm{b}}$; yth law di nu y rodaf $\mathrm{i}$ into thy hand now I will give it RB. 266 ; beth bynnac nu a dylyych, kymer yr un march ar dec whatever then thou art entitled to, take the eleven horses RB. 279 .

NoTE.-In the usual Mid.W. orthography the word should be written nw (=Ir. nu); it had gone ont of use, and so the scribes retained the spelling of an earlier period. Cf. Loth Mab. II. 195.

224. o, before vowels ot if; also or, os; negative ony, before vowels onyt ; with the present of the copula os, negative onyt.

(a) With present indicative, e.g. ot ey yr hon (sc. fford) issot ny deuy trachefyn wyth if thou goest by the lower one, thou wilt never return WB. p. 223; os by்w uýdaf $\mathrm{i}$... ti a glýwy் chwetleu o dianghaf if I live, thou shalt hear tidings, if I escape WB. 392; or dianghaf $i$... uýg kýwirdeb am cariat a uyd ar ý uorwỷn . . . onỳ dianghaf uinheu kỷndiweiret uýd ý uorwy் a chỷnt if I escape, the maiden shall have my loyalty and my love; if I do not escape, she will be as pure as before WB. 396 ; mi ath amdiffÿnaf os gallaf $I$ mill defend thee if $I$ can; ny் mwynha $\dot{y}$ gwaet onyt ýn dwẏm $\dot{y}$ keffir the blood is of no use unless it is got warm.

NoTE 1.-A negative clause continuing a elanse introduced by o has ae na with the subjunctive (\$236, note 1 ).

NoTE 2.- onyt sinks to the sense of except, but (Mod.W. ond), e.g. ny mynnaf $\mathrm{i}$ dim onyt mynet yr gware I desire nothing but to go to the play W B. p. 224; ny mynnaf i neb onyt Duw I desire no one but God Hg. I. 178.

(b) With the preterite and pluperfect, e.g. or bu (=os RB. I04) ar dy gam ẏ dyuuost ý mỷwn, dos ar dy redec allan if thou camest in at a walk, go out at a run WB. $45^{8}$; o ry dywedyssei hitheu 
dim a uei wrthwyneb ganthaw ef, hi a wnaei iawn idaw if she had said anything to displease him, she would give him satisfaction. Hg. II. I 3 .

(c) With the past subjunctive, e.g. o bei orderch itt goreu gorderch oedut if thou hadst a mistress, thou wouldst be a matchless lover IVB. 237 ; or bei eisseu dim arnaw ny adei ef hun uyth ar legat dyn if he lacked anything, he nould never allow sleep on any man's eye WB. 465 ; dywedut na bydei vy eneit ym corff ony delei =deuhei WB. 256) ef ym amdiffyn i they said that my life would not be in my body, unless she came to defend me RB. 187 .

NoTE 4.-It will be observed that in the last example corresponding to what in direct speech would be o daw the older text has the imperfect indicative, the later the past subjunctive.

NOTE 5.-os contains the infixed pronoun of the third person singular, os gallaf if I am able (to do) it; from such cases os developes into a special form of the conjunction. or comes from o+ ry as neur from neu + ry (\$ 95 note), so that originally it would have been used before those tenses with which ry was used. But it tended to spread beyond its proper bounds, ef. or clywy, or gwely RB. 195=o chlywy, o gwely WB. $119,120$.

225. 1. pan whence? e.g. pan iv dy echen zolhence is thy lineage? BB. $49^{\text {b }}$; guaur llv py dv pan doit. Ban deuaw o kad "hero of a host, whence comest thou?" "I come from battle" BB. ib.; pa le pan deuy di ... pan deuaf o lys Arthur "whence comest thou?" "I come from Arthur's court" RB. 200, I. Note the repetition of pan in the answer.

226. 2. pan when.

(a) With present (or future) indicative, e.g. kỷntaw geir a dy்wedaw $\dot{y}$ bore ban kyuodaw the first word that I will say in the morning when $I$ arise BB. $4 \mathrm{I}^{\mathrm{b}}$; ban wanha ynaud when his flesh becomes feeble BB. $10^{\mathrm{a}}$; pan agorawr (=agerer RB. 103, 24) y porth . . . bydhawt ragot ti gỳntaf $\dot{y} d$ agorawr $\dot{y}$ porth when the gate is opened, it will be opened for thee first WB. $45^{6}$.

NoTE.-This construction gives place to pan with the subjunctive.

(b) With a past tense of the indicative, e.g. a phan yt oed yn mynet yr $\log$ ac na welei neb y gyt ac ef namyn ar y drydyd . . . y dywawt and when he was going to the ship and sam no one with him save his two companions, he said RB. II. 67 ; a ffan deuthum 
ẏno hoffach oed genhýf and when I came there it pleased me more WB. 229 ; pan glywssynt hwy y uarwolyaeth ef yd ymgynullyssynt when they had heard of his death, they had assembled RB. II. 173 .

(c) With the subjunctive, e.g. pan delych dy hun yth wlat ti a wely when thou thyself comest to thy land thou wilt see RB. 6, Iо; pan agorer y creu beunyd yd a allan when the pen is opened every day, it goes forth RB. 78 ; pan elhei y teulu y yvet y gwin ... nyt aey ef y gyt a neb onadunt wy whenever his household went to drink the wine he would not go with any of them RB. 85 .

3. In some phrases.

(a) hyt pan until, e.g. ar pump meib hynny a uagassant hyt pan uuant weisson mawr and those four boys they reared till they were big lads RB. 43; Duw a wyr nat ymchoelwn hyt pann welhom y uorwyn God knows that we will not return till we see the maiden RB. I 7 .

(b) or pan from the time that, e.g. or pan gauas y tir ny allwys na chi na dyn na march y ganhymdeith from the time that it reached the land neither dog nor man nor horse could keep up with it RB. I4I ; or pann agoroch y drws hwnnw ny ellwch uot yno after ye open that door ye will not be able to be there RB. 40 .

(c) yr pan since the time that, e.g. kyvriuwch awch treul yr pan doethawch yma reckon up your expenditure since ye came hither RB. 228 ; gwedy dwyn ar gof onadunt eu collet yr pan gollyssynt arglwydiaeth ynys Brydein after they called to mind their losses since they had lost the lordship of Britain RB. II. I08.

4. since, e.g. gwae ni pann yn trewit o delli woe to us that we have been struck by blindness LA. 84; pa gyfryw wr yw awch tat chwi pan allo lleassu pawb uelly zohat kind of a man is your father that he can kill everyone in this way? RB. $22 \mathrm{I}$; pa drwc a digoneis i ytti pan wnelut titheu ẏmi . . . a wnaethost hediw what evil have I done to thee that thou shouldst do to me what thou hast done to-day? WB. 232.

5. that, e.g. ny wydyem pan oed ti a grogem we knew not that it was thou whom we were crucifying FB. I22. In prose it is 
common in the phrase pan yw that it is, e.g. y dywawt y gwr . . pan yw Peredur ae goruuassei the man said that Peredur had overcome him RB.

227. pei if, negative pei na; followed by the past subjunctive or by the pluperfect indicative which takes its place (\$ 1 09c), e.g. pei as gwypwn mi ae dywedwn if I knew it, I would tell it RB. 130; nyt oed gyfyg gennyf ymlad a thidi bei na bei yr anifeil gyt a thi I should not think it difficult to fight with thee if the beast were not with thee RB. I89; a phei na ry bylei y cledyf ar vodrwyeu y benffestin ef a vuassei agheuawl or dyrnawt honnw et nisi collisione cassidis mucronem hebetasset, mortiferum vulnus forsitan intulisset RB. II. 198; buassei well itti pei rodassut nawd yr mackwy it mould have been better for thee if thou hadst given protection to the youth RB. 216 .

NoTE.-pei, bei is in origin $\mathrm{sg} .3$ past subjunctive of bot. By itself it has the sense of if it were, e.g. pei oet idaw ef a ladyssit if he had been of age, he would have been slain $\mathrm{RB} .193$.

228. pryt na (nominal conjunction) since not.

(a) with the indicative, e.g. py holy di y mi pryt nam gedy yn $\mathrm{y}$ tarren honn what dost thou seek of me that thou dost not leave me in peace on this stony height? RB. 128 ; a phryt na thygyawd idaw geissyaw mynet y mywn trist vu ganthaw and since he did not succeed in getting in he was sad Hg. I. 39.

(b) With the subjunctive, e.g. pa uedwl yw dy teu di unben pryt na bwyttehych what is in thy mind, sir, that thou dost not eat? (that keeps thee from eating) RB. 292 ; py wyneb yssyd arnat ti pryt na delut y edrych y gofut a uu arnaf i what face hast thou that thou didst not come to see the grief that was upon me? RB. 176 .

229. pyr (py $+\mathrm{yr}$ for what?).

I. Why? e.g. pyr (=py rac RB. I26) y kyuerchy dy why dost thou call? WB. 486.

2. Since, that, e.g. gvae vi pir imteith genhide in kýueith woe to me that $I$ walked in associateship with thee $\mathrm{BB}$. $\mathrm{I}^{\mathrm{b}}$.

230. tra while; often preceded by hyt.

(a) With the past indicative, e.g. ny omedwyt neb tra barhaawd no one met with refusal while it lasted RB. I7; y 
tyuawd heint yndaw a nychtawt hyt tra uu uyw there developed in him a sickness and a walasting as long as he lived RB. 108 .

(b) With the subjunctive, e.g. tra vych ti yn kyscu mi a af y ymwelet ar iarll while thou art sleeping, I will go to see the earl WB. p. 2I4; hyt tra ym gatter yn vyw hanbyd gwaeth drem vy llygeit while I am left alive my eyesight will be worse RB. II9; tra uei y mywn coet ar vric y coet y kerdei while he was in a wood he would walk on the tops of the trees RB. Io8; pei nam goganewch... mi a gysgwn tra uewn jn aros vy mwyt if you would not laugh at me, I would sleep while I wait for my food RB. I62; hyt tra uei yn gorffywys yd archei eu blygaw yn vyw rac $\mathrm{y}$ vron while he was resting he asked that they should be flayed alive before him RB. II. 79 .

23I. wrth because; negative wrth na, e.g. adolwyn yw genhyf itt $y$ gadw yn da, wrth nas rodwn i ef iti yr y seith dinas goreu yth gyuoeth, ac wrth hefyt y lledir dy benn etwa ac ef I entreat thee to guard it well, because I would not give it thee for the seven best torens in thy kingdom, and because too I will yet cut off thy head with it CM. 3 I ; guerth na buost vffil because thou hast not been submissive BB. $I^{\mathrm{b}}$.

232. yn I. where, e.g. dos ragot $\dot{y}$ lys Arthur yn y (=yn lle RB. 195) mae goreu y gwyr go to Arthur's court zothere the men are best WB. I I9; yn (=1le RB. 195) y gwelych eglwýs can dy pater wrthi zishere thou seest a church, recite thy pater to it WB. I I9.

2. when, e.g. yn y bo canmoledig Gruffudd . . . cerddwn weithon ar ddarogan Merddin when Gruffudd has been praised, let us now pass to the prophecy of Merlin MA. $723^{\mathrm{a}}$; yn y bei orchyuygedic angheu a gyuodes y trydyd dyd who, wehen death had been overcome, arose on the third day $\mathrm{Hg}$. II. 76 .

Note.-See Rev. Celt. 28, p. 198.

233. yny until.

(a) With a past indicative (or historic present), e.g. wynt a drigyassant yny daruu idaw ef hynny they stayed until he had finished that RB. 267; dyuot a orugant yr holl niferoed hyny 
vydant yn emyl y kae the whole multitude came till they were beside the enclosure WB. p 224.

(b) With the subjunctive, e.g. arhowch y gyt a mi yny darffo ym gymryt gwrogaeth vyg goreugwyr wait with me till I have received the homage of my nobles $\mathrm{RB} .267$; y byryw[y]t y kalaned yn y peir yny uei yn llawn the corpses zerere cast into the cauldron till it should be full RB. 39 .

234. yr na since not, though not.

(a) With indicative, e.g. am ernyw yr na daw it afflicted me since he will not come MA. $183^{\mathrm{b}}$.

(b) With subjunctive, e.g. darogan yw idaw kaffel etiued ohonat ti yr nas kaffo o arall it is his fate that he shall have offspring of thee though he has had none of another RB. ror ; ny chyffroes un aelawt ar Gopart yr y uedru mwy noc yr na metrit not one limb of Copart was affected, though it was hit more than though it had not been hit $\mathrm{Hg}$. II. 149.

\section{NEGATIVE PARTICLES.}

235. ny, before a vowel nyt; infixed pronouns ny-m-, ny-th-, ny-s-, etc.

(a) Except before the imperative, ny is the regular negative in main clauses, e.g. ny chelaf I will not conceal; ny lyuassei neb no one dared; nyt oed da gennyf ynneu hynny that did not please me; ny bo teu dy benn may not thy head be thine.

(b) ny introduces relative clauses (where Bret. and Corn. like Ir. have na), e.g. $\dot{y} n \dot{y}$ wlad ny ry welei eiroet in a country that he had never seen.

NOTE.-In such clauses na is exceptional in Welsh, e.g. yssit nas keffych (by yssyd ny cheffych 120) there is something that thou wilt not get RB. $121-123$.

236. na, before a vowel nat; with infixed pronouns na-m- etc. This is the regular negative in dependent clauses, e.g. ryued yw gennyf i nam atwaenost I wonder that thou dost not know me; ef a gadarnhaei y gwennwynei y dwfyr hwnnw genedyl y Corannyeit 
ac na ladei ac nat eidigauei neb oe genedyl ehun he gave assurance that that water would poison the race of the Corannyeit, and would not kill and would not harm anyone of his own race $\mathrm{RB}$. 96 ; breid vu na syrthyawd yr llawr she almost fell to the ground Hg. I. 308 ; mi a wnaf itt na bo reit itt uot yn trist $I$ will lring it about for thee that there will be no need for thee to be sad; golychaf $y$ wledic pendefic mawr na bwyf trist $I$ zeill entreat the king, the great Prince, that I may not be sad FB. I82. Further examples will be found under the conjunctions (but can ny, cyn ny, ony).

NoTE 1.-na is found in the second member of a conditional sentence introduced by o (of which the negative is ony), e.g. o gwely vwyt a diawt, or byd reit itt wrthaw ac na bo o wybot a dayoni y rodi itt, kymer dy hun ef if thou seest food and drink, if thou hast necd of it, and no one has the courtesy and hindncss to give it thee, take it thyself RB. 195.

Note 2.-The use of na may be noted in sentences like the following: kanys estrawn genedyl a phaganyeit yweh ae nat atwen inheu etwa nach moes nach deuodeu for ye are foreigners and pagans, and I do not yet know your character or your customs RB. II. 134; a gwedy menegi y bawp o tywyssogyon Freine ar neilltu ac na chauas na phorth na nerth after he had set forth the case to cach of the chiefs of France separately and got neither help nor support RB. II. 74.

237. na, before vowel nac (cf. Ir. nāch-); with infixed pronouns na-m- etc. na(c) is used :-

(a) As the negative with the imperative, e.g. na dos do not go; nac amouyn amdanaw do not ask about it. na is also sometimes found with the subjunctive used in an imperative sense, e.g. na discynnych do not dismount WB. 399 .

(b) In negative answers to questions (\$ 241).

(c) Not preceded by a question, in vivid negation, e.g. dyret y uwytta, heb ef. nac af yrof a Duw, heb hi "come to eat," said he. "I will not go, between God and me," said she RB. 289; eres yw gennyf na uedrut gymedroli ar wneuthur esgidyeu wrth uessur. na uedreis, heb ynteu. mi ae metraf weithon "I am surprised that thou couldst not succed in making shoes by measurement." "I could not," said he; "I shall be able to do it none" RB. 70 ; erchi a oruc y iarll y Enit ymdiarchenu a chymryt gwisc arall ymdanei. na uynnaf yrof a Duw, heb hi the earl asked Enid to unrobe 
herself and put on another dress. "I will not, between God and me," said she.

NoTE.-For a similar nsage in the other British languages and in Irish see the "Transactions of the London Philological Society" 1898-9, page 54, note.

238. na, disjunctive particle; before vowels nac; with the article nar; with infixed possessive adjectives nam, nath, nae etc., e.g. tegach oed noc y gallei neb y gredu nae dywedut he ze'as fairer than anyone could believe or tell CM. I ; heb wybot dim or vrat nae thybyaw without knoving or suspecting anything of the treachery RB. II. 2 I 8 ; na-na, e.g. ny byd reit itt torri na gwaew na chledyf there will be no need for thee to break either spear or sziord; y Duw y dygaf vyg kyffes nae werthu nae ellwng nas gwnaf i I vone to God that I will neither sell it nor let it go RB. $5^{6}$; beth bynnac a uo y marchawc racco na byw na marw whatever becomes of yonder knight, whether he lives or dies RB. 289 ; py beth bynhac a gaffer drwy na thwyll na chedernit whatever is got through treachery or force RB. II. 206 ; pan dycko beich na mawr na bychan uo when he brings a load zehether it be great or small RB. Iо9.

\section{INTERROGATIVE AND RESPONSIVE}

\section{PARTICLES.}

\section{Interrogative Particles.}

239. a ; with the present of the copula ae $(\$ 155 \eta)$.

(a) In direct questions, e.g. a weleist di varchawc hast thou seen a horseman? ae amser ynni vynet yr byrdeu is it time for us to go to table?

(b) In indirect questions, e.g. govyn a oruc y gwr y Peredur a wydyat llad a chledyf the man asked Peredur whether he knew to smite with a szelord; edrych a oruc a yttoed ef yn deffroi she looked to see if he was stirring.

(c) ae-ae whether-or, e.g. yn amheu beth a dywedei ae gwir ae geu doubting whether what he said was true or false RB. II. 47 ; e kefreyth a deueyt bod en yaun provy ae moruyn ae nyt 
moruyn the lawe says it is right to try whether she is a maiden or whether she is not a maiden BCh. p. 40; ny wydyat hitheu beth a wnaei. . ae dywedut hynny ae tewi she did not know what she should do, whether she should tell that or keep silent R.B. 270 ; either-or, e.g. a uynny di ae diawt ae dim dost thou desire drink or anything? RB. 276 ; a thebic yw genhyf $\mathrm{i}$ na doeth y wrthunt heb lad ae rei onadunt ae cwbyl and I think that he did not leave them without slaying either some or all of them WB. p $22 \mathrm{r}$.

240. pony (=Ir. cani), before vowels ponyt; with the present of the copula ponyt=nonne? e.g. pony chlywy di dost thou not hear? RB. 272 ; ponyt oed iawn y titheu zoould it not be right for thee? RB. 246 .

\section{RESPONSIVE PARTICLES.}

24I. In answers to questions the verb or the predicate noun is often repeated, e.g. a gaffaf i letty gennyt ti, heb y Peredur. keffy, heb ynteu, yn llawen "shall I get a lodging zeith thee?" said Peredur. "Yes," said he, "gladly"; a yttiw Kei yn llys Arthur. Yttiw "is Kei in Arthur's court?" "Yes"; ae amser ynni vynet yr byrdeu. amser "is it time for us to go to table?" "Yes." In negative answers na(c) is used, e.g. a atwaenost di y marchawc racco mawr. nac atwen "knowest thou yonder great horseman?" " $N o$ "; dywet, heb ef, a vu ef gennyt ti a gwneuthur anuod arnat. na vu, myn vyg cret, heb hi, na cham nys goruc ym "tell me," said he, "reas he zeith thee and did he do violence to thee?" "No," said she, "and he did me no wrong"; ae byw. na vyw "is he alive?" "No." In answer to ae, nac ef (= Mod.W. nage) is found, e.g. dywet unbenn, heb ef, ae o anwybot ae o ryfyc y keissut ti colli ohonof $\mathrm{i}$ vy mreint... nac ef, heb y Gereint, ny wydywn i kaethu fford y neb "tell me, sir, is it through ignorance or arrogance that thou didst seek to make me lose my privilege?" "No," said Gereint, "I did not knoze that the road zeas debarred to any one" WB. p. 217.

NoTE. -nac ef is also found without a preceding question, e.g. arhowch vi yma, heb y Peredur, mi a af y ymwelet ar pryf. nac ef, arolwyd, heb wynt, awn y gyt y ymlad ar pryf "wait for me here," said Peredur, "I will go to visit the worm." "Nay, lord," said they," "let us go together to fight with the worm." 
242. Certain particles are used in answer.

ie, ieu, affirmatively, e.g. ae gwr y Arthur wyt ti. Ie myn vyg kret, heb y Peredur "art thou one of Arthur's men?" "Yes, by my faith," said Peredur; gouyn a wnaeth ef yr gwr . . . ae offeiryat oed ef. Ieu arglwyd, heb ynteu he asked the man if he zolas a priest. "Yes, Lord," said he.

do (cf. Ir. tō) affirmative, nado (Ir. nā thō) negatively, in answer to a preterite (or pluperfect of indirect question), e.g. a unben, heb ef, a leweist ti dy ginnyaw. do, heb ef "Sir," said he, "hast thou eaten thy dinner?" "Yes," said he; deffroi a oruc Arthur a gofyn a gysgassei hayach. do arglwyd, heb yr Owein, dalym Arthur awoke and asked if he had slept for some time. "Yes," said Owein, "for a while." a vwyteeist di dim hediw. nado, heb ynteu "hast thou eaten anything to-day?" "No," said he.

NotE.-Both ie, ieu and nado are found without a preceding question, e.g. ar hýnny llýma hitheu ýr iarlles ýn datlewygu. ie, heb hi, ae kychwyn a uýnny ti. ie, heb ef thereupon lo the countess recovered from her swoon. "Really," said she "dost thou desire to set forth?" "Yes," said he WB. 119; ie (=ieu RB. 210), heb $y$ Peredur, ẏma y bydwn heno "truly," said Peredur, we will remain here to-night" WB. 139; mi a debygaf...na cheueist na bwyt na diawt. nado yrof a Duw, heb ynteu "I think that thou hast got neither food nor drink." "No, betueen Gorl and me," said he RB. 275.

\section{THE INTERJECTION.}

243. Interjections proper are :-

a, ha ( = Ir. ã), in address, e.g. a vorwy்n, heb y Peredur, a doy் ti $\dot{y}$ dangos imi ỳr aniueil hwnnw "maiden," said Peredur, "zerilt thou come to shew me that beast?" ha (=a WB. 169) unbenn, heb y uorwyn, pei gwnelut vyg kyghor... ti a gaeut y drws "Lord," said the maiden, "if thou wouldst follone my advice, thou wouldst shut the door" RB. 235 .

oi a, e.g. oi a uorwyn dec a bery di bot vym march i am arueu yn vn lletty a mi heno hark! my fair maid, wilt thou see that my horse and my arms are in the same lodging with me to-night? RB. 217; dyhed a beth bot gwr kystal a thi heb gedymdeith; 
oi a wrda y mae y mi gedymdeith "it is a strange thing that a man like thee should have no companion." "But, my lord, I have a companion" RB. I 27.

oian a, e.g. oian a parchellan a parchell dedwit ho! little pig, happy pig BB. $26^{\text {b. }}$.

och, e.g. och Iessu na dyffv wy் nihenit kỷn dy்ffod ar wi llave lleith mab Guendit $O$ Jesus that my end had come before the death of Giendydd's son came upon my hand BB. $25^{\mathrm{b}}$; och, heb y Riannon, paham y rody di atteb uelly "alas!" said Riannon, "zehy dost thou anszeer thus?" RB. I 3 ; erchi y vendyth a wnaeth; och a truan, heb ef, ny dylyy gaffel bendyth he asked him for his blessing. "Unhappy ziretch," said he, "thou dost not deserve a blessing" RB. 236 .

ub, e.g. neu chwitheu pwẏ yंwch. kenhadeu Arthur ýssy்d ẏma yn erchi Olwenn; vb wyr nawd dy்w ragoch, yr ý by்t na wnewch hỷnny் "and who are you?" "Messengers of Arthur that are here seeking Olwen." "Alack! men, God preserve you. For the world do not do that" WB. 473.

244. Of an interjectional character are the following:-1lyma lo here! (like Fr. voici), e.g. llyma weithon ual yd hellawd Arthur $\dot{y}$ carw Lo non! this is hon Arthur hunted the stag WB. 402 ; llyma $\dot{y}$ uorwy்n $\dot{y}$ kefeist ti dy warthrud oe achaws See here is the maiden on whose account thou didst get thy shame WB. 407. Also llyman RB. 87 , WB. 185 , p. $92^{\mathrm{b}}$; llỳna to there! (like Fr. voilà), e.g. llyna yssýd iawnaf am hỷnny Lo! that is the fairest course zeith reference to that WB. 406 ; ie vorwỳn, heb y Kei, llyna vedru yn drwc "Indeed, woman," said Kei, "that is ill behaviour" WB. I23; nachaf lo! hehold! e.g. nachaf uarchawc yu dyuot yr porth behold a horseman coming to the gate RB. 233; wely dy (lit. dost thou see?) lo! behold! e.g. wely dy racco (= weluch chwi racw WB. p. 94a) $\dot{y}$ gaer Lo! yonder is the city IVB. 185 . 


\section{A Middle-Welsh Reader}





\section{LEAR AND HIS DAUGHTERS.a}

From the Red Book of Hergest.

I. Ac yna gGedy mar6 Bleiddu, y drychafwyt ${ }^{1} \mathbb{L}$ yr y vab ynteu yn vrenhin. A thrugein ${ }^{2}$ n:lyned y bu yn Mywyal y to rule, direct vrenhinyaeth ${ }^{3}$ yn wrabl, ac a adeilbys dinas ar auon Soram, ac ae gelGis Kaer Lyr; ac yn Saesnec y gelGir Leissestyr. Ac ny bu idas un mab namyn teir merchet. Sef oed 5 enceu y verchet ${ }^{4}$ Goronilla, Ragab, 5 Cordeilla. A diruabr y karei eu tat Gynt, a moyaf eissoes y karei y verch jeuaf idab Cordeilla.

2. A phan yttoed yn Mithrab parth ae henein, ${ }^{1}$ medylyab how a wnaeth pa Ged y gadawei ${ }^{2}$ y gyuoeth gredy ef $\mathrm{y}^{3}$ verchet. Io Sef a onaeth profi poy voyaf oe verchet ae karei, 6rth rodi idi y ran oreu or kyuoeth gan wr. A galsa $6 n[a] e^{4}$ attal y verch hynaf idas Goronilla, a gofyn idi pa veint

$x \quad y$ karei hi efo. ${ }^{5}$ A thygu a onaeth hitheu $y^{6}$ nef $a^{7}$ daear ${ }^{8}$ bot yn vay y karei hi euo noe heneit ehun. A chredu a 15 Gnaeth ynteu idi ${ }^{9}$ hynny, a dyGedut, ${ }^{10}$ kan oed kymeint ${ }^{11} \mathrm{y}$ karei hi euo a hynny, y rodei ynteu draean ${ }^{12}$ y gyuoeth genti hi y $6 r^{13}$ a defissei yn ynys Prydein.

3. Ac yn ol honno gali attas Ragua ${ }^{1}$ y verch eil hynaf idal, a gofyn idi pa veint $y$ karei hi euo. A thygu a 20

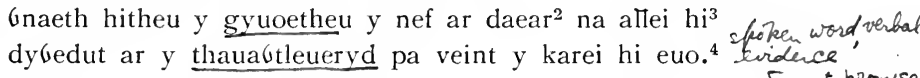
A chredu a onaeth ynteu hynny, ac adas idi hitheu y asaw topromise rodi $^{5}$ yr gor a desissei, a thraean ${ }^{6}$ y gyuoeth ${ }^{7}$ genti. his

${ }^{a}$ Letters enclosed in square brackets [ ] are wanting in the MS.

Variants from British MUSeum, Additional 19,707.

Ch. 1.-1 drycheuit 2 thrugeint 3 yn y Mywa hi 4 eu henweu 5 ragan

Ch. 2.-1 a heneint 2 yd adavei $3 y^{0} \quad 4$ wnaeth 5 ef 6 yr 7 ar 8 dayaer 9 idi hi 10 dywedut (orthi 11 gymeint 12 drayan 13 yr gor Ch. 3.-1 ragau 2 dayar $3 \mathrm{om} .4 \mathrm{y}$ karhei 5 y rodei hi (hi over line) 6 thrayan 7 kyfoeth 
dewre $\delta$ prowess, valow, prime of life

blynghäin to becone angry, frow

di-farmu to judge, decids against

\section{I40 LEAR AND HIS DAUGHTERS}

4. Ac yna y gelsis ${ }^{1}$ y verch jeuaf idal attab, a gouyn idi pa veint $y$ karei hi euo. ${ }^{2}$ A dybedut a Gnaeth hitheu \$97C. $\quad y$ rygaru $^{3}$ ef eiryoet ${ }^{4}$ megys y dylyei uerch garu y that, Ko cease from ac nat ytoed et $\mathrm{a}^{5}$ yn peidab ar karyant honnosa ac erchi $v$. Stoss 5 idal gliarandal yn graff pa veint oed hynny. A sef ${ }^{6}$ oed hynny, $y^{7}$ veint $y$ bei y gyuoeth ae jechyt ae debred. A blyghau a Midia $6^{8}$ a oruc ynteu, a dycedut (srthi, kan oed Tremygu to desfise kymeint y tremygassei euo a hynny, val na charei ${ }^{10}$ hi euo megys y karei y chwioryd ereill, ${ }^{11}$ y diuarnei ynteu hi hyt Io $\mathrm{na}^{b}$ chaffei neb ryb ran or ynys y gyt ac oynteu. Ny dy( at $^{12}$ ynteu nas rodei hi ${ }^{13}$ y wr ny hanffeic or ynys, o dambeinei yr kyfrys or honns y herchi heb argyfreu genti. Hyn heuyt a gadarnhaei hyt na lauuryei y geissal gar idi megys yr rei ereill. ${ }^{14}$ Kanys may y to become
angry craff finm, steadfast

5 karyssei ef hi nor rei ereill eiryoet, ${ }^{15}$ a hitheu yn $y$

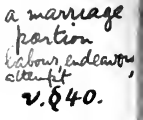
dremygu ynteu ${ }^{16}$ yn voy nor rei ereill. ${ }^{17}$

go-hin is delay; 5. A heb ohir o gytgyghor y wyrda y rodes y doy fourcounsel verchet hynaf idad y dywyssogyon ${ }^{1}$ yr Alban a Chernyd, a hanner $y$ gyuoeth ${ }^{2}$ gantunt hyt tra [vei] ${ }^{3}$ vyd ef, a 20 guedy bei varb, y kyoueth gantunt ${ }^{4}$ yn deu haner. Ac yna gGedy clybot o Aganipus vrenhin Freinc clot a phryt a thegoch Cordeilla, anuon kenadeu a onaeth oe herchi yn wreic idab, a dybedut orth y that y genadori. ${ }^{a}$ Ac ynteu a dybabt ${ }^{5}$ y rodei y verch idas ef heb argyfreu

25 genti, ${ }^{6}$ kan daroed ida6 rodi y gyuoeth ae eur ae aryant $\mathrm{y}^{7} \mathrm{~d}$ by verchet ereill. ${ }^{8}$ A phan gigleu Aganipus tecket $y$ vor6yn, ${ }^{9} \mathrm{kyfla}$ (nn vu oe charyat. A dy[6]edut ${ }^{10}$ a wnaeth bot idal ef digabn o eur ac aryant, ac nat oed reit idab ef high-borm, noble orth dim namyn g(reic deledi $6^{11}$ dylyedasc y kaffei blant

Ch. 4.-1 y gelwis ynteu 2 y karei ef 3 ac y dywavt hitheu y karei 4 eiroet $5 \mathrm{om}$. a karyat h(no 6 ac ysef 7 yny 8 a Ilidial om. 9 hi euo 10 nal y karei 11 megys y choioryd y Ileill ${ }^{b}$ dyuarnei ynten hi na 12 dywabt 13 na rodei ef hi chanfei 14 megys y Meil 15 hihi nor Ileill 16 tremygu ef 17 nor Meil

Ch. 5.-1 tywyssogyon 2 y kyfoeth idao 3 tra uei 4 yn gobyl udunt bynteu "genatori 5 ac y dywaot ynteu $6 \mathrm{om}$. 7 gan y 8 y Пleill 9 ae thelediwet add. 10 dywedut 11 teledio

\section{Cadarmhän to strengtha, fortify, confirm, ratify, Affirm}


etifes m. an heir; (coll) heirs

yspeid 8 . a while, a eface of timo, respite

daw m. a son-in-law; pl. difyon

gor-essyn to inade, overrum

\section{LEAR AND HIS DAUGHTERS}

ohanei $^{12}$ yn etiued ar $y$ kyuoeth. Ac yn diannot ${ }^{13} y$ kadarnhalyt y briodas y rygtunt. ${ }^{14}$ kriedas fem.

6. Ac ym pen yspeit yg kylch diGed oes Lyr y goresgynnoys y dofyon y ran or kyuoeth ${ }^{1}$ a ganhalassei ${ }^{2}$ ef yn oraol droy hir $o^{3}$ amser; ac y rannassant y rygtunt yn deu hanner. Ac o gymodloned y kymerth Maglaon tylyssalic yr Alban Lyr attab a deugein marchalic y gyt ac ef, rac bot yn gesilid gantal bot heb varchogyon $\mathrm{yn}^{4} \mathrm{y}$ $\frac{\text { di-annod }}{\text { withour delay }}$ abour, towards $=$ t

\section{5} osgord. A gGedy bot $\mathbb{L y r}$ yn y wed honno gyt a Maglaon, blyghau a oruc Cordeilla ${ }^{5}$ rac meint oed ${ }^{6}$ o 10

josero retinue v. .140 th distaib varchogyon gyt ae that, ${ }^{7}$ ac rac eu goasanaethoyr Gynteu yn teruysgu y Mys. A dyoedut a wnaeth wrth y gor bot $y^{8}$ digaon deg marchaoc ar hugeint gyt ae that, a gellog y rei ereill ymdeith. A guedy dybedut hynny irth Lyr, Midias a oruc, ac ymadas a Maglasin, a mynet I

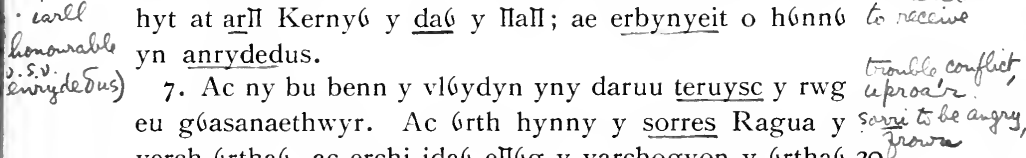

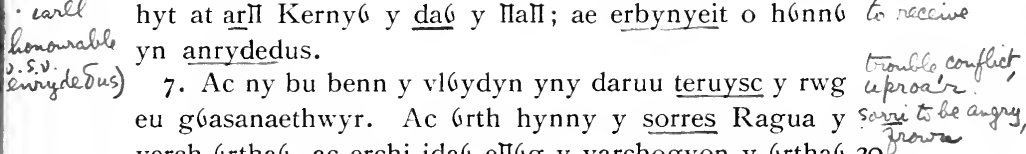

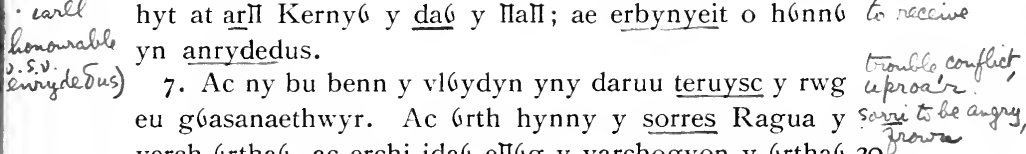

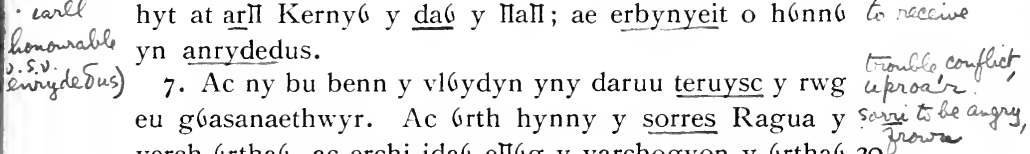
verch orthas, ac erchi idas enlg y varchogyon y orthas 20 eithyr pump marchasc ae goasanaethei. A thristas a iserout, move, onaeth Iyr yna yn vasir, a chychoyn odyna elchoyl hyt a second time, again at $\mathrm{y}$ verch yr hynaf idas, o dybygu trugarhau ohonaei to commiserate orthas oe gynnal ae varchogyon y gyt ac ef. Sef a wnaeth hitheu droy y Mit tygu y gyuoetheu nef a dayar 25 na chaffei ohir, ony ellygei $y$ holl varchogyon y orthas eithyr vn y gyt ac ef ae guasanaethei; a dy[6]edut nat oed reit y wr kyuoet ac euo vn Muossogroyd y gyt ac ef, na theulu namyn vn gor ae goassanaethei. A guedy na chaffei dim or a geissei gan y verchet, ellog y varchogyon 30 a onaeth eithir vn y gyt ac ef.

Ch. 5.-12 ohonei $18^{3}$ dianot $1 \AA^{4}$ y rydunt

Ch. 6. -1 y dofyon arna6 $y$ gyfoeth 2 gynhalassei $3 \mathrm{om} .4$ orth 5 Goronilla recte 6 a oed 7 gyt ac ef 8 from here to odyno (ch. 10, 1. 7) $\mathrm{om}$. 5 part with leave,

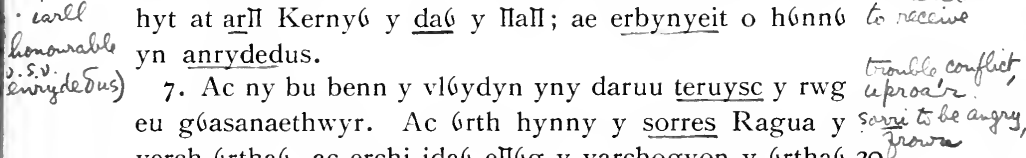

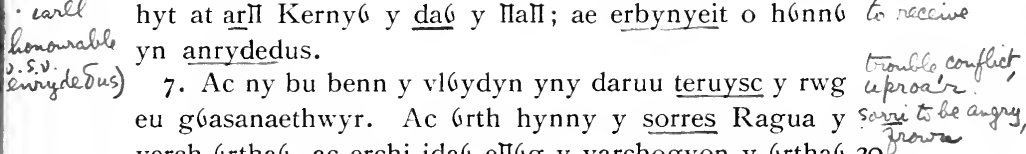

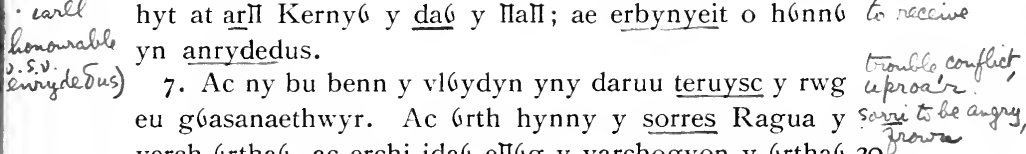

\section{senve)}

\section{cwily s shame gue $\delta$ f. frum v. $\& 7 \gamma$}


tilyng-dawd 8. dignily

medyant $m$. possession, powes, aultority

tristän to become sad, gricie

\section{LEAR AND HIS DAUGHTERS}

aurhile

8. A guedy bot velly rynald, dign ar gof a oruc y gyuoeth ae deilygdabt ae anrydet ae vedyant, a thristau yn valir,

ธ visit a medylyal gofoy y verch a athoed y Freinc idal.

Ac tacall to Pherey 0 unbrimf, unhind ovynhau hynny heuyt a onaeth rac mor digaryat y $=\pi$ 5 gellygassei ef hi y Grthat; ac eissoes ny alloys diodef y $t$ suffer to dishonour dianrydedu mal y daroed. A chych6yn tu a Ffreinc a Gnaeth.

9. A phan ytoed yn mynet yr llog ac na Gelei neb y gyt with two others ac ef namyn ar y drydyd, gan Gylar y dycaut yr gurylaw fates, fortumes ro ymadralid honn: "Ae ch6ich6i tyghetuenneu! pa le y accuslomed, usual kerdich ch6i dros abch gnotaedic hynt? Pa achals y level, even, kyffroassauch chli vivi eiryoet y ar vyg giastat detwydỳt? constint Kanys mby boen yo koffau kyuoeth giedy coller, no

Kanys may boen $y^{6}$ koffau kyuoeth gredy coller, no aughencetid
chytdiodef achenoctit heb ordyfneit kyuoeth kyn no wart, indugence
I5 hynny., May boen y6 genyf i yr arr hon goffav uyg kyuoeth am anryded yn yr amser honno, yn yr hon yd a many, mulitide; oed y sabl gan mil o varchogyon ym damgylchynu yn to surround y same, these kerdet y gyt a mi, pan vydon yn ymlad ar kestyll ac ar Ephender, ravage dinassoed ac yn anreithar kyvoeth vyg gelynyon, no $f_{2} ?$

20 diodef y poen ar achenoctit a onaeth y gGyr hynn y mi, y rei a uydynt yna dan vyn traen.a Och vi, a dGyweu pe.foduw jod nef a dayar! pa bryt y dab yr amser y galloyf y talu topayin returm elchilyl yn y gorthoyneb yr gGyr hynn? Och Cordeilta vyg karedic verch! mor wir $y^{6}$ dy ymadralid teu di, $=$ that it is 25 pan dyGedeist pany val y bei vyg gallu am medyant am
kyuoeth am jeuegtit, panyo velly y karut ti vyui! Ac
because of that, Grth hynny, tra vu vyg kyuoeth i yn gallu rodi rodyon, $=$ that it is 25 pan dyGedeist pany val y bei vyg gallu am medyant am
kyuoeth am jeuegtit, panyo velly y karut ti vyui! Ac
because of that, Grth hynny, tra vu vyg kyuoeth i yn gallu rodi rodyon, therefore paib am karei; ac nyt mi a gerynt namyn vy rodyon am

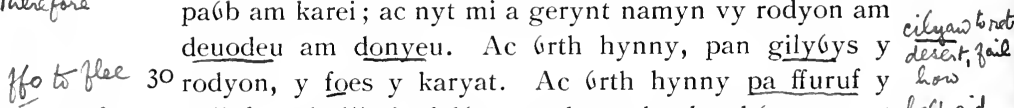
Folesech gallaf rackefilyd adoloyn nerth na chanhorthay y genyt help, aid 697c. ti, Grth rysorri yg kam ohonaf i Grthyt ti am dy doethineb dawn, 12 donyen sift. a leg. traet.

dedwy oyd happuess, telicity cyd- $\delta$ io $\delta$ ef to suffer

gor-Syfueid to experience, sujoy habitually. defaud, pl. defoden f. custom, practioe, halit, esdinance. 
all-tud a foreignes, alien; exile
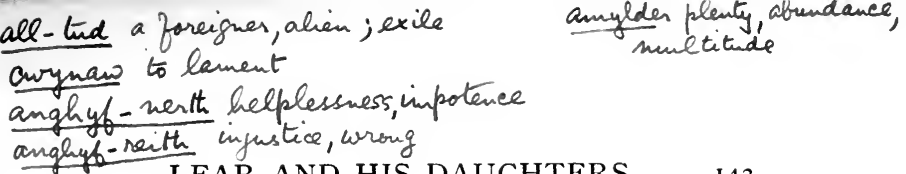

\section{LEAR AND HIS DAUGHTERS}

di, ath rodi yn dremygedic gan debygu bot yn waeth dy difed noth whioryd ereill, a thitheu yn well ac yn doethach noc Gynţy? Kanys gGedy a rodeis i o da a chyuoeth udunt h6y, y gonaethant h6y vyui yn allut ac yn echenalic om gollat am kyuoeth."

10. Ac y dan gliynal y aghyfnerth ofut yn y wed honno ef a doeth hyt ym Paris, y dinas yd oed y verch yndal. Ac anuon amylder o annercheu at $y$ verch a wnaeth $y$ dybedut y ryb agkyfreith a gyuaruu ac ef. A guedy dybedut or gennat nat oed namy[n] ef ae $[y]$ swein, sef a ro esqure wnaeth hit[h]eu anuon amylder o eur ac aryant, ac erchi mynet ae that odyno hyt y my(in ${ }^{1}$ dinas arall, a chymryt laf sick arnal y vot yn glaf, a goneuthur enneint idaw, ac ardymheru y gorff a symuda( ${ }^{2}$ dillat, a chymryt attal deugein marchabic ac eu kgeira $6^{3}$ yn hard ac yn syber $6^{4}$ oveirch $^{5}$ a 15 statel, wobbe dillat ac arueu; a giedy darffei hynny, anuon oe ulaen $a^{6}$ Aganipus vrenhin ac at ${ }^{6}$ y uerch y dyGedut y vot yn dyuot. A guedy daruot goneuthur kymeint ac a archyssei, ${ }^{7}$ anuon a (nnaeth Mythyreu ${ }^{8}$ at $y$ brenhin $^{2}$ ac at y verch ynteu $y$ dyciedut ${ }^{9}$ y uot $^{10}$ yn dyuot $^{11}$ ar y deugeinuet o varchogyon ${ }^{12} 20$

297e. gGedy $y^{13}$ rydehol oe dofyon o ynys Prydein, yn dyuot y to expel, bauish geissab porth gantunt 6ynteu ${ }^{13}$ y oresgyn y gyfoeth goresgen $\delta$ dracheuen. ${ }^{14}$ A phan gigleu y brenhin hynny, kych6yn a snaeth ef ae wreic ae deulu ${ }^{15}$ yn y erbyn ${ }^{16}$ yn anrydedus, honourable, woble, mal yd oed deilug ${ }^{17}$ erbynyeit ${ }^{18}$ gar a uei yn gyhyt ac euo ${ }^{19} 25$ to recive while yn vrenhin ar ynys Prydein. A hyt tra uu yn Freinc, y rodes y brenhin lywodraeth ${ }^{20}$ y gyuoeth ${ }^{21}$ ida6, mal $^{22}$ y bei hals idal caffel porth a nerth y oresgyn y gyuoeth drachefyn. ${ }^{23}$

I1. Ac yna yd anuonet goys dros Gyneb teyrnas Freinc v.w.y.p. 327

Ch. 10. - 1 hyt yn 2 y add. 3 kyweirao 4 yn hard sybero 5 veirych 6 ar 7 kymeint a hynny் $8 \Pi$ Iyr ${ }^{a}$ brenhin 9 ynteu y dywedut om. 10 ef $a d d .11$ yn dyuot om. 12 deugeinuet marehave $13 \mathrm{om}$. 14 kyuoeth drachefyn 15 teuln 16 yn erbyn Пyr 17 teilog 18 erbyneit 19 ef 20 Mywodraeth 21 kyuoeth 22 val 23 idav ef $a d d$.

$$
\text { teilwng }(y) \text { wonthy of, weet, fir for, desersum, acceptable }
$$




\section{I44 LEAR AND HIS DAUGHTERS}

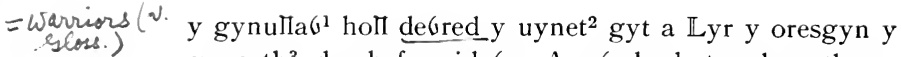
gyuoeth $^{3}$ drachefyn idas. A gGedy bot pob peth yn barabt, kychiyn a oruc $\mathbb{L} y r$ a Chordeilla y verch ar $\Pi u$ honn' gantunt, a cherdet yny doethant y ynys Prydein, wittont delay 5 ac yn diannot ymlad ae dofyon a chael ${ }^{4}$ y fudugolyaeth. gue $\delta$ t 5 befir, A gredy gGedu pob peth or ynys idal ef ${ }^{5} \mathrm{i}^{6}$ bu var6 $\mathbb{L}$ yr yn y dryded vl6ydyn; ac y bu [var6] $]^{7}$ Aganipus vrenhin Freinc. Ac yna y kymerth Cordeilla Mybodraeth y in. 83. deyrnas ${ }^{8}$ yn y llab ehun. Ac y cladoyt Lyr y myon a subterraveam Io dayardy $a$ a onaeth ehun y dan auon Sorram. Ar demylb vault $696 \mathrm{~A}(\mathrm{~b})$ honno ry inathoed $^{9}$ yn anryded yr dus a elsit yna ${ }^{10}$ Plup. $\{142$ guyl a f. Festiol, Bifrontisiani. A phan delei wylua y demyl11 honno, y wateh, ward deuei holl grefydayr y dinas ar wlat oe anrydedu. Ac y blegin, inaugurate dechreuitc pob gGeith or a dechreuit hyt ym pen $y$ I 5 vlaydyn. A gGiedy galedychu pump ${ }^{12}$ mlyned o Gordeilla

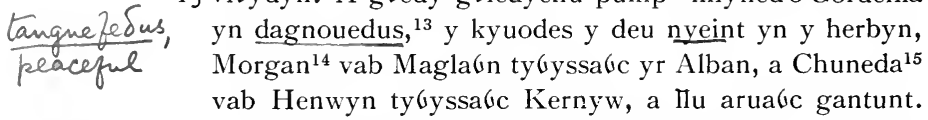

seize, capture A daly Cordeilla a wnaethant ae charcharu. ${ }^{16}$ Ac yn y 20 carchar honn $6^{17}$ o dolur kolli y kyuoeth ${ }^{18}$ y gonaeth ehun y Meith. death

Ch. 11.-1 y add. 2 orth eu hellog y 3 kyfoeth 4 chaffel 5 om. 6 y 7 varo 8 teymas a dayarty ${ }^{b}$ temyl 9 a wnathoed ehun 10 ena 11 demhyl cdechrewit 12 pvm (but a stroke has been added below as if to change $\mathrm{v}$ to $\mathrm{y}) 13$ dagneuedus 14 Margan 15 Chueda $16 \mathrm{~A}-$ chareharu : ae daly ae chareharu 17 hvnv 18 ehyfoeth 


\section{dayoni gooduess, virtúe, valour.}

anyanawe natural, native, imate

rad ?. grace, favour, blessing

ar-Serchocän ts exalt, honour

dyffygyaw to fail, lack

\section{THE STORY OF ARTHUR.}

From the Red Book of Hergest.

I. A gGedy marø Uthur Pendragon yd ymgynullassant holl wyrda ynys Prydein, jeirl a baroneit ${ }^{1}$ a marchogyon vrdajol ac escyb ac abadeu ac athrabion hyt yg Kaer Vudei. Ac o gytsynyedigaeth paßb yd archyssant y Dyfric archescob Kaer Lion ar Wysc vrdas Arthur y vab Ordawl
endacied ynteu ${ }^{2}$ yn vrenhin. Ac eu hagen ae kymhellei y hynny. Kanys pan gigleu y Saeson marbolyaeth ${ }^{3}$ Vthur Pendragon, ${ }^{4}$ yd ellygyssynt Gynteu genadeu hyt yn Germania

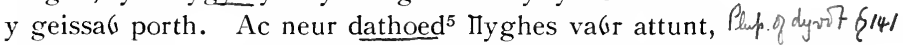
a Cholgrim yn tybyssabic ${ }^{6}$ arnadunt. Ac neur daroed io v.p.60 udunt goreskyn ${ }^{7}$ o Humyr hyt y mor a Chatyneis ${ }^{8}$ yn $y$ gogled. Sef oed hynny y dryded rann y ynys Prydein. A gGedy gGelet o Dyfric archescob drueni y bobyl ae twemi wretchedress, estitution hymdiuedi, ef a gymerth escyb y gyt ac ef, ac a dodes coron y teyrnas am ben Arthur. A phymthegmlisyd oed up. Snd. Pass. Arthur yna, ac ny chlyusit ar neb arall eiryoet ${ }^{9}$ y deuodeu o debred a haelder a oed arnal ef. Idal ef hefyt yd Sichester consent 5 ordain inghen weed,
necessity phenperf 
talym m. a while, period; ar dalym for a time ar-gywe du $(y)$ to injure, hurt cydymdeithocär to accompany, associate witt

\section{THE STORY OF ARTHUR}

to whom $\left\{80 \times, 4\right.$ py di6 bynhac y bo haelder anyana61 y gyt a phrofedic ${ }^{15}$ molyant praise, volyant, kyt bo eisseu arnal ar dalym, ${ }^{16} \mathrm{yr}$ hynny ny at constantwant Dur wastat aghenoctit y argy6edu idar.

2. Ac Grth hynny Arthur, kanys molyant a getym5 deithockaei ${ }^{1}$ haelder a dayoni, Munyaethu ryfel a oruc ar y tharrange, Saeson, hyt pan vei oc eu golut hay y kyfoethogei ynteu right
Eef-tadawl
inheritod y teulu ae varchogyon. Kanys iafinder a dyskei hynny idal; kanys ef a dylyei o dreftatall dylyet holl lywodraeth ynys Prydein. A chynnuПab a oruc ef yr holl ieuenctit Io a oed darystygedic idal ef, a chyrchu parth a Chaer Effrabc. ${ }^{3}$ A gredy gaybot o Golgrim hynny, kynultal a oruc ynteu y Saeson ar Yscotteit ar Ffichteit, ac y gyt cinumerable, $\mathrm{ac}^{4}$ aneiryf luossograyd nifer gantal dyuot yn erbyn
counters; $a$ counters; $a^{\prime}$ counbers Arthur hyt yg glan Dulas. A gGedy ymgyfaruot yna $=$ in. Dub-

150 bop $^{5}$ parth y dygGydassant llaver or deu lu. Ac or a rimerer ham. diwed Arthur a gafas y vudugolyaeth. A ffo a oruc Colgrim $^{6}$ y dinas Kaer Efrabc. Arthur ae lu a gychcollecr,eall gad 3 sg
pres. of
gadu Ceave
adtor, pernit
sarrange,
hifpose, array 
by Sin $f$. a troop, diviscion of an army

eu herbyn, ac eu ragot y nos honno y fford y doynt. A 5 waylay; am ambuel gGedy kaffel o Gadır guybot y fford y doynt y gelynyon, eu kyrchu a oruc Kador yn deissyfyt. A griedy bribau breah in peeces, eu bydinoed ac eu hyssigab a Mad Maber onadunt, kymell to shatter y Saeson a oruc ar ffo.

4. Ac Grth hynny diruabr dristyt a gofal a gymerth Bald $6 f^{1}$ yndab, ${ }^{2}$ Grth na alloys eП $6 g^{3}$ y vrabt or guarchae yd oed yndas. A medylyas a oruc py wed y gallei gaffel ${ }^{4}$ kyffur $^{5} y^{6}$ ymdidan ae vrabt; kanys ef a dybygei y kaffei bop $^{7}$ un onadunt ${ }^{8}$ ell deu rydit a g(raret yn hollabl, pei ${ }^{9}$ io completeff, allogestar keffynt ymdidan y gyt. A guedy na chaffei ffordarall Schave, yn y byt, eillab y wallt ${ }^{10}$ ae varyf a oruc, a chymryt telyn jugglen yn y lab, ac yn rith erestyn a glaryyd dyuot ym plith y camp Mu ar Muesteu. Ar clymeu ${ }^{11}$ a ganei ef a dangossynt y vot yn telynyabr. ${ }^{12}$ Ac or diwed guedy na thybygei neb 15 -

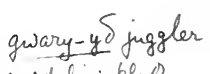
$y$ uot ef yn tywyssauc falst mal yd oed, nessau a oruc parth a muroed y gaer dan ganu y telyn. A gredy y adnabot or g6yr o vyon, y dynu ${ }^{13}$ a orugant orth raffeu y mysin. A gliedy guelet ohonal y vrabt, ymgaru a to caressoue andther orugant megys na ry ymwelynt ${ }^{14}$ drGy laGer o yspeit kyn 20 no hynny. Ac val yd oedynt uelly yn medylyau ac yn keissal ystryb py wed y gellynt ymrydhau odyno, ac yn tofree oneself from annobeithaf oe rydit, nachaf eu kenadeu yn dyuot o Germania, a whe chan Пlog yn Maßn o varchogyon aruabc gantunt, a Cheldric yn dywyssalc arnadunt, ac yn 25

toland disgynu yn yr Alban.

5. A guedy clybot hynny o Arthur, ymadals a or uc ynteu

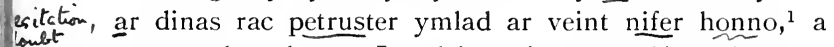
to leave mynet odyno hyt yn Lundein. Ac yno gals attab a oruc holl wyrda y deyrnas yscolheigon a Meygyon, ac $3^{\circ}$ 
gounes f. oppression, tyranny

\section{eisted with $y$ gaen $t$ besiege the city}

gua-sgaud shellen, protection

\section{8 \\ THE STORY OF ARTHUR}

Es consuct

ymgyghor ac Gynt beth a wnelynt ${ }^{2}$ am hynny. Sef a gabssant o gyghor y konsli húnn6; anuon kenadeu a orugant hyt ar Hobel ${ }^{3}$ vab Emyr Lydad, brenhin Brytaen Brittaxy Vechan, y uenegi ida6 yr ormes a dathoed gan y Paganyeit $5 \mathrm{ar}^{4}$ ynys Prydein. Kanys nei (uab $\mathrm{y}^{5}$ ch(iaer)oed Howel ${ }^{3}$ y Arthur. A gGedy clybot o Howel ${ }^{3}$ y ryfel ar aflonyduch disturbanc a oed ar y ewythyr, erchi parattoi Myges a oruc, ${ }^{6}$ a chynullas pymtheg mil o uarchogyon aruabc. Ac ar y goynt kyntaf a gafas yn y ol, y deuth y borth Hamont Io yr tir $y^{7}$ ynys Prydein. Ac Arthur ae haruolles ynteu or enryded y guedei aruoll gar kyfurd a honna; ac yn vynych ymgaru ${ }^{8}$ bop eilwers. alternately

6. Ac odyna goedy Mithrab ychydic o dieuoed, ${ }^{1}$ bynt a gyrchassant parth a Chaer LGytcoet, yr hon [a elwir $]^{2}$ hurv.wite 2,p.249 is Lincol yr abr honn, ac yssyd ossodedic yn y wlat a elwir Lindysei ar benn mynyd rog doy auon. Ac orth y gaer honno yd oed y Paganyeit yn eisted. A gliedy eu dyuot yno y gyt ac eu holl niferoed, ymlad a orugant ar aughlywedig Saeson. Ac aglywedic aerua a Gnaethant o honunt. ${ }^{3}$ unbeard of, unusual 20 Kanys chwe mil onadunt a dygoydassant yn yr un dyd hinns. Rei oc eu Mad, ereill oc eu bodi ${ }^{4}$ a gollassant eu heneideu. Ac orth hynny rei ${ }^{5}$ ereill yn gyflaun o ofyn adal y dinas a orugant, a chymryt eu $\mathrm{ffo}^{6}$ yn Me diogelich safecty ger-ffowys to cease, udunt. Ac ny orffobysoys Arthur oc eu hymlit hyt ${ }^{7}$ yn wood, grove, buch 25 MGyn Kelydon. Ac yno ymgynull o bop Me a orugant

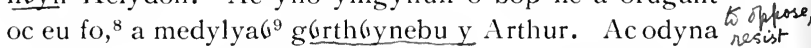
gGedy dechreu ymlad, aerua a onaethant or Brytanyeit

Kolefend
wood strothe, blow,
cast. Sentertain
receive 
$\frac{\text { tir-diwollawdr }}{\text { cy-war-sangu to trample upon, oppress, crush }}$

\section{THE STORY OF ARTHUR}

149

A phan welas Arthur hynny, yd erchis ynteu trychu y coet or parth honns yr Moyn, a chymryt y kyffyon stech, trimk, stem hynny ar trassprenneu ${ }^{12}$ ac eu gossot yn eu kylch, ac eu guarchae yno megys na cheffynt vynet odyno, yny ymrodynt idas, neu yny vydynt veirs o newyn. A goedy daruot goneuthur y kae, $y$ dodes Arthur y cae encloure,fence varchogyon yn vydinoed yg kylch y Mloyn. Ac yno y buant uelly tri dieu a their nos. A phan welas $y$ Saeson nat oed dim bliyt gantunt, rac eu mars oll o newyn Gynt a odologyssant ${ }^{13}$ y Arthur $y^{14}$ gellog yn ryd y eu Mlogeu y uynet y eu golat; ac adas idas ynteu eu heur ac eu haryant ac eu holl sult, a theyrnget idas bop ${ }^{15}$ bloydyn o Germania; a chadarnhau hynny gan rodi guystlon. Ac Arthur a gauas yn y gyghor kymryt guystye hostage hynny y gantunt, ac eu gellog ${ }^{16}$ y eu Mogeu.

7. Ac ual ${ }^{1}$ yd oedynt ${ }^{2}$ yn roygab moroed yn mynet tu ae g(slat, y bu ediuar gantunt g(ineuthur ${ }^{3}$ yr amot honnds covenan, compact ac Arthur; a throssi eu hoyleu drachefyn parth ac ynys sail , Prydein, a dyuot y draeth Totneis ${ }^{4}$ yr tir, a dechreu anreithas y goladoed hyt yn Hafren, a Mad y tir-20 diwollodron a orugant. Ac odyna y kymerassant eu hynt hyt yg Kaer Vadon, ac eisted orth y gaer, ac ymlad a hi. A gledy menegi hynny y Arthur, ryfedu a oruc $\hbar$ wondes leception, meint eu toy II ac eu hyskymundast, ${ }^{6}$ ac yn diannot crogi villaing eu goystlon. Ac ymadab a oruc ar Yscoteit ac ar 25 Ffichteit yd oed yn $y^{7}$ kywarsagu. A bryssyal a oruc hasten destroy, y distryo y Saeson. Goualus oed am adab Howel ap anxious eny heavy Emyr Lydar yn glaf yg Kaer Alclut o Grthrom heint. Sickmess, disease thast Ac or dibed guedy dyuot hyt y Me y guelei y Saeson, y dywabt ef ual hyn: "Kany" bo teilug gan yr 30 counsed ysgymunedigyon Saeson ${ }^{10}$ cads ffyd orthyf $i,{ }^{11}$ miui

(Ch. 6). 12 travs, 13 adologyssant, 14 eu, 15 heuỳt pop, 16 gollvg

(Ch. 7). 1 mal, 2 oedyn, 3 wneuthur, 4 traeth tutneis, 5 hyn, 6 hyscum. yndact, 7 yny eu, 8 hvel mab, 9 kyny, 10 tryllwyr anudonavl add., il vrthym ni? 
gwarad wy $\delta$ m. disgrace, shame, reproach

guir-abenth a true sacrifice

\section{0 \\ THE STORY OF ARTHUR}

likewise

a gadiaf ffyd Grth Dub; ac y gyt a hynny oe nerth ${ }^{12}$ ynteu a dialaf hedis waet vyg kiøtaltwyr arnadunt. ${ }^{13}$

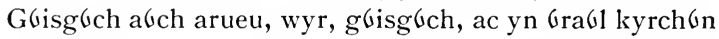
bradur a fraitor y bratwyr hynn. Heb petruster ${ }^{14}$ gan ganhorthay Crist $5 \mathrm{ni}$ a orfydon.' I Pl. Fur. of gorfod overcome, conger

8. A gGedy dywedut o Arthur hynny, Dyfric archescob Kaer Lion ar Wysc a safald ar ben bryn goruchel, a dywedut ual hynn a oruc: "Ha wyrda," heb ef, "y rei exalted, woble, yssyd arderchabc o gristonogail ffyd ohonalich, illustrious Io kyuodich; koffebch waet abch kibtawtlyr, yr honn yssyd ellygedic drGy urat y Paganyeit racco; kanys tragyGyda(@) waratwyd $\mathrm{y}^{6} \mathrm{y} 6 \mathrm{ch}$, onyt ymrodich $\mathrm{y}$ amdiffyn aich golat ach rydit. Ac orth hynny ymledich dros alich yourseloe gulat, ac or byd reit ywch, diodefoch ageu drosti

I 5 Kanys yr agheu honno a vyd budugolyaeth a buched yr eneit. $P$ by bynhac hedis a el y agheu, ef ehunan eternal
if you do
nof deviole
yourseloe life saliation 3 sg. Pres. Ind of a ymryd yn wiraberth y Dub, y gor a vu teilog gantad rodi y eneit dros y vrodyr. Ac Grth hynny poy bynhac ohanaøch a lader yn yr ymlad honn, bit yr agheu honno $y_{m-n}-n_{0} \delta_{i}$

penyd penance 20 yn benyt idal ac yn vadeueint oe bechodeu, y dan amot nas gochelo, or dambeina y dyuot."

9. A guedy kymryt bendyth y gor honno, bryssyal a oruc palib y wisgal eu harueu ymdanunt, ac ufudhau y gymenediweu yr archescob. Ac yna Arthur a wiscaud coat of mail 25 ymdanab Muruc a oed teilog y vrenhin. Penffestin eureit $3 s$. Impen remission Kobley helmet shoulden gymerth ar y ysgiyd, yr honn a elbit Gienn, yn yr hon yd oed delo yr argloydes Veir yn yskythredic; kanys ym yngastrait pop yg a reit y galbei ef arnei ac y coffei. Ac a roymbyt difficulty plistress 30 a Chaletu61 $\mathrm{ch}^{*} \mathrm{y}$ gledyf goreu, yr h(inn a wnathoedit yn a lance, spear tale ynys Avallach. Gleif a deck[a]a@d y deheu ef, yr honn a eloit Ron; vchel oed honno a Mydan ac adas y aerua. a Sas fir,

(Ch. 7). 12 ae y gyt ac nerth, 13 arnadunt $\mathrm{ry}, 14$ a heb petrus

meed weecssi! trouble

ymynediw, - en: a command, injunction

a Sassu 5 fit, adjust

ruymano to bind, gird

teccän Kadom, decorate 


\section{glew brave, stour; a brave man, hero. cedormid strength, force, securit, violence}

Ac odyna guedy Munyaethu y bydinoed o bop parth, inclom 'hair y Saeson yn hercyd eu deuabt kyrchu yn leb a onaethant, ac ar hyt y dyd yn Grabl gorthoynebu yr Brytanyeit. Ac to oppose, rescst

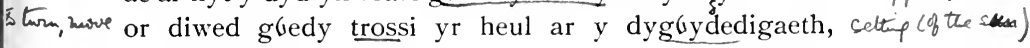
achub mynyd mabr, a oed yn agos udunt, 5 a onaeth y Saeson, a chynal honno yn Me castell udunt; to trust a chan ymairet yn amylder eu nifer tybygubot yn digaon vdunt o gedernit y mynyd. A guedy dayn or heul $y$ elain, next dyd arall rac Gyneb, Arthur ae lu a eskynnalod pen y mynyd. Ac eissoes Maluer o wyr a golles ef ; kanys hals io oed yr Saeson o penn y mynyd argywedu yr Brytanyeit $t$ infure, hur [noc yr Brytanyeit] yg gorthoyneb y mynyd argywedu facip the mountain yr Saeson. Ac or diwed gan vayhau grym a Mafur, gliedy caffel or Brytanyeit penn y mynyd, yn y Me Gynt a dangossassant eu deheuoed yr Saeson. Ac yn erbyn I 5

hynny y Saeson yn Gra(1) a ossodassant eu bronoed yn eu gorthoyneb synteu, ac oc eu holl angerd ymgynhal wehemence, force yn eu herbyn. A guedy treulas Maser or dyd uelly, Midia؛ a oruc Arthur rac hoyret y goelei y vudugolyaeth yn dyuot idas. Ac ar hynny noethi Caletublch*a oruc, 20

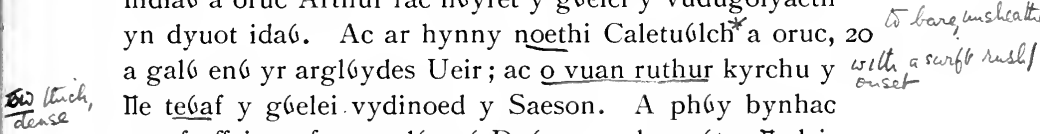
a gyfarffei ac ef, gan als enc Duba o vn dyrnabt y Madei. Ac ny orffolyssald ar vn ruthur honno, hyt pan ladald a Chaletfolch ehun trugein wyr a phetoar can $6 \mathrm{r}$. $\mathrm{A} 25$

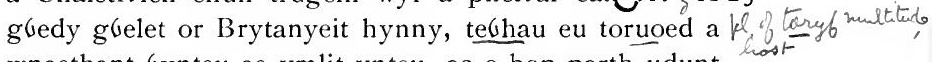
wnaethant Gynteu ae ymlit ynteu, ac o bop parth udunt goneuthur aerua. Ac yn y lle y dygoydassant Golgrim a Baldølf y vrabt a MaGer o vilyoed y gyt ac Gynt. A phan welas Cheldric perigyl y gedymdeithon, yn y Me 30

delay heb annot ymchoelut a oruc y gyt ar rei ereill ar ffo.

I0. A guedy caffel o Arthur y uudugolyaeth honno,

a eno duv : MS. duo duv.

\section{Caled - fwich (q. calad-belg) hand in makif nuteles. (the name of Mrtturis swond)}

tewhön to Anchen, close of the ranks 
menegi t make hnown, declare

ym-lyme tofollow, pursue

152

ef a erchis y Gador iarn Kerny' erlit y Saeson, hyt tra vryssyei ynteu yr Alban. Kanys menegi ar daroed idal ry dyuot yr Yscotteit ar Ffichteit y ymlad a Chaer Alclut, y the yd adaissei ef Howel y nei yn glaf. Ac 5 Grth hynny y bryssyei ynteu yno rac caffel y gaer arnab. Ac odyna Kador tybyssabc Kernya a deg mil y gyt ac ef a ymlynalid y Saeson. Ac nyt yn eu hol yd aeth, ¿size salety, sccurity namyn achubeit eu Mogeu yn gyntaf a oruc, rac caffel onadunt diogeloch nac amdiffyn or Mlogeu. A guedy ro caffel eu Mlogeu ohonab, dodi a oruc y marchogyon aruabc goreu a oed ar y hels yndunt, rac caffel or Saeson ford udunt, os yno y kyrchynt. A guedy daruot cadarnhau y Ilogeu arnunt uelly, ar vrys ymchoelut a oruc ar y elynyon ac eu Mad heb drugared, gan eilensi

I 5 gorchymynneu Arthur amdanunt. Rei o deudyblic boen a gy (arsegit, a rei onadunt o oergrynedic callonneu a ffoynt yr coedyd ac yr ח16yneu, ereill yr mynyded ar gogofeu y geissab yspeit y achbanegu eu hoedel. Ac ordiwed guedy nat oed udunt neb ryo diogeloch, yr hyn respite $=\frac{\text { diengis } 35.20 \text { a dihegis onadunt yn vrifedic, Gynt a ymgynullassant } a}{\text { prev. odi-ange, hyt yn ynys Danet. A hyt yno tybyssabc Kernyb ae }}$ Stuffie, donble, wo - joe Rearfuch lifetime Hech toge $\pi$ hyt yn ynys Danet. A hyt yno tybyssabc Kernyb ae hymlynald gan eu llad. Ac ny orffolyssald hyt pan las Cheldric; ac eu kymell bynteu on y lab gan rodi goystion.

25 II. Ac yna guedy kadarnhau tagnefed ar Saeson, yn y Me mynet a oruc yn ol Arthur hyt yg Kaer Alclut, yr hon ry daroed y Arthur y rydhau y gan yr Yscotteit ar Fichteit. Acodyna y kyrchalod Arthur ae lu hyt y Mureif, y wlat a eloir o eno arall Reget. Ac yno y guarchaeald besieged 30 ef yr Yscotteit ar Fichteit, y rei kyn no hynny a ymladyssynt yn erbyn Arthur. A gledy eu dyuot ar ffo hyt y wlat honno, aynt a aethant hyt yn $\mathbb{L}$ yn

a MS. ymgymuIlassant.

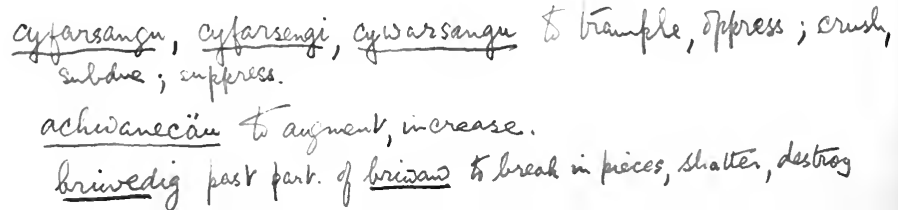




\section{$x$ cenyat in perf aid. $3 p l$. of canu $\$$ sing, celebrate in song, recite, ploy damwein accident, chance, fortume, event anghyf-yeitt alien in speech, fóreign, pl. - y Syou}

\section{THE STORY OF ARTHUR}

Lumonay, a chymryt yr ynysed a oedynt yn y Myn yn gedernit udunt. Kanys tri ugein ynys a oedynt yn y Myn, a thri ugein karrec, a nyth eryr ym pop karrec. A rei hynny pop Kalan Mei a doynt y gyt. Ac ar y Meis a

${ }^{x}$ genynt yna dynyon y wlat honno a adnebydei y dambeineu a delei yn y vloydyn rac Gyneb. Ac y gyt a hynny tri ugein auon a redei yr Пyn. Ac ny redei or Myn namyn vn avon yr mor. Ac yr ynyssed hynny y foyssynt $y$ gelynyon y geissal amdiffyn o gedernit y Myn. Ac ny vice

$5=$ coll. men jollowing, next dygrynoes udunt namyn ychydic. Kanys kynullab ro sone, a hitte a few Mogeu a wnaeth Arthur, a chylchynu yr avonoed ar Myn, surround, encmpars, hyt na chaffei neb vynet odyno. A phymtheg ni[w]arnabt y bu yn eu gorarchae uelly, hyt pan vuant veiro hyt ar $X$ vilyoed.

12. Ac mal yd oed Arthur yn eu guarchae uelly, i 5 nachaf vrenhin IGerdon yn dyuot a Myghes gantal ac amylder o bobloed achyfyeithydyon yn borth $\mathrm{yr}$ Yscotteit ar Freinc. Ac Grth hynny ymadab a oruc Arthur ar Myn, ac ymchoelut y arueu yn y Goydyl, ar rei hynny gan eu Mad heb drugared a gymheПloys ar ffo 20 y eu gulat. A guedy y uudugolyaeth honno ymchoylut draegefyn elchoyl y vynnu dileu kenedyl yr Yscotteit ar Fichteit hyt ardim. A goedy nat arbedei neb megys y keffit, ymgynnullar y gyt a wnaethant escyb y druan wlat honno y gyt ae hyscolheigon or a oed darystygedic 25 sulyect udunt, y gyt ac escyrn y seint ac eu creireu. Ac yn plof ereimarelic troetnoethon y deuthant hyt rac bron Arthur, ac erchi y drugared dros atlibin y bobyl honno, ac ar eu glinyeu ad-libin a wreteled pl. ob a
scumane wedianto y wedias hyt pan drugarhaei orthunt. Kanys digalon commiserate o berigyl a droc ry snadoed udunt; kanyt oed reit idas 30 dilit hyt ar dim yr hyn a dihagyssei onadunt. A gGedy erchi trugared onadunt ar y wed honno, wylas o warder a oruc Arthur, a rodi yr gGyrda seint hynny eu harch.

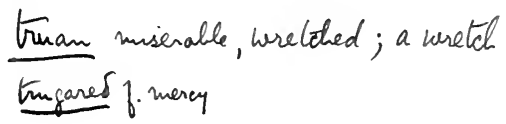

is pursue extinction vander

to aunihilate 5 spare, save 


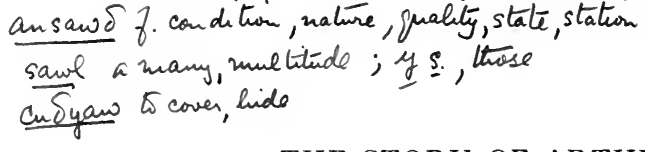

\section{54}

\section{THE STORY OF ARTHUR}

13. A gGedy daruot $a$ hynny, syMu a oruc Hobel uab \$gage, look Ewouden, maruel Emyr Lydas ac enryfedu ansalid y Myn, y sall avonoed ar sabl ynyssed ar sabl gerric ar sabl nythot eryrot a oed yn y Myn. Ac ual yd oed yn ryfedu hynny, Arthur a dybalit 5 Grthas bot Myn arall ynly Glat honno oed ryfedach no honno. Ac nyt oed bell odyno, ac ugeint troetued yn pedr-ougylspare y hyt, a vgeint yn y Met, a hynny yn bedrogyl; a pe.qkysg fish phedeir kenedyl o byscalst amry6 yndi; ac ny cheffit IO arall," heb ef, " yg Kymry ar lan Hafren, a dynyon y wlat honno ae geilo Lyn Lialn. Ar Myn honno, pan vo y mor yn Malon, y kymer y dofar yndal ac y amachstrom, whilferol morger(iyn, hyt na chudyo y glanneu. Ac y gyt ac yd cauldron] ymchoelo y mor draegefyn y dreial, y garthyt y Myn y t5 throw, east I 5 dofor a gymerei yndi, ac y boro ohonei megys mynyd, hyt pan el dros y glanneu. Ac o damweinei yna vot neb yn sefyll ae wyneb att y Пlyn, o chyuarffei dim o

spray 35 gmp. Ind of asgeПwrych honn hyt nas sucknei y Myn ef yndal. Ac o bydei ynteu ae 20 gefyn attab, yr nesset vei idi yn sefyll, nyt argybedei injure, hurt idal dim."

Tumahepeace,pacify I4. A gliedy hedychu ar Yscotteit y brenhin a aeth E. celcheret the fectival hyt yg Kaer Efrabc, y anrydedu goylua y Nadolic a oed yn agos. A phan welas ef yr egloysseu gbedy eu distryb 25 hyt y Maør, doluryal yn uabr a oruc. Kanys guedy to expel,bamise dehol Sanson ${ }^{\circ}$ archescob ar gGyrda mabr enrydedus ereill y gyt ac ef, Mlosci yr egloysseu ar temleu a Gnathoed y Saeson, a distry' guassanaeth Du' ym pop Me. Kanys phunderens pan deuthant yr anreithwyr hynny, y foes Samson archescob a seith escyb y gyt ac ef hyt yn $\mathbb{L} y d a d$. Ac 30 yno yn enrydedus yd erbynybyt hyt y dyd dicethaf oe

${ }^{a}$ MS. daruabt. $\quad{ }^{b}$ MS. dillan. $\quad$ eleg. Samson.

\section{triaw to ebb}

gurthyd $3 \mathrm{sg}$. pr. ind. of gurthod to give back, rgiet, renounce. 
a Surnaw S adorn, decorate

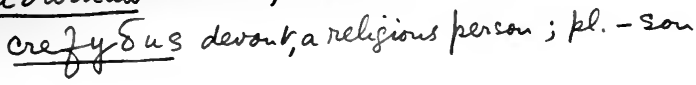

\section{THE STORY OF ARTHUR}

buche $\int$. vuched. Ac yno gredy gals paib y gyt or yscolheigon ac or bobyl o gyt gyghor paøb yg kyt ef a ossodes Priaf y gaplan ehunan yn archescob yg Kaer Efralc. Ar egloysseu dioreidedic hyt y MaGr ef ae hatnewwydays, ac ae hadurnabid ${ }^{a}$ o grevydusson genveinoed o wyr a 5 pl.genfent, a guraged. Ar gayrda bonhedigyon dylyedaic a ry hish convent nole deholassei y Saeson ac a ducsynt tref eu tat, ef a rodes? 3 P\&. Plupers. 8 o

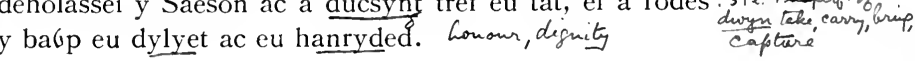

15. Ac ym plith y rei hynny yd oedynt tri broder, a hanhoedynt vrenhinabl dylyet, nyt amgen, Leu uab Io namely Kynuarch ac Vryen uab Kynuarch ac Arain uab Kynuarch. A chyn dyuot gormes y Saeson, y rei hynny oppression, tyramy a dylyynt tyGyssogaeth y goledi hynny. Ac yr gGyr pl.of gulad hynny, megys y balp or dylyedogyon ereill, ef a vynnaid talu eu dylyet. Ac 6 rth hynny ef a rodes y i5 Arain vab Kynuarch Yscotlont. Ac y Vryen y rodes Reget dan y tervyneu. Ac y Leu uab Kynuarch (y gar yd oed y chwaer gantal yr yn oes Emrys Wledic, ac yd oed idar deu vab ohonei, Gwalchmei a Medra(t), y honno y rodes tyw[y]ssogaeth Lodoneis a galedi ereill a 20 berthynei attei. Ac or diGed guedy dayn yr ynys ar y theruyneu yn hollabl ar $\mathrm{y}^{b}$ hen teilygdabt ae hedychu, ef a gymerth gareic. Sef oed y henG Guenhbyfar, yr honn a oed o uonhedickaf genedyl gGyr Rufein, ac a uagyssit yn Mys Kadar iarl Kerny6. Pryt honno ae 25 fryd aspect, benty beanty thegach a orchyfygei ynys Prydein. gorehyfysu to overcome, concuer

16. A phan deuth y gGanGyn araf ${ }^{x}$ rac Gyneb, ef a following, wert barattoes Ilyges ac a [a]eth hyt yn IGerdon. Kanys honno a vynei y goreskyn idal ehun. Ac ual y deuth yr tir, nachaf Gillambri vrenhin IGerdon ac amylder $[0]_{30}$ bobyl gantal yn dyuot yn erbyn Arthur wrth ymlad ac ef.

a MS. hardurna@d. ${ }^{b}$ ar $\mathrm{y}:$ ae MS.

\section{$x$ araf slow, gentle, mild}


noelt wahed, bare, unpritécted, unarmed

anghreiftr example

\section{6 \\ THE STORY OF ARTHUR}

A gGedy dechreu ymlad, yn y Me y bobyl noeth diarueu unarmed a ymchoelyssant drachefyn ar ffo yr Me y keffynt wascast ac amdiffyn. Ac ny bu vn gohir yn dala Gillamori ae because of that, gymell Grth ewyllys Arthur. Ac Grth hynny hol therefore 5 tywyssogyon IGerdon rac ofyn a doethant, ac o agreifft of then oun free wiel a ymrodassant oc eu bod yn wyr y Arthur.

I 7. A gGedy daruot idab oresgyn holl IGerdon ae hedychu, Arthur a aeth hyt yn Islont yn y lyges. A guedy ymlad ar bobyl honno, ef ae goresgynnuys. Ac odyna dros yr ro ynyssed ereill yd aeth y glot ef, ac na allei vn teyrnas gorthGynebu ida6. Doldan brenhin Godlont a Goinwas vrenhin Orch oc eu bod a deuthant y Grhau idal gan the Qrkney dalu teyrnget idas bop bloydyn. Ac odyna gGedy Mithras y gayaf honno heibas, Arthur a ymchoelald I 5 drachefyn hyt yn ynys Prydein, y atnelydu ansald y deyrnas ac y gadarnhau tagnefed yndi. Ac yno y bu deudeg mlyned ar vntu. ar a stretch

I8. Ac yna [y] gobahad attal marchogyon debr clotuabr o arall wladoed a phell teyrnassoed ac amylhau lmyy,malice $20 \mathrm{y}$ deulu, megys yd oed kyghoruynt gan teyrnassoed pel magnificence, poup y wrthal meint clot y lys, a ryodres
to compare, imitate A cheissal a wnaei balp kyffelybu a discyblu y wrth lys $\varangle$ shing, minta Arthür, ac y Grth y varchogyon ae deulu. Kanyt oed dim gan vn dylyedalic yn y teyrnassoed pell y orthunt, S. compare 1 irt 25 ony ellynt ymgeffelybu a marchogyon Arthur oc eu oneself, vie (with) g(jiscoed ac oc eu harueu ac oc eu marchogaeth. A fly gredy ehedec y glot ae volyant ae haelder dros eithafoed y byt, ofyn a gymerassant brenhined tramor teyrnassoed racdab, rac y dyuot y oresgyn eu kyfoetheu ac eu pl.of gofal, m. 30 g(iladoed. Ac Grth hynny rac gofeilon a phrydereu, sef a auxiety onaei palb ohonunt atnewydu y keyryd ar dinassoed ar

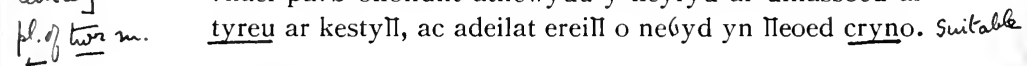
a MS. rootdres. 
Sef achals oed hynny, o delei Arthur am eu penn, megys y keffynt y Meoed kadarn hynny yn amdiffyn, or bei reit.

19. A gGedy glybot o Arthur bot y of yn velly ar balip, ymardyrchauel a oruc ynteu a medylyal goresgyn yr holl Europpa. Sef oed hynny, trayan y byt. Ac odyna 5 parattoi Myges a oruc. Ac yn gyntaf kyrchu $\mathbb{L} y c h l y n$ a oruc, hyt pan vei Leu uab Kynuarch y dal gan y chwaer a unelei yn vrenhin yno. Kanys nei [v]ab whaer oed Leu uab Kynuarch y vrenhin Lychlyn a uuassei uar6
yna. Ac ef a gymynassei y urenhinyaeth y Leu y nei; ro cymyn $\bar{q}_{\text {entust }}$ ac ny buassei teilug gan y Lychlynwyr hynny, namyn goneuthur Riçlf yn vrenhin arnadunt a chadarnhau eu kestyll ac eu dinassoed, gan dybygu gallu gorthøynebu y Arthur. Ac yn yr amser honno yd oed Walchmei uab Leu yn deudegmloyd, guedy y rodi oe ewythyr ef yg I 5 gwassanaeth Suplius bab Rufein. Ac y gan Suplius y kymerth ef arueu yn gyntaf. A gGedy dyfot Arthur, megys y dybesp@yt uchot, y traeth $\mathbb{L} y c h l y n$, Riçlff a shorc, eoast holl uarchogyon $y$ wlat y gyt ac ef a deuth yn erbyn Arthur, a dechreu ymlad ac ef. A guedy gellog Maber 20 , $t$ Pass! 6 iwedut sang $\{134(z)$ ren gore, diskesse,
seater o greu a gwaet o bop part[h], or diwed y Brytanyeit a oruuant gan lad Riçlf a MaGer oe wyr y gyt ac ef. A gGedy caffel or Brytanyeit y uudugolyaeth, kyrchu y dinassoed a orugant ac eu Mosci, a g(uascaru eu pobloed. Ac ny orfoyssassant hyt pan daruu udunt goreskyn holl 25 Lychlyn a Denmarc. A guedy daruot hynny, ef a urdaid Leu uab Kynuarch yn vrenhin yn $\mathbb{L} y c h l y n$.

20. Ac odyna yd hoylasd ynteu ae lyges hyt yn Freinc. A goledy kyweirab y toruoed, dechreu anreithas toplunder, rawage y wlat o bop parth a orugant. Ac yn yr amser honnc 30 yd oed Frollo yn tywyssabic yn Freinc y dan Les Lucius. amheraudor Rufein yn [y] Mywyal. A guedy clybot o trule, direct Frollo dyuotedigaeth Arthur, ef a gynullaud hol uarchogyon Freinc, ac a deuth y ymlad ac Arthur; ac 
glewder braven, bolduess, valour

I 58

\section{THE STORY OF ARTHUR}

ny allıys gortḩynebu idal. Kanys gyt ac Arthur yd oed holl ieuenctit yr ynyssed a oresgynassei. Ac orth hynny kymeint o lu a dywedit y uot gantab ac yd oed anald y vn tywyssalic neu y neb y erbynyas na

5 goruot arnal. Ac y gyt ac ef hefyt yd oed y ran oreu o Freinc, yr honn a ry unathoed y haelder yn roymedic oe garyat ynteu. A goedy gorelet o Frollo y dyguydab ef yn y ran waethaf or ymlad, yn y Me adab y maes a oruc y gyt ac ychydic o nifer, a ffo hyt ym Paris; ac dispersed,seatered 10 yno kynullai y wasgaredic bobyl attai a chadarnhau y gaer, a mynu elchayl ymlad yn erbyn Arthur o neighbours ganhortha[y] y gymodogyon. Yn dirybud y deuth Warming Arthur ae lu y warchae ynteu yn y dinas. A guedy Mithras mis heibal, doluryal a oruc Frollo o welet y toperish I 5 bobyl yn aballu rac newyn. A gofyn a oruc y Arthur 667 a vynnei eu dyuot ell teu y ymlad; ar hon a orfei onadunt, kymerei gyfoeth y MaП heb lad neb or deu lu.

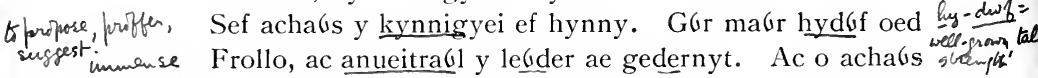
- Svied $\downarrow 20$ ymdiret yn y nerthoed yd archei ef y Arthur dyuot yn tumsraparr,aside neilltuedic y ymlad ac ef, o tybygu kaffel ford $\dot{y}$ iechyt o hynny. A Maßien uu Arthur wrth y genadori honno. Ereceive;
withstand bound if fall, chance Ac yn y Me anuon at Frollo y dywedut y vot yn dyuot, covenour, compact ac yn baralit y wneuthur yr amot honns ac ef ae gads.

25 21. A goedy kadarnhau yr amot honnc o bop parth, Gynt a deuthant ell teu hyt y myln ynys odieithýr y oulside dinas; ar pobloed o bop parth yn aros y syMu py damwein a darffei y rydunt. Ac yno y deuthant yn hard equipped $=$ easy wedus gyweir ar deu uarch enryfed y meint ae buanet, 30 hyt nat oed parast $y$ neb adnabot y bly y delei $y$ uudugolyaeth onadunt. A gGedy sefyll onadunt a drychafel $y$ harGydon o bop parth, dangos $a$ yr meaviotion , 


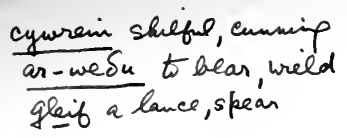

go-chel to avoid, shum, ward of e escape.

gurychys stour, resolute, bold

\section{THE STORY OF ARTHUR}

ispur ysparduneu yr meirych a orugant, a gossot o bop vn ar y gilyd y dyrnodeu muyhaf a ellynt. Ac eissoes kywreinach yd arwedoys Arthur y leif gan ochel dyrnalit mineed Frollo. Arthur ae g(ant ym pen y vron, ac yn herbyd 2133 (a) y nerth ef ae byryald hyt y daear. Ac yn y Me noethi y it of gledyf a oruc, a mynu Mad y ben. A Frollo a gyfodes 35s.prer. of burw
5 lWwow, cast strike,
hit, over thisow yn gyflym, ac a gleif gossot ar varch Arthur yn y d6yvron dyrnalit agheuali, hyt pan dygaydassant Arthur ae varch yr Mabr. A phan welsant y brenhin
:ancely, yn syrthaw, abreid vu eu hattal heb torri eu hamot, io himiden ac o un vryt kyrchu y Freinc. Ac mal yd oedynt yn torri eu kygreir, nachaf Arthur yn kyuodi yn gyflym wychyr, ac yn drychafel y taryan ac yn kyrchu Frollo. A sefyll yn gyfagos a wnaethant, a nelidyal dyrnodeu, a Mlafuryal pob un ageu ${ }^{a}$ y gilyd. Ac or difed Frollo 15 a gauas kyfle; a tharas Arthur yn y tal a onaeth. A forchiead phei na ry bylei y cledyf ar vodroyeu y benffestin, ef a modrory a ring vuassei agheuabl or dyrnabt honn6. ${ }^{b}$ A guedy guelet o Arthur y waet yn cochi y taryan ae arueu, ennynu o thindle, tire; infermed flamychedic lit ac o Gychyr irloned a oruc. A 20 wrath drycha[fel] Caletf(ulch ac oe holl nerthoed gossot a oruc, ar helym ar penffestin a phen Frollo a holltes yn deu hanner hyt y doy yscoyd. Ac or dyrnalt honno dygayda، a wnaeth Frollo, ac ae sodleu maedu y daear, ${ }^{c}$ holctit splir, cleave helmet pe. a gellıg y eneit gan yr Gybyr. A goedy honni hynny $25 \mathrm{t}^{\text {pound }}$ proctain dros y Muoed, bryssyal a oruc y kistalitwyr, ac agori porth y dinas ae rodi y Arthur.

22. A gGedy caffel y uudugolyaeth honno o Arthur, ranu y lu a oruc yn deu hanner. Y neill ran oe lu a

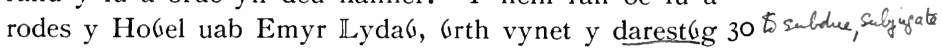
iton? Goitart tybyssabc Peitab. Ac ynteu ehun a[r] ran arall gantal y oresgyn y gollatoed ereill yn eu kylch. Ac yn y

$$
{ }^{a} \text { MS. ogeu }{ }^{\diamond} \text { MS. honno. } \quad c \text { MS. daeayar. }
$$
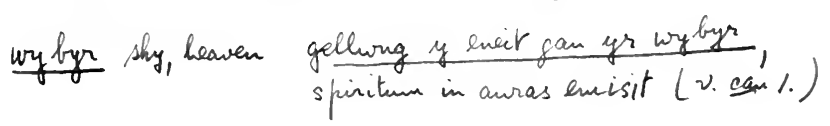
Tle $y$ deuth Howel vab Emyr Lydas yr wlat. Ef a gralus ancions gyrchbys y keyryd ar dinassoed; a Goittart gGedy MaGer o ymladeu yn ofalus a gymhelloys y orhau y Arthur; ac odyna Grasgoin o flam a hayarn a anreithoys; ae 5 tybyssogyon a darestyguys y Arthur.

23. A goedy Ilithrab nas mlyned heibal, a daruot y medyaur possession, Arthur oresgyn holl wladoed Freinc orth y vedyant ehun, ef a deuth elchoyl y Baris. Ac yno y dellis lys. Ac yno guedy gals palb or yscolheigon ar Meygyon, held $(u$
dal $)$ Io kadarnhau a onaeth ansalid y teyrnas, a gossot establish laws chicf staward kyfreitheu, a chadarnhau hedoch dros yr holl teyrnas. Ac yna y rodes ef y Vedwyr y bentrullyat Normandi a liefter Fflandrys. Ac y Gei y bensoydor y rodes ef yr Angio a Pheittal, a Thaber o wladoed ereill yr dylyedogyon ereill I 5 a oedynt yn y wassanaethu. Ac odyna guedy hedychu a thagnefedu pob Tle or dinassoed ar pobloed uelly, pan spring yttoed y goancyn yn dyuot, Arthur a ymhoeles y ynys Prydein.

24. Ac ual yd oed gaylua y Sulgoyn yn dyuot, guedy $20 \mathrm{y}$ veint uudugolyaetheu hynny o bop Пle, y gyt a diruabr leGenyd ef a vedylyøys dala Mys yn ynys Prydein, a glisgal y goron am y ben, a gliahabd attal y brenhined artybyssogyon a oedynt wyr idab o bop lle a orescynnyssei, (irth enrydedu goylua y Sulgoyn yn vrenhinabl 25 enrydedus, ac y atnebydu kadarnaf tagnefed y rydunt. A guedy menegi ohonal y ved6l y gyghorwyr ae ancylyt, ef a gauas yn y gyghor dala y lys yg Kaer Lion ar Wysc. Kanys or dinassoed kyvoethockaf oed ac adassaf yr ueint wylua honno. Sef achaøs oed. Or neill 30 parth yr dinas y redei yr auon uonhedic honno Wysc. 3 Pl Sint find. Ac ar hyt honno y doynt y brenhined, a delhynt dros y 3 pl. $m$ mp. Sul moroed, yn y Mogeu hyt y dinas. Ac or parth arall gGeirglodyeu a foresti yn y theckau. Ac y gyt a hynny adeiladeu a Myssoed brenhinawl a oedynt yndi oe myon,

\section{teceär 5 adon, decoraté}




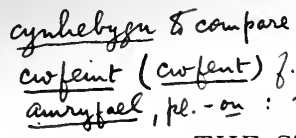

THE STORY OF ARTHUR

\section{I6I}

a thei eureit, megys nat oed yn y teyrnassoed tref a gynhebyckyt y Rufein o ryodres namyn hi. Ac y gyt a hynny arderchalsc oed o doy egloys arbenhic; vn o honunt yn ardyrchafedic yn enryded y $\mathrm{Vyl}$ verthyr, a chofeint o werydon yn talu molyant y Dus yndi yn wastat dyd a nos yn enrydedus urdasseid; arall a oed yn enryded y Aaron kedymdeith y merthyr honno, a chøfent yn honno a ganonwyr reolaldyr. Ac y gyt a hynny y dryded archescobalit a phenaf yn ynys Prydein oed. Ac y gyt a hynny arderchabc oed o deu cant yscol io o athrabion a doethon, a ed[ne]bydynt kerdetyat y syr ac course, motion

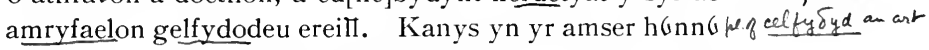
y keffit yndi y seith gelfydyt; $a[r]$ rei hynny dray gerdetyat y syr a venegynt y Arthur MaGer or damweineu a delhynt rac Пa⿱ Arthur yno dala Mys. Ac odyna gellig kenadeu dr6y amryfaelon teyrnassoed a glahald palb a orucpsyt o deyrnassoed Ffreinc ac o amryfaelon ynyssed yr eigaun, o[r] a dylyynt dyuot yr Mys.

25. Ac Grth y wys honno y deuthant yno: Ara@n uab 20 Kynuarch brenhin Yscotlont, Vryen y vrast brenhin Reget, Katıaחa@n MaG[h]ir brenhin Goyned, Kador Memenic tywyssalic Kernys. Tri archescob ynys Prydein : archescob Lundein, ac archescob Kaer Efrabc, a Dyfric archescop Kaer $\mathbb{L i o n}$ ar Wysc; a phenaf 25 onadunt oed dan bab Rufein, ac y gyt a hynny eglur
oed oe wassanaeth ae uuched; kanys pob kyfrya glefyt sery hind fo
sickuess / disease or a uei ar dyn, ef ae guaretei drGy y wedi. Ac y gyt gwedif.aprayen a hynny Gynt a deuthant y tybyssogyon or dinassoed bonhedic, nyt amgen, Morud iarll Kaer Loyd, Meuruc 30 Gloncester

Soreacter anterbing Derchester o Gaer Wyragon, Anaralst o Amuythic, Kynuarch iarll Kaer Geint, Arthal o Warwic, Owein o Gaer Leon, Chester Ionathal o Gaer Idor, Cursalem o Gaer Lyr, Grallabc heicester ap Leenalic o Salsbri, Boso o Ryt Ychen. Ac odieithyr

L. Coen weis

eqlun clear, lengiht, brilliant, renowned, famous 


\section{cynired t come togettien, assemble; brimp logettren; a concourse dad-sann \& recapituláte, rehearse, recite Krigian 5 durell, remain.}

162

THE STORY OF ARTHUR

besides hynny MaGer o wyrda, nyt oed lei eu boned nac eu mollebijts teilygdast nor rei hynny, nyt amgen, Dunast Vor uab Pabo post Prydein, Keneu uab Coel, Peredur uab Elidyr, Grufud uab Vogoet, Rein uab Elast, Edelin 5 vab Keledabc, Kyngar uab Bangab, Kynnar Gorbanyon, Miscoet Cloffacic, Run uab NGython, Kynuelyn [uab] Trunya(, Kadell uab Vryen, Kyndelic uab NGython. Ac y gyt a hynny MaGer o wyrda a oed ryhir eu henci. Ac y gyt a hynny or ynyssed yn eu kylch : Gillambri Io brenhin Iwerdon, Melwas brenhin Islont, Doldan brenhin Gotlont, Groynu[a]brenhin Orc, Leu uab Kynuarch brenhin $\mathbb{L} y c h l y n$, Echel brenhin Denmarc. Ac o Ffreinc y deuthant: Hodlyn tywyssabc Ruthyn, Leodgar iarII B6løyn, Bedøyr pentrullyat duc Normandi,

I 5 Borel o Cenomaøs, Kei penşydor duc yr Angis, Goittart o Beittal, ar deudec gogyfarch o Freinc, a Gerein[t]

Garannbys oc eu blaen yn dywyssabc arnadunt, Howel uab Emyr Iyda6 brenhin Brytaen Vechan, a Mlaber o byrda a oed darestygedic idas y gyt ar ueint darmerth a 20 chyniret mulyoed a meirych, megys yd oed dyrys eu datkanu a ryhir eu hyscriuenu. Ac odieithyr hynny ny thrigywys un tywyssabc y tu hon yr Yspaen ny delei Grth y wys honno. Py ryfed oed hynny? Haelder Arthur ae glot ae volyant yn ehedec dros y byt a kffy

tymne $\hbar /$ mole, drag, draw plus.

archbishipis palace

30 yn dala Mys. Ac or diwed guedy guisgab y vrenhinabl wisc am y brenhin a theckau y ben o goron y teyrnas ae sceptre deheu or deyrnwialen, ef a ducplyt yr egloys benaf, ac or tu deheu ac or tu asseu idab y deu archescob yny assw bef gynhal. Ac y gyt a hynny peţar brenhin, nyt amgen,

25 dynassei baøp yn ro[y]medic oe garyat.

26. Ac or dibed guedy ymgynullab palb yr gaer ar Gylua yn dyuot, yr archescyb a elwit yr Ilys Grth wiscas y goron am ben y brenhin. Ac odyna Dyfric archescob a gant yr offeren. Kanys yn y archescobty yd oedit 1

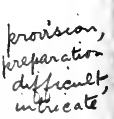


$c y-\omega y \delta-o l-(y)$ aelt $f$. harmony, music

brenhin yr Alban, a brenhin Dyuet, a brenhin Goyned, a brenhin Kernyø, yn herGyd eu breint ac eu dylyet, yn arcein petıar cledyf eureit noethon yn y vlaen. Ac $y_{f}$ gyt a hynny MaGer o gofenoed amryfaelon vrdassoed yn eu processio o pop parth yn ol ac ym blaen yn kanu amryfaelon gybydolaetheu ac organ. Ac or parth arall yd oed y vrenhines yn y brenhinwisc, ac escyb o bop parth $^{1}$ yn y doyn hitheu y egloys y mynachesseu, ${ }^{2}$ a phedeir goraged y petwar brenhin, a dywedassam ni uchot, yn arGein pedeir clomen ${ }^{3}$ purwen $^{4}$ yn y blaen yn ro herbyd eu breint Gynteu, ar goraged yn enrydedus gan diruabr lebenyd yn kerdet yn y hol. ${ }^{5}$ Ac or dised gGiedy daruot y processio $^{6} \mathrm{ym}$ pob vn or day egliys, kyndecket a chyndigrifet y kenit y kywydolaetheu ${ }^{7}$ ar organ ac na Gydynt y marchogyon py le gyntaf y i 5 kyrchynt $;^{8}$ namyn yn torfoed pob eilwers y kerdynt y alternately honn yr aur hon ac yr llall guedy hynny. A phei treulit y dyd yn gobol yn doywall wassanaeth, ny magei produce, lugende dim blinder y neb. Ac or dified guedy daruot yr offereneu ym pob vn or doy egloys, y brenhin ar 20 vrenhines a diodassant eu brenhinwisgoed y amdanunt. ${ }^{9}$

27. Ac odyna y brenhin a aeth yr neuad ar gayr oll y gyt ac ef. Ar vrenhines ar goraged oll y gyt a hi ${ }^{1}$ y neuad y vrenhines, gan gads hen gynefast Tro, pan enrydedynt y goyluaeu mabr, y g6yr y gyt ar goyr yn 25 boyta, ar goraged y gyt ar goraged yn wahanedic. A idisfore, gGedy kyflehau ${ }^{2}$ pasb $\mathrm{y}^{3}$ eisted yn heroyd y deissyfei y

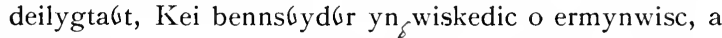
deissyteid to mil $^{4}$ y gyt ac ef o vn rys adurn a hynny ${ }^{5}$ o veibon dylyedogyon, a gychwynassant y wassanaethu or gegin 30

a dish of weat anregyon. Ac or parth arall Bedwyr a mil o veibon

(Ch. 26). 1 idi add., 2 machesseu, 3 colomen, 4 gvynyon, 5 yn ol, 6 prosessivn, 7 kywydolyaetheu, 8 a gerdynt, 9 y amdanadunt

'Ch. 27). 1 hitheu, 2 kyfyavnheu (?) 3 yn, 4 mil o wyr, 5 ac ynteu

privilege

orders

5

nuns

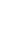


me $\delta$-sell f. a mead-cellas, cellar

164 THE STORY OF ARTHUR

he. of guirowid a
beverage, drinte

careful, unccaseng

exeess

excel

ke. of alof weallt

(hend, host. $v$. Pedor Kenic, 242, 248)

mawner, fasheon

embrasures; $p l$.

of brolch gap'

tables, bach ganmon 25 . insention derice cyffro cxatement

Io varchabc bynhac a vynnei ${ }^{8}$ vot yn glotuabr yn Mys Arthur, o vn ryø wisc yd aruerynt, ${ }^{9}$ ac o vn ryø arueu, aco un rys dybygyat ${ }^{10}$ marchogaeth. Y gorderchwraged o vn $\Pi$ is wisgoed ac o un dybygyat ${ }^{10}$ yd aruerynt. Ac ny bydei teilug gan un wreic garu ${ }^{11}$ vn gor, ony bei y uot I 5 yn brofedic teirgueith y miluryaeth. Ac uelly diveirach chaste y goneynt ${ }^{12}$ y goraged a goell, ar goyr yn glotuorussach oc eu karyat.

28. Ac or dised guedy daruot buyta a chy[ch]wynnu $\mathrm{y}$ ar $\mathrm{y}$ byrdeu, allan odieithyr $\mathrm{y}$ dinas yd aethant $\mathrm{y}$ 20 chuare $^{1}$ amryfaylon chwaryeu. ${ }^{2}$ Ac yn y Me marchogyon yn dangos arbydon, megys kyt bydynt ${ }^{3}$ yn ymlad yn iaun ar y maes. Ar goraged y ar y muroed ar bylcheu yn edrych ar chware. ${ }^{4}$ Ereill yn burs mein, ereill yn saethu, ereill yn rydec, ${ }^{5}$ ereill yn guare goydb $6[y] \Pi$, ereill yn govare taplas. Ac uelly ${ }^{6}$ dr6y bop ${ }^{7}$ kyfry 6 amryuaelon dychymygeu $^{8}$ guaryeu $^{9}$ treulaw yr hyn a oed yn ol or dyd gan diruabr lewenyd, heb lit a heb gyffro ${ }^{10}$ a heb gynhen. A phoy bynhac a vei vudugabl yn y guare, Arthur droy amlaf rodyon ae henrydedei. ${ }^{11}$ A gredy treulas y tri 30 dieu kyntaf uelly, ${ }^{12}$ y petwyryd dyd gals palp a wnaeth-

toffect mutrally

(Ch. 27.) 6 yr dothoed, 7 aualoed daeravl, 8 vynhei, 9 aruerhynt, 10 diwygyat, 11 karu, 12 ymwneynt

(Ch. 28). 1 wareu, 2 waryeu, 3 beynt, 4 ar $y$ gvareu, 5 redec, 6 y velly, 7 pop, 8 dychymygyon, 9 a gvaryeu, 10 a heb gyffro om., 11 henrydedhei, $12 \mathrm{y}$ velly

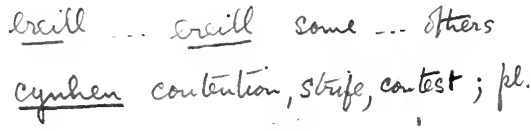

Whatremain of the day concubines haste

gGyrda y gyt ac ynteu yn wisgedic o amryuaelon wiscoed yn Mys y vrenhines aneiryf o amylder gGassanaethwyr yn wisgedic o amryfaelon wisgoed yn herGyd eu defaut ryotres pei ascrifenon, gormod o hyt a blinder a Gna@n yr ystorya. Kanys ar y veint teilygdast honno yd oed
ynys Prydein megys y racvlaenei yr holl ynyssed o amylder eur ac aryant ac alafoed dayra $61 .^{7}$ A phy 
xdyss m. Teachip, instruction, example, beharour
clodfori to make illustrious, render famous

THE STORY OF ARTHUR

poyt or a oedynt yg giassanaeth, a thalu ${ }^{13}$ y balp y wassanaeth ae lafur herGyd ual ${ }^{14}$ y dylyynt. Ac yna y rodent ${ }^{15}$ y dinassoed, ar kestyll, ar tir, ar dayar, ar escobaetheu, ${ }^{16}$ ar archescobaetheu, ${ }^{17}$ ar manachlogoed, ar amryuaelon urdasseu, megys y guedei y balp or ae 5 dylyei. ${ }^{18}$

29. Ac yna y gorthodes Dyfric archescob y archescobaut ae teilygdabt. Kanys geell oed gantab bot yn didrifur a buchedu yn y didryf no bot yn archescob. Ac yn y le Give bach, reject, sohtay place, fermitage ynteu y gossodet Dewi ${ }^{1}$ eGythyr $\mathrm{y}[\mathrm{r}]^{2}$ brenhin yn io archescob yg Kaer Lion ar Wysc. ${ }^{3}$ Buched honno oed agreifft $\mathrm{t}^{4}$ dayon $^{5}$ y balip or a gymerassei y dysc $\mathrm{C}^{x}$ ynteu. $\mathrm{Ac} \mathrm{yn}^{6}$ Me Sams $6 n^{7}$ archescob $\mathbb{L} y d a 6$ dray anoc Howel $^{8}$ uab Emyr $\mathbb{L} y d a{ }^{\prime}$ y gossodet Teila‘ escob ${ }^{9}$ Lan Daf, yr hon a glotuorei y uuched, ae deuodeu da a dangosssynt 15 $y$ uot yn Grda. Ac odyna escobast Gaer ${ }^{10}$ Vudei y Veugant, ac escobaut Gaer ${ }^{10}$ Wynt y Dywan, ${ }^{11}$ ac escobabt Lincol y Aldelmi.

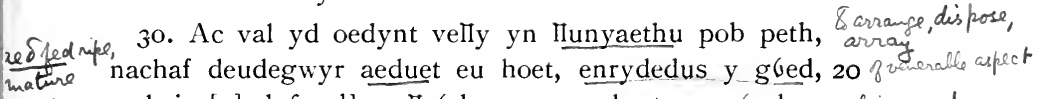
Silchester Winchester a cheig [o] olyfwyd ${ }^{2}$ yn Ma6 bop vn onadunt yn arGyd eu ohie-wood bot yn genadeu, ac yn kerdet yn araf, ac yn kyfarch guell y Arthur, ac yn y annerch y gan Les amheraidyr Rufein, ac yn rodi Mythyr yn y lab, ar ymadrabd honn ${ }^{2}$ yndal.

31. "Les amheraødyr Rufein yn anuon y Arthuryr hynn a haedGys. Gan enryfedu yn uair enryfed y 6 genyf i dy greulonder di athrudannaeth. ${ }^{2}$ Enryfedu $^{3}$

(Ch, 28). 13 thallu, 14 om., 15 rodet recte, 16 escobyaetheu, 17 ar archescobaetheu om., 18 y pavb ac y dylyei

(Ch. 29). 1 in marg., 2 yr, 3 arvyse om., 4 agriff, 5 a dayoni, 6 yny, 7 sampson, 8 hywel, 9 yn escob yn, 10 kaer, 11, doywan?

(Ch. 30). 1 o oliwyd, 2 ymadrodyon hynny

(Ch. 31). I anryfedu, 2 athrudanyaeth, 3 hefyt add.

\section{haeru to desewe, claim, merit creuloader cruelty, tyranny, opperession diudannaeth f. arrogance.}


cam-ryfygu 5 ack arrogantty
barmu to judge, decide, fix, pass judgment, deem

I66

\section{THE STORY OF ARTHUR}

ydayf gan goffau y sarhaedeu ${ }^{4}$ a wnaethost di $^{5}$ y Rufein. Ac anheilig y6 genyf nat atwaenost ${ }^{6}$ dy vynet oth dieithyr ${ }^{7}$ dy hun, ac na wydut ac nat $\mathrm{ytt}^{6} \mathrm{yt}^{8}$ yn medylyas provecation, ffence py veint trymder $y^{6}$ goneuthur kodyant y sened Rufein, $5 \mathrm{yr}$ honn a 6 dost $\mathrm{di}^{9}$ bot yr holl vyt yn talu goassanaeth idi. Kanys y deyrnget a orchymyncyt y dalu idi, yr hon ${ }^{10}$ a gafas Ulkassar a MaGer o amherodron ereill gGedy ef a chyn no minheu ${ }^{11}$ drby laber o amseroed-a honns gan dremygu' ${ }^{12}$ gorchymyneu kymeint ac vn

Io sened Rufein--a gamryvygeist $\operatorname{di}^{13}$ y attal. Ac y gyt a a hynny ti a dugost BGrgayn ac ynyssed yr eigaon yn holla(bl, brenhined $y$ rei hynny, hyt tra yttoed Rufeinabl uedyant yn eu medu, a dallasant teyrnget yr amherodron a vuant kyn no minheu. A chanys or veint sarhaedeu ${ }^{14}$ I5 hynny y barnoys sened Rufein y minheu iabn y genhyt satisfaction ti, wrth hynny minheu a ossodaf teruyn ytti yr AGst kyntaf yssyd yn dyuot, dyuot ohonat titheu hyt yn Rufein y wneuthur iaøn or sabl sarhaedeu ${ }^{14}$ hynny, ac porsession, power.
authoilly y diodef y vrabt a uarnho sened Rúfein arnat. Ac ony 20 deuy uelly, ${ }^{15}$ miui a gyrchaf dy teruyneu. ${ }^{16} A$ megys $y$ ranho y clefydeu, ${ }^{17} \mathrm{mi}$ ae ranaf ${ }^{18}$ ac a lafuryaf y doyn drachefyn orth sened Rufein."

32. A gGedy datkanu y Mythyr honno rac bron Arthur ar brenhined ar tywyssogion a oedynt y gyt ac ef, ef Caps.? 25 ac bynt a aethant y gyt hyt yn tor y kebri y gymryt dingurction kyghor py beth a onelhynt yn erbyn y kymynediceu hynny. Ac ual yd oedynt yn esgynnu ${ }^{2}$ gradeu y tor, steps

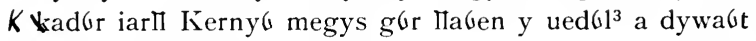
yr ymadralid honn: "Kyn no hynn ofyn a ry fu arnaf $i$ 30 rac goruot o lesged y Brytanyeit o hir hedoch, a cholli

(Ch. 31). 4 sarahedeu, 5 wnaethosti, 6 atwaenosti, 7 odieithyr, 8 ydoyt, 9 odosti, 10 hon, 11 thitheu, 12 tremygu, 13 gamryfygeisti, 14 sarahedeu, 15 dohy y velly, 16 terfynheu, 17 cledyfeu, 18 kymhellaf

(Ch. 32). 1 kymenediveu, 2 yskynnu, 3 y vedol $\mathrm{om}$.

?? by despising so great commonols as that of the senate of Rome 
clot eu milıryaeth, or honn y buant hoy eglurach no neb eidon to o genedloed y byt yn hollabl. Sef achals yb. Yn y Ile y peitter $a^{4}$ arueru o arueu, ac aruer or Gydb6yll ar daplas a serch goraged, nyt oes petrus yna Ilygru o lesged py beth bynhac a ry fei ${ }^{5}$ o nerth yno a chedernit 5 ac enryded a chlot. Kynys ${ }^{6}$ pump mlyned hayach ar $^{7}$ 3 pl. Parf ethynt yr pan yttym ni yn arueru or rys seguryt honno ar digrifoch, a heb arueru o dioy II ymlad. Ac orth cultioation yry ( $v$. hynny Dus yr mynu an rydhau ni or Mesged honno $(93 \times .4)$ ustan, a gyffroes goyr Rufein yn an herbyn, hyt pan alwem Io hunt, so that $\{226$ ni an clot ac an miloryaeth ar y hen gynefabt." Salo cole, summon,

33. A guedy dybedut o Gador yr ymadrodyon hynny a Mląuer o rei ereill, or diwed bynt a deuthant $\mathrm{yr}$ at, throwes eisteduaeu. A gliedy eisted o balp yn y le, Arthur a dybabt ual hynn orthunt: "Vyg kedymdeithon ar royd ${ }^{x} 5$ in prosperity iachersity ac ar dyrys, molyant yr rei hyt hynny ${ }^{1}$ ac yn rodi $\mathrm{eu}^{2}$ both ... and kyghoreu ac eu miloryaeth, ac $\mathrm{yr}^{4}$ abr honn o vn vryt rodich auch kyghor, ac yn doeth racvedylybich py beth conscolen, provide a uo ialn y atteb yn erbyn yr attebyon hynn. Kanys py beth bynhac ${ }^{5}$ a racvedylyer ${ }^{6}$ yn da yn y blaen y gan 20 $\operatorname{mim}_{\lim }^{a d}$ aceded doethon, pan del ar Geithret, hals vyd y diodef. Ac wrth hynny hals y gallon ninheu diodef ryfel goyr Rufein, os o gyffredin gyfundeb a chytgyghor yn doeth y racuedylyon py wed y gallom ni guahanu ac eu ryfel bynt. Ar ryfel honnw, heroyd y tebygaf i, nyt 25 mabr reit yn y ofynhau. Kanys andylyedus y maent illegal, wrong hoy ${ }^{7}$ yn erchi teyrnget o ynys Prydein. Kanys ef a

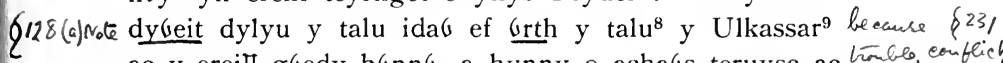
ac y ereill goledy honno, a hynny o achabs teruysc ac tramber conflict, licend,
inumiverfect anuundeb

(Ch. 32). 4 o, 5 ryffei, 6 kanys, 7 ?a, 8 mynnu

foresee, 6 (Ch. 33). I yr rei a profeis hyt hyn, 2 om., 3 y, 4 ar, 5 bynac, provide 6 racweler, 7 oy, 8 dalu, 9 ulkessar, 10 annundab, 11 hendadeu, 
wyr Rufein yr ynys honn, ac o dreis ${ }^{12}$ y gonaethant yn violence

tibutary trethas1.13 Ac Grth hynny py beth bynhac a gaffer droy deception treachery na thoyll na chedernit, ${ }^{14}$ nyt o dylyet y kynhellir honno. 3s. Pr.subj. of wyn $P$ ay bynhac a dycko treis, peth andylyedus a geis y

5 gynhal. A chanys andylyedus y maent by yn keissab teyrnget $y$ genhym ni, yn gynhebic y hynny Similar,
like ninheu a deissyfon teyrnget y gantunt hoy ${ }^{15}$ o Rufein, ar kadarnaf ohonom ni kymeret y gan y Mall. ${ }^{16}$ Kanys or goresgynbys ${ }^{17}$ Ulkassar $^{18}$ ac amherodron ereill guedy Io ef ynys Prydein, ac o achalis hynny yr abr honn holi teyrnget ohanei, ${ }^{19}$ yn gynhebic y hynny minheu a 1 judge, deem varnaf dylyu $\mathrm{o}^{20}$ Rufein talu teyrnget y minheu. Kanys ancestors vy rieni ynheu gynt a oresgynnassant ${ }^{21}$ Rufein ac ae kynhalassant, nyt amgen, Beli uab Dyfynwal gan I 5 ganhorthoy Bran y vrabt duc Børgbyn, gledy crogi petwar gdystyl ar hugeint ${ }^{22}$ o dylyedogyon ${ }^{23}$ Ruuein rac bron y gaer, ac ae dalyassant drGy laber o amseroed. A guedy hynny Custenin mab Elen a Maxen mab Lywelyn $n_{\text {r }}$ pob vn or rei hynny yn gar agos y mi o relationship 20 gerenhyd, ${ }^{24}$ ac yn vrenhined arderchalic o goron ynys Prydein--yr vn guedy y gilyd a gaussant amherodraeth Rufein. Ac orth hynny pony bernoch chøi bot yn ialn $y$ minheu deissyfeit teyrnget o Rufein? O Ffreinc ac or ynyssed ereill ny Grthebon ni udunt $6 y$, kany doethant 25 y hamdiffyn, pan y goresgynassam, ${ }^{25}$ nac oe guarafun. Ac $6 r$ th hynny ny orthebon ni udunt hoy ${ }^{26}$ or rei hynny."

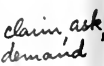

34. A guedy teruynu o Arthur yr ymadralid, Howel ${ }^{1}$ uab Emyr Lydas a Grthebald ym blaen ${ }^{2}$ palib y ymadralsd Fraeltu 6 ulter, Arthur ual hyn: "Pei ${ }^{3}$ traethei bop un ${ }^{4}$ ohonom $\mathrm{ni}^{5}$ a dectare 30 medylyas pob peth $y$ n yed(1), ny thebygaf $i^{6}$ gallu

(Ch. 33). 12 treis, 13 treulad, 14 gaffer a thvy I a chedernit, $15 \mathrm{vy}$, 16 teyrnget add., 17 o gverysgynnvys, 18 vlkessar, 19 oheni, 20 wyr add., 21 weryskynassant, 22 hugein, 23 dylyodogyon, 24 gerenyd, 25 gverys. cynassam $26 \mathrm{om}$.

(Ch. 34). 1 hywel, 2 ymlaen, 3 bei, 4 bavb, 5 oll add., 6 thybygaf 
newidyaw \& exchange (blow)

170 THE STORY OF ARTHUR

2ss.Pr. Subj. of geffych ti hynny, minheu ath gedymdeithockaf $t^{34}$ a deg mil o varchogyon aruabc y gyt a mi y ach6anegu $\mathscr{L}^{\circ}$ crease dy lu."

parabyl m.a 35. A gGedy teruynu o Howel ${ }^{1}$ y barabyl, Arain uab 5 Kynuarch brenhin Prydein a dywaut ual hynn: "Yr pan dechreualid vy arglayd $\mathrm{i}$ dywedut y ymadralid, ny \&ulter, deciar allat $\mathrm{i}^{2}$ traethu am taualit y veint lewenyd yssyd ym med6l i. Kanys nyt dim gennyf i a ry wnaetham ${ }^{3}$ oymladeu ar $\mathrm{yr}$ holl urenhined a oresgynnassam ${ }^{4}$ ni hyt hynn, os ¿deane cseape $10 \mathrm{~g} 6 \mathrm{yr}$ Rufein a gGyr Germania dihagant ${ }^{5}$ yn diarueu ${ }^{6}$ y leg di-aenf genhym ni, a heb dial arnadunt yr aeruaeu a onaethant Gynteu oc an rieni ni gynt. A chanys ${ }^{7}$ yr abr honn $y$ pereparation, provision, mae darpar ymgyfaruot ac Gynt, Magen $y^{6}$ genyf; a project wish for damunal yd byf y dyd yd ymgyfarffom ni ac Gynt. thirst I 5 Kanys sychet eu gGaet Gynt yssyd arnaf i yn gymeint 7. foumlem, spring a phei grelon fynhainn oer ${ }^{8}$ ger vy mron y yfet diabt ohonaei, pan vei arnaf diruabr sychet. ${ }^{9}$ Oia DuG!

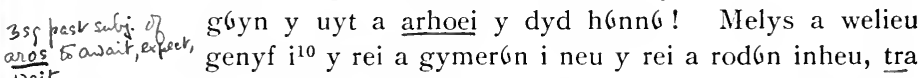
quardo dextrás 20 nevityon an deheuoed y gyt an gelynyon. Ar agheu conferemus honno yssyd uelys, yr honn a diodefon yn dial ${ }^{11}$ uy rieni am kenedyl, ac yn amdiffyn vy rydit, ac yn ardyrchauel $^{12}$ an brenhin. Ac Grth hynny kyrchon yr cowards hanher gGyr ${ }^{13}$ hynny; na safon yn eu kyrchu, hyt pan 25 orfom ni arnadunt 6y gan d6yn eu henryded, ${ }^{14}$ yd aruerom ${ }^{15} \mathrm{ni}^{16} \mathrm{o}$ laben uudugolyaeth. Ac y ach6aneckau dy lu ditheu minheu a rodaf day vil o varchogyon arualic gandeo tostand, stof

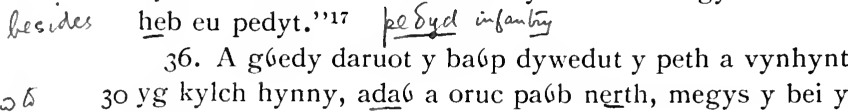
besides heb eu pedyt." 17 pe $\delta y d$ infonting
36 . A goedy daruot y baop dywedut y peth a vynhynt
30 yg kylch hynny, adas a oruc paob nerth, megys y bei $y$ $\frac{a \delta a n t}{\text { promise }}$

(Ch. 34). 34 gytymdeithockavn ditheu $X \vee \quad 5$ diaghant, 6 diaerua, 7 achavs, 8 loyv eglur, 9 ohonaei-syehet om., 10 crenhyfi, 11 graet add., 12 ardrychafel, 13 yr avr hon yr haner gvyr, 14 hanryded, 15 aruerhom, 16 ni oll, 17 pedyd 
allu ae defnyd yn $y$ wassanaeth. Ac yna y kahat o ynys Prydein ehun ${ }^{1}$ trugein mil o varchogyon arualic, heb $\operatorname{deg}^{2}$ mil a adalssei urenhin $\mathbb{L} y d a b$. Ac odyna brenhined yr ynyssed ereill (kany buassei aruer 0 varchogyon $^{3}$ ) pa(b onadunt a edebis pedydgant y sasl a ellynt eu kaffel. Sef a gahat or chwech ynys, nyt 5 a broop of amgen, Iwerdon ac Islont a Gotlont ac $\underline{Q}^{4}$ Orc a Lychlyn a Denmarc, ch6e ${ }^{5}$ ugein mil o pedyt ${ }^{6}$ ac $y$ gan tybyssogyon Freinc, nyt amgen, Ruthyn a Phortu a Normandi a Cenoman ar Angis a Pheitab, petwar ugein ro mil o uarchogyon. Ac y gan y deudec gogyfarch ${ }^{7}$ y v.p. 162 deuthant $^{8}$ y gyt a Gereint deucant ${ }^{9}$ marchalc a mil o varchogyon aruabc. A sef oed eiryf hynny oll y gyt, deu cant marchalic a their mil a phetbar vgein mil a chanmil, heb eu pedyt, ${ }^{6}$ yr hyn nyt oed hald eu gossot i 5 yn rif.

37. A guedy gGelet o Arthur palib yn barabt yn y reit ae wassanaeth, erchi a oruc y balp bryssyal y wlat ac ymbaratoi, ac yn erbyn Kalan Alist bot eu kynadyl oll y gyt ym porth Barberfloi ar tir Lydab, 6rth gyrchu 20 BGrgayn odyno yn erbyn goyr Freinc. Ac y gyt a to meet hynny menegi a oruc Arthur orth genadeu goyr Rufein na thalei ef tyrnget udunt hay ${ }^{1}$ o ynys Prydein. Ac nyt yr goneuthur ialn vdunt or a holynt yd oed ef yn kyrchu Rufein, namyn yr kymell teyrnget idas ef $0_{25}$ Rufein, megys y barnassei ehun y dylyu. Ac ar hynny yd aethant y brenhined ar goyrda palib y ymbaratoi heb vn annot, erbyn yr amser teruynedic a ossodyssit udunt.

38. A gGiedy adnabot o Les amheraldyr yr atteb a galıssei y gan Arthur, droy gyghor sened Rufein ef a 30 
ellygays kenadeu y wyssya brenhined y dofrein, ${ }^{1}$ ac erchi ${ }^{2}$ dyuot ac eu Tuoed gantunt y gyt ac ef Grth oresgyn ${ }^{3}$ ynys Prydein. Ac yn gyflym yd ymgynulassant yno Epistrophus ${ }^{4}$ vrenhin Groec, ${ }^{5}$ Mustensar 5 brenhin $^{6}$ yr Affric, Aliphantina urenhin yr Yspaen,

$v \cdot 1.182$ $v \cdot 1.182$ Hirtacus vrenhin Parth, Boctus brenhin Iudiff, Sertor ${ }^{7}$ brenhin ${ }^{6}$ Libia, Serx vrenhin Nuri, Pandrasius brenhin ${ }^{6}$ yr Eifft, Missipia ${ }^{8}$ brenhin $^{6}$ Babilon, Teucer duc Frigia, Euander duc ${ }^{6}$ Siria, Echion o Boeti, Ypolit o Creta, ${ }^{9}$ y IO gyt ar tywyssogyon a oedynt darestygedigyon udunt ar goyrda. Ac y gyt a hynny o vrdas y senedwyr Les, Kadell, Meuruc, Lepidus, Gaius, Metellus, ${ }^{10}$ Octa, Quintus, Miluius, Taculus, Metellus, Quintinus, Gerucius. ${ }^{11}$ A sef ${ }^{12}$ oed eiryf hynny oll y gyt, I 5 canbr a thrugein mil a phetGar can mil.

to equip themelves 39. A gliedy ymgyweiral onadunt $\underline{o}$ bop peth or a vei reit udunt, Kalan AGst hoynt ${ }^{1}$ a gymerassant eu hynt parth ac ynys Prydein. A phan Gybu Arthur hynny, ynteu a orchymynoys Mywodraeth ynys Prydein $y$ 20 Vedrabt y nei uab y chbaer, ac y Wenhbyvar vrenhines. Ac ynteu ae lu a gychoynoys parth a phorthua ${ }^{2}$ Hamton. A phan gafas y goynt gyntaf ${ }^{3}$ yn y ol, ef a aeth yn y logeu ar y mor. ${ }^{4}$ Ac val yd oed uelly o aneiryf amylder Mogeu yn y gylch, ar guynt yn royd yn y ol, gan = favourable trend, break 25 lecienyd yn roygal $y^{5}$ mor, mal am abr haner nos,

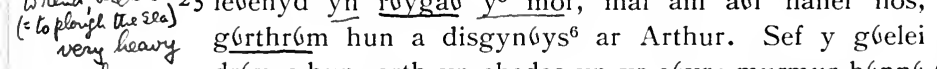
a bear droy y hun, arth yn ehedec yn yr abyr; murmur honno go-duer $\delta$ a ae odord a lanwei y traetheu o ofyn ac aruthred. Ac y orth y gormesin y gGelei aruthyr ${ }^{7}$ dreic yn ehedec, ac o 1 rom

the east

(Ch. 38). 1 dvvrein recte, 2 ac y erchi vdunt, 3 wereskyn, 4 epitrophus 5 goroec, 6 vrenhin, 7 settor, 8 mesipia, 9 greta, 10 metelus, 11 For Quintus Jerucius A has Quintus milnius katulus metelus Quintus cerutius (?), 12 Ac ysef

(Ch. 39). 1 vynt, 2 phorth, 3 kyntaf, 4 ar $y$ mor om., 5 om., 6 dygrydvys, 7 arthur

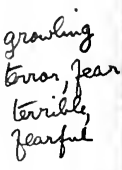


* girad lamentable, piteons, terrible dehougyl 5 interprer, intespretation

eglurder y Mygeit yn goleuhau yr holl wlat. A phob vn or rei hynny a welei yn ymgyrchu, ac yn ymlad yn irat ac yn greulasn. Ac or diwed y guelei y racdycededic dreic yn kyrchu yr arth, ac ae thanasl anadyl yn y fiery losgi, ac yn y vora yn Mosgedic yn y dayar. A 5 awake gledy duhunas o Arthur, ef a datkanald y weledigaeth ${ }^{8}$ yr guyrda a o[e]dynt yn y gylch. Ac bynt gan y dehogyl a dycedassant mae ${ }^{10}$ Arthur a arbydockaei y signity, imply dreic, ar arth a arbydockaei y kabr a ymladei ac ef, ar grant, huighty man ymlad a welei y rydunt a arGydockaei yr ymlad a vydei ${ }^{11}$ 10 y rydal ef ar kaør, ar uudugolyaeth a damweinhei ${ }^{12}$ y Arthur or kabr. Ac amgen no hynny y tebygei ${ }^{13}$ different from tarl Arthur ehun uot y dehogyl. Kanys ef a dybygęi y mae hecame of oe achals ef ar amherabtyr ${ }^{14}$ y grelei ef y vreidoyt. A : redect 5 gGedy rydec y nos, or dified pan yttoed guabr dyd yn is cochi tranoeth, ${ }^{15}$ Gynt a disgynnassant $y m$ porthua ${ }^{16}$ (hrovernight) uext day Barberfloy yn Lydas. Ac yn y Me tynu ${ }^{17}$ pebylleu a to pitch tents wnaethant, ac yno aros brenhined $\mathrm{yr}$ ynyssed $^{18}$ ar goladoed ac eu Mu atunt.

40. A guedy ymgynullal palb y gyt or yd oedynt yn 20 aros, Arthur a gychoynays odyno hyt yn Aggustudom, y Me y tybygei bot yr amheraldyr ae lu yn dyuot. A gGedy y dyuot hyt ar lann yr Avon Wenn ym BGrgGyn, ef a venegit idal bot yr amherabdyr guedy pebyllas nyt oed bell odyno, a chymeint o luoed gantab ac y dywedit 25 nat oed neb a allei gorthøynebu idas. Ac yr hynny cams bebylleu ae luesteu ar lann yr auon, megys y gallei yn excite, move restricted, royd ac yn ehang Munyaethu y lu, or bei reit idab, yn y arrange, dispose,

Me honns. Ac odyna yd anuones Arthur Boso o Ryt 30 Ychen a GGal[ch]mei uab Goyar a Gereint Garanıys hyt

(Ch. 39). 8 vreidvyt, 9 oed, $10 \mathrm{y}$ mae, 11 vei, 12 damweinei, 13 tybygei, 14 amheravdýr, 15 dranoeth, 16 ymhorthua, 17 tannu 18 ynyssoed 
annog towrge, encourage, recommend

blynghain to becoure angry, to frown

ym-a assu (ac) \& adapt oneself

\section{4 \\ THE STORY OF ARTHUR}

occasion (lit.
fuel, food)

ar amheralidyr Rufein, y erchi idal mynet o teruyneu Freinc, neu tranoeth rodi kat ar uaes y Arthur, y wybot poy oreu onadunt a dylyei Ffreinc. Ac annoc a inaeth jeuenctit Mys Arthur y Walchmei goneuthur gurthgassed rehollion, 5 yn Mys yr amheralidyr, megys y gellynt gaffel gosgymonn y ymgyuaruot a goyr Rufein.

4I. Ac odyna y trywyr hynny a gerdassant at $y r$ amheraldyr, ac a archassant idal mynet ymeith o Ffreinc, neu ynteu trannoeth rodi kat ar uaes y Arthur. Ac ual Io yd oed yr amheraldyr yn dybedut nat mynet ohonei a dylyei, namyn dyuot oe hamdiffyn ac y Mybyas, nachaf Quintinus nei yr amheraldyr yn dywedut bot yn hoy boastig, affectation gorhoffed a bocsach y Brytanyeit noc eu gallu ac eu glesder, a bot yn hoy eu tauodeu noc eu clefydeu.

I 5 Ac Grth hynny Mityas a oruc Goalchmei, a thynnu cledyf a Mlad y benn ger bronn y ewythyr. Ac yn y Me ar hynt retreakfrom kaffel eu meirych ac ymtynnu or Ilys ef ae gedym[d]eithon, ar Rufeinwyr ar veirych ac ar traet yn eu hymlit y geissa6 dial y gor arnadunt oc eu holl ynni.

20 Ac ual yd oed vn or Rufeinwyr yn ymordiwes a Gereint Garanbys, ef a troes arnab, ac a gleif ae g(bant tr6y y holl piesed f/33، arueu a throydab ehun, yny vyd yr Mabir y ar y varch yn var6. Ac ynablyghau a oruc Boso o Ryt Ychen, a throi y varch a oruc, ar kyntaf a gyvaruu ac ef, ef a ossodes

25 arnal yn y vogel, ac a rodes dyrnalit agheuabl idas, a chymell arnal ymadal ae varch ac ymadassu ar dayar. Ac ar hynny nachaf Marell Mut senedur oe holl ynni yn keissas dial Qsintilian ac yn ymordiwes a Gralchmei yn y ol ac yn mynnu y dala, pan ymchoelaud Goalchmei 30 arnalı yn gyflym, ac a chledyf Tad y benn yn gyfuch ae doy yscliyd; ac y gyt a hynny gorchymun idal, pan 5 mearure topank with \&ormmand elhei y uffern, menegi y Guintinal, yr honn a ladassei ef yn y pebyll, bot yn amyl gan y Brytanyeit y rys or boasting hoffter honno. Ac odyna ymbascu ae gedymdeithon 6 rejoin 
a dyGedut Grthunt ual hyn : "Dioer," heb ef, " kanys heb wybot $\mathrm{y}$ an brenhin y dechreuassam ni yr ymlad \$o guard agaust honn, reit oed yn ninheu ymoglyt rac an dyg(jydal yn $x$ $y^{1}$ ran waethaf or ymlad. Ac os uelly y dygoydon,

5 kollet maør oc an marchogyon a gohon, ac y gyt a hynny cyffroexcitement an brenhin a dygon ar gyffro ac irMoned orthym. Ac wrath Grth hynny geloch abch gleøder attabch, a chanlynGich vinheu droy vydinoed y Rufeinwyr. Ac o kanhorthbya fates, fortines an tyghetuenneu ni, ae Ilad Petrius ae dala ni a orvydon."

IO 44. Ac ar hynny dangos yr ysparduneu yr meirych a orugant, a throy vydinoed y marchogyon o ebroyd $=\$$ hreak through ruthur mynet drostunt hyt y Me yd oed Petrius yn dysgu y gedymdeithon. Ac yn gyflym Boso a gyrchasd

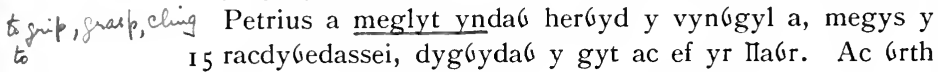
hynny ymgynullas a oneynt y Rufeinwyr y geissal y ymben $\operatorname{tgn}(n)$ yan ellog y gan y elynyon. Acor parth arall yd ympentyrrynt

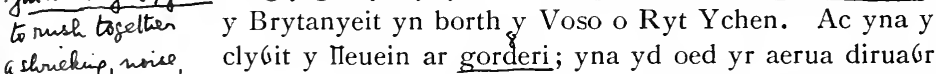
disturbance '20 o bop parth, hyt tra ytoedynt y Rufeinwyr yn keissal rydhau eu tybyssabc, ar Brytanyeit yn y attal. Ac yna dejawn th be able, y gellit goybot ply oreu a digonei a gbayb, pby oreu a
effect, do, accomplich saetheu, poy oreu a chledyf. Ac or diwed y Brytanyeit

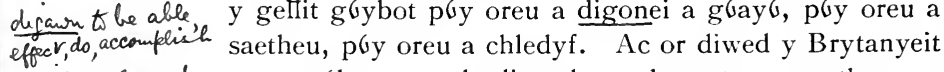
thechen closenp gan teohau eu bydinoed a dugant eu ruthur ar attached $?$ 25 karcharoryon gantunt droy vydinoed y Rufeinbyr, hyt pan vydynt ym perued kedernit eu hymlad ehunein a Phetrius gantunt. Ac yn y Me ymchoelut ar yr Rufeinwyr pelo ym Sifad (o) ymdiueit oc eu tywyssabc ac or ran vbyaf yn banach ac yn basgaredigach dangos eu kefneu a orugant orth ffo. 30 Ac 6rth hynny estug gantunt a inaeth y Brytanyeit, ac eu Mlad ac eu hyspeilab, ac erlit y rei a ffoynt, a dala damuman $t$ MaGer or rei a damunynt y eu dangos yr brenhin. Ac or desire, wish, seek for

$$
x \text { estiong }=\text { gestiong to lev down e. gantunt incunbentes }
$$


Fo array in troops, draw up in ballec array

Ev weaken to send, dispatch

Eraitars ballid, notle, illuctrious

wounded

$=$ Tintagel

I 78 THE STORY OF ARTHUR

iarll Kerny6, a Borel yn gyttywyssalic ida6. Ar taarranf Rufeinwyr kyrchu a wneynt heb geissal na Munyeithal pur in eu goyr nae bydinab, namyn oc eu holl lafur keissab goneuthur aerua or Brytanyeit, hyt tra yttoedynt Gynteu 5 yn bydinal eu gayr ac yn eu hamdiffyn ehunein. Ac wrth hynny gan eu g(tanhau yn ormod wynt yn dybryt a byly, fow gollassynt eu karcharoryon, pei na danuonei eu tyghetuen fate, fortum vdunt damunedic ganhorthly ar vrys. Kanys G6ittart

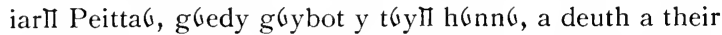
Io mil gantal. Ac or diwed gan nerth Dub ar kanhorthGy honne y Brytanyeit a oruuant, ac a talyssant eu haerua yrt toy lwyr. Ac eissoes yn y gyfranc kyntaf y collassant lawer. Kanys yna y collassant yr arderchalic tywyssabc Borel o Cenoman; yn kyuaruot ac Euander vrenhin Siria I 5 yn vrathedic gan y waeb y dygoydoys. Ina y kollassant hefyt petoar goyr bonhedigyon, nyt amgen, Hirlas o Piron a Meuruc o Gaer Geint ac Alidac o Dindagol a Hir uab Hydeir. Nyt oed halid kaffel guyr lebach nor rei hynny. Ac yr hynny ny chollassant y Brytanyeit 20 eu glewder, ${ }^{1}$ namyn oc eu Mauur kado eu karcharoryon. Ac or diwed ny allyssant y Rufeinwyr diodef eu ruthur, namyn yn gyflym ada's y maes a ffo parth ac eu pebyMeu, ar Brytanyeit yn eu herlit ac yn goneuthur aerua onadunt. Ac ny pheidassant yn eu dala ac yn eu Mad, 25 hyt pan ladassant Vltei a Chadell senedor ac Evander vrenhin Siria. A guedy caffel or Brytanyeit y vudugolyaeth honno, bynt a anuonassant y karcharoryon hyt ym Paris. Ar rei a dalyassant o newyd, Gynt ae hym[ch]oelassant ar Arthur eu brenhin oe dangos, gan 30 adal gobeith holl uudugolyaeth idal; kanys nifer mor ?3Phen. Phenerf. of caffel vychan a honno a gebssynt uudugolyaeth ar y sasl elynyon hynny. 
47. A gGiedy gGelet o Les amherabtyr Rufein meint y gollet ar dechreu y ryfel, trom a thrist uu gantab. A medylyas a oruc peidas ae darpar am ymlad ac Arthur a mynet y dinas AGuarn $y$ aros porth o newyd attab y gan Leo amheraødyr. A gwedy caffel o honal hynny yn y gyghor, $y$ nos honno ef a aeth hyt yn Legris. A goedy menegi hynny y Arthur, ynteu a raculaencys y fford ef. Ar nos honno, gan adal y dinas ar y $\Pi$ ab asseu idal, ef a aeth hyt y myun dyffryn y fford y kerdei Les amherabdyr ae lu. Ac yno y mynoys ef bydinal y Io wyr. Ac ef a erchis y Vorud iarl Kaer Loy 6 kymryt

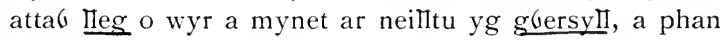
Slancester welei uot yn reit orthunt, dyfot yn ganhorthoy. Ac odyna y nifer oll y am hynny a ran6ys yn nal bydin, ac $y m$ pob bydin or nab chwe goyr a chwe ugeint a chwe i 5 chant a chwe mil, ar rei hynny yn gyweir o bop arueu, 6726 ar rann o bop bydin yn uarchogyon ar rann arall yn bedyt, a thywyssogyon y dyscu pob bydin yn y blaen. Ac yr vydin gyntaf y rodet Araon uab Kynuarch a Chador iarll Kernyb, vn yn yr anher deheu ar Mall yn yr anher 20 asseu. Ac yr vydin arall y rodet Gereint Garan孔ys a Boso o Ryt Ychen. Ac yr dryded y rodet Echel vrenhin Denmarc a Leu uab Kynuarch brenhin $\mathbb{L} y c h l y n$. Ac yr bedwared y rodet Howel uab Emyr $\mathbb{L}$ ydas a G(ialchmei uab GGyar, deu nei y Arthur. Ac yn ol y pedeir hynny 25 y gossodet pedeir bydin ereill drae kefyn oynteu. Ac yr behind them (firg $N_{0} 6$ gyntaf or rei hynny y rodet Kei benslydwr a Bedwyr bentrulyat. Ac yr nessaf idi y rodet Hodlyn iarl Ruthyn a Goittart iarM Peittal; ac yr tryded Owein o Gaer Leon a Ionathal o Gaer Weir; ac yr petwared 30 Warwick Vryen Vadon a Chursalem o Gaer Geint. Ac Arthur ehun a etholes ${ }^{1}$ Meg ida6 o varchogyon arualic o 
chwe goyr a chwe ugeint a chwe chant a ch6e mil. A $\underline{\text { rac }}$ in frouk, before bron Arthur sefylly dreic eureit, yrhonn a oed yn Me aroyd mstead of weary idab, megys y gellynt y gayr blin ar rei brathedic, pan anglen need,

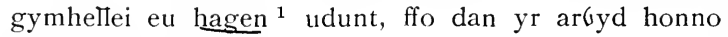
5 megys y gastell diogel.

48. A guedy Munyaethu palb yn y ansalid, Arthur a station dywalt val hynn urth y varchogyon: "Vyg kytuarsuffering with chogyon kytdiodeuedic $y m i,{ }^{2}$ chsi a snaethalich ynys Prydein yn argloydes ar dec teyrnas ar hugeint; y abch Io debred chis ac y abch molyant y kytdiolchaf ynheu trail hynny, y molyant nyt yttyo yn pallu nac yn dyffygyar, $8 / a i l$, lach

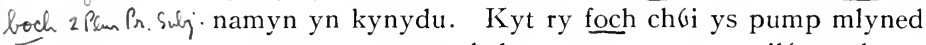
ease yn arueru o seguryt heb arueru o arueu a miloryaeth, yr hynny eissoes ny chollyssalich alich anyanalil dayoni, gooduess vintor, valow tremaincontinue 15 namyn yn wastat parhau yn ach bonhedic dayoni. Kanys y Rufeinwyr a gymellassabch ar ffo, y rei a oed pride, arrogance oc eu syberøyt yn keissal doyn abch rydit y gennoch, ac yn voy eu nifer nor einym ni. Ac ny allassant sefyll ugly, foul, base 3 Pl.Pres. yn alich erbyn, namyn yn dybryt ffo gan achub y dinas 20 honn. Ac yr abr honn y doant o honno droy y dyffryn $X \quad$ honn y gyrchu AGuarn. Ac yam hynn yma y gelloch chsitheu eu kaffel Gynt yn dirybud ac eu Mad megys deueit. Kanys gGyr y d6yrein a debygant ${ }^{3}$ bot Mesked ynabch ch6i, pan geissynt goneuthur abch golat yn 25 trethabl udunt a chwitheu yn geith udunt. Pony $\frac{\text { caelt }}{\text { captie }}$

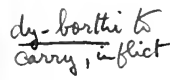
wybuant $6 y$ py ryd ymladeu a dyborthassabch chøi y wyr Lychlyn a Denmarc ac y tywyssogyon Freinc, y rei a oreskynassabch choi, ac a rydhayssalich y orth eu disgraceful hargloydiaeth waratoydus 6y? Ac Grth hynny, kan 30 gorfuam ni yn yr ymladeu kadarnaf hynny, heb amheu ni a orfydon yn yr ymladeu yscaon hynn, os o vn high,shghr, lasy. affection, nichination,
desire dihewyt ac o vn vryt y llafuryon y gyorarsagu yr hanner 1. MS. hageu 2 MS. yni 3 leg. debygynt cy-war-sangen to trample upon, oppress, crush. 


\section{tor belly; ar en tar against them \\ amog to unge, encourage, recommend}

coands gayr hynn. Py veint o enryded a medyant a chyfoeth a geiff palb ohonalich chGi, os megys kytvarchogyon ffydlaon yd ufudhelich chai ym gorchymynn ynheu? Kanys gGedy gorffom ni arnadunt, ni a gyrchon Rufein, $\checkmark$ possess a ni a gaffon y medu hi. Ac velly keff $6 \mathrm{ch}$ yr eur ar aryant ar Myssoed ar tired ar kestyll ar dinassoed; ac eu holl gyuoeth a geffich." Ac val yd oed yn dyGedut hynny Grthunt, paib o vn eir a gadarnassant bot yn gynt y diodefynt ageu noc yd ymedebynt ac ef, tra vei ef $\mathrm{ny}^{6}$ or blaen.

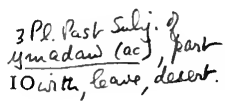

49. A gGedy goybot or amheraldyr y vrat yd oedit yn y darparu ida6, nyt ffo a oruc ef megys y darparyssei, namyn galo y lebder attab a chyrchu y dyffryn honno ar eu tor. A gals y tybyssogyon attab a dywedut 6 rthunt val hyn: "Tadeu enrydedus o arglGydiaeth, or rei y 15 dylyir kynal teyrnassoed y dayrein ${ }^{1}$ ar gorltebin yn darestygedic vdunt, koffe $6 \mathrm{ch}$ ych hendadeu, y rei yr gorescyn eu gelynyon ny ochelynt ellig eu priagt waet ehunein, namyn adac agreiff molyant yr rei a delei =anghreiffereample giedy Gynt. Ac velly yn vynych y goruydynt. A chan 20

oruot y gochelynt agheu, kanys ny dac y neb namyn yr neb y gGelho DuG, ar ansald y mynho DuG, ar amser y mynho. Ac Grth hynny yd achbaneckeynt hliy gyfoeth augmented, mereased

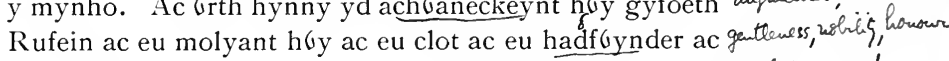
eu haelder. Ac o hynny y dyrchefynt 6ynt ac eu 25 both .. and harglbydiaeth ac eu hetiuedyon ar yr holl vyt. Ac Grth hynny gan damunal kyffroi ynaisch chwitheu y_kyfryb honno yd anogaf i hyt pan alsoch choi attauch auch anyana6l dayoni, a hyt pan safoch yndi gan gyrchu auch gelynyon yssyd yn auch aros yn y dyffryn honn 30 gan deissyfyt y gennuch auch dylyet. Ac na thebyguch y mae rac eu hofyn Gy y kyrcheis i y dinas honn, namyn

toprepare, intend

\section{obey}

\section{5}


o tebygu an herlit ni ohonunt hoy, ac yn de ohonam aerua diruabr eu meint ohonunt. A chanys yn amgen y gonaethant hay noc y tebygasson i, gonaon ninheu yn amgen noc $y$ tebygant Gynteu. Deisyfon ? 5 Gynt, ac yn leø kyrchon Gynt. A chyt gorffont, diodefon ni yn da y rythur gyntaf y gantunt; a velly heb amheu ni a oruydon. Kanys y neb a safo yn da yn y rythur gyntaf, mynych yo y vynet gan uudugolyaeth yn MaGer o ymladeu."

Ecome Eajass,

Io 5o. A gGedy daruot idal teruynu yr ymadrald honno happen affection, inclination, a Maber o rei ereill, pabb o vn dihewyt a rodassant eu doylab gan tygu nat ymedewynt ac ef; ac ar vrys gwisgab amdanunt eu harueu ac adas Legrys a chyrchu $v . p .181$ eager)

y dyffryn, y Me yd oed Arthur gGedy Munyaethu y

I 5 vydinoed. Ac yna gossot a onaethant hoynteu droy deudec bydin o varchogyon a phedyt yn herbyd 6,606 Rufeinall deuabt o chwe gGyr a thrugeint a chwe chant a chle mil ym pop bydin; ac ym pop vn ohonunt aleader, commander Ilybodyr, hyt pan vei o dysc honns y kyrchynt ac y due, pripee 20 kilynt, pan vei dylyedus udunt, ac y gorthGynebynt y eu gelynyon. Ac y vn or bydinoed $y$ rodes ${ }^{1}$ Les/ Kadell senedor o Rufein ac Aliphantina brenhin yr Yspaen, ac yr eil Hirtacus brenhin Parth a Meuruc senedor, ac yr tryded Bocus brenhin Nidif a Ganis

25 senedor, yr bedwared QGintus a Myrr senedor. Ar pedeir hynny a rodet yn y blaen. Ac yn ol y pedeir hynny y dodet pedeir ereill. Ac y vn or rei hynny y v. p.172 rodet Serx brenhin Ituri, ac yr eil Polites duc Ffrigia, of 172 yr tryded Pandrasius brenhin yr Eift, yr pedıared duc

30 Bitinia. Ac yn ol y rei hynny pedeir bydin ereill. Ac y vn ohonunt y rodet QGintus Carucius, ac yr eil iarm Lelli Hosti, yr tryded Sulpius, yr pedGared Marius 
senedør. Ac ynteu yr amherabtyr hont ac yma, yn = here o there (hunt
annoc y wyr ac yn eu dysgu py wed yd ymledynt. Ac = youden) $=t_{0}$ fix $\mathrm{ym}$ perued y $\Pi u$ yd erchis ef sefy eureit, yr honn a oed yn Me arbyd idab, ac erchi y baøp or a Gehenit y orth y vydin, gyrchu yno. Gwehaid Pasr 5

51. Ac or dified gGedy sefyll palb yn erbyn y gilyd Sulg. Pass of
5 gwahanu to separate onadunt y Brytanyeit or ne[i]

sound parth arall, pan glyussant sein yr arGydon, y vydin, yd oed brenhin yrYspaen ae gedymdeith yny Mywyal, ymgy-

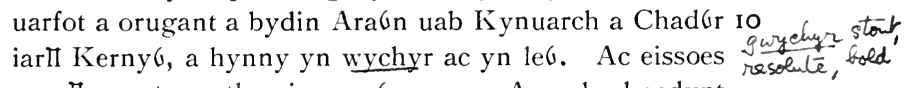
ny allyssant nae thorri nae glasgaru. Ac ual yd oedynt fience uelly yn ymlad yn dywal ac yn wychyr, nachaf Gereint Garanıys a Boso o Ryt Ychen ac eu bydin yn eu kyrchu sudden
indpected yn deissyfyt o rydec eu meirych, ac yn tyllu eu gelynyon $15 \%$ piere, wake a
breach through ac yn mynet drostunt, hyt pan gyfarfuant a bydin brenhin Parth, yr honn a yttoed yn kyrchu yn erbyn bydin Echel brenhin Denmarc a $\mathbb{L}$ eu vab Kynuarch brenhin $\mathbb{L} y c h l y n$. Ac yna heb vn gohir o bop parth ymgymysgu a onaethant y bydinoed, a mynet paib dros 20 y gilyd onadunt; ac aerua diruabr y meint o bop parth, ar Mleuein ar gorgeri yn Mlanb yr abyr o son; ar rei sound, woise Sbeat, stuke a throy eu goaet yn terfynu eu buched. Ac eissoes y kollet kyntaf a deuth yr Brytanyeit. Kanys Bedwyr a 25 las, a Chei a vrath6yt yn agheua(1. Kanys pan ymgyfarvu Vedwyr a brenhin Nidif, y brathayt a gleif yny dygaydays. A hyt tra yttoed Gei yn keissal dial Bedwyr, ym perued kat brenhin Nidif y brathbyt ynteu. Ac eissoes o defawt ${ }^{1}$ marchalic da, ar ystondard a oed 30 yn y lab gan lad a guasgaru y elynyon, agori fford idab a oruc; ac ae vydin gantal yn gyfan ef a doeth hyt ym 
di-Sarbod Econsides, care heb I. parmm cogitans Xgor-ahu to ery or call alond

I 84 THE STORY OF ARTHUR

plith y wyr ehunan, pei nar gyfarffei ac ef vydin brenhin Libia. Honnoa Gasgarbys y vydin ef yn hollabl, ac ynteu a ffoes a chorff BedGyr gantal hyt y dan y dragon eureit. Ac yna py veint o goynuan a oed gan wyr Normandi,

5 pan wellsant gorff eu tybyssabc yn vriGedic or sa@l welioed hynny? Py veint goynuan a sneynt wyr yr Angio 6rth welet gGelieu Kei eu tyGyssabc, pei kaffei neb encydspace oftime enkyt y goynas y gilyd gan y amdiffyn ehunan yg in the midst of kyfrig y bydinoed glaetlyt? bloody

Io 52. Ac orth hynny Hirlas nei Bedwyr yn gyffroedic o agheu Bedwyr a gymerth a gyt ac ef trychant marchalic,

a wild boar gelynawt hostile

a megys baed koet tray blith Masier o gon kyrchu droy blith y elynals vydinoed yr Me y gGelei arGyd brenhin Nidif, heb didarbot py beth a dambeinei idas gan gaffel I 5 dial y ebythyr ohonab. Ac or dised ef a gafas dyuot hyt y Me yd oed vrenhin Nidif, ac ae kymerth o blith y vydin, ac ae duc gantal hyt y the yd oed gorff Bedwyr,

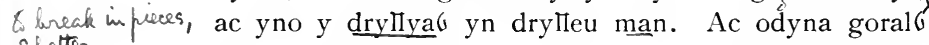
shatter

ar y gedymdeithon, a chan eu hannoc kyrchu eu 20 gelynyon yn vynych, megys gan atnewydu eu nerth, hyt pan yttoedynt eu gelynyon yn ofnabc ac eu callonoed 15 Tremble, quake chumpon Zcreulawn boesestrenglt: equent

yn crynu. Ac y gyt a hynny kyoreinach y kyrchynt y Brytanyeit oe dysc ynteu, a chreulonach y goneynt aerua. Ac Grth hynny grym ac angerd oe annoc ef a

25 gymerassant y Brytanyeit, a doyn ruthur y eu gelynyon; $\hbar$ attach ac o bop parth udunt diruasir aerua a orucpsyt. Y Rufeinwyr yna y gyt ac aneiryf o vilyoed y syrthassant. Yna y Mlas Aliphant vrenhi[n] yr Yspaen, a Misipia vrenhin Babilon, a Chointus Miluius, a Marius Lepidus 30 senedır. Ac o parth y Brytanyeit y syrthoys Hodlyn iarll Ruthun, a Leodogar iarl Bolbyn, a thri thycyssabc ereill o ynys Prydein, nyt amgen, Cursalem o Gaer Geint, a G(iallabic vab Lywynabc o Salsbri, $\not$ C $\operatorname{lol}$ Vryen o Gaer Vadon. Ac srth hynny guahanu a snaethant y bydinoed 
yd oedynt yn y Ilywyad, ac enkil drachefyn hyt ar y to retreat vydin yd oed Howel uab Emyr Lydas a Gralchmei uab GGyar yn y Ilywyað. A phan welas y glyr hynny eu kedymdeithon yn ffo, enynu o lit megys fflam yn enynu

a beath godeith, gan als y rei a oedynt ar ffo a chyrchu eu theindle, tire be
intfanced
5 gelynyon. A chymell ar ffo y rei a oedynt yn eu herlit Gynteu kyn no hynny gan eu bors ac eu Mad, a goneuthur aerua heb orfolys onadunt, hyt pan deuthant hyt ar vydin yr amheraødyr.

53. A phan welas yr amheraldyr yr aerua oe wyr, Io bryssyab a oruc yn borth udunt. Ac yna y gonaethplyt y Brytanyeit yn veirb; kanys Kynuarch tybyssabc Trigeri a doy vil y gyt ac ef a las yna. Ac yna y llas or parth arall trywyr, nyt amgen, Rigyfarch a Bolconi a Labin o Votlan. A phei bydynt tywyssogyon teyrnassoed, I 5 yr oessoed a delhynt gof hyt vrabt ac a enrydedynt eu molyant ac eu clot. Ac eissoes poy bynhac a gyfarffei a Hobel neu a Gbalchmei oc eu gelynyon, ny diagei ae eneit ganta6. A guedy eu dyuot, megys y dywesplyt uchot, hyt ym plith bydin yr amheraødyr, 20 iwrounded yn damgylchedic oc eu gelynyon y syrthassant y trybyr hynny. Ac Grth hynny Howel a GGalchmei, y rei ny magyssit yn yr oessoed kyn noc Gynt neb well noc bynt, pan welsant yr aerua oc eu kedymdeithon, yn Gychyr y kyrchassant hont ac yman, vn o bop parth yn gyffredin 25 5 harass yn dybalhau ac yn blinab bydin yr amherabdyr, ac \&uweary, moles, harass e. $\begin{aligned} & \text { leluelod } \\ & \text { loghtuing }\end{aligned}$ eu kedymdeithon; a Gral[ch]mei yn damunab oe holl dihewyt ymgaffel a tes amheralidyr y gymell arnal leger lold of icte peth a digonei ym miloryaeth. Ac nyt oed hald barnu 30 pby oreu, ae Hobel ae Gralchmei.

54. Ac odyna Gralchmei a gafas y damunedic hynt. Ac yn Gychyr kyrchu yr amheraldyr a oruc, a gossot arnal. Ac eissoes Les, megys yd oed yn dechreu 
Kflomish, prospen blodeual dewred y ieuenctit ac yn valor y ynni, nyt oed well dim gantal ynteu noc ymgaffel ar rys uarchabc clotualir honn6, yr honn a gymellei y wybot beth vei $y$ angerd ae debred. Ac Grth hynny diruabr lebenyd a

5 gymerth yndab wrth ymgaffel ohonas a gor kynglotuorusset a G6alchmei. Ac ymerbynyeit yn galet a onaeth $\times$ toncounter, pob vn ae gilid, megys na belat rog deu vilor ymlad a gyffelypit y honnw. A phan yttoedynt by yn nesidyal kaledyon dyrnodeu, a phob vn yn Mafuryas agheu y $\hbar$ rush logether Io gilyd, nachaf y Rufeinwyr ynn ympentyryal yn eukylch, vifour combrat ParV Pass.

hyt pan vu reit y Walchmei a Howel ac eu bydinoed enkilyas hyt ar vydin Arthur, gan eu Mad or Rufeinwyr yn drut. drud botd, arregant, wriced

55. A phan welas Arthur yr aerua yd oedit yn y

I 5 wneuthur oe wyr ef, tynu Caletvalch y gledyf goreu a unaeth, ac yn vchel dycedut val hynn: "Py achals y gedıch chøi y gareicolyon wyr hynn y genbch? Nac aet vn yn vys onadunt, nac aet. Kofferich alich deheuoed, y rei yn gyfriys yn y sall ymladeu kyn no 20 hynn a darestygassant dec teyrnas ar hugeint (orth vym medyant. Koffelich alich hendadeu, y rei, pan oedynt gadarnach g6yr Rufein no hedis, ae gonaethant yn drethalil udunt. Koffelich alich rydit, yr honn y mae yr cowands hanher goyr hynn yn keissab y doyn y genfich. Ac orth 25 hynny nac aet vn yn vyú onadunt, nac aet." A chan dywedut yr ymadrodyon hynny, kyrchu y elynyon ac eu bor6 dan y draet ac eu Mad. A phøy bynnac a gyfarffei ac ef, o vn dyrnalit y Madei ac ef ae varch. Ac 6 rth hynny palb a foynt racdal, megys y foynt aniueileit rac

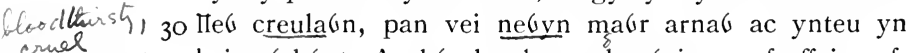
botit. ans hunger by chance keissal blyt. A phby bynhac o dambein a gyfarffei ac ef, 3 ss Pask suby. nys differei y arueu ef rac Caletublch, hyt pan vei reit of diffrd(rac), idab talu y eneit y gyt ae waet. Deu urenhin oc eu defend, provect (from) drycdambein a gyfaruuant ac ef, Sertor brenhin Libia abouthorom Wh. of guraigawl

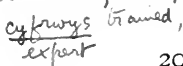


Trechaf strangest (superl of tren)

\section{THE STORY OF ARTHUR}

187

a Pholites brenhin Bitinia. Ar deu hynny gredy Itad eu cut of penneu a anuones Arthur y Rufein.

56. A guedy guelet or Brytanyeit eu brenhin yn ymlad uelly, ${ }^{1}$ gleoder ac ehofynder a gymerassant, a chan tebhau utendip $t$ eu bydinoed o vn vryt kyrchu y Rufeinwyr gan darparu break inrage mynet drostunt. Ac eissoes gorthoynebu yn wychyra oruc y Rufeinwyr udunt, ac o dysc Les amheraldyr Mafuryal y $x \quad$ talu aerua yr Brytanyeit. A chymeint uu yr ymlad yna o bop parth a chyt pei $^{2}$ yr abr honno y dechreuynt yr ymlad. Or neill parth yd oed yr arderchalc vrenhin $\mathrm{o}$ Arthur yn Mad y elynyon, ac yn annoc y wyr y sefyn yn oraø1. Ac or parth arall yd oed Les amheraldyr yn annoc y Rufeinwyr ac yn eu dysgu ac yn eu moli. Ac ny orfobyssei ynteu yn Mad ac yn bors y elynyon ac yn 8 strake, ove throw kylchynu y vydinoed ehun. A phy elyn bynac a 15 gyfarffei ac ef, a gorayb neu a chledyf y Madei. Ac uelly o bop parth y bydei Arthur yn goneuthur aerua. Kanys gGeitheu y bydynt trechaf ${ }^{3}$ y Brytanyeit, gGeitheu ereill y bydynt ${ }^{4}$ trechaf $^{3}$ y Rufeinwyr. A phan yttoedynt (queithen $\bar{z}_{\text {somes }}$ ) h6y $y^{5}$ yn yr ymfust honn6, heb wybot py di6 y dambeinei 20 to whom $680 \mathrm{~N}_{4}$ y vudugolyaeth, nachaf Morud iaril Caer Loyb yn dyuot ar Ileg a dybedassam ni y hadab uchot yg guersyll, ac yn deissyfy $t^{6}$ yn kyrchu eu gelynyon yn dirybud or tu yn $\mathrm{eu}^{7}$ hol ac yn mynet drostunt, gan eu guasgaru a goneuthur aerua diruabr y meint. Ac yna y syrthassant ${ }^{8} 25$ MaGer o vilyoed or Rufeinwyr. Ac yna y dygaydoys Les amheraødyr yn vrathedic gan leif neb vn, ac y bu varb. Ac yna, kyt bei droy diruabr lafur, y Brytanyeit a galssant y maes. ${ }^{9}=$ won the day imals = open field, baltefeid)

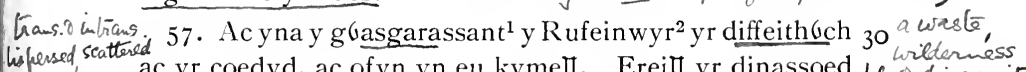
ac yr coedyd, ac ofyn yn eu kymelt. Ereill yr dinassoed per de dinas city,

(Ch. 56). 1 y velly? the initial letters are illegible, 2 chyn bei, 3 drechaf, 4 bydei, 5 by, 6 deissyfedic, $7 \mathrm{y}, 8$ syrthysant, 9 ar goruot add. (Ch. 57). 1 gvasgaryssant, 2 rei $a d d$. 
ar kesty $\Pi$ ac yr Пleoed kadarn y ffoynt; ar Brytanyeit oc eu hol $\mathrm{yn}^{3}$ eu hymlit, aco druanaf aerua ${ }^{4}$ yn eu Mad ac yn eu dala ac yn eu hyspeilas. Ac uelly megys y rodynt y ran vbyaf $^{5}$ onadunt eu doylas yn wreigasl y eu thind, gind 5 roymal ac y eu karcharu, y geissal ystynu ychydic $\mathrm{y}^{6}$ eu hoedel. A hynny ${ }^{7}$ o jaln vrabt ${ }^{8}$ Dus. Kanys eu hendadeu Gynteu kyn no hynny yn andylyedus a onathoedynt ${ }^{9}$ y Brytanyeit yn drethasl udunt; ar trufuse Brytanyeit yna yn nackau udunt y dreth yd oedynt yn IO andylyedus yn y cheissal gantunt. ${ }^{10}$

58. A gGedy caffel o Arthur y vudugolyaeth, ef a erchis gGahanu ar neilltu ${ }^{1}$ kalaned y wyrda ef y Grth $y$ elyna(sl galaned ac eu kyGeiryab o vrenhinall defalst, ac eu døyn $\mathrm{yr}^{2}$ manachlogoed a vei yn eu golat yn ansodedic, I 5 ac yno eu cladu yn enrydedus. Ac yna y ducpayt corff Bedwyr hyt y dinas ehun yn Normandi gan diruabr goynuan $y^{3}$ gan y Normanyeit. Ac yno y myon mynoent ar deheu y dinas y clad 6 yt yn enrydedus gyr ${ }^{4} \Pi a b^{6}$ y mur. Kei a ducpoyt yn urathedic hyt yg Kam, y kaste $\Pi^{5}$ a 20 (nnathoed ${ }^{6}$ ehun. Ac yno ny bu bell goedy hynny yny $\mathrm{vu}^{7}$ uars $\mathrm{Kei}^{8}$ or brath honn6. Ac yn y fforest a oed yn agos yno y myon manachlabc ermitwyr or enryded a dylyei iarll yr Angia y cladøyt. Hodlyn tybyssalic a ducpayt hyt $\mathrm{y}^{9}$ dinas ehun, yr hon a eloir y Tyruan, ac 25 yno y cladayt. Y goyrda ereill a erchis Arthur eu døyn yr manachlogoed nessaf udunt ar hyt y golatoed. ${ }^{10}$ Ac $\mathrm{yna}^{11} \mathrm{yd}$ erchis ef y $6 \mathrm{yr}$ y wlat honno cladu y elynyon, ${ }^{12}$ ac anuon corff Les amheraldyr hyt yn sened Rufein. Ac erchi menegi udunt na dylyynt hoy ${ }^{1314}$ teyrnget o ynys 30 Prydein amgen no honno. Ac yno y bu Arthur y gayaf

(Ch. 57). 3 oc eu holl ynni yn, 4 agheu, 5 vryatf, 6 om., 7 ac uelly, 8 varn, 9 wnaethoedynt, $10 \mathrm{yn}$ y cheissav yn andylyedus y ganthunt

(Cl. 58). 1 grvahanu a neilltua, 2 yr, $3 \mathrm{om}$., 4 ger, 5 hyt-kastell : hyt y casteII, 6 wnaethoed, 7 yny vu: y bu, 8 om., 9 yn y, 10 gvladoed, 11 odyna, 12 gelynyon, 13 vy, 14 tremygu y brytanyeit nac erchi add. 
hanno yn goresgyn y dinassoed y Murgoin. ${ }^{15}$ A phan yttoed yr haf yn dechreu dyuot, ac Arthur yn ysgynu mynyd Mynheeu ${ }^{16}$ Grth vynet parth a Rufein, nachaf genadeu o ynys Prydein yn menegi y Arthur ry daruot ${ }^{17}$ y Vedrabt y nei, uab y chøaer, goresgyn ${ }^{18}$ ynys Prydein a 5 g(isgab19 coron y teyrnas am y pen ${ }^{20}$ ehun $^{21} \mathrm{dr}$ (by greulonder a brat, a thynu22 GGenhGyfar vrenhines oe rieingadeir a ry gysgu ${ }^{23}$ genti, gan lygru kyfreith violate dGywall y neithoreu. ${ }^{24}$ pe. of neithawer a wedding feast

59. A gGedy menegi hynny y Arthur, yn y $\prod_{e}$ peidya $6^{1}$ io a oruc ae darpar am vynet y Rufein, ac ymchoelut parth ac ynys Prydein, a brenhined yr ynyssed y gyt ac ef. A gellig Howel uab ${ }^{2}$ Emyr Lydas a Mu gantas y tagnefedu ac y hedychu y golladoed. ${ }^{3}$ Kanys yr accursed yscymunedickaf ${ }^{4}$ vrador gan Vedrabit a anuonassei I5 Cheldric ${ }^{5}$ ty 6 yssabc y Saeson hyt yn Germania y gynulta، y Thu moyaf a gallei yn borth idab. A rodi udunt a oruc o Humyr hyt yn Yscotlont, ac yn ach(ianec kymeint ac a uuassei $\mathrm{y}^{6}$ Hors a Heingyst ${ }^{7}$ kyn no hynny yg Kent. ${ }^{8}$ Ac Grth hynny y deuth Cheldric ac Gyth cant ${ }^{9}$ Mog yn Masn 20 o wyr aruabic ganta610 o baganyeit, ${ }^{11}$ a gorhau y Vedrabt \& pay homage to oby ac ufudhau megys $y$ vrenhin. Ac neur daroed idas saccompany, gedymdeithockau atal yr Yscottyeit ar Ffichteit, a phalb pastsuly. or a (yypei ef idal gassau y ewythyr, ${ }^{12}$ hyt pan yttoedynt oll petwar ${ }^{13}$ ugein mil $\mathrm{r}$ (6g Cristonogyon a phaganyeit. 25

6o. Ac a hynny o nifer gantal y deuth Medralit ${ }^{1}$ hyt yn aber Temys, y lle yd oedynt Mogeu Arthur yn disgynnu. A guedy dechreu ymlad, ef $a^{2}$ wnaeth aerua diruabr

(Ch 58). 15 gvreseyn dinassoed borgoyn, 16 mynheu, 17 darvot? 18 grerescyn, 19 arwisgal ? 20 ben, 21 om., 22 thynhu, 23 chysgu, ry om. 24 neithoryeu

(Ch. 59). 1 peidal, 2 ac ellvg hvel m., 3 gvledi, 4 yscymunediccaf. 5 chledric, 6 om., 7 hengist, 8 ygrkeint, 9 ean, $10 \mathrm{om}$., 11 paganyeit, 12 The word before hyt is (a)rthur; between pav(b) and this there is a hole in the MS., 13 The initial letters scem to be deu, what follows is illegible

(Ch. 60). $1 \mathrm{om}$.

$X\left\{\begin{array}{l}v \text {. Gloss. I can " "That most accursed } \\ \text { Traitor of a Medrawd" } \\ \text { of. } 190,10 \\ 192,2,5\end{array}\right.$ 
onadunt yn dyuot yr tir. Kanys yna y dygoydassant Araon uab Kynuarch, brenhin Yscotlont, a GGalchme[i] ${ }^{3}$ uab $^{4}$ GGyar. Ac yn ol Araon y deuth Owein vab ${ }^{4}$ Vryen yn vrenhin yn Reget, y gor gGedy hynny a vu clotuabr 5 yn Maber o gynhenneu. Ac or diwed, kyt ${ }^{5}$ bei dr6y diruabr lafur a throy eu $\Pi$ Tad, ${ }^{6}$ Arthur ae lu a gafas y tir. A chan talu yr aerua oynt a gymellassant Vedrabt ${ }^{7}$ ae lu ar ffo. A chyn bei mwy eiryf Mu Medrabt no Пlu Arthur, shiefful, curning necessary Io ymladeu. ${ }^{8}$ Ac 6 rth hynny y bu dir yr anudona $61^{9}$ gan perjured, eissoes kywreinach a doethach yd ymledynt o beunydya(1 daily of. 189,15; $192,2,5$ 'dress' a halit monestic

Vedralt gymryt y ffo. Ar nos honno, gledy ymgynullab wichereds, y wascaredic ${ }^{10}$ lu y gyt, yd aeth hyt yg Kaer Wynt. A Winchester goedy clybot o Wenhoyuar ${ }^{11}$ hynny, diobeithas a oruc, a mynet o Gaer Efralic hyt yg Kaer ${ }^{12}$ Lion ar Wysc. I $5 \mathrm{Ac}^{13}$ y my $6 \mathrm{n}$ manachlabc goraged $\mathrm{a}^{14}$ oed yno grisgab $\mathrm{yr}$ abit ymdanei ac adal cado y diseirdeb yn eu plith o chastity hynny allan. Ar abit honno a vu ymdanei hyt agheu.

61. Ac odyna Arthur a gymerth Mit mabr yndab am golli ${ }^{1}$ ohonal y sall vilioed hynny, a pheri cladu y wyr. 20 Ar trydyd dyd kyrchu Caer Wynt a oruc ac yn diannot y chylchynu. Ac yr hynny ny pheidays Medralt ar hynn a dechreuassei, namyn, gan annoc y wyr, eu gossot yn vydinoed a mynet allan or dinas y ymlad ac Arthur y ewythyr. A goedy dechreu ymlad, aerua valor o pob 25 parth a wnaethant. Ac eissoes moyaf vu yr aerua o wyr ugly, foul, base Medrabt; ac yn dybryt kymell arnal adal y maes. Ac han-burllaw ny hanboy lloys ${ }^{2}$ Medrabt yna gohir orth gladu y toconsider romember ladedigyon, namyn ffo a oruc parth a Chernyb. pryderus anxious

62. Ac wrth hynny Arthur, yn bryderus ac yn Midiabc

(Ch. 60). 2 aeth ac a add., 3 goalchmei, 4 mab, 5 only ky is lergible, 6 a throy eu Ilad om., 7 medravt, 8 o beunydyaul ymladeu : wyr arthur, kanys kyfroys oedynt o peunydyaol ymlad, 9 kelwydaoc add., 10 gbasgaredigyon, 11 vrenhines add., 12 ygkaer, 13 yno add., $14 \mathrm{om}$.

(Ch. 61). 1 rygolli, 2 handenvys 


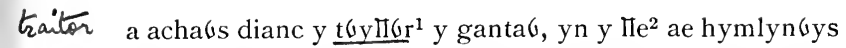
hyt y wlat honno hyt ar lan Kamlan, y lle yd oed Vedrabt yn y aros. ${ }^{3}$ Ac Grth hynny megys yd oed Vedrabt glebaf a goychraf yn cyrchu, yn y Ile gossot y varchogyon yn vydinoed a oruc. Kanys grell oed ganta6 y lad neu ynteu a orffei, no ffo yn hoy no hynny. Kanys yd oed ettwa ganta6 o eiryf trugein mil. Ac o hynny y gonaeth ef whech ${ }^{4}$ bydin, a whech ${ }^{5}$ guyr a

\section{5} 3 ss Past. Sulf: O coin-ied to overeome, confuer thrugeint a chwe ${ }^{6}$ chant a chwe $e^{6}$ mil ym pob bydin o wyr aruabc. Ac or rei nyt aed ${ }^{7}$ yn y chwech ${ }^{4}$ bydin ef a 10 wnaeth bydin idas ehun, a rodi Mywodron y bop vn or rei ereill oll. ${ }^{8}$ A dyscu parb onadunt ac eu hannoc y ymlad a oruc, gan adaí udunt enryded a chyfoeth, os ef a orffei. Ac or parth arall Arthur a ossodes y wyr ${ }^{9}$ lleidys a ynteu dr6y na6 bydin; a gorchymyn y balo onadunt ${ }^{10}$ I 5 o wladoed ereill o dysc y brator ${ }^{12}$ y geissal y digyfoethi ynteu. "Ar bobyl a GelGch ${ }^{13}$ racko," heb Arthur, " $\mathrm{a}^{14}$ gynull6yt o wlatoed 15 amryfaelong ac aghyfyeith ${ }_{1}$ ynt a

eble, faint Ilesc ag aghyfroys ar ymlad. Ac ny allant gorthóynebu 20 untrained, yGch, kanys kyfrays ybich ch6i.",16 Ac velly palb onadunt yn annoc y wyr or parth arall. ${ }^{17}$ Ac yn deissyfyt ym- sudden, uncexpected! gyfaruot a onaeth y bydinoed yghyt, ${ }^{18}$ a dechreu ymlad a hange blows newidyal dyrnodeu yn vynych. A chymeint vu yr aerua yna o bop parth ac megys yd oed gGynfan ${ }^{19}$ y rei 25 a laventw Sarouse meirs yn kyffroi y rei by 6 ar lit ac ymlad, ac megys yd seary, oed blin a Tlafuryus ${ }^{20}$ y yscriuenu nae datkanu. Kanys prisomere. o bop parth y brethynt ac y brethit Gynteu; Gynt a ledynt Imperf. Ind. Pass.

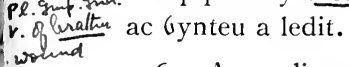

63. Ac or diwed gGedy treulab MaGer or dyd yn y mod

(Ch. 62). I y mynychet honno $a d d ., 2$ ef $a d d . .3$ arhos, 4 whech, 5 the, 6 whe, 7 aeth, 8 rodi Ilywodraeth $y$ pop bydin oll, $9 \mathrm{lu}, 10$ ohonunt, 11 ysgymun, 12 brador, 13 welhochi, 14 ar, 15 wladoed, 16 y $6 \mathrm{chi}, 17$ or parth arall : o pop parth, 18 ygyt, 19 koynuan, 20 Ilafurus

\author{
accursed \\ To dis possess, depries \\ of tavitarý


guychye stour, resolute, bold girad lamentable, piteous, terrible crcu-lawn Glosdthirsty, cruel

192

honn6, Arthur ae vydin a gyrch6ys y vydin y g6ydat ${ }^{1}$ of 189,15 ; bot y toyllor gan Vedrabt yndi, ${ }^{2}$ ac agori ffyrd udunt ar 190,11 clefydeu, ${ }^{3}$ ac yn diannot mynet drostunt, a goneuthur ${ }^{4}$ aerua diruab $\mathrm{r}^{5}$ onadunt. Kanys yn y Me y dygGydGys 1. 5 yr yscymunedickaf ${ }^{6}$ vrador honn6 gan Vedrabt, a MaGer o vilioed y gyt ac ef. Ac eissoes yr hynny ny ffoyssant ${ }^{7}$ Wfock logetter y rei ereill, namyn ymgynullab y gyt ${ }^{8}$ or maes on, ac yn heroyd eu gleøder keissal ymgynhal a gorthoynebu y Arthur. Ac Grth hynny goychraf a girattaf ${ }^{9}$ a Io chreulonaf aerua a vu y rydunt yna o bop parth, ac eu bydinoed yn syrthal. Ac yna o bop ${ }^{10}$ parth $y^{10}$ Vedrabt $y$ syrthassant ${ }^{11}$ Cheldric $^{12}$ ac Elafy ${ }^{6},{ }^{13}$ Egberinc ${ }^{10}$ brenhin or Saeson; or G6ydyl Gilapadric, ${ }^{14}$ Gillamori, Gillasel, Gillamor. ${ }^{15}$ Yr Yscottyeit ar Ffichteit ac oynt ac eu bith .. an well-migh, ahost 15 hargloydi oll hayach a las. Ac o bleit ${ }^{16}$ Arthur y Mas on the side of Osbrinc brenhin $\mathbb{L} y c h l y n$, Echel brenhin Denmarc, ${ }^{17}$ Kador Lemenic ${ }^{18}$ iarl Kernyb, Kasballaøn, a MaGer o leg. viliaed. vililioed ${ }^{19} \mathrm{y}$ gyt ac $6 y n t e u,{ }^{20} \mathrm{r} 6 \mathrm{~g}$ y Brytanyeit a chenedloed ereill a ducsynt y gyt ac Gynt. Ac ynteu yr arderchabc

20 vrenhin Arthur a vrath6yt yn agheuab1, ac a ducplyt Avalcou odyna hyt yn ynys Avallach y iachau y welieu. Coron $y^{21}$ teyrnas o ynys Prydein a gymynnoys ynteu y deadly; mortall
wounded
th leal his
wounds 542 A.D. Gustenin ${ }^{22}$ vab Kador iarll Kerny6 y gar. Doy vlyned a deugeint ${ }^{23}$ a phump kant goedy dyfot Crist yg knabt 25 dyn oed hynny yna.

X (Ch. 63). 1 goydyat, 2 yndianc, 3 cledvfeu, 4 tristaf, 5 om., 6 ysgymunediceaf, 7 foassant, 8 yghyt, 9 girattaff, 10 om., 11 syrthyssant, 12 chledric, 13 elefy6ys, 14 gillapadric, 15 gillamor gillasel gillamori, 16 pleit, 17 denmarch, 18 Îymenie, 19 vilyoed, 20 6ynt, 21 om., 22 gustenlin, 23 deu vgeint

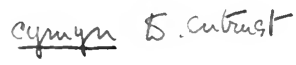




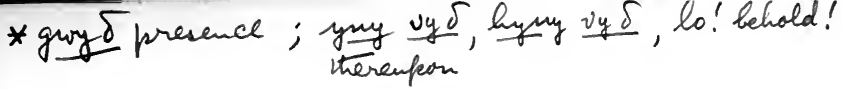

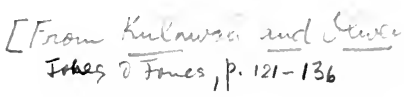

\section{THE HUNTING OF TWRCH TRWYTH.}

= hyd uehen tite evening

I. Kerdet a orugant $\omega \dot{y} \dot{y}$ dy்d honn

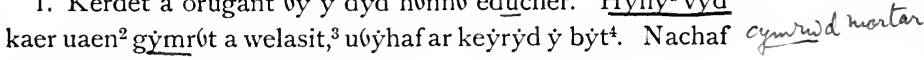
gor ${ }^{5}$ du $m 6 \dot{y}^{6}$ no thr $\dot{y}\left(\dot{y} \mathrm{r}^{7} \dot{y}\right.$ byt h(inn a welant ${ }^{8} \dot{y}$ dyuot or said they gaer. Amkeudant ${ }^{9}$ (rthal: "Pan doy ti, ${ }^{10}$ (rr?" "Or gaer a amcandsand weloch ch(i ýna."11 "Pieu $\dot{y}$ gaer?"12 "Meredic a wỳr

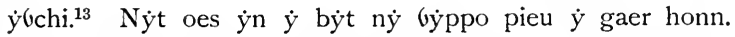
Wrnach Gaur pieu."14 "P $\dot{y}$ uoes $\dot{y} s s \dot{y} d \dot{y}$ osp a phellenhic $\dot{y}$ diskỷnnu ỳn ẏ gaer honn?" “Ha vnben, Dul ach notho! ${ }^{15}$

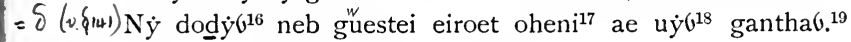

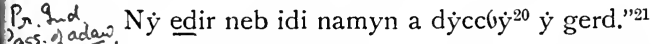

2. Ky்rchu yं porth a orugant. Amkaud ${ }^{1}$ Gorhy்r Gualstabt Ieithoet: "A oes porthaur?"2 "Oes. A titheu ${ }^{3}$ ny bo

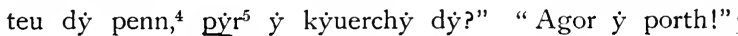

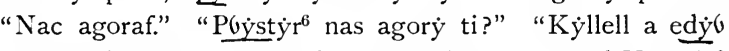
$\dot{y} \mathrm{~m}$ mby $\mathrm{t}^{7}$ a llỷnn $\dot{\mathrm{y}}$ mual, ${ }^{8}$ ac amsathỳr ýn neuad Vrnach. ${ }^{9}$ Namýn ý gerdaur a dýcc $\dot{y}^{10} \dot{y}$ gerd ny்t agorir."11 Amkaud

Kei :12 " $\dot{Y}$ porthaor, $\dot{y}$ mae kerd genhýf i." "Pa gerd $\dot{y} s s \dot{y} d$ genhỳt ti?" "Ý "Mi a af $\dot{y}$ dy்wedut hy்nny் $\dot{y} V$ rnach $^{13}$ Gaor, ac a dy்gaf atteb $\dot{y t} . "$

Variants $\mathrm{H}=$ Red Book of Hergest, P= Peniarth MS. $1 \mathrm{~V}$.

(Ch. 1). 1 yny H, 2 uavr $H, 3$ welynt $H, 4$ voyhaf or byt $H, 5$ or $\mathrm{H}, 6$ oed $a d d . \mathrm{H}, 7$ yn add. $\mathrm{H}, 8$ a welant om. $\mathrm{H}, 9$ ac $\mathrm{y}$ dywedassant oynteu $\mathrm{H}, 10$ deuy di $\mathrm{H}$. 11 racco $\mathrm{H}, 12$ heb oynt add. $\mathrm{H}, 13$ yuch choi $\mathrm{H}$, 14 bieu $\mathrm{H}, 15$ nodho $\mathrm{H}, 16$ deuth $\mathrm{H}, 17$ eiryoet ohonei $\mathrm{H}$, 18 vywyt $\mathrm{H}$, 19 ganta6 $\mathrm{H}, 20$ dycko $\mathrm{H}, 21$ gantas $a d d$.

(Ch. 2). 1 heb y H, 2 borthaor $\mathrm{H}, 3$ thitheu $\mathrm{H}, 4 \mathrm{dy}$ dauavt yth benn $\mathrm{H}, 5$ py rac $\mathrm{H}, 6$ Py ystyr $\mathrm{H}, 7$ boyt $\mathrm{H}, 8 \mathrm{ym}$ bual $\mathrm{H}, 9$ ornach gaor $\mathrm{H}$, 10 dycko $\mathrm{H}, 11$ yma heno bellach add. $\mathrm{H}, 12$ Heb y kei yna $\mathrm{H}$, 13 ornach $\mathrm{H}$ 


\section{agalen f. a whetstone}

cleis a stripe

maen cleis marble

groynseid having a white haft grumseid having a dark-coloured

\section{THE HUNTING OF TWRCH TRWYTH}

3. Dýuot a oruc $\dot{y}$ porthaur $\dot{y}$ my்on. Dýwabt ${ }^{1}$ Wrnach

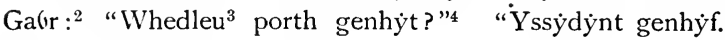

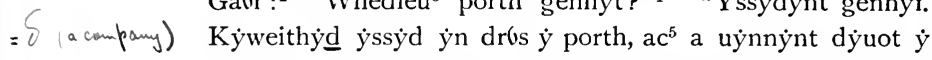
mý(n." "A ouỳnneist ti ${ }^{6}$ a oed gerd ganthunt?" "Gouỷnneis. ${ }^{8}$

5 Ac vn onadunt a dỳwabt gallel ${ }^{9}$ ýslipanu cledẏueu." 10 "Oed"

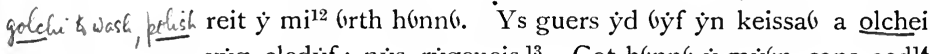

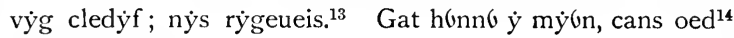
gerd ganthar."

iwill. Mabs.

4. Dýuot ${ }^{1} \dot{y}$ porthaur ac agori $\dot{y}$ porth. A dỷuot Kei $\dot{y}$ Io my்on ehun. A chýuarch guell a oruc ef $\dot{y}$ Wrnach Gairr. Kadeir a dodet $\dot{y}$ danab. ${ }^{2}$ Dýwalt ${ }^{3} \mathrm{Wrnach}^{4}$ : "Ha or, ae goir a dy்wedir arnat gallel ${ }^{5}$ ýslipanu cledẏueu?" " Mi ae

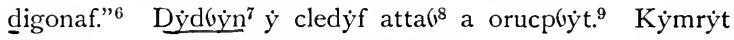
agalen gleis a oruc Kei $\dot{y}$ dan $\dot{y}$ geffeil. "P(ýy well genhỳt cesseil

dys wyn k bing Messeil ceseil as $y$ 15 arna6,, 10 ae guỷnseit ae grimseit?" "Yr honn a uo da genhỳt ti, malpei teu uei, gona arnab." Glanhau a oruc hanher $\dot{y}$ lleill gỳllell idar, ae rodi $\dot{y} n \dot{y}$ la a oruc. "A reinc dy் uod di hỷnny்?" "Oed well genhy்f noc ýssy்d ẏm golat, bei oll ýt uei" val hỷnn. Dỷhed a beth bot gor kýstal "one side gite lled Anclive fo. 20 a thi heb gedẏmdeith." "Oia orda, mae ${ }^{12}$ imi gedẏmdeith

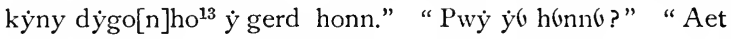
$\dot{y}$ porthaur allan, a mi a dy்wedaf ar aróydon idau. ${ }^{14}$ Penn $\dot{y}$

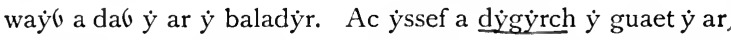
y guỷnt ac a diskỷn ar $\dot{y}$ baladýr." ${ }^{15}$ Agori $\dot{y}$ porth a upon, dia 25 wnaethpoỳt, a dýuot Bedwýr $\dot{y}$ mýon. Dýwabt ${ }^{16}$ Kei : victorious, giglted "Budugaul $\dot{y} 6$ Bedwỳr, kỳn ny் digonho" ${ }^{17} \dot{y}$ gerd hon." X "CCi toin a struped whetistone from under his arm"

(Ch. 3). 1 ac y dywavt $H, 2$ orthav $H, 3$ chwedleu $H, 4$ y gennyt $H$, in $\mathrm{P}, \mathrm{y}$ has been added over the line, $5 \mathrm{om}$. $\mathbf{H}, 6$ ouynneist di $\mathbf{H}$, 7 gantunt hoy H, 8 heb ef add. H, 9 goybot H, 10 ohonab yn da $a d d . \mathrm{H}$, 11 as oed $\mathrm{H}, 12$ ynni $\mathrm{H}, 13$ ac nys keueis $\mathrm{H}, 14$ kan oes $H$

(Ch. 4). 1 a orue $\mathrm{H}, 2$ geyr bron gornach add. $\mathrm{H}, 3$ ac y dywabt $\mathrm{H}$, 4 orthav add. H, 5 arnat ti y godost $\mathrm{H}, 6 \mathrm{Mi}$ a onn hynn yn da heb y kei $\mathrm{H}$, 7 Doyn H, 8 ornach H, 9 wnaethpoyt atta6 $H, 10$ a gouyn or deu poy oed oreu gantal $\mathrm{H}, 11$ pei bei oll ual $\mathrm{H}, 12$ y mae ymi $\mathrm{H}, 13$ dycko $\mathrm{H}$, 14 ida6 $\mathrm{y}$ arwydon $\mathrm{H}, 15$ eilweith add. $\mathrm{H}, 16$ ac y dywa t $\mathrm{H}, 17$ wypo $\mathrm{H}$

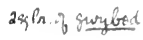
dyheo discardant, strange? pitcons, a pity? dyher a bett "i digawn to be able, effect, do, accomplish; forind. isp. digonof 
cyllell-bren the wooden lath of a scabbard

\section{THE HUNTING OF TWRCH TRWYTH 195}

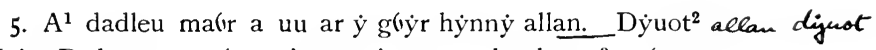
Kei a Bedwỳr $\dot{y}$ mýon. A guas ieuanc a doeth gy $\mathbf{t}^{3}$ ac by்nt $\dot{y}$ mÿon, vn mab Custennhin heussabr. Sef a onaeth ef ae kerdsman

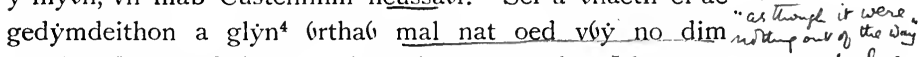
ganthunt $^{5}$ : mýnet $^{6}$ dros $\dot{y}$ teir catlýs a wnaethant ${ }^{7}$ hýt pan dýuant $^{8} \dot{y}$ mýon $\dot{y}$ gaer. Amkeudant ${ }^{9} \dot{y}$ gedymdeithon orth vab Custenhin: "Goreu dy்n $\dot{y}\left(1 ., \mathrm{O}^{11}\right.$ hỷnny் allan $\dot{y}$ gelwit Goreu mab Custenhin. Guascaru a orugant $6 \dot{y} \dot{y}$ eu

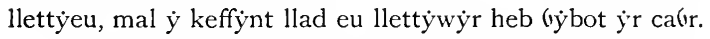

6. $\dot{Y}$ cledýf a daruu $\dot{y}$ (rrteith. Ae rodi a oruc Kei $\dot{y} n$ llab Io gurtenit. 5 , tressing Wrnach Kaor, ${ }^{1} \dot{y}$ malphei $\dot{y}$ edrych a ranghei $\dot{y}$ uod idab $\dot{y}$ weith. ${ }^{2}$ Dýwaot $\dot{y}^{3}$ kalır: "Da $\dot{y}$ ' $\dot{y}$ gueith, a ranc bod $\dot{y} 0$ givein shedt

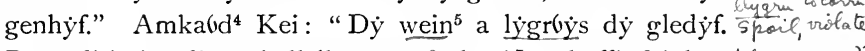
Dýro di imi ý diot $\dot{y}$ kellellprenneu ${ }^{6}$ oheni, a chaff(sýf inher "lerme ey nen goneuthur rei newy்d $\mathrm{d}^{8}$ idal." A chy்mryt $\dot{y}$ wein ohonat, ar I 5 cledyf $^{9} \dot{y}{ }^{\circ} \dot{y} \cdot 1 l a b$ arall. Dýuot ${ }^{10}$ ohonab vch pen $\dot{y}$ kaur, malphei ${ }^{11} \dot{y}$ cledýf a dottei $\dot{y} n \dot{y}$ wein. $\dot{Y}$ ossot a oruc $\dot{y} m$ "ara phen" ${ }^{12} \dot{y}$ kaur, a llad $\dot{y}$ penn $\dot{y}$ ergyt $\dot{y}$ arnat. Diffeithav $\dot{y}$ gaer, a doy்n a vỷnnassant o tlýsseu. ${ }^{13} \quad \dot{Y} g$ kỷuen $\dot{y}$ r vn alay waste dy $\dot{y} \dot{y} m$ phen $^{14} \dot{y}$ vloýdyn $\dot{y}$ deuthant $^{15}$ y lys Arthur, a 20 chledyf Wrnach Gaor gantunt.

7. Dywedut a inaethant y Arthur y ual y daruu udunt. Arthur a dywalot: "Pa beth yssyd ialnaf y geissal gyntaf a frecious or annoetheu hynny?" "Ia(naf yo," heb oynteu, "keissav Mabon uab Modron. Ac nyt kaffel arnab nes kaffel Eidoel 25 car himsmar uab Aer y gar yn gyntaf." Kyuodi a oruc Arthur a milwyr ynys Prydein ganta' y geissab Eidoel. A dyuot a orugant hyt yn rac Kaer Glini, yn y Me yd oed Eidoel yg

(Ch. 5). 1 om. H, 2 gan y goyr a oed allan am dyuot Bedwyr a Chei $\mathrm{H}$, $3 \mathrm{~A}$ dyuot goas ieuanc oed $\mathrm{H}, 4 \mathrm{yg}$ glyn $\mathrm{H}, 5$ mal-ganthunt om. H, 6 dyuot $\mathrm{H}, 7$ a wnaethant om. H, 8 yttoed $\mathrm{H}, 9 \mathrm{Y}$ dywedassant $\mathrm{H}$, 10 ti a orugost hynn goreu dyn oyt $\mathrm{H}, 11 \mathrm{Ac} \mathrm{o} H$

(Ch. 6). 1 gavr $\mathrm{H}, 2$ goeith $\mathrm{H}, 3$ ac $\mathrm{y}$ dywavt $\mathrm{H}, 4 \mathrm{Y}$ dywalot $\mathrm{H}$, 5 wein di $H, 6$ kyMlellbrenneu $H, 7$ ohonei $H, 8$ ac y wneuthur ereill o newyd $H, 9$ chedyf $P, 10$ a dyuot $H$, 11 mal pei $H, 12$ ynteu $y m$ penn $H$, 13 or da ar tlysseu $\mathrm{H}, 14$ penn $\mathrm{H}, 15 \mathrm{P}$ ends 
tarren a plot of uncultivated land

$x \mid$ "withor thee too secking to do me harmi"

\section{I96 THE HUNTING OF TWRCH TRWY'TH}

karchar. Seuyll a oruc Glini ar vann y gaer; ac y "rempart dywavt: "Arthur, py holy di y mi, pryt nam gedy yn y tarren honn, nyt da im yndi, ac nyt digrif, nyt guenith, nyt pleasenth oats keirch im, kyn ny cheissych ditheu wneuthur cam im?"|x

5 Arthur a dywaut: "Nyt yr droc itti y deuthum i yma, namyn y geissab y karcharabr yssyd gennyt." "Mi a rodaf danparn to prepare, y carcharaor itti, ac ny darparysswn y rodi y neb. Ac y

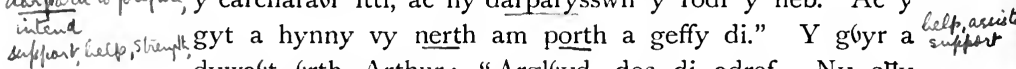
powen dywalit Grth Arthur: "Argloyd, dos di adref. Ny elly

Io di uynet ath lu y geissab peth mor uan ar rei hynn." Arthur a dywabt: "Gorhyr Gralstalt Ieithoed, itti y mae iaon man fine

quest mynet yr neges honn. Yr holl ieithoed yssyd gennyt, a havip the sane chyfyeith byt ar rei or adar ar anniueileit. Eidoel, itti y mae iaon mynet y geissab dy geuynderb y $y^{6}$ gyt am goyr i. Kei

I5 a Bedwyr, gobeith $y^{6}$ gennyf y neges yd eloch ymdanei $y$ chaffel. Euch im yr neges honn."

8. Kerdet a orugant racdunt hyt att voyalch Gilgori. Gouyn a oruc Gorhyr idi: "Yr Duo, a bdost ti dim y brth blachbind oungl Uabon uab Modron, a ducpoyt yn teirnossic ody rong y vam 20 ar paret?" Y ubyalch a dywalt: "Pan deuthum i yma gyntaf, eingon gof a oed yma, a minneu ederyn ieuanc oedon. Ny wnaethplyt g(eith arnei, namyn tra uu vyg geluin arnei bob ucher. Hedio nyt oes kymmeint kneuen Grenlaw, taffend, ohonei heb dreular. Dial Duo arnaf, o chigleu i dim y orth \$133(b)

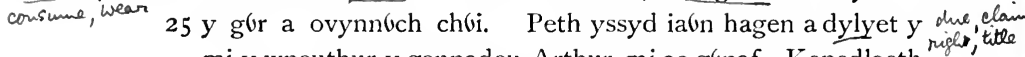
mi y wneuthur y gennadeu Arthur, mi ae gonaf. Kenedlaeth vileit yssyd gynt rithoys Dur no mi ; mi a af yn gyuarwyd ragoch yno."

9. Dyuot a orugant hyt yn Me yd oed karo Redynure. IPS. Pnet.0 30 "Kar6 Redynure, yma y doetham ni attat kennadeu Arthur, Perf. of dyfod kany udam aniueil hyn no thi. Dywet, a wdost di dim y orth Uabon uab Modron, a ducpoyt yn deirnossic y orth $y$ uam?" Y karb a dywalit: "Pan deuthum i yma gyntaf, nyt 
syz (call) stars

1 "The noirs of my wings are mere stumps"

\section{THE HUNTING OF TWRCH TRWYTH 197}

oed namyn vn reit o bop tu ym penn. Ac nyt oed yma oak goet namyn un o gollen derwen. Ac y tyfwys honno yn dar
saphing can keing. Ac y dygoydoys y dar goedy hynny. A hedio
gerstyma nyt oes namyn oystyn coch ohonei. Yr hynny hyt hedio oak goet namyn un o gollen derwen. Ac y tyfwys honno yn dar
saphing can keing. Ac y dygoydoys y dar goedy hynny. A hedio
gerstyma nyt oes namyn oystyn coch ohonei. Yr hynny hyt hedio guystyma nyt oes namyn (yystyn coch ohonei. Yr hynny hyt hedio witheredsturt yd oyf i yma; ny chigleu i dim or neb a ouynnoch choi. Miui hagen a uydaf gyfar(yd yoch, kanys kennadeu Arthur yoch, hyt Ile y mae aniueil gynt a rithoys Du6 no mi."

Io. Dyuot a orugant hyt he yd oed cuan Cum Kablloyt. owl "Cuan Com Cabllyyt, yma y mae kennadeu Arthur. A odost di $\operatorname{dim} y$ (rth Vabon vab Modron a ducpoyt?" et cetera. Io "Pei as goypon, mi ae dywedon. Pan deuthum i yma gyntaf, y com mair a welich glynn coet oed. Ac y deuth kenedlaeth o dynyon idab, ac y diuabyt. Ac y tyubys yr eil coet yndab. Ar trydyd coet $y^{6}$ honn. A minneu neut ydynt yn gynyon pl of cyustimp stem rort, |boneu vy esgyll. Yr hynny hyt hedio ny chiglef i dim or 15 plopasell wing gor a ouynnoch ch(i. Mi hagen a uydaf gyuarwyd y genadeu $(2133(b)$ Arthur, yny deloch hyt Me y mae yr anniueil hynaf yssyd yn y byt honn, a moyaf a dreigyl, eryr Goern Aboy. Trigyl 39q. Pr. Ind of traglaw, to

II. Gorhyr a dywalot: "Eryr Gwern Aboy, ni a doetham gennadeu Arthur attat y ouyn itt a odost dim y orth Vabon 20 uab Modron a duc" et cetera. Yr eryr a dywalt: "Mi a deuthum yma yr ys pell o amser. A phann deuthum yma gyntaf, maen a oed $\mathrm{y} \underline{\mathrm{m}}$, ac $\mathrm{y}$ ar $\mathrm{y}$ benn ef $\mathrm{y}$ pigon $\mathrm{y}$ syr bob pigo $t$ feck at D la handucher; weithon nyt oes dyrnued yn y uchet. Yr hynny hyt hedis yd oyf i yma. Ac ny chiglef i dim y brth y gor a 25 ouynnoch choi, onyt un treigyl yd euthum y geissab uym boyt hyt yn $\mathbb{L} y n n \mathbb{L} y 6$. A phann deuthum i yno, y Medeis uyg cryuangheu y myon ehavc o debygu bot vym boyt yndab wers vabr. Ac y tynnbys ynteu ui hyt yr affoys, hyt pann

searcely, uu abreid im ymdianc y gantab. Sef a oneuthum inheu, mi 30 ymoiane to R? can. am holl garant, mynet yg gorys (rrthal y geissal y diuetha. strife, hostelity Kennadeu a yrroys ynteu y gymot a mi. A dyuot a oruc cymod $t_{5}$ ynteu attaf i y diot dec tryuer a deugeint oe geuyn. Onyt prepertation, make 
curyufan of a lament, wailing

gris tam 5 groan, a groaming

pressennowl pertaing thins world

\section{I98 THE HUNTING OF TWRCH TRWYTH}

ef a wyr peth or hynn a geissoch choi, ny onn i neb ae goypo. Mi hagen a uydaf gyuaroyd yoch hyt Ile y mae."

I 2. Dyuot a orugant hyt Ile yr oed. Dywedut a oruc yr eryr: "Ehalc $\mathbb{L} y n \mathbb{L} y 6$, mi a deuthum attat gan gennadeu

5 Arthur y ouyn a udost $\operatorname{dim} y$ (rth Vabon uab Modron, a ducpoyt yn teirnossic y orth y uam." "Y gymeint a wypoyf i, mi ae dywedaf. Gan bob Mans yd af $\mathrm{i}$ ar hyt yr auon back a hend, uchot, hyt pan deloyf hyt y mach mur Kaer Loy(. Ac yno $\mathrm{y}$ keueis i ny cheueis eirmoet o droc y gymeint. Ac mal $\mathrm{y}$ Io crettoch, doet un ar uyn doy ysgoyd i yma ohonalch." Ac $\delta$ "distress" $\delta$ lshoulde ysef yd aeth ar doy ysgoyd yr ehavc, Kei a Gorhyr Gualstabt

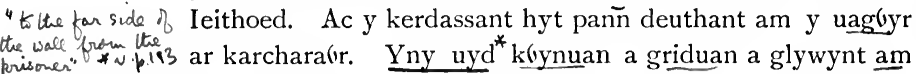

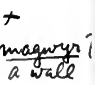
"on the far side of the y uagoyr ac by. Gorhyr a dywalit: "Pa dyn a goyn yn y wall trom them "I 5 maendy honn?" "Oia or, yssit le idal y goynal y neb yssyd yma. Mabon uab Modron yssyd yma yg carchar; tost herd, severe ac ny charcharbyt neb kyndostet yn Miro carchar a mi, na charchar $\mathbb{L}$ ud $\mathbb{L} a 6$ Ereint neu garchar Greit mab Eri.", " Oes as regards obeith gennyt ti ar gaffel dy ellong ae yr eur ae yr aryant ae wealth

20 yr golut pressenna(l, ae yr catwent ac ymlad?" "Y gymeint cadwenrba ohonof i a gaffer a geffir droy ymlad." Ymchoelut ohonunt to returm, tur oy odyno, a dyuot hyt Ile yd oed Arthur. Dywedut ohonunt $y$ Ile yd oed Mabon uab Modron yg karchar. 6 summon Goyssyal a oruc Arthur milwyr yr ynys honn, a mynet hyt 25 yg Kaer Loyb, y Me yd oed Mabon yg karchar. Mynet a oruc Kei a Bedwyr ar d6y yscbyd y pysc. Trayttoed vilwyr Arthur yn ymlad ar gaer, roygab o Gei y uag('yr a chymryt $y$ carcharaior ar y geuyn. Ac ymlad ar goyr ual kynt $[$ ar omir. Dilogiaply goyr.] Atref y doeth Arthur a Mabon gantal yn ryd.

30 13. Dywedut a oruc Arthur: "Beth ialnhaf weithon $y$ geissav yn gyntaf or annoetheu ?" "Ia(nnhaf yo keissal deu geneu gast Rymhi." "A wys," heb yr Arthur, "pa du ${ }^{x} y$ mae hi?" "Y mae," heb yr un, "yn Aber Deugledyf."

$$
\begin{aligned}
& x \text { tur side, negion, part; } \\
& \text { pa du where }
\end{aligned}
$$


garscon

achub to occupy, seize, precipitate oneself, smatch nodi tomark, notify, specify

["he sprong forwand in that
direction" $]$

\section{THE HUNTING OF TWRCH TRWYTH 199}

Dyuot a oruc Arthur hyt yn ty Tringat yn Aber Cledyf. A gouyn a oruc orthal: "A glyweist ti y orthi hi yma? Py rith y mae hi?" "Yn rith bleiđast," heb ynteu, "ae deu 3s. Pr. Ind.of geneu genthi yd ymda. Hi a ladaud vy ysgrybul yn vynych.

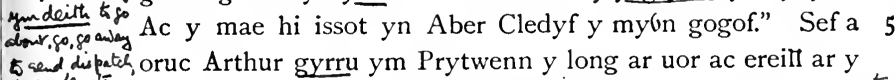
5 send, dispatch, oruc Arthur gyrru ym Prytwenn y long ar uor ac ereill ar y
drive, hasten drive, hastam tir y hela yr ast; ae chylchynu uelly hi ae deu geneu. Ac
tone.transform eu datrithab o Dub y Arthur yn eu rith ehunein. Goascaru t5 surroundenconpass, a oruc Mu Arthur bob un bob deu. in ones and twos

14. Ac ual yd oed Guythyr mab Greidabl dydgueith yn Io kerdet dros vynyd, clywei leuein a gridua[n] girat; a girad lamoutable, garscon oed eu clybot. Achub a oruc ynteu parth ac yno. Ac mal y deuth yno, dispeilab cledyf a wnaeth, a Mad $y$ toynpath orth y dayar, ac ev diffryt uelly rac $y$ tan. Ac $y$ "and so saved then dywedassant bynteu orthav: "Doc uendyth Duo ar einym i 5 gennyt. Ar hynn ny allo dyn vyth y waret, ni a doon y delwen, "recove" waret itt." Hoyntoy wedy hynny a doethant ar nab hestabr a earm measure, alt

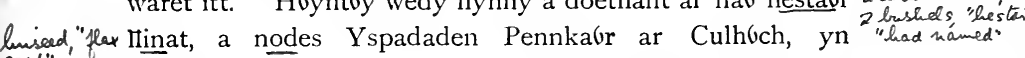
soed" uessuredic oll heb dim yn eisseu ohonunt eithyr un "and the Minhedyn; ar morgrugyn cloff a doeth a honno kynn y nos. 20

I5. Pan yttoed Gei a Bedwyr yn eisted ar benn Pumlumon ar Garn Goylathyr ar wynt moyaf yn y byt, edrych a wnaethant yn eu kylch. Ac oynt a velynt voc mwg smoke mavr parth ar deheu ym pell y orthunt heb drossi dim gan y trossi 5 him, goynt. Ac yna y dywabt Kei : "Myn Mab vyng kyueillt, 25 friend a warrion, syll dy racco tan ryssur." Bryssyab a orugant parth ar muc, to hastem chempromec, a dynessau parth ac yno dan ymardisgoyl o bell. Yny uyd ${ }^{*}{ }^{\circ} \omega_{a}$ teh

Dillus Uaruabc yn deiuab baed coet. Llyna hagen $y$ ryssor moyaf a ochelaud Arthur eiryoet. Heb y Bedwyr yna orth Gei : "Ae hatwaenost di ef?" "Atwen," heb y 30 sic Ms. Kei; "Myna Dillus Uarruabc. Nyt oes yn y byt kynnyuan log Maruabc a dalyo Drutwyn keneu Greit uab Eri, namyn kynnyuan o leaśchanded) uaryf y gor a wely di racko; ac ny moynhaa heuyt, onyt yn "and ltat too wiel be of no

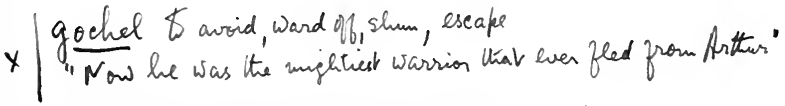
mory hän, 5 use, employ, enjoy, profit 


\section{THE HUNTING OF TWRCH TRWYTH}

vyo y tynnir a chyllellprenneu oe uaraf, kanys breu uyd yn lerictle "Whar is?" uaro." "Mae an kynghor ninneu orth hynny?" heb y

Bedwyr. "Gadon ef," heb y Kei, "y yssu y wala or kic; gualaf.a wooden tweegors 5 y buant oynteu yn goneuthur kyllellbrenneu. Pan oybu Gei undoubted, centain yn diheu y uot ef yn kyscu, goneuthur poll a oruc dan y a par, hole draet moyhaf yn y byt. A tharal dyrnalit arnal anueitrabl immense guassutopress, y ueint a oruc, ae wascu yn y poll, hyt pan daroed crithian to pluch udunt y gnithiab yn $\Pi 6$ yr ar ky llellbrenneu y uaryf; a goedy ro hynny y lad yn gubyl. Ac odyna yd aethant ell deu hyt yg Kelli Wic yg Kernyo, a chynllyuann o uaryf Dillus Uarualic gantunt. Ae rodi a oruc Kei yn Mab Arthur. Ac yna y kanei Arthur yr eglyn honn :

I 5

"Kynnllyuan a oruc Kei

5 o uaryf Dillus uab Eurei ;

pei iach, dy angheu uydei."

surri to be Ac am hynny y sorres Kei, hyt pan uu abreid y uilwyr yr ynys honn tangneuedu y rong Kei ac Arthur. Ac eissoes nac $y r$ anghyfnerth ar Arthur nac yr Mad $y$ wyr nyt 20 ymyrroys Kei yn reit gyt ac ef o hynny allan.

16. $\widetilde{A c}$ yna y dywabt Arthur: "Beth ialnaf weithon $y$ geissab or annoetheu?" "Ialınaf yo keissal Drutwyn keneu Greit uab Eri." Kyn no hynny ychydic yd aeth Creidylat uerch Lud Lav Ereint gan Wythyr mab Greidadl. A chynn 25 kyscu genthi dyuot G(bynn uab Nud ae doyn y treis. violemer rap - Kynnullar Mu o Wythyr uab Greidall a dyuot y ymlad a Goynn mab Nud. A goruot o Wyn, a dala Greit mab Eri a eafture Glinneu eil Taran a Gorgorst Letlom a Dyfnarth y uab; a dala o Penn uab Nethavc a N(yython a Chyledyr Wyllt y "Lin out"

30 uab. A Ilad Noython a oruc, a diot y gallon, a chymhell ar Kyledyr yssu callon y dat; ac am hynny yd aeth Kyledyr yg g(yylt. Clybot o Arthur hynny, a dyuot hyt y Gogled. 
di-foryn vid, idle, unused, unloüched (of a vingin)

guychyr stour, resolute, bold

achub yr cyferlt to be first at the charge

THE HUNTING OF TWRCH TRWYTH 201

A dyuynnv a oruc ef Goynn uab Nud attab, a gellong y wyrda y gantab oe garchar, a goneuthur tangneued y rong Goynn mab Nud a Goythyr mab Greidabl. Sef tangneued a wnaethpoyt, gadu y uorbyn yn ty y that yn diubyn or doy

day barth; ac ymlad bob duv kalan Mei uyth hyt dyd bralt or 5 dyd hinno allan y ring Giynn a Goythyr; ar un a orffo onadunt dyd brait, kymeret y uorbyn. A gredy kymot y

"Dun-mane" goyrda hynny uelly, y kauas Arthur Mygdon march Goedo a gerflo Pres.
suly. of gor-vor
overcome $\$ 160$ chynnlyuan Cors Cant Ewin. "Hundred - claws"

17. Giedy hynny yd aeth Arthur hyt yn Iydas, a 10 Mabon uab Mellt gantav a Grare Grallt Euryn, y geissab deu gi Glythmyr L[ed]ewic. A goedy eu kaffel yd aeth Arthur hyt yg gorlewin Iwerdon y geissab Gorgi Seueri, ac Odgar uab Aed brenhin Iwerdon gyt ac ef. Ac odyna $y^{\prime} d$ aeth Arthur yr Gogled, ac y delis Kyledyr WyIt. Ac yd I 5 "caught"

"whar afte" aeth Yskithyrwynn Pennbeid; ac yd aeth Mabon mab Mellt, a deu gi Glythuyr Ledewic yn y latı a Drutwyn geneu Greit mab Eri. Ac yd aeth Arthur ehun yr erhyl, a Chauan ki hunt, chase Arthur yn y las. Ac yd esgynniys Kav o Brydein ar Lamrei kassec Arthur, ac achub yr kyfuarch. Ac yna 20 gic Mss. "armedhim y kymerth Kal o Brydein nerth boyellic, ac yn wychyr iniff, dexterous trebelit $y$ doeth ef $\mathrm{yr}$ baed, ac y holldes y benn holcti tosplit, yn deu hanner. A chymryt a oruc Kav yr ysgithyr. Nyt fang, tiusk y kon a nottayssei Yspaden ar Golhoich a ladaud y baed, Reg. Yspad[ad]en. namyn Kauall ki Arthur ehun.

I8. A griedy Пlad Ysgithyrwyn Bennbeid, yd aeth Arthurae niuer hyt yng Kelli Wic yng Kerny6. Ac odyno y gyrroys Meno mab Teirgoaed $y$ edrych a uei y tlysseu y rong deu glust Torch Troyth, rac salwen oed uynet y ymdarab vain, needless ac ef, ony ${ }^{1}$ bei y tlysseu gantal. Diheu hagen oed y uot ef 30 yno; neur daroed idal diffeithab traean Iwerdon. Mynet a v.p.60

to sech oruc Men'y ymgeis ac (rynt. Sef y guelas bynt yn Esgeir Oeruel yn Iwerdon. Ac ymrithav a oruc Meno yn rith 1. MS. ac ony, corr. Loth. to transform
oussef

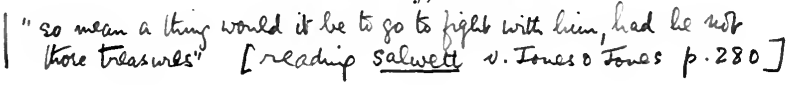


ysglyfyow 5 suatch

ymor $\delta$ wies (ac), to over take, come up with, touch

\section{THE HUNTING OF TWRCH TRWYTH}

ederyn ; a disgynnu a wnaeth uch penn y goal, a cheissab lais

by. my. ysglyffyab un or tlysseu y gantal; ac yn chauas dim hagen gurych bristles namyn un oe wrych. Kyuodi a oruc ynteu yn wychyr da sshake oneself ac ymysgytyab, hyt pan ymordiwedald peth or goenoyn ac flawless, whole 5 ef; odyna ny bu dianaf Meno uyth.

19. Gyrru o Arthur gennat goedy hynny ar Odgar uab cauldron Aed, brenhin Iwerdon, y erchi peir Dibrnach Wydel, maer steward idab. Erchi o Otgar idab y rodi. Y dywabt Diornach: ( "Du6 a wyr, pei hanffei well o welet un oloc arna6, nas $X$ Io kaffei." A dyuot o gennat Arthur a nac genthi o Iwerdon. Kych(iynnu a oruc Arthur ac ysgaon niuer ganthad, a mynet hghr, shight, ym Prytwen y long, a dyuot y Ywerdon; a dygyrchu ty make for Dibrnach Wydel a orugant. Grelsant niuer Otgar eu meint. portion, share A goedy boyta onadunt ac yuet eu dogyn, erchi y peir a I 5 oruc Arthur. Y dywalt ynteu, pei as rodei y neb, y rodei (rrth eir Odgar brenhin Iwerdon. Gkedy Meueryd nac udunt, kyuodi a oruc Bedwyr ac ymauael yn y peir, ae dodi ar geuyn Hygoyd goas Arthur; brabt oed hinno unuam y Gachamori goas Arthur. Sef oed y sbyd ef yn wastat 20 ymdoyn peir Arthur a dodi tan $y$ danab. Meglyt o Lenlleavc Wydel yg Kaletvolch, ae ellong ar y rot, a Mad togit, gras
clingto

entre, all

ar once. "before theer very eyes.

Dibrnach Wydel ae niuer ach[1]an. Dyuot Muoed Iwerdon ac ymlad ac by. A goedy ffo y lluoed achlan, mynet Arthur ae wyr yn eu goyd yn y Mong, ar peir yn Maln o sGIIt money, heasw 25 I (ierdon gantunt; a diskynnu yn ty $\mathbb{L}$ Gydeu mab Kelcoet "dis ym Porth Kerdin yn Dyuet. Ac yno y mae messur y peir. a imeasuression

20. Ac yna y kynnumbys Arthur a oed o gynifyor yn teir ynys Prydein ae their racynys, ac a oed yn Freinc "oits 3 adgace "piched dogs" a Llydal a Normandi a Golat yr Haf, ac a oed o gicor dethol "horses of $30 \mathrm{a}$ march clotuabr. Ac yd aeth ar niueroed hynny oll hyt yn renown" IGerdon. Ac y bu ouyn malr ac ergryn racdab yn Iwerdon. A guedy disgynnu Arthur yr tir, dyuot seint Iwerdon attab y erchi nald idal. Ac y rodes ynteu navd udunt hoy, ac $y$ gellung clefyb ar y rod to brandish a sword in circle * v. Pedeir Keinc, p. 161. q. p.203, hine 31 $X \mid$ "hod huows, thangh he should be the better of gectipe one ghimpse git, 


\section{THE HUNTING OF TWRCH TRWYTH 203}

rodassant bynteu eu bendyth idab ef. Dyuot a oruc goyr victuals Iwerdon hyt att Arthur a rodi boyttal idal. Dyuot a oruc Arthur hyt yn Esgeir Oeruel yn IGerdon, yn y tle yd oed Torch Troyth ae seithlydyn moch gantab. Gellong kon arnal o bop parth. Y dyd honno educher yd ymladald y 5 Goydyl ac ef; yr hynny pymhet ran Iwerdon ${ }^{1}$ a onaeth yn diffeith. A thrannoeth yd ymladaod teulu Arthur ac ef; namyn a gaossant o droc y gantab, ny chaossant dim o da. $\mathrm{Y}$ trydyd dyd yd ymladaud Arthur ehun ac ef nab nos a nab nieu; ny ladabd namyn un parchell oe uoch. Gouynnoys ro yump his y goyr y Arthur peth oed ystyr yr hoch honno. Y dywabt ynteu: "Brenhin uu, ac am y bechaot y rithoys Dub ef yn hoch." -

2I. Gyrru a onaeth Arthur Gorhyr Goalstaut Ieithoed y geissab ymadraud ac ef. Mynet a oruc Gorhyr yn rith ederyn, a disgynnv a onaeth vch benn y wal ef ae seithlydyn i 5 moch. A gouyn a oruc Gorhyr Gbalstabt Ieithoed idab: "Yr y gor ath wnaeth ar y delo honn, or gelloch dywedut, $y$ harchaf dyuot un ohonauch y ymdidan ac Arthur." Gortheb a onaeth 5 answer, reply pl: fadan, Grugyn Gorych Ereint (mal adaned aryant oed y wrych oll; wing $y$ fford $y$ kerdei ar goet ac ar uaes y g(eelit, ual y Mithrei y 20 Clattrei wrych). Sef atteb a rodes Grugyn: "Myn y gor an gonaeth ni ar y delo honn, ny wnaon, ac ny dywedon dim yr Arthur. Oed digaon o droc a onathoed Dul ynni, an goneuthur ar $y$ delo hon, kyny deleuch ch6itheu y ymlad a ni." "Mi a cribcoub dywedaf yoch yd ymlad Arthur am y grib ar ellyn ar 25 razor shears,cissons goelleu yssyd rong deu glust Torch Troyth." Heb y Grugyn: "Hyt pann gaffer y eneit ef yn gyntaf, ny cheffir y tlysseu hynny. Ar bore auory y kychoynnon ni odyma ; ac yd aon y wlat Arthur, ar meint moyhaf a allom ni o droc a onaon yno." Kychoyn a orugant hoy ar y mor parth a 30 Chymry. Ac yd aeth Arthur ae luoed ae ueirch ae gon ym $X$ Prytwen, a tharab lygat ymwelet ac Gynt. Disgynnu a onaeth "Oteg saw thein 


\section{THE HUNTING OF TWRCH TRWYTH}

Torch Triyth ym Porth Cleis yn Dyuet. Dyuot a oruc Arthur hyt ym Mynyo y nos honno. Trannoeth dywedut caitle y Arthur eu mynet heibal. Ac ymordiwes a oruc ac ef yn Mad goarthec Kynnwas Korr y Uagyl. A guedy Ilad a oed yn

5 Deugledyf o dyn a mil kynn dyuot Arthur, or pan deuth "And be ovestook him Arthur, y kychoynnoys Torch Troyth odyno hyt ym Presseleu. Dyuot Arthur a Muoed y byt hyt yno. Gyrru a oruc hurr, chase Arthur y wyr yr erhyl, Ely a Thrachmyr, a Drutwyn keneu Greit mab Eri yn y lav ehun; a Goarthegyt uab Kab yghongyl Io arall, a deu gi Glythmyr Letewic yn y lab ynteu; a Bedwyr $?$ "Ind he ranged" a Chauall ki Arthur yn y lab ynteu. A restru a oruc y milwyr oll o deu tu Nyuer. Dyuot tri meib Cledyf Divblch, goyr a gauas clot malor yn Mad Ysgithyrwyn Pennbeid. Ac yna y kychlynn(yys ynteu o Lynn Nyuer, ac y doeth y stood at bay i 5 Gom Kerbyn, ac y rodes kyuarth yno. Ac yna y lladalod ef warrin, champion bedwar ryss(or y Arthur, G(iarthegyd mab Kav, a Tharavc Allt Cloyt, a Reidon uab Eli Atuer, ac Iscouan Hael. A goedy llad y goyr hynny, y rodes yr eil kyuarth udunt immediately yn y Me, ac y Madalod Goydre uab Arthur, a Garselit Wydel, $x 20$ a Gleo uab Yscalit, ac Iscabyn uab Panon; ae doluryab tgrieve ynteu yna a onaethpoyt.

towerds day 22. Ar bore ym bronn y dyd drannoeth yd ymordiwedaud rei or goyr ac ef. Ac yna y Madabd Huandab a Gogigor a

Phenn Pingon, tri g(ueis Glebllyt Gauaeluabr, hyt nas g(lydyat

- 25 Duo was yn y byt ar y helo ynteu, eithyr $\mathbb{L}$ aesgenym ehunan, gor ny hanoed well neb ohonal. Ac y gyt a hynny y Madalid Makier o wyr y blat, a Golydyn saer, pensaer $y$ Arthur. Ac yna yd ymordiwedalid Arthur ym Pelumyauc ac ef. Ac yna y Madalid ynteu Madalic mab Teithyon, a Goyn 30 mab Tringat mab Neuet, ac Eiryaln PennПoran. Ac odyna yd aeth ef hyt yn Aber Tybi. Ac yno y rodes kyuarth udunt. Ac yna y Madaud ef Kynlas mab Kynan, a Goilenhin bre[nh]in Freinc. Odyna yd aeth hyt yg 


\section{di-gribyaw (y) to altack

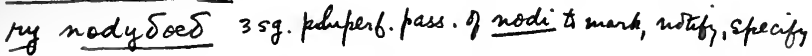

\section{THE HUNTING OF TWRCH TRWYTH 205}

Glynn Ystu. Ac yna yd ymgollassant y goyr ar con ac ef. losesigrqhim Dyuynnu a oruc Arthur Goyn uab Nud attab, a gouyn ida6a bydyat ef dim yorth Torch Troyth. Ydywabtynteunasgoydyat.

23. Y hela y moch yd aeth y kynnydyon yna oll hyt yn pl. zeymny $\delta$ Dyffryn $\mathbb{L} y c h 6 r . \quad$ Ac y digribybys Grugyn Goallt Ereint 5 udunt a Iloydabc Gouynnyat; ac y Madass[ant] y kynnydyon, hyt na diengis dyn yn vyo onadunt namyn un gor. Sef a oruc Arthur dyuot ae luoed hyt he yd oed $x \mid \begin{aligned} & \text { Grugyn a } \mathbb{L} \text { Gydabc, a gellong yna arnadunt a oed o gi } \\ & \text { rynodydoed yn } \Pi \text { (6yr. Ac orth yr abr a dodet yna ar kyuarth, } 10 \text { gawr a shour, }\end{aligned}$

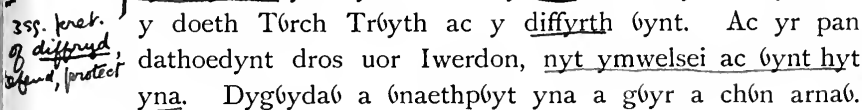

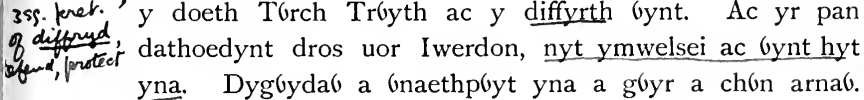

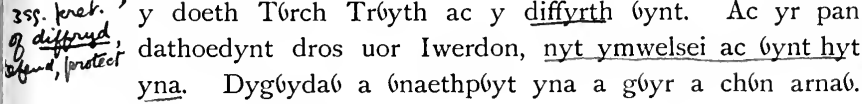
"be had neor ser eyes on them tiel Ymrodi y gerdet ohonal ynteu hyt ym Mynyd Amano. Ac yna y Ilas bano oe uoch ef. Ac yna yd aethplyteneit is * dros eneit ac ef. Ac y Mad6yt yna Torch Llabin. Ac yna y Mlas arall oe voch; Gloys oed y enb. Ac odyna yd aeth hyt yn Dyffrynn Amano. Ac yno y Mas bano a young a bennwic. Nyt aeth odyno gantal oe uoch yn vyo namyn Grugyn Goallt Ereint a $\mathbb{L}$ Gydabc Gouynnyat. 20 Or Me honno yd aethant hyt yn $\mathbb{L}$ Gich EGin. Ac yd ymordiwedaud Arthur ac ef yno. Rodi kyuarth a onaeth Achilles ynteu yna. Ac yna y Madaud ef Echel Uordoyt Ton, ac Aroyli eil Goydabc Goyr, a Maber o wyr a chon heuyt. Ac yd aethant odyna hyt yn Lloch Taby. Yscar a onaeth $25 \%$ lcave, pars Grugyn Gorych Ereint ac oynt yna. Ac yd aeth Grugyn mor Swyd thigh = son odyna hyt yn Dintywi. Ac odyna yd aeth hyt yg Keredigyaon, ac Eil a Thrachmyr gantab, a Iliaus gyt ac multitude, hos/bynt heuyt. Ac y doeth hyt yg Garth Grłgyn. Ac yno u/ (so ds) $y^{1}$ Mas Lloydabc Gouynnyat yn y mysc. Ac y lladald 30 mithein midet Ruduy6 Rys, a Mavergyt ac ef. Ac yna yd aeth $\mathbb{L}$ oytabc hyt yn Ystrat YG. ${ }^{\text {Ac yno y kyuaruu goyr } \mathbb{L} y d a b}$ ac ef.

\section{to this}

* myuned eneid dros eneid to engage in a life-for-life struggle 


\section{ellowg to dismiss, dispatê, let; shed (blood)}

\section{THE HUNTING OF TWRCH TRWYTH}

peiss-awg

Ac yna y Madalod ef Hir Peissaluc brenhin $\mathbb{L} y d a$, a Lygatrud Emys a Gorbothu, ebythred Arthur, vrodyr y uam. Ac yna y llas ynteu.

24. Torch Troyth a aeth yna y rong Taby ac Euyas. 5 summon 5 Goyssyab Kernyo a Dyfneint o Arthur yn y erbyn hyt yn aber Hafren. A dywedut a oruc Arthur orth vilbyr yr ynys honn: "Torch Trbyth a ladaud llaber om goyr. Myn. valow manliness, gorhyt goyr, nyt a mi yn uyb yd aho ef y Gernyb. Nys hravery, shangth ymlityaf $\mathrm{i}$ ef bellach, namyn $\stackrel{x}{\mathrm{~m} y n e t}$ eneit dros eneit ac ef a $x_{\sim} \cdot p .205$

Io wnaf. Goneuch choi a onelhoch." Sef a daruu o gyghor battation gantal ellong kat o uarchogyon, a chon yr ynys gantunt, hyt yn Euyas, ac ymchoelut odyno hyt yn Hafren, ae ragot tried, tested yno ac a oed o vilwyr prouedic yn yr ynys honn, ae yrru to waylay
an ambis by sheer "fence) anghen yn anghen yn Hafren. A mynet a onaeth Mabon mecessity, "force ${ }_{15}$ uab Modron gantal ar Wynn mygdon march Goedo yn Hafren, a Goreu mab Custennin, a Meno mab Teirgoaed y rong $\mathbb{L} y n n \mathbb{L} i\left(i a n\right.$ ac ${ }^{A}$ ber Goy. $\vee$ A dygoydao o Arthur arnab, a ryssbyr Prydein gyt ac ef. Dynessau a oruc Osla Gyllelluar a Manabydan uab Llyr a 20 Chacmori goas Arthur a Goyn Gelli, a dygrynnyal yndab, \$seiz, clute Clagaw toplunge, ac ymauael yn gyntaf yn y traet, ae gleicab ohonunt yn inmerse cuch $2 .(53)$

Hafren, yny yttoed yn Menbi odyuchtab. Brathu ambs o/ Uabon uab Modron or neil[1] parth, a chael yr ellyn y gantab. Ac or parth arall y dygyrchoys Kyledyr Wyllt y 25 ar amis arall gantab yn Hafren, ac y duc y goelleu y gantal. $X$
make for sel
upon; drian cinb coub(fem.)Kynn kaffel diot y grib, kaffel dayar ohonab ynteu ae draet. Ac or pan gauas y tir, ny alloys na chi na dyn na canhym-deith, to march y ganhymdeith, hyt pan aeth y Gerny6. Noc a gaffat accompany, keep o droc yn keissab y tlysseu hynny y gantab, goaeth a gaffat up with save $30 \mathrm{yn}$ keissab diffryt $y$ deu or rac eu bodi. Kacmori ual y $X_{v} \cdot 1 \cdot 12$ for tynnit ef y uynyd, y tynnei deu uaen $X_{\text {ureuan }}$ ynteu querustone yr affoys. Osla Gyllelluarr yn redec yn ol y torch, y dygoydoys y gyllel oe wein ac y kolles; ae wein ynteu

\section{givel pare qunthen"}

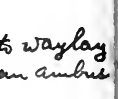


y holer ("he was forced oury Cormuall.)

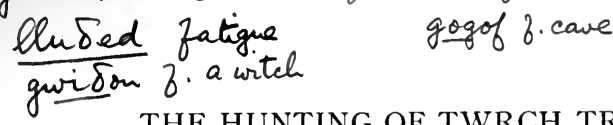

THE HUNTING OF TWRCH TRWYTH 207 keissab y grib. O dric y gilyd y kaffat $y$ grib $y$ gantab. Ac odyna y holet ynteu o Gernyb, ac y gyrroyt yr mor yn $y$ 5t "rom misching goedy hynny yn Maon or dofyr, ual y tynnit ef y uynyd, $y$ tynnei hitheu ef yr affoys. Odyna yd aeth Arthur a lluoed, hyt pan ymordiwedaud ac ef yg Kernyo. Goare oed a gafat o droc gantal kyn no hynny y orth a gaffat yna gantal yn straight lefore gyueir. Ny wybubyt vyth o hynny allan pa le yd aeth, ac Xim, headion aeth-lym Anet ac Aethlem gantal. Ac odyno yd aeth Arthur y "thbatchumielf ymeneinal ac y uoro y ludet y arnab hytyg KelliWic yg Kernyb. Weariness"

25. Dywedut o Arthur: "A oes dim weithon or anoetheu Io heb gaffel?" Y dywaut vn or g(1yr: "Oes. Guaet y widon "the blood. "id, uplandsy Ordu merch y widon Orwen o penn Nant Gouut yg g(irthtir daughten of the "
Hell Uffern." Kychøyn a oruc Arthur parth ar Gogled, a dyuot hyt Me yd oed gogof y wrach. A chynghori o gurach f: a ler, send Wynn uab Nud a Goythyr uab Greidaol gellong Kacmori a $15^{\text {hag, witch }}$ Hyghyd y urabit y ymlad ar wrach. Ac ual y d euthant y seize, swatch myon yr ogof, y hachub a oruc y wrach; ac ymauael yn by Hygoyd herbyd goallt y benn, ae darab yr Ilaor deni. undeh ha (p.39) Ac ymauel o Gacmori yndi hitheu herbyd goalt $y$ phenn, ae thynnu y ar Hygoyd yr Haor. Ac ymchoelut a 20 oruc hitheu ar Kacmiri, ac eu dygaboli yll deu, ac eu diaruu, ae to belabour, gyrru allan dan eu hub ac eu hob. $x$ A Midyab a oruc Arthur almost gris weite yr ogof. Ac yna y dywedassant Glynn a Goythyr (irthab: gris weilter leasant for us' "Nyt dec ac nyt digrif genhym dy welet yn ymgribyab a 25.5 wrangle
gorach. Gellong Hir Amren a Hir Eidyl yr ogof." A mynet with,"scuffeng a orugant. Ac or bu droc trafferth y deu gynt, graeth uu trowble, "plight" drafferth y deu hynny, hyt nas goypei Dub y vn ohonunt

- ell pedwar allu mynet or Ile, namyn mal y dodet ell pedwar ar Lamrei kassec Arthur. Ac yna achub a oruc Arthur 30 v. Lloss su. dros yr ogof, ac y ar y dros a uyryei y wrach a Charnwennan wing antate y gyllell, ae tharal am y hanner, yny uu yn deu gelorn hi. A iilt) chymryt a oruc $\mathrm{Ka} v$ o Brydein graet $\mathrm{y}$ widon ae gado ganthav.

\section{"Took aim at" "until she was as two tubs"}

\section{$x$ Sloss. pushing and kiching them. Traus. "spueahing and scualling"} llidyaw to hecome angry.

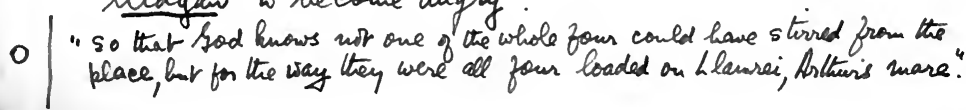


yneid pl. of ynad (O.w. equat) $m \cdot$ a judge

208

\section{THE PROCEDURE IN A SUIT FOR LANDED PROPERTY.}

Puipenac auenno kefroy் haul am tir a dayar. ${ }^{1}$ Kefroet panuenno o nautethid kalangayaf allan. Neu onauu5 ethid mey. Kanis ${ }^{2}$ eramseroyd henny ybit agoredic keureith am tir ay dayar.

Oderuit yr haulur mennu Io holi tir en eramseroyt hinni deuhet $^{1}$ ar er argluit yerchi did $y$ guarandau $y$ haul a hinni aretir. In edid hunnu datkanet y haul. $\mathrm{Ni}$ I 5 dele $y$ dithun $^{2}$ kaifail ateb. edithun. Kanis haul dissiuit yu $\mathrm{ar}^{3}$ guercheidveith ${ }^{-}$ac wrth hinni yguercheidveith a deleant oyt urth porth.

20 Yaun yu irhalur y ludyas udunt onit ekeureyth ay deweyt ydeleu. Ac ena emay $^{4}$ ereneyt ev guarandau. A gouin pale emay eu porth.

25 Odeweduuant pot eu porth eneu kemmut euhun. Roy oyt trideu udunt. Obit en
I. Pwy bynnac a uynno kyffroi hawl am dir a dayar, kyffroet pan uynno o nawvet dyd kalan gayaf allan, neu o nawvet dyd Mei. Kanys yn yr amseroed hynny $y$ byd agoredic kyvreith am dir a dayar.

2. O deruyd yr hawlwr mynnu holi tir yn yr amseroed hynny deuet ar yr arglwyd y erchi dyd $y$ warandaw y hawl, a hynny ar $y$ tir. Yn y dyd hwnnw dadganet $y$ hawl. Ny dyly kaffael atteb y dyd hwnn. Kanys hawl dysseivyt yw ar sudden pacted $y$ gwercheidweit. Ac wrth hynny $y$ gwercheidweit a dylyant oet wrth borth. Iawn yw yr hawlwr y ludyas udunt, onyt y gyvreith a dyweit $y$ dylyu. Ac yna y mae iawn yr yneit eu gwarandaw, a govyn pa le y mae eu porth. O dywedant bot eu porth yn eu kymmwt eu hun, roi oet $=$ no $\delta_{i}$
Sinstitile
a claim

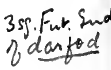

(Ch. 1). 1 the second $a$ is added over the line, 2 add yn with several MSS.

(Ch. 2). 1 h over the line, 2 omit, 3 add y with many MSS., 4 add iaun with many MSS.

$$
\begin{aligned}
& \text { X pl. of gor-cheidioad m. a guardian, custodian } \\
& \text { oed m. age; appointed hims, respite, delay. } \\
& \text { porit f. help, assistance, support } \\
& \text { lendyas to hinder }
\end{aligned}
$$


eli ${ }^{5}$ kemut naunieu. Obit tridieu udunt. O byd yn yr en etredit neu uot llanu a trey eil gymmwt, naw nieu. $O$ eregthun ac eu porth. Os byd yn y trydyd neu vot kin hanner did ebernir eroyt . llanw a threi yryngthunt ac petheunos or did hunnu ebit eu porth, os kyn hanner dyd tide o ebb 5 before midday eroyt. Os guedi hanner did y bernir yr oet, pythewnos petheunos otrannoyth. Ac or dyd hwnnw y byd yr essev achaus yu henne. oet; os gwedy hanner dyd, Kanydoys did kubil ac nat pythewnos o drannoeth. Ac yaun talu drill did en lle did. Ac en eroyt barnedic hunnu. emay yaun deuod ar etir ${ }^{6}$ ac vynt ac eu porth. = reckon

\section{Ac ena ymay yaun} guneythur ${ }^{1} \mathrm{du}^{2}$ pleit ac eiste $\mathrm{en}^{3}$ keureithiaul. Esseu ual etestedyr en keureythiaul. Eiste orbrenhin neu or neb a uo enile. ay keuen ar er $\mathrm{eul}^{4}$ neu ar $\mathrm{er}^{5}$ hin. Rac aulonidu er hin oyuyneb ef. $\mathrm{Ar}$ enat llis neu egnat ekemut erhun henau auo en eiste rac euron ef. Ac $\operatorname{ar}^{6}$ llau assu $y$ hunnu er egnat arall auo enemays neu er eneid. ${ }^{7}$ Ac ar ellau

yssef achaws yw hynny; Io

kanyt oes dyd kwbyl, ac nat iawn talu dryll dyd yn lle portion, fragment dyd. Ac yn yr oet barnedic hwnnw y mae iawn dyvot ar $y$ tir ac wynt ac eu porth.

3. Ac yna y mae iawn gwneuthur dwy bleit ac eisted pleid f a side, party yn gyfreithiawl. Sef ual yd eistedir yn gyfreithyawl. Eisted or brenhin neu or neb 20 a uo yn y le ae gevyn ar yr heul neu ar yr hin, rac avlonydu yr hin oe wyneb incommode ef. Ar ynat llys neu ynat $y$ supere of hen oed kymmwt, yr hwn hynaf a uo, 25 yn eisted rac y uron ef. Ac before fin frouk ar y llaw assw y hwnnw yr ynat arall a vo yn y maes. o/2en count Ac ar y llaw deheu idaw yr

(Ch. 2). 5 leg. ereil, $6 e$ over the line

(Ch. 3). $1 n$ and $y$ over the line, 2 leg. dui, 3 MS. eneu, 4 the $e$ over the line, 5 added over the line, 6 add y with many MSS., 7 after neu some letters cancelled; er eneid added over the line 
eq. idaw.

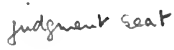
an appariton, a beadle

deheu ydau ereferiat neu er eferieit. ${ }^{8} \quad$ Ac egkell ${ }^{9}$ er argluid edeu heneuid. Ay guirda o hinny allan o pop5 thu ydau. Odena ford $\mathrm{yr}$ eneyt keuarvyneb ac eu ${ }^{10}$ darimret yeubraudle. Keghaus er haulur ar ellau assu ydau ar eford ar haulur Io enessav ${ }^{\prime} y_{\text {dau }} \cdot$ en eperued $^{11}$ ar kanllau ar ellau arall ydau. Ar ${ }^{12}$ rigyll en seuill trakeuen ekeghaus ${ }^{13}$. er amdiffinur ar ellau deheu ar I 5 eforth ar amdiffinhur enessau 'ydau' eneperued. ay kanllau or tu arall ydau. arigill traigeuen entheu. Gwedi darvo eiste euelly . bes. ringyle.

20 Kemerer $^{14}$ mach ar keureith. Esseu meychyeu auid ar ${ }^{15}$ tir ay dayar. Guystlon ${ }^{16} \mathrm{o}$ dynyon $\cdot$ deu$^{17}$ dyn neu auo 25 emedyant er argluid edant. muy o popleit arey $^{18}$ hinni

effeiryat neu yr effeiryeit. Ac yg kylch yr arglwyd $y$ deu hyneuid; ae wyrda o hynny allan o bob tu idau. Odyna fford yr yneit gyvarwyneb opposite ac wynt y darymret y eutpas a of brawdle. Kynghaws yr accomsel hawlwr ar y llaw assw idaw ar $y$ fford, ar hawlwr yn nessaf idaw yn y perved, ar kanllaw ar y llaw arall idaw; a supposte ar ringyll yn sevyll tracheuyn y kynghaws. Ar bleit arall $y$ tu arall yr fford; yn nessaf yr fford kynghaws yr amdiff- defendant ynnwr ar y llaw deheu ar $y$ fford, ar amdiffynnwr yn nessaf idaw yn y perued, ae ganllaw or tu arall idaw; ar rhingyll traegevyn ynteu. Gwedy darvo eisted yvelly, kymerer mach ar gyvreith. Sef meichyeu a vyd ar dir a dayar, gwystlon o dynyon, deu dyn neu a vo mwy o bob pleit. Ar rei hynny yn power medvant yr arglwyd yd ant. 3Pl. Presel

(Ch. 3). 8 in marg., where it has been written twice, the first entry having been mutilated by the cutting of the margin, 9 on $p .103$ the phrase is ýny gỷlch, 10 leg. uy $\mathrm{y}$ or the like, 11 after this ydau with a stroke beneath it, 12 after this some letters cancelled, 13 some words omitted which in the text of the Laws are: leq. nessaf. ar bleit arall $y$ tu arall yr ford yn nessat yr fford kyglaus, 14 MS. Kemerert, 15 MS. $a^{r}$, 16 some letters cancelled, $17 e$ over the line, $18 h$ after $a$ a surety
guarante
3Pl. Prese
1 myner cancelled and $r$ written above it. 
gosteg silence, the proclaiming of silence in court

biiv f. Cattle; a standard of value

camlwrw a fine, penally for the lesser offences.

A SUIT FOR LANDED PROPERTY

Odena guedi henne e dodir tellued $^{1}$ essev yu hene. ${ }^{2}$ Gostec ar emays. Puipenac a thorro etelleued honno teyr biu $^{3}$ camluru a tal ne nau ugeint. Ar geyr adeweter guedi er ostec bot hunnu ${ }^{4}$ en diuunyant er neb ay deweto. ac yr keghaus edevether irporth ydau.

Guedi daruo eyste ${ }^{1}$ en keureithaul mal y redewessam ny vchot ena e may yaun yr egnat deueduit wrth e dupleit ymdeveduch o keureith weithion. Ac ena may yaun iregnat gouin $\dot{y} \mathrm{r}^{2}$ haulur puy de keghaus $^{3}$ di a puy de kanllau . ac ena e may yaun ${ }^{4}$ yr haulur ev henwi. Ac ena may yaun eregnat gouin ir haulur a dodycollia kaffayl eneu pen vinteu. Ac ena ema yaun yr haulur ${ }^{5}$ dodav heb eff. Ac ena may yaun eregnat ${ }^{6}$ ac yr kanllau ' a sauant huy ydau ef en erenmay ef enidody arnadunthuy. ${ }^{7}$ Ac
4. Odyna gwedy hynny y dodir tyllwed. Sef yw hynny, gostec ar $y$ maes. Pwy bynnac a dorro y dyllwed honno, teir buw camlwrw a ${ }^{5}$ ? geir a dywetter gwedy yr Pres saly. Pass. ostec, bot hwnnw yn divwyn- profitless yant yr neb ae dywetto, ac yr kynghaws y dywetter yr io porth idaw.

5. Gwedy darvo eisted yn gyvreithiawl, val y rydywedassam ni uchot, yna y mae iawn yr ynat dy vedut wrth y 15 dwy bleit: "ymdywedwch o gyvreith weithyon." Ac according to law yna $y$ mae iawn $y r$ ynat ovyn yr hawlwr: "pwy dy gynghaws di a phwy dy 20 ganllaw?" Ac yna y mae iawn yr hawlwr eu henwi. Ac yna y mae iawn yr ynat ovyn yr hawlwr: "a dody colli a chaffael yn eu pen 25 wynteu?" Ac yna y mae iawn yr hawlwr dywedut, "dodaf," heb ef. Ac yna y mae iawn yr ynat ovyn yr kynghaws ac yr kanllaw, a 30

(Ch. 4). $1 u$ over the line, $2 h$ over the line, $3 i$ over the line, 4 after this did cancelled

(Ch, 5). $1 y$ over the line, 2 MS. hỳr, 3 ke over the line, 4 after this eregnat cancelled, $5 \mathrm{lcg}$. haulur deueduyt, 6 add gouin yr kyghaus, $7 \mathrm{~h}$ over the line

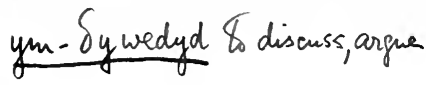


priodolderm.proprie täry righr

\section{A SUIT FOR LANDED PROPERTY}

ena emay yaun ${ }^{8}$ udunt huin- savant hwy idaw ef yn yr theu dewedvyt sauun.

5

Ac guedi hinny emay yaun eregnat gouin eramdiffenvr ${ }^{1}$ puy dekeghaus ditheu apuy de kanllau. Ac ena emay Io yaun ydau entehu eu henwi. Ac ena emay yaun ${ }^{2}$ yr egnat gouin ydau entehu' a did ev kolli a kaffayl en eu pen Ac ena may yaun ydau I 5 entheu dewetuyt dodau heb ef. Ac ena emay iaun ${ }^{3}$ hyn $y$ mae ef yn $y$ dodi arnadunt hwy. Ac yna $y$ mae iawn udunt hwynteu dywedut : "savkn.". eregnat devetvit wrth erhaulur ' haul di weython de haul. Ac ena emay ${ }^{4}$ yaun 20 yhaulur ${ }^{5}$ decreu.

Llema essit yaun yr haulur edewetuyd $^{1}{ }^{1}$ menegi $\cdot$ yuot ef en briodaur ar etir hun-

6. A gwedy hynny y mae iawn yr ynat ouyn $y r$ amdiffynnwr: "pwy dy gynghaws ditheu, a phwy dy ganllaw?" Ac yna y mae iawn ydau ynteu eu henwi. Ac yna y mae iawn yr ynat ovyn idaw ynteu, a dyd ef? 35 . $P$. $q$. golli a chaffael en eu pen. Ac yna y mae iawn idaw ynteu dywedut : "dodaf," heb ef. Ac yna $y$ mae iawn yr ynat dywedut wrth yr hawlwr: "hawl di weithon dy hawl." Ac yna y mae gupen.25
3 holi iawn yr hawlwr dechreu.

7. Llyma yssyd iawn yr hawlwr y dywedut, menegi $y$ vot ef yn briodawr ar $y$ tir hwnn yma ar dayar. Ac o byt a amheuo idaw ef $y$ vot $=$ byd yn briodawr, bot ganthaw ynteu a gatwo y briodolder o ach ac edrif, hyt y mae descent, digawn yn y gyvreith, ae

(Ch. 5). 8 after this yregnat cancelled

(Ch. 6). 1 l over a cancelled $i, 2$ over the line, 3 over the line; aftcr this irhaulur cancelled, $4 e$ over the line, 5 leg. yrhaulur

(Ch, 7). I MS. edewetduyd 
agkeureithiaul yar ybriodolder' ac osid ay hammehuho ${ }^{2}$ emay ydau $\mathrm{ef}^{3}$ ay guyr . yreherru enagkeureithiaul. Ac essev emayentehu $u^{4}$ endodi ar ekeureith deleu deuot en keureythaul traykeuen er lle ereherruyd en agkeureithyaul $1^{5}$ ohonau.

Oderuit bot rey adewetho dodi keythveid ac guybedyeid or un pleyt Ninni adewedun egellir ene warhandawer atteb er amdiffenhur.

Heb amdiffenhur ${ }^{1}$ myuy essit briodaur o $\mathrm{acch}^{2}$ ac edriu ac esseu eduyf en guarchadu empriodolder ${ }^{3}$ val emay goreu edeleauvy $y$ guarchadu ac osid ay hameuho $y^{\cdot} a^{4}$ henni emay ymy ageidu digaun ${ }^{5}$ bot en guir adewedau. A thitheu obuosty ema ty haythost en keureythaul odema. Ac osid a hamehuo hinni. emay ymy digaun ayguyr. ryyru yn anghyvreithyawl $y$ ar $y$ briodolder. Ac osit ae hamheuo, y mae idaw ef digawn ae gwyr y ryyrru yn anghyvreithyawl. Ac yssef $y$ mae ynteu yn dodiar $y$ gyvreith, dylyu dyvot yn gyvreithyawl traegevyn yr lle y ryyrrwyt yn anghyvreithyawl ohonaw.

8. O dervyd bot rei a dywetto dodi ceidweid a progereidwadwituess gwybydyeid or un bleit,.... gurylysiad an owybyeid or un bleit, "geye-wituess Ninni a dywedwn y gellir, yny warandawer atteb $y_{\wedge} I 5 \quad \Lambda^{r}$ amdiffynnwr.

9. Heb yr amdiffynnwr: "Mivi yssyd briodawr o ach ac edrif. A sef yd wyf yn gwarchadw vym priodolder, 20 to guard, protect val y mae goreu y dylyaf $\mathrm{A}_{\wedge} \mathfrak{\wedge}$. warchadw. Ac osit ae hamheuo imi hynny, y mae imi dgeidw ${ }^{x}$ digawn bot yn wir a digawn a geidew dywedaf. A thitheu, o buost 25 ti yma, ti a aethost yn gyvreithyawl odyma. Ac osit a hamheuo hynny y mae imi digawn ae gwyr."

(Ch. 7). 2 the third $h$ over the line, 3 digawn has probably been omitted, $4 h$ over the line, $5 r$ over the line

(Ch.9 ). 1 leg. eramdiffenhur, 2 there is something like an $h$ over the second $c, 3$ the third letter seems to have been altered to $p, 4 \mathrm{y}$ am ; leg. y mi ? 5 leg. digaun ageidu

$$
\text { X } 3 \text { ss. Pres. Snd. of cadw to leeep, preserve, main taim }
$$




\section{A SUIT FOR LANDED PROPERTY}

Ninni adewedun ket darfo eramdiffenur rohi atheb kin oyholy ev or haulur bot en anolo er ateb eny warandao

5 ef er haul ac odena atebet.

Ac guedy darfo vdunt euduy kegheussayth mal edewedassam ni vchot. Gouenet Io er egnat udunt aydy்gaun hyn adewedassant. Ac gouenet udunt auennant guellau eu kykeussayth. ${ }^{1}$ Ac obit ay menno gather ${ }^{2}$ ydau. Ac 15 onibit ay menno kyemeret eregnat euduy kegheussayth ${ }^{3}$ a dadkanet huy. A guedy estadkano aynt eregneyt allan. ar effeyryhet $y$ gyt 20 ac vy'a. Righyll ygyt aguy · hy eu kadv. Rac doust dynyon ywarandu $\mathrm{u}^{4}$ arnadu $\mathrm{n}$. Oderuit idyn deuot ywarandau arnadunt huntheu ${ }^{5} \mathrm{ev}$ 25 adely talu teyrbuy kamluru hir brenhin. Ac o bit ebrenin enemays ' ev adele talu kamluru deudeplic am hinny. Ac ena guedy edeystedont 30 huy emay iaun 'yr effeyryat. guedya duy ydangos oduy
Io. Ninni a dywedwn, kyt darffo yr amđiffynnwr roi atteb kyn noe holi ef or hawlwr, bot yn anolo $\mathrm{yr}$ atteb, yny warandao ef $y r$ hawl, ac odyna attebet.

I I. A gwedy darffo udunt eu dwy gyngheusaeth, val $y$ dywedassam ni uchot, govynet yr ynat udunt, ae digawn yr hyn a dywedassant, a gouynet udunt a vynnant gwellau eu kyng- 5 improve, heussaeth. Ac o byd ae mynno, gatter idaw. Ac ony byd ae mynno, kymeret yr ynat eu dwy gyngheussaeth, a dadganet hwy. A gwedy rechearsereate as dadgano, aent yr yneit allan, ar effeiryeit y gyt ac wy, ar ringhyll y gyt ac wy $y$ eu kadw, rac dyvot dynyon $y$ warandaw arnadunt. $\mathrm{O}$ dervyd y dyn dyvot y warandaw arnadunt wynteu, ef a dyly talu teirbuw kamlwrw a fine yr brenhin. Ac o byd $y$ brenhin yn y maes, ef a dyly talu kamlwrw deudyplic am hynny. Ac yna gwedy yd eistedont hwy y mae iawn 3 Pl. Pr.Sulj.

(Ch. 11). l ky over the line, $2 h$ over the line, 3 ssa over the line, 4 leg. ywarandaw, 5 the second $h$ over the line 
geir cyfarch a supplementary question asked after the trial, before the verdict is given.

\section{A SUIT FOR LANDED PROPERTY $2 \mathrm{I5}$}

er yaun ${ }^{6}$ udunt. Akanu yr effeiryat gwediaw Duw y onadunt huyntheu eu pader dangos o Duw yr iawn Ac guedy epader emay yaun udunt. A chanu onadunt yr egnat dadkanu eduykeg- wynteu eu pader. A gwedy hessaith eylweyth.

$y$ pader $y$ mae iaun $\mathrm{yr} 5$

ynat dadganu y dwy gyngheussaeth eilweith.

Ac o deruit bot enreyt ${ }^{1}$ egeỳr keuarch. Elleger deu oy ouyn. Ac obit reyt $y r$ bleyt egouener egeyr keuarhc ydy vrth kemyrit keghor ${ }^{2}$ aynt tuy kan kanyat ${ }^{3} \mathrm{yr}$ egneyt hyeu keghor 'ac essev edant ynẏuer ebuant en . eukehussayth ' heb auo muy aguas yr argluyd ygyt aguy• yeu kadu Rac deuod neb yeu keghor' ygyt ac huy ac odau neb atadunt ay keghoro talet ef kamluru er brenin a bot en anolo ekeghor. Ac guedy edarfo ekeghor deuent edeu hinny ar eregneyt $t^{4}$ adatkane $n t$ egneẏth ${ }^{5}$ ekeghor.

Oderuit nabo reyt urth eyr keuarch yaun yu gadayl udunt vintheu eu ardelu

12. Ac o dervyd bot yn reit y geir kyvarch, ellynger deu oe ovyn. Ac o byd reit ro yr bleit y govyner $y$ geir kyvarch idi wrth gymryt kynghor, aent wy gan ganyat yr yneit $y$ eu kynghor. Ac yssev yd ant, $y$ niver $y$ buant 15 yn eu kyngheussaeth, heb a vo muy, a gwas yr arglwyd y gyt ac wy y eu kadw rac dyvot neb y eu kynghor y gyt ac wy. Ac o daw neb 20 attadunt ae kynghoro, talet ef gamlwrw yr brenhin, a bot yn anolo y kynghor. A gwedy y darffo y kynghor, deuent $y$ deu hynny ar yr 25 yneit a dadganent yr yneit $y$ kynghor.

. I3. Odervyd naboreit wrth ey̆r kyvarch, iawn yw gadael udunt wynteu eu hardelw, a 30 a voucher

(Ch. 11). $6 u$ over the line

(Ch. 12). I some MSS. add wrth, $2 h$ over the line, $3 y$ over the line, 4 the second $e$ over the line, $5 n$ over the line; leg. eregneit 


\section{moryhhäu touse, employ, engoy, profit

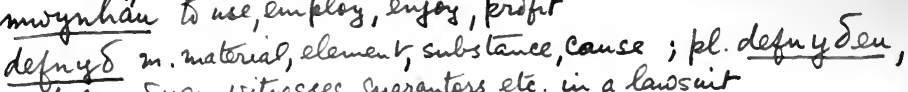 defny $\delta$ yen wituesses, guarantors ete. in a lawsuit}

\section{I6 A SUIT FOR LANDED PROPERTY}

agerru deu youyn puy eugubideyt ' ac eu kedweyt · a phale emaynt $\cdot$ odewedant eu bot ene mays ' munaher vynt. 5 odewedant $^{1}$ eubot en ${ }^{2}$ un kemut ac vy rodher oyd trideu ${ }^{3}$ udunt. Odewedant eubot en ereil kemud rodher oyd naunyjeu udunt. Odewetant

Io eubot egulat arall vynt ${ }^{4}$ neu lanu neu trey eregthunt ac vy ' oyt petheunos or did hunnu os kin hanner did vit - os guedy hanner did

I 5 petheonos odranoyth $\cdot$ ar did hennu endyd kolli akaffayal. of.p.212 Abot eguystlon egkarch ${ }^{5}$ brenin ' hit edid hunnu' ac erchi y paup deuot ay devni20 dev kanthau edid hynnu. hit ar etir. Kenebo duun kan edu bleyd $\cdot$ hinny. Neu ${ }^{6}$ edyu endid keuereit barnedic.

25

En etrededet guedi edelePres.Subj.Pass.? her vyneb ${ }^{1}$ iaun yu i paup dyfod eistet enelle mal ereystedus gyrru deu y ovyn pwy eu guibydyeit ac eu keidweit, a pha le y maent. Odywedant eu bot yn y maes, mwynhaer wynt. $\mathrm{O}$ dywedant eu bot yn un kymwt ac wy, rodher oet tridieu udunt. $\mathrm{O}$ dywedant eu bot yn yr eil gymwt, rodher oet naw nieu udunt. O dywedant eu bot yg gwlat arall neu lanw neu drei yryngthunt ac wy, oet pythewnos or dyd hwnnw, os kyn hannerdyd $y$ byd. Os gwedy hannerdyd, pythewnos o dranoeth, ar dyd hwnnw yn dyd kolli a chaffael. A bot y gwystlon yg karchar $y$ brenhin hyt $y$ dyd hwnnw. Ac erchi $y$ bawp dyvot ae devnydeu ganthaw y dyd hwnnw hyt ar y tir. Kynnybo duungan y dwy bleit hynny, neud ydiw accordant. acreeable yn dyd kyvreith barnedic. decided, five

I4. Ynytrydyd dyd guedy $y$ delher wyneb yn wyneb iawn yw $y$ bawb eisted $y n y$ lle, val y ryeistedws y dyd kynt. Ac o bydant meirw

30 rey or guir auu en ekegedid kint $\cdot$ ac obetant meiru

(Ch. 13). 1 ed over the line, 2 over the line, $3 e$ over the line, 4 omitted in several MSS., 5 leg. karchar e, 6 written twiee over ; leg. neud

(Ch. 14). 1 leg. vyneb en vynep; there are remains of the missing words on the margin 


\section{cynnig to propose, proffer, suggest}

dodi ym mhen un 5 suggest, submit, entrust, hand over

\section{A SUIT FOR LANDED PROPERTY}

kussaeith doder ereill en eu lle $\cdot$ a guedi er $^{2}$ eisteter ena emae yaunt yr haulur $\cdot$ kenic $y$ devnidieu iam etestion ay keidveit ${ }^{3}$ adeueduit evot ef en paraut. Ac ena emayyaun ir ${ }^{4}$ amdifinnur gurtheb ac esev ateb a dere $\cdot$ deueduit yvot ef en paraut ' ay defnetyeu kanhau val $y$ hedeuis ac ena emae yaun yr brenin hercki dankos eguestelon en emays. kanys vint essit vechieu. ${ }^{5}{ }^{6} \mathrm{Ac}$ ena emay yaun ir egnat deuedut kosb er anostec' esseu eu hene teir biu camluru abot en anolo egeir adeueter. punishment, fine

Ac ena emae yaun ir haulur dodi em pen er eneyt pan niu $\delta 155(a)(\beta)$ effo adedeuis ${ }^{1}$ en kentaf testion ' akeitueit - a deleu ohonau enteu ${ }^{2}$ muenhau en kentaf Ac ena emay yaun yr eneit erchi ydau enteu duyn $y$ keditveit ${ }^{3}$ ay testion rei or gwyr a vu yn y gyngheussaeth, dotter ereill yn eu lle. A gwedy yr eistether, yna y mae iawn yr hawlwr kynnic y devnydyeu y am y dystyon ae geidweit, a dyuedut $y$ vot ef yn barawt. Ac yna y mae iawn yr amdiffynnwr gwrtheb. Ac yssef atteb a dyry, dyuedut $y$ vot ef yn barawt, ae devnydyeu ganthaw, val $y$ hedewis. Ac yna y mae promised (a dand iawn $\mathrm{yr}$ brenhin erchi dangos y gwystlon yn $y$ maes; 15 machsures, kanys wynt yssyd veichieu. guaranton Ac yna y mae iawn yr ynat dywedut kosb yr anostec. disturbance, Sef yw hynny teir buw kamlwrw a bot yn anolo y 20 geir a dywetter.

15. Ac yna y mae iawn yr hawlwr dodi ym pen yr yneit panyw efo a edewis yn gyntaf dystyon a cheidweit, 25 a dylyu ohonaw ynteu eu mwynhau yn gyntaf. Ac use yna y mae iawn yr yneit erchi idaw ynteu dwyn $y$

(Ch. 14). 2 some MSS. yd, 3 the second $i$ over the line, 4 after this brenin cuncelled, 5 kanis-vechieu interlined, in part on the margin and illegible, 6 there seems to be a lacuna here; some MISS, have: Ac ena goedy dangosser y goystlon y mae iaon yr brenhin erehi yr righyll dodi gostec ar y maes

(Ch. 15). 1 leg. aedeuis, 2 leg. enteu en, 3 leg. keidveit 
breint (bryein, lrein) m. prii clege, prerogative; state, condition. tref-ted ang m. an in heritor

\section{I8 A SUIT FOR LANDED PROPERTY}

$y$ eu muinahu./ Ac ena emae yaun idau enteu eu duin huy ene keuil ${ }^{4}$ ef ac eudangos ' esseu eu rei 5 aedeueis $^{5}$ ef erei a enguis en edit kyntaf $\mathrm{Ny}$ dele er amdifennwr llessu yrun onadunt kanivir ${ }^{6}$ nabo da idau adeueduit. ${ }^{7}$ Ar hun a llesso Io onatuunt kin guibot bet aduedoent $^{\circ} 8$ bit sauedc ${ }^{9}$ hunu - er amdifenur aeil gouin $^{10}$ aoes breint $\mathrm{yr}$ reihinny. Ac obit doent rac15 dunt ${ }^{\circ}$ esseu pa achaus ${ }^{11}$ egeill ef gouin hinny vrth na eill alldut bot en vybitiat ar a foregiger, alien; treftadauc. Ac na eill gureic' ar gur. Ac ekit 20 ahene ni heill llauer o deneon bot yn vibetiet nac en kedueit heruit breint ar amdifenur ni lluger arnau deueduit hinny.

25

Oderuit ir amdifenur readau testion auo gwell no rei aedeuis er haulur' ae ouot en guell yu breint ay o bot 30 en amlach Amennu ohonau geidweit ae dystyon $y$ eu mwynhau. / Ac yna y mae iawn idaw ynteu eu dwyn hwy yny kyvyl(?) ef ac eu dangos. Sef yw rei a edewis ef $y$ rei a enwis yn y dyd kyntaf. Ny dyly yr amdiffynnwr llyssu yr un on- to reject adunt, kany wyr na bo da idaw a dywettont. Ar hwn a lysso onadunt cyn gwybot beth a dywettont, bit savedic establuled hwnnw. Yr amdiffynnwr a eill ovyn a oes breint yr rei hynny. Ac o byd, doent 399 . Impen. racdunt. Sef pa achaws y geill ef ovyn hynny, wrth na eill alltut vot yn wyby-eys-wituess dyat ar drevtadawc, ac na eill gwreic ar wr. Ac y gyt a hynny ny eill llawer o dynyon vot yn wybydyeit nac yn geidweit herwyd breint. Ar amdiffynnwr ny lwgyr arnaw dywedut hynny. disurwantage

16. O deruyd yr amdiffynnwr ryadaw tystyon a uo gwell nor rei a edewis yr hawlwr-ae o vot yn well eu breint ae oe bot yn amlach-

(Ch, 15). 4 some MSS. have kyjlch, 5 the second $e$ over the line; leg. aedewis, 6 the second $i$ over the line, $7 \mathrm{leg}$. adeueduint, 8 o over the line, 9 leg. sauedic, $10 i$ over the line, 11 the second $a$ over the line 
ysgolherg scholan, clesk, priest

\section{A SUIT FOR LANDED PROPERTY}

219

kannal hinny. Iaun $\mathrm{eu}^{1}$ a mynnu ohonaw gynnal cyanal to sustain; dangos aguedi dangosso ef hynny, iawn yw eu dangos. etestion nityaun ${ }^{2}$ yr haulur A gwedi dangosso ef $y$ eu llessu vyntheu. Ena emai dystion, nyt iawn yr hawlwr iaun yr enat gouin yr haulur eu llyssu wynteu. Yna y may breint de destion dy. Ac ena emay yaunt yr haulur mae iawn yr ynat ovyn yr hawlwr: "Mae breint dy where is? deueduit breint $y$ testion $\cdot$ ae dystyon di?" Ac yna $y$ vntoe en veirri neu en maeiawn yr hawlwr dywedut kegheoron $^{3}$ ae vnteu en veneich $^{4}$ neu en ahtraon ae vnteu en efferiet neu en escoleicion ae vinteu en lleecion breinaul Guedi daruo ir enat gouen ir haulur breint etestion iaun eu $\mathrm{yr}$ enat gouin yr amdifenur breint $y$ testion Ac ena emay yaunt yr amdifennur deuedut ebreint goreu avo oy testion Ac ena emay yaunt $y r$ enat datkanu deubrein yreduedasant eduypleit yeu testion.

Ena emay yaun yr enat gouin ir duipleit ${ }^{1}$ a sauant huy hen erhen ededis en y dodi en eu pen . llema paup breint y dystyon, ae wynteu Io yn veiri neu yn gynghelloryon, ae wynteu yn veneich neu yn athrawon, ae wynteu teachers yn effeiryeit neu ysgoleigyon, ae wynteu yn lleygion brein- I 5 privilged niawl. Gwedy darvo yr ynat govyn yr hawlwr breint y dystyon, iawn yw yr ynat govyn yr amdiffynn $\mathbf{w}$ vreint $y$ dystyon. Ac yna y mae 20 iawn yr amdiffynnwr dywedut $y$ breint goreu a vo oe dystyon. Ac yna y mae iawn yr ynat dadganu deu vreint y rydywedassant y 25 dwy bleit y eu tystyon.

I7. Yna y mae iawn yr ynat gvyn yr dwy bleit a $=x$, savant hwy yn yr hyn yd ydys yn y dodi yn eu pen. $30 \quad x$ or guebethit en deueduit Llyma bawb or gwybydyeit

(Ch. 16). 1 leg. eu eu, $2 t$ over the line, $3 \mathrm{leg}$. keghelloron, 4 MS. venich

Ch. 17). I There is a smudge between $p$ and $l$ 
dygyn hard, severe; a tesr, proof. creirhär Es canse 5 surear by relies

220 A SUIT FOR LANDED PROPERTY

esauahant - llema popun or duipleit yn amheu guibytied $y$ kilit nasdegant yr degin. ket as deuetoent ar eutauaut

5 leuerit jaun eu yr eneit ena ev kreirhau' ac guedi askreirhauont emay yaun vddunt menet allan. Ac edrych ${ }^{2}$ er hyn jaunaf aueloent vrth a Io gluassant. Ac oguelhant bot en vell testion eneill rei noe gilit - diuarnent huy eguaethafe testion. Oderuit bot en kestal eutestion - diuarner er I 5 amdifennur ' kanys etheuis ef testion a vey guell noc aoet kan ellall. Ac nis cauas. Ac ena emay jaun yr egneit barnu deuot er 20 haulur ar etir. ar e breint edoet pan kechuinuus ${ }^{3}$ en agkaefreithiaul yarnau

25 Ac guediheni emay ${ }^{1} \mathrm{yr}$ eneit proui ekedueit ${ }^{2}$ y edric a duc pop rey onadunt huy bot en priodaur ebleit emaent enikanhelu a deueduit o yn dywedut y savant. Llyma bob un or dwy bleit yn amheu gwybydieit y gilyd nas dygant yr dygyn, kyt as dywettont ar eu tavawt sperken wor leveryd. Iawn yw yr yneit yna eu kreirhau. A gwedy askreirhaont y mae iawn udunt vynet allan, ac edrych yr hyn iawnaf a welont wrth a glywassant. Ac o gwelant bot yn well testyon eneill rei noe gilyd, divarnent hwy y gwaethaf $y$ dystyon. $\mathrm{O}$ dervyd bot yn gystal eu tystyon, divarner yr amdiffynnwr; kanys edewis ef tystyon a vei well noc a oed gan y llall, ac nys kauas. Ac yna y mae iawn yr ygneit yueit barnu dyvot yr hawlwr ar y tir, ar y breint yd oed pan gychwynws yn aghyvreithyawl y arnaw.

18. A gwedy hynny $y$ mae iawn yr yneit provi $y$ keidweit, y edrych a dwng ${ }^{x}$ pob rei onadunt hwy bot yn loft sides briodawr $y$ bleit y maent yn y chynhelu; a dywedut o geidweit pob rei eu bot yn

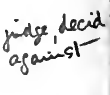

30 keituueit pop rey eu bot en priodaur Ac odamheuir

(Ch, 17). $2 h$ over $c, 3 h$ over the line

(Ch. 18). I leg. emay iawn, 4 MS. ekeuit

$x$ turgg 3 gg. Pr. Sud. of tyagn 5 swear, take an oath. 


\section{A SUIT FOR LANDED PROPERTY}

vntheu yaun eu eucreirhau ar nep akellio $y$ kedueit onaduunt $\mathrm{y}$ vrht ellu kollet etir'o seif ekeitueit or duepleit kehedet $\mathrm{yv}^{\cdot}$ ar lle ebo kehedet deuhanner vit.

Ked barner ydau deuod yr tir' nikecuuin egur aoet ene mediant kynt erdau okeill kaffael · tu · atal · ydau en er un lle ac en kastal edeudir vrth na burir odena ef. Ac nideleir talu tir ambreinaul en lle tir abreint ohonau val kegkalloraith neu vaerony neu redit.

Ac ena emay yaun er egneit deuot traceukeuen $y$ eu braudle ac ena emay yaun vdunt kemrit kedernit $a^{1}$ bot vrth ebraut a kamrit mach areugober. Ac ena edeleant er eneit datcanu eduy kegheusaeh ' a guedi hene datcanu eu uaraut ${ }^{2}$ ac ena ebrenin adele redhau eguestelon - oeu carcar.

(Ch. 20). 1 leg. ar, 2 leg. braut briodawr. Ac ot amheuir Pres. Ind. Pass wynteu, iawn yw eu kreir- dombr, despecto, hau. Ar neb a gilio y geid-call in question. weit onadunt $y$ wrth $y \underline{l l w}$, un oath kollet y dir. O seif y keidweit 5 or dwy bleit, kyhyded yw. equalis, parity Ar lle y bo kyhyded deuhanner vyd. dwicled in tro ergal halves

19. Kyt barner idaw dyvot yr tir, ny chychwyn y gwr a 10 move oed yn $y$ medyant gynt yrdaw, o geill gaffael tu a an quivalent? thal idaw yn yr un lle ac yn gystal y deu dir, wrth na because .. met (?) vwryir odyna ef. Ac ny I5 dylyir talu tir ammreiniawl without prislege yn lle tir a breint ohonaw, val kynghelloraeth neu vaeroni neu rydit.

20. Ac yna y mae iawn yr 20 yneit dyvot tracheukevyn $y$ eu brawdle. Ac yna y mae iawn udunt kymryt kedernit ar vot wrth $y$ vrawt, a chymryt mach ar eu gobyr. 25 a fee, pay Ac yna y dylyant yr yneit dadganu y dwy gyngheu- a pleading saeth, a gwedy hynny dadganu eu brawt. Ac yna $y$ brenhin a dyly rydhau y 30 gwystlon o eu karchar. 


\section{THE PRIVILEGE OF ST. TEILIO.}

The following Latin Charter (Lib. Land, page 118) deals with the same subject, and illustrates the Welsh :

Priuilegium Sancti Teliaui est et ecelesiae suae Landaniae, datum sibi et onmibus successoribus suis in perpetuo a regibus istis et principibus Brittaniae, confirmatum apostolica anctoritate, cum onnibus legibus suis in se plenariis sibi et terris suis, libera ab omni regali sernitio, sine consule, sine proconsule, sine connentu intus nec extra, sine expeditione, sine uigilanda regione. Et cum omni institia sua; de fure et furto, de rapina, de homicidio, de arsione, de rixa, de sanguine, de refugio niolato ubique in terra sancti, de assaltu uiarum et extra nias, de faciendo iudicio et patiendo, de omni populo Sancti Teliaui in curia Landauiae; de communione aquae et herbae, campi et siluae populo ecclesiae Sancti Teliaui; cum mercato et moneta in Landauia ; cum applicatione nauium ubique per terras Sancti Teliaui libera pro regibus et omnibus nisi ecclesiae landauiae et episcopis eins. De opprobrio et onmi iniuria quod rex Morcanhuc et sui homines fecerint episeopo Saneti Teliaui et suis honinibus, iden rex Morcanhuc et sui homines rectum faciant episcopo et suis hominibus, et iudicium patiantur in curia Landauiae. Omnis lex quae fuerit regali, omnis etiann et in curia plenarie episcopali Landauensi.

Lýmma $\dot{y}$ cýmreith ha bry்ein eccluýs Teliau o lanntaf arodes breenhined hinn ha touysssocion Cymry

5 ẏntrýcýguidaul dy eccluýs teliau hac dir escip oll gueti ef amcytarnedic o audurdaut papou rumein $\dot{y}$ holl cýfreith didi hac dy thir hac di dair ' Io rýd o pop guasanaith breennin byddaul heb mair . heb cýghellaur' heb cýhoith . dadlma ymeun gulat hac ny dieithỳr heb luýd ' heb

I 5 gauaỳl heb guýlma ýcyfreith idi ýnhollaul o leitýr o latrat 'o treis ' odẏnnyorn .
Llyma y gyvreith a breint eglwys Deilaw o Lanndaf, a rodes $y$ brenhined hynn a thywysogyon Cymry yn dra- etemal gywydawl y eglwys Deilaw ac yr escyp oll gwedy ef, amgadarnedic o awdurdawt ratified, pabeu Ruvein. Y holl gyvreith idi ac $y$ thir ac $y$ dayar; ryd o bob gwasanaeth brenhin bydawl; heb vaer, heb gynghellawr, heb gyhoed cy hoe of pul dadylva y mewn gwlat ac yn $y$ dieithyr; heb luyd, heb avael, heb wylva. Y chyvreith idi yn hollawl o leidyr, o ladrat, o dreis, o dynyorn,

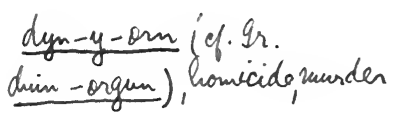

(t)

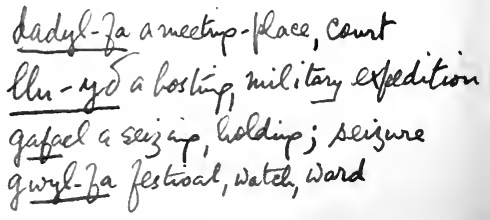




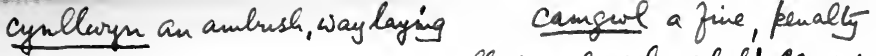

o cýnluýn hac o losc ${ }^{\circ}$ o amry்son canguaẏt ahebguaẏt $\cdot \dot{y}$ diruý haý camçul ýndi didi ýn hollaul o o dorri naud $\dot{y} n n$ lann hac $\dot{y} n-$ dieỳthýr lann • orachot ýnn luhỳn hac dieithýr luhỳn.

un place o cýrch $\dot{y}$ popmýnnic artir teliau hay guir' hay braut dy lýtu $\dot{y} r$ ecluýs ygundy teliau ýnn lantaf ' hac ny lys $^{\circ}$ dufÿr ha guell hac choỳt ha maýs ýncýfrýtin dy lýtu teliau cýfnofut habathoriaỳth ẏnn lanntaf hac aperua ardir teliau dýr loggou adis-

" " cýnno nìthir $\dot{y}$ pop mýnnic $\dot{y} t$ uoy rýd rac brennin arac paup namýn dy teliau aý eccluýs lantam ' ha dy் escýp · har mefyll har sarhaýthar cam har ennuet a gunech ${ }^{1}$ brennhin morcannhuc hay gur hay guas dy escop teliau hac dy gur hac dy guas dýuot brennhin morcannhuc $\dot{y}$ gundy teliau ẏn lanntaf $\underline{\mathrm{d} \dot{y}}$ gunethur guir ha cýfreith. ha diguadef braut $x_{\text {diam }}$ $\dot{y}$ cam a diconher dy escop teliau ha dy gur ha dy guas. ythir haý daýr dy luydd dy uuner digauayl b ha pop o gynllwyn ac o losc, o amryson gan waet ac heb waet. $\mathrm{Y}$ dirwy ae chamgwl yndi idi yn hollawl o dorri nawd yn llann ac yn diethyr llann, 5 o ragot yn llwyn ac diethyr llwyn, o gyrch [

ar dir Teilaw. Ae gwir ae justice, right brawt y deulu yr eglwys yg lydw Gwndy Teilaw yn Llandaf ro ac yny llys. Dwvyr a gwellt gross a choet a maes yn gyffredin $\dot{y}$ deulu Teilaw. Cyvnewiteom, merchandise a bathoriaeth yn Llandaf, ac mintage, mint

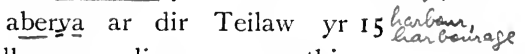
llongeu a discynno yny thir pa le bynnac $y$ bo, ryd rac brenhin a rac pawb namyn y Deilaw ac eglwys Landaf ac y hescyp. Ar 20 mevyl ar sarhaet ar cam ar gannic ae wr ae was y escop Teilaw ac $y$ wr ac $y$ was, dyvot brenhin Morgann yc y 25 Wndy Teilaw yn Llandaf y wneuthur gwir a chyvreith a law, sighr diodef brawt yam y cam a paes. Sulj. Pass.y \& digonher y escop Teilaw difawn ts be ac $y$ wr ac $y$ was. Y thir ae 30 accomplise dayar di luyd ${ }^{\oplus}$ divuner eve-fetrona
diavael. A pob cyvreith a lond vo $y$ vrenhin Morgannwy yn

mefyl $8.8 \mathrm{~m}$. disfrace, shame, insult

$$
\text { di-afael exempt from seigure }
$$

sarhaed f. an insulr, affrow

cam wrong, injustice

enywed damage, injury 
cyfreith auo dy brennin $[y]$ lys, eu bot $\wedge_{\wedge}$ yn hollawl y $\wedge$ oll morcannuc $\dot{y}$ n lys ou bot escop Teilaw yn y lys ynteu. oll ýn hollaul dy escop teliau Ae vot yn emelldigedic ac accursed ný lýs yntou hay bot yn yscumunedic $y_{y}$ neb ae $5 \dot{y}$ nemelldicetic hac $\dot{y}$ y scu- torro ac ae divanwo $x$ breint munetic $\dot{y} \underline{\underline{r}}$ neb aitorro hac hwnn, ac ef ae blant wedy aý dimanuo $\dot{y}$ brýeint hunn. ef. Yn vendigedic ac ef ae hac ef hay plant guety ef. blant ae enrydedockao ${ }^{\circ} \mathrm{y}$ Hỳnn bendicetic hac ef hay breint hwnn ac ae katwo. Io plant aý enrýdedocao $\dot{y}$ - Amen.

breint hunn hac aý $\operatorname{cat}(\omega 0){ }^{2}$

Amen.

1. leg. gunel. 2. o $o$ added in later hand.

$$
\begin{aligned}
& X_{3 e d} \text { sg. Pres. Suly. of di-fanw }(0 . \omega \cdot \underline{\text { dimanw }}) \& \text { disparage, slighr } \\
& \text { - 3rd. sg. Pres. Suly. of enryde Su E celelenato }
\end{aligned}
$$


${ }^{x}$ hafod a summes dwellip

225

v. Gackson, Farly Celtie Nature Pactry, p.63.

VI. MORAL VERSES.

Zaleip?

5 tungr

bantife, fair, delightfal

equally swift

shiffe, ingenions; an antist

ber, thin, lunaciated binch-treas

haedu to deserve,

clain, menit

wiched

gitt, matal endowment

rough

whike, dissinitar to

loud proision trugar daffar Dul goreu.

hard, dry

bass stonr, pat

v. $\{129$

Kalan gaeaf, garo hin, purdu bran, buan o vras:
Kalan gaeaf, kalet graoun, grain, "berre's" deil ar gychoyn, Mynnwynn Maun: apool y bore gynn noe vynet "The morric before his going woe thim who gwae a ymdiret y estralin.

Kalan gayaf, kein gyfrin; a confidant "fine is a seorer shared" kyfret awel a dryckin: (<drof him) forl weather gGeith keluyd yo kelu rin.

Kalan gayaf, cul hydot, $\quad$ pl. of hy $\delta$ a stag melyn blaen bedo, guedo hauof: gwe dw desented, desolate, foweh grae a haed meuyl yr bychot. a trifle

IO

Kalan gayaf, crom blaen gorysc, the smallen branches of a tiee gnaut o benn dirieit teruysc: trmble, conflict, uproar Me ny bo dain ny byd dysc. "Where here is no natinal gitt thene wrel wealter

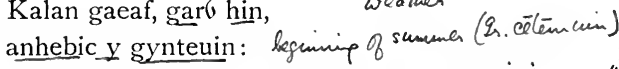
namwyn Dur nyt oes dewin. a magicion "Ifisines"

Kalan gaeaf, kein gyfreu

$x$

pe. og $\operatorname{cog}$ a cuchoo

"the merciful proridence of hod is bes"

"what is parched is hard"

20

"surfer is the shindy"

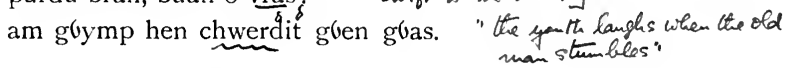

$P \quad$ cusyup m. a fall

(*)

kyfren words, song'v. Com Leywarch Hen. 162. (qf. p. 229 infra) 
3g. Pr. Fnd. of garsi to be angry, frown kindliness
Kalan gaeaf, cul kerwyt, gwae wann pan syrr; byrr vyd byt: goir guell hegaroch no phryt.

Kalan gayaf, $110 \mathrm{~m}$ godeith, aradyr yn rych, ych yg gweith: or kant odit kedymdeith. "concliness" friend" 
nihy $\delta$ splendan, splendid? Mhurysa ammad shiffel, fine

?. ayfel :?powerful, stiong

227

[q. Lewis, Hen Gerddi Crefyddal, pp.11-13]

VII. DOOMSDAY.

Deus Dus delwat,

createn $<$ delw $t$-iad

leg. gulad

Goledic, guaed neirthyat.

a streugtheres, stay

Crist Jessu g(yliat,

a guardion

sway RGysc rihyd amnat

Aduelach kaffat. prer.pass. of caffel to get $\beta 145$

Nym gonel heb ranned

Moli dy trugared.

$\mathrm{Ny}$ dyfu yma,

Guledic, dy gynna.

cyma, equally good, pear v. W. f. 246

Ny dyfu, ny் dyfyd

10

Neb kystal a Douyd.

Ny ganet yn dyd plisys people

Neb kystal a Dub.

Nac nyt adef

uef to aduit, achuootedg, allow

Neb kystal ac ef.

5

$\mathrm{Vch}$ nef, is nef

Nyt goledic namyn ef.

Vch mor, is mor

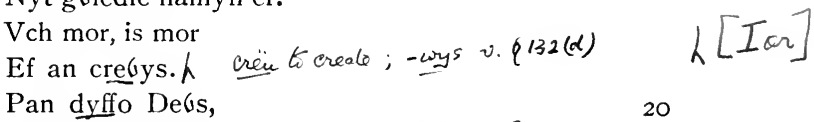

v.p.91

v.p. 93

Ef an gwnaho mair tros. = twost noise?

20

Dyd brabt yn echwrys. violent, fierce

Kennadeu o dris

Gwynt a mor a than,

Luchet a tharyan,

Eiryf $a b^{1}$ goengan. white and fair

Iwow

I 5

a vile, people

$\mathbb{L}$ oyth byt yg griduan

quioftan Egroan, a groaning

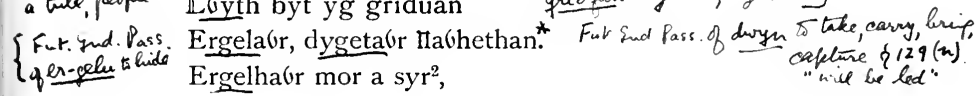
Ergelhaor mor a syr²,

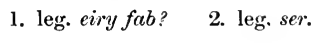
"nise be led".

25

* = llywethan are of the constellations (a popular etymology for Leviattan). int ieg. Ergelener [huan] 'the sm will be hid' ses hevis. 
? Nar of crynu to Femble, Guake

228

\section{DOOMSDAY}

Pan discynho Pater

i mectep, dispute, sinit, judgunant pleform horm, trimpect

$Y$ dadyl ae nifer, a mumber, host, retinine

A chyrn* gopetror go-bedr-on the four comers (of the wored)

5 Ac ennynnu mor. 5 Lundle, fire; be inflamed

\$152 5 Hyny ubynt marwalor, cinders mancion

\$130 (3ig. Fut.) Loscalit ynyal ran devert, wild

Rac y vaor varan. baran whath, fury

Ef tynho aches flood-tide (<L.uccessus)

IO Rac y varanres. baram-res [rank of soldiar, host] v. Lewish 152

? Diffurn dyd reges ebt-tide; adversity

woe to him who

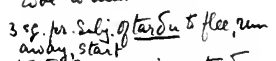

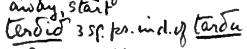

rus red, zuddy I5

ontside of, beyoud?

Sonit Peter

Grae ae harhoes. 3 sp peres of aros to await, expect, wait

Ef tardho talabr; ?pl of tal $t=$ "mynyddocdd" yma? hewis)

Terdit nef y labr. = fus

GGynt rud dygetabr v. $\ell 28$

Ech y gadoynaor. plof caduryn chaim

Neu byt mor wastat

Nal pan great. prev. pass.op crër, to creale

Seith Pedyr ae dywabt, $\quad \$ 133(b)$

20 Dayar diwarnabt. 3 sg. Zur of di-jarmu Fijudge, decide against

Dywalst dus Sadorn on Salunday

Dayar yn vn fforn. a furnace

Sadorn vore royd nuryo eavy, procperous, faisurable

358 fut. $\{152$ n.2 25

tositmelt; allo stexp, seak ?

adfy $\delta 3 s$. fur. of ad-7od 5 30 powerfot, wealthy

a tremblip, ivaking
In ginaho ny Culloyd. Culweys hod

Tir bydalit tywyd, Gywyó a tempest, storem

Grynt y todo glyd. gwys wood, hroes

Ebryn pop dyhed, ?

Pan losco mynyded.

Atuyd triganed a trumper blast?

A chyrn rac rihed.? feg rhiedd = his Blajesty? Lew Kyfoethalc ae henuyn, 355 . pr. ind if an fon sead, dispatch Mor a tir a Myn.

Atuyd cryn dygryn terrar 
DOOMSDAY

229

A dayargychwyn. an earthquake

Ac uch pop mehyn flace, countyy? (dimin if ma 'place'. Lewis A maro mein uudyn. ( $\left.\ln \delta y_{n}\right)$ ?

Eryf argeloch concealument, scelucion

thenidle, fine; inflamed

a wave

thunder Taryan ymrythich.

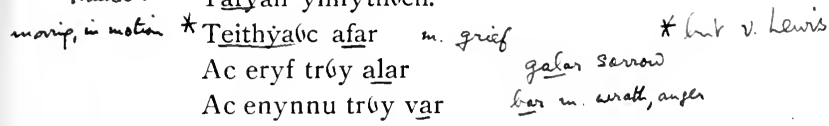

5

IO

Rwg nef a dayar.

Pan dyffo Trindact 35. Pn. Sugig dyfod $\$ 141,4.6$.

$Y$ maes maestalst, = field of didgunent. Bur v.Leuis $144-5$.

$\mathbb{L} u$ nef ymdanas, $\{\varnothing 53,164$

LGyth Mydan attao,

$\begin{array}{ll}\text { cattyl a soug, lay, A chathleu egylyon. } \\ \text { poem } & \text { Drychafant o vedeu }\end{array}$

cyrs pe.q cers crapt,ant, song

Drychafant o vedeu;

Eirant o dechreu.

Eirant kon coet,

Ar gymeint adoet. as.oed appraited time; destin; 180

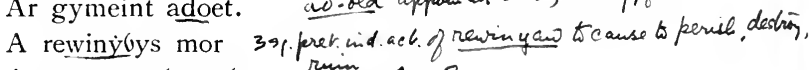
A wnant malor galor, rum gôr?

Pryt pan dyffo

Ef ae guahano.

25

laose 17 "Y Y sabl a uo meu,

Ymchoelant o deheu.

cambersin, inivith A digonby kamwed, Ymchaelent y perthgled. = parth-gles lept. hand side

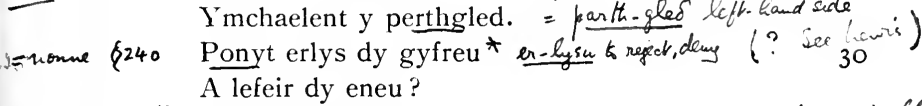

N. havis. II Dy vynet yn du hynt yn nanheu pl. of nant a valley Yn tywyil heb icumereu. We o llenfes hight

* Eyfren words, song v. Cam Llywarch Her, p. 162 $(06 \cdot 1.225$ supura). 
230

DOOMSDAY

Ac ym oed y ereu, ? (g) eiren

Ac ym oed $\mathrm{i}$ ieitheu,

Ac ym oed i ganwlat a hundred countries Ac eu cant Moneit. fill, the full of anythin Canuet golat pressent the present world $\mathrm{N} \dot{y}$ bum heb gatwent. cadwent battle, fight, contest Oed mynych kyfar chwers tromble, angen Yrof am ${ }^{1}$ kefynderí.

Oed mynych kyryschydat cousin

Yrof y am kywlat. empatriot

Oed mynych kyflafan an ontrage, slaughten

Yrof $\mathrm{i}$ ar truan.

Am gorya hon vyth ;

Nym genaei dyn byth. 3 nd sp. Inp.o Conditional Am gyrrbys yg croc,

A wydon yn oc. ?

Am gyrroys ym pren

Dipynoys vym pen.

Tafá ti vyn deu troet,

2xdsg. Inperat. meanif?

dykyen thang down

Mor tru eu hadoet. ad-oed appeinted time; destivg, fate.

Taual dy 'r boenet, = "teinila di mor boenus yus esgym

Escyrn vyn traet. fy whraed"

Taual dy vyn day vreich;

Ny ny dybyd eu beich. $\quad(141$

25 Taual dy vyn doy yscoyd;

Handit mor dyuyd. v. Lowis

Taual dy 'r cethron a spike

Y myan vyg callon.

Taual dy gethrabt beg. gethrat < cethr 'nail'

$30 \quad$ Yrwg vyn deu lygat.

v. Lewis Tauab yr da allat,

Coron drein ym iat. cad the upfeer part of the head

v. Lewis

Tauab dy oestru,

1. MS. eim. 
* Lewis: = "O Dywysog, mi wyddem mai ti a grogem. Dywysog nef a phob gwlad, mi wyddem ymble y hyddit. Pe baem ni'm groybod hynny, lrist, fe giliem oddi wrttyt."

\section{DOOMSDAY}

A wanpolyt vyn tu. gwanpwyd pastind pass. D, Swam to fierce

$=$ ther ir was (D. Lewis)

ifue had huawn thee Bei ath Gybydem,

Teu $\dot{y}^{6}$ chitheu

Mal yr yoch Ilau deheu.

I 6 ch ny byd madeu

Vy gwan a bereu."

* "A wledic, ny wydyem

ber a spike, lance.

Pan oed ti a grogem.

GGledic nef, gGledic pop tut,
$\mathrm{Ny}$ wydem ni, Grist, tut vyhut. $\|^{\text {tud }} \sim$ keiple,
$\sim$. Lewis.

Crist, ath athechem." dimal

"Nyt aruollir goat

Gan loyth eissyfflat.

TPe. Enperf. of gurybod

= derbymir,

digonsanch : 2 Pl. Pret. 7 digawn to be alle, efecer, do, accompleish
IO

? accurred (v.hewis)
Digonsabchi anuat

Yn erbyn Dofydyat.

Can mil egylyon

Yssyd imi yn tyston,

A doeth ym kyrchas

Gledy vyg crogal.

$\mathrm{Yg}$ croc yn greulet

Myhun ym graret.

Yn nefoed bu cryt, oryd a trembly, tremar
I 5

\section{to fetch, liring}

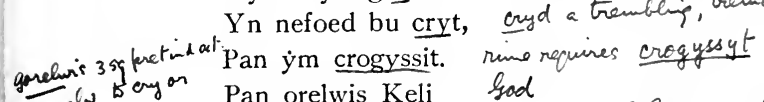

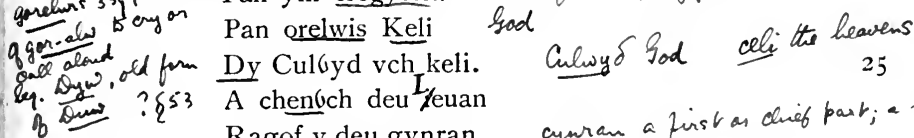
Ragof y deu gynran, cymran a first as chiof part; a leades A deu lyfyr yn ach $\Pi$ lab Yn eu darlleav.

35p.Fut.q dylod Nys deubi ryrys

Rygossliy rygossys.

bydd ieluri, ceich Ac abch bi wynnyeith to read hi: Fur. $(152$ n.2) Goerth auch ynuyt areith.

? 30

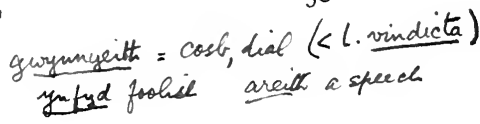
=olerwy dd, oblegid 
232

DOOMSDAY

Fut Ind. Pass. if caen Kayator y dyleith "clo nen for ar ddrus" to sent, close. Arnalich y vffern Meith." death Perf.5g. 3 of seilaw k Crist Jessu uchel ry seilas trycha[n] mil found, establesc; nemain? bloydyned,

$$
5 \text { Er pan yttyo ym buched. buched life, saluation }
$$

Clevelum thine; Ac eil mil kyn croc

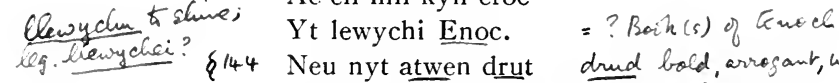

sing, number 914 Neu nyt atwen drut drud bold, arrogant, wicked the presentwored IO Geint eu heissyllut. progeny

of. awch bi 231,32 A chyt auch bei odit. scarcely, hardly, narely cyte thengh $\left\{205^{-}\right.$Trychan mil bloydyned namyn vn

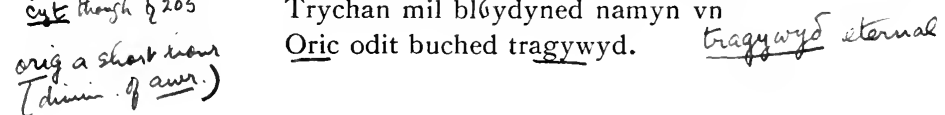




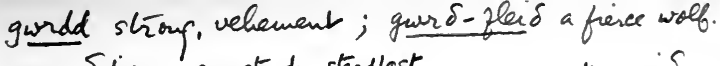

ger-Sifing very steady, steadfast

bar m. wratt, anges

gordwy ippression, violence

astirng to lower, overcome

go. leiith 5 dissolve

freing stout

\section{TO GWENIVYNIWYN.}

there is tome,

ghave:\{155B' Ysym argloyd g(ird, gordiuling y var,

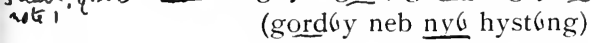

di-wreid an uprooting

gos. Jling very severe, austere

ale-glewy dealing wounds in

aer-llew hion of battlo

Cleith death

binwysg strop, inipetions, swift

a. amber

fierce

gly ${ }^{6}$ diwreid gordvleid ${ }^{1}$ gorvlug,

glel dywal, ny dal, ny ding.

nyw v. $\$ 49(c)$

\$154A(a) Y Ssit ym argloyd aerglayf ner nerthuabr, wa a land 5

?

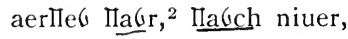

ny oleith Meith yr Myfyrder,

protection

ny odef cam, nyw kymer.

goolden-swand-red Yssit ym arglloyd eurgledyfrud gabr, $\delta$

plylleafuablede

sPr.gud. 2 tolit

entail, diminish

3 Prignd of eronit

acand, aness, accominales

breisc Mafnalir broysc Mofrud, a shayen of men (Gir sed-Canded)

cowardice

a portecton. Yssit ym argloyd argledyr anal beird,

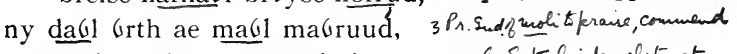

ny grain golut, nyw golud. go-hen 5 hindes, obstuct

rong, pansgyic

am bardeir yn eidal,

am karyat kadarn arnal,

poeting, muse

am kerd, am kynnelo ohonat.

I5

jaltern, example, model

Yssit ym argloyd argledyr cat a tharyf, ?toryb multitede, host

a theruyn ar gywlat, cy-wlad a neyblowing lérictory, bordérland

$?$ klotualor IIabr, Itai agthaeat, angharad unclosed, spen, bibral koryf toryf, teruysc oe anghat. hand 20

gubdia aruler Yssit ym wledic wlat amdiffyn Mary, generous, gracions, gentto

(llawer dyn ae govyn)

$?\left(u \cdot V_{0 c}\right)$ gwalchlan wosparth warth wrthryn,

shä-sfeared gialpar gianar Glienwynwyn. a chig, lord.

${ }^{1} \mathrm{r}$ over d ${ }^{2} \mathrm{r}$ over 6

maner. Ins qleargaim an adwantage.

guarth disgrace, shame

coryb poumel, saddle-bow; metaph. släy, sufpert.

gurltingn resistance, opposition

lenfysg hromble, conflict, uproan.

guosparit sufperst 


\section{CYNDDELW TO RHYS AB GRUFFUDD.}

(a) BLACK BOOK, page $39 b$.

Assuýnaw naut Duv diamhev ${ }^{1} \dot{y}$ daun

ae donýauc wiffinnhev.

ar dy guir erir aerev.

ar dy் gulad guledic dehev.

$5 \quad$ Assuinaf archaf eirchad $\dot{y}$ mgelwir.

naut kỷuir ky்gwastad.

ar dy drissev aer. drussad.

ar di drissaur gvaur gwenvlad.

Assuinaw archaw arch vaur $\dot{y}$ periw.

IO

a peris new a Maur.

naut rac dy uar car kertaur.

ar dy pirth ar di porthaur.

Assuinaf naut haut haelon deheuparth

diheuporth kertorion.

ath turuf oth tarianogion.

ath toryf oth teern meibon.

Assuinaf $\dot{y}$ ch naut na cheluch $\dot{y}$ ch porth.

can perthin attreguch.

gostecwir Mis gosteguch.

20

gostec beirt bart aglÿwuch.

Assuinaf naut haut ${ }^{2}$ haelvonet worsset.

nyth orsseiw teernet.

ar dy torif corýf kýwrisset

ar dy் teulu teilug met.

1. MS. diamehv. 2. MS. haut naut with marks of transposition. 


\section{CYNDDELW TO RHYS AB GRUFFUDD 235}

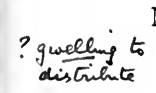

Metcuin ev gwiraud metkirn ae gwallav. ae gwellig in eurdirn.

a gloev $\dot{y}$ ved in edirn.

a gliv deur. a glev teeirn.

Teernweilch Pridein prydaw ẏch priwgert.

ých priwclod a digaw.

$\dot{y}$ ch bart $\dot{y}$ ch beirnad výtaw.

$\dot{y} c h$ porth perthin $\dot{y} v$ ataf.

Attep a ganaw ar canhuýw vý argluit•

ergliv. wi. can dothuif.

IO

Meissaun Miw Mev gliv glevrvit.

Maessa di var di bart wif.

Viw kertaur im ruw. ruisc. morkimlaut gurt.

ruisfirt kirt kert. vahaut.

assuin asserv herv hirvlaut.

$u \delta$ alond, leing, assuinaf ar wut naw. naut.

(b) Red Book.

intercession,

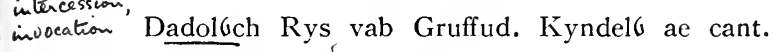

ginoder, entreat Assoynaf nabd Dul (diamheu dy daon,

gifted lencowed ath donyalic byf inneu)

$\begin{array}{ll}\text { before? } & \text { ar dy wyr, eryr aereu, } \\ & \text { ar dy wlat, wledic deheu. }\end{array}$

Assuynaf, archaf arch valir y beryf peryb the beatos

a beris nef a Maur,

naud rac dy var, car kerdaor,

ar dy byrth, ar dy borthabr.

Assoynaf, archaf (eirchat ym gelwir) naud kywir kyngwastat

P. of drows cloon, ar dy drysseu, aer drossyat, ar dy dryssabr, guayr guenwlat. 

gostegn: 5 proclain silence; gostégwur a silences
guriraurd a beverage, drink guyró green, fresh, vigarous

\section{CYNDDELW TO RHYS AB GRUFFUDD}

appropriate, pertinent

Assuynaf arich naud, na cheluch arch porth, ¿an perthyn attreg $6 \mathrm{ch}$. a stapping, delay Gostecwyr Mys, gosteguch:

"Gostec, beird! bard a glywch." trim suppers (dihen undoulted, diheuborth kerdoryon, centain) ?doryb tory6 multitude, host hael-fous some it pormel, saddle -bow; we tajh stay, su fout

a mead banpuct gwanchadu to guand, protect ruter I 5 teymwalch a royal thawh, kero cond praise, emlogy

20
Assuynaf nald hald haeloned worsaf gwon-sab supfent, bulwark (nyth orseif teyrned)

$?$ hinigs do wor wilkstand the

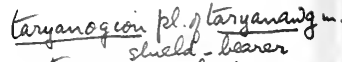
taym. Tab a ling's sow

ath daryf oth duranogyon,

ath doryf ath deyrnueibyon.

\section{kl. o hael}

ar dy doryf, koryf kywryssed, cy-wrisse coutention, stuffe ar dy deulu teilling med.

Medgwyn eu goín eu goirabt, medgyrn ae goarchae, b lesiegs ae gGercheids yn eurdyrn, p. 8 enr swinm goldena gloeb yfet yn etyrn, soveraignty, supromanded, a gly debr, a gleb deyrn. Teyrnweilch Prydein, prydaf aich prifgerd, prydu Ksing,
enlagy aich prifglot a dygaf, arich bard, aich beirnyat vydaf, panegyric auch porth perthyn $y(a$ attaf.

Atteb a ganaf a ganoyf; argloyd, isp. P. Subj: of canu

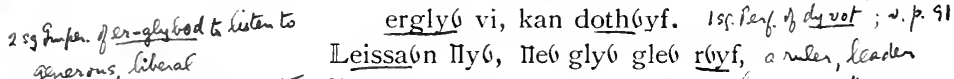

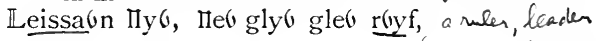

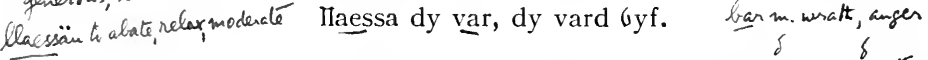
sway 25 Wyf kerdabr ym royf roysc morgumlabid gayrd, the nagie of

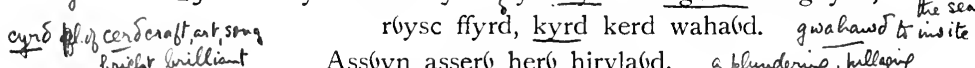
us a lond. hing Assuyn assero hero hirvlavd, a plumderie, pullegie asscynaf ar ud naf nabd. the Land

$$
\text { hir-jlaws a long tumuer }
$$




\section{A REligious POEM.}

BLACK BOoK.

In enu domni

meu $\dot{y}$. voli.

maur $\dot{y}$ uolaud.

Molawe douit.

maur $\dot{y}$ kinnit

ar $\dot{y}$ cardaud.

Duu an amuc.

Duu an goruc.

Duu an guaraud.

Duu an gobeith.

teilug pirfeith.

tec $\dot{y}$ purfaud.

Duu an dýli.

Duu issi vrý.

vrenhin trindaud.

Duu a broued

in $\dot{y}$ truyted

i $n^{1} \dot{y}$ trallaud.

Duu a dýfu.

oe garcharu

gan vuildaud.

Guledic deduit

an gunel in rit

erbin dit braud.
RED BOok.

Yn eno Dñi,

meu y moli ; mavr y molabt.

Molaf Douyd, mabr y gynnyd

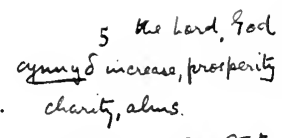

ar y cardabt. charit, ahus.

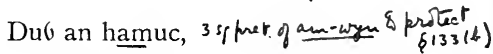
Duw an goruc,

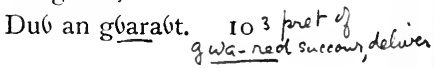

Dub an gobeith, teilong perffeith,

tec y purffait. pure/penfect happiness

Dub an dyly,

Duo yssy bry, above I 5

brenhin trindaut.

D zैo a prouet

ynn yn droydet liwy droy y drallabt. Frallowd f. persecution,

Duw a dyuu 20

oe garcharu gan uvull ${ }^{t} \not a$ ait.

Goledic detwyd deduyd haffy, Geseed, an gonel ni yn ryd erbyn dyd bras[t]. 25

1. drwy MA.P.268a. 
3 sg pa. Suby: of durgu totake, carry, time, cepture

$\varepsilon^{51}$

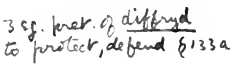

\section{crogf.cross}

bedissyand fominerse

$\frac{\text { adfeitaw } \&}{\text { dechine, decay }} 20$
An duch ir gulet

ir $\dot{y}$ varet.

ae werindaud.

$\dot{\mathrm{Y}}_{\mathrm{m}}$ paraduis.

Ym Paradoys,

An doc yr wled 2ss. Imper.y

yr y wared gwares meckmess ae werindalt. gwerindawd

im pur ky்nnuis rac puis pechaud.

pure, perfect ym pur gynnoiys to receive admit, ads) rac poys pechaot.

An gunel iechid

ir $\dot{y}$ penid

ae pimp dirnaud.

Io Dolur eghirith. gnef, anguish

Duu an diffirth

ban kymirth cnaud.

An ginel iechyt mayt He work yr y penyt ae pym dyrna $n_{\hat{A}}^{\boldsymbol{n}}$ ot.

Dolur eghyrth- terrble, painfue Duo an diffyth, pan gymerth knalit.

Din a collei

bei nas prinhei

Dyn a gollei wa he lost pei nas prynei-

I5 diuei devaud.

Or croc crevled $\dot{y}$ deuth guared ir vedissýaud.

Kadarn bugeil

Crist nid adweil.

$\dot{y}$ teilýgdaud diuei deuabt. instom, $\ell_{\text {. }}$

Or groc greulet crenled 2.0 $y$ deuth gwaret cremlyd blocedstam gory yr vedissyaivt.

Cadarn uugeil

Crist nyt agueil

$y$ teilyngdabt. 
239

XI. A DIALOGUE BETWEEN UGNACH UAB MYDNO AND TALIESSIN.

"Marchauc a girch $\dot{y}$ dinas, ae cun gwinion ae cirn bras, nyth adwaen, mi ryth welas."

"Marchauc a kirch ir aber

upen $\dot{y}$ ar march cadarn kadfer, dabre genhiw ; nym gwatter." $P_{n}$. Suly. Pass. of $5 \frac{\text { cad. Hfer shan }}{\text { in bacte }}$ gwadu to deny, nefuse.

"Mi nýd aw ina in aur,

goden puppre, design gotev gueith y godriccaur: go-driceauer a lingeres, sojouruer elhid bendith new a llaur." ?

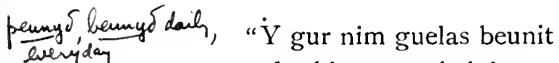
$\dot{y}^{1}$ tebic $\dot{y}$ gur deduit, dedwy $\delta$ haffy, blessed, vintuous

whither ba hid ei dý? a phan doit?" 2 sp p. Ind of dyvot $(\nu \cdot p .90,614$, n.1)

v. $\{225$

$?\{51$

"Ban deuaw o Caer Seon

v. p. $249,2.3$ o imlat ac Itewon, it aw Caer Lev a Gwidion."

I 5

"Dabre de genhiw ir dinas, ath uit met ara phellas, v. Sloss. ac eur coeth ar di wanas."

"Mi nýd adwaen $\dot{y}$ gur hý

bold

. am eter. a metev tan a gueli :

20 tec a chuec y diwedi."

chueg sweet.

1. leg. vyt.

edew $3 \mathrm{sg}$. Pn. Ind. of a daw to promise 
240

$?$

$\{51$

$5 \quad 651$

$\{51$

peun of teremost, cher

bivad a challengen

IO

increase, angment

Eodeserwe, claim, merit

\section{A DIALOGUE}

"Dabre genhiw im tino, vally, vale ath uit guin gorýsgelho, 3 rdsg. Ps sulj. of "gos.ysgeh" t5 Vgnach ýw vy் heno mab Mỳdno."

"Vgnach, bendith ith orsset! yon-sed? seav, throre, count ath vo rad ac enrydet!

Taliessin viw inheu, talaw itti dy gulet."

"Taliessin, penhaw or guir, beitad $\dot{y} g$ kert kỳuergir, tric ima hid dy் merchir."2

a conflict, contest on weduesilay

"Vgnach, mvihaw y alaw, ath vo rad $\dot{y}$ gulad pennhaw: ny haetaw kabil, ny thrigiaw:" neproif

2. ir added in a later hand. 
llwm bare, poos

loggrue Tocerrupr, man, spoil, violate; 241,3 5 became foul destroy gwaes an ontey, on gy distiers; pe. - en

hreis handh, seancely

- cawn m. Lool.) reed grass, stalles, coarse grass; sg. conim

v. Sackson, Farly Celtie Nature Patry, p.50

XII. WINTER.

heen, shanp 'L Llym awel, llum brin, brys a hill, mount = an-haws anhaut caffael clid: a sheeter

v. $\varnothing 97(\mathrm{c}) 1$

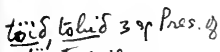

tö to cover very hiph/lond

hiel, promoutory

"led of the lake"

baltersome, boister ons

plofpysg a fish ieq,ashect of ice

divedy ovenin

adi to sunow

plof cad-wr a warrion

thio colows, hue

discugared, idle llicrid rid, reuhid lin, ry seiw gur ar vn conin.

rewhid 3 sp pres. of rewi if frage.

Ton tra thon toid tu tir, goruchel guaetev rac bron baney plo of bam a heighr bre: breit allan or seuir. pres. pass. of gas-setyle ts withstand, stand Oer lle lluch rac brÿthüch tumult, storm gaeaw, crin caun, calaw trüch, cur, bovken kedic awel, coed in i bluch.

$X \quad$ Io

Oer guely pisscaud yg kisscaud cysgand shade, shelter, shadow iaen, cul hit, caun bary்whaud, baryfhan Tigrow a beard birr diuedit, guit gvýrhaud. bends (v.9129) (v. $\$ 129)$

Qttid eiry், guin $\dot{y}$ cnes, nid a kedwir oe neges, oer llinnev, eu llyju heb tes. heav, hor wealther, scunshime "warmith" Ottid eiry், guin aren, (arien) hoar-frost segur $\dot{y}$ scuid ar iscuit hen, rýuaur guint, reuhid dien. buds

$$
\left.\begin{array}{l}
\text { yspuyd a shield } \\
\text { ysgury } \delta \text { a shoulden }
\end{array}\right\}
$$

Ottid eiry ar warthaw rev ${ }^{1}$, rew frost, ice

20 goscupid guint ${ }^{2}$ blaen guit tev, tew thich, deuse liadir ýscuid ar yscuit glev. glew hrove, stour; a brave man, hero

1. In MS. res has been altered later to reo.

2. MS. gint

Q Calaf (coll) slaths, reeds guys (coll)wood, trees.

for 3 nd sg. Pres. Ind. endings in - id

v. $\delta 129$ 
242

v. di-tryssio trhastan, spaedifor endinf v.(129)

gonwy a steed, wan. horse

v. annoryd natire, temper "timbers"

v. Rlutyr. a cowand

anaf m. a blemish, wound.

WINTER

Ottid eiry, tohid istrad, ystrad a vale, valley diurýssint vy keduir y cad, mi nid aw, anaw nim gad." I do nor go, a wound does wor Ottid eiry o dv riv, inim a slope karcharaur goruit, cul biv, hiw cattle nid annuyd hawdit hetiv. = haf $-\delta y \delta$ a summer's day Ottid eiry, guin goror a borden, side mýnit, llum guit $\widehat{\log }$ ar mor: gay $\delta$ ma st of a ship le

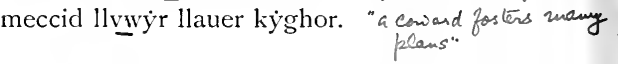

meccid 3 sg Pr. ind. If maga to nowirich, (\$129) reas, erimp uf, engender, conceive 


\section{Glossary}





\section{adaw gobeith 178,30}

\section{GLOSSARY}

The paragraphs refer to the Grammar. voc.=causing vocalic mutation (lenation). nas. = causing nasal mutation. spir. = causing spirant mutation. coll. =collective. n.l.=nomen loci. chw follows c, $\delta$ follows d, ng follows $\mathrm{g}$ in the order of the alphabet.

l. a (voc.) rel. part. $\$ 82 \mathrm{fr}$. With pers. pron. (\$ 48 ff.) sg. 1 am, sg. 2 ath (voe.), sg. and pl. 3 ae, ay, as, pl. 1 an, pl. 2 ach.

2. a(voe.)interr. part. $\$ 239$. With pres. of eopula ae. ae. . ae whether. . or: o either -.. or

3. a (voc.) interj. $\$ 243$.

4. a (spir.) prep. with, see 1. ac.

5. a (spir.) conj. and, see 2. ac.

6. a (voc.) prep., see 1. o.

6 . a- used to infix pronoun. $\$ 94$. With pers. pron. sg. 1 am, sg. 2 ath, sg. and $\mathrm{pl} .3$ as.

abad m. an abbot; pl. -eu.

aballu to perish. $15 \mathrm{~s}, 15$.

aber a river-mouth, esturery.

aber-fa f. harbour, harbonerage.

aberth sacrifice. 1511,17 .

abid f. a habit, monastic dress.

abreio scarcely, hardly. $159,10$.

$197,21 \% .200,17$.

1. ac, a (spir.) prep. with, \$162.

With art. ar; with poss. adj. sg. 1 am, sg. 2 ath (voc.), ser. $3 \mathrm{~m}$. ae (voc.) f. ae (spir.), pl. 1 an, pl. 2 ach, pl. 3 ae.

2. ac, a (*pir.) conj. and, as. \$ 198. With art. ar; with poss. adj. sg. 1 am, sir. 2 ath (voc.) ete. ac ...ac both .. and.

1. ach (awch, ych) your. $\$ \$ 57,58$.

2. ach lineagc, descent; pl. -oed.

3. ach, see 1. a, 1. ac, 2. ac.

achaws $m$. cause, reason. pa a.

why? 218, 16. o a. becruse \$ 199.

Cf. achwysson.

achenoctid, see anghenoctid.

aches (from Lat. accessus) flood-

tide. 225, 9. See CZ. V, p. 566.

achlan entive, all. 2(12,22. 23.

achub to occupy, seize, precipitate omeself, snatch. 151,5. 180, 19. 199, 12. 201,20 (see cyfarth). $207,17$.

achubeid to seize. $152,8$.

achwanecäu to augment, increrse. achwaneg more.

achwanegu to increase.

achwysson (pl.) causes. 161, 15. achyfyeith, see anghyfyeith. adan f. $a$ wing; pl. -e $\delta .203,19$. adar (eoll.) birds ; sg. ederyn.

adaw to leave, allow. pres. ind.

pass. edir. $152,4.158,8,193,10$. adeilad to build, a building; pl. -eu. $139,3$.

ad-feilaw to decay, decline. 238, 20. ad-fod to exist, be. fut. ind. sg. 3 adfy $\delta 228,29.33$.

ad-libin " wetrhed remuant. 153 , 28.

ad-na-bod to recognisc, know. \$144.

pres. ind. act. sg. 1 adwaen.

ad-newy $\delta$ to renew. 155, 4. 184,20

adolwyn to beseech. 142,31. pret.

pl. 3. adologyssant. 149, 10 . adref homevard. 196, 9. atref

$198,29$. adwaen, see adnabod.

17. adwy a gap, opening; pl. -eu. 175,

a oas fit, meet, suitable.

a oassu to fit, adjust. 150, 26.

a $\delta$ aw to promise. $170,+7 / 177,7$.

218,27 . pres. ind. sg. 3 e $\delta$ ew $239,20$. adef to acknouledge, admit, allor.

227,14 .

a $\delta$ felach ? $227,5$.

a $\delta$-fwyn-derm. gcntleness, nobility,

honour. 181, 24.

a $\delta$-oed $\mathrm{m}$. appointcd time; destiny,

fate. $229,21.230,20$.

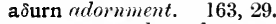

asurnaw to adorn, decorate. 155,5 .

1. ae, see 1. a. 2. ae, see 2. a.

3 , ae, see 1 . ac. 4. ae, see 2 . ac. aed, see myned.

Ae $\delta$ (Ir. Aed) n. pr. m. 201, 14.

ae $\delta$ fed ripe, mature. $165,20$.

aer slanghter; pl. -eu.

Aer n. pr. m. $195,26$.

aer-fa f. slaughter; pl. -eu. 
aer-glwyf dealing uornds in battle. 233,5 .

aer-llew m. lion of battle. 233, 6 . aeth, see myned.

aeth-lym lecn and sharp. Aeth-lem

f. the nreme of a sour. 207, 8 .

af, see myned.

Afallach n.1. Avellon.

afar m. grief. 229,8 .

af-lony $\delta$ to infommode. $209,23$.

aflony $\delta$ wch disturbanec. 148, 6 .

afon f. a river; pl. -oe $\delta$.

afory to-morrou: 203,28 .

Affric $A$ frice.

affwys m. an rebyss, deep, lottom.

197,29 . 206, 32. 207,2 .

agalen $\mathrm{f}$. " whetstone. 194,14 .

agori to open; part. agoredig.

agos near; comp. nes; sup. nessaf.

angel an angl ; pl. engylyon.

anger $\delta m$. vhemenes, force. $151,17$.

184,24 . $186,4$.

angeu, see angheu.

anghad f. hamel. $233,20$.

anghaead unclosed, open, liberal. 233,19

anghen (agen) m. necd, necessity:

a. yn a. by sheer necessity 206,14 ;

cf. $\mathrm{Hg}$. II. $197,25$.

anghenoctid (achenoctid) $" * a n t$,

indigene. $142,20.146,3$.

angheu (agheu, ageu) f. derith.

150,15 .

angheuawl deadly; mortally wounded. 159, 8, 18. 183, 26.

anghlywedig unhearl of umusurel.

sagrift anghreiftt (agreiff, agriff) frcmple.

165. 12. 156,5 $\wedge$ 181,19

anghyf-nerth lelplessmess, im.

potenee. 143,6 .

anghyf-reith injustice, wrong.

anghyfreithiawl unjust, uromgful. anghyfrwys untrained, enslilled. anghyf-yeith alien in speech,

forcign. 191, 19. pl. -y jyon. 153, 17 . anghyolwch? 229,6 .

aho, see myned.

alaf wealth; pl. -oe $\delta . \quad 164,9$.

Alban Scotland. yr A. 141, 7 .

allan out, outureds, outside.

hynny a. thenceforth.

allt a cliff. A. Clwyd (wrongly,

instead of Clud) Dumbarton.

all-tud "foreigner, alien; erile.

am (voe.) prep. about, on account

of. \$164. am hynny therefore.

am-blygu to embrace. 148,12 v. 1. amcaw $\delta$ said $(h e)$. amkeuoant said they. \$ $133(b)$.

am- $\delta$ iffyn to defend, protert; de fence. amsiffynwr m. a defendant in $a$ lausuit.

am-gadarnedig confirmed, ratified. amgen lifferent. nyd a. namely. amherawdyr m. an emperor; pl. amherodron.

amherodraeth f. cmpire, dominion.

amheu to doubt, dispute, eall in question.

amlach, amlaf, see amyl.

amlwg clear, monifest.

ammreiniawl (ambreinawl) without

mivilege. $221,16$.

amnad? 227,4

amod m. a rovenant, compact.

149, 17. 1,7), 20. 158, 24, 159, 10. amryfael ravious, differmt; pl. -on. amryson a quarrel. $223,2$.

am-ryw worisus, divers.

am-sathyr " treading, moring of feet. 193,15 .

amser m. time; pl. -oe $\delta$.

amug, see amwyn.

amws m. " stallion; pl. emys. am-wyn to motect. $\$ 133(b)$. pret. ind. act. $\mathrm{se}$. 3 amug.

Amwythig Shrexsluer\%. 161, 31. amyl frequent: numerous; comp. amlach; sup. amlaf.

amylder plenty, rbundrnee, multi-

trude. $145,23$.

amylhäu to inerease, angment.

1. an (yn) oxt. $\$ 57$.

2. an, see 1. a.

3 . an, see 1 . and 2 . ac.

anadyl brerith.

anaf m. a blemish, round. 242, 3. anaw poetry, muse. $233,13$.

anaw $\delta$, see an-haw $\delta$.

an-dylyedus illegal, urong. 167, 26.

an-eiryf inmumerable, countless;

a countless number. 184, 27.

an-fad evil, erime. $231,14$.

an-feidrawl immense.

anfon to send, dispateh. pres. ind. sg. 3 enfyn 228,31 .

Angiw Anjou.

an-haw $\delta$ not erisy, difficult. 241,2. anhebig (y) unlitie, dissimilor (to). 225,15 .

anheilwng unuorthy.

anher, see hanher.

anifeil m. an animal, beast; pl. -eid. 


\section{GLOSSARY
ardrychafel 169,27}

annerch to grect, address; pl. -eu grectings. 143,8 .

annobeithaw (o) to despair (of). annod delay. 171, 27.

annoeth (anoeth) a precious thing; pl. -en. 165, 13. 187, 13. Cf. Areh. I, p. 453.

annog to urge, eneourage, recommend.

annwyd nature, temper. 242,6 .

an-osteg f, disturbance, disor

anreg f. $a$ dish of meat; pl. -yon. 163,31 (fercula).

anreithaw to plunder, rovage.

anreithwr m. a plunderer.

anryde $\delta$, see enryde $\delta$.

ansaw $\delta$ f. condition, nature, quality, ansoóedig established, founded. state, station. $\quad 160,10 . \quad 180,6.181,22$ ant, see myned.

an-udonawl jerjured, treacherous, wiclicel. 149, $31 \mathrm{v} .1$. 190, 10

an-uundeb (-dab) discord, disunion, confliet. 167,30 .

an-waethach 10 less. $145,20 \mathrm{v} .1$. anwyl $a$ friend; pl, -yd. 160, 26. anyanawl natural, native, innate.

1. ar (voe.) prep. on, over, for, before. $\$ 165$. within 146,25 . ar hynt there upon. About to, on the point of. ar gychwyn 225,2 .

2 . ar, see 1 . and 2 . ac.

3. $a r=a$ (rel. part.) + ry, see $\$ 95$ note.

4. ar, see 1. o.

aradyr a plough.

araf slow, genitle, mild. 155, 27.

arall another, other; pl. ereill.

$\$ 68$. ereill . . ereill some. . others.

arbed to spare, scue. $153,23$.

ar-benhig ohief, mineipal.

arch f. a request. $153,34 . \quad 234,9$. arch-esgob m, an archbishop; pl. archesgyb.

archesgobaeth an arehbishoprie; pl. -eu.

archesgobawd f. an arehbishopric. archesgob-dy m. an arehbishop's palaee.

archyssant, see erchi.

ar-dymhern to temper, warm. $143,13$.

ar-oelw a voucher. 215, 30.

ar-derchawg exalted, noble, illustrious.

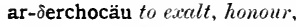

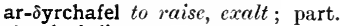
ar-ôyrchafedig.

areith f. a specch. $231,33$.

aren (arien) hoorfrost. 241, 17.

arf m. a weapon; $p l$. -eu.

arfawg rimed.

3r-fer to be wont, be aceustomed; use, mont.

arferu (o) to use, employ, enjoy, be aceustomed.

arfoll to entertain, receive. 148,10 ;

231,12 .

ar-gelwch eoneculment, seclusion.

$229,4$.

ar-gledyr m. " protector.

arglwy $\delta$ n. a lorel; 1 l. -i.

arglwy $\delta$ es f. r lacly, mistress.

arglwy biaeth f. lordship.

ar-gyfreu $a$ marriage portion.

140, 12. 24.

ar-gywe $\delta$ (y) to injure, huvt.

arnaf etc., see ar $\$ 53$.

aros to awcit, expect, wait. past

subj. sg. 3 arhoei; pret. sg. 3 arhoes. arth $\mathrm{m}$. a bear. $172,27$.

aruthre $\delta$ terror, fear. $172,28$. aruthyr terrible, fearful. $172,29$. ar-weôu to bear, wicld. 159, 3 . arwein to eary, bear. 163, 3. 10. arwyo f. a token, mark; a battle. standard; signal; pl. -on. 150, 26. 15s, 32. 180,4 . 183, 8. 194, 22 .

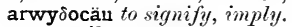

aryant silver.

as (es), see 1. and 6. a.

asgell $a$ wing; pl. esgyll.

asgell-wrych m. spray. 154, 18.

asgrifenu, see ysgrifenu.

asgwrn $a$ bone; pl. esgyrn.

asserw bright, brilliant. 235, 15.

assw (asseu) left.

asswyn an invocction. 235, 15.

asswynaf $I$ invole, entreat.

at (voc.) prep. to. $\$ \$ 53,166$.

attal to restrain, withhold, hinder.

atteb (at-heb) m. to ansuer; an ansuer, defenee; pl. -yon. 167,19. 169, 1 . attregwch $a$ stopping, delay.

234,18 . 236, 2 .

1. ath, see 1 . and 6. a.

2 . ath, see 1 . and 2 . ac.

athechem? 231,11 .

athoe $\delta$, see myned.

athraw a teceher; pl. -on. 145, 3 .

$161,11.219,13$.

awdurdawd m. authority. 222,7 .

awch, see ach. 
awel m. a breeze, wind. 241, 1. awn, see myned.

awr f. hour. yn a. now. 239, 7.

yr a. hon now. $142,15$.

awssen absence. 177,6 .

awst $A$ ugust. $166,16$.

1. ay, see 1.a.

2. ay, see 1. and 2. ac.

\section{ba, see pa.}

bach a bend, angle. 198, $\mathrm{s}$.

bae $\delta$ m. a boar. b. coed a wild

bow: 184, 12; pl. bei $\delta .201,16$.

Bajon n. 1. Bath. 179, 31.

bagyl f. a erook, eruteh. Cwrr y

Fagyl n. l. 204, 4

1. ban loud. $22 f, 18$.

2 . ban, see pan.

bann $\ell$ height; pl. baneu 241, 6 .

b. y gaer lattlement ; 196, 1.

banw a pigling. porchell . . hyt tra wo en denn . . ac o henne eny el e moch yr coet bamu vyt BCh. 92,28 .

bar in. wrath, anyer. 229, 10 .

233,1 .

28 baraf, see baryf.

baran-res rank: of soldiers, host. $228,10$.

Barberfloi n. l. Brrffenr.

bar $\delta$ m. a poet, brid; pl. beir $\delta$.

baro-eir song, panegyrie. 235, 14.

barfawg becided. $199,31$.

barn judgment. $188,6 \mathrm{v}, 1$.

barnu to judge, decide, fix, press judg-

ment, deem. past. part. barnedig.

barwn m. a baron; pl. -eid, -yeid. baryf (baraf) $\alpha$ beard.

baryfhäu to grow a beard. 241,12 .

Cf. baryf-lwyt rew FB. 244. 9.

bathoriaeth f. mintage, mint. 2223,14 . bedissyawd f. the umiverse. $238,18$. bedw f. (coll.) bireh-trees. 225, 9.

Bedwyr n, pr. m.

be $\delta$ m. a grave; pl. -eu.

1. bei, bey, see bod.

2. bei a fault.

beich a burden, load. 230,24 .

beioad m. a ehrllenger. 240,9.

beirnad (beirnyad) m. a julge.

$235,7.236,19$.

bendigedig blessed.

bendyth (bendith) f. a blessing.

bennwig f. a young som. 205, 19.

ber a spike, lance; pl. -eu. 231, 5.

beth, see peth.

beunyoyawl daily. $\quad 190,9$. biw f. eattle. 242, 5 ; a standard of value. teirbuw 211,5 .

blaen $\mathrm{m}$, point, top, end, front. or b. in front, oe f. before him, ym b. pawb before any one else, yn ol ac ym b. behind and before.

blaen-we $\delta$ highest state, summit. 169, 21. RB. II. 41,33 .

blaw $\delta$ tumult, commotion. 235, 15.

blei $\delta$-ast f. $a$ she-u'olf.

blin werny, wearisome.

blinaw to verry, molest, harrss.

blinder wrariness.

blodeuaw to flowrish, mosper. 186,1.

blwch? $241,10$.

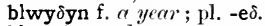

blynghäu to become angry, to frov'n. $140,7.17 \%, 23$.

blyne $\delta$ f. years (after numerals).

bo, see bod.

bocsach f. a boasting, vaunting.

$174,13$.

boch, see bod.

bod to be, state of being (verb snbst. and copula) $\$ 152 \mathrm{ff}$.

bos goodwill, pleasuie. oc eu b. of their oun free will. 156, 6. 12.

bodi to droum.

bogel $f$. the navel. 174, 25.

Bolwyn n. 1. Boulogne. 184, 31. bon stem, root, stump; pl. -eu.

bone $\delta$ lineage, noble birth. 162, 1 .

bonhesig hereditary, immate 180,15 : nollle; pl. -yon; superl. bonhe $\delta$ ickaf.

bore $\mathrm{m}$. morning. $\mathrm{y} \mathrm{b}$. in the morming. $225,3$.

brad $\mathrm{m}$. and $\mathrm{f}$. treachery, plot.

bradwr m. a traitor; pl. bradwyr. bran $\mathrm{m}$. and $\mathrm{f}$. a raven; pl. brain.

bras stout, fat. 241, 2. 227. 21.

Cf. Gnawd buan o vain, gnawd buan o vras $M A, 845^{\text {h }} 15$.

brath m. a strb, wound. 188, 21.

brathu to wonmd, stab, spur. impf, ind. act. pl. 3 brethynt; impf. ind. pass. brethid; part. brathedig.

1. brawd f. judgment, dry of judgment. $185,16$.

2. brawd m. a brother; pl. brodyr, broder.

brawd-le m. a judgment seat.

bre lill, promontory; 243, 7 .

Redyn-fre n.l.

breich $m$. and f. an arm. 230, 23.

brei $\delta$ hardly, seareely. 241, 7 .

breiswyd f. a dieam, vision. 173, 6 ; v. 1. ib. 14 . 
breiniawl privileged. 219, 14.

218,14 breint (bryein, brein) m. privilege, prevogative; state, fontition. 221, 22. breisg stout. 233, 10 .

brenhin, (breenhin, brennhin, brennin) a king; pl. -e $\delta$.

brenhinawl kingly, royal.

brenhines f. a queen.

brenhin-wisg royal robe; pl. -oe $\delta$.

brenhinyaeth f, limglom.

brethid, brethynt, see brathu.

breu brittle. $20 \%, \mathrm{I}$.

breuan f. a hromlmill, quern. $206,31$.

briwaw to breal in pieces, shatter, destroy. past part. briwedig. 147,3. broder, brodyr, see brawd.

bron (bronn) breast; pl. bronnoes; dwy-fron liersts. rac b. befire, in front of; ger b. before; $\mathbf{y m}$ b. $\mathbf{y}$ dy $\delta$

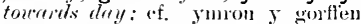
Hg. II, 248, 17 ; dynyon ymron aghen, ib. 201,34 .

brwysg strong, impetuons, surft. $2: 33,10$.

bry adv. above. $237,15$.

bryd mind, thouglet; o un f. with one accort. 175, li).

bryn (brin) m. a hill, mount.

brys m. hroste; ar f. in haste.

bryssyaw to hastin.

Brytaen f. Britrin. B. Fechan

Bittumy. Brytanyeid Britons. brythwch tummlt, storm 229, 7 ;

241,8 . brythwch greaf MA. 189a46. bu, see bod.

bual a trimling-hom.

buan suift, ropid. 151,21. 225, 21. buaned suriftress. flectress. $158,29$.

232,5 - buche $\delta$ f. life, salvation. $150,15$. bucheôu to live. 165,9 .

buougawl rictorious, gifted. 164,28.

buougolyaeth f. victory, trimml h; pl. -eu. 144,5 .

buoyn? $2 \cdot 29,3$.

bugeil m. a shepherul. 238, 19.

bwlch $a g(1)$; pl. bylcheu embra. zures. 164,22 .

Bwlwyn n. 1. Bomlogne. 162, 14.

bwro ur. a table : pl. byroeu.

Bwrgwyn n. 1. Buryumly.

bwrw to throur, erist, strike, hit, overthrour. impf. ind. act. sir. 3 byryei ; pret. ind. sg. 3 byryaw $\delta .159,57$ bwyell-ig a small hatchet. 201, 21. bwyd m. meat, fool.

bwyta to erit, riet of eriting.

bwyttal victuls. 203,2 .

bychan small.

bychod a trifte. $227,10$.

1. byd m. wonld. gwyn y f. hapmy he! 170, 18. goreu $\mathrm{yn} \mathrm{y} \mathrm{b}$. best of all; gwas yn y b. any youth.

2. byd, see bod.

bydawl iarthly. 22.2. 11.

by $\operatorname{in} \mathrm{f}$. a tro(t)), alivision of an army ; pl. -oe $\delta$.

by dinaw to arrery in troops, to drow u) in battle aria?.

byhud ? 233,9 .

bylchau, see bwlch.

byrr (birr) short, brift.

byryei, see bwrw.

byth (fyth) ceer.

byw (I) alive; (2) lifi.

bywyd life. $193,9 \mathrm{\%} .1$.

cabil reproof. 241,, 13.

cad f. (1) brattli, roói c. ar faes to give bettle ; (2) "brttriliom.

cadarn stron!, firm, pouer ful.

cadarnhäu to strengthen, fortify, confirm, ratify, affirm.

cadeir f. a chrrir, seat.

Cadell n. pr. 1 .

cad-ffer stromg in brttle. 2H. 5 .

cad-lys f. " fortificl court. 195, 5.

cadw to lecp, mesere, maintain.

Cad-wallawn n. pr. m.

cadwent f. britle, fight, contest. 198,$20 ; 230,6$.

cad-wr nl. " trarior; pl. cedwyr.

241, 15. 24:2, 2.-n. pr. m.

cadwyn " chain; pl. -awr. 228,16, cadyr strong, firm. $241,22$.

cae m. an enclosure, fince. 149,6. cael, see caffel.

caer f. a citadel, fortiess, city. pl. ceyry $\delta 156,31$. 193, 2. C. Alclud (Ir. Ail Clñaide) Dnmbarton, C. Efrawg York, C. Fadon Borth, C. Fudei Silchester, C. Geint Canterbury, C. Idor Dorehester, C. Lew Dimes Jinlle1, C. Loyw Gluncester, C. Lyr Leicester, C. Lleon Chester, C. Llion ar Wysc Caevleon, C. Lwydcoed Lincoln2, C. Seon Segontim,3 C.

1 See Rhys, Celtic Heathendom, p. 406.

2 According to Holder, Altkeltischer sprachschatz II, col. 192, Lêturetum is the old British

nan:e for Liehtield in Staffordshire.
in 1. 14 . Co. Rhys, l.e., p. 272 . in 1. 14. Cf. Rhys, l.c., p. 272 . 
Weir Waruick, C. Wynt Winchester, C. Wyrangon Worcester. caeth captice; pl. ceith. caeu to shut, close. fut. ind. pass. cayator. 232,1 .

Cafall the name of one of Avthur's hounds. Cabal, Nennius ed. Mommsen, 1. 217.

obtrin, sucreed 184,15 . pres. ind. sg.

2 ceffy, pl. 2 ceffwch, pret. pasi. caffad (cahat), ete. $\$ 145$.

calaf (coll.) stallis, recels ; 241, 9. calan 11. C'alcudls; c. Awst first of Auqust: c. gaeaf All Srints' Ilay; c. Mei Hay-tlay. calane $\delta$ conjses, pl. of celein. 188, 12 . caled hard, serere; pl. -yon.

Caled-fwlch (Ir. calad-bolgr) n. hard in making notehes, the name "f Arthur's swort.

calon (callon) heart; pl. -eu, -oe $\delta$. cam roolicel, wong; wrong, in justice; gan g. womgfilly, unjustly. camgwl refine, penalty. 225, 3.

v. l. for camlwrw Leg. IV all. 40), 2 . camlwrw a fine, penalty for the lesser offences. cam-ryfygu to act arogantly. 166, 10. C. . Hg. I. 219, 28. cam-we $\delta$ sin, iniquity. 2:29, 28 . 1. can (gan) (voc.) prep. $x \cdot i t h, b y$. $\$ 167$. With pron. end. \$53. gellwngy eneit gan yr wybyr spiritum in arras emisit 159, 25; yr yscymmuedickaf vadwr gan Velrawt that most aceursed traitor of a Mcuraud $189,15$.

2. can (gan) conj. since. $\$ 202$.

3. can, see 1 . cant.

canal, see cynhal.

canfed humdredth, a hundredth provt. 230, 5 .

can-fod to perceive. $\$ 160$.

canhorthwy help, witl. $\lambda$ 178, 8. 10. canhorthwyaw to hcly. 176,8 . canhwyf, ree canu.

canhym-deith to accompany, licep up with. 208, 29.

cani, see cany.

can-lyn to follow.

can-llaw m. a supporter. 212, 11 ; 213,$21 ; 214,10$.

can-mawl to praise, commend. canonwr m. a canon; pl. -wyr. cans, see canys.
1. cant (can) (nas.) m. a hundred.

2. cant, see canu.

canu to sing, celebrate in song, recite, play; pres. snbj. act. $\mathrm{sg}$. 1 canwyf; impf. ind. pl. 3 cenynt; pret. ind. se. 3 cant.

can-wlad a hundred countries. 232,3 .

can-wr a hundred men 151, 25. 172,15 .

cany (cani), before vowels canyd,

conj. since not, $\$ 212$.

canys (cans) i.e., can with the present of the copula, for, since. $\$ 202$.

caplan m. "chaplain. 155, 3.

car a frienel, relretive; pl. -ant.

Caranwys C'nmotensis. 179, 21 .

carchar m. " prison, geol.

carcharawr m. " prisomer; pl.

carcharoryon.

carcharu to imprisom. 242, 5.

cardawd chrorty, clms. 237,7 .

carn a crim.

carreg a rorl ; pl. cerrig.

carn-wyn having "white hilt.

Hence carnwennan $f$., the name of Arthur's knife. 207,31 .

caru to love. impf. ind. act. pl. 3 cerynt; past part. caredig.

carw u staif. 196, 29.

caryad m. love, affiction. 233, 15. caryant 140, 4, either miswritten for caryat or formed like mol-yant, me $\delta$-yant, S.

cassäu to licite.

casseg f. a mare.

castell un. a castle, fortress; pl. cestyll.

cathyl f. a song, lay, poem ; pl. cathleu. 229,17 .

Catyneis 1. 1. Caithness. 145, 11. Caw 1. pr. 11. 201, 19.

cawn in. (coll.) reed grass, stalks, coarse grass; 241,$9 ; 12$; $\mathrm{sg}$. conin.

cawr m. a giant, mighty man; pl. cewri.

cawssei, see caffel.

cayator, see caeu.

cedernid strcugth, force, security, violence.

cedig battlcsome, boistcrous. 241, 10.

cedwyr, see cadwr.

cedymdeith, see cydymdeith. cefeis, see caffel. 
cefyn (keuen) back; pl.cefneu; dan. gos eu cefneu to flee, trike to flight. drachefyn bohind, back, agrin ; traegefyn behind him; dyfod t. to return 213,8 ; trach-eu-cefyn 221,21 ; drae-cefyn wynteu bchind them. $179,26$.

cefynderw a pousin. plant yr henvam a uyd kenyn-dyru BCh. $75,28$. cegin f. a kitehen.

Cei n. pr. m. Criius.

ceidwad n. a uithess: pl. keidweid. ceing f. a bianch. 165, 21. 197, 3 . cein brautiful. fair, delightful.

Ceint (Cent) hent. 189, 19.

ceissaw to seeli, fetel, endeavour. ceirch oats. $196,4$.

ceith, see caeth.

celfy $\delta$ slilful, ingenious; an artist.

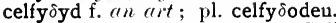
celi the hearens. 231, 25. Celi God. 231, 24.

celu to hide, eonceal.

$X$ celwrn m. " picee? 207,32 .

celwy oawg lying, false. 190, 10. Celyón: llwyn C. 148, 25=coit Celidon, Nennins, p. 199.

Celli-wig f. the nome of Arthur's court in Cormuall, now Callington. cenedlaeth f. a race, lind.

cenedyl f, a rare, lind; pl. cened. loe $\delta$.

ceneu u. $a$ whelp. 198, 32. 199, 4.

32. Ceneu n. pr. m, $1+2,3$.

cennad $m$. and $\mathrm{f}$. a messenger, emissary, embassy; pl. -eu.

cennadwri f. a message, tidings.

cenfeint a content; pil. cenveinoe $\delta$.

cenwch, see l. can.

cer $\delta$ eroft, art, som!; pl. cyr $\delta$.

ceróawr m. a eraftsman, minstiel, bard : pl. cerooryon.

ceroed to wall, travel, journey, go. cerôedyad a course, motion. 161,11.

Ceredigyawn Caidigan. 205, 28. cerenhyó relationship. 168, 20.

Cernyw Cormuall.

cerwyd a strog. 226, 1 .

cerwyn f. a caldron. Cwm C., n. 1. 204,15 .

cesseil the armpit. 194, 14.

cethr $a$ spike; pl. -awd. 230, 29. cethron a spitie. $230,27$.

cewily $\delta$ shame. $141,8.142,31$. cewssynt, see caffel. cwn. cicwr a footsoldier; coll. infantry.

$202,29$.

cig m. flesh.

ciglef, see clybod

cil a reress, nool:

Cil-gwri n.l.

cilyaw to retreat, desert, fail.

cily $\delta$ a mate, follour. $\$ \div 2$.

ciwdawdwrm.e eitizen, inhabitant.

claóu to bur y.

claf sipl:. 143, 13. 149, 28.

cleojy m. a surord; 1 l. -eu, per

metatlıesim clefy ôeu.

clefyd n. sicliness, disense. 161,27.

clefyôu, see cleôyf.

cleigaw to plunge, immerse. 206,21.

cleis a stripe. 194, 14. Cf. maen

cleis, marble. Lluwyd.-Porth Cleis

I. 1. 204,1 .

clid " shelter. 241,2 .

clod $1 \mathrm{~m}$. and f. fume, renou'n.

clod-fawr famous, eelebraterl.

clodfori to malie illustyous, irnder.

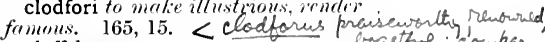
cloff lame.

clomen (colomen) f. a dore. $163,10$.

clust m. an ear: 201, 29. 203, 26.

clwm a ture; pl. clymeu moduli

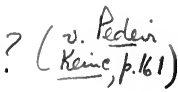

$147,14$.

Clwyd a river-name. $204,17$.

clybod to hear. impf. ind. act.

sg. 3. clywei ; impf. pass. clywid;

pret. ind, $x$. 1 ciglef; $*$. 3 cigleu.

$\$ 133$ b. clybod ar to lieat of.

clymeu, see clwm.

cnawd flesh. 238, $12 . \quad 192,24$

cnes stin. 241, 14.

cneuen a nut. 196, 23.

cnithiaw to pluek: $200,9$.

coch red.

cochi toredden, become red. 173,16 .

cosyant m. provoration, offence.

166,4 .

coed (coyt) m. (coll.) a uruor, trees;

bae $\delta$ c. a wild bor $)$ pl. coydy $\delta$.

coeth yure, fine. eur c. refined gold.

cof memory, recollection.

coffäu to remember, to call to mind.

cog a euckoo; pl. -eu.

congyl f. a eorner, angle. 204, 9. colled m. loss; pl. eu 175, 31 .

collen hazel. c. derwen an oak

sapling. 197, 2.

colli to lose, be lost. 238, 13.

conin, see cawn.

corff a body, coipse.

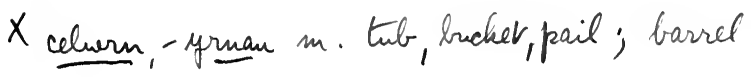




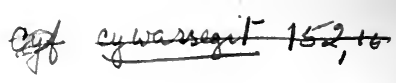

corn " horn, trumpet; a drinling horn. pl. cyrn, cirn.

coronf. " eroun.

coryf pommol, sadalle-bow ; metaph. stay, snpport. 233, 20; 234, 23. Arch. 1, p. $4 \times 7$.

cosb punishment, fine. $217,1 \mathrm{~s}$.

craff firm, sterdfest. 140,5 .

cras hard, dry. 225, 20.

crawn, see croni.

credu to belicre. pres. subj. pl. 2 crettoch.

crefyôs devout ; areligions person.

pl, -son. 155, 5.

crefyowr m. " religious person.

144,13 (miswritten for crefftwyr = operarii Geoffrey II, 14).

Creioylad n. jr. f.

creir 1n. a relic; pl. -eu. 1.33, 26. creirhäu to ereuse to sweet by relies. 221. 2.

crettoch, see credu.

crëu to crente. 227, 19. 22, 18. creu gore, blood.

creu-lawn blood-thirsty, cruel; compar. creulonach.

creulon-der cruclty, tyramy, oppression.

creu-lyd blood-strined, gory; f. creuled. $231,20.238,16$.

crib f. a comb. 203, 25 .

crin withered, brittle. $2+1,9$.

Crist Christ.

cristawn $\alpha$ Christian; pl. cristonogyon.

cristonogawl Christirn.

crog f. a cross.

crogaw, crogi to rrucify, hang.

croni to hoard, amass, acem illute.

pres. ind aet. sig. 3 crawn $233,12$.

crwm bent. 225,11 .

crychyad $\alpha$ shale (in musie); pl.

-eu. 147,14 v.l.

cryd a trembling, tremor. 231, 22.

cryfang a talon; pl. -heu 197, 28.

cryn atrembling, qualing. 2:2s, 33. cryno suitable. 156,32 . compar.

-ach. $169,2$.

crynu to tremble, qualie. $184,22$.

past part. crynedig 152, 16.

cuan an oul 197, 8; 9 ; a rock-oul,

Lhwyd.

cuóyaw to cover, hide. 154, 13.

culleren, thin, emaciated.

Culwy $\delta$ Gorl. 228, 24. 231, 25.

Custenhin n. pr. m. Constantine. cwbwl (cwbyl) entire, whole. cweiraw, see cyweiryaw.

cwfeint (cwfent) f. convent, assem-

$b l y$; pl. cwfenoe $\delta$.

cwm in. a valley. 197, 12.

cwnsli m. counsel. 148, 2 .

cwrr an edge, corner. C. y Fagyl

II.l. 204,4 .

cwymp m. a fall. 225, 22 .

cwynaw to lament.

cwyn-fan f. a lrment, wriling.

cychwyn, cychwynnu to set out, more, strit. deil ar sychwyn = dail yn syrthio MA.361 h, n. 8 .

cyd (ced) comj. though ; \$205.

cyd ac, y gyd ac together with.

y gyd yg cyd together 155, 2. \$ 171

y gyd a hynny liliemiss 204, 26. 218, 20. cyd-oiodef to snffer. 142,14 . past.

part. -edig (y) suffiring (uvith).

cyd-siolch to congratulate. 180, 10. cyd-farchawg n. alinight-comrade. cyd-gynghor joint counsel. 15.5, 2. cyd-synyedigaeth f. consent. $14, \overline{5}, 4$. cyd-tywyssawg m. a joint leriler.

178,1 .

cyd-ym-deith m. a companion, comrrile; pl. -on.

cydymdeithocäu to aecompany, assuciate with. 146, 4.

cyf-agos newr.

cyfan whole, entire. $193,32$.

cyfar trouble, anger; 230,7 . Cf.

Rhyfedd ym fyw llyw llawged gan gryfar o grwy grotid MiA. 301 a 17.

cyf-arch (keuarch) to request, rsk; c. gwell to gret; geir cyfarch $\alpha$ supplementriry question aslied after the trial, bifore the verdict is giren.

cyf-ar-fod to meet, cncounter, touch ; $\$ 160$.

cyfarth to brok, ba!y; rosi c. rendre les abois, to stand at ba $y$. achub yr c.

(sie leg.) to be first at the charge.

cyf-arwyo ni. " fride.

cyf-ar-wyneb(ac) omposite (to) 210,5 . cyf-eillt m. "friend.

cyf-eir f. yn-y gyfeir strright before lim, herallome. 2017,6.

cyf-enw a namesalie. yor kyuenw yr vn alyd ym phen y vlwydyn that day a ycar. 19.5, 19.

cyf-ergir 11 . and f. a conflict, con. test. 240,9 .

cyf-ing narrow, strait. 175, 17.

cyf-lawn full, complete. 


\section{$>c y f-u r \delta$ "Of such high rank" 148," (v.Pedeir Keinc p. 172)}

cyflafan f. an outrage, slaughter. cyf-le m. an opportunity. $159,16$. cyflehäu to dispose, amange, place. $163,27$.

cyf-lym sharp, quick, speedy.

cyf-newid ( $\mathrm{O} . \mathrm{W}^{2}$. cyfnofud) f. coin, merchandise. 223, 13. Cf. ef a holltir furyf y gyfnewit; haner crwn a vyd RB. 2. 146, 19.

cyfodi to arise.

cyf-oed having the same age, so old. 141, 28.

cyf-oeth m. porrer, dominion, lingdom, wealth; pl. -eu.

cyfoethawg pouerful, wealthy.

cyfoethogi to enrich.

cyfranc f. an encounter, fight, combat. 178, 12.

cyf-red equally suift. 225, 6.

cyf-reith f. lax, right; pl. -eu.

cyfreithiawl legal, laufil.

cyfreu plumage? 225,17 . aetion? $229,30$.

cyf-rin a confidant. 225, 5 .

cyfrwch a meeting. 147,5 (v.l.).

cyfrwng in. mean, interval. yg c.

in the midst of 184,9 .

cyfrwys trained, expert. $\quad 186,19$.

190, 9 v.1. $191,21$.

cyf-ryw m. the same kind. 181, 27.

a lind 161, 27. similar, lilie, such.

cyf-uch of equal height. yn $\mathrm{g}$. ac on a level with. 174,30 .

cyf-un-deb unity, concord. 167,23. cyf-yawnhäu to adjust, arrange. 163,27 v.l.

cyf-yeith having the same langurige. 196, 13.

cyf-yl nearness, proximity. yn y gyfyl near him.

cyff m. stoek, trunk, stem; pl. -yon. cyffelybu to compare, imitate.

cyffredin common. yn $\mathrm{g}$. in common 185, 25. 223, 12 .

cyffro m. excitement. 164, 27. 176,6.

cyffroi (kefroy) to excite, arouse, disturb; c. cyfreith (hawl) to institute a legal action (a claim). past part. cyffroedig. $184,10$.

cyffur occasion, opportunity. 147,9. cynghaws m. a counsel, advocate. cynghellawr m. a chancellor, the king's prineipal steuard oi reeve. cynghelloraeth f. chanccllorship. cyngheusaeth f. a pleading.

cynghlodforussed equally renomened. 186,5 . cynghor (keghor) 11. counsel, advice; caffel yn y gyghor to decide. cynghorfynt eney, malice. 156, 20.

Cf. LA. $12,19$.

cynghori to advise.

cynghreir f. a cotcuant, truce. 159,12 .

cyngwastad constont. 234,6 . 235,27 .

cyhoe $\delta$ pullic. 222,12 .

cy-hyd having equal length. yn gyhyd ac as long a.s.

cyhyde $\delta$ equality, parity. 221,6.7.

cylch m. a circle. yg c. reomed, about, tomeards, comerning; yn eu c. about them, around them; yg c. hynny about that.

cylchynu to survonend, encompass, besiege. $146,17 \mathrm{v} .1$

cyllell f. a knife, dagger.

cyllell-bren the wooden lath of $\%$ scrobard; pl. -eu 195, 14. wooiden tweezers 200,5 .

cyllell-fawr big-knived. 206, 19.

cymhell to compel, force, drive, exact. c. y law to foree one to sur. render.

cymenn uise; compar. cymhennach. 175,28 .

cymer, see cymryd.

cymmeint of equrel size, as much, as many, so great, so many.

cymmvd m. a commote, a division of country.

cymod to propitiate, make perece. $197,32.201,7$.

cymodawg a neighbour ; pl. cymodogion.

cymod-lone $\delta$ a coneord, agreement. cymrwd mortar. $193,2$.

Cymry (pl. of Cymro m. a Welsli. man) Wales. 154, 10. 203, 31. 222, 4. cymryd (kemyrit) to take. pret. ind. sar. 3. cymerth, cymirth. c. arnaw

to feign; c. eu ffor $\delta$ (hynt) to set out;

c. ffo to take to flight.

cymyn to entrust. $157,10 . \quad 192,22$

cymynediw a command, injunc-

tion; pl. -eu; 150, $24 ; 166,26$.

1. cyn (cynn) prep. before. $\$ 170$.

2. cyn (gynn) conj. soomer, befowe.

$\$ 204$. gynn noe fyned before he yoes. $225,3$.

3. cyn a stump; pl. -yon. 197, 14. cynadyl a meeting, assembly. $171,19$.

cyn-deced as fair: $\quad 163,14$. 
cyn-digrifed as pleasant. 163, 14. cyn-dosted equally harsh. 198, 17. Cyn-delig n. pr. m. 162, 7 .

Cyn-oelw n. pr. m.

Cyn-farch n. pr. m.

cynefawd eustom, usage. 163, 24. $167,1$.

Cyn-felyn n. pr. ns.

cynhal, cynnal (kanal) to sustoin, support, maintrim.

cynhebig similar, like.

cynhebygu to eompare. $161,2$.

cynhelu to support. $220,30$.

cynhen contention, strife, contest;

pl. cynhenneu.

cynhyrfu to exeite, more. $173,27$. cynired to eome together, assemble; bring together: a eoncourse. 162, 20.

Cyn-las n. pr. m.

cynllwyn an ambush, "raylaying. $223,1$.

cyn-llyfan a leash, a slip.

cynna equally good, peer. $\quad 227,9$. cynnal, see cynhal.

cynnelw pattern, example, model.

233,16

cynnifywr (coll.) m. combatants, wariois. 20\%, 27 .

cynnig to propese, proffer, suggest. cynnullaw to collect, cull together. cynnwys to receive, admit, adopt. 238,5 . Ar sawl a oed dan geithiwet henyt ef ae kynnwyssawd ym paradwys LA. 13312 ; Creawdyr celi an kynnwys ni yn trugared, FB. 1996.

1. cynny $\delta$ m. a huntsman; pl. -yon. $205,4.7$.

2. cynny $\delta$ inerease, mosperity. 237,6 . ef a doeth att Walchmei. Ac a gyuarchawd grwell idaw. Duw a ro kynnyd arnat, heb $y$ Gwalehmei Hy. I. $223,2$.

cynnyou to inerease. 180, 12.

cyn-ran m. a first or chief part; a leculer. 231, 27 .

cynt adv. formerly, before. yn $\mathrm{g}$. sooner, ratler 181, 8.

cyntaffirst; yn gyntaf first, at first. cyntefin (Ir. cetemuin) the begimning of summer. $225,14$.

Cyn-was n. pr. m. 204, 4 .

cyny (kene) conj. though not. \$205. cyrch m. an attack, onset, raid. cyrchaw to fetch, bring. 231, 18 . cyrchu to ritack, set "pon, march "pon, malif for, cpurvach.
a firch 239,'

$>$ cyt, $v \cdot \delta 17$

cyrn, see corn.

cyryscwy $\delta$ ad a quarrel, eontention? $230,9$.

cysgawd m. shade, shelter, shaclow. 241, 11 .

cysgu to sleep.

cystal equally good, as good.

$>$ cy-war-sangu to trample upon, oppress, erush. $149,26.152,16$. 180,32 .

cy-weir prepared, equipped, eomplete. $158,29.179,16$.

cyweiryaw to prepare, equip, lay out.

cy-weithy $\delta$ a company. 194, 3.

cy-wir tive, just. $234,6$.

1. cy-wlad f. a neighbouring terri. tory, borderland. 233, 18. Rybu Vran vab Llyr In rwymadur mat yekamp yokyulat yorkm MA. 180 b 13.

2. cy-wlad m. a compatriot. 230,10 . cywrein slicilful, cunming.

cy-wrisse $\delta$ contention, strift. 234 , 23. 236,11 .

cy-wy $\delta$-ol-(y)aeth f. hrimony, musie; pl. -eu 163, 14. Used alio as sy. pa gywydolyaether $y w$ honn? L.A. 82,10 .

chwaer f. a sister; pl. chwiory $\delta$. chware to play; play; pl. chwaryeu.

chwech, chwe (whe) (spir.) si.r.

chwedyl m. a story, tale, neus, tidings; pl. chwedleu.

chweg sucet. $239,21$. chwerthyn to smile.

(\$ 129) 225, 22.

chwer $\delta$ i $\delta$ chwerw bitter. 230,7 .

chwi you. Emphatic chwichwi, conjunctive chwitheu, chitheu. $\$ 45$. Chwintus n. pr. m. Quintus.

da (1) good, profitable; (2) goods, wealth, benefit.

dabre come! \$141.

dad-ganu to recapitulate, rehearse, reeite. 173,6 .

dadolwch intereession, invoeation.

$235,17$.

dad-rithaw to re-transform, 199, 8. dadyl m. and f. a meeting, dispute, suit, judgment; pl. dadleu (used as sg. mase. and pl.) a dispute.

dadyl-fa a meeting-place, court.

O. IV. dadlma $222,13$.

$>$ dafad f. a sheep; pl. defeid.

daear, 139,14 v. dayar 
daffar movision. 225,19 ; ef. gwnaetl Duw trvgar gardaui Fl3. 15,14 .

dangos (dankos) to shem, diselose, moduce. d. cefneu to flee; d. bronnoes to face: d. deheuoe $\delta$ turn the right to, face: d. ysparduneu y to sput:

dala (daly) to hold, seize, retrin, hold back, eapture. act. pret. ind. sir. 3 delis (dellis), past subj. pl. 3 delhynt, pluperf. pl. 3 dalyassant.

dam-gylchu to surround; past part. damgylchedig.

dam-gylchynu to swromml. 14:, 17. damunaw to desive, $\| \dot{i s h}$, seck for,

part. damunedig.

damwein $\mathrm{m}$. accident, thance, for-

tune, event; pl. -eu; o $\delta$. by chance. damweinaw $(\mathbf{y})$ to happen to, to befall. 173, 11. 150,21

danfon to send, dispanteh. 178, 7 . dar f. an orlitiee. 197,2 .

dar-estwng to subtue, subjugate, yiclel; past part. darestyngedig.

dar-fod to ccase, end, come to pass,

hafpen. pres. ind. act. st. 3 deryw;

fut. ind. sur. 3 dervy $\delta$; impf. ind.

$\mathrm{sg}$. 3 daroe $\delta$; eond. sig. 3 darffei. $\$ 160$.

dar-lleaw to reat. 231, 29.

darmerth morision, preparation.

$162,19$.

dar-o-gan mophecy, mogmostiration : pl. daroganneu.

darpar (am) il. pripuration (for),

181,12 darparu to prepere, intend. 196, 7. $210,7$.

dathoedd, see dyfod.

157,7 l. daw m. a som-in-lan; pl. dofyon. 2. daw, see dyfod. dawn gift, mental endocment; pl.

donyeu.

dayar (dayr, dair) f. earth, land, gronnel.

dayar-dy a subterranean valt. dayar-gychwyn an carthquale; $229,1$.

18/29 dayoni goodness, virtue, valour. dayrawl carthly, mundane, material. 164,9 . de, see dy. dechreu to begin, imangmate; $a$ beginning, origin. dedwyo hrppy, blessed, virtuous. dedwyoyd happiness, felicity. defawd f. custom, mactice, habit, ortimaner: pl. defodeu.

defny $\delta$ m. material, element, sub. stamee, erave; ; pl. defnyoeu, defnyoyeu uitmess's, guarnntors, ete. in a law'suit. deg, deng (uas) tom. \$4l.

deheu (1) right (derter), righteons, (2) the right hand or $\mathrm{arm}$, the right side of the body, south, South-Wales; pl. -oe $\delta$.

Deheu-barth South-Males.

dehongyl (dehogyl) to intripret; intervetation. $173,8.13$.

dehol to erpel, banish. 143,21. 15.5, 7 .

deifaw to rorst. 199,28 .

deil (eoll.) leares.

deissyfeid (deissyfyt, dissiuit) to demand, request, seck, merit.

deissyfyd (dysseifyd) sudde $n$, wexpectel. $147,3 . \quad 187,23.208,17$.

1. delhynt, see dala.

2. delhynt, see dyfod.

delw f. image, form.

delwad n. ereritor. 227,1 .

delwyd, see dyfod.

deni, see l, tan.

derwen f. an oali-tree. collen d. a young ort:

dethol select, picket. 2012,29 .

deu n. two; f. dwy (dui, du). $\$ 42$ (a).

deubi, see dyfod.

deu-seg (nas.) twelve.

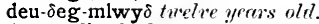

deu-syblig double, two-fold. 214,29.

deugeint forty.

deugeinfed forticth; ar $\mathrm{y}$ d. with

forty men. \$ 165 .

Deu-gleoyf the name of a eantref in Pembrolie. 204, 5.

deu-hanner divided in two equal halves. 221,7 .

deuth, see dyfod.

Dewi n. pr. m. David.

dewin un. a magician. $225,16$.

dewis to choose, prefer.

dewr brave.

dewre $\delta$ prouess, valour, mime of life. $140,6.150,10.186,1.4$. carviors 144, 1, (omnem armatum militem).

Dews(Deus) Lat. Deus. 227, 1.20.

1. di, see ti.

2. di (dy) (voc.) O.W. =later i, y, prep. to. di $\delta$ i to her. \$ 195 .

di-aerfa without slanghter. 170, 10 (vic legr.) 
di-afael exempt from seizure. 223,32 .

di-angc to escope. pret. ind. act. $\mathrm{sg}$. 3 diengis (dihegis).

di-al to avenge; vengcance.

di-am (O. WV.) for. $\$ 164$.

di-amheu undoubted, ecrtain, evident. 235,18 .

di-anaf flavless, whole. $202,5$.

di-annod without delay.

di-anrydesu to dishonour. 142, 6.

di-arfeu nnarmed. 156,1 .

di-arfod nmprepared. $177,30$.

di-arfu to disarm.

diawd drinl: $170,16$.

did, see dodi.

di-drifwr m. a hermit. 165, 8 .

di-dryf a solitary place, hermitage. 165,9 .

di-Sarbod to eonsider, eare. heb $\delta$. parnm cogitans 184, 14. impf. ind.

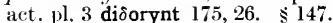

di-eithyr outside. \$ 172 . yn $\mathrm{y} d$. $222,14$.

diën buds. 241, 19. Arch I. p. 503. dieu, dieuoe $\delta$, see dy $\delta$.

difa to destioy, ammul. 197, 13.

di-fanw (O. VV. dimanw) to disprorage, slight. pres. subj. act. sg. 3 difanwo. 224,7 .

di-farnu $X$ judge, decide against.

140, 9. 220, 13. 16 . fut. sig. 3 diwarnawd $228,20$.

di-fei faultess, perfect. 238, 15 .

di-fetha to alestro\%. 197, 31 .

di-fryssio to hasten, speed. 242, 2.

di-funer cxempt from allegiunce to

a lord. 223, 31.

di-fwlch without a notch. Clesyf D.

n. pr. m. $204,12$.

di-fwyn roid, idle, munsed, $n n$.

tourled (of a virgin). 201, 4.

di-fwyngant profitless. 211,8 .

diffeith werste.

diffeithaw to lay waste.

diffeithwch n. a waste, wilderness. differei, see diffryd.

diffryd (rac) to defend, protert

(firm). past. subj. act. $\mathrm{s}$. 3 differei; pret. ind. $s$. . 3 diffyrth, diffirth. $\$ 133 \mathrm{a}$.

diffurn? $228,11$.

di-garyad unloring, unkind. 142,4.

1. digawn (dygawn) us. $a s u f f$ cienry; sufficient.

2. digawn to be able, to effect, do, aecomplish; pres. ind. sir. 1 digonaf. di-gribyaw (y) to attack. 205,5.

Cf. yn-gribiaw.

digrif jleasant, agrceable.

digrifwch pleasure, enjoyment.

di-gyfoethi to dispossess, deprive of territory. 191, 17.

diheu undonbted, certain, d.-porth firm support. $234,14$.

di-hewyd affection, inclination, desive 175, 25. 180, 32. 182, 11. ?acly

diliuu to exterminate, annitilate. dilid to pursue.

di-luy $\delta$ exempt from hosting. 223,31 . dillad (coll.) clothes, dress. 154, 8. $\operatorname{dim}$ a thing, something; nothing, naught. dilëu hyd ar sim to anniti late; dilid hyd ar sim to pursuc to extinction: arlv. at all.

$\operatorname{din} a$ fortiess. DinTywi n. 1. 205,27. Din-dagwl n.l. Tintagel.

dinas 11 . a city, citadel; pl. dinas soe $\delta$.

di-obeithaw to despair. 190, 13.

di-od to trike off, divest, extract.

di-osef (0. IV. diguadef) to suffer, undergo, withstrind.

dioer verily, covtrimly, 176, 1.

di-o-gel safe, sfewre.

diogelwch safety, seeurity.

diolch (i) to thank.

dipynwys, see dybynu.

dir neressriry. 190, 10 .

dir-fawr verly gieat, huge, cnormous. dirieid wickifl. 225, 12 .

dirwy f. a finc, mulet.

di-rybus mithnut vaining. 158, 12. disgyblu to study, imitate like a disciple). 156, 22. Cf. Hr. I. 208, 5 . disgynnu to dismount, desfend, aliglit, land, put up at.

dispeilaw to unslicatlic. $199,13$.

dissifid, see deissyfyd.

distryw to destroy, demolish.

ditheu, see titheu.

dithwn (U. IV.) this dra. 208, 15. I6. di-wall carcful, mectising. 164, 5 .

1. diwarnawd m. $a$ d $a y$.

2. diwarnawd, see di-farnu.

diwedy $\delta$ m. rening. 241, 13. diwe $\delta$ end or d. at last.

di-weir chaste. 164,15 .

diweir-deb chastity. $190,16$.

diwethaf last. $154,30$.

di-wreis an " prooting. 233, 3.

di-wreisedig unooted, demolished.

$155,4$.

di-wyll enltivertion. 167,8 . 
dodi (dody) to place, put, give, charge. pres. ind. act. sg. 3 did; dodi ar $\mathrm{y}$ gyfraith to appeal to the law; dodi $\mathrm{ym}$ mhen un to suggest, submit, entrust, hand over.

do $\delta$ yw, doent, see dyfod.

1. doeth wisc, sage. $143,3$.

2. doeth, see dyfod.

doeth-ineb wisdom. 142, 32.

Dofy $\delta$ m. the Lord, God.

Dofy $\delta$ yad $\mathrm{m}$. the Lord. 231, 15. dofyon, see l. daw.

dogyn portion, share. 202, 14.

doi $\delta$, see dyfod.

dolur grief, anguish. 144, 20.

doluryaw to grieve. 154, 25. 204, 20 .

domni= Lat. Domini. . 237, 2 .

donyawg giftcd, endowed. 235, 19.

donyeu, see dawn.

dos, see myned.

dothuif, doy, doynt, see dyfod.

drachefyn, see trachefyn.

dragon, dreig f. a dragon; 172, 29.

a battle standard. pl. dreigeu.

$150,26,180,2$. 184, 3 .

drein (coll.) thorns. $230,32$.

dros, see tros.

drudbold, arrogant, wicked. 186, 13 . $232,8$.

drudannaeth f. arrogance. 165,28 (protervia).

Drud-wyn m. the name of a hound.

$204,8$.

drwg bad, evil ; mischief, harm.

drws door, entrance; pl. drysseu.

drwy, see trwy.

drycin (i.e. dryg-hin) foul weather.

$225,6$.

drychafel to raisc, lift; rise.

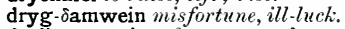
dryll $\mathrm{m}$. portion, fragment; pl. -eu. dryllyaw to break in pieces, shatter. dryssawr m. a doorkceper. 234, 8 . drysseu, see drws.

du black.

duc m. a duke.

duch, dug, see dwyn.

du-hunaw to avelke. 173,6 .

Du-las (Ir. Dub-glas) a river-name. $146,14$.

du-un accordant, agreeable. 216, 23.

duw (dyw) : pob d. on every day.

201, 5. d. Sadwrn on Saturday. 228,21 . 240,10 .

Duw in. God. pl. dwyweu 142, 21. dwfrein, see dwyrein.

dwfyr (dwfwr) m. water. dwrn a fist, hand; pl. dirn. 235, 2. dwy, see deu. dwyweu, see Duw. dwywawl divine.

dwy-law (pl. of llaw) hands.

dwyn to take, carry, bring, capture; $\$ 133$ (b). d. ar gof to call to mind. d. ruthur to attack. d. yr dygyn to affirm on oath. pres. ind. act. sg. I dygaf; fut. ind. pass. dygetawr (\$ 129. n.); imper. sg. 2 dwg; pres. subj. ss. 3 duch (\$ 110 n. 2 ; ; pret. ind. sg. 3 dug.

dwyrein (dwfrein, dwyfrein) the east. 172, 1. 181, 17 .

1. dy, see 2. di.

2. dy (de) (voc.) poss. adj. thy. $\$ 57$.

3. dy (de), see ti.

dy-borthi to carry, inflict. 180, 26. dy-bryd ugly, foul, base. 178, 6 ; 180,$19 ; 190,26$.

dybynu to hang down. 230, 18. dycco, dyccwy, see dwyn.

dychymyg $\mathrm{m}$. invention, device ; pl. -eu, -yon. 164, 26.

dy $\delta(O . W$. did) m. day, daytime, daylight, date; pl. dieu (after numerals), dieuoe $\delta$, dy $\delta$ yeu; d. brawd Doomsday; hanner d. mid-dry.

dy $\delta$-gweith on a certain day, one day. $199,10$.

dy- $\delta$ wyn to bring. 194, 13.

Dyfed Demetia.

Dyfnarth n. pr. m. 200, 28.

Dyfneint n. l. Devon. 206, 5.

dyfod (deuod, douot) to come. \$141. dyfodedigaeth f. a coming, arrival. dy-fryssyaw to hasten. $242,2$. dyfuant, dyfy $\delta$, see dyfod.

dyfynnu to summon. 201, 1. 205, 2. Dyfyn-wal n. pr. m.

dyffo, see dyfod.

dyffryn m. a valley. D. Llychwr

the valley of Loughor.

dyffygyaw to fail, lack. 145, 24.

180,11 .

dy-gaboli to belabour, beat soundly

$207,2 \mathrm{l}$.

dygaf, dygetawr, see dwyn.

dygonho, see 2 . digawn.

dy-gryn terror. 228,33 .

dygrynnyaw to seize, elutch.

206,20 .

dy-grynöi to avail, profit. $153,10$.

175,30 .

dy-gwyolaw to fall, chance.

dygwy $\delta$ edigaeth f. setting (of the sun). 151, 4 . 
dygyn hard, severe; a test, proof. See dwyn.

dy-gyrchu to make for, set upon; draw. 194, 23. 202, 12. 206, 24.

1. dy-he $\delta$ discordant, strange? piteous, a pity? 194, 19.'

2. dyheó? 228, 27. Here MA.

$73 \mathrm{~b} 6$ has the variant tuedd, pl. of tu ' country-side, country.'

dy-leith derath. $232,1$.

dylyed f. due, claim, vight, title.

dylyedawg high-born, noble; pl. dylyedogyon. 140, 29. 155, 14. 156,24 .

dylyedus due, proper. 18:, 20 .

dylyu (deleu) to have a right to, deserve, be due, ove. 171,26. 2is,20. 23. $217,25.237,19.4$

dyn $n$. and f. Cheman being, ment; coll. men 204, 5. pl. -yon (deneon).

dy-nessäu to approach, draw near. dyn-y-orn (ef. Ir. duin-orgun) homicide, mueter. $222,17$.

dyrchefynt, see drychafel.

dyrn-awd m. a blov; ; pl. dyrnodeu. dyrn-fe $\delta$ a handbreadth. $197,24$. dy-rooi to give. pres. ind. act. sg. 3 dere, dyry; imperat. sg. 2 dyro. dyrys (1) difficult, intricate: (2) adversity. 162,20. 167, 16. 175, 18 . dysg m. teaching, instruetion, cxample, behaviour. 164, 12. 182, 19. 184, 23 (hortamen). 187, 7. 191,17 dysgu to teach, instruet.

dysseifyd, see deissyfyd.

dywad, see dywedud.

dywal fierce. 183, 13. 233,4.

dywalhäu to harass. 185, 26.

dyfy $\delta$, see dyfod.

dyw, see duw.

dywedud to say. $\$ 133$.

dywygyad (di-) manner, fashion. 164,12 .

1. e, see $\mathrm{y} \delta$.

2. e, see 4. y.

eb-rwy $\delta$ swift, quiek. $176,11$. ebryn? 228, 27.

ech ontside of, beyond? 228, 16.

Cf. FB. 66,8 ; 106,$30 ; 140,31$; MA. $208 \mathrm{a} 49$.

Echel Aclilles.

echenawg needy, destitute. 143, 5 . echwrys violent, ficree. 227,22 ; Cf. FB. 159,5 ; 199, 20 . MA. 247, 24. 36 . ed, see $\mathrm{y} \delta$.

ederyn, see adar.

edifar veqentent, sorry. $149,17$.

edir, see adaw.

edirn (etyrn) sovercignty, supremacy. 235, 3. 236, 15.

edrych to look, see. $164,23.220,9$. ed-rif deseent, lineage. 212,29 . Cf.

MA. $168 \mathrm{a} 51$.

ed-ucher ( =lıyd ucher) till evening.

193, 1. 203, 5 .

edyw, see ydyw.

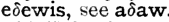

ef (eff) he, it. $\$ \$ 45 ; 47$. Emphatic

efo (effo) ; conjunct. ynteu. $\$ 45$ (b). (c)

efelly thus, so. See felly.

efo, effo, see ef.

Efyas n. 1. a eantred in Herefordshire. 206,4 .

effeiryad m. a priest; pl. effeiryeid. eglur clear, bright, brilliant, renouned, famons. 167, 1. 169,22. eglur-der brightuess, brillianee.

$173,1$.

eglwys f. chureh; pl. eglwysseu.

egnad (O.W.), pl. egneyd, see ynad.

englyn m. a stanza of three or four lines. $200,13$.

engylyon, see angel.

enghyrth (eghirith) torrible, wain-

ful. 238, 10. FB. 1772 ; MA. 351b 21 . ehang nmrestrieted, fice. 173,29 .

ehawg m. a salmon. 197,28 .

ehedeg to $f y .172,29$. 156,27 162,24

ehofyn-der fearlessness, eomfidence,

convoge. $187,4$.

ehunan himself; pl. ehunein $\$ 60$. ei, see myned.

eion his; eiount theirs. $\$ 55$.

Eifft Egypt. yr E. $172,18$.

eigawn ocean, sea. 161, 18.

eingon f. an anvil. 196, 21 .

1. eil seeond, next. eil hynaf eldest

but one; eilweith a second time,

again : bop eilwers alternately. 2. eil a son. 200,$28 ; 205,24$, eilenwi to fulfil, accomplish.

152,14 . 169,22 .

eillaw to shave, to eut (hair).

einym ours. 169,14 . $\$ 55$.

eirant they will arise. 229,$19 ; 20$.

See RC. VI, 27.

eirchad a suitor, suppliant. 234,5. eir-m-oed since my time. $198,9$. $\S 197 \mathrm{n}$.

${ }^{1}$ For oed dyhed kelu y ryw was hwnn WB. 475, RB. 116 has ys oed gryssyn kelu \&c. 
eiry snou:

Eiryawn n. pr. m. 204, 30.

eiryf number. $172,14$.

eir-y-oed (eiroed) ever, aluays.

$\S 197$ n. 140,3 .

eisseu vant, indigenee. 146, 2.

$199,19$.

eissoes yet, nevertheless.

eissyfflad hell. 231, 13. v. l. issaf wlad, MA. 74b 14. eissyflat, FB. $161^{34}$ v. l. Eissyf wlad MA. $27 a^{56 .}$

See FB. 30228. eissyllud progeny, followers. 232,9 .

Cf. FB. 44,$2 ; 203,24$; MA. 143 a 39.

$169 \mathrm{a}, 35$.

eiste $\delta$ (eyste) to sit ; e. wrth y gaer

to besicge the city.

eiste $\delta$-fa f. a seat, throne; pl. -eu. eithaf end, cxtremity; pl. -oe $\delta$.

eithyr prep. except. \$ 172 .

el, see myned.

Eynpr. el-chwyl a sccond time, again. 14l, $20422.142,22$.

elhei, elhid, elhynt, eloch, see myned.

Elen n. pr. f. Helen.

ell (ill, yll) all, see $\$ 67$.

ellwng to dismiss, dispateh, let ; shed (blood). past. subj. act. sg. 3 ellygei, pret. ind. sy. 3 ellygwys, etc. past part. ellyngedig.

ellyn a razor. 203, 25.

em, see yn.

emelldigedig accursed.

Emrys n. pr. m. Ambrose.

Emyr n. pr. m.

en, ena, see yn, yna.

encil, encilyaw to retieat. $185,1$.

encyd space of time. 184,8 .

ene, see yny.

eneid (eneyt) m. life, soul; pl. -eu;

myned e. dros e. to engage in a life-

for-life struggle.

enfyn, see anfon.

enguis $(O . \mathrm{V}$.$) , see enwi.$

enill to gain, win. $145,18$.

enneint an ointment, a bath. 143,

13. Cf. RB. 76, 11 .

Enoc n. pr. m. Enoch.

ennynu tokindle, fire; be inflamed. enryde $\delta$ (anryded) m. honour; dignity. 142, 16. 144, 11. 145, 21.

enryde $\delta$ u (anrydedu) to celebrate. 154,23 . pres. subj. act. sg. 3 enryde $\delta$ ocao.

enrydesus honourable, noble, venerable, dignificd. 143,24 . of 141,17 154,26

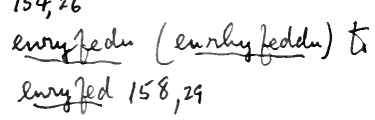

enteu (entheu, entehu)pers. pron. so. $3 \mathrm{~m}$. \$\$ $45(\mathrm{c}) ; 46(\mathrm{c})$.

enw (heno) m. a name.

enwi to name. pret. ind. act. sg. 3 enguis $(0, \mathrm{~W}$.) $21 \mathrm{~s}, 5$.

eny, see yny.

enywed (ennuet) damage, injury.

Sew y turyw ac enwywet llosgy tey a

thorry araidyr $\mathrm{BCh} .63,8$.

l. er, vee I. yr.

2. er (yr) prej. for. $\$ \S 53,197$.

3. er, see 1. y.

er-byn agrainst; yn erbyn to mect, agrinst, by. \$ 173 . yn awch e. agciust you. 180, 19.

erbynyaw to reccive; withstand.

erbynyeid (erbyneid) to receive.

141,16 . 143,25 .

erchi (hercki) to ask, request, bid;

pres. ind. act. ig. 1 archaf.

eregthun, eregthunt, see rwng.

ereill, see arall.

ereint silver. 200, 24. 203, 19.

205, 5. Cf. Rhys, Celt. Heathendom, p. 125 .

erestyn m. $\iota$ juggler. 147, 13. The parallel passage in M. A. 53 la 55 has: ac en rith kroesan ac arwestdyn ac gwareyt.

ereu 230, $1=$ eireu MA. $73 \mathrm{~b} \pm 6$, see geir.

er-gelu to hide. fut. ind. pass. ergelawr 227,28 . ergelhawr ib. 29. er-glybod to listen to. imper. sg. 2 erglyw 235, 10. 236, 22 .

er-gryn dread, fear. 202, 31.

er-gydm. a stroke, blow, east; pl. -eu.

er-hyl hunt, chase. 201, 18; 204, 8 . er-lid to pursue.

er-lysu to reject, deny. $229,30$.

ermid m. ahermit. pl. -wyr.

ermud? $232,10$.

ermyn-wisc $a$ robe with border of

ermine. $161,29$.

eryf? $229,4.9$.

eryr m. an eagle; pl. -od 154, 3.

metaph, a leader.

es, see $\$ \$ 94$; 159 n. 2.

Esgeir Oervel n. l. Seiscenn Uar-

beōil in Ireland. 201, 32. 203, 3.

esgob m. a bishop; pl. escyb.

esgobaeth f. a bishoprie; pl. -eu.

esgobawd a bishopric.

esgolheig n. a scholar, clerk; pl. -ion.

esgyll, see asgell.

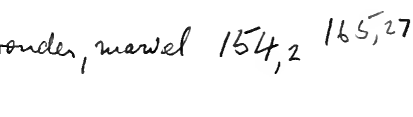


esgyrn, see asgwrn.

esgynnu to aseend, mount, climb. esmwyth-der m. ease, rest. estrawn a stranger. 225, 4. estwng = gestwng to let down.

e. gantunt incumbentes 176,30 . etife $\delta \mathrm{m}$. an heir; coll. heirs. 141, 1. pl. -yon 181, 26. eto, see etwa. etheuis, see a $\delta a w$. ethol to choose, select. ethynt, see myned. etwa (eto) yet, still. ettwa $191,7$. eu their. \$57. eu hun themselves. eur n. gold.

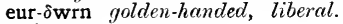
pl. - $\delta$ irn $235,2.236,14$. eureid golden, gilt, set with gold. 184, 3 (avieus). 750,25' 16/,1

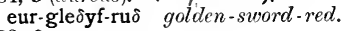
$233,9$.

euryn golden. $201,11$. ewin f. a nail, talon, claw. 201, 9. ewythyr m. an uncle (brother of one of parents, grand-parents, or great-grand-parents); pl. ewythre $\delta$ $206,2$.

eyl-weyth, see 1. eil.

fal (mal) conj. as. \$ 216 .

felly thus. yfelly 164, 30, 166, 20. fi, fifi, see mi.

fry above.

fyhud? 231,9 .

fyn (nas.) $m y$. $\$ \S 57,59$.

ffalst cuming. $147,16$.

Ffichteid Piets.

fflam f. a flame, fire. 160, 4. 185, 4.

fflamychedig inflamed, flaming. $159,20$.

Fflandrys Flanders.

ffo to flee. $\lambda$ ar ffo in flight.

fforo f. a road, way, passage, means; pl. ffyr $\delta$.

fforest f. $a$ forest; $\mathrm{pl}$ - $-\mathrm{i}$.

Ffreinc f. France.

ffuruf $\mathrm{f}$. form, manner; pa ff. how? ffustaw to strile, beat. 175,2 .

ffwrn f. a furnace. 228,22 .

ffy $\delta$ faith. 149,31 .

ffyo-lawn faith ful. $181,3$.

ffynhawn f. " fountain, spring. ffyr $\delta$, see ffor $\delta$.

gadael (gadayl) to leave, allow. 215,29 . See gadu. gadaw to lecere. gadu to leave, allow, permit. pres. ind. act. $\mathrm{sg}$. 2 gedy; $\$ \mathrm{sg}$. $3 \mathrm{gad}$ 146,2 ; pl. 2 gedwch ; imper. pass. gat-her.

gafael (gafayl) f. a seizing, holding; scizure, $222,15$.

gafael-fawr of mighty grip.

Glewlwyd G., 204, 24 .

galar sorrou. 229,9 .

galw to call, summon, name. pres ind. pass. gelwir; imper. pl. 2 gelwch.

gallel, gallu to be able; power, might. pres. ind. act. sg. "2 gelly; sg. 3 geill, ete.

gan, see can.

ganed, see geni.

garscon? 199,12

garth a mountain ridge. 205, 29. garw rongh.

gast f. $a$ biteh.

gawr f. and $\mathrm{m}$. a shout, ery; battle. $205,10.229,23$.

gayaf (gaeaf) m. winter. 156, 14 gefeil tongs, pincers. geffeil 194,14.]

1. geir (geyr) m. a vord, vequest. pl. -eu ; o un eir with one accord.

2. geir (gyr, ger) near. g. llaw near, close by. g. bronn before, $\$ 168$. gelfin $a$ beak: $\quad 196,23$.

gelyn u. an enemy; pl. -yon.

gelynawl hostile.

gellwng to loose, let loose, let, clismiss, deliver np, drane (a sword).

pret. ind. act. pl. 3 gellygassant.

geneu n. jours, mouth. 229, 31 .

geni to be born; pret. ind. pass. ganed. 227,12 .

genthi, genti, see can.

ger, see 2. geir.

Gereint n. pr. m. 203, 9. 211, 8.

Gillamor (Ir. Gilla mōr Big Lad) n. pr. m. 192, 14 .

Gillamwri (Ir. Gilla Muire the servant of Mrry) n. pr. m. 192, 13.

Gilpadrig (Ir. Gilla Pādraig the servant of Patrick) n. pr. m. 192, 13. gily $\delta$, see cily $\delta$.

girad lamentable, piteous, terrible. $173,3 . \quad 192,9$.

glan f. a bank, shore; pl. glanneu. glanhäu to clean, polish. 194, 16. gleif $\mathrm{m}$. and f. a lance, spear. $\mathrm{Hg}$.

II. $91,12=$ paladyr omn CM. 87,32 . gleis, see cleis.

glew brave, stout; a brave man, hero. -n. pr. m. 204, $20 . \quad 233,4$

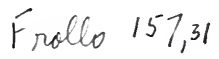


158,19 glew-der bravery, boldness, valour. Glew-lwyd n. pr. m, 204, 24. glin m. a knee; pl. -yeu. gloew bright, sparkling. $235,3$. glud tenacious, fast, diligent. 175, 5. MA. 285 a 1. glyn (wrth) an adhering (to), fol. lowing elose. 195, 4. glynn m. a valley, glen. 197, 12. $204,14$.

Glyth-myr n. pr. n. 201, 12 , Glythfyr ib.

glyw m. a vuler. $233,3 . \quad 235,4$. gnawd eustomary, usual, common. gnotäedig accustouned, nsual.

142, 11 . 145, 22 .

gobeith hope.

go-bedr-or the four-corners (of the voorld). 228, 3. FB. 199, 20. 160, 19. MA. $236 \mathrm{~b} 28$.

go-ben-y $\delta$ m. a pillow; pl. -eu. go-byr m. a fee, pay. 221, 25. go-chel to avoid, ward off, shum, eseape. $148,30.150,21 . \quad 159,3$. 169,28 .

Godlont Gothland. 156, 11 .

go-driccawr m. a lingerer, sojour-

\&f. qn ner. 239,8 . 172,28

go-def to suffer, allow, permit. 233,8 .

gooith m. a heeth. 185, 5. 226, 4. gooeu purpose, design. 239, 8.

Jg g. gweith Mynaw FB. 187, 29. gof in. a smith. 196, 21.

gofal m. anxiety 147,6 ; pl.gofeilon

156,30 .

gofalus anxious. 149,27. 160, 3 . gofud m. affliction, injury. 143,6. gofwy to visit. $142,3$.

gofyn(wrth) to ask (of), seek: 199,2. gofynnyad an asking; demand.

$205,20$.

Gogigwr n. pr. m. 204, 23.

go-gle $\delta \mathrm{m}$. the North. 145, 12.

200, 32. 201, 15 .

go-gof f. a cave; pl. eeu.

go-gyfarch prominent, eonspieuous.

Read with Add. gogyfuro (duodeeim pares), q. v. 162,$16 ; 171,11$.

go-gyf-ur of equal rank, peer.

$171,11, \mathrm{v} .1$.

go-hir to delay; delay, respite. golchi to wash, polish. 194, 6 . go-leith to dissolve. 233, 7. FB. 58,30 . goleuhäu to light up, illumine, $173,1$. golud wealth. 198, 20. 233, 12. go-lus to hinder, obstruct. $233,12$. golwg f. a look, glance.

gor-alw to evy or eall aloud. 184,18. pret. ind. act. sq. 3 gorelwis. 231,24 , FB. 283,10 . NA 195 a 54.

gor-cheidwad m. a gurerdian, eustodian; pl. gwercheidweid 208,17 . gor-chyfygu to orercome, conquer. $155,26$.

gor-chymyn (gorchymun) to $\mathrm{com}$ mand, commend, eommit to; a eommand, injunetion; pl. -eu.

goróerch-wraig f. a concubine; pl. - wrage $\delta 164,12$.

gorderi m. a shrieking, noise, disturbance. 176, 19, 183, 22.

gor-difwng very steady, sterdfast. 233,1 .

Gor- $\delta$ u n. pr. f. $207,12$.

gorowy oppression, violence. 233,2.

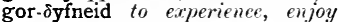
habiturilly. 142, 14. FB. 28, 18; 44,$13 ; 88,27 ; 258,22$.

gorelwis, see gor-alw.

gor-esgyn to invade, overrun.

I. goreu best.-n.pr. m. $195,8$.

2. goreu, see gwneuthur.

gor-flwng very severe, austere. 233,3 .

gor-fod to overeome, eonquer. $\mathrm{g}$. ar 181,4 . pres. ind. sg. 3 gor-yw $230,13$. s 160 .

gor-ffowys to eease, rest. $157,25$.

gor-hoffder m. a boasting, vaunt.

ing. 174,34 .

gor-hoffe $\delta$ a boasting, affectation.

$174,13$.

gor-llewin the West.

gormes f. opluession, tyranny.

gormod excess; 164,6 . yn o. too much, 176, 6 .

gor-or m. a border, side. 242,7 .

gor-se $\delta$ (gworsse $\delta$ ) f. a seat, throne, eourt. 234.21. 240, 4.

gor-sefyll to withstand, stand. pres. ind. act. so. 3 gorsseiw 234,22 . pres. pass. gorseuir 241,7 . Cf. MA. $160 \mathrm{~b} 2$.

gor-uchel very high or loud. $150,7$. 241,6 .

gorug, see gwneuthur.

Gor-wen n. pr. f. $207,12$.

gorwy $\delta$ m. a steed, uarhorse. 242,5 . 
"gor-ysgelu to orevflow (the boull). pres. subj. sg. 3 gorysgelho 240,2 .

$\mathrm{Ni}$ dldoilai eirif ar ra dillarl

$\mathrm{Na}$ gwin grysgelo nae ysurarlaul

MiA. 222 b 18.

Cf. gwin gorysgalawe RB. 103,18. gorysgalane in large bouls E. Lh.

gosgor $\delta$ retinue. $141,9$.

go-sgubaw to sweep. pres. ind. act. s.r. 3 gosgupiô $241,21$.

gosgymonn (literally fuel, food) ocersion. 174, 5 . Rib. 114,$4 ; \mathrm{Hg}$. Il. 34,30 ; FB. 6,$8 ; 306,16$.

gossod to mit, establish, set, attael, thrust. g. ar to attack; g. drwy arrange. past part. -edig $148,16$.

gosteg f. silence, the proctriming of silenet in court. 211, 3. 8. 234, 20). gostegu to prorlaim silence. 234,19 . gostegwr m. a silencer. 234, 19. gra $\delta$ f. $\alpha$ stc $p ;$ pl. -eu. 166, 27. grawn m. grain (eoll.) 2:25, 1.

Greid n. pr. m. 198, 18.

Greidawl ^l. pr. m. 199, 10.

grio-fan to groan, a groaning.

Groeg f. Greece.

Gruffú n. pr. m. 162, 4. 235, 17.

Grugyn n. pr. m. 203, 19.

grwm-seid having a dark-eoloured haft. 194,15 ; NA. 954a 2 . Cf. gwrym-dudet FH. 83, 19; gweilch gwrym-de 84,4 .

grym force, strength, effort. 151,13. 184,24 .

gwad m. a denial. 231, 12.

gwadu to deny, vefuse; pres. subj. pass. gwatter 239,6 .

gwae woe! g. a. woe to him who.. 225,4 . 10. g. wann woe to the reak! $226,2$.

gwaed m. blood. $150,10$.

gwaed-lyd bloody. 184, 9.

gwae $\delta$ an outer $\eta$, ery of distress; pl. -eu.

gwaeth worse; gwaethaf vorst.

gwa-hanu to separate. past. subj. pass. gwehenid 183, 5 . pass. part. gwahanedig.

gwa-haw $\delta$ to invite.

gwal a lair. 202, 1 ; 203, 15.

gwala f. " fill, sufficiency. 200, 3.

gwalch a hrevk; metaph. a leader;

pl. gweilch.

gwalch-lan a band of heroes?

233,23 . MA. 150a, 40; 161 B 20.

Gwalchmei n. pr. m. 173,31 .

gwal-par strong-speared. 233, 24. gwalstawd m. an interpreter. MA. 128a, 42 . Cf. Rhŷs, Celt. Heathendom, p. 489.

gwallaw to serve liquor. 235, 1. Ane. Laws, I. 32 . \& viii.

gwallt the hair of the head.

1. gwan to pierce; pret. ind. act. sg. 3 gwant, \$133 a ; past. ind. pass. gwanpwyd, \$ 134, (f).

2. gwan (gwann) feeble, weak.

gwanar a chicf, lord. 233, 24. IIA. 181 a 40; 203 b 19 ; 220a 34; v. Poden 221 a $45 ;$ b 37.

gwanas a clasp, buckle. 239, 18. FB. 250,21 . 18, 19; 23, 16;59, 14; MA. 144 b $26 ; 177$ a $19 ; 205$ b $4 ; 269$ a $29 ; 299$ b $46 ; 48$.

gwanhiuu to verken. $178,6$.

gwanwyn m. spring. 155, 27.

gwaradwy $\delta$ n. disgrare, shame, reproach. 150, 12.

gwaradwyous clisgraceful. 180, 29. gwarafun to forbid, refuse. 168, 25. gwarandaw to listen, hear.

gwarawd, see gwa-red.

gwar-chadw to guru'd, proteet;

g. ar to besiege. $146,1 \mathrm{~s}$.

gwarchae to besiege; in. a siege.

gwar-der humanity, pity. 153, 33.

gware to ylay: ni. a yame, play;

pl. gwary-eu. Cf. chware.

gware n. pr. m.

gwa-red to succour, help, reseue; help, deliverctee. pret. ind. act. s.r. 3 gwarawd.

gwar-e $\delta$ meckness. 238, 2. RB. II. 1223 .

gwarth disfrace, shame. 233, 23. gwarthaf upper part, surface.

ar $\mathbf{w}$. on the top of 241,20 .

gwartheg lime, cattle.

Gwarthegyd n. pr. m. 204, 9.

gwary-y $\delta \mathrm{m}$. a juggler. 147, 13. Hg. II. 10, 15.

gwas m. a youth, lad, servant; pl. gweis.

Gwasgwin Gascony. 160, 4.

gwassanaeth service, attendance.

gwassanaethu to serve.

gwassanaethwr m. $\alpha$ servant.

gwa-sgaru (tr.and intr.) todisperse, scatter. past part. gwasgaredig.

gwa-sgawd shelter, protection. 148,$28 ; 156,2$.

gwasgu to press, crush.

gwastad level, even, eonstant, temperate; yn w. constantly.

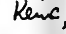

243

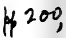




\section{gwercheidweid v. gor-cheidwad}

GLOSSARY.

$26 ;$

gwastadawl constant. 169,4 . v.l. (sic leg.)

gwawr dawn. 173, 15. metaph. $234,8$.

gwayw (gwaew) m. and f. a lance, spear; pl. gwewyr. 175, 2.

gw $\delta a m$, gw $\delta$ ost, see gwybod.

gwedi prep., conj. rfter. \$174. 210

gwe $\delta$ f. form, frishion. pa (py) we $\delta$ how?

gwe oi f. a prryer. 16I, 28.

gwe diaw to pray. 2l5, 1.

gwe $\delta$ u to befit, to submit. 144,6 .

148, 11. 165, 5 .

gweous fitting, meet, scemly.

Gwe $\delta w$ n. pr. m. 201,8 .

225,9

gwe $\delta \mathbf{w}$ deserted, desolate, lonely.

gwehenid, see gwahanu.

gweilch, see gwalch.

gwein f. a sheath, scabbard.

gweir-glaw $\delta$ f. a meadow; pl.

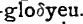

gweis, see gwas.

1. gweith m. work, task, yg g. at work. 226,5 .

2. gweith f. n turn, time; dyō-g. once; weithon (weithyon) this time. now; pl. -eu sometimes. -eu ... -eu ereill now ....agrin. 187,18 .

gweith-red $\mathrm{m}$. an action, decd; pan del ar weithred eum ad actum accedit $167,2 \mathrm{I}$. RB. II $84^{6}$.

gweled to see, provide, crrange.

gweledigaeth f. r vision, drerm.

gweli f. a wound; pl. -eu, -oe $\delta$.

gwely m. a bed. 241,11 .

gwell better; 204, 26. cyfarch

g. to greet.

gwelläu to immore, amend. 214,12.

gwelleu shears, seissors. 203, 25.

gwellig les. gwelling? to distribute? 235,2 . FB. 45,15 . MA. 172 b 15 ;

181 b 39 vil., 140 b 12 .

gwellt (gwell) grass. 223, 12. Cf.

Peredur, ed. K. Meyer, $\$ 80,16$.

gwen a smile. $225,22$.

gwen-gan white and fair. 227, 26. Gwen-hwyfar (Ir. Find-abair) n. pr. f. 172,20 .

gwenith m. wheat. 196, 3.

gwenn, see gwynn.

Gwenn f. the name of Arthur's shield.

gwen-wlad f. a happy land. 234,8 . $=$ Heaven, MA. 173 b $24 ; 177$ a 42 ; 189 b $20 ; 222$ b 38 . gwenwyn in. poison. 202, 4.

Gwenwynwyn n. pr. m. 233, 24 .

gwer-, see gor-

gwerin-dawd f. virginity. $23 \mathrm{~s}, 3$.

L.A. 17,$4 ; 65,21$.

n. 1 .

gwern (coll.) alder-trees. G. Abwy

gwers f. a while, spaee of time.

$19 \frac{7}{6}, 29$. 194, 6. pob eil-w. alter. nately, in suceession. gwers . . $\mathrm{g}$.

arall $175,29$.

gwersyll a camp; pl. -eu. = Eecause 231,33 gwerth-fawr valuable. comp.

gwerthfawrogach 169,1 .

gwery $\delta$ f. a virgin. 161, 5 ; pl. -on.

gwestei m. a guest. 193, 9.

gwewyr, see gwayw.

gwioon f. a witch.

gwin n. uine.

gwir (1) true, truly. g-aberth

15i, 17. g. gwell truly better. 2:26, 3 .

(2) justice, right. 223,27 .

gwirawd a breverge, drink; pl.

gwirodeu. $164,2 . \quad 235,1$.

gwisg f. dress, clothing; pl. -oeô.

gwisgaw to put on, vecer; part.

gwisgedig dressed, clad.

gwlad f. a lingdom, country; pl.

-oeô, gwledi; $\mathrm{g}$. pressent the present

world. G. yr Haf n. l. 212, 29.

gwledig in. a ruler.

gwledychu to rule, reign.

gwleô f. a feast, brinquet. 238, 1. 240,7

Gwndy n. 1. 223, 10.

gwnel, see gwneuthur.

gwneuthur to malie, do, form. $\$ 142$.

gwnn, see gwybod.

gwor-saf support, bulwerk: 236,9. gworsse $\delta$, see gorse $\delta$.

gwosparth support 233,23 . Cf.

gosparth Brython MA. 124 b 38.

gwr m. a man, husband, vossal ;

y gwr he who 239, 10; (applied to

(rod) 203, 17. pl. gwyr men, soldiers

179,11 .

gwrach f. a hag, witch.

gwrage $\delta$, see gwreig.

gwrawl manly, brave, stout; pl.

gwrolyon. 139,3 .

Gwrbothu n. pr. m. 206, 3.

gwr-da m. a noble. pl. gwyrda;

gwyrda seint holy men; MA. 142a.

gwro strong, vehement. 233, 1.

$235 \overline{2}, 13$; g.-fleio a fierce rolf 233,3 . gwreig f. a voman, wife; pl. gwrage $\delta$. 


\section{$>$ groylaw, crying, weeping, 142,9. \\ 153,32}

gwreigawl momamish, couardly ; pl. gwreigolyon. 186,17 .

Gwr-gi (Ir. Fer-ehī) n. pr. m.

Gwr-gwst (Ir. Fer-gus) n. pr. m. gwrhäu to pay homage.

gwr-hyd manliness, valour, bra. very, stvength.

Gwrhyr n..pr. m.

gwrteith to dress, mend, temper ; a dressing ; 195, 10. Cf. Hg. 38, 37 . pl. -yeu.

gwrth (wrth) voc. (1) prep. against, towards, for, for the purpose of; wrth hynny becanse of that, therefore; y-wrth fiom, of; in comparison with. $\$ \S 53,194$. (2) conj. becanse. $\$ 231$. gwrth-dir borclerland. 207, 12.

gwrth-eb to ansuer, reply.

gwrth-gasse $\delta$ rebellion, dissension. 174,4 . $\mathrm{Hg} .276,2$. LA. 15, 26; CM. 110, 28.

gwrth-od to give back, reject, renounce 165,7 . pres. ind. act. sg. 3 gwrthyd $154,14$.

gwr-thrwm revy heavy. 149, $2 \mathrm{~s}$. $172,26$.

gwrthryn resistance, opposition. $233,23$.

gwrth-wyneb opposite, adverse; yg g. y myny $\delta$ facing the monntain; talu yn $\mathrm{y} \mathrm{g}$. to pay in return. $142,23$.

gwrth-wynebu (y) to oppose, resist. gwrthyd, see gwrth-od.

gwrych (coll.) bristles. G. Ereint n. pr. in. $203,19$.

gwrys strife, hostility. 197, 31. FB. 63,$25 ; 85,12 ; 159,5 ; 193,6$; 199,$20 ; 200,9$.

gwrysg (coll.) the smaller bramehes of a tree. 225, 11.

Gwy the Wye. Aber G. 206, 17.

Gwyar n. pr. m. 173,31 .

gwybod to knou, recognize; know ledge, rontesy. \$ $\$ 143$.

gwybyoiad m. an eye-vituess; pl. gwyby gyeid.

gwychyr stout, resolute, bold; superb. gwychraf. 183,$13 ; 191,4$; $192,10$.

Gwydre n. pr. m. $204,19$.

1. gwy $\delta$ m. (coll.) vood, trees 241 , 13. 21. mast of a ship 242, 8 .

2. gwy $\delta$ mesence; yny vy $\delta$, hyny vys lo! behold! thereupon; 193, 1; 198,13 . 199, 27. yn eu g. at onee $202,24$.

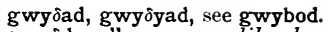

gwy $\delta$-bwyll some game like chess; 164,$24 ; 167,3$. See RB. 153,5.

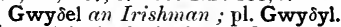

$>$ gwyl-fa f. festival, witch, ward; pl. eu.

gwyliad n. a guardian.

gwyllt wild; aeth yg g. he became mad. RB. 100, 6, 8. Cyledyr W.

gwyneb (wyneb) face. $209,23$. 216,27

Gwyne $\delta$ Venedotia, North Wales. 161,22 .

gwynn m., gwenn f. white, blessed; pl. -ion. gwyn y fyd happy he! 170, 18. Gwynn n. pr. m. 200, 25. Avon Wenn 173, 23.

gwyn-seid having a white haft. 194, 15. Cf. Laws I. 586, 726 . II. 866 , evii.

gwynnyeith pain, torture. 231, 32 .

FB. 185, 5. FB. 303, 3; MA. 193 a 13. gwynt m. wind, favourable wind. gwyr, see gwybod.

Gwyr n. 1. Gower. 205, 24.

gwyr $\delta$ green, fresh, vigorous.

$236,25$.

gwyr-häu to incline, bend. 241, 13.

FB. 241,8 .

1. gwys f. a summons, command.

2. gwys, see gwybod.

3. gwys $a$ soue. '205, 17.

gwyssyaw to summon. 198, 24 . gwystylm. a hostage; pl.gwystlon. gwystyn m. a vithered stumip.

197,4 .

Gwythyr n. pr. m. Vietor.

gynn, see cyn.

gynt, see cynt.

gyr, see 2. geir.

gyrru to send, despatch, drive, hasten 199, 6 ; ry-yrru (reherru) $213,4$. gyt, see cyt.

1. ha, see 2. ac.

2. ha interj. \$ 243 .

hac, see 2. ac.

haeôu to descrve, claim, merit.

hael generous, liberal; pl. -on.

haelder $\mathrm{m}$. generosity. 145,17 .

hael-fone $\delta$ one of moble deseent.

234,21 .

haf summer. Gwlad yr H. 202, 29. haf- $\delta \mathrm{y} \delta$ a summer's day. 242, 6 .

hafod a summer duelling. 225, 9. Cf. RB. II. $27 \%, 5$.

Hafren $\mathrm{f}$. the Severn.

hagen houever, yet, indeed.

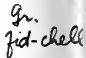


han-bwyllaw to consider, remember 190,27 . RB. $120 ; 17315$.

handit, see hanfod.

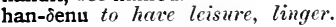
190,27 v. 1 .

han-fod to arise, issue; procetd from, desrend. $\$ 160$.

hanner (hanher) m. a half, middle. 140,20 . 179,20. h.dy $\delta$ midday; h. nos midnight; h. gwr a eoucerd $170,24$. 180,32 .

har $\delta$ fair, beautiful, comely.

hawdit, see haf- $\delta \mathbf{y} \delta$.

haw $\delta$ easy, pleasant; compar. haws.

1. hawl f. a claim.

2. hawl, see holy.

hawlwr m. a elaimant.

haws, see haw $\delta$.

hayach wellnigh, almost. 167, 6 .

$192,15$.

hayachen almost. 207,23 .

hayarn iron, sword. 160,4 .

1. heb, hebyr says. \$ 151 .

2. heb (voc.) prep. without, besides.

$\S \S 16$ (i) ; $53 ; 175$.

hebrwng to eonduct, eseort.

hebyr, see 1 . heb.

hesiw to-day.

heowch peace.

heoychu to male peace, paeify.

hefyd also, in addition.

hegarwch m. kindliness. 226, 3 .

heibaw adv. prest, by. 156,14. 204, 3. heint m. a sielness, disease. 149,28. hela to hunt, chase.

helw posscssion; ar $\mathbf{y}$ h. in his possession. 152, $11 ; 204,25$.

helym f. a helmet. 159, 22 .

hen old; an old man. superl. hynaf.

hen-dad $\mathrm{m}$. an aneestor; pl. -eu.

heneint (henein) old age. $139,9$.

1. heno, see enw.

2. heno to-night.

henw, see enw.

herw a plundering, pillaging. 235, 15. Cp. Gwynfyd herwr ywr hirnos MA. 361 a i7.

herwy $\delta$ aceording to, by; yn h. aceording to; yn h. $\mathbf{y}$ nerth with all his might. h. fal 165,2 .

hestawr, a corn measure of about two bushels. $199,17$.

heul $\mathrm{f}$. and $\mathrm{m}$. the sum.

heussawr m. a herdsman. 195, 3 . FB. 174,1 . hi she, her: Emphatic hihi, eon. junct. hitheu. $\$ 45$.

hin weather. '209, 22.

hir long, tall; drwy h. o amser for a long time 141,5 . Compar. hwy.

Hir n. pr. m. $206,1$.

hir-flawô a long tumult. $235,15$.

Hir-las n. pr. 11. 178, 16. 184, 10 . < hit, v. hy \&.
hitheu, see hi.

hob: dan eu hwb ac eu h. pushing

and lieking them. 207,22 .

hoedel lifetime, life. $152,18$.

hoff-der m. a boasting. 174, 34. L.A.

143,22 .

holy (holi) to claim, ask, search,

demand; imper. sg. 2 hawl.

holl, see oll.

hollawl whole, entive; yn h. rom.

pletely, altogether.

hollti to split, eleave.

honni to proclaim. 159, 25.

honno, see hwnnw.

Howel (Hywel) n. pr. m.

Humyr the Humber. 145, 11.

Huandaw n. pr. m. 204, 23.

1. hun slee?. $172,26$.

2. hun, pl. hunein self. $\$ 60$.

hwb, see hob.

hwch $\mathrm{m}$. and f. a pig. $2(13,11$.

hwnn m., houn f., hynn n. this.

pl. hynn. $\$ s 61 ; 62$.

hwnt yonder; h. ac yman (yma)

here and there. $185,25 . \quad 183,1$

hwnnw m., honno f., hynny n.

that. pl. hynny. $\$ \$ 61,62$.

1. hwy (wy), hwynt they, them.

Emphatie (h)wyntwy, conjunct.

(h)wynteu. $\$ 45$.

2. hwy, see hir.

hwyl f. a sail; pl. -eu.

hwylaw to scil. $157,28$.

hwynt, see 1 . hwy.

hwyred slowness, tardiness. 151,19 .

hy bold. $239,19$.

1. hyd f. length; prep. as far as, $u p$ to, $\$ 177$; eonj. as long as, as far as, $\$ 214$; h. na so that not \$214; until almost 154,13 ; h. pan unit, so that $\$ 22$; h. tra while. $\$ 230$. ba h. whither? hy-dwf well-groum, tall. 158, 18. ^ hy $\delta$ a stag; pl. od. 241, 12.

Hy-gwy $\delta$ n. pr. m. $202,19$. hynaf, see hen.

hynefio m. an elder. $210,3$.

hynn, see hwnn.

hynny, see hwnnw. 
hynt f. a eourse, preth, journey. ar h. immeliately. $174,16.175,6$.

hyny vy $\delta$, see 2 . gwy $\delta$.

1. i (voe.) prep., see 1. $\mathbf{y}$.

2. $\mathrm{i}$, see mi.

3 . $i$, see $y \delta$

iach sound, whole. $200,16$.

iachau to heal.

iad the uprer part of the heal.

230,32 .

iaen ice, a sheet of ief. 241, 12 .

iarll (jarll) m. an crill ; 1., ieirll.

iawn (yaun, jaun) (1) right, just ;

ymla ó yn i. to fight in rality. smperl.

-haf, -af 198, 30. 31. (2) a recomprense, satisfrution. 166, 15. 18.

iawnder m. right.

i $\delta$ aw, i $\delta$, see $1 . y$.

low a Jrw ; 1) - on.

iechid herlth, salvation. 158, 21.

ieith f. lamguage; pl. -oe $\delta$, -eu.

Iessu Jesus.

ieuanc youmy ; superl. jeuaf.

ieuenctid eaily mamhool; youth. leuan n. pr. m. John. 231, 26.

in, see yn. ima, ina, see yma, yna. inheu, inneu, see $\mathrm{mi}$.

176,6 ir-llone $\delta m$. and f. wrth. 159, 20 .

is belone, benwth. 5 53, 178 .

Iscawyn n. pr. m. 204,20 .

Islont Iecland.

issod below. 199, 5.

Lindysei 148,16

Iweroon f. Ireland. 155, 28.

llad (Ir. laith) liquor, drink. Sic leg. 230,31 ? Cf. F13. 201, 22; 23 .

lladrad robbery. 222, 17.

lla $\delta$ to strike, slay, eut, cut off, kill. impf. ind. pl. 3 lle $\delta$ ynt; impf. pass. lleôid; pret. pass. llas. 1. part. lla $\delta$ edig. \$134(a).

Llaesgenym n. pr. m. 204, 2.J.

llaessäu to relax, abate, modevate.

llafur m. labour, excrtion, toil, effort.

llafuryaw to labour, enderevonr, attempt. $140,13.159,15 . \quad 166,21$. 180, 32. 186, 9 .

llafuryus (llafurus) laborious. $191,27$.

llafyn " blade; pl. llafneu, llafnawr.

y llall the other ; pl. y lleill. $\$ 70$.

Llamrei the nome of Aithur's mare. $211,211$.

llann an enclosure, land. 223, 5; L1. daf n. 1. Llandorff. llanw (1) to fill. 175,
$198,7 . \quad 209,4 . \quad 216,11$.

(2) tide.

llary generous, grceious, gentle. 233, 31. MIA. 249 b $48 ; 247$ a $48 ; 241$ b 42 . llas, see lla $\delta$.

llathru to glitter, glisten.

llaw f. a hand; pl. dwy-law. cymhell $\mathrm{y} 1$. to foree to surrender; 152,23 ; rag 11 . at hand, imminent.

llawch protection. 233,6 . MA. 192 b $8 ; 247$ b 6.

llawen glad, ga?, merry. 11. yw genyf gavdeo $170,13$.

llawer many, much.

llawhethan $227,28=11$ ywethan 1

MA. 73 a 18 v.l. one of the constellations. Cf. Barddas I., 404.

llaw-hir long-hrouded.

llawn full.

llawr m. the ground; the earth; 239, 19. 234, 10. 239, 9. yr ll. to the ground; y lawr down.

lle 11. place; pl. -oes. where $225,13$. ynlle instead of, for 180,2 ; yn y lle immediately; yssid le ioaw gwynaw he hus reason tolament; pa le where? with subjunetive elause, where. $225,13$.

llechu to lurk, hicle. 177, 22 .

lled $\mathrm{m}$. breadth. 154,7 .

Lledewig, see Llywedig. Llydewig.

lled-lwm half-bore, holf-nahed.

Gwrgwst L1. n. pr. m. 200, 28.

llefaru to speak. $229,31$.

llef m. voice, soumel.

llefein to shout, ery; m. a shouting.

llefery $\delta$ to say; speech, utterance.

$139,22.202,16$.
lleng a legion. 179,$12 ; 187,22$ (fem.?)

Llengrys 11.1 . Lengriae. $\quad 179,6$.

llei le'ss, inferior. 162, 1.

lleidyr in. a thief; pl. lladron.

1. Ileill, see llall.

2. lleill: y 1l. one of two. 194,17. $\$ 71$.

lleis roice. 153, 4 .

lleissawn generous, liberal. 235, 11.

MA. $154 b 11 ; 159 \mathrm{~b}$.

lleith drath. 232, 2. 233, 7.

llemenig striding, bounding.

Cadwr Ll. n. pr. m. 161, 23.

llenwi to fill. $206,22$.

Lles n. pr. m. Lucius. 157, 31.

llesg fieble, fciint. 191, 20.

llesge $\delta$ f. feebleness, sloth, eovar-

dice. 166,$30 ; 167,5.9$. 180, 23 .

lletty m. a lodging; pl. -eu. $195,9$.

1 A popular etymology for Leviathan. 


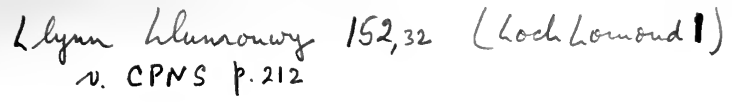

GLOSSARY.

lletty-wr m. a host. 195,9 .

Lleu n. pr. m.

lleufer f. and in. light; pl. -eu.

llew m. a liun. 1\$6, 30. 235, 11.

lleweny $\delta$ joy.

llewychu to shime. Hewychi 232,7 ,

leg. llewychei ? MA. 243 b 9.

lleyg n. a lay-man; pl. -yon.

lliaws m. a multituele, host.

lholiang llicrio, see llygru.

llid $\mathrm{m}$. anger, indigmation.

190,29 llidyaw to become angry.

llin, see 1. llynn.

llinad (llin-had) coll. n. linseed, sg. llin-hedyn. 199, 18. 20 .

llithraw to slip, glide along, porss

by. 11. at to flock to. 145, 23.

llithrei $2(13,20)$ leg. llathreiglistened;

cf. RB. 2,2 .

1. lliw (llyw) n. colon, hre. 164,13.

241, 16.2 . lliw, see 1. llyw.

llof-ruo (lit. red-handed) a slaycr of men. 233,10 .

llong f. ship; pl. -eu.

lloneid fill, the full of amything.

llosg aisom. 2:3, 1 . Wosgedie

llosgi to bum, set on fire. 173,5

buck, v. llu m. a liost, army; pl. oe $\delta$.

lewef >lluched lightwing. 227, 25. pl. llucheid. 185,27 .

Lluo n. pr. m. 198, 1s. See Rhŷs,

Celt. Heatl. p. 125.

llused fatigne. $\quad 207,9$.

lluoyas to hinder. 208, 21.

lluest a cam ; pl. -eu.

Llundein London.

llunyaethu to arrange, dispose, array. 146, 5. 165, 19. $182,14$.

llunyeithaw to arrange, put in orden. 178,2 .

lluoss-og-rwyô ammltitude. 141,28. llurug f. a coret of mail. 150, 25.

llu-y $\mathrm{y}^{\mathrm{n}}$. a hosting, military $e x$ pedition. 222,$14 ; 223,32$.

llw m. an oath. $221,4$.

llwch a lalie. $229,5.241,8$. L1.

Tawy 205, 25. Ll. Eurin 205,21

llwdyn m. the young of animals;

pl. llydyn. 203, 4 .

llwfyr in. a coward. 242,9 .

llwgyr harm, damage, disadvantage. 218,25 .

llwm bare, poor. 226,4. 241, 1 . 242,8 .

llwrw (Ir. lorg traek) : yn 11. $\alpha s$ regards? 198, 17. loco, vice, Davies. llwyd grey.
Llwyoawg n. pr. 11. $205,6$.

Llwyoeu n. pr. m. 202, 25.

llwyn (lluhyn) m. a mood, grove, bush ; pl. -eu.

llwyr complete; yn 11. $\%$ holly, eompletely.

llwyth m. a tribe, people. 227, 27.

Llychlyn Nomaiy. 157, 9:

Llychlyn-wr m. a Norseman. 157,11 .

Llychwr n. 1. Soughor. 205, 5.

llydan broud, extensiver.

Llydaw Armorien, Brittrmy.

Llydewig Armoricrm, Breton.

Glythmyr L1. 201, 12 .

llydw " host, houshole, rommunity; 223, 10; 13. See MA. 308 1, 28, 249 a 14,343 a 51 .

llyfyr m. a book.

llyfyr-der m. comerdice. 233, 7 .

llygad m. an eye. taraw 1. in the tuintiling of rin eye, immedirtely.

Llygad-ru $\delta$ n. pr. m. Led-eye. 206,2 .

llygru to corrupt, mar, spoil, violate. $167,4.189,3$. 195, 13; to become foul $241,3$.

llyngcu to sucrilow. 3 ss.par. ind llure 154,12

llynghes f. a fleet. $145,9$.

llymleen, shair. 241, 1 .

llyma lo here! $169,17(\mathrm{cn}) . \$ 244$.

llyna lo there! $169,16\left({ }^{\prime} w\right) . \quad \$ 244$.

1. llynn (llin) f. a lalip, pool; pl. llynneu. L1. Lliwan 206, $17=\mathrm{Linn}$ Liuan, Nennius ed. Mommsen, p. 214.

2. llynn a drink. 193, 15.

llynnwyn m. a prool. 22.j, 1. Leg.

Wall. 480 b 4.

Llyr n. pr. m, 139, 1. 206, 19.

llys f. a court, palace; pl. llyssoe $\delta$. llyssu to reject. 218,7 .

llythyr m. an epistle, letter; pl. -eu.

1. llyw (lliw) n. a leader. 235,11 . 236,23 .

2. llyw, see 1. lliw.

Llywelyn n. pr. m.

llywodraeth f. management.

llywodyr m. a leader, commander ; pl. llywodron.

llywyaw (llywaw) to rule, direct.

ma, see mae.

mab m. a son; pl. meib, meibon.

Mabon n. pr. m. 195, 24 . See Rhŷs, Celt. Heath., p. 21. 
mach m. a surety, guarantor; pl. meicheu, meychyeu. 210,$20 ; 21$; 217,$14 ; 221,25$.

Madawg n. pr. m. 204, 29.

maseu to forgive; forgiveness. 231,4 madeueint forgiveness, remission. $150,20$.

mae (may) is ; pl. maent. what is? 219, 7. $\$ \S 152$. 154 (a). maesu to beat, stivile, pound. 159, 24. 183,23 .

maen m. stone; pl. mein; m. freuan quern-stone. m.-dy m. a stone house. $198,15$.

maer (mair) m. a steward, recve; pl. meirri. $202,7.219,9$.

maerony f. steucurlship. $221,18$. maes (mays) m. an open field, open court, battlefield; rooi cad ar f. to give battle; cawssant y m. they u०om the day.

maestawd majesty; maes m. field of judgment 229, 13. MA. 165 a 22 ; 171 b 51 ; 195 a 9 .

magu to rear, bring "p, to produce, engender, conceinc. pres. ind. sg. 3 meccio 242, 9 . FB. 244,21 . M 363 a $21 ; 33$.

magwyr f. a wall. 198, 12 .

mal (fal) conj. $a s ; w h e n . \$ 216$. malpei (malphei) as if. y m. 195, 11 . mam f. mother.

man fine, small, insignificant. 184,$18 ; 196,10$.

manach m. a monk; pl. meneich. manachlawg f. a moncestery, convent ; 188,22 . m. gwrage $\delta 190,15$. pl. -logoe $\delta 165,4$.

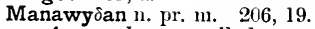

march in. a horse; coll. horsemen. 202,30 . pl. meirch, meirych. 143,15 . 162, 20. ar feirych on horscback 174,18 .

marchawg m. $\ell$ linight; pl. marchogyon.

marchogaeth horsemanship, riding.

1. marw dead; pl. meirw.

2. marw to die. $145,1.149,9$. marwawr (pl.) cinders. 228, 6 . marwolyaeth (marwolaeth) f. death. 145,7 .

mawl, see moli.

mawr great, big ; compar. mwy ; super. mwyhaf, mwyaf.

mawr-fuo great gain or adrantage ; 233, 11 .

Maxen n. pr. m. Maximus. mecci $\delta$, see magu.

me $\delta$ mead.

me $\delta$-gell f. a mead-cellar, cellar. 164, 2. 204, 27

me $\delta$-gorn m. a mead-horn; pl.-girn 235,1

me $\delta$-gwyn a mead-banquet. $235,1$.

$236,13$.

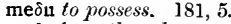

me $\delta \mathrm{wl} \mathrm{m}$. thought, mipose, mind.

medyant m. possession, pover, authority.

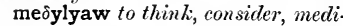
tate.

mefyl f. and m. disgrace, shame, insult. $225,10$.

meglyd (yn) to grip, grasp, cling to. 176,$14 ; 202,20$. FB. 51,$12 ; 141,29$; 183,$24 ; 247,7$.

megys conj. as, like, as it were. $\$ 217: \mathrm{m}$. na as if not; with subj. so that $145,23 . \quad 180,3$.

mehyn place, comtry? 229, 2. FB. 123,$28 ; 133,25 ; 169,1 ; 190,29$; 202,$8 ; 210,10$.

Mei May. 208, 5.

meicheu, see mach.

mein, see maen.

meint f. size, number, quantity,

length; such. pa f. how much.

Meir Mary (the Virgin).

meirw, see marw.

melyn yellow.

melys sweet. $170,18$.

Mellt n. pr. m. 201, 11.

menegi to male known, declare. meneich, see manach.

Menw n. pr. m. 201, 28.

merch f. a daughter ; pl. -ed.

Merchyr: dyw M. on Wednesday. $240,10$.

meredig irrational, foolish. 193, 5 .

RB. 115, 18. Laws I., 260.

merthyr m. a maityr. 161, 4 .

messur m. a measure, impression.

202,26 .

messuredig measured, according to measure. $199,19$.

meu mine; $\$ 55$.

Meugant n. pr. m.

Meuruc n. pr. m. Mauricius. meycheu, see mach.

mi (fi, fy, i) I, me. Emphatic mifi, conjunctive minheu, inneu. $\$ 45$.

1. mil f. a thousand; pl.-yoe $\delta$.

2. mil m. an animal; coll. 204, 5. pl. -eid. 
mil-wr m. a varrior.

milwryaeth f. provess, wavfare.

164,$15 ; 175,25 ; 177,8 ; 185,30$.

mill-dir f. a mile.

minheu, minneu, see mi.

mis m. a month.

moch (coll.) swine.

mo $\delta \mathrm{m}$. manner. $191,30$.

modrwy f. a ring; pl. -eu.

moes eustom. 193, 7. RB. II. 300, 1. molawd praise. 237,4 .

moli to praise, commend. pres. ind. sg. 3 mawl. 233,11 .

molyant praise, fame. 146, 2. 4 (probitas) ; 156, $21 ; 181,19 ; 185,17$.

1. mor (voc.) with adjectives, how, so, $\alpha s$.

2. mor m. sea; pl. -oe $\delta$.

mor $\delta$ wyd m. a thigh. 205, 23 .

Morgannwg Glamorgan.

mor-gerwyn f. a maelstrom, whirlpool. $154,13$.

mor-gymlaw $\delta$ the raging of the ser. 235,13 . MA, $173 \mathrm{a}^{31}$; $193 \mathrm{~b}^{7}$; $254 \mathrm{a}^{44}$; 266 a 29 .

mor-grug (lit, anthill), ants; sg. -yn m. 199,20 .

Moru $\delta$ n. pr. $\mathrm{ml}$.

morwyn f. a maiden; pl.morynyon. mud dumb, mute.

mul m. a mule; pl. -yoe $\delta$.

muner m. a lord, king.

mur m. a wall, vampart; pl. -oes.

X y Mureif Morray. 152, 28.

murmur a growting. $\quad$ 772, 27.

mwg m. smole. 199, 23.

mwy, mwyhaf, see mawr.

mwyalch f. a blackbird. 196, 17.20.

mwyhäu to increase, augment.

mwynhäu(muenhau) to use, employ,

enjoy, profit. 199,$33 ; 216,4 ; 217,26$;

$218,1$.

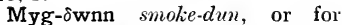

Myng-own dusky-maned, the name

of a horse. 201, 8. Gwynn m. 206, 15.

myhun I myself. $\$ 57$.

myn (in oaths) by. 203, 1. 206, 7 . mynaches m. a nun; pl. mynach esseu.

myned to go; m. dros to break through, penetrate; $\$ 140$.

mynnu (mennu) to desire, wish, seek, endeavour.

mynwent f, a graveyard, 188, 17.

LA. 84,8 .

mynwgyl neck. $176,14$.

mynych frequent. mynyched m. frequeney. y m. hwnnw so often. 191, 1. v. l.

myny $\delta$ m. a mountain; pl. -e $\delta$.

y fyny $\delta$ upwar $d, u p$.

Mynyw Menevia, St. David's, mysg midst.

y mywn (mewn) within, in; o f inside, within. \$181.

1. na (spir.), before vowels nad not $\S 236$.

2. na (voe.), before vowels nag not. $\$ 237$.

3. na (spir.), before vowels nac nor:

\$238. na . . na either . . or 168, 2.

naccäu to refuse.

nachaf lo, behold! 187, 21, (voc.)

$153,16.189,3.193,2$.

1. nad (nat), see 1. na.

2. nad is not (dependent). \$155( $\epsilon$ ).

Nadolig Christmas. 154, 23.

$\mathrm{Naf} \mathrm{m}$. the Lord. 235, 16. 236, 28 .

1. nag $x$ refusal. $202,10.16$.

2. nag, see 2. 3. na.

nam, see 1. 3. na.

namyn, namwyn conj. except;

after a negative, but. $\$ 219$.

nant a valley; pl. nanheu 229, 32 .

l. nar $=$ na + def. art.

2. nar $=$ ra + ry. $184,1 . \$ 95 \mathrm{~N}$.

naw (nas.) nine.

naw $\delta \mathrm{m}$. protection, sanctuary.

nawfed ninth. $208,5$.

neb any; any one, someone. $\mathbf{y}$ neb a who. $\$ 64$.

nef n. heaven; pl. -oe $\delta$.

neges f. a business, affrir, quest. nei m. a nephew; pl. nyeint. neill one (of two); ar neill-du on one side. $\$ 69 ; 71$

neill-du-edig apart, aside.

neirthyad m. a strengthener, stay.

227,2 ; FB. 241,21 ; MA. 193b, 1. neithawr $a$ vedding feast; $\mathrm{pl}$. neithoreu, -yeu 189,9 .

ner m. a lord. 233, 5 .

nerth $\mathrm{m}$. and f. sipport, help,

strength, power; pl. -oe $\delta$.

nerth-fawr mighty. 233,5 .

1. nes prep. nutil. $\$ 182$.

2 . nes, nessaf, see agos.

nessäu to draw near. 147, 16 ,

nessed nearness. yr n. however. near. $154,20$.

Nethawg n. pr. m.

1. neu (voc.) or, nor. $\$ 220$.

2 . neu now, before vowels neud;

with ry, neur. $\$ 221$. 
newidyaw to exchange (blows). 186,$8 ; 191,24$. tra newitywn an delsenoes quando dextias conferemus. 170,19 .

newy $\delta$ ner. o n. aner, arain, recently. 17s, 28. 179, 4. 195̃, 15v.l. newyn m. hunger. 149,$5 ; 186,30$. ni (ny) we, us. Emphatic nini, conjunct. ninheu, ninneu. $\$ \$ 45$ (a). nifer m. a number, host, retinue; 1). -oe $\delta$.

no (spir.), nog, with def. art. nor, conj. than. \$22.2.

nodi to marl, notify, specify. 199, 18. pluperf. pass. sg. 3 ry nody $\delta$ oe $\delta . \quad 205,10$.

no $\mathrm{i}$ to protect, meserve; pres. subj. sg. 3 notho (nodho) 193,8 .

noe, see no.

noeth naked, bare, nmprotected, unamed; jl. -on.

noethi to brre, to unsheathe.

Normanyeid Normans.

nos f. miglit.

nottäu to morle, specify. 201, 24 .

Nuồ и. pr. n. $210,25$.

Nwython n, pr. m.

1. ny (spir.) before vowels nyd, not. $\$ 235$.

2. ny, see ni.

1. nyd, see 1. ny.

2. nyd is not. \$ $155(\delta)$.

nyeint, see nei.

Nyfer the viver Nevern. 204, 12. nym, nys, see 1 . ny.

1. nyth $\mathrm{m}$. a nest; pl. -od. 154, 3 . 2. nyth, see 1. ny.

nyw, see $\$ 49$ (c). $233,2.8 .12$.

1. o (a) (voc.) prep. of, from, with, for; with passive verb, by. o gyfreith according to law 211,17 . \$183. with def. art. or (ar).

2. o (spir.), before vowels od, or, os conj. if ; new. ony, onyd ; with the pres. of copula os, neg. onyd. $\$ 224$. obry belone.

1. oc prep. $=1$. o before pronouns beginning with a vowel. $\$ 183$.

2. oc? 230,16 .

och ah! alas! o. fi ahme! 142,21. odi to snow. 241 passim.

odid seareely, hardly, ravely.

226,6 . 232, $11 ; 13$.

odolygyssant, see adolwyn.

oóieithyr outside 158,$26 ; 164,19$;

o. hynny besides. $161,34,162,21$.

oóyma hence. odyna thence, from that time. odyno from there.

ooy-rwng from betueen. 196, 19. ooy-uchtaw above it. 206,22 oe, see 1. o. oe $\delta$, oeofynt, see bod. oed (oyd) m. age; appointed time, respite, delay. $208,20$.

oer cold; dive, cruel, decally. o.-grynedig fearfully trembling. $152,16$.

1. oes $\mathrm{f}$. life, lifetime, age, generation; pl. oessoe $\delta$.

2. oes (oys) there is, $\$ \S 152,154 \beta$. oestru ? 230, 33 .

ofn-awg timorous. 184,21

ofyn m. fear. 148, 22. 187, 31 .

of ynhäu to fear. 142,4 . 167, 26. offeren mass; pl. -eu. 162, 29.

ohan-, ohon-, see $s s 53,183$.

oia interjection. $\$ 243$.

ol track ; yn ol after, behind. a oes

yn ol or dy $\delta$ what remained of the day.

olyf-wy $\delta(o l i w y \delta) \mathrm{m}$. coll. oliverood. $165,21$.

oll, holl, all. $\$ 67$.

onaônt of them. \$53.

oni, onyt, see ny.

or, see 1.2. 0 .

Orc, Orch the Orlineys. 156, 12. 162,11 .

organ f. a musical instrument, organ. $163,6.15$.

orig (dimin. of awr) a slowt hour. 230,13 .

os, see 2 . o.

osid if there is. $213,22,28 . \$ \$ 152,154$ osp m. a stranger, guest. 193, 7. ottid, see odi.

Owein n. pr. $\mathrm{m}$.

pa, ba (voc.) what? $\$ 80$.

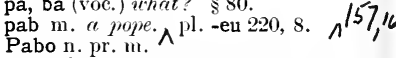

pader f. the Patemoster. 215,4.5. pagan a pagan, heathen; pl. -yeid. paladyr m. a spear-shaft. 194, 23. pallu to fail. 180, 11 .

pan (pann) (1) whence, \$ 225.

(2) (voc.) when, \$226. (3) that ; pan yw 155a $(\beta)$; hyd pan until, so that. yr pan since. 170,5 .

parabyl m. a speech. $170,4$. paradwys f. Paradise. 238, 4. parattöi to meyare. 148,7 . parawd prepared, ready, easy. 144,3 . 158, 24. 30 . parchell m. a young pig. 203, 10. 
pared m. a wall, partition. 196, 20. parhäu to remain, continue. $180,15$. parth $\mathrm{m}$. and f. part, divection; 149, 2. 201, 5. p. ac touchds. 139, 9 . Parth Parthia. 172, 6.

parth-gle $\delta$ left-hand side; sic leg. 229, 29. MA. 274a 25.

pawb everyone, everybody.

pebyll m. a tent; pl. -eu.

pebyllaw to pitch a tent or tents, encamp. $173,24$.

pechawd n. sin ; pl. pechodeu.

pedeir, see pedwar.

pedr-ongyl square. 154,7. RB. II.

12,31 .

pedwar $m$. pedeir f. four.

pedwyry $\delta$ m. pedware $\delta$ f. fourth. peoyd infrontry.

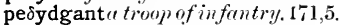

Pedyr Petcr. $228,19$.

pei if he reve. 200,16 , conj. if. $\$ 227$.

peidaw (peidyaw) (ac) to cerse (from). 140, 4. 179, 3. 190, 21; p. 0167,3 v. 1.; p. yn $178,24$. RB. II. 253, 10.

peir m. a rauldron. 202, 7. 14. peiss-awg coated. Hir P. n. pr. in. 206,1 .

pell far, distant; ym p. far off;

o b. from a far. comp. bellach further.

193,16 v. 1 .

pellenhig a stranger. 193,7 .

penn a head, top, point, end; mouth.

225,12 . pl, -eu. am b. against $\widehat{146,26}$.

uch b. over, above; ym p. at the end.

Penn n. pr. m.

pennaf (penhaf) foremost, chief.

Penn-beis chief of boars. 201, 16. penn-cawr chicf giant.

Penn-dragon chief leader.

penn-ffestin a helmet. 151), 25;

159, 17. RB. II. 55, 19; 155, 7; 162,14. penn-saer m. a chief craftsman.

$204,27$.

penn-swy $\delta \mathrm{wr}$ m. a chief steacard.

$160,13$.

penn-trullyad m. a chief butler. 160,12 .

penyd penance. $\quad 150,20 . \quad 238,8$.

Peredur n, pr, m.

perfe $\delta$ middle, centre. 176, 26 .

$183,3.29 .210,10$.

perffeith perfect. 237,12 .

peri to cause, make, create. $190,19$.

$234,10$.

perigyl $m$. and f. $a$ danger; pl.

perigleu. $151,30.153,30$. perthcled, see parth-gle $\delta$. 21 .

2. perthyn appropriate, pertinent. 234,18 . 235, 8. MA.191a, 26 ; 22Sa, 26. peryf m. the Creator. 234, 9. MA. 228 als.

petrus in. a doubt. 150,4 v. 1 . 167,4 .

pettrussaw to doubt. I69,7.

petrusder hesitation, dombt. 147, 28.

$150,4$.

peth " thing, something, somerlhat. peth, beth $=$ pa beth whrit? $\leqslant \leqslant 74.79$. 2(1)3. 11 .

peuny $\delta$ adv. driily, everyelay. beuny $\delta 239,10$.

peuny $\delta$-yawl daily. $190,9$.

phellas: ara phellas 239,17 . " $" h$ irh

I hare set apart," Skene, FB. I., 289 ;

Pucrle s.v. granas has: a ryfullias

"which I hrove prepared."

pieu whose is?" 193, 5. 6. to whom

it brlonss, 16, 7. $\$ \$ s 3,161$.

pigo to peck at. 197,23 .

pimp, see pump. < pise - v. vegs

plant (coll.) children.

pleid f. a side, party; o b. on the side of.

plith : o blith from among; trwy blith through the midst of; ym plith among.

plwyw people. 227,12 . L.A. 106 , $19 ; 22$. RB. II. $270,24$.

pob each, every; bob un, bob deu in ones and twos; pob eilwers alter. nately; \$43. pobmynnig any place. 223,8 .

pobyl f. people; pl. pobloe $\delta$.

poen f. pain; pl. -eu. 142,13 . poened pain, torment. 230,21 .

pony, hefore vowels and with pres. of cop. ponyd, interrog. part. = Lat. nomne? $\$ 240$.

1. porth m. a gate, griterray; pl. pirth. 193, 11. 194, 3. 234, 12 .

2. porth f. help, assistance, support. $175,6.176,18.196,8$. $208,20.25$.

3. porth a port, harbour. P. Ceroin n. 1

porthawr m. $\iota$ dookeeper.

193, 12. 17: 234,12 .

porth-fa f. a port, 172,21

post a post, pillar. Pabo p.

Prydein 162, 3.

pren $\mathrm{m}$, a tree, cross. $230,17$. 
Presseleu n.l. 204, 6.

pressennawl pertcining to this world. 198, 20. LA. 130, 31; 142, 4.

pressent present. gwlad p. this world, 230, 5 ; 232, 10. NIA. 272a, 16; 281,36 .

priawd own. 181, 18.

prif-ger $\delta$ a prenegyric. 235, 5.

prif-glod loud preise, eulogy. 235,6 .

priodas f. marringe. 141, 2.

priodawr $\mathrm{m}$. a proprietor, landowner. $212,24.27 ; 213,8 ; 220,28$. 31 .

priodol-der 11. proprietary right. 212,$28 ; 213,1.20 . \quad$ RB. II. $341,21$. processio (procesiwn) procession. profi to try, test, tempt. 139, 11. 237,17 . p. part. profedig 146,1 ; 164,$15 ; 206,13$.

1. pryd aspect, beanty. 140, 22 ; $155,25$.

2. pryd m. time; pa bryd when? p. pan when 229, 25. p. na since not. $\$ 228$.

prydu to sing, compose poetry. $235,5$.

pryder care, anxiety ; pl, -eu.

pryderus anxions. $190,29$.

Prydein f. Britain.

Pryd-wenn f. (fair-shaped) the name of Arthw's ship. 199,6;202,12. prynu to buy, redeem. 238, 14.

Pumlumon n. 1. Plimlimon. 199,22. pump (nas.) five.

pur pure, perfect. $238,5$.

pur- $\delta \mathrm{u}$ jet black. 225, 21.

pur-ffawd pure, perfect happiness. 237, 13. MA. 315 b14.

pur-wynn $\mathrm{m}$. -wenn f. pure-white. pwll m. a pit, hole. 200, 6.

pwy who? which? 139,11. 194, 14 .

who; p. bynhac whoever. \$ 81 .

pwys a weight, burden. 238, 6.

pwystyr why? 193,14.

py (voc.) what? $\$ 185$; pyr why? \$ 229. py diw (O. $W^{5}$.) to whom. $146,1 . \wedge$ s 80 n. 4.

pyd m. a pitfall, snare. 177,25 .

MA. 231 b4 ; RB. II. $76,10$. pylu to make blunt. 159, 17.

RBII. 106, 31; 56, 33; 71, 19; 161, 1 . pym, see pump.

pymhed fifth.

pymtheg (nos.) fifteen.

-pynhag -soever. \$ 81 .

pyr, see py. pysg m. a fish; pl. -awd. 154, 8.

198, 26. 24l, 11.

pythew-nos a fortnight. 209,6 . $216,13.16$.

racco (racko) yonder. $\$ 63$.

rad f. grace, favour, blessing. $/ 40$,
5. 12 . 145,19 .

raff a rope; pl. -eu. 147, 4.

rag prep. before, for, from. $\$ \$ 52$,

186. yn r. 195. 28. p yr. wherefore?

193,13 v. 1 . r. wyneb following, next. rag- $\delta$ ywedud to foretell. 176,15 . p.

part. rag $\delta$ ywededig a foresaid. 173,3.

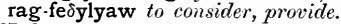
$167,18.20 ; 169,4$

rag-fiaenu to excel, 164, s. RB. II. 293,$29 ; 350,11$. r. $\mathbf{y}$ ffor $\delta$ iter praecedere. 179,7 .

ragod (rachod) to waylay; an am-

bush. 147,$1 ; 177,16 ; 206,12 ; 223,6$. rag-weled to forsce, provide.

167,20 . 169,4 . part. weledig 169.2 v.1. rag-ynys f. an adjacent island. $202,28$.

ranc: $r$, bo $\delta$ content, satisfaction.

$195,12$.

ranghei, see rengi.

rann $\mathrm{f}$. a division, part, portion, share. $\operatorname{ran} 228,7$. pl. -e $\delta .227,6$. rannu to divide. $141,5 . \quad 179,14$. redeg (rydec) to run, race, pass by. redyn ferm. Redyn-fre n. l. (Fernhill) 196, 29.

Reged f., n. 1. 152, $29 . \quad 155,16$. reges $e b b$-tide; adversity. $228,11$. CZ. V, p. 566.

* rengi bo $\delta$ to satisfy, please. pres. ind. sg. 3 reinc 194 , 18 ; past subj. sg. 3 ranghei 195,11 . RB. II. $329,18$. MA. $321 \mathrm{~b}, 31$.

rei (rey) some, few. y rei those, such; pob rei both sides $\$ 66$; rei . . rei (ereill) some . . some $\$ 75$.

reid (wrth) need (of), necessity, trouble,

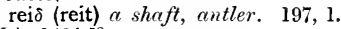

MA. 148 b 58 .

Reiown n. pr. m. 204, 17.

reinc, see rengi.

Rein n. pr, m. Reqin.

reolawdyr regular. 161, 8. RB.

II. 171,16 ; CM. 14, 15 .

restru to vange. 204,11 .

rew frost, ice. 241, 20.

rewi to freeze. pres, ind. act. sg. 3 rewhi $\delta 241,3.19$. `\$ 129. 
rewingaw to cause to perish, destroy, ruin. $3 \mathrm{sg}$. pret. ind. act. rewinywys 229,22 . cp. MA. $140 \mathrm{a}$, 33 ; FB. 146,6 .

rid, see ryd.

riein-gadeir f. a queen's throwe. 189,8 . 22.

rieni pl. ancestors. 168,$13 ; 170,12$.

rif number. 171,16 .

ringhyll (ringyll) m. an apparitor, a beadle. 210,12. $18 ; 214,21$.

rihe $\delta$ ? $228,30$. FB. 11,$10 ; 174,2$. rihy $\delta$ splendon, splendid? '227, 4.

M A. 195a, 12; 229, 21 ; FB. 6, 24; 8, 5 ;

110,$12 ; 112,3 ; 211,15 ; 212,17 ; 305,7$. rin a secret. 225,7 .

rith form, gnise.

rithaw to shape, create, transform.

196,$27 ; 197,7$.

riw a slope. 242,4 .

ro prep. between. $\$ 53$.

rod f. a wheel. gellwng cle $\delta \mathrm{yf}$ ar

y r. to brandish a sword in civele.

202, 21. MA. 286a,35. L.Glyn Cothi 92,10 .

ro $\delta \mathrm{m}$. and f, a gift; pl. -yon.

rofi, see ro.

rosi (roy, rohi) to give, put, place,

grant, surender.

Ron the name of Arthur's lance.

ruo red, middy. $228,15$.

Ru $\delta$-fyw n. pr. n. 205, 31.

Rufein f. Rome. 181, 4.

Rufeinawl Roman.

Run n. pr. m.

ruthur (rythur) f. a rush, onset.

151, 21. 24. $176,12,24 . \quad 178,21$.

182, 6. 8. 184,25

Ruthyn n. 1.

rwng (yrwng) prep. between.

s\$ 53, 187.

rwyó easy, fiee, prosperous, fav. ourable; 172,24 . ar r. in prospeivty; glew-r. 235, 11.

rwyf m. a mler, leader, 236, 23. 25.

rwygaw to rend, break. 198, 27.

r. (y) mor to plough the sea 149, 16. 172,25 .

rwymaw to bind, givd. 150, 29.

188, 5. p. part. rwymedig bound, attached. 162, $25.158,6$.

rwysg suay. $227,4.235,13$.

ry verbal particle. $\$ \$ 95,96,97$.

ry- intensive prefix, very, too.

ry-fawr 241,19 . ry-hir $162,8$.

rych a furrove, 226, 5 . ryd $a$ ford. 241, 3. R. Ychen

Oxford 161, 34.

rydec, see redeg.

ryô fiee. 198, 29. 237, 24.

ryoaw, see ro.

ry $\delta$ häu to free, liberate.

ryoid f. freedom, franchise, privilege.

186.23. $221,19$.

ryoynt, see ro.

ry-fe $\delta a$ wonder ; wonderful.

162,23 . compar. -ach, 154,5 .

ryfe ou to wonder. $149,23,154,4$.

ryfel m. war. 167,25 .

ry-gosswy, ry-gossys? 231, 31 .

Rymhi n. l.

rynawd awhile. 142, 1.

ryodres magnificence, pomp. 156 ,

21. 161,2 .

ryrys? 231,30 .

Rys n. pr. m. 205, 31. 235, 17.

rysswr m. a varrior, champion. 199,$26 ; 29 ; 204,16 ; 206,18$. CM. 1 , $25 ; 2,3$.

rythur, see ruthur.

ryw m. kind, sort; such; 167, 7 .

$174,33.186,2$. neb ryw any. 140,10 .

Sadwrn : duw S, on Saturday. $228,21$.

saer m. a craftsman, wright.

Saesneg f, the English language. Saeson, see Seys.

saeth an arrow; pl. -eu. 176, 23. saethu to shoot with arrovs. 164,24. safant, see sefyll.

safedig (p. part. of sefyll) esta.

blished, fixed, valid. 218, 11.

Salsbri n. 1. Salisbury.

salwen vain, needless. 201, 29.

Samsun n. pr. m. Samson.

sant $\mathrm{m}$. $a$ saint; pl. seint. 202, 32 .

sarff $a$ serpent; pl. seirff.

sarhaed f. an insult, affront; $\mathrm{pl}$, -eu. $166,1.223,21$.

sawdl a heel; pl. sodleu. 159, 24, 183,23 .

sawl a many, multitude; y s. those.

$\S 77$.

sef that is, this is. $\$ 47$.

sefir, see sefyll.

sefyll (trans. and intrans.) to stand, to stop, stand fast, fix. pres. ind. $\mathrm{sg}$ 3 seif, pass. sefir, pl. I safwn, pl. 3 safant (sauahant), pret. scr. 3 safaw $\delta$ segur disengaged, idle. $241,18$. seguryd m. ease. $\quad 167,7.180,13$. seif, see sefyll. 
seilaw to found, establish; remain? perf. sg. 3 ry seilas. 232,3 .

sein $a$ sound. 183,8 .

seint, see sant.

seith seven. s.-lydyn seven young ones. $203,4.15$.

Seith Pedyr Saint Peter. 228, 19.

Cf. Rhŷs, Lect. p. 371.

sene $\delta$ f. a senate. 166, 4. 15.

sene $\delta \mathrm{wr}$ m. a senator. 172, 11. ser, see syr.

serch love.

Seys m. a Saxon, Englishman; pl. Saeson. 146, 12.

Sibli f. the Sibyl. $169,17$.

sodlau, see sawdl.

son f. a soumd, noise. 183, 22.

sorri to be angry, frown. 141, 19,
$142,32 . \lambda$ pres. ind. sg. 3 syrr. 226,2 . sugnaw to suck. imperf. ind. sg, 3 sucknei 154, 19 ,

Sul-gwyn m. Whitsunday. 160,19. 202,24 ,

swy $\delta$ an office. $202,19$.

syberw stately, noble. $143,15$.

syberwyd mide, arrogance. 180, 17. syched $\mathrm{m}$. thirst. $170,15$.

syllu to gaze, look. 154, $1 ; 199,26$. symudaw to change. $143,14$.

syr (coll.) stars. 161, 11. 197, 23. 227,29 .

syrr, see sorri.

syrthaw to fall. 159, 10 . pret. $\mathrm{pl}, 3$ syrthassant 185,$21 ; 187,25$.

tad m. $\alpha$ father ; pl. -eu; hen-dad an ancestor:

tafaw ? 230, 19 sqq.

tafawd a tongre; pl. tafodeu. evidence. 139,$22 ; 220,4$.

tangnefe $\delta$ peace. 201,2 .

tangnefe $\delta$ u to make peace, parify, cppecise.

tangnefe $\delta$ us peaceful. $\quad 144,16$.

1. tal $\mathrm{m}$. forehcad. $159,16$.

2. tal payment, value. tu a thal an equivalent? $221,12$.

talawr, pl. of tal? 228, 13.

Taliessin n. pr. $\mathrm{m}$.

talu to pay, give in return, requite, give, forfeit ; reckon. 209, 12. for a time 146, 2.

l. tan, dan (voc.) prep, under; deni under her. \$188,

2. $\tan$ i1. fire. swllt m. money, treasure. 149,12 .

tafawd-lefery $\delta$ spolien word, verbal

talym m. a uhile, period. ar dalym tanawl fiery. $\quad 173,4$,

tannu to stretch. $\quad$ t. pebylleu tentoria figcre. 173,17 v. I.

taplas f. tables, backgammon. 164,$25 ; 167,4$.

taraw to strikc. t. lygad in the twinkling of an cye. 203, 32 .

tarou to flce, run avay, start, pres, ind. sg. 3 ter $\delta \mathrm{i} \delta$; pres subj. sg. 3 tardho 228,$13 ; 14$. FB. 93,18; 94,$27 ; 104,29 ; 125,6 ; 151,5 ; 163,16$; $198,21$.

tarren $\mathrm{f}$, a plot of uncultivated land. 196, 3.

l. taryan f. a shield; pl. .eu.

2. taryan thunder. 227,$25 ; 229,7$.

FB. $171^{22}$; IIA. 287 b 11 .

taryanawg m. a shield-bearer; $\mathrm{pl}$. -ogion. 234, 15. 236, 7.

taryf, leg. toryf ? 233, 17, 236, 7 . tawl, see toli.

tebig similar, like. 239,11

tebygu to deem, think, sumpose. teccäu to adorn, decorate. tecced beanty. $140,26$.

teg fair, pleasant.

tegwch m. beaty $140,22.155,25$.

Teilaw n. pr. m.

teilwng (y) worthy of, meet, fit for, deserving, acceptable. 150,17 .

teilyng-dawd f. dignity. 155, 22 .

164, 7. 142,2 238,21

teir-gweith three times.

Teir-gwae $\delta$ "Three-shouter" n. pr. m. 201,28

teir-nossig three nights old.

teithyawg moving, in motion. 229,8 . mal ton teithiawe llwyfenyd FB. 192, 26.

Teithyon n. pr. m. 204, 29.

telediw handsome, frir: 140,29 telediwed faimess. 140,27 v. 1. telyn $a$ hrip). 147, 12.

telynawr a harper. $147,15$.

temyl (temhyl) f. a temple; pl.

temleu. $144,11.12 ; 152,27$.

Temys the Thames. 189, 27. terfyn $\mathrm{m}$. an end, limit, boundary, tcrm; pl. -eu, -heu. 166, 16. 20. terfynu to end, finish. 168, 27. 183,24 ; p. part. terfynedig ap. pointed. 171, 28.

terfysg m, trouble, conflict, uproar.

141,$18 ; 167,29 ; 225,12 ; 233,20$.

terfysgu to disturb, 141,12 .

tes heat, hot weather, sunshine. 241,16 .

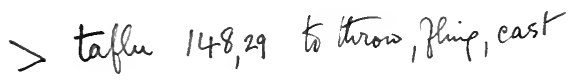


1. teu thine. $\$ 55$.

2 . teu silent? 231,2 .

teu-lu a household, retainers, community; pl. -oe $\delta$.

tew thick, dense. 151,$22 ; 241,21$. tewhäu to thicken, to close up the ranks. 151,$26 ; 176,24 ; 187,24$.

teyrn (teërn, teëirn) $\ell$ king, ruler ; pl. teerne $\delta$; t.-fab n. a king's son; t.-walch m. a royal hawk, hero; t. - wialen f. a sceptie.

teyrnas m. and f. a lingdom; 144,9. 162,31 . pl. -ssoe $\delta$. 156,28

teyrn-ged f. tribute. 166,6 .

ti (di) thon, thee; emphat. tydi, conjunct. titheu. $\$ 45$ (a)

tino a valley, vale. 240,1. FB. 157, 7; 210,8 .

tir m. land; pl. -e $\delta$.

tir-diwollawdr $a$ husbandman; pl. - odron. 149,20 .

tire $\delta$, see tir and twr.

titheu, see ti.

tlws m. a jevel; pl. tlysseu.

to $\delta$ i to melt. 228,26 .

töi to cover: pres. ind. sq. 3 töi tohi $\delta 241,5 ; 242,1$. FB. 157,4 .

toli to curtail, diminish; pres. ind. sir. 3 tawl $233,12$.

ton $\mathrm{f}$ a wave. 229, 6. 241, 5 . tor belly; ar eu t. against them.

181,14 . RB. II. 48,$12 ; 97,30 ; 157,23$. torritobreak, violate. $183,12.223,4$ toryf multitude, host; $1 \mathrm{ll}$. torfoe $\delta$.

$151,26.233,20.234,16.23$.

tost hard, severe.

Totneis n. 1. Totness.

1. tra (spir.) prep. beyond, across, orer. \$ 189.

2 . tra (voc.) conj. while. \$ 230 . tra-chefyn backurards, back, behind, again. \$189 N. See cefyn.

Trach-myr n. pr. m. 204, 8 . traeth m. a shore, coast; pl. -eu. traethu to utter, declare. $168,29$.

170,7 .

trafferth tromble. $207,27.28$.

tragywy $\delta$ eternal. $232,13$.

tragywy oawl eternal. 150, 11. trallawd f.persecution, trial. 237,18.

LA, 19, 27; 21, 27; 28, 25 .

tra-mor over-sea. $156,28$.

trannoeth (lit. over might) next day. traws transierse. ar t. across. $149,3 \mathrm{v} .1$.

traws-brenneu pl, lateral branches of a tree. 149,3. Cf. trauskeyg, Anc. Laws I. 290, 3. trayan (traean) m. a third. 139, 17;

157,$5 ; 201,31$.

trebelid swift, dexterous. 201, 22,

RB. II. 56,27. MA. $279 \mathrm{a}^{35}$

trechaf (superl. of tren) strongest.

187, 19. \$37(b).

tref f. a dwelling-place, home.

tref-tadawg n. an imheritor. 218,18.

tref-tadawl inherited. 146, 8 .

trei $c b b .209,4 ; 216,11$.

treiaw to $e b b .154,14$.

treiglaw to travel; pres. ind. sg. 3

treigyl. $197,18$.

treigyl m. a course, joumey. 197,26.

treis f. violence, rapine, rape.

$200,2 s .222,17$.

tremygu to despise. $140,8.166,9$. treth f. a tribute. $188,9$.

trethawl tributriry. $168,2.186,23$. treulaw to spend, consume, vear. tri (spir.) m. teir f. three.

tri-dieu three days, $149,8.164,29$. 209,1 .

trigane $\delta$ a trumpet blast? 228, 29.

A thriganed kyrn a gwerin tryar

FB. 2117 ; Cf. 68 ; MA. $124 b^{46}$.

trigiaw to duell, remain. 162,22 .

240 , 10. 13 .

trindawd f. the Trinity.

trist sad. 179,2 .

tristäu to bccome sad, grieve. 142,2 . tristaw to become sad, grieve.

141,21.

tristyd m. gricf. 147,6 .

Tro Troy. 163,24 .

troed $\mathrm{n}$. a foot; pl. traed. ar traed on fuot. $174,18$.

troed-noeth bare-foot; jl. -on.

$153,27$.

troed-fe $\delta \mathrm{m}$. a foot (measure). 154,6. tröi to tuin (tr. and intr.).

tros, dros (voc.) prep. across, orer ; myned dros to break through; eneid dros eneid a life for life struggle. s $53 ; 190$.

trossi to tum, move (tr. and intr.) $149,18.151,4 . \quad 199,24$.

tru sad, wretched. $230,20$.

truan miserable, wretched; a wetch. trueni un. wht holness, misery. tru-gar meveiful. 225,19 . trugare $\delta$ f. merry. 227,7 . trugarhäu (wrth) to commiserate. trugeint (trugein) (nas.) sixty. trwch cut, brolien. 241, 9.

trwm m., trom f. heaty, sal.

trws $227,21=$ trwst noise? Cf. yna by $\delta$ mawrdrwst MA. 73a. 
trwssyad (trwssad) ni. one who arranges, or disposes. 234, 7; 235, 28. Cf. trwssyaw, trwssa, Hzc. I., $214,37$. trwy (drwy) (voc.) prep. through.

$\$ 191$. drwy y hun in his sleep 172,27. trwy $\delta$ ed to visit, pass, sojourn. $237,18$. FB. 5912 . MA. $844 a, 21$. try-chan (nas.) three hundred. trychu to cut doun. 149, 1. trydyo m. trede $\delta$ f. third, one of three; ar y d. with two others. 142, 9. § 165 .

try-fer a trident. 197,33. MA.

$317 \mathrm{~b} 13$

trym-der 11. gravity, seriousness. 166,14 .

try-wyr three men. $174,7 . \quad 193,3$. tu m. side, region, part; or tu yn eu hol from behind them; tu ac twecirds; pa du where? 198, 32 . tud people, country. 231, 9.

twng, see tyngu.

twll perforated, piereed. 2015. 23, twr m. a tower; pl. tyreu. 156, 32;

166, 25. 27. tireó 131, 6.

twrch m. " bor $r$.

twrwf m. a liost, multitude. 234, 15.

twyll $\mathrm{m}$. and f. teception, teachery. $178,9$.

twyllwr m. a traitor.

twynpath m. a mound. 199, 14.

1. ty, see ti.

2. ty II. a house; pl. tei.

tybygu, see tebygu.

tybyaw to suspect. $177,27$.

tyfu to grove.

tynghedfen f. fate, fortme; pl. -nneu. $142,10$.

tyngu to suear, take an oath. pres.

ind. act. s. 3. twng 220, 27. 233, 4 . tyllu to pievec, make a breach.

$183,15$.

tyllwe $\delta$ (tellwe $\delta$ ) f, stillness, $211,2$. tynnu to pull, drag, drau, retreat; $147,18.162,25.223,9$. t. pebylleu to pitch tents. $173,17$.

tyreu, see twr.

tyrnged, see teyrn-ged.

tyst " witness; pl. -on, -ion.

tywy o a tenupest, storm. 228, 25.

tywyll darliuess. 229, 33.

tywyssawg m. a leader, mine, ehirf; pl. -ogion.

tywyssogaeth leaderstip, domi. nion.

uch (voc.) prep. above; uch ben above, over: 5193. uched height. $197,24$.

uchel high, tall, loud. 150, 32;

186,$16 ; 234,3$.

ucher evening. $\quad 196,23 . \quad 197,24$.

uchod alv. above. 187,$22 ; 198,8$. u $\delta$ (uut, wut) m. a lord, ling, the

Lorl. 235,$16 ; 236,28$.

uount to them, see l. $\mathbf{y}$.

ufu $\delta$-häu to obey. $\quad 150,23 . \quad 189,22$. ufull-dawd humility, louliness.

237,22 .

uffern hell.

ugeint (ugein) m. trenty. $\operatorname{deg}$ ar hu. thirty.

Ugnach n. pr. $\mathrm{m}$.

Ul-Cessar Julius Cusar.

un one; same. 163, 29. 221, 13

? any. 164, 14. \$ $164(4)$.

un-ben m. a rhieftan.

un-fam having the same mother.

202,18 .

un-ryw of the same lind, similar.

un-tu: ar u. at a stretih. 156, 17.

R13. II. $308,33$.

uróas m. a rank, order, diguity;

¡l. uróasseu, uróassoe $\delta$.

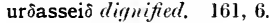

uroaw to ordrin.

uroawl ordained.

Uryen n. pr. m. Urbigenus.

Uthur n. pr. m.

weithon, weithyon, see gweith.

wrth, ree gwrth.

wut, see uó.

wy (hwy) they, them; emphat. wyntwy, conjunct. wynteu.

wybyr sky, heaven. 159, 25. See

1. can.

wyf, see bod.

wyneb face; rac w. following, next. 151,9. 153,6. 155, 27. w. yn w. fure to face. 216,27 .

wyth eight.

whe, see chwech.

whedleu, see chwedyl.

whiory $\delta$, see chwaer.

1. y (voc.) prep. (1) to, (2) from, of. s 19.5.

2. y def. art., see 1. yr.

3. $\mathbf{y}$ verb. particle, see $\mathbf{y} \delta$.

4. $\mathrm{y}$ (voe.) his, (spir.) her, their. \$57.

$x$ y-am (voc.) (1) from off; (2) including. \$164.

y-ar (1) from ; (2) upon. \$ 165.

1. ych II. an $o x ;$ pl. -en.

2. ych your: $\$ \$ 57,58$.

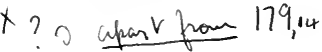


ychydig some, a little, a feu. y-dan (voc.) prep. under. \$188. ydys, ydyw, see bod.

y $\delta$ verb. particle, before consonants

y. $\$ 91$.

yfed to drink. $202,14$.

yfelly, see felly.

y-gan (voc.) prep. from. \$ 167 .

yng a strait, difficulty, distress. $15(1,29$.

ynghyd (ac) together (with).

y7.

1. ym, see yn.

2. ym, see bod.

yma here, hither.

ym-adaw (ac) to part with, leave, desert; past subj. pl. 3 ymedewynt.

ym-adraw $\delta$ m. to speak; speech, discourse; pl. ymadro $y$ yon. 142, 10.

ym-aoassu (ac) to adapt oneself. $\mathbf{y}$. ar sayar to meaure one's length on the ground. $174,26$.

ym-afael (yn) to take hold of, grasp, 202, 17. 206, 21. 207, 17. 19. yman here. hwnt ac g. munc hac nunc illac 185, 25.

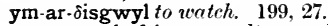

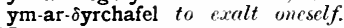
$157,4$.

ym-baratöi to prepare oneself. 171,19 .

ym-ben-tyr(r)-yaw to rush together. 176,$17 ; 186,10 ; \mathrm{Hg}$. II. 163,1 . ym-choelud (-chaelud) to return, turn. 189, 11. 206, 12. 229, 27. 29. y. ar to turn upon, set upon. 174, 29. 207,20 . y. y arfeu yn y Gwy $\delta y l$ to attack the Irishmen. pret. ind. sg. 3 ymhoeles. 160,17 .

ym-da, see ym-deith.

ymdan (voc.) prep. about. \$ 164.

ym-daraw (ac) to contend (with). $201,29$.

ym-deith to go about, to go, go away.

141,14 . pres. ind. $s g .3$ ym-da $199,4$. ym-dynnu (o) to retreat (from.).

$174,17$.

ym-oianc to escape. 154, 18. 197, 30.

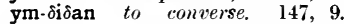
203,18 .

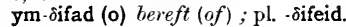

$176,28$.

ym-oifedi destitution. 145, 14.

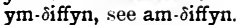

ym-oired to trust. y. y 225, 4 ,

y. $\mathrm{yn} 151,7.158,20$.

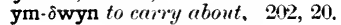

ym-oywedyd to dissuss, argue.

211,16 .

ymeith (o) out (of), away (from).

174,8 .

ym-eneinaw to anoint oneself.

207,9 .

ym-erbynyeid to enconnter, rombat.

186,6 .

ym-ffust m. a conflict, struggle.

187,20 ; RB. II. 84,$24 ; 90,31$;

162,10 .

ym-gaffel (ac) to get hold of, engage in battle. 185, 19, 186, 2.

ym-garu to caress one another. $147,19.148,12$

ym-geffelybu (ac) to imitate. 156,25.

Her. Il. 89, 14; 102, 2; LA, 44, 8;

RB. II. 80,12 .

ym-geis (ac) to seek. 202, 31 .

ym-gelu (rag) to hide (firom).

$146,27$.

ym-golli (ac) to lose sight (of).

$205,1$.

ym-gribyaw (ac) to wrangle (with).

207,25 .

ym-gyf-ar-fod to encounter. 146, 14.

169, 15. $170,14.174,6$.

ym-gyffelybu (ac) to compare one-

self, vie (with). 156, 25.

ym-gynghor (ac) to consult. 148, 1.

ym-gym-mysgu to engage each

other. 183, 20. Hg. I. 55, $26 ; 282,19$.

RB. II. 28,12 .

ym-gynhal to resist. 151, 17. 192, 8, ym-gynull to gather together.

148,25 .

ym-gynullaw to flock together:

145, 1. 152, 20. 173, 20. 192, 7 . ym-gyrchu to attack. 173, 2. ym-gyweiraw (o) to equip oneself (with). 172, 16.

ymhoeles, see ym-choelud.

ym-la $\delta \mathrm{m}$, to fight; a fight; pl. -eu. ym-lid to pursue. 148,24. 188, 2. fut. sg. 1 ymlidyaf 206, 9 . ym-iynu to follow, pursue. 152, 7. 22. 191, 1.

ym-o-glyd (rag) to guard against.

176, 3 ; RB. II. 46,$34 ; \mathrm{H}$. I. $28,5$. ym-oroiwes (ac) to overtake, come up with, touch. 174, 20. 28. 202, 4. 204, 3. 28. 207, 3 .

ym-rithaw to transform oneself. $201,33$.

ym-rodi togive oneself up, surrender, devote oneself. $145,22 . \quad 149,5$. 150,12 . 156,6 . pres. ind. sg. 3 ymry $\delta 150,17$. 


\section{APPENDIX}

\section{Additional Variants to "Lear and his Daughters" from MSS. at Peniarth. $\mathrm{P}^{1}, \mathrm{P}^{2}, \mathrm{P}^{3}, \mathrm{P}^{4}=$ MSS. No. $22,44,45,46$.}

Ch. I.-1. 2, thrugein mlyned: dev vgeýn P2-1. 3, ef a adeilvs $\mathrm{P}^{2}-\mathrm{a}$ thri ugein mlyned y goledichoys (goledychos $\mathrm{P}^{3}$ ) ef yn (ravll ac yd adeiloys (adeilos $\mathrm{P}^{3}$ ) dinas $\mathrm{P}^{3} \mathrm{P}^{4}-$ 1. 4, leýrcester $\mathrm{P}^{2}$.

Ch. 2.-1. 2, yd adahhei $\mathrm{P}^{4}$.

Ch. 3.-1. 4, leueryd om. $\mathrm{P}^{2} \mathrm{P}^{4}-1$. 5, adal y rodi hitheu yr gor $\mathrm{P}^{3}$.

Ch. 4.-1. 3, y rygaru: yr caru $\mathrm{P}^{3}-1$. II, nas rodi hi $\mathrm{P}^{3}-$ 1, I2, damweinhei $\mathrm{P}^{4}$.

Ch. 5.-1. 2, yr Alban: e gogled $\mathrm{P}^{2}-1.8, y$ rodei ... genti : $\dot{y}$ rodey heb ty்r na daýar na ssvllt $\mathrm{P}^{2}-1$. I 5 , kadarnhawyt: grinaethporyt $\mathrm{P}^{3}$.

Ch. 6-1. I2, ellvng er rey ereyll y் emdey்th P?2

Ch. 8.--1. 5, gellygassei y urthar $\mathrm{P}^{3}$.

Ch. 9.-1. I, ydoed P3-1. 3, Or* ty்ghetven lýtýavc ep ef pa brỳd edav dy்d e gallwẏf $\dot{y}$ talu vdvnt wy hỷn $\mathrm{P}^{2}$. O chwichwi yr tyghetueneu P3. Oiar teghetuenneu py le, \&c. P*-1. 4, pa achos y kyffroassoch uiui yar \&c. P3-1. 7, gytdiodef $\mathrm{P}^{3}-1$. I4, traet $\mathrm{P}^{3} \mathrm{P}^{4}-\mathrm{ib}$. Owi $\mathrm{P}^{3}-1$. 16, talu yny girthineb yr griyr hyny $\mathrm{P}^{3} \mathrm{P}^{4}-1$. 21, vy rodyon: vyn da $\mathrm{P}^{3} \mathrm{P}^{4}-1.25$, yn gam $\mathrm{P}^{3}$.

"Strachan says: "I can't read the second letter except as r." 
Ch. I0.-1. I, aghyfnerth : trueni $\mathrm{P}^{3}-1.2$, ef a doeth, \&c. : dy்nessav parth ar dýnas edoed $\dot{y} \operatorname{ver}(s i c)$ endav $\mathrm{P}^{2}-\mathrm{ib}$., ym Paris: $\dot{y} g$ cariz $\mathrm{P}^{3} \mathrm{P}^{4}-1.4$, ar gyuaroed $\mathrm{P}^{3}-1$. 5, namy்n vn marchavc ac essweýn $\mathrm{P}^{2}$; namyn ef ae yswein $\mathrm{P}^{3} \mathrm{P}^{4}$ 1. 7 , mynet ae that, \&c. : dwýn $\dot{y}$ that hyt en dýnas arall ac eno dywedwyt $\dot{y}$ vot en glaf $\mathrm{P}^{2}-1$. 16, wedy yr dehol $\mathrm{P}^{3}$.

Ch. II.-l. I I, a (nnaeth: re gwnathoed $\mathrm{P}^{2}-\mathrm{a}$ wnathoed $\mathrm{P}^{3} \mathrm{P}^{4}-1$. I2, anryded Bifrontisiani : anry்ded $\dot{y} \mathrm{r}$ devforvavl ianus $\mathrm{P}^{2}-\mathrm{l}$. I3, delhei $\mathrm{P}^{4}$-ib. ac ena ed emky்nvlley் holl seýry் a chreffdwỳr e dỷnas $\mathrm{P}^{2}$-gredyfwyr (sic) $\mathrm{P}^{3}$ crefuyd(iyr $\mathrm{P}^{4}$. 


\section{Index}





\section{INDEX}

The references are to paragraphs. $n .=$ note.

$\bar{a}$, eausing vowel-change 7 (a).

$a$, rel. part. $82-83$; with infixed pron. 49 (b), 50 (a) ; usage 83 (a); expressing subj. or obj. 86 ; gov. by prep. 87 (a); without antecedent 87 (b).

$a$, infixing part. $50(\mathrm{c}) ; 94 ; 159 \mathrm{n} .2$; superseded by $y d 85 \mathrm{n}$.

$a$, interrog. part. 239 ; lenat. after $18(\mathrm{~g})$.

$a$, ar, conj. 198; mutat. after, 21 (d).

$a$, ar, prep. 162; after adj. $34(\mathrm{~b})$; mutat. after, 21 (c).

$a$, prep. $=o 183$.

$a, h a$, interj. 243.

absolute ending -sit $132 \mathrm{n}$.

accent, $4 ; 11 \mathrm{n} .1$; shifting of 8 ; vowel variation due to 8 ; secondary acc. $11 \mathrm{n} .1$.

accusative 26 ; traces of 25 ; in poetry 26 ; of relative 51 .

arh, prep. 163

arliaws, conj. 199.

adjective, 30-39; lenat. of 16 ; lenat. after positive $16(\mathrm{c})(\alpha)$; after compar. $16 \mathrm{n.} 4$; endings of 27 (c); gender in 30 ; stems in $-i-,-o-,-u-, 30$ note; plur. forms 31 ; attributive 32 ; predicative 32 ; number in 33 ; inflected adj. 34 (a); order in sentence 34 (a); foll. by prep. $o, a 34$ (b) ; concord 35 ; predicative adj. with yn 35 ; adj. phrases 36 ; comparison 37 ; construction of compar. and superl. 38 ; equative 39 ; with mor $39 \mathrm{n}$. 2 ; adv. use 40 ; poss. adj. 57 : poss. adj. with prep. 58 (a), with conj. 58 (a), with $y$ 58 (b), anticipating genit. $59 \mathrm{n}$.

abnabot, paradigm of 144 .

adverb 40 ; lenat. $16(\mathrm{~h})$; adv. phrases 16 (h); with demons. force 63 . -aduy, verbal in 117 .

$a e$, interrog. of copula $155(\mathrm{a})(\eta)$

ae, interrog. part. 239 (c).

agent. expression of with verb noun, 122 am, prep. 164 ; lenat. after 16 (i) ; with pron. end. 53 ; yam 164.

am. (na), conj. 200 .

amal, conj. 216.

analogy, in verb. conjugation $7 \mathrm{n} .1$; in mutat. 12 ; 16 n. $7 ; 39$ n. 1 ; in plural formations 27 (d) ; in pronouns $45 \mathrm{n} .2$; in formation of subjunctive $110 \mathrm{n} .1$.

answers, 241.

apodosis, imperfect in $107(\mathrm{~d})(\beta)(\gamma)$.

apposition, lenation in $16 \mathrm{n} .4 ; 17$ (b).

ar, prep. 166; lenat. after 16(i); with pron. end. 53 ; or $a$, ar $n y, 87$ (a) ; yar, 165.

arall, use of 68 .

arganeot, paradigm of 160 .

article, 23 ; Jenat. after 16 ; fused with conj. or prep. 23 ; syntax of 24 .

as, as (ys) oed 159n. 2.

$-a t$, ending of imperf. ind. $3 \mathrm{sg} .131$ (b). att, prep. 166 ; lenat. aft. 16 (i); with pron. end. 53.

attributive adj. $32 ; 33$.

awr, yr awr conj. 201.

-awr, -iawr, plur. suff. 28 B. (a).

-awt, plur. suff. 28 B. (b).

behet, prep. $177 \mathrm{n}$.

bot, lenation after, $16(\mathrm{~g})(\beta)$; paradigm of 152 ; usages of 153 ; bydun, etc. 107 n. 3 ; special fut. form 152 n. 2 ; $b i t$, consuetudinal 152 n. 3 ; bydaf, use of 156 (a); bydwn, use of 157 ; bewn, 158 ; past subj. 158; compounds of 160 ; boet, after kyt $205 \mathrm{n}$. 
caffael, cael, paradigm of 145 .

can, yan, prep., lenat. after 16 (i) ; with pron. end. 53 ; with vb. noun 126 (c); use of $167 ; y$ gan 167 .

can, conj. 202 ; not foll. by yd 93 (1). caniot, paradigm of 160 .

canys, copula 155 (a)(a); $202 \mathrm{n}$.

canys, conj. $202 \mathrm{n}$.

cardinals, see numerals.

caru, paradigm of 127 .

case, 25 ; traces of lost case-endings 25 ; syntax of cases 26 ; expression of case in relative 86 .

cer, ger, prep. 168.

clauses, subjunct. in main clauses 113 ; in subord. cl. 114; concessive cl. 114 (c); conditional cl. $114(\mathrm{~d})$; cl. of comparison 114 (e); temporal cl. 114 (f) ; final cl. $114(\mathrm{~g})$; relat. cl. $114(\mathrm{~h})$. clybot, use of imperf. of $107 \mathrm{n} .2$. collective nouns, 29.

com-, Celt. prep. 39 n. 1.

command, subjunct. in $113(\mathrm{~b})$; in indirect speech $113(\mathrm{~b})(\beta)$.

comparison of adj. 37 ; lenat. after 16 n. 5 ; no plural 33 ; construction of compar. 38 ; foll. by no (c) 38 (a); clauses of comparison 114 (e).

composition, lenation in 16 n. 6 .

concessive clauses, 114 (c).

concord, of vb. and subject 101; 103 ; of adj. with noun 32,33 ; of adj. after yn 35 .

conditional of bot $107 \mathrm{n.} 3$; impf. in conditional sentence 107 (d) ; plupf. in condit. 109 (b); subj. in condit. cl. 114 (d) ; impf. condit. 131.

conjugation of verb $98 \mathrm{sq}$. ; analogy in 7 note 1 .

conjunctions, 198-234; lenation after 16 (1) ; lenation of init. cons. $16 \mathrm{n} .13$; spirant mutat. after $21(\mathrm{~d})$; with poss. adj. 58 (a). consonants, classification of 3 ; graphic representation of $3 \mathrm{n}$.; orthog. variation $3 \mathrm{n}$.; consonantal changes 11 ; infl. of accent on cons. changes $11 \mathrm{n} .1$; mediae > tennes $11(\mathrm{~g})(\alpha)$; mutation of cons. 12 ; consonants vowel-flanked 12 ; table of cons. mutations 13.

consonantal stems, 27 (d).

consuetudinal present, $106(\mathrm{~b})$.

copula, 155 ; yttiw etc. 154 n. 4 ; nat 155 (a) $(\epsilon)$; nyt $155(\mathrm{a})(\delta)$; position of 159 ; preceding pred. $159 \mathrm{n} .2$; with neu 221 ; os, onyt ....

customary action in past time, 107 (c). $c w t, c w$, conj. 203 ; mutat. aft. 21 n. 1. cyiariot, paradigm of 160 .

cyırwivg, prep. 169.

cyn-, in equative 39 ;

cyn, conj. 204; not foll. by yd 93 . cyn, prep. 170.

cyt, cyn, conj. 205 ; not foll. by yd 93 (I).

cyt ac, prep. 171; y gyt ar, conj. 206.

chwech, nas. mutation after 20 (c).

dariot, paradigm of 160 .

dative, traces of 25 ; expressed by in-

fixed pion. 51.

declension, in Old Celtic 25.

deng, usage of $41 \mathrm{n}$.

delw, nom. conj. 207.

denominative vb. 128 (b).

deponent, 99.

di, O.W. prep. 195; and n.

diam, O.W. prep. 164.

diar, O.W. prep. 165.

dieithyr, prep. 172.

dim, used as pron. 73 .

diphthongs, 1 and $n$.

distributives, 43.

diuch, prep. 193.

$d o$, in answers, 242. 
dual, $25 ; 42$ (a); lenation of adj. after dual noun, $16(b)(\alpha)$; lenat. of genit. after dual $16(\mathrm{~b})(\beta)$; traces of dual inflection 25.

duch, $110 \mathrm{n} .2 ; 138 \mathrm{n}$.

$d y$ - before infixed pron. $50 \mathrm{f}$.

dyrot, paradigm of 141 .

dylyu, with vb. noun $12 \mathrm{I}$.

-e- infixed pron. 48 ; use of 49 (b).

-edic part. end. 116.

$-e d$, pl. suffix $28 \mathrm{~B}$ (d).

einom etc. 55 .

- eint, 3, plur, end. impf. ind. 131.

eissoes, conj. 208.

-eit, -ieit, plur. suff. $28 \mathrm{~B}(\mathrm{e})$.

eithyr, prep. 172.

eithyr na, conj. 209.

ell, ill, yll, 67.

emphatic pronoun 45.

endings of verb, $3 \mathrm{sg}$. of simple vb. 129 ;

3 sg. conjunct. $129 ; 3$ pl. primary ending 129 ; see imperat. indicat. subjunct. vb. noun.

epenthetic vowel 10 .

equative in comparison of adj. 39.

erbyn, prep. 173.

$e t$, in noret etc. 222 and $\mathrm{n}$.

-et, pl, suffix. $28 \mathrm{~B}$ (c).

final clauses, $114(\mathrm{~g})$.

future 105; exp. by pres. tense 106 (e); special future endings 130 .

futurity, subj. of 113 (c).

gallu, to express passive with vb. noun 121.

gender, in nouns 25 ; in adjs. 30 ; 32 ; genitive, lenation of noun in gen. 16

(b) $(\beta)$; traces of gen. case 25 ; syntax of gen. in prose 26 ; in poetry 26 ; gen. of rel. pron. 88 .

ger, see cer. gily $\delta, 72$ and $\mathbf{n}$.

gorvat, paradigm of 160 .

guar, prep. $165 \mathrm{n} .3$.

gwares, $110 \mathrm{n} .2 ; 138 \mathrm{n}$.

gwedly, wedy, prep. 174 ; with preverb.

yd $93 \mathrm{n} .3$; with vb. noun=perf. part.

126 (b).

gwedy, conj. 210.

gwelet, use of imperf. of 107 n. 2.

gweith, with card. numbers 44.

gwneuthur, with vb. noun 123 ; paradigm of 142.

gwrth, O.W. prep. 194, see wrth.

gwybot, paradigm of 143 .

$g y t$, see cyt ac.

$h$, sign of subjunctive 110 ; history of $h$ in subj. 110 n. 2.

$h$, in sentence constr. 22 ; after infix. pron. and possess, $m 22$ (a); after infix. pron. $e 22$ (b); after 3 sg. f. poss. $y 22(\mathrm{c})$; after $1 \mathrm{pl}$. poss. an 22 (d); after $e u 22$ (e); after ar bef. ugeint 22 (f).

ha, interj. 243.

hagen, conj. 211.

hanrot, paradigm of 160 .

-hau, denom. vb. end.1 28 (b) ; spreading as $-a$ to other vbs. 137 .

-haw, 3 sg. fut. end. 130 (b).

-hawr, ending of fut. pass. 130 .

-hawd, -hawt, fut. end. 3 sg. 130.

-hawnt, fut. end. 3 pl. 130.

$h e b$, prep. lenat. aft. 16 (i); with pron. end. 53 ; usage 175 .

heb, verb 151.

her'yt, conj. 213.

herwyd, prep., usage of 176 .

herwyd, conj., usage of 213 .

historic infinitive, 125.

historic present, 106 (d).

hallre, 67 note.

hun, hunan, 60. 
hwde, 149.

hwnn, etc. dem. pron. 61; usage of 62 ; yr hwnn, foll. by rel. clause, 62 (c).

liwnt, 63 .

hwnnw, hynny, 61 ; usage 62 .

hyt, prep., lenat. after $16(\mathrm{i})$; usage 177 ; liyt pan 2262 (a).

liyt, nominal conj. 214 .

$i$, causing vowel infect. $6 ; 7$ n. $2 ; 11$ (b) ; 131 ; in pl. 27 (a) ; in pron. prep. 52 (b) ; infection due to lost $i 7 \mathrm{~b}$.

$-i$ pl. suffix 28 B (f)

$-i$ - stem in adj. $30 \mathrm{n}$.

$-i$ ending of $3 \mathrm{sg}$. impf. 131 (a).

$i e, i e u$, in answers 242 and $\mathrm{n}$.

igridu, $53 \mathrm{n}$.

ill, ell, yll, 67 .

imperat. mood, 115 ; pass. of 115 ; negat. of 115; endings of 137 ; infl. of denom. rbs. in liau sprcads to other verbs 137 .

imperf. tense, indic. 105; use of 107 ; in indirect speech 107 (b); of repeated action 107 (c); as sec. fut. or condit. 107 (d); as sec. tense to a fut. 107 (d) $(\alpha)$; in apod. of fut. or condit. clause $107(\mathrm{~d})(\beta)$; in apod. of past clause $107(d)(\gamma)$; with negat. $107 \mathrm{n}$. 1 ; use of impf. of clybot 107 n. 2; use of impf. of gwelet $107 \mathrm{n} .2$; endings of impf. 131.

indicative mood, with $r y 96 \mathrm{~A}$; pres. ind. with $r y 97$ (c) 1 ; use of 105-109; pres. 106 ; plupf. 109 (a) ; influence of ind. upon subjunct. form $110 \mathrm{n} .1$; indic. stem in O.W. $110 \mathrm{n} .1$; plup. ind. replacing past subj. 111 and $n$. ; ind. in consec. el. $114 \mathrm{n} .4$; end. of pres. and fut. 128; end. of plupf. 135 ; past ind. of lot used as subj. $152 \mathrm{n}$. 7 ; ind. with conj. lyyt 214 ; ind. of consequence with liyt na 2142 (a); ind, with mal 216 ; ind. of consequence with mal na 2163 (a).

indirect speech, impf. in 107 (b); pret. in $108(\mathrm{~b})$; command in $113(\mathrm{~b})(\beta)$.

infecting vowel, see $a, i$.

infection of vowel, $6 ; 7$ (b); 7 n. $2 ; 11$ (b) ; 27 (a); 52 (b).

infinitive, in Welsh 104; usage, 120; historic inf. 125 ; see verbal noun.

infixed pron. lenat. after 18 (a); forms of 48 ; use of $49-51$; after yny 49 (b) ; after rel. $a 50(\mathrm{a})$; with preverbal $y d$ 50 (b) ; $93 \mathrm{n} .2$; after infixing part. $a$ 50 (c) ; after $r y$ - 50 (d) ; 93 n. 3 ; after n'u 50 (e); after $d y$ - of cpd. vbs. 50 (f); after $n a, n y, 50$ (g); after tra, 50 (h) ; expr. accus. of relat. 51 ; infix. pron. with pass. vb. 102 ; with nonrel. vb. $102 \mathrm{n}$.; meaningless 159 n. 2 ; with o $224 \mathrm{n} .5$.

inflected adj., position of $34 \mathrm{a}$.

inflection, noun 25 .

interjection, lenat. after $16(\mathrm{~m})$. forms of $243-4$.

interrogative, lenat. after interrog. pron. $18(\mathrm{c})$; interrog. part. a $18(\mathrm{~g})$; interrog. pron., forms of 79 ; pwy 79 ; peth, beth 79; pa, py 80; and n. 1; $p n, p y$, in earlier lit. $80 \mathrm{n} .2$; path awr, pythaur 80 n. 2; pa, py foll. by prep. $80 \mathrm{n} .3$; padiw, pydiw $80 \mathrm{n} .4$; puey bynnar, pa-, py- bynnar 81; indirect interrogation $114 \mathrm{~B}(\mathrm{~b})$.

$i$, prep. with pron. end. 53 ; usage 178.

issem, ysef 47 .

-it, imperat. end. $3 \mathrm{sg} .137$.

ithr, prep. 179 .

lenation, $=$ vocalic mutation 12 ; table of 13 ; lenat. of $g, 13 \mathrm{n} .1$; of $d 13 \mathrm{n} .2$; exceptions to rules 15 ; usage 14-18; 
noun and adj. after $y r, 16$ (a) ; noun or adj. after noun, 16 (b); after dual $16(b)(\alpha)$; of noun in genit. $16(b)(\beta)$; after prop. nouns $16(\mathrm{~b})(\gamma)$; of vb.noun in genit. $16(b)(\delta)$; of noun aft. compar. adj. $16(c)(\alpha)$; of adj. repeated $16(\mathrm{c})(\beta)$; after adv. yn 16 (d); aft. numerals $16(\mathrm{e})$; aft. pron. $16(\mathrm{f})$; after vb. $16(\mathrm{~g})$; after parts of bot $16(\mathrm{~g})(\beta)$; of adverbs $16(\mathrm{~h})$; aft. preps. $16(\mathrm{i})$; after negat. $16(\mathrm{k})$; after mor, neu 16 (l); aft. interj. 16 $(\mathrm{m})$; of vocative $16(\mathrm{~m})(a)$; aft. superl. adj. 16 n. 5 ; in composit. $16 \mathrm{n}$. 6 ; of noun after adj. 16 n. 5 ; of noun prec. by depend. genit. $16 \mathrm{n} .7$; in poetry $16 \mathrm{n} .7$; post-verbal $16 \mathrm{n} .12$; of prep. $16 \mathrm{n} .13$; of pron. 17 ; after infixed pron. $18 \mathrm{a}$; after rel. part. $a$ 18 (b); after interrog. 18 (c); of predicate after copula $18(\mathrm{~d})$; after $y t, y d$ 18 (e) ; 91 n. 2 ; after $r y$-, 18 (f) ; after interrog. $a 18(\mathrm{~g})$; after conj. $18(\mathrm{~h})$; after negat. 18 (i) and n.; in dual, 25 ; analogical lenat. $39 \mathrm{n} .1$; after $n y$, relat $21 \mathrm{n} .2$.

llall, pl. lleill, 70.

llas. 134 (a).

lle, nominal conj. 215.

y lleill, 71.

llyma, llyna, 244.

-m-, infixed pron. 48.

$m$, final, $>n$ in Celtic $20 \mathrm{n}$.

mad, not foll. by yd 93 (i).

mae, use of 154 (a); copula $155(\mathrm{a})(\lambda)$

mal, ral, conj. 216.

med, 'says,' form and use 150 .

megys, conj. 217.

meu, etc. poss. pron. 55 .

$m i$, etc. simple pron. 45 .

minheu, etc. conj. pron. 45.

mivi, etc. emph. pron. 45. $m o r h$, not foll. by $y d 93(\mathrm{k})$.

moes, imperat. 148.

moods, 104 ; indic. 105-110 ; subj. 110114 ; imperat. 115 ; see indicative, subjunct., imperat., infinitive.

mor, lenat. aiter 16 (l), mor - a expr. equality with adjs. 39 n. 2.

multiplicatives, 44 .

mutation of cons., table of 13 ; vocalic mut. see lenation; nasal mut. in Mid. W. MSS. 19; after vyn 20 (a); after yn 20 (b) ; origin of, after numerals 20 (c) ; spirant mut. 21 ; after numerals 21 (a); after 3 sg. f. poss. adj. 21 (b); after prep. 21 (c); after $a(c)$ $n o(c) 21(\mathrm{~d})$; after $n y, n a 21$ (e) after kwt $21 \mathrm{n} .1$.

myn, conj. 218.

mynet, paradigm of 140 . mynn, nominal prep. 180.

mywn, nominal prep. 181.

'n, poss. adj. 57 .

$n$, neut. stems in 27 (d).

- $n$ - infix. pron. 48.

$n a(c)$, mutat. after 21 (e); with infixed pron. $50(\mathrm{~g})$; with imperat. 115 ; with infixed pron., use of 237 ; disjunctive particle 238; in answers 241 ; nac ef, in answers $241 \mathrm{n}$.

na, nat, negat. part., use of 236 ; in condit. sent. $236 \mathrm{n} .1$; with infixed pron. 237.

narhaf, interj. 244.

nado, 242 and $\mathrm{n}$.

nage, 241.

namyn, namwyn, 219.

narrative tense, 108.

nasal mutation, see mutation.

nat, dependent neg. of copula 155 (a)

(є).

$n e b$, use of 64 . 
negative particles, 235-238; special vb. form with negat. 130 (b).

$y$ neill, use of $69 ; y$ neill - y lleill, 71 . nem, prep. with pron. end. 53.

nes, prep., use of 182.

$n e u$, lenat. after 16 (l); with infixed pron.

50 (e); with vb. part. ry $95 \mathrm{n}$.; conj. 220.

neur, 95 n. ; 221.

neut, not foll. by $y d l, 93(\mathrm{~h})$; as copula 155 (a)(८); conj. 221.

neuter, lost in Welsh 25; neuter - $n$ stems 27 (d); of demons. pron. 61 .

ni etc. pers. pron. 45.

nini etc. pers. pron. 45.

ninneu etc. pers. pron. 45.

no, noc, mutat. after 21 (d); after compar. adj. 38 (a); use as conj. 222.

nocet, nogyt 222.

nominative, old nominat. 25 ; syntax of nom. 26.

nouns, lenat. of init. cons. 16 ; lenat.

after proper nouns $16(\mathrm{~b})(\gamma)$; art. with prop. nouns 24; cases of 25 ; formation of pl. 27-28; collective nouns 29 (c); noun predic. with $y n$ 35 ; plurals with cardinal nos. 42 (a); see also verbal nouns.

$n u$, conj. 223.

number, in nouns, 25 ; in adjs. 33 ; in vb. 100 ; express. of number in passive vb. 100 ; number of vb. in rel. clause 103.

numerals, lenat. after $16(\mathrm{e})$; nasal mutat. after 20(c); spirant mutat. after 21 (a); cardinals 41 ; ordinals 41 ; syntax of 42 ; distributives with $p o b$ 43 ; multipl. with gweith 44 .

$n w y, 49$ (c).

$n y$, mutation after 21 (e); mutat. aft. non-relative $n y 21 \mathrm{n} .2$; mutat. aft. relat. $n y 21 \mathrm{n}, 2$; infixed pron. after non-rel. ny $49 \mathrm{c}$; special relat. form of $n y 49 \mathrm{c}$; with infix. pron. 50 (g); in negat. of relat. 82 ; 86 ; gov. by prep. 87 (a); rel. $n y$ without antec. 87 (b) ; usage 235.

$n y r=n y \quad$ ry $95 \mathrm{n}$.

$n y s$, in later Mid. W. $50 \mathrm{n}$.

$n y t$, negat. of copula 155 (a)( $\delta) ;(a)(\kappa)$. $n y w, 49 \mathrm{c}$.

$o$, prep., lenat. aft. $16(\mathrm{i})$; aft. adjs. 34 (b); aft. superl. adjs. 38 (b); with pron. end. 53 ; aft. vb. noun, 122 ; $=$ of 183 ; with art. 183 .

$o$, conj., mutat. aft. 21 (d) ; with infixed pron. $50(\mathrm{~h})$; not foll. by $y d, 93(\mathrm{l})$; use of 224 .

$-o-$, old pl. stems in, 27 n. 1 ; adj. stems in $30 \mathrm{n}$.

-o subjunct. end. 138.

object, position of 85 .

oblique cases, traces of, 25 .

oc, prep. 183.

orh, interj. 243.

odieithyr, prep. 172.

oduch, prep. 193.

oed, impf. of bot, use of 107 n. $3 ; 154$ (b). -oed, pl. suffix $28 \mathrm{~B}(\mathrm{~h})$.

oet, in eirmoet, eiryoet $197 \mathrm{n}$.

oes, use of $154(\mathrm{a})(\beta)$.

oia, interj. 243.

oian $a$, interj. 243.

oll, use of 67 ; with numerals 67 .

-on pl. term. in adj. 31 (b).

ony, onyt, conj. 224 ; 224 n. 2.

or, conj 224 ; 224 n. 4.

or a 87 (a) ; or $n y 87$ (a) ; or $y, 87$ (a); or pan $226 ; 2$ (b).

order of words, dependent genit. 26 ; adj. 34 (a); noun 34 (a); adverb 40; numerals 41 ; copula 159.

ordinals, see number.

orthography of Early W. $12 \mathrm{n}$.

$o s$, conj. 224 and n. 5 . 
$o s$, (bot) 152 ; copula 155 (a) $(\xi)$

osit, ossit, 152 ; use of $154(\mathrm{a})(\beta) ; 154$ n. 1 .

ot, conj 224.

-ot, pl. suffix $28 \mathrm{~B}(\mathrm{~g})$.

pa, py, with peth 79 ; used adject. 80 ; meaning of, $80 \mathrm{n} .1$; without noun following $80 \mathrm{n} .2$; followed by prep. 80 n. 3 ; pa - - bynnar, 81.

padiw, pydiw, 80 n. 4.

paham, 80 n. 3.

pahar, 80 n. 3 .

pan, with infix. pron. 49 (b); foll. by yd 93 (l); with yw 154 (a) ( $\beta)$; pan= whence, 225 ; = when 226; hyt pan 226. 2 (a); or pan 226. 2 (b); yr pan 226. 2 (c).

particles, preverbal 91-97; negat. 235 sqq. ; disjunct. 238 ; interrog. 239 ; responsive 241.

participle, passive 104; part. in -edic 116 ; pres. part. equiv. 126 (a); perf. part. equiv, 126 (b).

parth (ac), prep. 184.

passive, numb. exp. in pass. voice 100 ; pers. in pass. 102 ; 103 ; pass. part. 104 ; imperat. pass. 115 ; part. pass. in -edic, 116 ; old pass. end. 129 ; 130 ; pret. and perf. 134 ; periphr. pass. of plupf. 136 (b).

$p a w b$, use of 66 .

pei, conj. not foll. by yd 93 (l); uses of 227 ; origin of $227 \mathrm{n}$.

periphrasis, verbal noun with gwneuthur 123; periphrastic plupf. with -oed, active 136 (a); passive 136 (b).

perfect. indic. with ry. $96 \mathrm{~A} \mathrm{(a);} \mathrm{per-}$

fect part. equiv. 126 (b) ; use of 105 ; v. preterite.

person in verb, 102-103; in passive

102 ; in 1 and 2 pers. of pass. 102. personal pron. see pronoun. pettion, 158.

peth, as pron. 74 ; interrog. 79.

peun-, old accus. 25.

pieu, in rel. clause $83(\mathrm{a})(\beta)$; paradigm 161 ; use of 161.

pluperfect, with ry $96 \mathrm{~A}(\mathrm{~b})$; use of 105,109 ; plupf. indic. replacing subj. $109 \mathrm{c}$; types of plupf. ind. 135 ; periphr. plupf. act. and pass. $136(\mathrm{a})(\mathrm{b})$. plural, old Celtic, 27 ; pl. of nouns 27 ; vowel change in pl. 27 (a); pl. endings $-e u,-i e u, 27$ (b); -on, -ion, 27 (c) ; old consonantal pls. 27 (d); pl. suffixes 28 ; pl. in adjs. $31 ; 33$; pl. of nouns with card. numerals 42 (a); $3 \mathrm{pl}$. end. of impf. 131 .

$p o b$, in distributives 43 ; used as adj. 66 ; pob un 66 ; pob rei 66 .

pany, interrog. 240.

ponyt, copula $155(\mathrm{a})(\theta)$.

possessive, pronouns 55,56 ; adjs. table of 57 ; prec. by prep. or conj. 58 (a). predicate, lenation of, after copula 18

(d); pred. before copula 159; after copula 159.

predicative adj. 32 ; plural of 33 ; after yn 35 ; pred. noun with yn 35 .

preposition, lenat. after 16 (i); lenat. of $16 \mathrm{n} .13$; nasal mut. after 20 (b); spirant mut. after 21 (c); with poss. adj. 58 (a) ; suffixed to $p a, p y 80 \mathrm{n}$. 3 ; forms and usage 162-197.

present indic. 105 ; actual pres. 106 (a) ; as fut. $106(\mathrm{e})$; pres. subj. endings 110.

preterite with $r y-97$ (a); use of 105 ; 108 ; in indir. speech 108 (b); = perfect 108 (c); endings of 132 ; absolute end. in $132 \mathrm{n}$; $s$ - pret. 133 ; $t$ - pret. 133 (a); reduplic. in $133(\mathrm{~b})$; pret. pass. 134 .

pronoun, lenation of 17 ; lenat. after interrog. 18 (c); tables of $45-90$; $\mathrm{mi}$, 
etc. 45 ; mivi etc. 45 ; minheu etc. 45 ; weakening of, after vb. 45 ; construct. of indep. prons. 46 ; infixed pron. 48-51; after pan 49 (b); with ry 49 (c); with ny 49 (c); anticipat. obj. $49 \mathrm{n}$.; express dat. 51 ; with prepos. $52-53$; simple pron. with pron.prep. 54 ; conjunct. pron. with pron.prep. 54 ; $m e u$, etc. 55 ; poss. pron. syntax of 56 ; demonstr. pr. 61 ; syntax of 62 ; pronominal use of $\operatorname{dim} 73$; peth 74 ; rei 75 ; ryw; sawl 77 ; un 78; interrog. 79 ; relat. $82,84$.

prothetic vowel, 9.

pryt (na), conj. 228.

pwy, 79; pwy with noun, 79n.

pwy gilyd 185.

$p y$, see $p a$; prep. 185 ; with poss. pron.

185 ; pyr 229.

pynhac, pynnac 81 .

pyr, 229.

rac, with pron. end. 53; usage 188; $y$ rac 186.

reduction of cons. 12 ; of prons. 45 .

reduplication $133(\mathrm{~b})$.

rei 62 (b); y rei, foll. by rel. 62 (c) ; pob rei 66 ; as pron. 75 .

relative, $n y$ relat. and non-relat. $21 \mathrm{n}$.

2 ; express. of inflected rel. 62 (c); rel. pron. $82-84$; rel. $a$ with $y d 84$; expr. of genit. of rel. 88; Welsh equiv. to Eng. rel. gov. by prep. 89 ; substitutes for 90 ; verb in rel. clauses 103 ; subjunct. in rel. cl. 114 (h).

repeated action, 107 (c).

responsive particles, 241.

ro, prep. with pron. end. 53.

rodi, roi, paradigm of 146 .

rwng, prep. with pron. end. 53; usage 187; odyrwng 187; yrwng 187. rwy, rel. form of $r y 49$ (c).

$r y$, verbal part. lenat. after $18(\mathrm{f})$; with infix. pron. $49(\mathrm{c}) ; 50(\mathrm{~d})$; in rel. clause $83(\mathrm{a})(\gamma)$; reduced to $r, 95 \mathrm{n}$.; $y+r y 95 \mathrm{n}$.; with indic. $96 \mathrm{~A}$; with perf. indic. $96 \mathrm{~A}(\mathrm{a})$; with plupf. 96 $\mathrm{A}(\mathrm{b})$; with subj. $96 \mathrm{~B}$; with pres. subj. $96 \mathrm{~B}(\mathrm{a})$; with past subj. $96 \mathrm{~B}$ (b); with vb. noun $96 \mathrm{C}$; in early W. poetry 97 ; with pret. indic. 97 (a); with subj. 97 (d); with fut. 97 (d); in later poetry $97(\mathrm{~d})$; with pres. indic. $97 \mathrm{C} 1$; in subord. cl. $97 \mathrm{C} 2$; with pres. and impf. of darvot $97 \mathrm{C}$ n.; not found after neg.; mad; interrog. and rel. a 971 ; with infix. pron. 97.3 ; with subj. of wish 97.3 (b); with vb. noun 120 (b); with conj. o 224 n. 5.

rydhau, paradigm of 127.

$r y w$, rel. form of $r y 49$ (c).

$r y w$, pron. usage of 76 .

$-s$, infixed pron. anticipating object 159 n. 2.

-s- preterite 133.

$-s$ stems in, $27(\mathrm{~d})$.

- $s$ - subjunctive 110 n. 2.

sawl used as pron. 77 .

secondary tense, impf. as, $107(d)(\alpha)$.

sef, ssef, 47.

semivowels 3 .

sentence, sound changes within 12 .

singular formed from collect. nouns $29 \mathrm{c}$.

sit, pret. and perf. end. $132 \mathrm{n}$.

spirant mutat. 21 , see mutation.

stems in $-s 27$ (d); neut $-n-27$ (d); in $-o-27 \mathrm{n} .1$; in $-u-27 \mathrm{n} .1$; $-n-27 \mathrm{n} .5$; adj. stems in $-i-30 \mathrm{n}$; ; in $-u-30 \mathrm{n}$. subject, position when emph. 85 .

subjunctive, with $r y 96 \mathrm{~B}$; pres. subj. with $r y 96 \mathrm{~B}(\mathrm{a})$; past subj. with $r y$ 96 B.(b); subj. of wish with $r y 97$ 
3 (b) ; replaced by plupf. indic. 109 c. ; ending of pres. subj. 110 ; formation of, $110 ; h$ as sign of, 110 ; new formation in Mid. W. $110 \mathrm{n}$. 1 ; subj. stem in 0.W. $110 \mathrm{n} .1$; stem of subj. and indic. $110 \mathrm{n} .1$; influence of indic. upon $110 \mathrm{n} .1$; confusion of subj. with indic. $110 \mathrm{n} .1$; subj. in $h 110 \mathrm{n} .1$; history of subj. in $h 110 \mathrm{n} .2$; $s-$ subj. $110 \mathrm{n} .2$; early history of $110 \mathrm{n} .2$; tenses of subj. 111 ; pres. 111 ; impf. 111 ; past 111 ; past subj. in later Mid. W. 111 ; replaced by plupf. ind. 111 and $n$; perf. in subj. 111; plupf. in subj. 111 ; subj. replaced by indicat. 111 n.; usage 112-114; in main clauses $113 \mathrm{~A}$; of wish $113 \mathrm{~A}(\mathrm{a})$; of command $113 \mathrm{~A}(\mathrm{~b})$; express futurity 113 (c) ; after vbs. of thinking, swearing, etc. $114(\mathrm{a})$; in subord. cl. $114 \mathrm{~B}$; in indirect interrog. $114 \mathrm{~B}(\mathrm{~b})$; in concessive cl. 114 (c); in condit. cl. 114 (d); in cl. of comparison 114 (e); in temporal cl. $114(\mathrm{f})$; after vbs. of effecting, commanding, desiring 114 (g); in final cl. $114(\mathrm{~g})$; in relat. cl. $114(\mathrm{~h})$; endings of pres. subj. 138 ; of pass. subj. 139; form of past subj. 139; subj. with hyt 214 (b); of purpose with hyt na 214. 2 (b); after mal 216. 1 (b) ; of purpose after mal na 216. 3 (b).

substantive verb, forms and usage 154 . suffixes, pl. 28 ; of comparat. 37 (a); of verbal noun 119 .

superlative adj., lenat. after $16 \mathrm{n} .5$, no pl. forms 33 ; form of 37 ; foll. by prep. o 38 (b) ; construction 38 .

syllable, loss of final syll. $30 \mathrm{n}$.

syntax, of the art. 24 ; of cases 26 ; of genit. in prose and poetry 26; of numerals 42: of poss. pron. 56 . tan, dan, prep. lenat. aft. $16(\mathrm{i})$; with pron. end. 53 ; with vb. noun, 126 (c) ; usage 188; ymdan 164; adan, ydan, 188.

tawr, dawr, paradigm of 147.

temporal clauses, 114 (f).

tenses, see present etc.

-tor, verbal ending 129.

tra, conj. with infix. pron. $50(\mathrm{~h})$; foll. by yd 93 (I); usage 230 .

tra, trag, prep., mutation after 21 (c) ; usage 189.

tri, mutation after 21 (a).

tras, dros, trus, prep., lenation after 16

(i); with pron. end. 53 ; usage 190. trwy, drwy, prep., lenation after 16 (i) ; with pron. end. 53 ; usage 191.

$t u(a c)$, prep. 192.

$-u, 3$ pl. end. of pron.-prep. 52 (b).

$-u$ - stems in $27 \mathrm{n} .3 ; 30 \mathrm{n}$.

$u b$ interj. 243.

$u c h$, prep., lenation after 16 (i); with pron. end. 53 ; usage, 193.

$-u d, 3 \mathrm{pl}$. end. of pron. prep. 52 (b). $u n$, as pron. 78 .

verb, end. 3 sg. pres. ind. act. 7 n. 1; 98 ; lenat. after, $16(\mathrm{~g})(\mathrm{a})$; lenat. of, 18 ; posit. in Celt. sent. 85 ; conjugation, $98-161$; classes of, 98 ; deponent, 99 ; voice, 99 ; number, 100 ; concord with subj. $101 ; 103$; person, 102 ; mood, 104; verbs of thinking, swearing, etc., 114 (a); verbs of effecting, commanding, etc., $114(\mathrm{~g})$; paradigm of reg. vb. 127; vowel infection in obj. 128 (a); denominative vb. 128 (b) ; verbs in -hau 128 (b); ending of $3 \mathrm{pl}$. 129 ; irreg. vb. $140-152$; see indic. etc.

verbal noun, lenat. of, $16(b)(\delta)$; witl $r y, 96 \mathrm{C}$; 120 ; formation, 118 ; suffixes, 119; usage, 120 ; voice in, 121 ; 
agent with, 122; with gwneuthur, 123; continuing finite vb. 124; as historic infin. 125; special use after $y n, 126$; with gwedy, 126 (b) ; with tan, 126 (c) ; with can, 126 (c). vocative, lenation in, $16(\mathrm{~m})(\alpha)$. voice, in vb. noun, 121 ; see number, passive.

vowels, vowel system, 1 ; orthog. variat. $1 \mathrm{n}$; quantity, 2; long, 2 (a); lialf-long 2 (b); accented, $2 \mathrm{~A}$; unaccented $2 \mathrm{~B}$; short, $2 \mathrm{~B}$; changes, 5 ; infecting, 5 ; infecting vowel preserved, 6 ; lost, 7 ; vowel-infection in $3 \mathrm{sg}$. pr. ind. act. $7 \mathrm{n} 1$; variation of, due to accent, 8 ; weakening, 8 ; prothetic 9 ; epenthetic, 10 ; change in adj. 31 (a) ; infection in vb. 128 (a) ; irregular vowel infection, $128 \mathrm{n}$.

woly $d y$, interj. 244 .

wish, subjunctive of, $113 \mathrm{~A}$ (a).

word groups, mutation of cons. in, 12. wrth, prep., with pron. end. 53 ; usage 194.

wrth, conj. 231.

$w y$, usage of, $45 \mathrm{n} 2$; becoming wynt, $45 \mathrm{n} 2$.

wyf, etc., as copula, 155 (a) $(\mu)$.

wynt, usage, $45 \mathrm{n} 2$; history of, $45 \mathrm{n} 2$. wynteu, usage, $46 \mathrm{n}$.

$y$, semi-vowel, $3 \mathrm{n}(\mathrm{g})$.

$y$, prep. lenat. after, 16 (i); with pron. end. 53 ; with poss. adj. 58 ; after vb. noun, 122; usage, 195.

$y$ 'her,' mutat. aft. $21 \mathrm{~b}$.

$y d, y t, y r, y$, verb. part., lenation after

18 (e); with infix. pron. $49 \mathrm{~b}$; 50 (b);
$93 \mathrm{n} 2$; with rel. $a 84$; superseding $a$ 85 note; after or 87 (a); yr 91; yr for $y d 91 \mathrm{n} 2$; yt $91 \mathrm{n} 2$; $y$ not lenating $91 \mathrm{n} 2$; origin of non-lenat. $y$ $91 \mathrm{n} 2$; $y t$ lenat. $91 \mathrm{n} 2$; usage 92 ; 93 ; after gwedy $93 \mathrm{n} 3$; before ry $93 \mathrm{n} 4$; $y d$, use of in $\mathrm{RB}$; in $\mathrm{WB}$; and in later Mid. W, 94 ; infixing pron. 94. $-y d \mathrm{pl}$. ending $28 \mathrm{~B}$ (i) ydoed, etc., 154 n 3 ; usage, 154 (b). $y d y w$, use of, 154 , and $\mathrm{n} 3$. $y l l$, see $\mathrm{ell}$. yma, adv. 63.

$y n$, prep. with vb. noun, $16 \mathrm{n} 8$; lenat. $16 \mathrm{n} .8$; yn predic. $16 \mathrm{n} 8$; nasal mut. after, $20(\mathrm{~b})$; with predic. noun and adj. 35 ; with adj. 40 ; with pron. end. 53 ; with vb. noun, 126 ; usage, 196.

$y n$, conj., usage, 232.

ynt, copula, $155(\mathrm{a})(\gamma)$

ynteu, usage, $46 \mathrm{n}$.

yny, conj. with infix. pron. 49 (b) ; 50

(h) ; not foll. by $y d, 93$ (I) ; usage, 233.

-yon, pl. ending 31 (c).

$y r$, see article.

$y r$, prep. with pron. end. 53 ; usage,

187; yr pan, 226 c; yr na, 234.

$y r$ for $y+y r, 87$ note.

$y r$ for $y+r y, 91 \mathrm{n} 3 ; 95 \mathrm{n}$.

ys, ydys 152

$y s$, copula, $155(\mathrm{a})(\alpha) ; y s$ ced $159 \mathrm{n} 2$. $y s y d, s y d$, in relat. cl. $83(\mathrm{a})_{(\alpha)}$; usage, $154(\mathrm{a})(\beta) ; \quad 155(\mathrm{a})(\kappa)$.

yssit, yssydynt, usage, 154 (a) n 1.

yttoed, usage, 154 (b).

yttiw, usage, $154(\mathrm{a}(\alpha)$; copula, $154 \mathrm{n} 4$. $y w$, copula, $155(\mathrm{a})(\beta)$; pan $y w, 155$ $(\mathbf{a})(\beta)$ 


\section{CORRIGENDA}

P5, l.14 bor 'S Sing' read 'S sang'

P. 7, 1. I 5, for mynwgl read mwnwgl

P. 20, 1. 34, for Aften read After

P. 37, 1. 20, for thee read me

P. 110, l. 21, for on read on

P. 123, l. 31, for as read as

? \& P. 140, 1. 28, for 19,707 read 19,709

P. I 4 I, 1. 32, for I 2 dianot read 13 dianot

ib., for 13 y rydunt read i 4 y rydunt

P. 145, 1. 27, for 19,707 read 19,709

ib., 1. 29, for dywyasavc read dywyssavc

P. 15 I, 1. 25, for can wr read canwr

P. I 52, 1. 19, for ordiwed read or diwed

P. $153,1.27$, for troet noethon read troetnoethon

P. $154,1.5$, for yny read yn $y$

P. 155, 1. 2, for gyt gyghor read gytgyghor

P. 162, 1. I I, add comma after Gotlont

ib., for Gbynw read G(ynw[as]

ib, for Gerein read Gerein[t]

P. I66, 1. 28, for kador read Kador

P. 167, 1. 19, add full stop after hynn

P. I69, 1. 16, for vrytanyeit read Vrytanyeit

P. 182, 1. 21, dele the full stop after Les

P. 184. 1. 20, for ge ynyon read gelynyon

ib., 1. 33, read a[c] Vryen

P. 192, 1. 18, for vililioed (sic MS.) read vilioed

-P. I95, l. I, for allan. Dýuot read allan dýuot

P. 198, 1. i I, for ehalic. read ehauc,

P. 199, 1. 31, for Uarrualic (sic MS.) read Uarualic

P. 20I, 1. 20, for kyfuarch (sic MS.) read kyfarth

ib., 1. 24, for Yspaden read Yspad[ad]en

P. 202, 1. 2, for yn read ny 
P. $210^{\text {b }}$, l. 4, for idau read idaw

ib., 1. 20, for rhingyll read ringyll

ib., 1. 33, for nessat read nessaf

ib., for kyglals read kyghals

P. $2 \mathrm{I}^{\mathrm{b}}$, 1. 15, for dyvedut read dywedut

P. $212^{b}, 1.5$, for savun read savwn

P. $22^{\text {b }}$, l. I I, for ydau read idaw

P. $213^{\text {b }}$, l. $2 \mathrm{I}$, for dylyaf read dylyaf $\mathrm{fi}$

ib., l. 24, for ageidw read a geidw

P. 2 I $6^{2}, 1.22$, for $\mathrm{Neu}^{5}$ read $\mathrm{Neu}^{6}$

P. $216^{\text {b }}, 1.23$, for Kynnybo read Kynny bo

P. $219^{\text {b }}, 1.19$, for amdiffynnur vreint read andiffynnwr breint

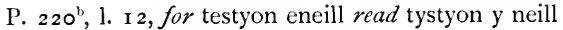

ib., 1. 20, for ygneit read yneit

P. $223,1.5$ and 6 , for diethyr read dieithyr

Ib., 1, 2 2, 25 and 33, for Morgannuc read Morgannwc

Ib., 1. 29, for a digonher read digonher

P. $227,1.21$, dele the comma after tros

P. 229, 1. I, read dayargychwyn

P. 23I, 1. 26, for ieuan read Ieuan

P. 234, l. 16, for teern meibon read teernmeibon

P. 237 , note I, for M.A. read MA. p. 268 a.

P. $237^{\text {b }}$, 1. 17 , for $\mathrm{Dal}$ read Dub

P. 239, 1. 20, for a metev read am etev

P. 24I, 1. 7, for or seuir read orseuir

Ib., 1. 31, for di luyd read diluyd 


\section{Publications}

OF THE

University of Manchester. 



\section{MANCHESTER UNIVERSITY PUBLICATIONS.}

\section{ANATOMICAL SERIES.}

No. I. STUDIES IN ANATOMY from the Anatomical Department of the University of Manchester. Vol. iii. Edited by Alfred H. Young. M.B. (Edin.), F.R.C.S., Professor of Anatomy. Demy 8vo, pp. ix. 289, 23 plates. 10s. net. (Publication No. 10, 1906.)

"All the papers contained in the volume are real additions to the knowledge of the subject with which they deal. For three of the studies Prof. Young is either in part or wholly responsible, and he is to be congratulated on the vigour shown by the Manchester School of Anatomists."-Nature.

"This work affords admirable evidence of the virility of our younger British Universities. It is a notable addition to an already notable series."-Mediral Review.

"This forms the third volume of the Studies in Anatomy issued by the Council, and contains contributions of considerable interest. The volume is well printed and bound. It speaks well for the activity of investigation at Manchester."-Lancet.

"The volume is well got up and is evidence of the continuation of the excellent work which has been carried on for so long a period, under Professor A. H. Young's supervision, and has been encouraged and stimulated by his own work."-British Medical Journal.

"Throughout the papers, careful research and accurate observation are manifested, and they will repay careful perusal. To the Anatomist, as well as the practical physician or surgeon, they will prove valuable."

-Edinburgh Medical Journal.

\section{CLASSICAL SERIES.}

No. I. A STUDY OF THE BACCHAE OF EURIPIDES. By G. Norwood, M.A., Assistant Lecturer in Classies. Demy 8vo, pp. xx. 188, 5s. net. (Publication No. 31, 1908.)

\section{ECONOMIC SERIES.}

No. I. THE LANCASHIRE COTTON INDUSTRY. By S. J Chapman, M.A., M. Com., Stanley Jevons Professor of Political Economy and Dean of the Faculty of Commerce. Demy 8vo, pp. vii. 309 . 7s. 6 d. net. (Publication No. 4, 1904.)

"Such a book as this ought to be, and will be, read far beyond the bounds of the trade."-Manchester Guardian.

"There have been books dealing with various phases of the subject, but no other has so ably treated it from the economic as well as from the historical point of view."-Manchester Courier.

"The story of the evolution of the industry from small and insignificant beginnings up to its present imposing proportions and highly developed and specialised forms, is told in a way to rivet the attention of the reader .... the book is a valuable and instructive treatise on a fascinating yet important subject."-Cotton Fartory Times.

"Highly valuable to all close students." Srotsman.

\section{4, Cross Street, Manchester}




\section{SHERRITT \& IIUGHES}

\section{MANCHESTER UNIVERSITY PUBLICATIONS. ECONOMIC SERIES.}

(Gartside Report, No. 1.)

No. II. COTTON SPINNING AND MANUFACTURING IN THE UNITED STATES OF AMERICA. By T. W. UTtLey, B.A., Gartside Scholar. Demy 8vo, pp. xii. 70. 1s. net.

(Publication No. 8, 1905.)

"Mr. Uttley is to be congratulated on the performance of a not al. together easy task, and his book, in conception and execution, appears to fulfil admirably the intentions of the Trust."-Manchester Courier.

"The writer gives ample details concerning wages and other features connected with typical mills... and the information thus gathered is of interest and value to the factory operative as well as the student and economist."-Cotton Factory Times.

"Mr. Uttley describes bow he visited the mills in various States in a very systematic and detailed manner. Altogether the report makes an admirable and welcome collection of information, and will be found on many occasions worthy of reference."-Textile Mercury.

\section{(Gartside Report, No. 2.)}

No. III. SOME MODERN CONDITIONS AND RECENT DEVELOPMENTS IN IRON AND STEEL PRODUCTIONS IN AMIERICA, being a Report to the Gartside Electors, on the results of a Tour in the U.S.A. By Frank Popplewell, B.Sc., Gartside Scholar. Demy 8vo, pp. vi. 119. 1s. net.

(Publication No. 21, 1906.)

"The author has employed his time weil, and has given a clear idea of modern conditions."-Nature.

"The American methods of iron and steel production are described, from the practical as well as the statistical side."-Manchester Courier.

"Mr. Popplewell writes clearly and well, and he is to be congratulated upon having carried his task through in so entirely a satisfactory manner."-Manchester City News.

"America's progress in iron and steel is more wonderful than any bald statistics of production with which we are so familiar can indicate. How that progress has been effected-effected under labour, transport and other difficulties-Mr. Popplewell tells us in an interesting and keenly intelligent review."-Manchester Guardian.

"A minute observation of detail . . characterises the whole work." -Iron and Coal Trades Review. 


\title{
MANCHESTER UNIVERSITY PUBLICATIONS. ECONOMIC SERIES.
}

\begin{abstract}
(Gartside Report, No. 3.)
No. IV. ENGINEERING AND INDUSTRIAL CONDITIONS IN THE UNITED STATES. By Frank Foster, M.Sc., Gartside Scholar. Demy 8vo, pp. 1x. 106 . 1s. net.

(Publication No. 22, 1906.)

"The report under review is of very great interest to those connected with the manufacturing branch of engineering in this country, many of whom will have to relinquish their preconceived notions regarding American methods, if Mr. Foster's conclusions are to be accepted."

-Electriral Reriew.

"The book altogether is very readable, and one we can heartily recommend to all interested in the economics of engineering."

- The Practiral Engineer.

"Mr. Foster's observation of facts is fresh and interesting ... the technical side of his report exhibits much carc."-Manchester Guardian.

"The book is well worth reading."-Iron and Coal Trades Review.

"There is much in the book which will be new to English readers, even to those who have studied the reports of the Moseley and other recent 'commissions." "-Belfast News Letter.
\end{abstract}

No. V. THE RATING OF LAND VALUES. By J. D Chorlton, M.Sc. Demy 8vo, pp. viii. 177. 3s. 6d. net.

(Publication No. 23, 1907.)

"A timely and temperate treatise on a subject of growing interest." -Pall Mall Gazette.

"The writer is learned, intelligent, progressive, fair and lucid."

"The facts and deductions are well put."-Western Mail.

-Progress.

"Chapters upon the scheme of the Royal Commission (minority report) -'Building Land,' 'The Future Increase of Land Values,' 'The Municipal Bill,' and others. . . set forth with clearness and detail some of the many interesting and difficult subjects in connection with valuation, rates and rating."-Estates Gazette.

"Mr. Chorlton has made a contribution to this interesting controversy which is worthy of the serious attention of all persons interested in the subject."-Lacal Government Chronicle.

"The arguments for and against this proposed reform in the taxation of land have never been more fairly and freely stated." -Liverpool Daily Post and Mercury.

"Mr. Chorlton deals clearly and concisely with the whole subject of rating and land values."-The Standard.

60, Chandos Street, London, w.c. 


\section{SHERRATT \& HUGHES}

\section{MANCHESTER UNIVERSITY PUBLICATIONS. ECONOMIC SERIES.}

"The impartiality and candour of Mr. Chorlton's method are beyond dispute, and his book will repay careful study by all who are interested in the question, from whatever motive."-Westminster Gazette.

"The first half of this book deserves to become a classic..... is one of the best books on a practical economic question that has appeared for many years. It is not only scientifically valuable, but sn well written as to be interesting to a novice on the subject."-The Nation

"This thoughtful and judicially expressed treatise."

-Manchester City News.

"A very businesslike and serviceable collection of essays and notes on this intricate question."-Manchester Guardian.

\section{(Gartside Report, No. 4.)}

No. VI. DYEING IN GERMANY AND AMERICA. By SYDNEY H. Higgins, M.Sc., Gartside Scholar. Demy 8vo, pp. xiii. 112. 1s. net.

(Publication No. 24, 1907.)

"The book will ... make a valuable addition to the technical literature of this country."-Tribune.

"The work is one which .... should receive the attention of those who desire a general view of the German and American dyeing industries."-T'extile Manufacturer.

"A perusal of the work leads us to the conclusion that much useful work is being done by the Gartside scholars, which will give these young men an excellent insight into the working conditions of various industries."-Textile Recorder.

No. VII. THE HUUSING PROBLEM IN ENGLAND. By Ernest Ritson Dewsnop, M.A., Professor of Railway Economics in the University of Chicago. Demy 8 vo, pp. vii. 327 . $5 \mathrm{~s}$. net.

(Publication No. 25, 1907.)

“Mr. Dewsnúp's book is most valuable as it provides all essential information on the subject."-Standard.

"All those who are interested in this question, no matter what their economic predilections, may ponder with advantage Professor Dewsnup's pages."-Newcastle Daily Chronicle.

"The study brings together so weighty an array of facts and arguments that it cannot but prove instructive and suggestive to all classes of economists interested in its subject."-Scotsman.

"Professor Dewsnup's view of the whole problem was stated in 1903, in a form which won the Warburton Essay Prize at the Manchester University. Now revised and brought up to date, his valuable work has taken permanent form."-Westminster Gazette.

(Gartside Report, No. 5.)

No. VIII. AMERICAN BUSANESS ENTERPRISE. By Douglas KNoop II.A. Price 1s. 61. net. (Publication No. 30, 1907.) 


\section{MANCHESTER UNIVERSITY PUBLICATIONS. EDUCATIONAL SERIES.}

No. I. CONTINUATION SCHOOLS IN ENGLAND \& ELSEWHERE: Their place in the Educational System of an Industrial and Commercial State. By Michael E. Sadler, M.A., LL.D., Professor of the History and Administration of Education. Demy 8vo, pp. xxvi 779 . $8 \mathrm{~s}$. 6d. net.

(Publication No. 29, 1907).

This work is largely based on an enquiry made by past and present Students of the Educational Department of the University of Manchester. Chapters on Continuation Schools in the German Empire, Switzerland, Denmark, and France, have been contributed by other writers.

No. II. THE DEMONSTRATION SCHOOL RECORD. No. I. Being Contributions to the Study of Edncation from the Department of Edncation in the University of Manchester. By Professor J. J. Findlay. 1s. 6d. net. (1'ublication No. 32, 1908.)

\section{HISTORICAL SERIES.}

No. I. MEDIAVAL MANCHESTER AND THE BEGINNINGS OF LANCASHIRE. By James TAIT, M.A., Professor of Ancient and Mediæval History. Demy 8vo, pp. x. 211. 7s. 6d. net.

(Publication No. 3, 1904.)

"Patient and enlightened scholarship and a sense of style and proportion have enabled the writer to produce a work at once solid and readable."-English Historical Review.

"A welcome addition to the literature of English local history, not merely because it adds much to our knowledge of Manchester and Lancashire, but also because it displays a scientific method of treatment which is rare in this field of study in England."-Dr. Gross in American Historical Review.

"La collection ne pouvait débuter plus significativement et plus heureusement que par un ouvrage d'histoire du Moyen Age dû à M. Tait, car l'enseignement mediéviste est un de ceux qui font le plus d'honneur à la jeune Université de Manchester, et c'est à M. le Professeur Tait qu'il faut attribuer une bonne part de ce succès."-Revue de Synthèse historique.

"The two essays are models of their kind."-Manchester Guardian.

No. II. INITIA OPERUM LATINORUM QUAE SAECULIS XIII., XIV., XV. ATTRIBUUNTUR. By A. G. LiTTLE, M.A., Lecturer in Palæography. Demy 8vo, pp. xiii. 273 (interleaved). 15s. net.

(Publication No. 5, 1904.)

“Whoever has attempted to ascertain the contents of a Mediæval miscellany in manuscript must of ten have been annoyed by the occurrence of a blank space where the title of the treatise ought to be. Mr. Little has therefore earned the gratitude of all such persons by making public a collection of some 6,000 incipits, which he arranged in the first instance for his private use, in compiling a catalogue of Franciscan MSS."English Historical Review.

60, Chandos Street, London, w.c. 


\section{MANCHESTER UNIVERSITY PUBLICATIONS. HISTORICAL SERIES.}

No. III. THE OLD COLONIAL SYSTEM. By GERALD BERKELEY Hertz, M.A., B.C.L., Lecturer in Constitutional Law. Demy 8vo, pp. xi. 232. 5s. net.

(1'ublication No. 7, 1905.)

" Mr. Hertz gives us an elaborate historical study of the old colonial system, which disappeared with the American Revolution. . . . . He shows a remarkable knowledge of contemporary literature, and his book may claim to be a true history of popular opinion."-Spectator.

“Mr. Hertz's book is one which no student of imperial developments can neglect. It is lucid, fair, thorough, and convincing."

- Glasgow Herald.

“Mr. Hertz's 'Old Colonial System' is based on a careful study of contemporary documents, with the result that several points of no small importance are put in a new light . . . . it is careful, honest work . . . . The story which he tells has its lesson for us."-T'he T'imes.

"Both the ordinary reader and the academic mind will get benefit from this well-informed and well-written book."-Scotsman.

No. IV. STUDIES OF ROMAN IMPEIRALISM. By W. T. ARnold, M.A. Edited by EDwate Fiddes, M.A., Lecturer in Ancient History, with Memoir of the Author by Mrs. HumpHry WARD and C. E. Mostage. With a Photogravure of W. T. Arnold. Deny 8vo, 400 pp. 7s. 6d. net.

(I'ublication No. 16, 1906.

"Nrs. Humphry Ward has used all her delicate and subtle art to draw a picture of her beloved brother; and his friend Mr. Montague's account of his middle life is also remarkable for its literary excellence."-Athenutum.

"The memoir . . . . . tenderly and skilfully written by the "sister and friend,' tells a story, which well deserved to be told, of a life rich in aspirations, interests, and friendships, and not without its measure of actual achievement."-T'ribune.

"This geographical sense and his feeling for politics give colour to all he wrote."-l'imes.

"Anyone who desires a general account of the Empire under Augustus which is freshly and clearly written and based on wide reading will find it here."-Manrhester Guardian.

"Nothing could be better than the sympathetic tribute which Mrs. Humphry Ward pays to her brother, or the analysis of his work and method by his colleague Mr. Montague. The two together have more stuff in them than many big books of recent biography."

- Westminster Gazette.

The Memoir may be had separately, price 2s. $6 \mathrm{~d}$. net.

34, Cross Street, Manchester 


\title{
SHERRATT \& HUGHES
}

\section{MANCHESTER UNIVERSITY PUBLICATIONS. HISTORICAL SERIES.}

\author{
No. V. CANON PIETRO CASOJA'S PILGRIMAgE TO \\ JERUSALEM IN THE YEAR 1494. By M. M. NEWETT, \\ B.A., formerly Jones Fellow. Demy Svo., pp. 427. 7s. 6d. net.
}

(Publication No. 26, 1907.)

"Thoroughness is characteristic of introduction, the copious notes, appendix and index.... Miss Newett's translation is spirited and in. teresting. . . ."-Manchester Courier.

"Casola's narrative richly deserved the honours of print and translation. The book is a credit to its editor and to the historical school of Manchester University."-Morning Leader.

"His narrative is at once simple and dignified in style, convincing and interesting in its pictures of the conditions governing travel by sea and land four centuries ago."-Daily T'elegraph.

"The book is like a gallery of medirval paintings, full of movement and colouring, instinct with the vitality of the time."-Birmingham Post.

"Niss Newett's introduction is a contribution of considerable value to the history of European commerce."-Spectator.

"Forms a noteworthy addition to the number of books from which a knowledge can be gained of the itineraries of the pilgrims to Palestine."

-Scotsman.

"The whole volume is fascinating. It presents a lively picture of bygone times, abounds in curicus facts and recalls quaint and pleasing ceremonies, and exhibits the andent pilgrim of the past in his true light. Miss Newett is alike to be congratulated on her translation, her Introduction (which takes up a third of the volume), and her notes."

-Manchester C'ity News.

"The work which Miss Margaret Newett has probably saved from oblivion is as intrinsically interesting as it should prove instructive to the student of history."-Daily News.

"One of the most delightful narratives that record the impressions of a pious pilgrim."-Westminster Gazette.

"One of the most comprehensive of the itineraries is that now translated, an important feature of it being its full description of the city of Venice."-7'he Time.s

No. VI. HISTORłCAL ESSAYS. Etlited by T. F. Tour, M.A., Professor of Medieval and Modern History and JAmes TAIT, M.A., Professor of Ancient and Medieval History. Demy 8vo, pp. xv. 557. 6s. net. Reissue of the Edition of 1902 with Index and New Preface (Publication No. 27, 1907.)

"Diese zwanzir clıronologisch greorlneten Aufsitze heissen in der Vorrede der Herausgeber Festchrift, behandeln zur Hiilfte ausser-englische

60, Chandos street, London, W.C. 


\section{MANCHESTER UNIVERSITY PUBLICATIONS. HISTORICAL SERIES.}

Themata, benutzen reichllich festländische Literatur und verraten überall neben weiten Ausblicken eine methodische Schulung die der dortigen Facultät hohe Ehre macht." Professor Liebermann in Dcutsche Literaturzeitung,

"Imperial history, local history, ecclesiastical history, economic history and the methods of historical teaching-all these are in one way or another tonched upon by scholars who have collaborated in this volume. Men and women alike lave devoted their time and pains to working out problems of importance and often of no slight difficulty. The result is one of which the university and city may be justly prond." The late Professor York Powell in the Manchestcr Guardian.

"Esso contiene venti lavori storici dettati, quattro da professori e sedici da licenziati del Collegio, e sono tutto seritti appositamente e condotti secondo le più rigorose norme della critica e su documenti." R. Predelli in Nuovo Archivio Veneto.

"La variété des sujets et l'érudition avec laquelle ils sont traités font grand honneur à la manière dont l'histoire est enseigné à Owens College." Revuc Historique.

"No one who reads these essays will do so without acknowledgring their ability, both in originality and research. They deal with historic subjects from the beginnings of Ceesar-worship to the detention of Napoleon at St. Helena, and they deal with them in a thoroughgoing fashion." Guardian.

"Par nature, e'esi un recueil savant, qui témoigne du respect et de l'émulation que sait exercer pour les études historiques la jeune et déjà célèbre université." Rcvue d'histoire ccclésiastique (Louvain).

"All these essays reach a high level; they avoid the besetting sin of most of our present historical writing, which consists of serving up a hash of what other historians lave written flavoured with an original spice of error. . ... They are all based on original researeh and written by specialists." Professor A. F. Pollard in the English Historical Review.

"Sie bilden einen schönen Beweis fur die rationelle Art, mit der dort dieses Studium betrieben wird." P'rofessor 0 . Weber in Historische Zeitschrift.

The Index can be purchased separately price $6 \mathrm{~d}$.

34, Cross Street, Manchester 


\section{SHERRATT \& HUGHES}

\section{MANCHESTER UNIVERSITY PUBLICATIONS. MEDICAL SERIES.}

No. I. SKETCHES OF THE LIVES AND WORK OF THE HONORARY MEDICAL STAFF OF THE RUYAL INFIRMARY. From its foundation in 1752 to 1830 , when it became the Royal Infirmary. By Edward Mansfield Brockbank, M.D., M.R.C.P. Crown 4to. (illustrated). Pp. vii. 311 . 15s. net.

(Publication No. 1, 1904.)

“Dr. Brockbank's is a book of varied interest. It also deserves a welcome as one of the earliest of the 'Publications of the University of Manchester." -Manchester Guardian.

"We have a valuable contribution to local Medical Literature."

$$
\text { -Daily Dispatch. }
$$

No. II. PRACTICAL PRESCRIBING AND DISPENSING. For Medical Students. By William KirkBY, sometime Lecturer in Pharmacognosy in the Owens College, Manchester. Crown 8vo, $220 \mathrm{pp}$. 5s. net.

(Publication No. 2, 1904, Second edition, 1906.)

"The whole of the matter bears the impress of that technical skill and thoroughness with which Mr. Kirkby's name nust invariably be associated, and the book must be welcomed as one of the most useful recent additions to the working library of prescribers and dispensers."

- Pharmareutiral Journal.

"Thoroughly practical text-books on the subject are so rare, that we welcome with pleasure Mr. William Kirkby's 'Practical Prescribing and Dispensing.' The book is written by a pharmacist expressly for medical students, and the author has been most happy in conceiving its scope and arrangement."-British Mediral Journal.

"The work appears to be peculiarly free from blemishes and particularly full in practical detail. It is manifestly the work of one who is a skilled chemist, and an expert pharmacist, and who knows not only the requirements of the modern student but the best way in which his needs may be met."-Mediral Press.

"This is a very sensible and useful manual."-The Hospital.

"The book will be found very useful to any students during a course of practical dispensing."-St. Bartholomew's Hospital Journal.

"The book is a model, being tutorial from beginning to end." - The Chemist and Druggist.

No. III. HANDBOOK OF SURGICAL ANATOMY. By G. A. Wright, B.A., M.B. (Oxon.). F.R.C.S., Professor of Systematic Surgery, and C. H. Preston, M.D., F.R.C.S., L.D.S., Lecturer on Dental Anatomy ; Assistant Dental Surgeon to the Victoria Dental Hospital of Manchester. Crown 8vo, pp. ix. 205. Second edition. 5s. net. (Publication No. 6, 1905.)

60, Chandos Street, London, W.c. 


\section{MANCHESTER UNIVERSITY PUBLICATIONS. MEDICAL SERIES.}

"We can heartily recommend the volume to students, and especially to those preparing for a final examination in surgery."-Hospital.

“I)r. Wright and Dr. Preston have produced a concise and very readable little handbook of surgical applied anatomy. . . . The subject matter of the book is well arranged and the marginal notes in bold type facilitate reference to any desired point."-Lancet.

No, IV. A cOURSE OF INS'TRUCTION IN OPERATIVE SURGERY in the University of Manchester. By WILliaM Thorburs, M.D., B.S. (Lond.), F.R.C.S., Lecturer in Operative Surgery. Crown 8 vo, pp. 75. 2s. 6c. net.

(Publication No. 11, 1906.)

"'This little book gives the junior student all that he wants, and nothing that he does not want. Its size is handy, and altogether for its purpose it is excellent."-Unirersity tieriew.

"As a working guide it is excellent."-Eidinburgh Medical Journal.

No. V. A HANDBOOK OF LEGAI MEDICINE. By W. SELLARS, M.D. (London), of the Middle Temple and Northern Circuit, Barrister-at-law. With Illustrations. Crown 8vo, pp. vii. 233. 7s. 6 d. net.

(Publication No. 14, 1906.)

"This is quite one of the best books of the kind we have come across."-Law T'imes.

No. VI. A CATALOGUE OF THE PATHOLOGICAL MUSEUM OF THE UNIVERSITY OF MANCHESTER. Elited by J. Lonrain S.mith, M.A., M.D. (Edin.), Professor of Pathology. Crown 4to, 1260 pp. 7s. 6d. net. (Publication No. 15, 1906.)

"The catalogue compares very favourably with others of a similar character, and, apart from its value for teaching purposes in an important medical school such as that of the University of Manchester, it is capable of being of great assistance to others as a work of reference." -Edinburgh Medical Journal.

"In conclusion we need only say that Professor Lorrain Smith has performed the most essential part of his task-the description of the specimens-excellently, and an honourable mention must be made of the book as a publication."-British Medical Journal.

No. VII. HȦNDBOOK OF DISEASES OF THE HEART. By Graham Steell, M.I., F.R.C.I', Professor of Medicine, and Pliysician to the Manchester Royal Infirmary. Crown 8vo, pp. xii. 389,11 plates ( 5 in colours), and 100 illustrations in the text. 7s. 6d. net. Publication No. 20, 1906.) 


\section{SHERRAT'T A HUGHES}

\section{MANCHESTER UNIVERSITY PUBLICATIONS. MEDICAL SERIES.}

"It more truly reflects modern icleas of heart disease than any book we are acquainted with, and therefore may be leartily recommended to our readers."-Treatment.

"We regard this volume as an extremely useful guide to the study of diseases of the heart, and consider that no better introduction to the subject could possibly have been written."-Hedical Times and Hospital Gazette.

"We can cordially recommend Dr. Steell's book as giving an excellent and thoroughly practical account of the subject of which it treats." Edinburgh Medical lieview.

\section{PHYSICAL SERIES.}

No. I. THE PHYSICAL LABORATORIES OF THE UNIVERSITY OF MANCHES'TER. A record of 25 years' work. Demy svo, pp. 142, 10 Plates, 4 Plans. 5s. net. (Publication No. 13, 1906.)

This volume contains an illustrated description of the Physical, Electrical Engineering, and Electro-Chemistry Laboratories of the Manchester University, also a complete Biographical and Bibliographical Record of those who have worked in the Physics Departiment of the University during the past 25 years.

"The book is excellently got up, and contains a description of the department of physies and its equipment, a short biographical sketch of the Professor with a list of his seientitic writings and a well-exeented portrait and a record of the career of studeuts and others who have passed through Dr. Schuster's hands. Alumni of Owens will welcome the volume as an interesting link with their alma mater."-Glasgow Herald.

"This interesting and valuable contribution to the listory of the Manchester University also contains several illnstrations, and forms the first of the "physical series" of the publications of the University of Manchester."-The Times

"A record of achievement of which no man need be ashamed"Westminster Gazette.

"It is a menorial of which any man wonld be justly proud, and the University of which he is both an alumnus and a professor nay well share that pride."-Munchester Gaurdian.

\section{PUBLIC HEALTH SERIES.}

No. I. ARCHIVES OF THE PUBLIC HEALTH LABORATORY OF THE UNIVERSITY OF MANCHESTER. Edited by A. Sheridan Delépine, M.Sc., M.B., Ch.M., Director of the Laboratory and Procter Professor of Comparative Pathology and Bacteriology. Crown 4to. pp. iv. 451. £1. Is. net.

(Publication No. 12, 1906.)

60, Chandos Street, London, W.C. 


\section{SHERRATT \& HUGHES}

\section{MANCHESTER UNIVERSITY PUBLICATIONS PUBLIC HEALTH SERIES.}

"The University of Manchester has taken the important and highly commendable step of commencing the publication of the archives of its Public Health Laboratory, and has issued, under the able and judicious editorship of Professor Slleridan Delépine, the first volume of a series that promises to be of no small interest and value alike to members of the medical profession and to those of the laity. . . . Original communications bearing upon diseases which are prevalent in the districts surrounding Manchester, or dealing with food- and water-supplies, air. disposal of refuse, sterilisation and disinfection and kindred subjects. will be published in future volumes; and it is manifest that these, as they successively appear, will form a constantly increasing body of trustworthy information upon subjects which are not only of the highest interest to the profession but of supreme importance to the public."

The Lancet.

"It is safe to say that as these volumes accumulate they will form one of the most important works of reference on questions of public health, and ought, at all events, to be in the library of every public authority."-Manchester Guardian.

"The volume.... speaks well for the activity of investigation in Manchester."-Lancet.

\section{THEOLOGICAL SERIES.}

No. I. INAUGURAL LECTURES delivered during the Session 1904-5, by the Professors and Lecturers of the Faculty of Theology, viz. :-

Prof. T. F. Tout, M.A.; Prof. A. S. Peake, B.D.; Prof. H. W. Hogg, M.A.; Prof. T. W. Rhys Davids, LL.D.; Rev. W. F. Adeney, D.D.; Rev. A. Gordon. M.A. ; Rev. L. Hassé, B.D.; Rev. Canon E. L. HICKS, M.A.; Rev, H. I. Lockett, M.A.; Rev. R. Mackintosh, D.D.; Rev. J. T. Marshall, D.D.; Rev. J. H. Moulton, D.Litt.

Edited by A. S. Peake, B.D., Dean of the Faculty.

Demy 8vo, pp. xi. 296. 7s. 6d. net.

(Publication No. 9, 1905.)

" The lectures, while scholarly, are at the same time popular, and will be found interesting and instructive by those who are not theologians. .. The entire series is excellent, and the volume deserves a wide circulation."-Scotsman.

"This is a very welcome volume ... All these lectures were delivered to popular audiences, yet they are far from superficial, and will be found of great value to busy pastors and teachers."-Christian World.

"We welcome the volume as a most auspicious sign of the times."

-Spectator.

34, Cross Street, Manchester 


\section{SHERRATT \& HUGHES}

\section{MANCHESTER UNIVERSITY PUBLICATIONS. THEOLOGICAL SERIES.}

"The lectures themselves give a valuable conspectus of the present position of Theological research. . . . They are, of course, not addressed to experts, but they are exceedingly valuable, even when allowance is made for their more or less popular form."-Examiner.

"The whole volume forms a very important and valuable contribution. to the cause of Theological learning."-Rerord.

"This is a most interesting and valuable book, the appearance of which at the present moment is singularly significant. . . B But it is impossible. in a brief review to indicate all the treasures of this rich volume, to read which carefully is to be introduced to the varied wealth of modern Biblical scholarship."-Baptist.

"This volume is of the most exceptional value and interest."

"This is a book of more than common interest." -Expository Times. -Review of Theology and Philosophy.

"The writers of these lectures do not attempt to offer more than samples of their wares : but what is given is good, and it may be seen that theology without tests is destitute neither of scientific value nor of human interests."-Athenirum.

\section{LECTURES.}

No. I. GARDEN CITIES (Warburton Lecture). By RALPH Neville, K.C. 6 d. net.

(Lecture No. 1, 1905.)

No. II. THE BANK OF ENGLAND AND THE STATE (A Lecture). By Sir Felix Schoster. 6d. net.

(Lecture No. 2, 1905.)

No, IIF. BEARING AND IMPORTANCE OF COMMERCIAI. TREATIES IN THE TIVENTIETH CENTURY. By Sir THOMAS BARCLAY. 6d. net.

(Lecture No. 3, 1906.)

No. IV. THE SCIENCE OF JANGUAGE AND THE STUDY OF THE GREEK TESTAMENT (A Leeture). By JAMES HoPE Moulton, M.A., Litt.D. 6d. net. (Lecture No. 4, 1906.)

No. V. THE GENERAL MEDICAL COUNCIL: ITS POWERS. AND ITS WORK (A Lecture). By Donald Macalister, M.A., M.D., B.Sc., D.C.L., LL.D. $6 d$ net.

(Lecture No. 5, 1906.)

No. VI. THE CONTRASTS IN DANTE (A Lecture). By the Hon. William Warren Verion, M.A. 6d. net.

(Lecture No. 6, 1906.)

No. VII. THE PRESERVATION OF PLACES OF INTEREST OR BEAUTY (A Lecture). By Sir Robert Hunter. 6d. net.

(Lecture No. 7, 1907.)

60, Chandos strect, London, W.C. 


\section{MANCHESTER UNIVERSITY PUBLICATIONS. CALENDARS.}

CALENDAR OF THE VICTORIA UNIVERSITY OF MAN. CHES'TER. Session 1904-5. Demy 8 vo, $1100 \mathrm{pp}$. 3s. net.

(Publication No. 17.)

CALENDAR OF THE VICTORIA UNIVERSITY OF MAN. CHESTER. Session 1905-6. Demy 8vo, $1200 \mathrm{pp}$. 3s, net.

(I'ublication No. 18.)

CALENDAR OF THE VICTORIA UNIVERSITY OF MAN. CHESTER. Session 1906-7. Demy 8vo, 1300 pp. 3s. net.

(Publication No. 19.)

CALENDAR OF THE VICTORIA UNIVERSITY OF MANCHESTER. Session 1907-8. Demy 8vo, 1400 pp. 3s. net.

(Publication No. 28.)

The following are in preparation and will be issued shortly :--

\section{Celtic Series. No. I.}

AN INTRODUCTION TO EARLY WELSI, By the late Prof. J. Strachan, M.A., LI.D. Demy 8vo.

This work will comprise a Grammar of Early Welsh with special reference to Middle-Welsh prose. 'To the grammar will be added selected passages from Early Welsh texts in prose and verse, together with notes and a vocabulary.

In the Press.

A GLOSSARY TO THE BLACK BOOK OF CHIRK MANUSCRIPT OF THE WELSH LAWS. By TIMOTHY LEWIS, B.A. Demy svo.

This will include the oldest copy of a complete glossary to the "Laws of Howel Dda," contained in the "Black Book of Chirk," and will be based on the photouraphic facsinile of that manuscript which is about to be published by Dr. J. Gwenogrryn Evans in lis collection of Welsh texts.

[n Preparation.

\section{Educational Series.}

THE TEACHING OF HISTORY IN GIRLS' SCHOOIS IN NORTH ANU CENTRAL, GERIIANY. A Report by E. Dodge, M.A.

[In the Press. 


\title{
SHERRA'TT \& HUGHES
}

\section{MANCHESTER UNIVERSITY PUBLICATIONS.}

\author{
Historical Series.
}

HANES GRUFFYDD AP CYNAN. The Welsl text with translation, introduction, and notes by ARTHUR JONES, M.A., Jones Fellow in History. Deniy svo.

[In Preparation.

THE CROMWELLIAN CONQUEST AND SETTLEMENT OF IRELAND. By Robkrt DUNLOP, M.A., formerly Berkeley Fellow. Demy 8vo.

This work will consist of a series of unpublished documents relating to the History of Ireland from 1651 to 1659 , arranged, modernized, and edited, with introduction, notes, ete., by Mr. JUNLOP.

\section{Medical Series,}

[In Preparation.

DISEASES OF THE EAR. By W. MILLIGAN, M.D., Lecturer on Diseases of the Ear and Nasal Surgeon to the Manchester Royal Infirmary.

[In Preparatio

DISEASES OF THE EYE. By C. E. GLASCOTT, M.D., Lecturer on Ophthalmology, and A. Hill Griffith, M.D., Ophthalmic Surgeon to the Manchester Royal Infirmary.

[In Preparation.

HANDBOOK OF NERVOUS DISEASES. By JUDSON S. BURY, M.D., Lecturer on Clinical Neurology and Physician to the Manchester Royal Infirmary.

[In Preparation

The following works, though not technically Publications of the University of Manchester, are also issued from the University Press :-

MELANDRA CASTLE, being the Report of the Manchester and District Branch of the Classical Association for 1905. Edited by R. S. Conway, Litt.D. Introduction by Rev. E. L. Hicks, M.A. Demy 8vo. Illustrated. 5s. net.

TRANSACTIONS OF THE INTERNATIONAL UNION FOR COOPERATION IN SOLAR RESEARCH (Vol. i., First and Second Conferences). Demy 8vo, $260 \mathrm{pp}$. and plate. 7s. 6d. net.

THE BOOK OF RUTH (Unpointed Text). 6d. net.

SCENES FROM THE RUDENS OF PLAUTUS, with a Translation into English Verse. Edited by R. S. Conway, Litt.D., Professor of Latin in the University. $6 \mathrm{~d}$. net. 


\section{SHERRAT'T \& HUGHES}

THE TEACHING OF HISTORY AND OTHER PAPERS. By H.

L. Withers. Edited by J. H. Fowler. Crown 8 vo, 270 pp. 4s. 6d. net.

"An interesting memorial of a teacher who was a real enthusiast for education."-The Times..

"We can cordially commend this little book to the somewhat limited but slowly widening circle who are likely to be interested in educational principles and organization."-The Guardian.

A TARDINESS IN NATURE AND O'THER PAPERS. By MARY

Christie. Edited, with Introductory Note and Memoir, by MAdD

Withers. Crown 8 vo, $331 \mathrm{pp}$. 3s. net.

"The éssays upon Thackeray, George Eliot, and R. L. Stevenson in this volume could scarcely be bettered."-The Guardian.

"The life-story of a quite remarkable woman-of a woman who used her gifts always to the furthering of all that is sweetest and noblest in life."-Tribune.

MUSiCAL CRITICISMS. By Arthur Johnstone. With a Memoir

of the Author by Henry Reece and Oliver Elton. Crown 8vo, 225 pp. 5s. net.

"Without the smallest affectation or laboured attempts at smartness, Mr. Johnstone contrived always to throw fresh light on the matter in hand, and at the same time to present his opinions in a form which could be understood and enjoyed by the non-musical reader."Westminster Gazette.

"Everyone who welcomes guidance as to what is best in music, everyone who watches with some degree of fascination the power of analysis, everyone who reads with a sense of satisfaction English, as it may be written by a master of the craft, should read this book."The Musical World.

MANCHESTER BOYS. By C. E. B. Russell. With an Introduc-

tion by E. T. CAmpagnac. Crown 8vo. 2s. 6d. net.

“Mr. Charles E. B. Russell has written a most interesting and thought-compelling book on a subject of almost vital importance."Yorkshire Post.

"Altogether it is an inspiring book."-Liverpool Daily Post and Mercury.

34, Cross Street, Manchester 

sit

mat yth anet p.56. 
